\title{
The role of livestock in food security, poverty reduction and wealth creation in West Africa
}

\section{Molina-Flores, Baldomero}

FAO

2020-07-07

Molina-Flores , B , Manzano-Baena , P \& Coulibaly , M D 2020 , The role of livestock in food security, poverty reduction and wealth creation in West Africa . FAO . https://doi.org/10.4060/ca8385en

http://hdl.handle.net/10138/317526

https://doi.org/10.4060/ca8385en

cc_by_nc_sa

publishedVersion

Downloaded from Helda, University of Helsinki institutional repository.

This is an electronic reprint of the original article.

This reprint may differ from the original in pagination and typographic detail.

Please cite the original version. 

(A) Organization of the United Nations

The role of livestock in food security, poverty reduction and wealth creation in West Africa

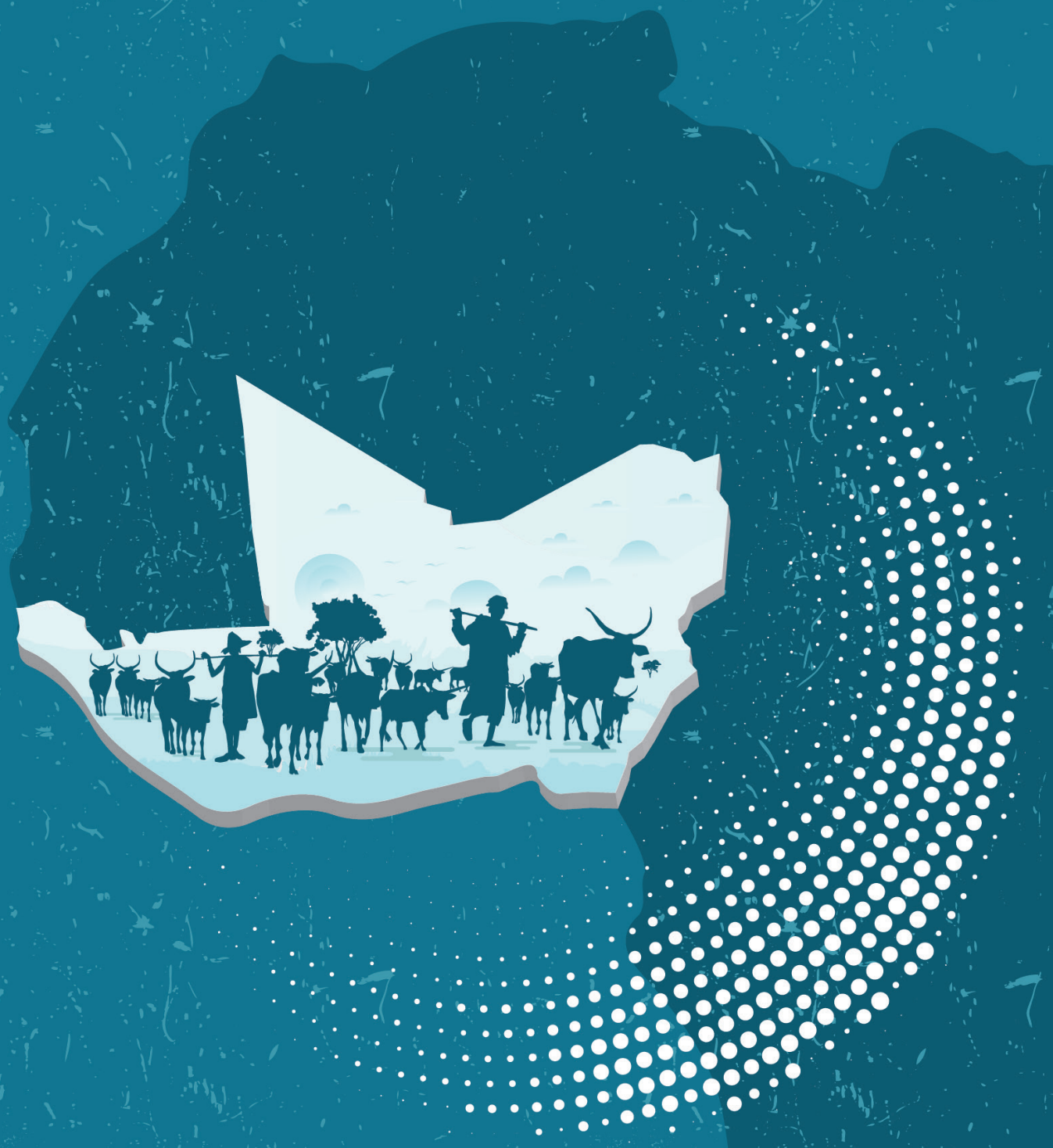





\title{
The role of livestock in food security, poverty reduction and wealth creation in West Africa
}

\author{
Baldomero Molina-Flores, Pablo Manzano-Baena \\ and Mamadou D. Coulibaly
}

\author{
Edited by \\ Berhanu Bedane
}

Food and Agriculture Organization of the United Nations Accra, 2020 


\section{Required citation:}

Molina-Flores, B., Manzano-Baena, P. and Coulibaly, M.D. 2020. The role of livestock in food security, poverty reduction and wealth creation in West Africa. Accra. FAO.

https://doi.org/10.4060/ca8385en.

The designations employed and the presentation of material in this information product do not imply the expression of any opinion whatsoever on the part of the Food and Agriculture Organization of the United Nations (FAO) concerning the legal or development status of any country, territory, city or area or of its authorities, or concerning the delimitation of its frontiers or boundaries. The mention of specific companies or products of manufacturers, whether or not these have been patented, does not imply that these have been endorsed or recommended by FAO in preference to others of a similar nature that are not mentioned.

The views expressed in this information product are those of the author(s) and do not necessarily reflect the views or policies of FAO.

ISBN 978-92-5-132339-7

(c) FAO, 2020

\section{(9) (1) $(0)$}

Some rights reserved. This work is made available under the Creative Commons Attribution-Non Commercial-Share Alike 3.0 IGO licence (CC BY-NC-SA 3.0 IGO; https://creativecommons.org/licenses/ by-nc-sa/3.0/igo/legalcode).

Under the terms of this licence, this work may be copied, redistributed and adapted for non-commercial purposes, provided that the work is appropriately cited. In any use of this work, there should be no suggestion that FAO endorses any specific organization, products or services. The use of the FAO logo is not permitted. If the work is adapted, then it must be licensed under the same or equivalent Creative Commons licence. If a translation of this work is created, it must include the following disclaimer along with the required citation: "This translation was not created by the Food and Agriculture Organization of the United Nations (FAO). FAO is not responsible for the content or accuracy of this translation. The original [Language] edition shall be the authoritative edition."

Disputes arising under the licence that cannot be settled amicably will be resolved by mediation and arbitration as described in Article 8 of the licence except as otherwise provided herein. The applicable mediation rules will be the mediation rules of the World Intellectual Property Organization http:// www.wipo.int/amc/en/mediation/rules and any arbitration will be conducted in accordance with the Arbitration Rules of the United Nations Commission on International Trade Law (UNCITRAL).

Third-party materials. Users wishing to reuse material from this work that is attributed to a third party, such as tables, figures or images, are responsible for determining whether permission is needed for that reuse and for obtaining permission from the copyright holder. The risk of claims resulting from infringement of any third-party-owned component in the work rests solely with the user.

Sales, rights and licensing. FAO information products are available on the FAO website (www.fao.org/ publications) and can be purchased through publications-sales@fao.org. Requests for commercial use should be submitted via: www.fao.org/contact-us/licence-request. Queries regarding rights and licensing should be submitted to: copyright@fao.org. 


\section{Contents}

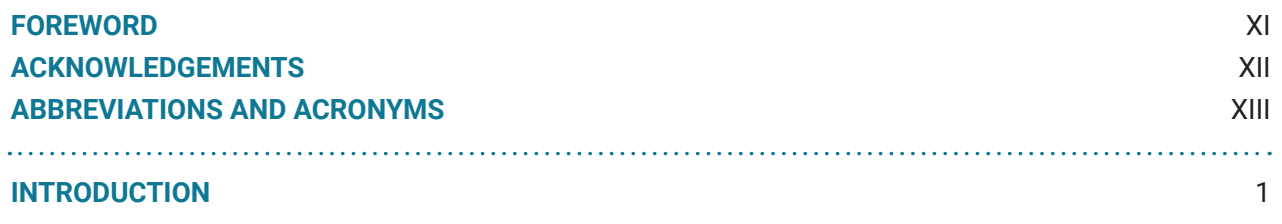

$\begin{array}{ll}\text { CHAPTER I } & 5\end{array}$

THE ENVIRONMENT FOR LIVESTOCK REARING IN WEST AFRICA

$\begin{array}{lll}1.1 & \text { Natural resources } & 5\end{array}$

$\begin{array}{ll}1.2 \text { Human population } & 12\end{array}$

$\begin{array}{ll}\text { CHAPTER II } & 17\end{array}$

LIVESTOCK POPULATION AND DISTRIBUTION IN WEST AFRICA 17

2.1 Livestock numbers by species and distribution in West Africa 18

$\begin{array}{lr}\text { CHAPTER III } & 25\end{array}$

LIVESTOCK GENETIC RESOURCES IN WEST AFRICA 25

$\begin{array}{ll}3.1 & 25\end{array}$

3.2 Non-conventional livestock 43

\begin{tabular}{ll}
3.3 & Livestock breeding and conservation programmes \\
\hline
\end{tabular}

$\begin{array}{ll}\text { CHAPTER IV } & 53\end{array}$

LIVESTOCK PRODUCTION SYSTEMS IN WEST AFRICA 53

$\begin{array}{lll}4.1 & \text { Historical perspective and current status } & 53\end{array}$

$\begin{array}{lll}4.2 & \text { Pastoral system } & 54\end{array}$

$\begin{array}{lll}4.3 & \text { Agro-pastoral systems } & 60\end{array}$

$\begin{array}{lll}4.4 & \text { Peri-urban system }\end{array}$

CHAPTER V

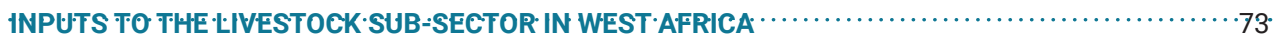

$\begin{array}{lll}5.1 & \text { Feed and livestock feeding } & 73\end{array}$

$5.2 \quad$ Water and livestock watering 82

$\begin{array}{ll}5.3 & 85\end{array}$

$\begin{array}{lr}\text { CHAPTER VI } & 95\end{array}$

DISEASES PREVALENT IN WEST AFRICA AND ANIMAL HEALTH CARE 95

6.1 An overview of main animal diseases reported in West Africa 96 
6.2 Number and spatial distribution of disease outbreaks $\quad 99$

6.3 Control and prevention measures against major animal diseases 103

6.4 Human resources in the livestock sub-sector 107

$\begin{array}{lll}6.5 & \text { Financing the livestock sub-sector } & 108\end{array}$

CHAPTER VII

OUTPUTS FROM THE LIVESTOCK SUB-SECTOR IN WEST AFRICA 113

7.1 Overview on livestock products in the region 113

$\begin{array}{lll}7.2 & \text { Meat and meat products } & 114\end{array}$

$\begin{array}{lll}7.3 & \text { Milk and dairy products } & 117\end{array}$

$\begin{array}{ll}7.4 & 119\end{array}$

$\begin{array}{ll}7.5 & \text { Other animal products } \\ \end{array}$

CHAPTER VIII 125

TRADE IN LIVE ANIMALS AND ANIMAL PRODUCTS IN WEST AFRICA 125

8.1 Current demand and consumption of animal products in West Africa 125

$\begin{array}{ll}\text { 8.1.2 Milk and dairy products } & 128\end{array}$

$\begin{array}{lll}8.1 .3 & \text { Eggs } & 128\end{array}$

$\begin{array}{llr}8.2 & \text { Trade dynamics } & 129\end{array}$

$\begin{array}{ll}\text { CHAPTER IX } & 145\end{array}$

POLICIES AND LEGISLATIONS GOVERNING THE LIVESTOCK

SUB-SECTOR IN WEST AFRICA 145

$\begin{array}{lll}9.1 & \text { Livestock policies } & 145\end{array}$

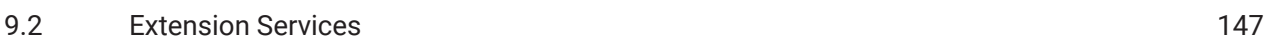

$\begin{array}{lll}9.3 & 148\end{array}$

$\begin{array}{llr}9.4 & \text { Trade policies } & 149\end{array}$

9.5 Natural resource base policies 150

$9.6 \quad$ Animal Health Policies $\quad 151$

9.7 Policies on livestock statistics and data collection 152

$9.8 \quad$ Economic development 152

9.9 Policies on Trade 156

9.10 Animal Health and Traceability 157

$\begin{array}{lll}9.11 & \text { Policies on Pastoralism and transhumance } & 157\end{array}$

9.12 Livestock Legislation and Regulation 158

9.13 Animal health 159

9.14 Regulations on Transhumance at national level 159

9.15 Regulations on Pastoralism and Transhumance at regional level 160

$\begin{array}{lr}\text { CHAPTER X } & 167\end{array}$

THE ROLES OF THE LIVESTOCK SUB-SECTOR IN WEST AFRICA 167

10.1 Diversity of livestock roles 
$\begin{array}{lll}10.2 & \text { Food security, nutrition and health } & 168\end{array}$

$\begin{array}{lll}10.3 & \text { Economic roles } & 169\end{array}$

$\begin{array}{lll}10.4 & \text { Equality and empowerment } & 171\end{array}$

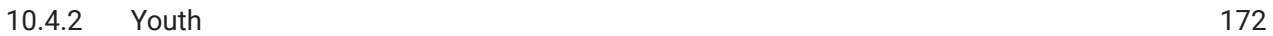

$\begin{array}{lll}10.5 & \text { Socio-religious roles } & 173\end{array}$

$\begin{array}{lll}10.6 & \text { Environmental roles } & 174\end{array}$

$\begin{array}{lr}\text { CHAPTER XI } & 179\end{array}$

CONSTRAINTS LIMITING THE DEVELOPMENT OF THE LIVESTOCK

SUB-SECTOR IN WEST AFRICA 179

$\begin{array}{lll}11.1 & \text { General limitations and constraints } & 179\end{array}$

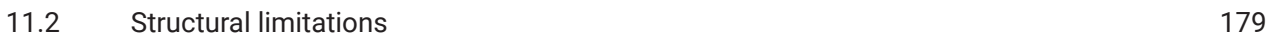

$\begin{array}{ll}\text { 11.2.1 Animal breeding and genetics } & 180\end{array}$

11.2.2 Husbandry and management 181

$\begin{array}{ll}11.2 .3 \quad \text { Land tenure } & 181\end{array}$

$\begin{array}{ll}11.3 & 182\end{array}$

$11.4 \quad$ The constrains related to livestock inputs 184

$\begin{array}{lll}\text { 11.4.1 Feed and feeding systems } & 185\end{array}$

$\begin{array}{ll}11.4 .2 & 185\end{array}$

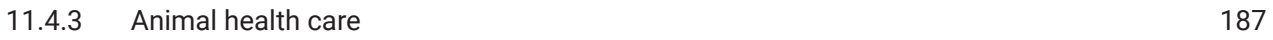

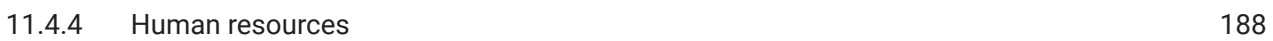

$\begin{array}{ll}11.5 & 188\end{array}$

$11.6 \quad$ Livestock emergencies 191

$\begin{array}{ll}11.6 .2 & 192\end{array}$

$\begin{array}{ll}\text { 11.6.3 Civil and socio-political conflicts } & 193\end{array}$

$\begin{array}{ll}\text { CHAPTER XII } & 197\end{array}$

THE PROSPECTS OF THE LIVESTOCK SUB-SECTOR IN WEST AFRICA 197

12.1 Trends in shifting production systems or level of intensification 197

12.2 The trends of demand and supply of food of animal origin 199

12.3 Livestock global trends and their impact on West African livestock sub-sector $\quad 200$

$\begin{array}{lr}\text { BIBLIOGRAPHY } & 203\end{array}$ 


\section{Figures}

Figure 1. Political map of West Africa.

Figure 2. Rainfall and wind patterns determining climate in West Africa. $\quad 7$

Figure 3. Agro-ecological map of West Africa.

Figure 4. Evolution of agricultural area in West Africa (1963 - 2013). 10

Figure 5. Evolution of rural and urban population in West Africa (1960 - 2020). 14

Figure 6. Livestock population estimate of major species in West Africa (2009, 2012 and 2017). 18

Figure 7. Comparison of livestock population among different regions of Africa (2017). 19

Figure 8. Cattle, sheep, goat and pig populations' growth in West Africa (2008 - 2017). 20

Figure 9. Poultry populations' growth in West Africa (2008 - 2017). 20

Figure 10. Ruminant livestock distribution in West Africa. 22

Figure 11. The risk status of West African local breeds reported by selected countries. 48

Figure 12. Livestock production systems distribution in West Africa. 54

Figure 13. Cyclic annual transhumance routes in West Africa.

Figure 14. Number of outbreaks of major cattle diseases in West Africa (2010 - 2014). 100

Figure 15. Number of outbreaks of major sheep and goat diseases in West Africa (2010 - 2014). 100

Figure 16. Number of outbreaks of major poultry diseases in West Africa (2010 - 2014). 101

Figure 17. Number of outbreaks of livestock bacterial diseases reported in West Africa (2010 - 2014).

Figure 18. Number of outbreaks of some parasitic diseases affecting livestock in West Africa (2010 - 2014).

Figure 19. Number of outbreaks of some zoonotic diseases in West Africa (2010 - 2014). 102

Figure 20. Spatial distribution of animal disease outbreaks in West Africa (2005 - 2015). 103

Figure 21. Proportion of veterinary drugs expenditures in selected West African countries. 107

Figure 22. Meat, milk and egg production trends in West Africa. 117

Figure 23. Milk production trends in selected West African countries. 120

Figure 24. Per capita consumption of major livestock products in West Africa. 126

Figure 25. Average number of eggs consumed per person and year in West Africa. 129

Figure 26. Trade balance for live animals in West Africa. $\quad 130$

Figure 27. Volume and value for the four most important meat import types in West Africa. 139

Figure 28. The evolution of chicken and eggs import in selected West African countries. 140

Figure 29. The three transhumance migratory corridors in West Africa. 161

Figure 30. Rainfall data in the Sahel (1900 - 2010). 183 


\section{Tables}

Table 1. Surface area of West African countries.

Table 2. Demographic characteristics of West Africa. $\quad 13$

Table 3. Number of breeds per livestock specie in West Africa. $\quad 17$

Table 4. Native cattle breeds of West Africa and their performance. 32

Table 5. Native sheep and goats breeds of West Africa and their performance. 37

Table 6. Crop residue production and quantity available in Gambia. 76

Table 7. Availability and stocking capacity of crop residues in Burkina Faso. 76

Table 8. Crop residues production in Niger.

Table 9. The quantity of selected agro-industrial by-products produced in eight countries of West Africa.

$\begin{array}{ll}\text { Table 10. The amount of selected animal feed imported by West African countries. } & 81 \\ \text { Table 11. The amount of selected animal feed exported by West African countries. } & 81\end{array}$

Table 12. The distribution of water points in Niger per administrative region 84

Table 13. The list of ten most reported animal diseases in West Africa (2010 - 2014). 99

Table 14. The number of personnel working in the livestock sub-sector in West Africa by category.

Table 15. The annual budget planned by and allocated to livestock department in West African countries (in USD).

Table 16. The amount of major animal products produced in West African countries in 2013.

Table 17. The proportion of meat produced per species and per AEZ in West Africa. 115

Table 18. Monetary value of annual output of the major livestock products in West Africa. $\quad 116$

Table 19. The amount of Day-Old-Chicks produced in selected West African countries. 121

Table 20. The monetary value in USD of Day-Old-Chick production

$\begin{array}{ll}\text { in selected West African countries in } 2011 . & 121\end{array}$

Table 21. The amount of hide and skin produced in West Africa in 2013.

Table 22. The demand for major animal products in West Africa. 127

Table 23. The number of live animals by species imported by West African countries. 133

Table 24. The number of live animals by species exported by West African countries. 134

Table 25. The price of live animal for the major livestock species in West Africa (in USD). 135

Table 26. The price range and average price of different livestock species in Ghana (in USD). $\quad 136$

$\begin{array}{ll}\text { Table 27. Import and export of dairy products, Togo. } & 137\end{array}$

Table 28. The volume and value of animal products imported by West African countries. $\quad 139$

Table 29. The volume and value of animal products exported from countries in West Africa. $\quad 141$

Table 30. The average retail prices of major animal products in West Africa. 142

Table 31. The proportion of demand for animal products covered by local

$\begin{array}{ll}\text { production in West Africa. } & 169\end{array}$

Table 32. Contribution of livestock to agricultural and national GDP in West African countries. $\quad 169$ 


\section{Photos}

Photo 1. Azawak cattle breed (Niger). 26

Photo 2. Bororo cattle breed (Niger). 26

$\begin{array}{lr}\text { Photo 3. Djeli cattle breed (Niger). } & 26\end{array}$

$\begin{array}{lr}\text { Photo 4. Fulani cattle breed (Ghana and Senegal). } & 27\end{array}$

$\begin{array}{lr}\text { Photo 5. Gudali cattle breed (Ghana and Niger). } & 27\end{array}$

$\begin{array}{lr}\text { Photo 6. Maure cattle breed (Mali). } & 28\end{array}$

$\begin{array}{lr}\text { Photo 7. Wadara cattle breed (Nigeria). } & 28\end{array}$

$\begin{array}{lr}\text { Photo 8. Kuri cattle breed (Niger). } & 29\end{array}$

$\begin{array}{lr}\text { Photo 9. N'Dama cattle breed. } & 29\end{array}$

$\begin{array}{lr}\text { Photo 10. Muturu cattle breed (Nigeria). } & 30\end{array}$

Photo 11. Somba cattle breed (Benin). $\quad 30$

Photo 12. Ghana shorthorn cattle breed (Ghana). 30

$\begin{array}{ll}\text { Photo 13. Baoule cattle breed. } & 30\end{array}$

Photo 14. Fulani sheep breed (Benin and Niger). $\quad 31$

Photo 15. Touabire sheep breed (Mauritania). 33

Photo 16. Touareg sheep breed (Niger). $\quad 33$

Photo 17. Macina sheep breed (Niger). $\quad 34$

$\begin{array}{ll}\text { Photo 18. Djallonke sheep breed. } & 34\end{array}$

Photo 19. Sahelian goat breed (Niger). $\quad 35$

Photo 20. Red Sokoto goat breed (Nigeria).

Photo 21. Maradi goat breed (Niger). 36

Photo 22. Djallonke goat breed. $\quad 36$

$\begin{array}{ll}\text { Photo 23. Azawak and Azarghaf camel breeds (Niger). } & 38\end{array}$

Photo 24. Arewa and Talon horse breeds (Niger). $\quad 39$

Photo 25. Korhogo pigs breed and crossbreed pig (Côte d'Ivoire and Liberia). 40

Photo 26. Local chicken breeds (Ghana and Togo). 41

Photo 27. Wassa Chè and Shika-Brown chicken breeds (Mali and Nigeria). 42

Photo 28. Guinea fowl and quail production (Ghana and Nigeria). 43

Photo 29. Rabbit and Guinea pig production (Liberia and Benin). 44

Photo 30. Grasscutter and giant rat production (Côte d'Ivoire and Ghana). 45

Photo 31. Fulani cattle herders crossing the Niger River at Diafarab (Mali). 55

Photo 32. Nomadic and transhumant livestock at watering point (Niger). 56

Photo 33. Cattle on a crop field deposit manure improving soil fertility (Niger). 60

Photo 34. Milking goats in a village of Ségou District (Mali). 61

Photo 35. Young woman fattening goats for sale (Niger). 62

Photo 36. Milking time in a smallholder dairy household (The Gambia). 63

Photo 37. Cross-bred dairy cattle in peri-urban Bamako (Mali). 64

Photo 38. Commercial cattle fattening operation (Senegal). $\quad 65$

Photo 39. Smallholder semi-intensive pig production operation (Liberia). 67

Photo 40. Commercial large-scale intensive pig production operation (Cabo Verde). 68

Photo 41. Semi-intensive layer-chicken production operation (Liberia). 69

Photo 42. Intensive commercial poultry farm near Sikasso (Mali). 70

Photo 43. Local storage of harvested forage (Benin). 75 
Photo 44. Cattle feeding on crop residues (Senegal).

Photo 45. Quality livestock feed provided to farmers during drought (Senegal). 80

Photo 46. Cattle watering at the river (Niger). $\quad 82$

Photo 47. Nomadic and transhumant livestock at watering point (Niger). 84

Photo 48. Advertisement of private veterinary clinic (Ghana). 87

Photo 49. Regional Veterinary Office's community clinic in Ho (Ghana). 87

Photo 50. Accra and Kumasi Veterinary Diagnostic Laboratories (Ghana) 88

Photo 51. Cattle in a resting pen at Kumasi slaughterhouse (Ghana). 89

Photo 52. Cattle hide left to dry on frames before transferred to tannery (Mali). 90

Photo 53. Niamana livestock market in Bamako (Mali). 92

Photo 54. Small ruminants' market (Niger). $\quad 92$

Photo 55. Cattle transportation in Borno State (Nigeria). 92

Photo 56. Laboratory training workshop on diagnosis of CBPP in Bamako (Mali). 96

Photo 57. Inspected meat transported from slaughterhouse to market (Senegal). 98

Photo 58. Sheep showing neurological signs at a market near Monrovia (Liberia). 104

Photo 59. Vaccination of goats against PPR and Pasteurellosis (Mali). 105

Photo 60. Transporting sheep from Burkina Faso to Cote d'Ivoire for Tabaski market 131

Photo 61. Group photograph of participants of the animal health network meeting,

Abuja, Nigeria, 2015 


\section{Boxes}

Boxes page 1. Grasscutters or guinea pigs? Enabling environment in West Africa. 45

Boxes page 2. The Gouanan pastoralist conflicts in Mali. $\quad 59$

Boxes page 3. The West Africa Livestock Innovation Centre (WALIC). 86

Boxes page 4. Lactose intolerance and its importance for food security in West Africa. 128

Boxes page 5. The trade of donkey skin and its impact on livelihoods in West Africa. 132

Boxes page 6. Trade in dairy products in Togo 137

Boxes page 7. Chicken and egg production environment in West Africa. 140

Boxes page 8. The experience of grazing reserves in Nigeria. 150 


\section{Foreword}

A significant proportion of the 377 million people in West Africa depends directly or indirectly on livestock value chains for food, as input to crop production, transport, as a source of cash, investment, and storage of wealth, for ritual and social purposes, or as insurance during impending crises. In some Sahelian countries, such as Burkina Faso, Mali, and Niger, about 60 percent of the population is involved in livestock production. In these countries, livestock production contributes between 37 and 82 percent to the agricultural GDP. The demand for animal products as a source of quality protein and micronutrients is increasing with population growth, urbanization, growing middle class, and due to shifting consumer preferences towards animal products. The protein in meat, milk, and eggs is dense and more bio-available than plant-based protein.

Despite the considerable potential of livestock in West Africa subregion, it however leaves much to be desired in terms of utilization. The per capita consumption of food of animal origin remains very low, even lower by the sub-Saharan Africa standards. Projections show that the consumption of poultry meat, pork, and eggs is rapidly increasing and without a doubt, aiming to reach six to seven folds in West Africa by 2050. Likewise, milk consumption is likely to triple during the same period. To meet this growing demand, countries in West Africa must engage in accelerated sustainable livestock production undertaking.

Meeting such a growing demand, requires tremendous efforts such as increasing public and private investment towards the livestock subsector. The current public expenditure in the livestock sub-sector falls short of the minimum target of three percent of national budgets allocation agreed upon at continental level. Poor husbandry practices, inadequate feed and water, the prevalence of various animal diseases, poor extension services, and inadequate infrastructure and limited market access pose as impediments to the growth of this subsector. This is further exacerbated by climate change and extreme weather conditions, as well as incidences of conflicts and insecurity that are spreading over the years in the Sahel.

For countries in the West Africa subregion, attainment of global and regional commitments of eradication of poverty and hunger (SDGs $1 \& 2$ ) cannot be realized without a well-performing livestock subsector. Up-to-date, and reliable information on the potentials, opportunities, and challenges of the livestock subsector is key for proper planning of appropriate interventions and informed decisionmaking. This book attempts to contribute in this regard through knowledge-sharing based on different studies commissioned by the Food and Agriculture Organization of the United Nations (FAO) in West Africa in recent years. We hope that the book provides timely and valuable information for those working in the livestock subsector in West Africa.

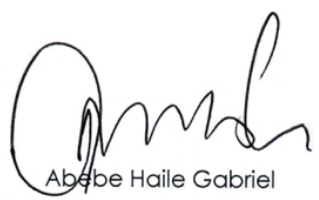

Assistant Director-General and Regional Representative FAO Regional Office for Africa 


\section{Acknowledgements}

This book was written by Baldomero Molina-Flores, Pablo Manzano-Baena and Mamadou D. Coulibaly under the direction of Berhanu Bedane. FAO wishes to acknowledge the specific contributions of the following individuals listed not necessarly by order of the level of assistance.

Dr. E. Fallou Gueye (International Project Coordinator at FAO Djibouti and IGAD) provided valuable comments and inputs during the initial conception and structuring of this book. He also reviewed later chapter two, livestock productions systems in West Africa. Professor Cheikh Ly (former animal production and health officer of FAO Regional Office for Africa) contributed ideas throughout the preparation of this book and reviewed chapter nine, policies and legislations governing the livestock sub-sector in West Africa and chapter 12, the prospects of the livestock sub-sector in West Africa. Professor Makkar Harinder (former animal production officer at livestock production systems branch of FAO headquarters) reviewed part of chapter five, particularly the animal feed component of the inputs to the livestock sub-sector in West Africa and provided valuable information resources. Dr. Ahmed El Idrissi, (former senior animal health officer, at animal health service of FAO headquarters) reviewed the animal health infrastructures and diseases prevalent in West Africa in chapters five and six. Dr. Bouna Diop (acting secretary of the joint FAO/OIE global PPR secretariat) reviewed chapter ten, the roles of the livestock sub-sector in West Africa. Dr. Vivian Iwar (acting executive director of the regional animal health centre for West Africa) reviewed chapter nine, policies and legislations governing the livestock sub-sector in West Africa. Dr. Ibrahim Wora Salami (animal production and health consultant at FAO Regional Office for Africa) reviewed chapter seven, outputs from the livestock sub-sector in West Africa. Dr. Baba, Soumare (regional manager of ECTAD for West and Central Africa) reviewed chapter 11 , constraints limiting the development of the livestock sub-sector in West Africa. Dr. Markos Tibbo (senior livestock development officer in FAO Subregional Office for Gulf States and Yemen) reviewed parts of chapter one, two and three. Last but not least, Dr. Bruce Mukanda (former senior programmes and projects officer at AU-IBAR) reviewed chapter eight, trade in live animals and animal products in West Africa. The editorial review was carried out by Dr. Berhanu Bedane (Livestock Development Officer at FAO Subregional Office for Southern Africa) and the graphic design and publication by Mr. Tinashe Mpariwa.

We wish to thank all of them for their valuable inputs. 


\section{Abbreviations and acronyms}

AAGDS Accelerated Agricultural Growth and Development Strategy

AEZ Agro-ecological zones

AGRA Alliance for Green Revolution in Africa

AHS African Horse Sickness

AIRS Animal identification and Recording System

APESS Association for the promotion of livestock in the Sahel and Savannah

ARI Agricultural Research Institute (Ghana)

ARIS Animal Resources Information System (AU-IBAR)

ASF African swine fever

AU African Union

AU-IBAR AU Inter-African Bureau for Animal Resources

BoA Bank of Agriculture (Nigeria)

BQ Blackleg

BRICKS Building Resilience through Innovation, Communication and Knowledge Services

BSL3 Bio-Safety Level 3

CAADP Comprehensive Africa Agriculture Development Programme

CAHWs Community Animal Health Workers

CBPP Contagious Bovine Pleuropneumonia

CDC Centers for Disease Control and Prevention

CEF Common External Tariff (ECOWAS)

CERCAD Centre for the study, research, communication and support for development

CFS Committee on World Food Security

CILSS The Permanent Interstate Committee for Drought Control in the Sahel

CIRAD French International Center for Agricultural Research for Development

CIRDES International Research and Development Center on Livestock Production in the Subhumid Zone

CMC Crisis Management Centre (FAO/OIE)

CMDT Malian company for the development of Textile

CORET Confederation of Traditional Herder Organizations in Africa

CTA Technical Centre for Agricultural and Rural Cooperation

CW Cemented Wells

DAD-IS Domestic Animal Diversity Information System (FAO)

DAGRIS Domestic Animal Genetic Resources Information System (ILRI)

DM Dry Matter

DNPIA National Directorate of Production and Animal Industries (Mali)

DOC Day Old Chicks

DPH Dermatophilosis

DW Drilled Wells

EBID ECOWAS Bank for Investment and Development

ECF East coast fever

ECOWAP ECOWAS Agricultural Policy

ECOWAS Economic Community of West African States

ECTAD Emergency Centre for Transboundary Animal Diseases

EMPRES Emergency Prevention System (FAO)

EU European Union

EVD Ebola Virus Disease

F1 First Filial Generation

FAO Food and Agriculture Organization of the United Nations 
FAO/SFW FAO Subregional Officer for West Africa

FAOSTAT FAO's Statistical Database

FERAP Exchange's Fluidification and Policy Reconciliation Project

FEWS Net Famine Early Warning System Network

FMD Foot-and-mouth disease

GDP Gross Domestic Production

GF-TADs Global Framework for the progressive control of Transboundary Animal Diseases

GGWSSI Great Green Wall for the Sahara and Sahel Initiative

GHG Greenhouse Gas

GLEWS Global Early Warning System for Animal Diseases

HMP Human Motricity Pumps

HPAI High Pathogenic Avian Influenza

HWD Heartwater Disease

IBD Infectious Bursal Disease

ICAR International Committee for Animal Recording

IDPs Internally Displaced People

IGAD Inter-Governmental Authority on Development

ILCA International Livestock Centre for Africa

ILRI International Livestock Research Institute

INERA National Institute of Environmental and Agricultural Research (Burkina Faso)

ITC International Trypanotolerant Centre

itc International Transhumance Certificate

Lac Lactation

LGP Length of Growing Period

LiDeSa Livestock Development Strategy

LNERV National Laboratory of Livestock and Veterinary Research (Senegal)

LSD Lumpy Skin Disease

MARA Minstry of Agriculture and Animal Resources (Côte d'Ivoire)

MDGs Millennium Development Goals

ME Metabolizable Energy

MM Mange Mite

MoFA Ministry of Food and Agriculture (Ghana)

MRA Ministry of Animal Resources (Burkina Faso)

MRAH Ministry of Animal and Fisheries Resources (Côte d'Ivoire)

MRAN Ministry of Animal Resource of Niger

NA Not Availble

NAIP National Agricultural Investment Plan

NAPA National Adaptation Programmes of Action

NAPRI National Animal Production Research Institute (Nigeria)

NCD Newcastle Disease

NEPAD New Partnership for Africa's Development

NGO Non-Govermental Organisation

NVQSN National Veterinary Quarantine Services of Nigeria

NVRI National Veterinary Research Institute (Nigeria)

OECD Organisation for Economic Co-operation and Development

$\mathrm{OH}$ One Health

OIE World Organisation for Animal Health

ONERA National Office for the Use of Animal Resources (Burkina Faso)

PACE Pan African Programme for the Control of Epizootics

PADFAu Grass-cutter Value Chain Development Support Project (Benin) 


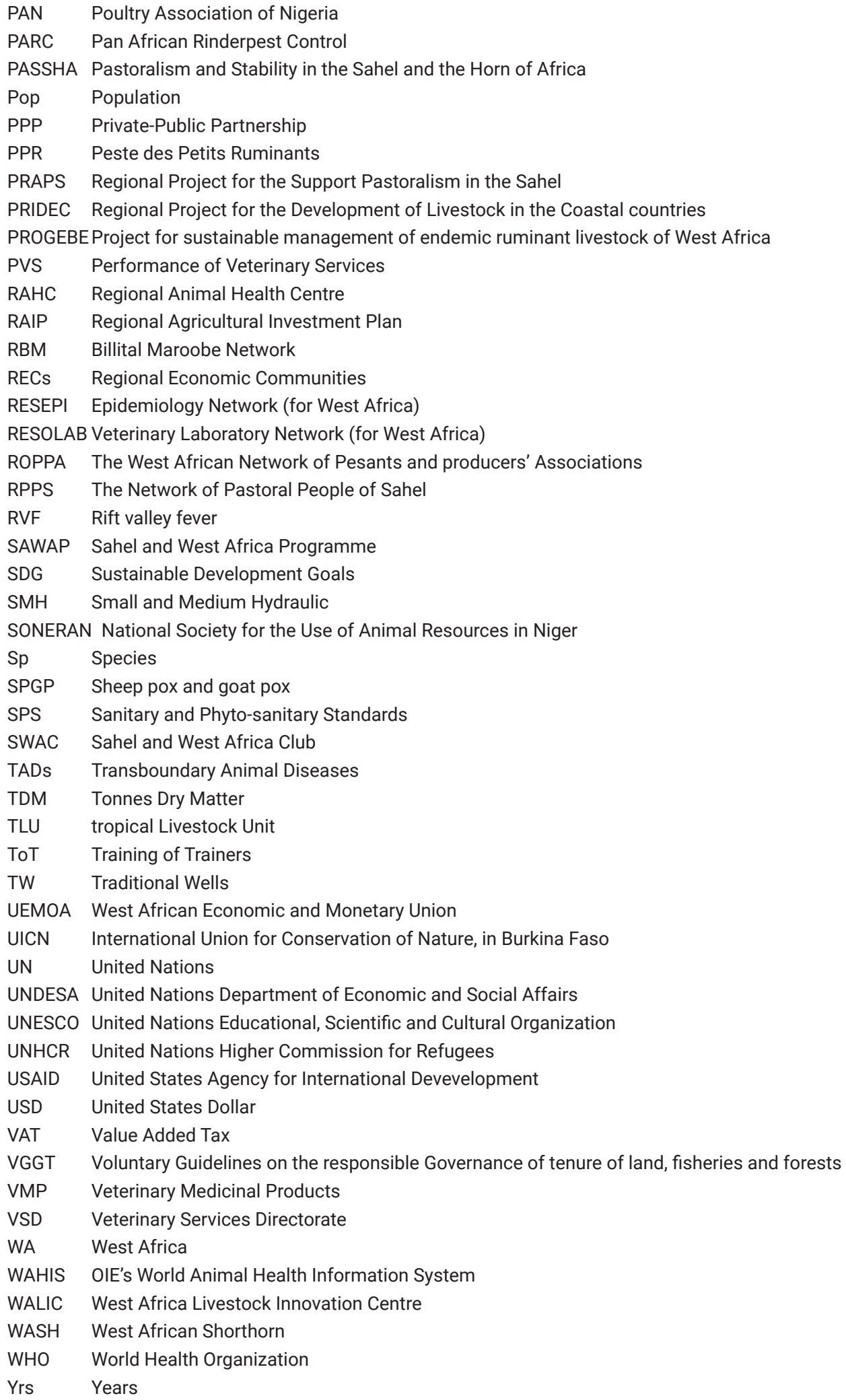




\section{Units}

$\begin{array}{ll}{ }^{\circ} \mathrm{C} & \text { degrees centigrade } \\ \mathrm{cm} & \text { centimeter } \\ \mathrm{g} & \text { gram } \\ \mathrm{h} & \text { hour } \\ \mathrm{ha} & \text { hectare } \\ \mathrm{kg} & \text { kilogram } \\ \mathrm{km}^{2} & \text { square kilometre } \\ \mathrm{It} & \text { litre } \\ \mathrm{m} & \text { metre } \\ \mathrm{m}^{\star} & \text { million } \\ \mathrm{m}^{3} & \text { cubic meter } \\ \mathrm{mj} & \text { millijoule } \\ \mathrm{ml} & \text { milliliter } \\ \mathrm{mm} & \text { millimeter } \\ \mu \mathrm{m} & \text { micrometer }\end{array}$




\section{Introduction}

A significant number of Western African countries, particularly those in the northern half of the region, depend on livestock as a source of generating substantial revenue and ensuring livelihoods of the populace. In this regard, FAO has conducted several studies and held various workshops in recent years to gain a better insight into the challenges and opportunities presented by the livestock sub-sector in West Africa. The outcomes of these studies and workshops conducted between 2009 and 2014 were published and distributed as hard copy reports and disseminated as on-line publications.

The review reports on the livestock sub-sector value chains, cross-border transhumance, animal feed resources, among others, were informative in their own right. Still, the fact that they targeted specific areas of livestock in a fragmented manner did not address the need of readers whose wish was to have a comprehensive understanding of the livestock sector in West Africa. It is in response to this demand for a comprehensive outlook of the West African Livestock sector that different reports and studies have been compiled into this one book, an idea which was conceived in 2014.

Although the first draft of the book was compiled towards the end of 2015, filling the various gaps of the first version and improving its quality faced challenges and required more time and effort to complete than initially expected. The delays meant that some of the information became outdated, and there was a need to update the draft. Eventually, the different chapters of the completed and updated book were reviewed by subject matter experts, whose inputs and comments were pivotal to enriching the current version. The publication of this book attempts to fill the gap of a need for comprehensive information on the potential, performance, challenges, and prospects of the livestock sub-sector in West Africa. The book has twelve chapters, covering almost all aspects of livestock in the region.

Chapter one describes the geography, climate, and the available resources supporting livestock rearing in West Africa. Chapter one also describes the demography and distribution of the population involved in the agricultural sector, in general, and particularly in livestock production. Chapter two is dedicated to livestock resources, covering the number of different species and their distribution per country and across countries.

Chapter three presents the rich bio-diversity of West Africa in animal genetic resources by describing the different breeds per species, the type of product for which they have a comparative advantage, and their productivity. Chapter four of the book describes the different livestock production systems practiced across West Africa. Cross-border transhumance is described in detail, in part to address the growing conflicts due to competition on grazing land and limited water resources among different groups of pastoralists and crop farmers. The last part of the chapter covers emerging livestock production systems around urban areas with different levels of intensification.

The status of inputs required for livestock production, such as feed, water, infrastructure, and services, are presented in chapter five. Where relevant, chapter five, details the amount of these inputs available locally and those inputs issue of imports. Animal health care, as one of the primary inputs into livestock production, is described in chapter six, together with different animal diseases and zoonosis in West Africa.

Chapter seven of the book deals with the volume and value of different types of animal products generated in the region by providing changes over time where information is available. The chapter covers all the major animal products, i.e., meat, milk, egg, with statistics on volume per country in most cases and the monetary value generated. 
Trade of live animals and animal products within West Africa and beyond is the focus of chapter eight. It provides details on the value and volume of different livestock-based commodities and trade balances. Both regional and international trading partners are listed per animal product or inputs where applicable.

Chapter nine of the book is on the legal framework governing the livestock sub-sector in West Africa. It covers the national and regional livestock policies and legislations on various aspects of livestock. Policies on investment, trade, natural resource management, animal health, among others, are discussed. The chapter also covers regional level regulations such as the ones on cross-border transhumance, food safety, and veterinary drugs.

The roles played by the livestock sub-sector in West Africa are listed and described in chapter ten. The diversified roles of livestock contributing to food security and nutrition, poverty reduction, savings, wealth creation, and cultural and traditional roles are described and examples provided. Chapter eleven highlights the constraints hindering the development of the livestock sub-sector in West Africa, these constraints/challenges being grouped under three main categories, namely structural, institutional, and emergencies. The constraints are discussed in detail, and where available, possible solutions are proposed.

The last chapter, i.e., chapter 12, covers the prospects of the livestock sub-sector in West Africa. Chapter 12 also addresses global trends in livestock transformation as a response to growing demands for animal products to feed the fast-growing population. Equally, the chapter discussed the impacts a fastgrowing population implies on the sub-sector in West Africa.

Attempts were made to enrich the information provided by including short case studies focusing on different aspects of the livestock sub-sector in West Africa. Eight case studies covering salient issues in the region, i.e., the substitution of bush meat with rearing non-conventional animals, conflicts due to transhumance, donkey skin trade and experience of attempting to settle pastoralists using grazing reserves, etc. are discussed. 
THE ENVIRONMENT FOR LIVESTOCK REARING IN WEST AFRICA
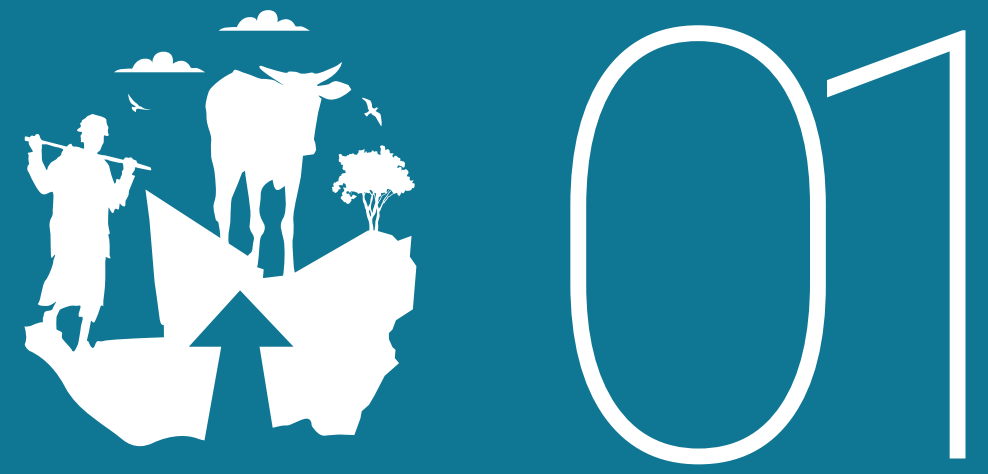



\section{CHAPTER I}

\section{THE ENVIRONMENT FOR LIVESTOCK REARING IN WEST AFRICA}

\subsection{Natural resources}

The livestock sub-sector in West Africa uses a significant amount of natural resources. The geographic location and climate define the availability of these natural resources, which in turn influence livestock production in the region. The knowledge of areas with similar rainfall patterns, temperature, elevation and latitude, collectively known as agro-ecological zones (AEZ) serves to understand the potential or constraints of land-use of a given area. Such knowledge will assist in improving the existing land-use situation through increasing production or limiting land degradation. In the case of livestock production, not only suitability of different AEZ for rearing different animal species matters, but also the distribution of disease agents and most importantly vectors depend on prevailing climate and vegetation (FAO, 1996).

Land is a crucial natural resource for all sorts of agricultural production, including livestock. West Africa is endowed with agricultural land, varying between 62 and 95 percent of the total land area of individual countries. In an era of agricultural revolution marked with climate change and socio-economic dynamics such as population growth, outdated production systems are forced to give way to new ones in order to suit new situations. Therefore, land tenure and land use patterns are also fundamental to understand livestock production issues in West Africa (Riddell, 1982).

\subsubsection{Geographic location}

The Western Africa region extends from the Sahara in the north, to the Atlantic Ocean in the south and along the Atlantic Ocean in the West ${ }^{1}$. The eastern border is less precise, being placed on a line running from Mount Cameroon to Lake Chad. For the purpose of this book, all the countries within the mentioned geographical borders except Mauritania are considered as West African countries. These countries are Benin, Burkina Faso, Cabo Verde, Côte d'Ivoire, Gambia, Ghana, Guinea, Guinea Bissau, Liberia, Mali, Niger, Nigeria, Senegal, Sierra Leone and Togo, all members of the Economic Community of West African States (ECOWAS). The total surface area of the region is 5.1 million Square Kilometres $\left(\mathrm{km}^{2}\right)$, which is about 17 percent of the land mass of the African continent. Two countries, Niger and Mali together, with their vast arid and semiarid areas, cover almost half of the West African region (Jarrett, 1980 and NWE, 2013). 


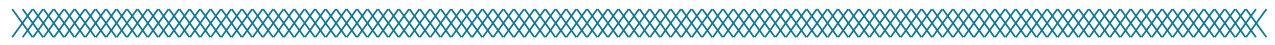

Figure 1. Political map of West Africa

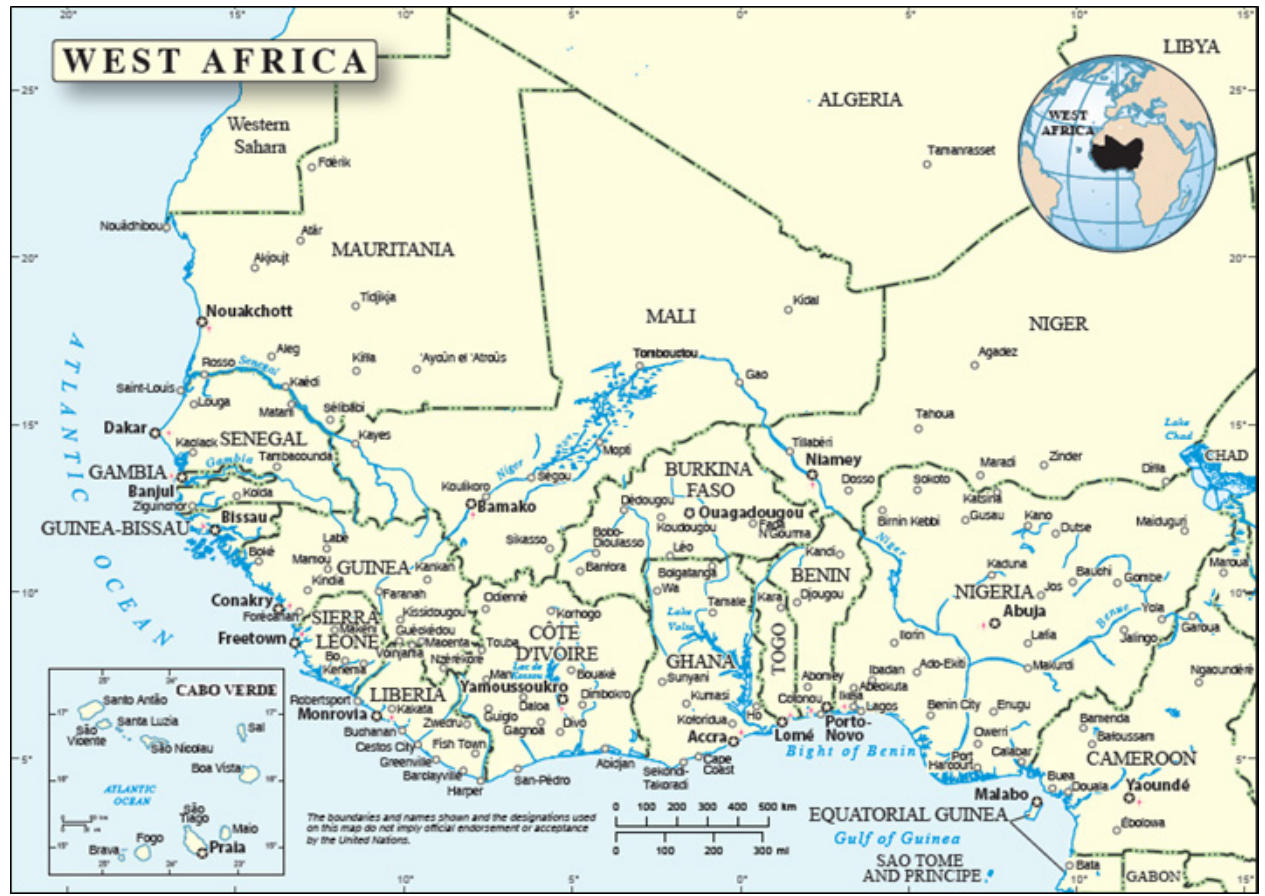

Source: Adapted from UN West Africa map, 2014.

Table 1. Surface area of West African countries

\begin{tabular}{|c|c|c|c|}
\hline Country & Area in km² & $\%$ from West Africa & $\%$ from Africa \\
\hline Benin & 112620 & 2.2 & 0.4 \\
\hline Burkina Faso & 274200 & 5.4 & 0.9 \\
\hline Cabo Verde & 4033 & 0.1 & 0.0 \\
\hline Côte d'Ivoire & 322460 & 6.3 & 1.1 \\
\hline The Gambia & 11300 & 0.2 & 0.0 \\
\hline Ghana & 239460 & 4.7 & 0.8 \\
\hline Guinea & 245857 & 4.8 & 0.8 \\
\hline Guinea Bissau & 36120 & 0.7 & 0.1 \\
\hline Liberia & 111370 & 2.2 & 0.4 \\
\hline Mali & 1240000 & 24.3 & 4.1 \\
\hline Niger & 1267000 & 24.8 & 4.2 \\
\hline Nigeria & 923768 & 18.1 & 3.0 \\
\hline Senegal & 196190 & 3.8 & 0.6 \\
\hline Sierra Leone & 71740 & 1.4 & 0.2 \\
\hline Togo & 56785 & 1.1 & 0.2 \\
\hline West Africa & 5112903 & 100.0 & 16.8 \\
\hline
\end{tabular}

Source: Calculated from TWF, (2014). 


\subsubsection{Climate}

The climate in West Africa ranges from hot and dry in the North to warm and moist along the Atlantic Ocean in the south. The mean annual temperatures in the region are usually above 18 degree centigrade $\left({ }^{\circ} \mathrm{C}\right)$, but have increased over the last 50 years, while the distribution of rains varies from place to place and from year to year. The rains, general, are becoming more erratic and less in volume. There are two distinct seasons in the northern part of West Africa, encompassing countries like Burkina Faso, Mali, Niger, parts of Nigeria and Senegal. The southern part of the region, covering countries like Benin, Côte d'Ivoire, Ghana, Gambia, Guinea, Guinea Bissau, Liberia, Sierra Leone and Togo, has four different seasons. The climate of the island nation of Cabo Verde is warm and temperate, following a two-season pattern similar to the region's northern part. There is slight difference from country to country in length and the starting and ending time of these seasons (Jalloh et al., 2013 and Niang, et al., 2014).

The two seasons of the northern part of West Africa are the relatively longer dry season running from October to May and the rainy season from June to September. The dry season, particularly from November to March, is the period when cold air mass blows dust from the Sahara towards the south causing different degrees of haze, known also as the harmattan, while the rainy season is the period when this part of West Africa receives annual mean precipitation ranging from $300 \mathrm{~mm}$ in the north to $1,300 \mathrm{~mm}$ further to the south depending on the AEZ (up to $1,513 \mathrm{~mm}$ in Cabo Verde). Between latitudes $10^{\circ} \mathrm{N}$ and the southern part of the Sahara, mean annual temperature ranges from $9^{\circ} \mathrm{C}$ to $17^{\circ} \mathrm{C}$, but can rise up to $30^{\circ} \mathrm{C}$, while in the central Sahara the mean annual temperature ranges from $10^{\circ} \mathrm{C}$ to $35^{\circ} \mathrm{C}$, but it may be as high as $58^{\circ} \mathrm{C}$ during the day and as low as $4^{\circ} \mathrm{C}$ at night (FAO, 1983 and UNEP, 2006).

The four seasons of the southern part of West Africa are the long rainy season, extending from midMarch to July, the August short dry season, the short rainy season of September and October and finally the long dry season, which starts around mid-November and extends till mid-March. The latter is also called the harmattan season as mentioned earlier. The southern part of West Africa receives heavy rains

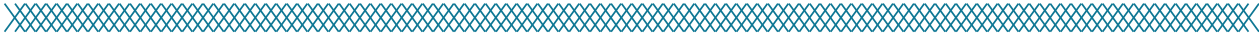

Figure 2. Rainfall and wind patterns determining climate in West Africa
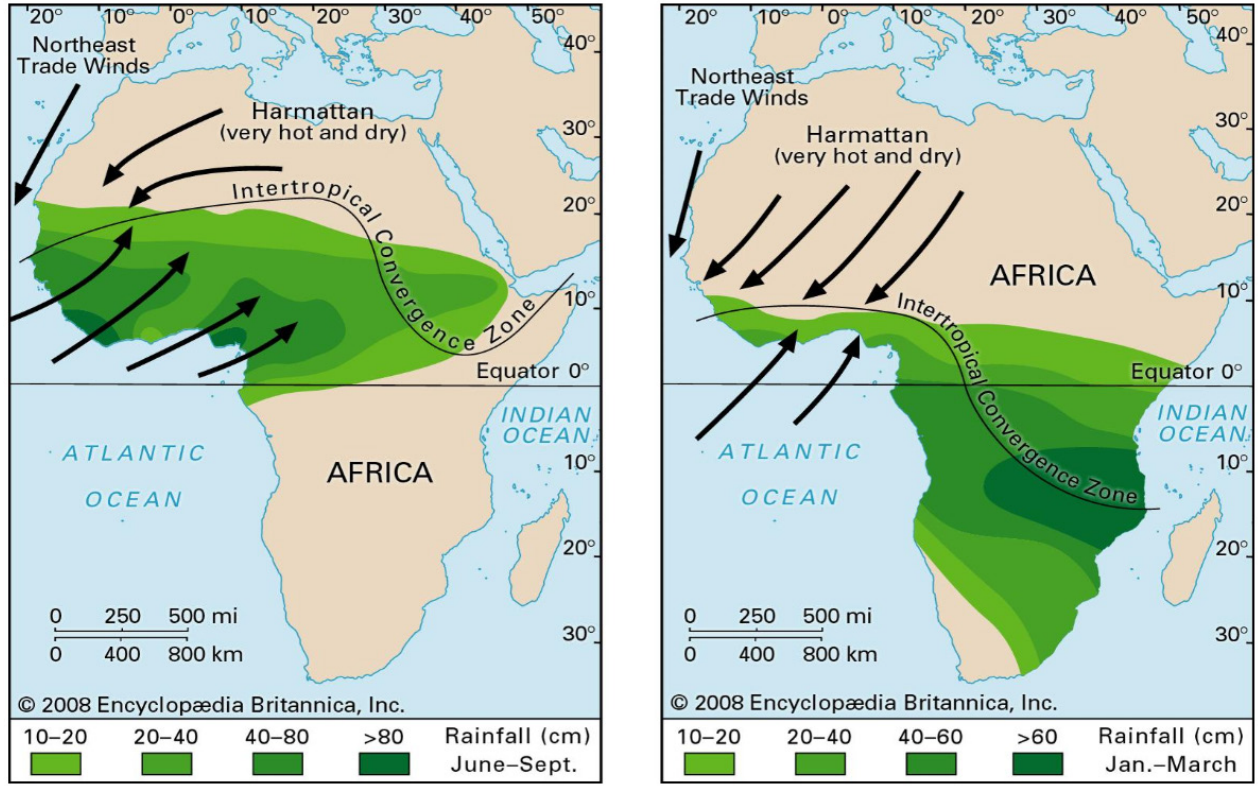

Source: EB, (2008). 
during the long rainy season, favorable for the growth of pasture and plants in general. Areas within $10^{\circ}$ of the Equator have a mean annual temperature of about $26^{\circ} \mathrm{C}$ with a range of $1.7^{\circ} \mathrm{C}$ to $2.8^{\circ} \mathrm{C}$; the diurnal range varies between $5.6^{\circ} \mathrm{C}$ and $8.3^{\circ} \mathrm{C}$ (FAO, 1983 and UNEP, 2006).

\subsubsection{Agro-ecological zones}

As mentioned above, the West African region extends from the Sahara in the North to the tropical rain forest close to the coast of the Atlantic Ocean in the South. Based on the relationship between the major climates, moisture zones and warm/cool surfaces, several schemes have been described to classify land resources in West Africa into agro-ecological zones (Chevalier, 1933; Aubréville, 1949; Keay, 1959; and Jahnke, 1982). The type of classification used varies widely from one country to another. Regardless the case, however, they all fall into two categories, one based on average annual rainfall and the other on moisture index. Using the HarvestChoice classification (HarvestChoice, 2010), West Africa spreads between four agro-ecological zones: i.e. tropic-warm/arid, tropic-warm/semi-arid, tropic-warm/ sub-humid and tropic-warm/humid. But given that the annual rainfall-based system is the one more frequently used in individual countries in West Africa (HarvestChoice, 2010), this book will follow this system in describing AEZs in the region. Hence, following an increasing north to south rainfall gradient, the AEZs found in West Africa are: Sahara, Sahel, Sudan and Guinea (Figure 3).

Y.

Figure 3. Agro-ecological map of West Africa

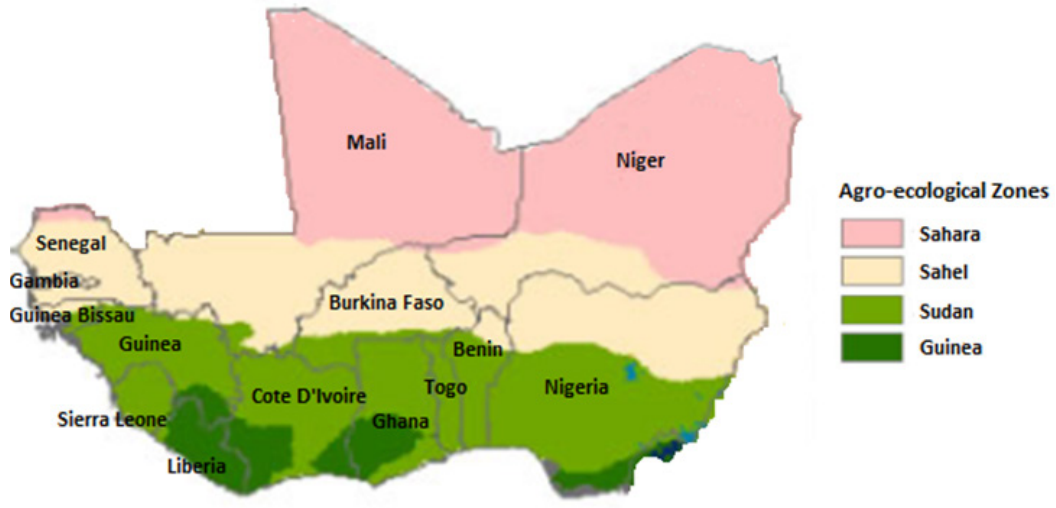

Source: Adapted from HarvestChoice, (2010).

\section{Sahara agro-ecological zone}

The Sahara AEZ or arid zone is found in the extreme north of the West African region, located in Mali and Niger and covering 80 and 57 percent of their national territory respectively. This zone covers an area of 1.5 million $\mathrm{Km}^{2}$, almost one-third of the total surface area of the West Africa. The Sahara AEZ of the region has hot desert type climate receiving a very low to an extremely low annual average precipitation, ranging between 50 and $300 \mathrm{~mm}$. The average high temperatures are often between $38^{\circ} \mathrm{C}$ and $46^{\circ} \mathrm{C}$, while average low temperatures mainly stay around $21^{\circ} \mathrm{C}$ and $29^{\circ} \mathrm{C}$. The climate becomes extremely hotter and drier, when the scorching, desiccating and sometimes dust-laden harmattan wind blows. The Length of Growing Period (LGP) is less than 75 days, therefore most of the zone is devoid of any form of vegetation and there is no agricultural production of any sort. However, in areas bordering semi-arid $A E Z$, where rainfall reaches around $300 \mathrm{~mm}$, some sort of plants adapted to the arid conditions, such as acacia trees, palms, succulents, spiny shrubs, and grasses, may be found and livestock rearing, mainly nomadic camel and goat production, occurs (FAO, 1996; Geesing and Djibo, 2001 and Coulibaly, 2003). 


\section{Sahel agro-ecological zone}

The Sahel AEZ or semi-arid zone lies between the Sudanian Savannah and the Sahara, covering parts of the Gambia, Senegal, central Mali, Burkina Faso, southern Niger and northern Nigeria. The climate is very hot year-round, with average high temperatures between $36^{\circ} \mathrm{C}$ and $42^{\circ} \mathrm{C}$ during the hottest period, while the average low temperatures are between $15^{\circ} \mathrm{C}$ and $21^{\circ} \mathrm{C}$ during the coldest period. The annual mean rainfall is low, between $100 \mathrm{~mm}$ at the border with the Sahara AEZ and $600 \mathrm{~mm}$ further south at the border with Sudanian AEZ. The rainfall is concentrated on a short period of the year, showing great spatial, annual and inter-annual variability. Vegetation cover is fairly continuous, dominated by annual grasslands (Cenchrus biflorus, Schoenefeldia gracilis and Aristida stipoides) and savannah acacias (Acacia tortilis, Senegalia senega ${ }^{2}$ and Acacia laeta), with areas of woodland (Commiphora africana, Balanites aegyptiaca, Faidherbia albida and Boscia senegalensis) and shrub-land (Panicum turgidum and Aristida sieberanas). With an LGP in the range of 75 to 180 days, only irrigation-based crop production and seasonal migratory type of livestock production is possible. This zone includes the vast interior delta of Niger River in Mali (some $30,000 \mathrm{~km}^{2}$ ), where recessional agriculture is practiced (FAO, 1996; Geesing and Djibo, 2001; Coulibaly, 2003; Kagone, 2001 and Aregheore, 2005).

\section{Sudan agro-ecological zone}

The Sudan AEZ or sub-humid zone extends in a band several hundred kilometres wide across center and southern Senegal, through southern Mali, Burkina Faso, southern Niger and northern Côte d'Ivoire, Benin, Gambia, Ghana, Guinea and Nigeria. The climate is hot, with mean monthly temperatures that can rise to $30^{\circ} \mathrm{C}$. The average annual precipitations ranges from $750 \mathrm{~mm}$ to $1,100 \mathrm{~mm}$. The vegetation is of the wooded to shrubby savannah type or open forest, characterized by the coexistence of trees (Combretaceae, Caesalpinioideae and Acacia sps.) and grasses (Andropogoneae, Hyparrhenia, Loudetia and Aristida). An LGP in the range of 180 - 270 days allows cultivation of several crops such as sorghum, millet and groundnuts. Good vegetation cover, availability of crop residues as source of animal feed makes this zone of choice for livestock production, although competition over land and presence of tsetse flies are major problems (FAO, 1996; Geesing and Djibo, 2001; Coulibaly, 2003; Kagone, 2001; Aregheore, 2005; Oppong-Anane, 2001 and Aregheore, 2009).

\section{Guinea agro-ecological zone}

The Guinea AEZ or humid zone extends from western Senegal to eastern Nigeria, including portions of the Gambia, Guinea Bissau, Guinea, Sierra Leone, Côte d'Ivoire, Liberia, Ghana, Togo and Benin. The climate is generally hot and humid, with average annual temperature of about $26^{\circ} \mathrm{C}$. Average annual rainfall range between $800 \mathrm{~mm}$ to $1,200 \mathrm{~mm}$ in the north and between $2,500 \mathrm{~mm}$ to $4,500 \mathrm{~mm}$ in the southern part of this AEZ, distributed mainly within the monsoonal-type rainy season (June to November). The LGP (May/June to September/October) varies about 150 days in the northern part to 210 days in the southern part. This clearly explains why the vegetation in the northern zone is the most wooded savannah in West Africa (129 trees/ha) and in the south most layer of the zone is dominated by the rainforests. The main crops cultivated in this AEZ are maize, cassava, rice, millet, sorghum and groundnuts, but sugar cane, banana and beans are also grown in the wetter parts. Livestock, mostly trypanotolerant cattle, sheep and goats are few in numbers (FAO, 1996; Coulibaly, 2003; Aregheore, 2005; Oppong-Anane, 2001; Aregheore, 2009 and Larbi, 2012).

\subsubsection{Land tenure and use patterns}

Land tenure is the relationship, whether legally or customarily defined, among people, as individuals or groups, with respect to land and realted natural resources such as water and trees that defines how access is granted to rights to use, control, and transfer land, as well as associated responsibilities 


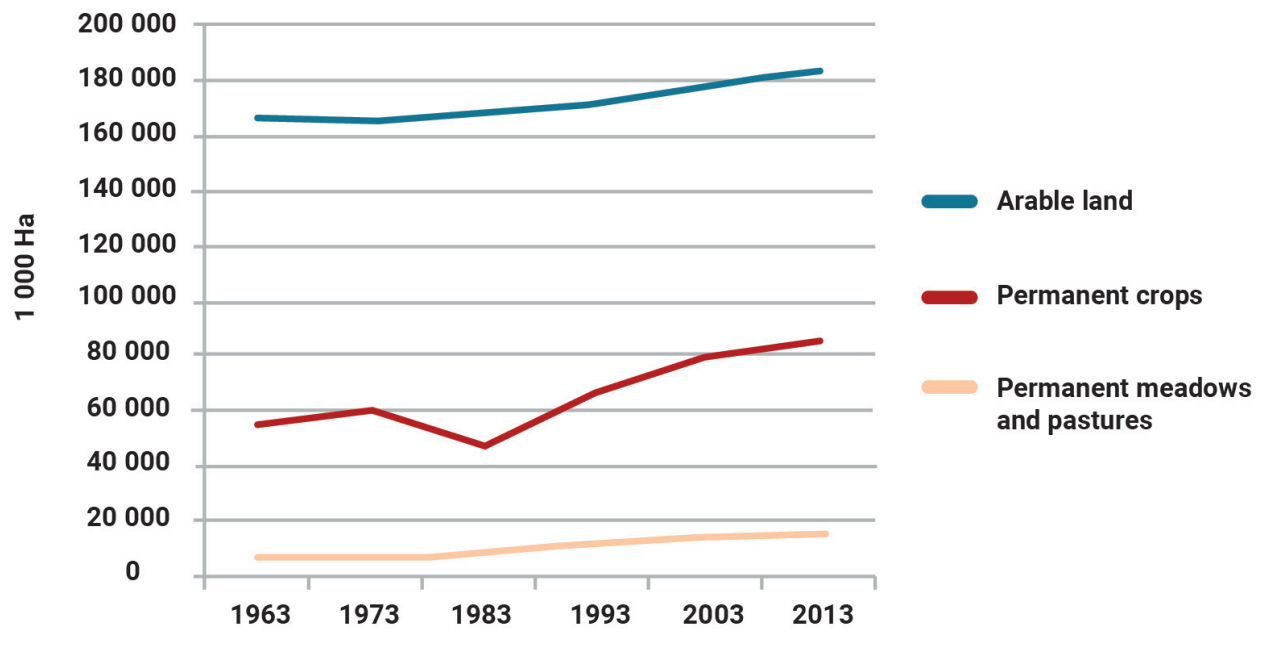

Source: FAOSTAT (2019).

and restraints (FAO, 2002). Land tenure structures are complex and vary between and within countries. In the case of West Africa, usually a general framework of land tenure rules and regulations exist in form of laws and acts specific to each country. However, due to lack of capacity or lack of political will to enforce these rules, or to inherent weaknesses in them, West African countries, likewise most developing countries of the world, are confronted with land problems in different dimensions and of varying magnitude, being livestock owners in general and pastoralist in particular, the worst affected with this problem.

To present days, the legacy of dual land tenure systems, that is the statutory represented by national policy and customary and the community-based system, prevail in most West African countries. Communal land ownership is the expression used to describe the system whereby land is collectively owned by an extended family, clan or community of ancestrally related people with the control or administration of the land vested in the community leader or his appointees. Statutory land tenure system on the other hand comprises leaseholds and freehold tenures. In leasehold land tenure system, the ownership rights are granted by the State for a term which may vary from 35 to 99 years, depending on the situation and specific country laws. The right is only legalized through registration of the property leading to the production of a formal title deed or lease document (Riddell, 1982).

However, whether officially recognized or not, community-based tenure systems predominantly dictate who has access to land and natural resources. In many cases, access to land has been implemented through customary land tenure arrangements rather than through the use of land tenure rules set by laws and regulations of the country. The only significant regions where this is not the case are in urban and peri-urban areas-where freehold tenure systems supported by land registration systems have been put in place development zones such as irrigation schemes or plantations (Bruce, 1998). 
Although customary system has been able to support economic activities and has enabled land marketing of one form or another, pressures due to population growth, infrastructure developments, ownership insecurities, widespread land disputes and associated litigations, and world economic trends make it imperative that it adapts to a formal system of registration of title. In many countries and over the years, various attempts have been made towards title registration, but they have not been very effective. It can be argued that land tenure reforms should build upon the strengths of indigenous tenure systems and take into account the social and political dynamics that influence how productive resources are acquired, used, contested and underutilized (Bassett and Crummey, 1993).

In West Africa, land and range resources are under intense pressure especially as a result of expansion in agricultural activities resulting from population growth and its associated growing needs of the populations. According to data from (FAOSTAT, 2019), the West African region has about 101 million hectares of farmland that have experienced a 62.3 percent increase between 1963 and 2013. Moreover, there are nearly 183 million hectares of permanent meadows and pasture suitable for livestock production that has experienced a 90.5 percent increase between 1963 and 2013 (Figure 4). This decline in forested land was mainly due to clearing for the expansion of crop production and pastureland (Chakravarty et al., 2012).

Considering the total surface area of West Africa, it can be noted that the stocking density has considerably changed over time. Based on calculation made using figures from (FAOSTAT, 2019), it has dropped from 19 ha per Tropical Livestock Unit ${ }^{3}$ (TLU) in 1961 to 5.5 ha/TLU in 2013. If this trend continues, it will be only 3 ha/TLU in 2030 and 1 ha/TLU in 2050. This has implications for traditional agricultural production system, which are being compelled to intensify and take advantage of technological innovations that support increased productivity of livestock per unit of land. This in general is taking a tremendous amount of time because farmers, especially the pastoralists, have they own believes and views about intensification.

Deforestation due to bush fire (especially in the Sudan and Sahel AEZ) and the obstruction of livestock migratory routes and ways to watering points are also major causes of the shrinking of rangelands in many West African countries. Rangelands in humid zones receiving high rainfall generally produce dense woody component and tall grasses. These are generally of low nutritive value and quickly become coarse and unpalatable for livestock. This ultimately leads to an over-production and under-utilization of the grass in these rangelands vis-à-vis the grazing livestock (De Leeuw, and Reid, 1995).

Except in government owned or operated farms and few private intensive farms, the majority of livestock in West Africa graze on natural pasture belonging to village communities. Since the land tenure system does not ensure the community ownership other than utilization, livestock production in pastoral areas remains precarious. Difficulties to access pasture and water resources are at the heart of many permanent conflicts between crop farmers and pastoralists. The current status of land tenure system in rural areas constitutes a real bottleneck for agricultural intensification (key to food security and poverty reduction through job creation) as it does not allow security for investments. In the course of discussing problems confronting pastoralists in West Africa, the usual factors that readily come to the fore are water, animal feed, animal health and more recently conflict. Very little attention is paid to the issue of land tenure and access right to pastoral resources (Williams et al., 2004a). 


\subsection{Human population}

Population can be seen both as an asset in terms of its inescapable and multi-feature inputs in almost any production system and as the final beneficiary (direct or indirect) of basically all product generated from agriculture, especially living and lifestyle commodities. The livestock sub-sector plays a significant socio-economic role in West Africa, providing income and employment for the region's population. These roles are increasing in importance as the sub-sector grows because of increasing human populations, incomes and urbanization rates. The number, distribution by occupation in the agricultural sector and other characteristics of the population is a central issue that this section deals with bearing in mind the peculiarities of the West African subregion.

\subsubsection{Demographic characteristics of West Africa}

The human population of West Africa was estimated at 376.8 million in 2018. Nigeria alone contributes to more than half of this figure (52.0 percent). With an average 2.7 percent annual growth rate, it is a subregion with one of the highest population growth rates, ranging between 1.2 percent in Cabo Verde to 3.9 percent in Niger. It is slightly skewed toward the male gender, with an average sex ratio of 101.3 males for 100 females (UNDESA, 2019).

With youth below 15 years of age making up of 44.0 percent in 2015, the population is relatively a young one. This figure varies widely between countries, ranging from 30.0 percent in Cabo Verde and 50.2 percent in Niger (UNDESA, 2019). Life expectancy at birth in West Africa is estimated at 59.3 years for male and 61.7 years for female in 2017, with the longest life expectancy in Senegal 65.4 years for male and 69.4 years for female compared with the lowest 51.6 years for male and 52.8 years for female in Sierra Leone (World Bank, 2019a).

Across countries and overall at Regional level, the population is unequally distributed, with higher concentration in southern and coastal areas compared with northern arid and semiarid zones. The average population density over the whole subregion was estimated by (UNDESA, 2019) at 62.9 inhabitants per $\mathrm{km}^{2}$ in 2019 , with significantly large differences between countries, ranging from the lowest 15.6 inhabitants per $\mathrm{km}^{2}$ in Mali to as high as 225.3 inhabitants per $\mathrm{km}^{2}$ in the Gambia.

Illiteracy rates in West Africa are the highest in the world, reaching 40 percent of the adult population (65 million adults). Of the 10 countries with the world's lowest recorded adult ${ }^{4}$ iliteracy rates, seven are in West Africa: Benin (44 percent), Burkina Faso (38 percent), Guinea (50 percent), Mali (34 percent), Niger (50 percent), Senegal (30 percent) and Sierra Leone (33 percent) (UNESCO, 2015).

\subsubsection{The proportion of urban and rural population in West Africa}

The large proportion of West Africa's population still resides in rural areas. Figures show that overall, the proportion of the population living in rural areas in West Africa is estimated at 55.5 percent against 44.5 percent in urban areas (Table 2). The proportion of the population living in rural areas ranges between 35.7 percent in Cabo Verde and 83.8 percent in Mali (UNDESA, 2018). However, in most of the countries there is a clear indication of an increasing trend in urbanization, as it was captured in a study conducted by the 36 covering the period of $1960-1990$ and projected through 2020 (Figure 5).

In fact, while the proportion of rural population in most West African countries in 1960 was 80 percent or higher, it dropped to between 50 and 80 percent in 1990 in most of the coastal countries. In the 2020 
Table 2. Demographic characteristics of West Africa

\begin{tabular}{|c|c|c|c|c|c|c|c|c|c|c|}
\hline & $\begin{array}{l}2018 \text { in } \\
\text { Million }\end{array}$ & $\%$ WA & $\begin{array}{l}\text { Male in } \\
\text { Million }\end{array}$ & $\begin{array}{l}\text { Female in } \\
\text { Million }\end{array}$ & $\begin{array}{l}\text { Male } \\
\text { per } 100 \\
\text { female }\end{array}$ & $\begin{array}{l}\text { Density } \\
\text { Pop./ } \\
\text { Km2 }\end{array}$ & $\begin{array}{l}\text { \% Rural } \\
2015\end{array}$ & $\begin{array}{l}\text { \% Urban } \\
2015\end{array}$ & $\begin{array}{l}\text { Below } \\
15 \text { Yrs } \\
\%\end{array}$ & In Agr. \% \\
\hline Benin & 11.48 & 3.05 & 5.73 & 5.75 & 99.61 & 101.9 & 54.3 & 45.7 & 42.4 & 41.4 \\
\hline Burkina Faso & 19.75 & 5.24 & 9.86 & 9.89 & 99.62 & 72.2 & 72.5 & 27.5 & 44.9 & 28.7 \\
\hline Cabo Verde & 0.54 & 0.14 & 0.27 & 0.27 & 100.73 & 134.9 & 35.7 & 64.3 & 42.3 & 48.0 \\
\hline Côte d'Ivoire & 25.06 & 6.65 & 12.66 & 12.41 & 101.94 & 78.8 & 50.6 & 49.4 & 29.8 & 13.4 \\
\hline Gambia & 2.28 & 0.61 & 1.13 & 1.15 & 98.40 & 225.3 & 40.8 & 59.2 & 38.3 & 33.9 \\
\hline Ghana & 29.77 & 7.90 & 15.08 & 14.68 & 102.73 & 130.8 & 45.9 & 54.1 & 42.0 & 66.5 \\
\hline Guinea & 12.41 & 3.29 & 5.98 & 6.43 & 92.97 & 50.5 & 64.9 & 35.1 & 45.1 & 29.7 \\
\hline Guinea Bissau & 1.87 & 0.50 & 0.92 & 0.96 & 95.43 & 66.7 & 57.9 & 42.1 & 41.3 & 68.0 \\
\hline Liberia & 4.81 & 1.28 & 2.42 & 2.40 & 100.93 & 50.0 & 50.2 & 49.8 & 41.5 & 46.2 \\
\hline Mali & 19.08 & 5.06 & 9.55 & 9.53 & 100.24 & 15.6 & 60.0 & 40.0 & 47.5 & 65.3 \\
\hline Niger & 22.44 & 5.96 & 11.27 & 11.17 & 100.92 & 17.7 & 83.8 & 16.2 & 50.1 & 75.9 \\
\hline Nigeria & 195.88 & 51.99 & 99.24 & 96.64 & 102.69 & 215.1 & 52.2 & 47.8 & 43.8 & 36.6 \\
\hline Senegal & 15.85 & 4.21 & 7.72 & 8.13 & 95.02 & 82.3 & 54.1 & 45.9 & 42.7 & 32.0 \\
\hline Sierra Leone & 7.65 & 2.03 & 3.82 & 3.83 & 99.52 & 106.0 & 59.2 & 40.8 & 41.7 & 58.8 \\
\hline Togo & 7.89 & 2.09 & 3.92 & 3.97 & 98.93 & 145.0 & 59.9 & 40.1 & 41.3 & 34.5 \\
\hline West Africa & 376.76 & 100.00 & 189.57 & 187.22 & 101.26 & 62.9 & 55.5 & 44.5 & 43.2 & 41.2 \\
\hline
\end{tabular}

Source: figures from different sourcesfigures from different sources (a UNDESA, 2018, bUNDESA, (2019), ${ }^{\mathrm{c} T W F},(2014)$ and dWorld Bank, 2019a).

projection, this proportion is expected to drop further to between 15 and 50 percent in most parts of countries like Nigeria, Côte d'Ivoire, Benin and Senegal. Already by 2020, half of the projected 388 million people residing in West Africa will live in urban areas, and urbanization is expected to reach 65 percent by 2050 (UNFPA, 2010). Studies conducted by OECD in 2013 showed that urbanization is having impact on livestock production, income, lifestyle and consumption preference of the population (OECD/FAO, 2016).

\subsubsection{Population engaged in agriculture and ivestock production in West Africa}

About 41.2 percent of the West African population is engaged in agriculture or related fields. This proportion ranges from the highest figure in Guinea Bissau (68 percent) to the lowest in Cabo Verde (13.4 percent) (World Bank, 2019a). Agriculture in West Africa is mainly subsistence, makin use of low input and inadequate technology and, therefore, resulting in low output per unit of land or animal. If population growth trend takes place as projected, there is a pressing need for intensification of production as to meet the Regional demand for food. This is particularly true for the livestock subsector, as there is already more and more demand for food of animal origin and the projections show many folds of increase in the years to come triggered by rapid urbanization, growing middle class and as a result of these, shift in consumer preference towards animal products. 
Figure 5. Evolution of rural and urban population in West Africa (1960 - 2020)
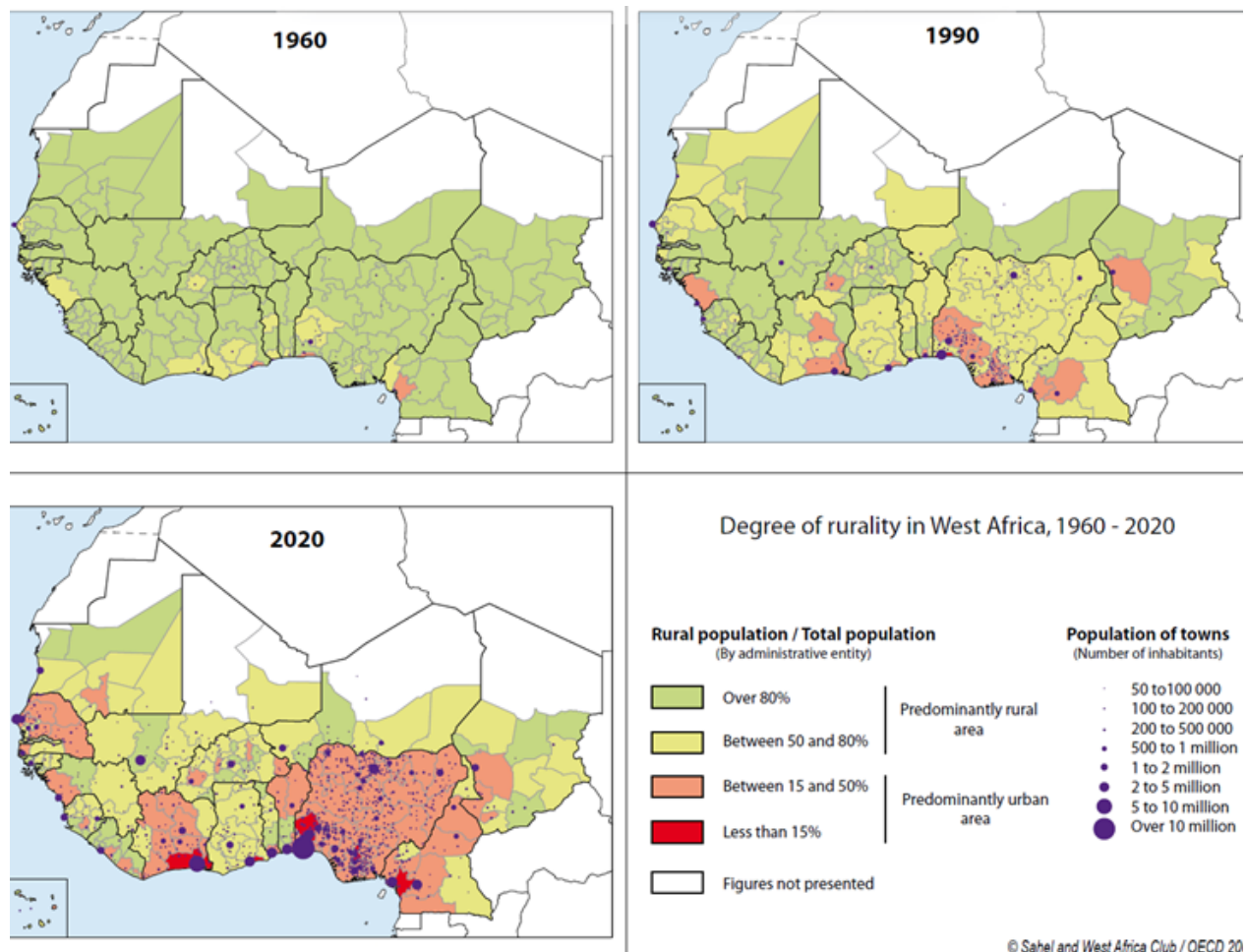

Degree of rurality in West Africa, 1960 - 2020

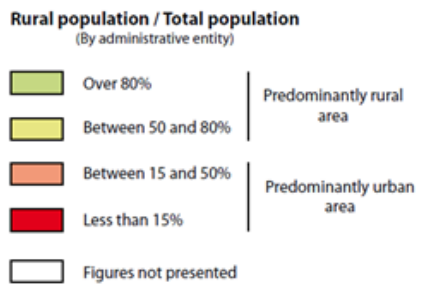

Population of towns 50 to 100000 100 to 200000 500 to 1 million

- 1 to 2 million

- 2 to 5 million

5 to 10 million

Over 10 million

OSahel and West Africa Club / OECD 20

Source: SWAC/OECD, 2007.

The FAO subregional office for West Africa (FAO/SFW) has conducted several livestock sub-sector reviews, studies on priority diseases and cross border transhumance and value chain studies. The results were published either as hard copy prints or as web publications. These publications at country or regional level will be cited across this book under the name of consultants who compiled the reports for ease of referencing. Calculations made using data collected from the livestock sub-sector reviews in West African countries indicate that, during 2011/2012, livestock on average (excluding Nigeria which has 83.5 percent of the West African Gross Domestic Product - GDP) contributed 13. 8 percent to the agricultural GDP in the subregion. The contribution of livestock to agricultural GDP ranges from the lowest 4.5 percent in Côte d'Ivoire to the highest 26.2 percent in Guinea. In the case of Sahelian countries (i.e. Burkina Faso, Mali, Niger and Senegal), 60 percent of the total population drive their living from livestock and the sub-sector contributes more than 30 percent to the agricultural GDP (Ly, Fall and Okike, 2010). According to FAO data, the percentage of rural households owning livestock in Ghana (1998) and Nigeria (2004) was 50 and 46 percent respectively, while the share of income from livestock was estimated to be four percent for both countries (FAO, 2009). 


\section{LIVESTOCK POPULATION AND DISTRIBUTION IN WEST AFRICA}
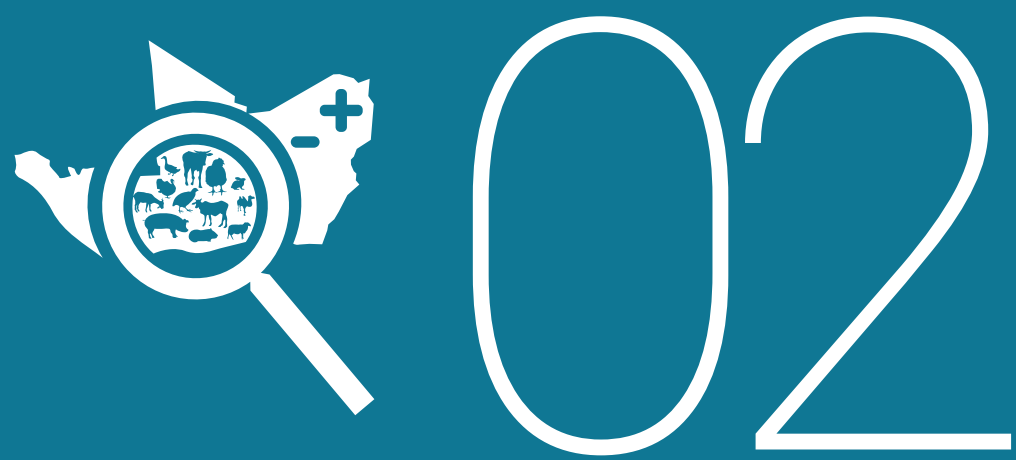



\section{CHAPTER II \\ LIVESTOCK POPULATION AND DISTRIBUTION IN WEST AFRICA}

The animal resources of economic importance in West Africa include ruminant species (i.e. cattle, goats, sheep and camels); non-ruminant species such as horses, donkeys and pigs; poultry (chicken, ducks, turkey, guinea fowl and ostriches); and non-conventional animals such as guinea pig, rabbit, grasscutter and giant rat. The number of breeds of these species kept by producers in the subregion is large and diverse (Table 3). Information on the number per species, sex and age group, spatial distribution, production and productivity, reproductive parameter, etc. of animal resources is sketchy and not readly available for all the countries in a harmonized manner. Statistics provided by different organizations and agencies are often different or contradictory, making it difficult to better understand the sub-sector and plan interventions or making decisions. While this is one of the areas on which a lot of effort is needed, this book attempts to provide the latest available quantitative information on livestock in West Africa.

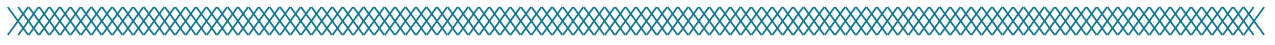

Table 3. Number of breeds per livestock ${ }^{5}$ specie in West Africa

\begin{tabular}{|l|r|r|r|}
\hline Species & Local breeds & Exotic breeds \\
\hline Cattle & 63 & 23 \\
\hline Sheep & 37 & 4 \\
\hline Goats & 21 & 5 \\
\hline Pig & 15 & 7 \\
\hline Chicken & 59 & 30 \\
\hline Horses & 35 & 4 \\
\hline Donkeys & 6 & 0 \\
\hline Camel & 10 & 0 \\
\hline TOTAL & 246 & 73 \\
\hline
\end{tabular}

Source: Domestic Animal Diversity Information System (DAD-IS, 2019). 


\subsection{Livestock numbers by species and distribution in West Africa}

\subsubsection{Livestock numbers by species}

According to FAOSTAT data of 2017, the animal population in West Africa was estimated at about 103.44 million TLU distributed as follows: cattle 74.3 million, sheep 102.95 million, goats 157.75 million, 3 camels 29 million, pigs 13.68 million, horse 1.96 million, donkeys 2.12 million and chicken 559.91 million (Figure 6). Livestock population in 2009 and 2012 gathered from FAO/SFW livestock sector reviews are also displayed in Figure 6.

以

Figure 6. Livestock population estimate of major species in West Africa (2009, 2012 and 2017)

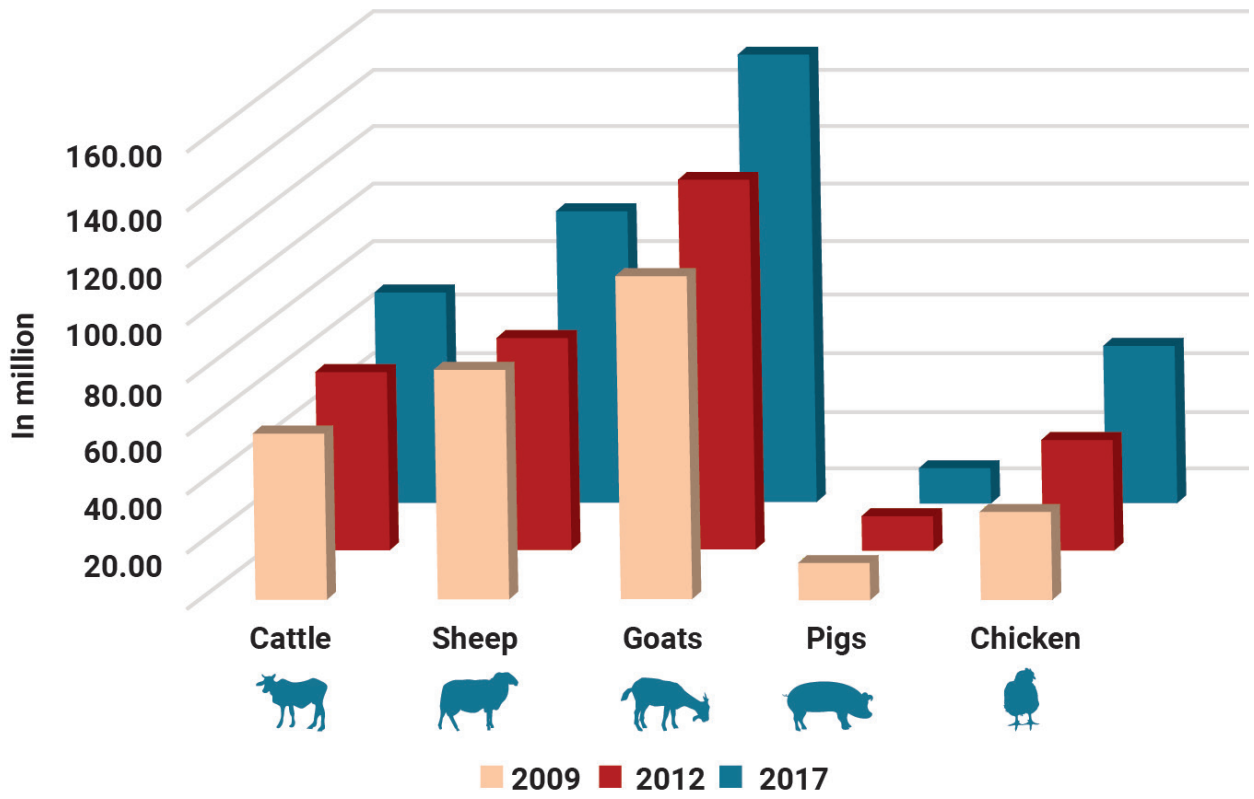

Source: Compiled from FAO/SFW livestock sector reviews and FAOSTAT (2019).

When comparing livestock population among different regions of Africa, West Africa leads the others in the number of goats and sheep, representing 37.3 and 27.0 percent respectively of the continental population. It also possess large proportion of pigs (36.1 percent), chicken (29.2 percent), horses (27.5 percent) and cattle (21.4 percent), second to East Africa in terms of pigs, horses and cattle and second also to North Africa in chicken numbers (Figure 7).

Both the type of species and the total number per species varies from country to country. However, cattle, sheep, goat and poultry are the major species found all over the subregion. In terms of livestock distribution per country, Nigeria owns the largest proportion in West Africa: 55 percent of pigs, 49 percent of goats, 41 percent of sheep, 28 percent of cattle and 25 percent of chicken.

The Sahelian countries like Burkina Faso, Mali and Niger are endowed with ruminant species together accounting for 46.6 percent of cattle, 38.7 percent of sheep and 35.5 percent of goats in West Africa. The coastal countries (i.e. Benin, Côte d'Ivoire, Ghana and Togo), on the other hand have advantage on 


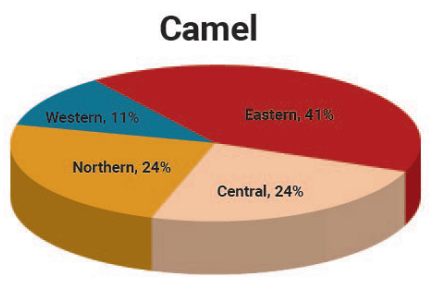

Cattle

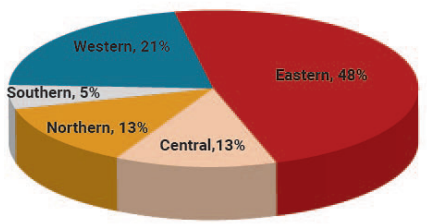

Pigs

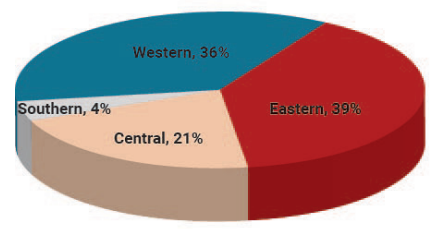

Chicken

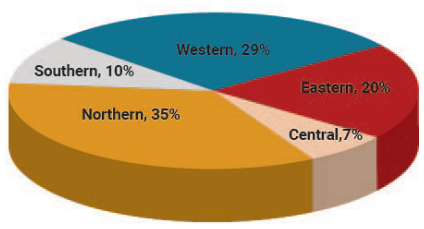

Goats

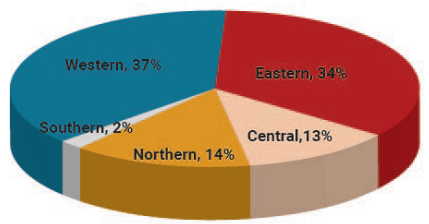

Sheep

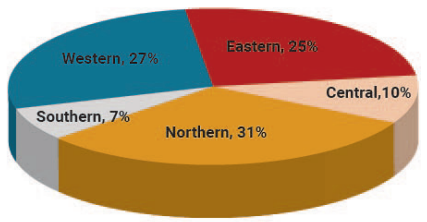

Source: FAOSTAT (2019).

monogastric animals particularly chicken contributing 34.9 percent of the regional population. Nigeria and Senegal, which has both Sahelian and coastal part are excluded from this comparison.

Figures on annual livestock and poultry population growth are important indicators for better understanding of the dynamics involved and management of the sub-sector. Unfortunately, as census or nationwide surveys are not commonly conducted in the livestock sub-sector in West African countries, accurate and timely information is not readily available.

According to data from (FAOSTAT, 2019), over the period between 2008 and 2017, population growth for the main livestock species in West Africa (cattle, sheep, goats, pigs and poultry) followed an increasing trend. Average growth per year in the ruminants' species has been highest in goats (5.01 percent), followed by cattle (3.77 percent) and sheep (3.64 percent). Among the monogastric animals, the poultry sub-sector has experienced the most significant growth in terms of numbers, with an average growth per year of 3.25 percent, while the growth of pigs has been the lowest in the region, with an average growth per year of 1.52 percent. It is, however, noteworthy that these average patterns hide huge differences among countries in population growth in the five species, where specific peaks and drops are observed within the period under study. Nevertheless, it is not clear whether these increase and reduction in livestock population is due to a specific factor or unreliable statistics used for comparison. 


\section{Livestock number in million}

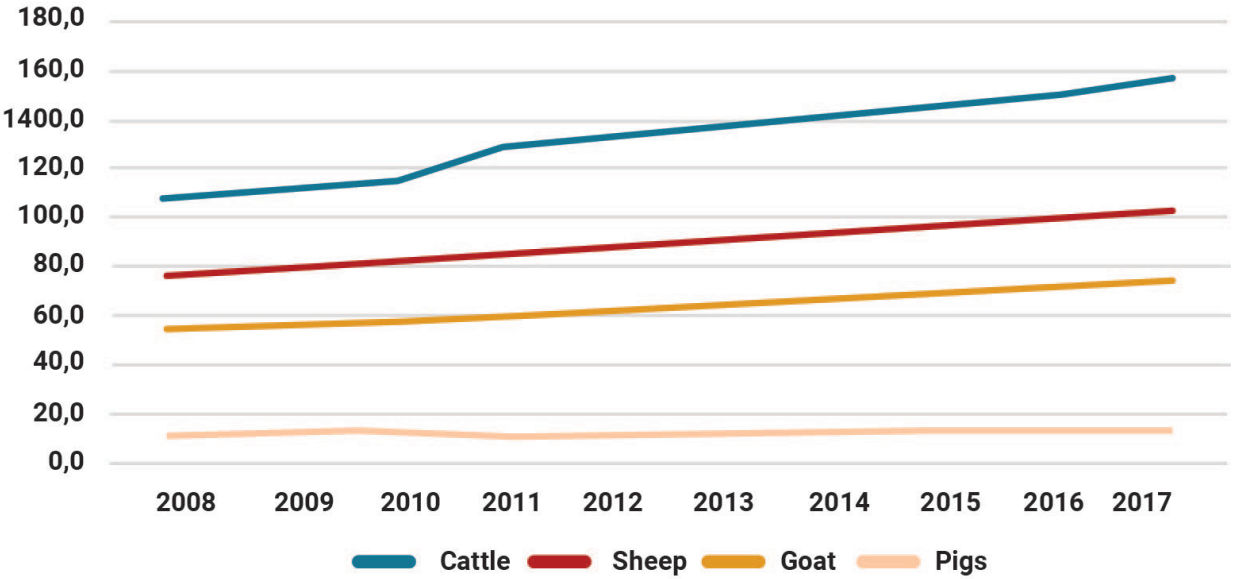

Source: FAOSTAT (2019).

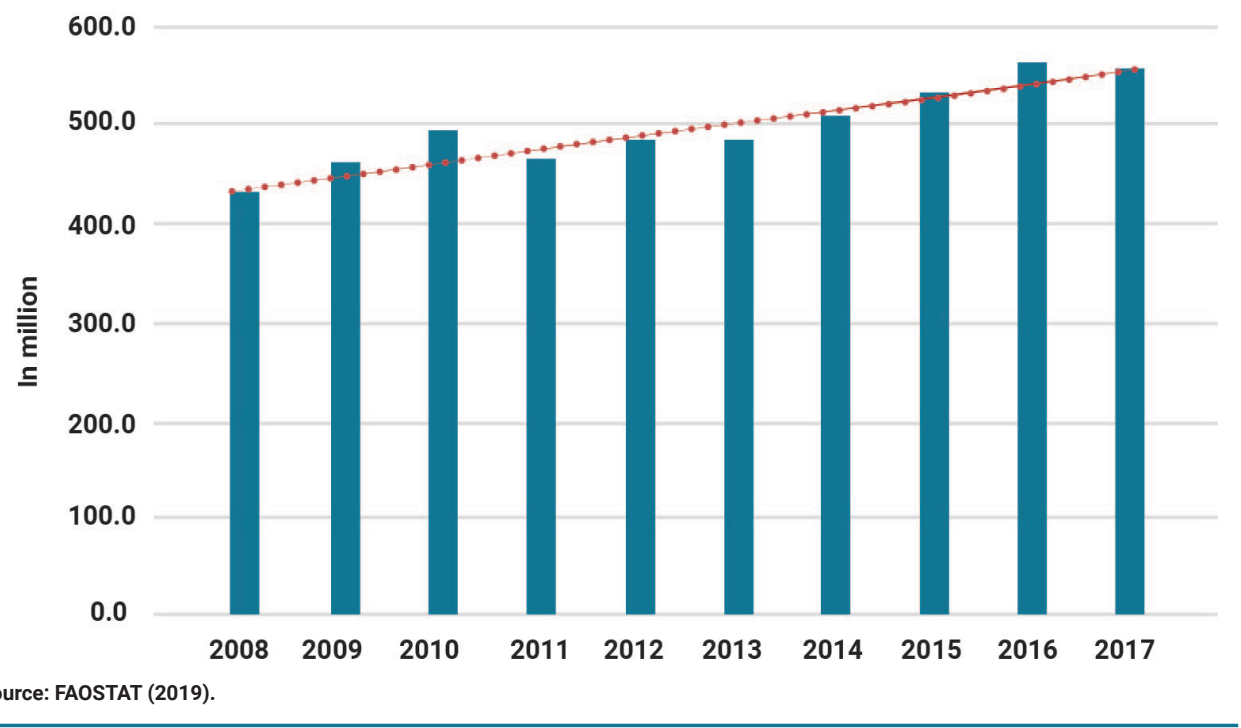

20 The role of livestock in food security, poverty reduction and wealth creation in West Africa 


\subsubsection{Livestock distribution by agro-ecological zones in West Africa}

Ruminant livestock are raised across most of West Africa where environmental conditions allow (Figure 10). The heavily forested areas of West Africa and the deserts have very low densities of livestock. Cattle, sheep and goats are the most widespread species in the sub-humid areas, while camels are restricted to drier areas, particularly in the arid parts of West Africa. In the arid and semi-arid parts of West Africa, where the potential for crop production is limited due to moisture unavailability, cattle, camels, sheep and goats are raised in low input/low productivity, pastoral systems in which mobile stock can take advantage of seasonal, patchy vegetation growth. In the more settled humid, sub-humid and tropical highland areas, cattle and small ruminants largely contribute to mixed crop-livestock farming or agro-pastoral systems, where they perform many roles and can increase crop production by providing draft power and manure while at the same time converting organic material not suitable for human consumption into high-value food and non-food products (Jahnke, 1982 and McDowell and De Haan, 1986). Exact figures on the distribution of livestock per AEZ in West Africa are rarely available. However, based on the above-described understanding, the following section attempts to provide an estimate distribution of livestock in the four AEZs of the region.

\section{Sahara AEZ}

The Sahara AEZ is basically the driest zone in West Africa. Only those animal species, which are adapted to long distance mobility in search for pasture and water points can survive. Camels, goats and donkeys are animal species most commonly found here. Some poultry, evidently in settlements (Oasis and around towns) under backyard system, may also found. Recalling that Mali and Niger are the only West African countries within the Sahara AEZ, approximate livestock population holding in the Malian Sahara zone are 87 percent of camels, 41 percent for sheep and goats, 14 percent of cattle, 43 percent of donkeys and 24 percent of horses; while in Niger Sahara zone are 31 percent of camels, 57 percent for sheep and goats, 30 percent of cattle, 43 percent of donkeys and 83 percent of horses. The proportion of poultry in this AEZ is extremely low almost negligible (McDowell and De Haan, 1986 and Robinson et al., 2011).

\section{Sahel AEZ}

As mentioned earlier, the Sahel AEZ in West Africa encompasses parts of Gambia, Senegal, central Mali, Burkina Faso, southern Niger and northern Nigeria. The Sahel AEZ is by far the most adequate zone for animal production and consequently holds the highest proportion of livestock population in the above listed countries. Specific livestock distribution figures are not available for all the countries sharing the Sahel AEZ. As an illustration, cattle, sheep and goat raised in the Sahel zone make about 36 percent, 25 percent and 39 percent of the total livestock population expressed in tropical livestock units in Senegal, Niger and Burkina Faso respectively. In Nigeria, about three-quarters of all livestock are found in the Sahel AEZ, which is 70 percent of cattle, 81 percent of camels, 76 percent of sheep and 76 percent of goats. Readers are cautioned that these numbers, do not take in to account the seasonal migrations due to transhumance between different AEZ AEZ (Robinson and Conchedda, 2014). Hence, livestock figures may vary from one season to another for a given AEZ.

\section{Sudan AEZ}

The Sudan AEZ is probably the second largest agro-ecological band stretching throughout West Africa, passing across central and Southern Senegal, through southern Mali, Burkina Faso, southern Niger, northern Côte d'Ivoire, Benin, Gambia, Ghana, Guinea, Nigeria and Togo. The Sudan zone is also an important livestock rearing area when considering the proportion of livestock held in different countries. As an illustration, the zone accounts for about $58,52,70$ and 15 percent of the total tropical livestock units possessed by Senegal, Niger, Benin and Ghana, respectively. Similar information could not be derived for the other countries, owing to the lack of data (Bourn et al., 1994 and Saka, 1996). 


\section{Guinea AEZ}

Stretching from western Senegal to eastern Nigeria, along the Guinean Gulf area, the Guinea zone is the largest agro-ecological zone in West Africa. Livestock population that is found in the zone is mostly made-up of dwarf-type animals that show a good level of adaptation to humid wet environment with a high degree of resistance to tsetse fly infestation and trypanosomiasis. The size of livestock population varies widely with the individual country, but again precise and complete data is lacking. Available information show that about 25 percent of the livestock population expressed in TLU in Benin, 74 percent in Ghana and 8 percent in Senegal are found in the Guinean zone (McDowell and De Haan, 1986 and Robinson et al., 2011).

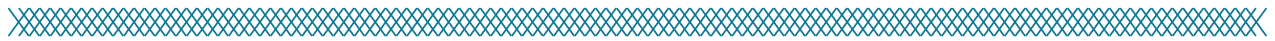

Figure 10. Ruminant livestock distribution in West Africa

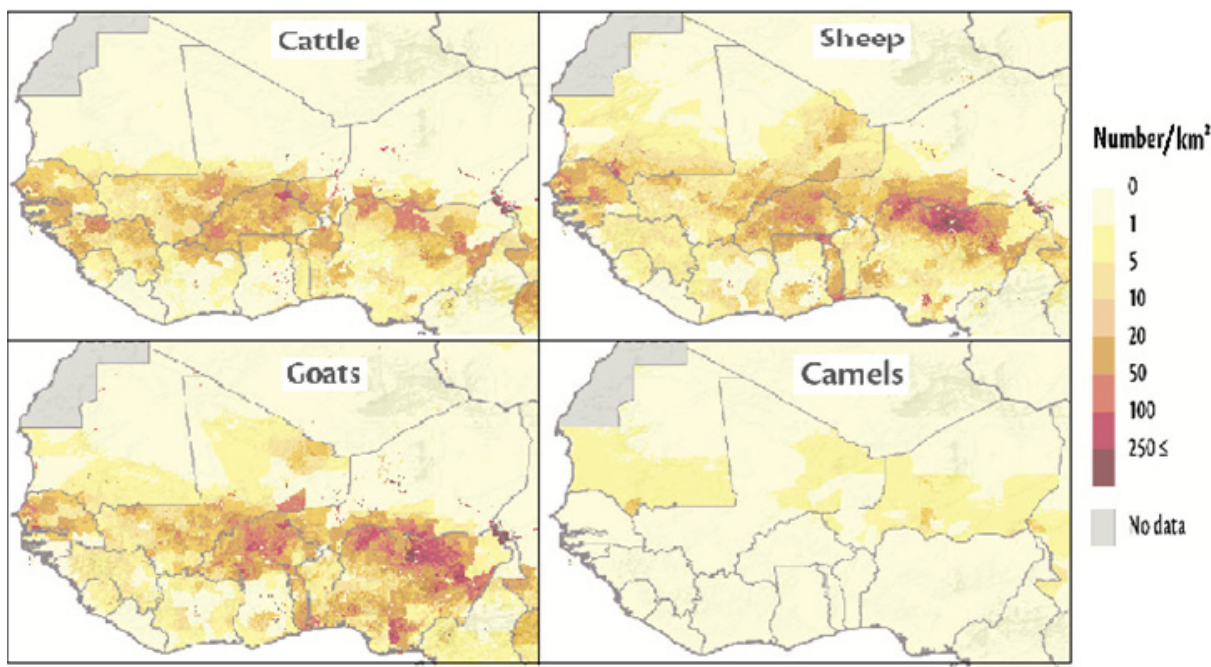

Source: Adapted from Adapted from Sebastian, (2014). 


\section{LIVESTOCK GENETIC RESOURCES IN WEST AFRICA}
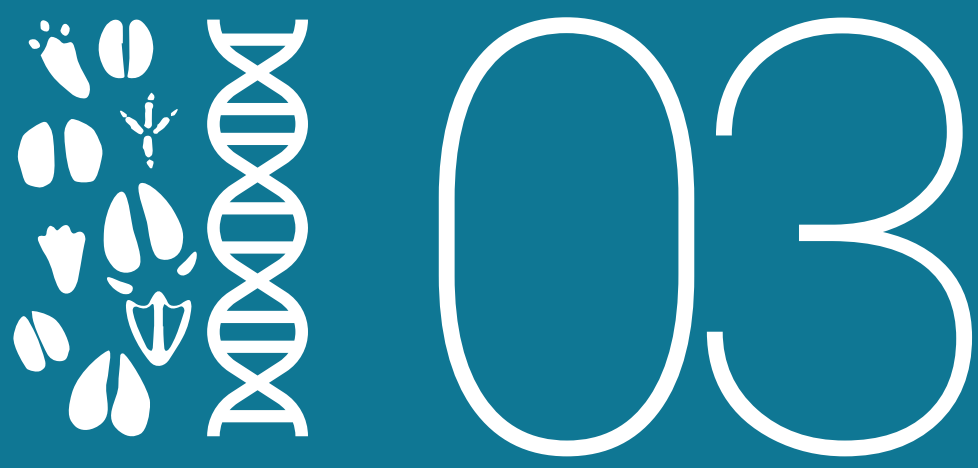



\section{ChAPTER III LIVESTOCK GENETIC RESOURCES IN WEST AFRICA}

\subsection{Livestock breeds by species}

West African farmers keep various livestock species and within these there is a wide range of welladapted native breeds and ecotypes, demonstrating a rich biodiversity. It worth noting that most of these breeds are not yet fully described and characterized. Therefore, a thorough research beyond the scope of this book is required. Exotic breeds have also been introduced in West Africa, either as pure breeds or through crossbreeding schemes, aimed at the rapid development of animal production through intensive practices. With very few exceptions, there is no accurate data on the current status of the different breeds and whether the numbers are decreasing, increasing or stable. Nevertheless, distribution, estimated population sizes, purpose and some performance data of the main West African native livestock breeds are described in the following section.

\section{Cattle}

West Africa differs from the rest regions of Africa for having a significant population of both zebu-type (Bos indicus) and taurine-type (Bos taurus) sub-species of domestic cattle. The region is predominantly populated with zebu breeds and varieties of stabilized crossbreeds (B. taurus $x B$. indicus), well adapted to high temperatures, drought and shortage and poor quality of animal feed (Payne, 1970). These breeds are mainly found in the Sahel and the Sudan AEZs. The habitat of taurine cattle in West Africa is mainly restricted to the more humid and tsetse-infested Guinea AEZ, where the zebu cattle, with little or no trypanotolerance trait, cannot survive (Maule, 1990). These taurine breeds, significantly threatened with assimilation or extinction, are the descendants of the original African domestic cattle and represent a unique genetic resource (Epstein, 1971). The main cattle breeds found in West African are presented below.

\section{Azawak cattle}

This is a Zebu-type cattle native to the Azawak Valley in north-eastern Nigeria, south-western Niger and south-eastern Mali. It is also named as Tuareg, Adar (in Hausa language), Tagana (in Fulani language) and Arab (in Niger). It is a medium-frame shorthorn with prominent hump and medium-length horns. Red, black, dark grey, fawn and pied coat colour are the most common. It is a very well adapted breed to arid zones where it is used for beef, milk and sometimes as a packing animal. A significant number of cattle of this breed are currently found in Niger, Nigeria, Mali and Burkina Faso (Mason, 1996 and Rege and Tawah, 1999). 

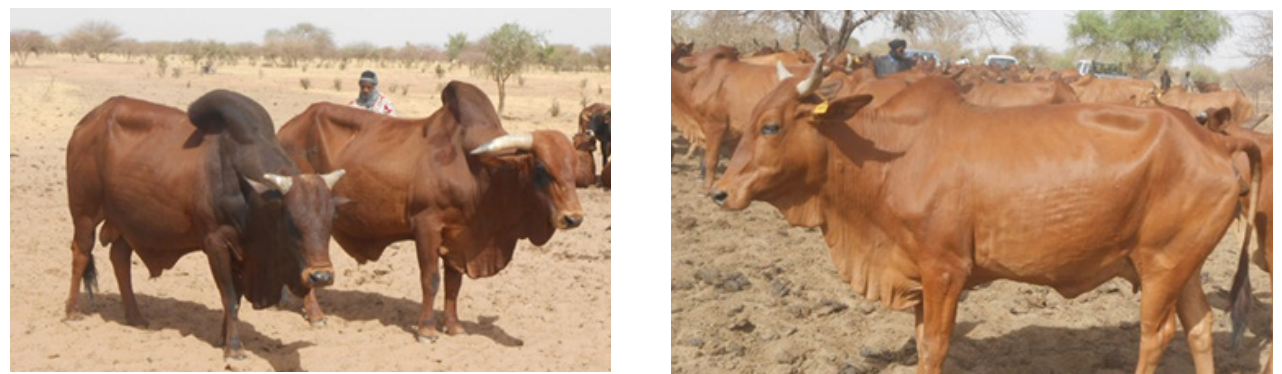

CFAO/DAD-IS

\section{Bororo cattle}

Bororo breed is a Zebu-type breed, which got its name from the ethnic group who first owned it, Mbororo or simply Bororo. Nowadays it is also found in Benin, Mali, Niger and Nigeria. The breed is also known as Borodji, Rahaji and Fallata and is traditionally used for meat and milk production. This zebu breed is one of the largest of its type in the region and is distinguished by its big hump, large dewlap, deep burgundycoloured coat, pendulous ears and long, thick horns. It is perfectly adapted to long marches in arid and semi-arid areas, and therefore typical in transhumant pastoral systems (Portar, 1991).

Photo 2. Bororo cattle breed (Niger)

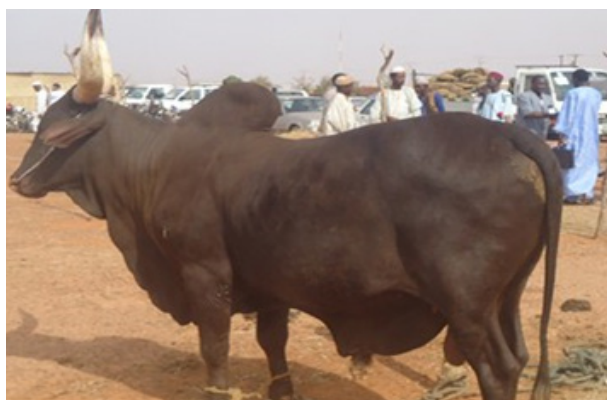

(C)FAO/DAD-IS

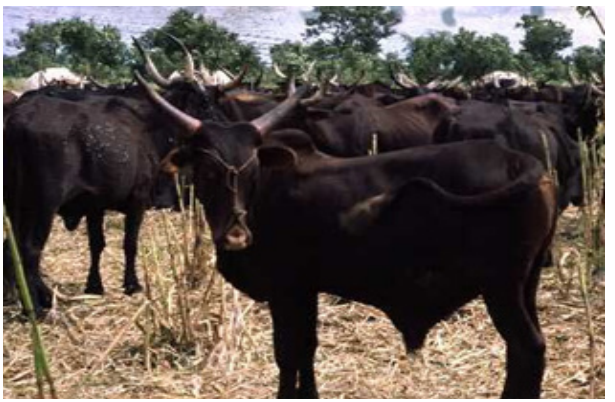

CILRI/ reported as Fellata

\section{Djeli cattle}

Djeli breed, described by some authors (Rege, 1999) as a strain of Fulani, is a Zebu-type cattle breed found in Niger River basin, throughout north-eastern Burkina Faso, the south-west corner of Niger and neighbouring areas of northern Benin and north-western Nigeria. It is also named as Nigerian Fulani, Diali and Jali. It is a medium size breed, presenting lyre-shaped horns and white and black coat colour in speckled or patchy pattern (Felius, 1995). It is said to have good beef potential and easily fattened.

Photo 3. Djeli cattle breed (Niger)
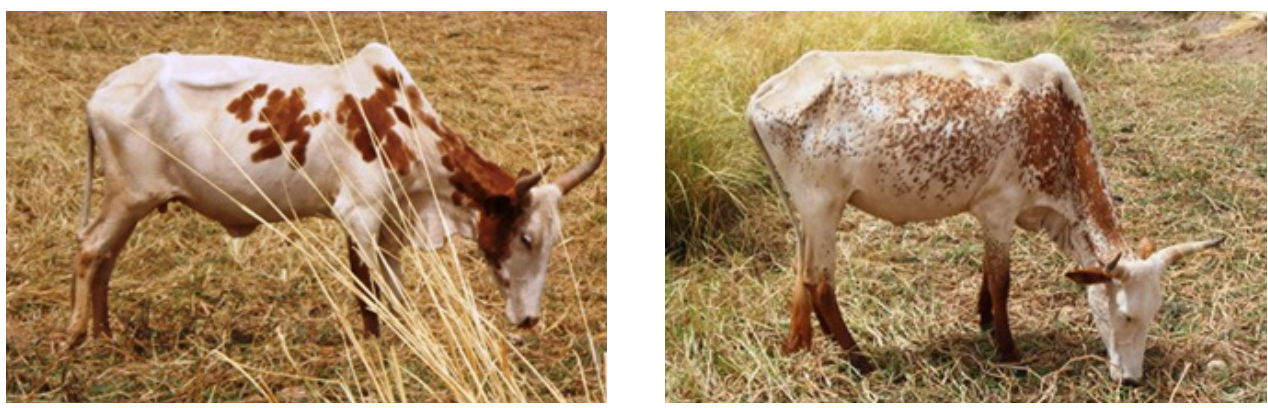

(CFAO/DAD-IS

26 The role of livestock in food security, poverty reduction and wealth creation in West Africa 


\section{Fulani cattle}

This is a general name for different zebu-type cattle varieties (i.e. Bunaji, Samburu, Macina, Sudanian, Gobra or Toronke) spread across Burkina Faso, Côte d'Ivoire, Gambia, Ghana, Mali, Nigeria, Senegal and Togo (Rege and Tawah, 1999). It is a breed with medium to long (up to $140 \mathrm{~cm}$ ) lyre-shaped horn and with common white, black, black-pied, red, red-pied coat colours. The Bunaji variety is well known for its milk potential in Nigeria whereas the Gobra for its beef potential in Senegal. They can trek long distances in search of grazing and water (Mason, 1996).

Photo 4. Fulani cattle breed (Ghana and Senegal).

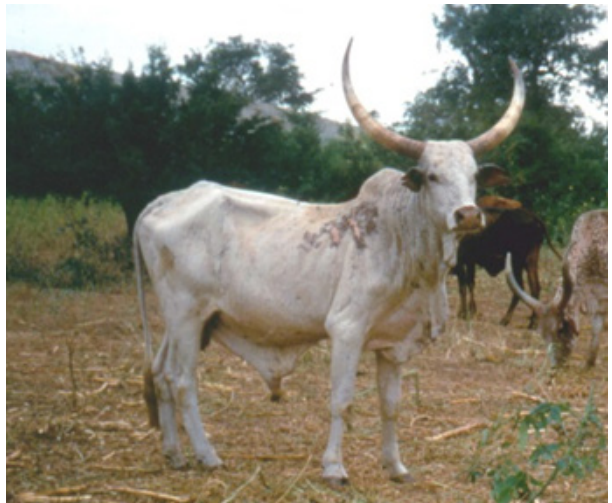

CFAO/DAD-IS/I. Hoffmann

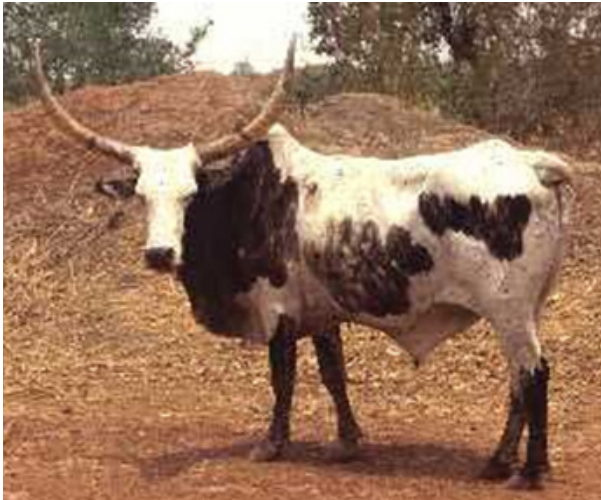

CILRI/DAGRIS (reported as Gobra)

\section{Gudali cattle}

The Gudali breed is a medium to large size zebu-type breed found in Benin, Burkina Faso, Ghana, Mali, Niger, Nigeria and Togo with two different ecotypes. The Sokoto Gudali has a uniform cream, light grey or dun colour, with highly developed dewlap and skin folds and almost absent horns. The Adamawa Gudali is usually pied but can also present a white, black, red or brown coat, with medium-length, thick and crescent-shaped horns, and a pendulous hump. Both have good beef and dairy characteristics (Ngere, 1985 and Tawah and Rege, 1996).

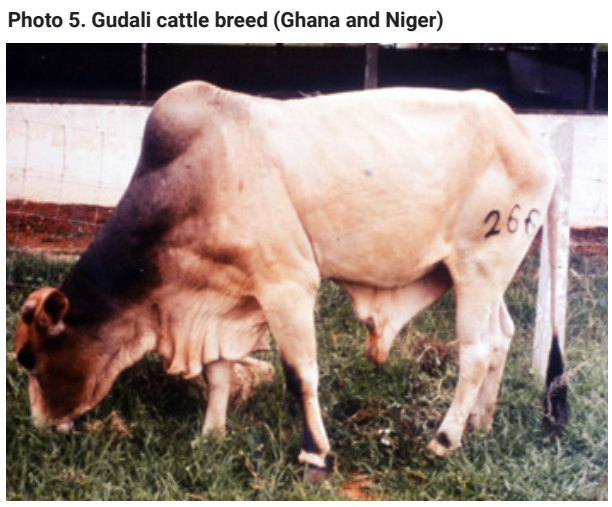

CFAO/DAD-IS/K. Boa-Amponsen

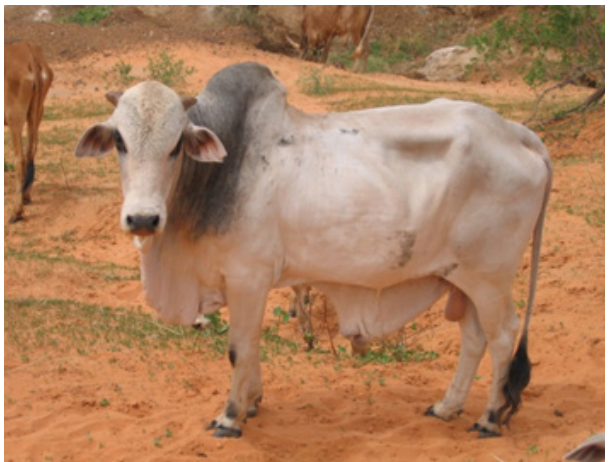

CFAO/DAD-IS/A.

\section{Maure cattle}

This is a Zebu-type cattle with red or red pied and sometimes black colour patterns, moderate hump, slight dewlap and relatively short and slender horns round in cross-section and grey or brown in colour. It is also named as Arab, Mauritanian, Moor and Moorish. Although originally it was from the Sahel band in Mali, it is also found now in neighbouring Mauritania. It can walk long distances and is reared by nomadic Arab and Berber tribes, where it is primarily used as a dairy and draft animal (Felius, 1995). 


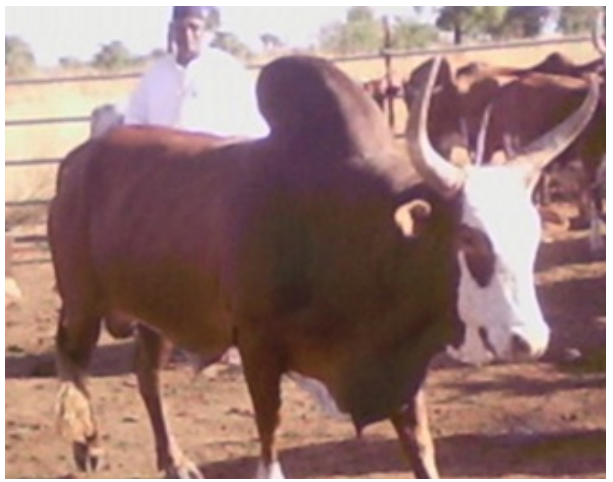

(C)AM. Maiga

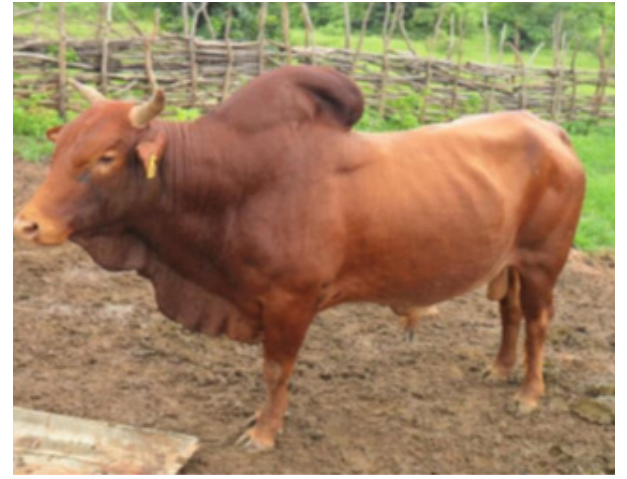

CDNPIA

\section{Wadara cattle}

The Wadara cattle breed is a medium-sized lightly built zebu cattle, with short, moderately thick, round or flat horns with blunt tips; presenting a small erect hump and moderately developed dewlap. Its coat colour is usually dark red, black, pied or brown. In West Africa it is found in northeastern Nigeria. The breed is also known by the names Shuwa, Arab Shuwa or Arab Choa. This breed is reared under stressful environment by semi-nomadic people. It is used for work mainly for riding and as pack animals, meat and milk (Portar, 1991).

Photo 7. Wadara cattle breed (Nigeria)

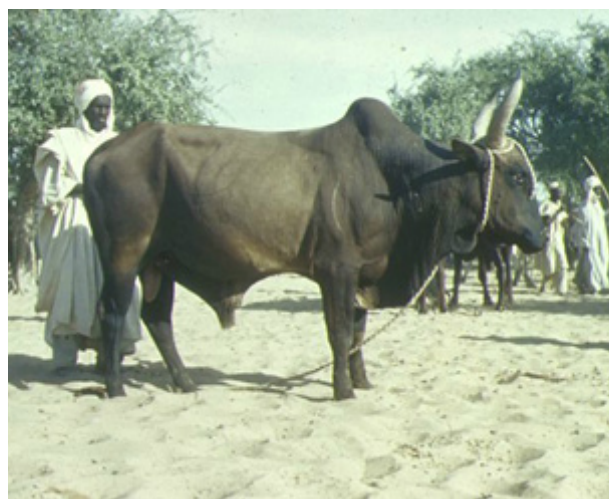

(C) Racesbovines.canalblog/Braford (reported as Shuwa)

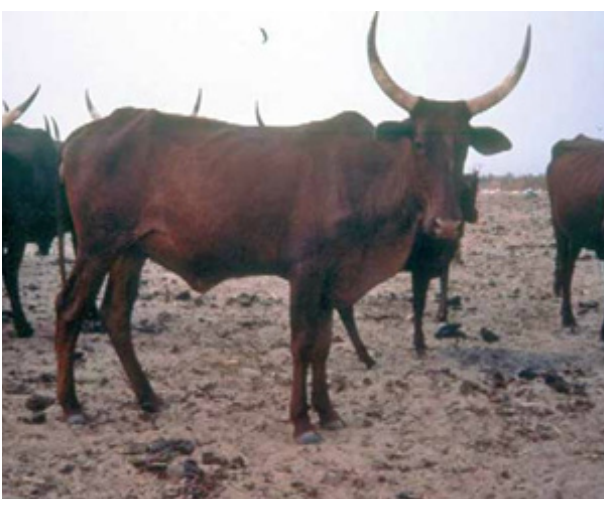

\section{Kuri cattle}

Kuri breed is a large-bodied hump-less longhorn taurine-type cattle whose exact historical origin is unknown. Generally white in colour, the breed has distinctive, inflated, spongy horns, unknown in any other cattle breed. In West Africa Kuri cattle are reared in Niger and Nigeria in areas adjacent to Lake Chad, spending a considerable time in the water and being excellent swimmers. Its population size has declined and is being also threatened by uncontrolled crossbreeding. The breed is mainly used for meat, milk and work (Blench, 1999). 


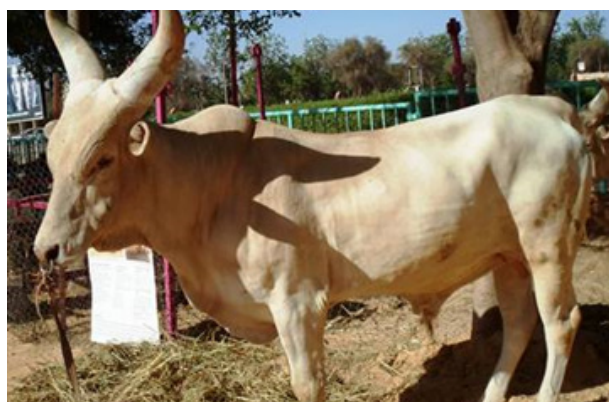

CFAO/DAD-IS

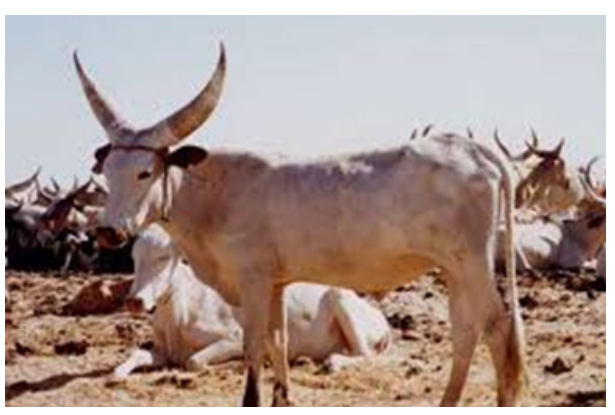

OILRI/DAGRIS

\section{N'Dama cattle}

The N'Dama cattle breed is the most representative B. taurus breed originated from the Fouta-Djallon highlands of Guinea and now distributed throughout West Africa (except Benin, Cabo Verde and Niger). It is a hardy breed, medium size compact body type with a large and strong head and with lyre-shaped black-tipped horns. The coat, with short and thin hair, is fawn coloured but varies from sand to black colour (Starkey, 1984). The breed is well recognized for its resistance to trypanosomiasis, being reared mainly for beef production in tsetse infested zones (Dwinger, et al., 1992).

Photo 9. N'Dama cattle breed

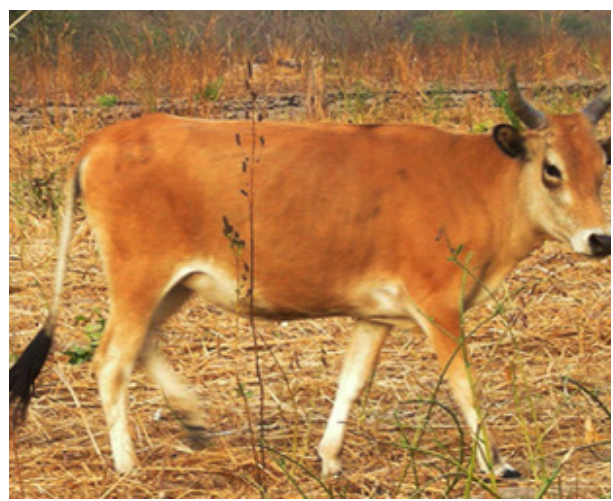

○ILRI

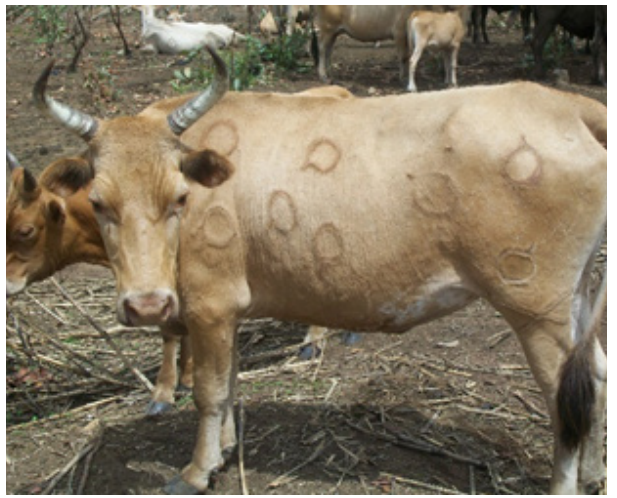

\section{West African Shorthorn (WASH)}

The West African Shorthorn breed is a taurine-type cattle with several ecotypes disseminated throughout West Africa, such as Muturu (Nigeria), Somba (Togo and Benin), Ghana Shorthorn and Baoule (Ghana and Côte d'Ivoire) and Lagune (Benin, Ghana, Togo and Côte d'Ivoire). It has small compact body, short fine-boned limbs, no hump, straight back, a broad head and very short horns. The coat varies widely from the most frequent black and white to red and white, however uniform black, red, grey or tawny coat colours are also observed (FAO, 1994). 
Photo 10. Muturu cattle breed (Nigeria.

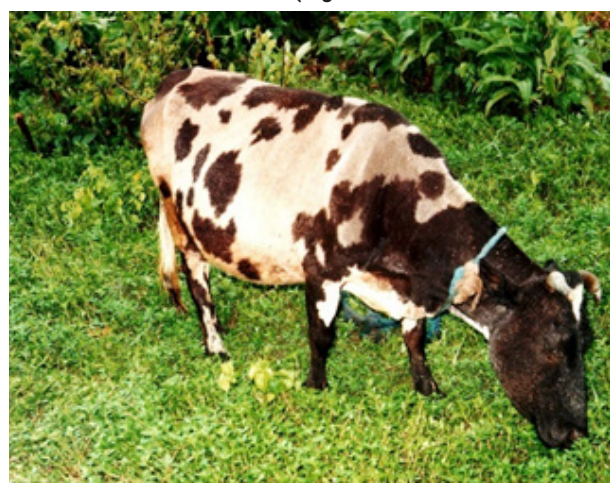

CFAO/DAD-IS/OA Adebambo

Photo 11. Somba cattle breed (Benin).

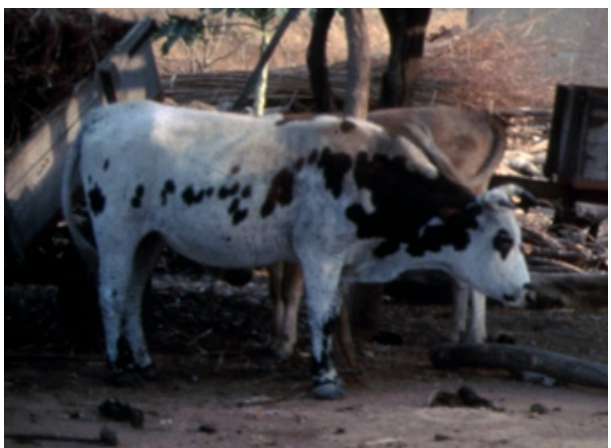

CFAO/DAD-IS/OA

Photo 12. Ghana shorthorn cattle breed (Ghana)
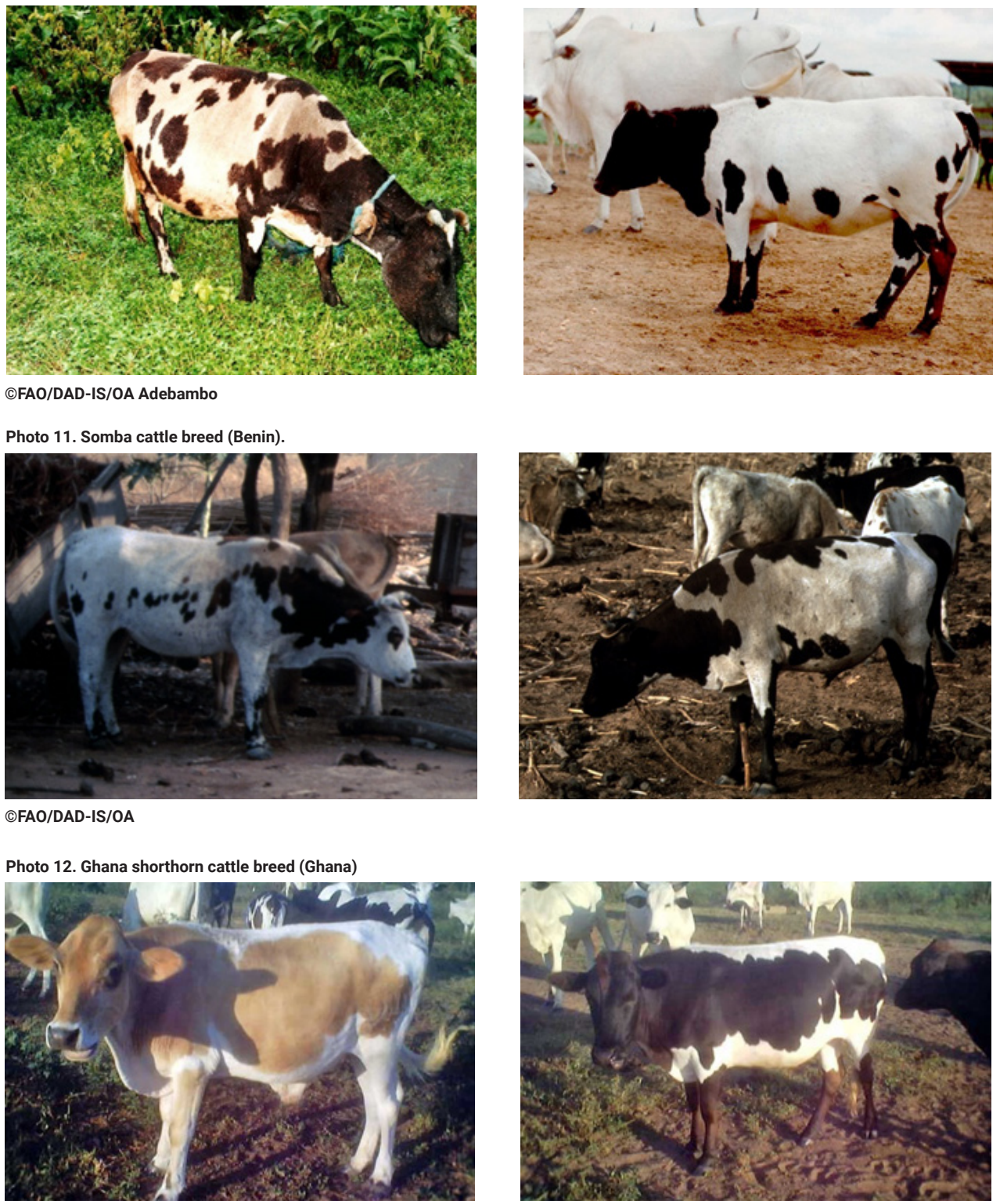

CILRI/DAGRIS

Photo 13. Baoule cattle breed

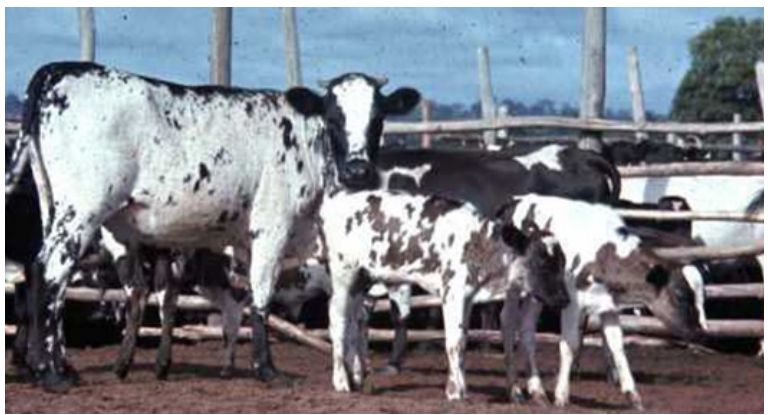

CILRI/DAGRIS

30 The role of livestock in food security, poverty reduction and wealth creation in West Africa 


\section{Stabilized crossbreed cattle}

The Stabilized crossbreed cattle are found along the Savannah band of West Africa, where zebu and taurine cattle intermingled historically and still mix freely today, acquiring over time a fairly good level of stabilization. They are distinguished by having small cervico-thoracic humps instead of the high thoracic humps, which characterize the zebu. These animals received numerous names such as Mere and Bambara in Mali, Lobi in Burkina Faso, Diakorè in Senegal, Sanga in Ghana, Keteku in Nigeria and Borgu in Benin and Togo (Rege and Tawah, 1999).

\section{Exotic cattle breeds}

Zebu-type breeds, such as the Indian Sahiwal (Senegal, Sierra Leone) and, more recently, the Latin Americans Girolando (Benin, Burkina Faso) were introduced to West Africa. European taurine-type breeds, including the Abondance, Brown Swiss, Flevick, Friesian/Holstein, Jersey, and Montbeliard, were also brought into Burkina Faso, Côte d'Ivoire, Mali, Nigeria and Senegal (FAO, 2007). Production yields of these breeds are variable from country to country according to production systems ${ }^{6}$.

\section{Sheep and Goats}

Numerous breeds/varieties of sheep and goats are found in the West African region. Many of them seem to be the same breed, different only based on geographical locations or ethnic group rearing them. The West African native sheep breeds are of the thin-tailed type, which can be classified in hairy and woolen sheep types. The hairy sheep types can be roughly divided into the Sahelian type (long-legged) in the norther part of West Africa and the Tropical type in the South, sub-grouped under the Forest (dwarf) and Savannah (small) types. The goats described in this book are also classified in large breeds from the Sahel and smaller breeds from the Tropics (Forest and Savannah types) (Epstein, 1971). The dwarf sheep and goats are the only ones in the coastal areas and known to be trypanotorelants (ILRI, FAO and UNED, 1979). Some crossbreeds between Sahelian and Tropical-type sheep/goats can be found in the Savannah areas, where both types geographically converge (Wilson, 1991). The major sheep and goat breeds in West Africa are described below.

\section{Fulani sheep}

This Sahelian type-haired sheep breed is known under different names within the semi-arid zone of the region, where it is mainly distributed. The coat colour is white, bicolour black and white or brown and white with the black or dark brown on the fore and the white on the hind quarters. The breed has pendulous long ears and a long thin tail. Rams have a throat ruff and are horned, but ewes are normally polled. It is reared under a pastoral and agro-pastoral production system and mainly used for meat and milk production (Blench, 1999 and FAO, 2007).

Photo 14. Fulani sheep breed (Benin and Niger)

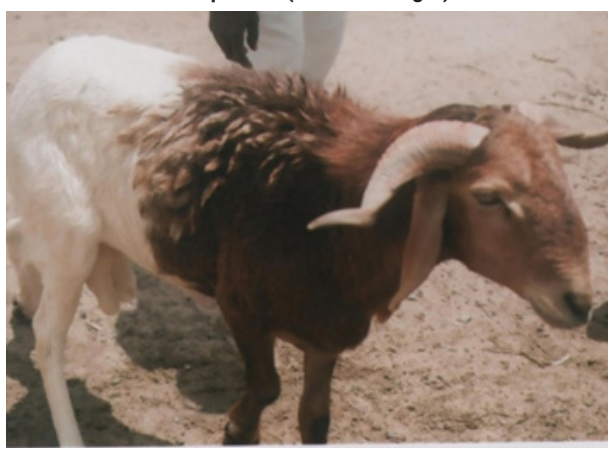

(CV. Codjia

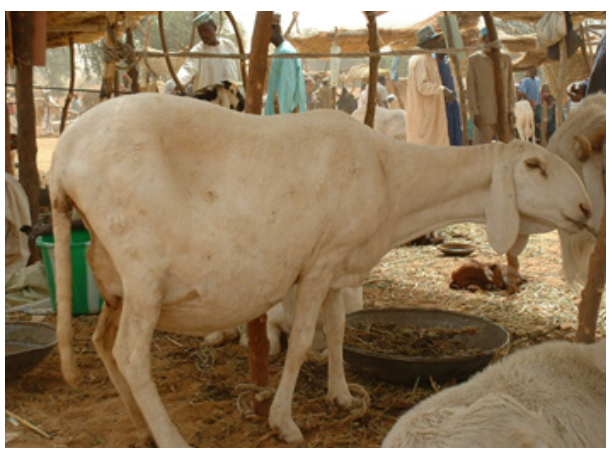

(CA. Djibrillou (reported as Bali Bali) 
Table 4. Native cattle breeds of West Africa and their performance

\begin{tabular}{|c|c|c|c|c|c|c|c|}
\hline \multirow[t]{2}{*}{ Breed/Strain } & \multirow[t]{2}{*}{$\begin{array}{l}\text { Location / } \\
\text { Country }\end{array}$} & \multirow[t]{2}{*}{$\begin{array}{l}\text { Estimated } \\
\text { Pop. (in } \\
\text { Million) }\end{array}$} & \multicolumn{2}{|l|}{ Mature weigh $(\mathrm{kg})$} & \multicolumn{2}{|c|}{ Withers height (cm) } & \multirow[t]{2}{*}{$\begin{array}{l}\text { Main use } \\
\text { (in order of } \\
\text { importance) }\end{array}$} \\
\hline & & & Male & & Male & male & \\
\hline $\begin{array}{l}\text { Azawak (Tuareg, Adar, } \\
\text { Tagana, Arab) }\end{array}$ & $\begin{array}{l}\text { Mali, Nigeria, } \\
\text { Niger }\end{array}$ & 4.6 & $350-500$ & $300-410$ & $128-135$ & $122-130$ & Meat, work, milk \\
\hline $\begin{array}{l}\text { Bororo (Borodji, Rahaji, } \\
\text { Fallata) }\end{array}$ & $\begin{array}{l}\text { Benin, Mali, } \\
\text { Niger, Nigeria }\end{array}$ & NA & $400-450$ & $255-410$ & & $130-140$ & $\begin{array}{l}\text { Milk (380-400 lt/ } \\
\text { lac), meat, work }\end{array}$ \\
\hline $\begin{array}{l}\text { Djeli (Nigerian Fulani, } \\
\text { Diali, Jali) }\end{array}$ & $\begin{array}{l}\text { Niger, Nigeria, } \\
\text { Burkina Faso, } \\
\text { Benin }\end{array}$ & NA & & 300 & & $115-130$ & Milk, meat, work \\
\hline $\begin{array}{l}\text { Fulani Group (Bunaji, } \\
\text { Samburu, Macina, } \\
\text { Sudanian, Gobra, } \\
\text { Toronke) }\end{array}$ & $\begin{array}{l}\text { Burkina Faso, } \\
\text { Côte d'Ivoire, } \\
\text { Gambia, Ghana, } \\
\text { Mali, Nigeria, } \\
\text { Senegal and } \\
\text { Togo }\end{array}$ & 17.9 & $280-665$ & $248-410$ & $120-152$ & $115-140$ & $\begin{array}{l}\text { Milk ( } 627-1034 \text { It/ } \\
\text { lac), meat, work, } \\
\text { manure }\end{array}$ \\
\hline $\begin{array}{l}\text { Gudali (Sokoto, } \\
\text { Adamawa) }\end{array}$ & $\begin{array}{l}\text { Benin, Burkina } \\
\text { Faso, Ghana, } \\
\text { Mali, Niger, } \\
\text { Nigeria and } \\
\text { Togo }\end{array}$ & 4.5 & $495-660$ & $240-355$ & $130-138$ & $116-132$ & $\begin{array}{l}\text { Meat, milk (1101.3 } \\
\text { It/lac), work }\end{array}$ \\
\hline $\begin{array}{l}\text { Maure (Arab, } \\
\text { Mauritanian, Moor, } \\
\text { Moorish) }\end{array}$ & Mali & 0.7 & $250-700$ & $250-350$ & $125-140$ & $110-128$ & $\begin{array}{l}\text { Milk (586-1206 lt/ } \\
\text { lac), work, meat }\end{array}$ \\
\hline $\begin{array}{l}\text { Wadara (Shuwa, Arab } \\
\text { Shuwa, Arab Choa) }\end{array}$ & Nigeria & 1.3 & $350-475$ & $250-300$ & $135-140$ & $125-128$ & $\begin{array}{l}\text { Work, meat, milk } \\
(450-1820 \text { lt/lac) }\end{array}$ \\
\hline Kuri & $\begin{array}{l}\text { Niger and } \\
\text { Nigeria }\end{array}$ & 0.1 & $500-750$ & $360-450$ & $140-180$ & $126-145$ & Meat, milk, work \\
\hline N'Dama & $\begin{array}{l}\text { All West Africa } \\
\text { (except Benin, } \\
\text { Cabo Verde and } \\
\text { Niger) }\end{array}$ & 7.0 & $220-360$ & $180-300$ & $95-120$ & $90-115$ & $\begin{array}{l}\text { Meat, work, milk } \\
(500-600 \mathrm{lt} / \mathrm{lac}) \text {, } \\
\text { manure }\end{array}$ \\
\hline $\begin{array}{l}\text { WASH (Muturu, Somba, } \\
\text { Ghana Shorthorn, } \\
\text { Baoulé, Lagune) }\end{array}$ & $\begin{array}{l}\text { Liberia, Nigeria, } \\
\text { Côte d'Ivoire, } \\
\text { Ghana, Togo and } \\
\text { Benin }\end{array}$ & 2.1 & $150-395$ & $115-280$ & $86-117$ & $82-110$ & $\begin{array}{l}\text { Meat, milk, rituals, } \\
\text { work, manure }\end{array}$ \\
\hline
\end{tabular}

Source: Compiled from latest available estimates, if multiple in same year, highest estimate used; combines estimates from different countries if applicable.

\section{Black Maure sheep}

Also referred as Moor, Mauritanian and Arab, this Sahelian type sheep breed is found in Mali and Senegal within West Africa. Generally black with white tip to the tail, the coat has long, coarse stiff black hair in loose ripples over a softer undercoat. It has a strong head with flat forehead, convex facial profile in males but less so in females. Rams of this breed have flat spiral triangular shaped horns but ewes usually are hornless with broad, pendulous ears and long and lightly fleshed legs. This breed is used for meat and milk under pastoral arid areas (Portar, 1991 and FAO, 2007). 


\section{Touabire sheep}

This is a Sahelian type sheep breed found in Mali and Senegal. The breed is also known as Ladoum, White Maure, White Arab and Short-hair Maure. The coat of this breed is short and stiff, usually white with variable number of black spots. It has a large body size, strong head with flat forehead, markedly convex facial profile in males. Males have horns typically curved backwards and then forwards, absent in females. The ears are long to medium, rather broad and pendulous. Touabire sheep breeds are reared by pastoralist tribes in arid areas for milk, meat and skins (Portar, 1991 and Mason, 1996).

Photo 15. Touabire sheep breed (Mauritania)
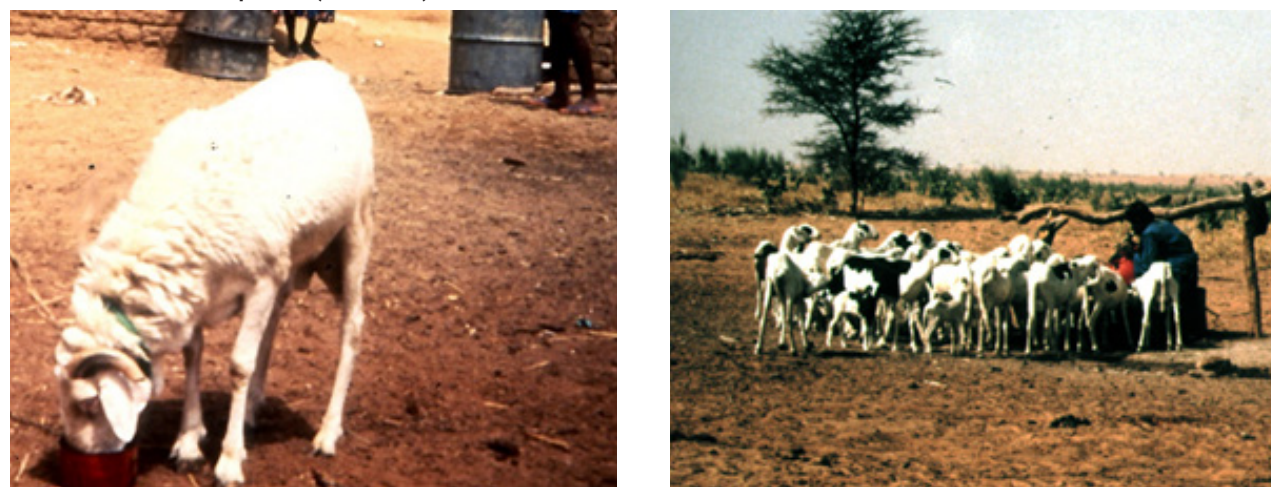

CDAD-IS /M. Kane

\section{Touareg sheep}

This breed belongs to the haired Sahelian sheep group and is subdivided into two varieties; Grand Targui and Petit Targui. In West Africa it is found in pastoral arid areas of Mali and Niger. The coat colour is white with some fawn or roux spotting but red colour also occurs. The breed has prominent forehead with strongly convex facial profile and narrow muzzle. The horns are strongly ribbed and spiral backwards, usually present in males and absent in females. Touareg sheep is reared under semi-arid to arid pastoral and agro-pastoral production systems for meat and milk (Wilson, 1991 and Blench, 1999).

Photo 16. Touareg sheep breed (Niger)

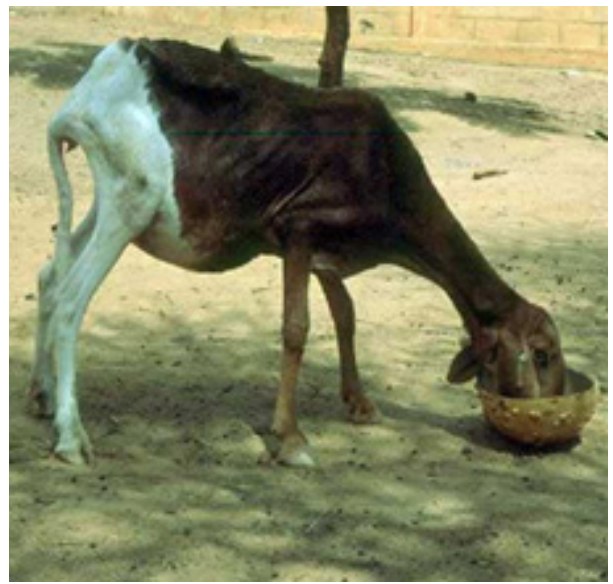

CILRI/DAGRIS

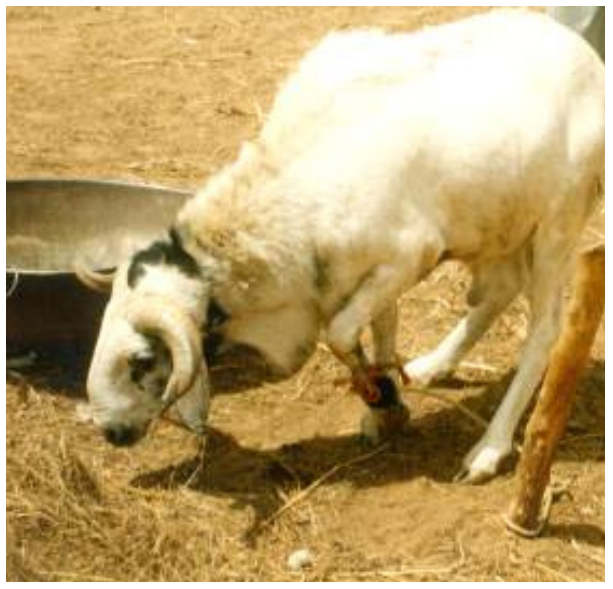

(C)A. Djibrillou (reported as Ara Ara) 


\section{Macina sheep}

This breed is a medium size sheep belonging to the thin-tailed woolen type breed group. The Macina sheep breed has a slightly convex facial profile, with strong prismatic shape horn directed backward. The fleece is generally white, but may be bicolour with brown and black spots, presenting a moderate wool fibre and clean fleece. It is reared by the Fulani pastoralists in Mali and in Niger and maintained under a sophisticated system of flock stratification involving milk, meat and wool production sub-units (Mason, 1996 and Blench, 1999).

Photo 17. Macina sheep breed (Niger)

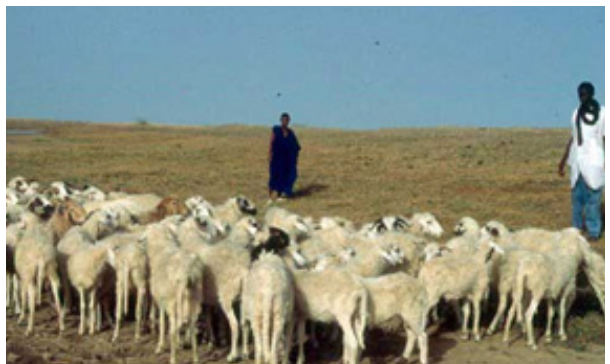

CILRI/DAGRIS

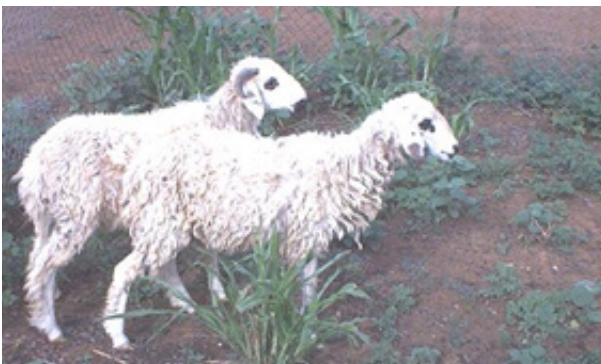

CMEN (reported as Koundoum)

Djallonke sheep

This is a tropical dwarf-type breed, widely distributed in West Africa, adapted to coastal areas and recognized for its trypanotolerant traits. It has a strong and broad head, flat forehead, profile slightly bulging in male and wide muzzle. The rams usually have well developed horns, but in ewes the horns are fine and short when present. Ears are short, narrow and pendent or semi-pendent. This breed has a hairy short coat, although males very often have a heavy mane, white or pied with black forequarters and white hindquarters. It is reared mainly for meat and milk production (Wilson, 1991 and FAO, 2007).

Photo 18. Djallonke sheep breed

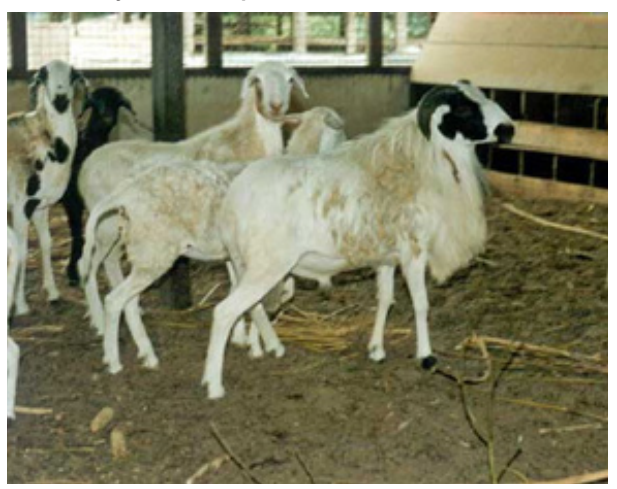

CILRI/DAGRIS

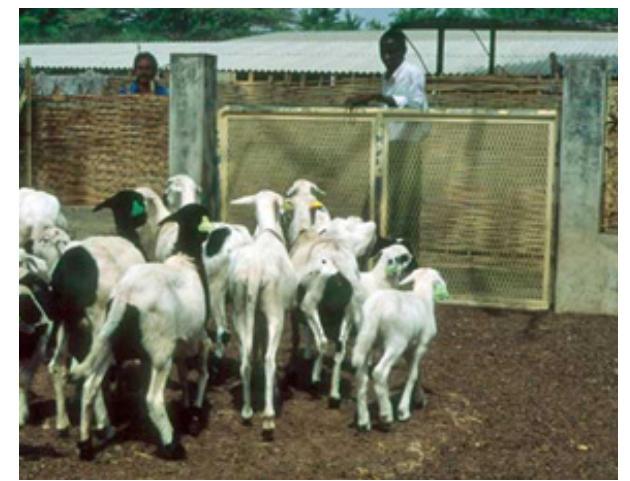

\section{Sahelian goat}

The Sahelian goat breed group is widely distributed in the semi-arid and arid zones of the Sahel known under different names. In recent years, it has penetrated farther south following drought, even though it is highly susceptible to trypanosomiasis. This is a large size breed with small head, fine and triangular in shape with flat forehead, and flattened ribbed horns usually present in both sexes. The Sahel goat breed has pendulous long wide ears, long thin neck, beards, toggles and manes (in males) are common. The coat colour is very variable between subtypes. The breed is used for milk, meat and skin (Portar, 1991 and Mason, 1996). 


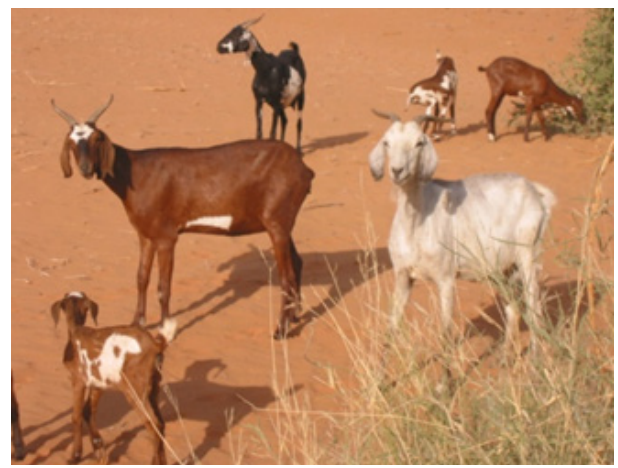

(CA. Djibrillou

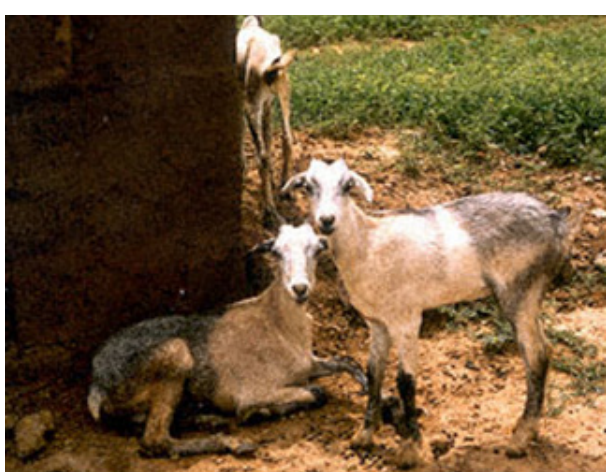

CV. Matlova

\section{Red Sokoto goat}

This is a relatively small-sized Savannah-type breed widespread under agro-pastoral systems in Niger and Nigeria. It has a fine head with prominent forehead. Both sexes have short to medium horns, horizontal to semi-pendulous medium-size ears, profuse beard in males but usually absent in females. Toggles in this breed are rare. The forehead often covered with hair, light mane in males, short thin neck, red colour coat (lighter in Nigeria) may have a black back stripe and the tail hair is usually black. This breed is reared for meat and milk and known for their good quality skin (Wilson, 1991 and FAO, 2007).

Photo 20. Red Sokoto goat breed (Nigeria)

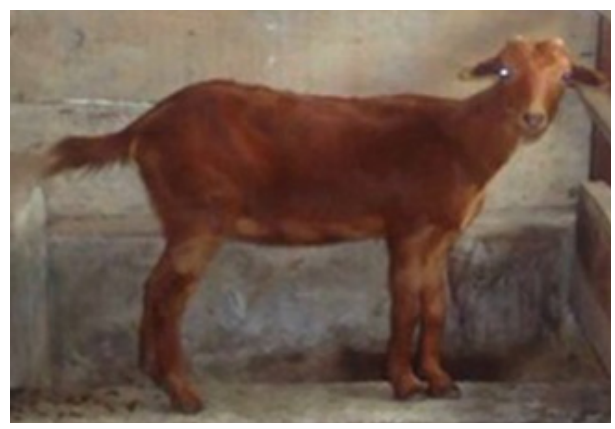

CDO.Okunlola \& OA Olorunnisomo

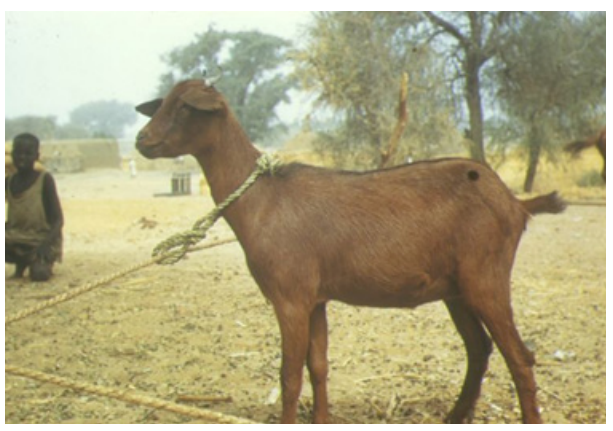

CCIRAD-EMVT (reported as Maradi)

Maradi goat

This breed is very similar to the savannah-type Red Sokoto goat and it may have some influence from forest-type goats. Maradi goat breed is mostly found in Niger and North-Western Nigeria, today also in Benin, Burkina Faso, Mali, Senegal and Togo. It is also known as Zinder Brown and Chèvre Rousse de Maradi. This breed does not support long distance treks, one of the reason why it is reared under agropastoral (mixed farming) system. The main purpose of this breed is for meat and milk production, but they are mostly known internationally for their thin, flexible and remarkably strong skin (Wilson, 1991 and FAO, 2007). 


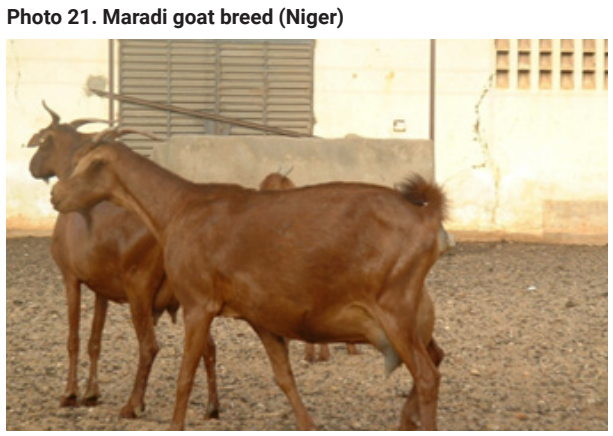

(c) A. Djibrillou

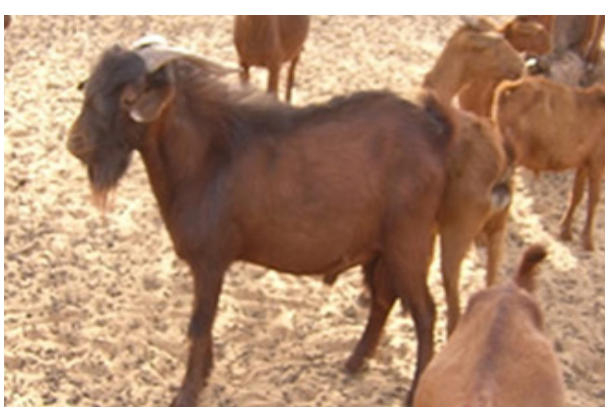

๑MEN

\section{Djallonke goat}

This is a tropical trypanotolerant forest-type breed, known under multiple names in West Africa. Markedly dwarf, the breed has a strong head and bulging forehead, straight or slightly dished profile, horns curl outwards and backwards in males and light, sharp in females. Djallonke goat breed has short to medium horizontal ears, toggles occasionally present in both sexes, males normally bearded and with a weak mane, and females occasionally have beards. Their short and stiff coat is variable in colour (brown, blacks, whites, reds, pied and mixed). It is reared mainly for meat (Portar, 1991 and Mason, 1996).

Photo 22. Djallonke goat breed

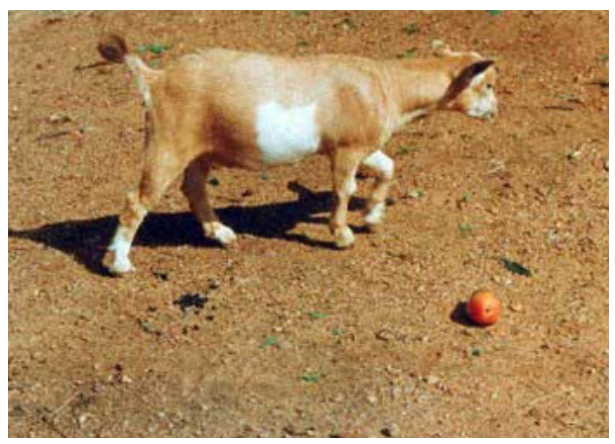

@ILRI/DAGRIS

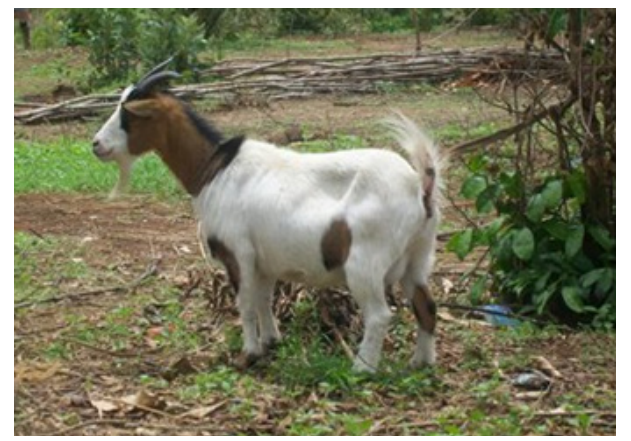

OILRI (reported as West African Dwarf)

\section{Stabilized crossbreeds sheep and goats}

These are small to medium size sheep and goats originated from early crosses of Sahelian and tropicaltype animals, which are found in several West African countries. The Mossi sheep (Fulani x Djallonke) is found in Burkina Faso (about 120,000 head). The Vogan sheep (Sahel x Djallonke) is confined to Togo and Benin (about 118,500 head). Djallonke and Red Sokoto goats have been recently crossbred in Nigeria giving place to a "new breed" formation (Nwachukwu et al., 2013).

\section{Exotic sheep and goat breeds}

There are some exotic breeds imported to West Africa mainly by government institutions, for crossbreeding with indigenous breeds, generally with little success. Some example of these include Merino, Wensleydale and Langhe sheep, which were introduced in Nigeria, Anglo-Nubian goats in Cabo Verde, Ghana and Mali. More recently, Majorera goats were imported to Senegal and Boer, Kalahari goats and Dorper sheep in Niger (FAO, 2007). Mali has the following exotic breeds of sheep (i.e. Merino, Karakul and Charmoise) and goats (i.e. Angora, Alpine and Saanen) (DAD-IS, 2019). 
Table 5. Native sheep and goat breeds of West Africa and their performance.

\begin{tabular}{|c|c|c|c|c|c|}
\hline Breed/Strain & Location / Country & $\begin{array}{c}\text { Estimated } \\
\text { Population (M) }\end{array}$ & $\begin{array}{l}\text { Mature weigh } \\
(\mathrm{kg})\end{array}$ & $\begin{array}{l}\text { Withers } \\
\text { height } \\
(\mathrm{cm})\end{array}$ & $\begin{array}{l}\text { Main use } \\
\text { (in order of } \\
\text { importance) }\end{array}$ \\
\hline $\begin{array}{l}\text { Fulani sheep (Peul, Peul-Peul, } \\
\text { Foulbe, Bornu, Sambourou, } \\
\text { Toronke, Balami, Bali Bali, Uda, } \\
\text { Yangasa) }\end{array}$ & $\begin{array}{l}\text { Benin, BF, Cabo Verde, } \\
\text { Ghana, Mali, Niger, } \\
\text { Nigeria, Senegal }\end{array}$ & NA & $30-50$ & $65-75$ & $\begin{array}{l}\text { Meat (cd 50\%), } \\
\text { milk }\end{array}$ \\
\hline $\begin{array}{l}\text { Black Maure sheep (Moor, } \\
\text { Mauritanian, Arab) }\end{array}$ & Mali, Senegal & NA & $80-90$ & $35-45$ & $\begin{array}{l}\text { Meat, milk (42 } \\
\text { lt/lac) }\end{array}$ \\
\hline $\begin{array}{l}\text { Touabire sheep (Ladoum, } \\
\text { White/Short-Hair Maure, White } \\
\text { Arab) }\end{array}$ & Mali, Senegal & NA & $35-47$ & $65-90$ & $\begin{array}{l}\text { Milk (33-66 lt/ } \\
\text { lac), meat (cd. } \\
40-50 \%) \text {, skin }\end{array}$ \\
\hline $\begin{array}{l}\text { Touareg sheep (Grand Targui, } \\
\text { Petit Targui) }\end{array}$ & Mali, Niger & NA & $41-33$ & $60-80$ & $\begin{array}{l}\text { Meat (cd 46\%), } \\
\text { milk (33-66 lt/ } \\
\text { lac) }\end{array}$ \\
\hline $\begin{array}{l}\text { Macina sheep (Koundoum, } \\
\text { Goundou, Tillabery) }\end{array}$ & Mali, Niger & 0.63 & $28-35$ & NA & $\begin{array}{l}\text { Wool }(39 \mu \mathrm{m} / 1.2 \\
\mathrm{kg}), \text { meat }(\mathrm{cd} \\
40 \%), \text { milk }(85- \\
165 \mathrm{lt} / \mathrm{lac})\end{array}$ \\
\hline $\begin{array}{l}\text { Djallonke sheep (West African } \\
\text { Dwarf, Forest, Guinea, Ghana } \\
\text { Dwarf, Nigerian Dwarf, West } \\
\text { African Maned, Mosi Vogan) }\end{array}$ & $\begin{array}{l}\text { All West Africa (except } \\
\text { Cabo Verde, Liberia and } \\
\text { Niger) }\end{array}$ & $\begin{array}{l}(\mathrm{BF}, \mathrm{GH} \\
\mathrm{GU}, \mathrm{TO})\end{array}$ & $20-30$ & $40-60$ & $\begin{array}{l}\text { Meat (cd } \\
48-50 \%), \text { milk } \\
(26-87 \text { lt/lac) }\end{array}$ \\
\hline
\end{tabular}

\begin{abstract}
Sahelian goat group (Sahel, West African Long-legged, Desert, Sudan, Fulani, Peul, Peulh, Voltaique, Maure, Touareg)
\end{abstract}

Red Sokoto goat (Red Skin, Kano Brown, Kyasuwa, Katsina Light Brown, Mambilla)

Maradi goat (Zinder Brown, Chèvre rousse de Maradi)

Djallonke goat (West African Dwarf, African Pygmy, Guinean/ Ghana/Nigerian Dwarf, Ghana Forest, Forest Dwarf)

\begin{tabular}{|c|c|c|c|c|}
\hline $\begin{array}{l}\text { Benin, Burkina Faso, } \\
\text { Côte d'Ivoire, Ghana, } \\
\text { Mali, Niger, Nigeria, } \\
\text { Senegal }\end{array}$ & NA & $40-27$ & $70-80$ & $\begin{array}{l}\text { Milk (54-155 lt/ } \\
\text { lac), meat (cd } \\
43-49 \%), \text { skin }\end{array}$ \\
\hline Nigeria, Niger & 3.5 (Niger) & 27 & $66-67$ & $\begin{array}{l}\text { Meat (cd } 43- \\
48 \%) \text {, milk (34- } \\
84 \text { lt/lac), skin }\end{array}$ \\
\hline $\begin{array}{l}\text { Niger, Nigeria, Benin, } \\
\text { Burkina Faso, Mali, } \\
\text { Senegal, Togo }\end{array}$ & NA & $23-30$ & $62-67$ & $\begin{array}{l}\text { Skin, meat } \\
(52 \%), \text { milk (140- } \\
150 \mathrm{lt} / \mathrm{lac})\end{array}$ \\
\hline All West Africa & NA & $18-25$ & $30-50$ & $\begin{array}{l}\text { Meat, skin, } \\
\text { rituals, manure }\end{array}$ \\
\hline
\end{tabular}




\section{Camel}

The dromedary or one-humped camel (Camelus dromedarius) is one of the two species within the genus Camelus, which is found in West Africa. Camels are very important animal in West Africa arid and semi-arid areas, where they are primarily reared by pastoralists in Burkina Faso, Mali, Niger, Nigeria and Senegal. They are mainly used as packing and riding animals, occasionally may be used for draught, but also provide milk and occasionally meat (Epstein, 1971 and Mason, 1996). It is difficult to estimate the daily milk yield of the dromedary under pastoralist production system for because studies are not conducted often times. However, a study undertaken in Northern Niger estimates up to 1,760 litres per year (Saley and Steinmetz, 1998). Camel meat, which is considered a luxury among pastoralists, is rarely consumed in West Africa, except for northern Nigeria, where camels are thought to be extensively used for meat. According to different studies, in general, camels have a higher dressing percentage (54-57 percent) than pastoralist cattle (45-50 percent) (Kamoun, 2005).

Camel breeds in West Africa have not been characterized in most countries and the descriptions available in the literature are scarce and not well defined in some cases. They are known under different names reflecting a region, a tribe or simply the coat colour of the animal. Therefore, it is possible that the same breed has several designations. The variations in nutrition and terrain encountered across the subregion have resulted in the development of different groups or types of camels, which can be classified according to the topography of the area where they are reared (plains or mountain), the purpose for which they are used (pack or riding) or the geographical area where they inhabit (northern Sahara, Haggar or central Sahara and southern Sahara) (Mukasa-Mugerwa, 1981).

The Sahelian camel is the most common and widespread breed in the region and several varieties are described in the Sahel areas of Mali, Niger, Senegal and Nigeria. The Mehari is known for their endurance and speed (up to $40 \mathrm{~km} / \mathrm{h}$ ), has fawn colour, large slender body and small hump. The Adrar, raised by the Tuareg tribes found in Niger and Mali, and mostly used for pack and riding, is distinguished for the white colour, which can be also greyish with light coloured extremities. The Aür is a tall and light riding camel of great speed in desert areas, but further South tends to grow bigger and heavier due to increased feed availability. The Berabish, a medium sized strong and broad packing camel, with brown coloured long hair, is found along the Niger River basin, better adapted to humid conditions and considered a trypanotolerant breed. The Gandiol is a large heavy packing animal, found predominantly in northwestern Senegal. Other camel breeds reported in the subregion are the Azawak, Azarghaf and the Gouré, kept by Tuareg, Hausa and Fulani (Peuhl) pastoralists in western and central Niger who use them primarily for packing (Wardeh, 2004 and DAGRIS, 2019).

Photo 23. Azawak and Azarghaf camel breeds (Niger)

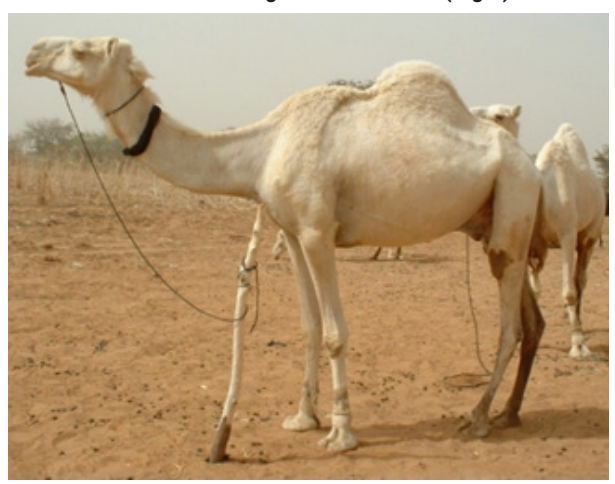

CFAO/DAD-IS/O. Pinguet

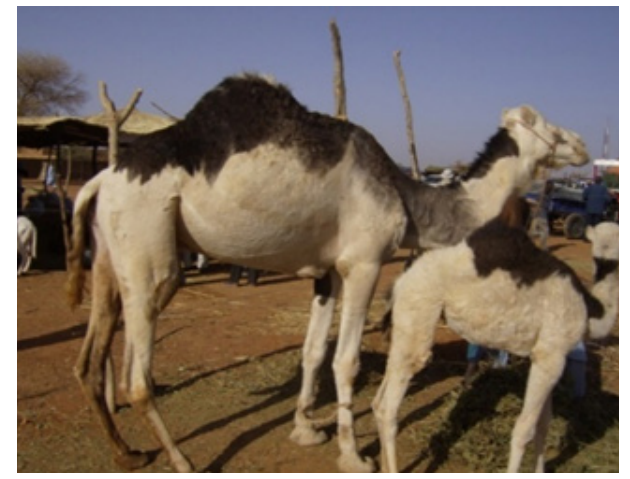




\section{Horses and donkeys}

Both horses (Equus caballus) and donkeys (Asinus asinus) are the main providers of animal traction for agricultural work and general transport in the Sahara and Sahelian AEZs of West Africa (Starkey, 2000). However, attempts to spread southwards these animals had little success due to the presence of tsetse flies and high prevalence of trypanosomiasis, equine piroplasmosis and African horse sickness (Mitchell, 2017). In general, the importance of equines in the subregion has been seriously underestimated and, despites poor management in terms of nutrition, health and housing, local breeds are well-known for their endurance and some are reported to be trypanotolerant (Wilson, 2017). Most indigenous breeds have not been characterized and the descriptions available in the literature are scarce and not well defined in some cases. There is not much information about indigenous donkey breeds in West Africa. Most countries report them as native of North Africa, widespread distributed, particularly within pastoralist communities, and very resistant to drought. However, some local donkey breeds or strains are reported in Mali, such as the Gourma, Miankala, Sahel, Yatenga Bandiagara, Koro and Bankass and Dogon (DAD-IS, 2019).

To the contrary, horse breeds have been and are far more abundant and diverse in West Africa. Several very similar local breeds or strains of pony-type horses exist and have been historically used in war and hunting, ceremonies and as bride-price, being considered as indications of wealth across West Africa (Naish, 2015). Several ethnic groups bred and gave also their names to these small horses, including the Fulani, the Hausa the Bornu, the Chamba, the Irigwe and the Piti of Nigeria; and the Bandiagara, Djerma, Mossi, Songhai and Yagha of the Niger River basin (Hendricks, 2007). Unfortunately, their population seem to have declined substantially in recent decades, suffering a gradual process of replacement by the larger Barb (or Berber) horse from North Africa and the Dongola horse originated in Sudan, being today often referred as West African Barb and West African Dongola horses (Blench, 1993). Other local horse breeds or strains are reported in the region, such as the Koto-Koli (Benin and Togo); Bobo (Burkina Faso); Chadian (Ghana); Beledougou, Nioro, Dombi, Dongalow, Hodh and Sahel (Mali); Arewa, Soudan and Talon (Niger), Bhirum and Sulebawa (Nigeria); Fleuve, Fouta, M' Par and M'bayar (Senegal) (DAD-IS, 2019).

Photo 24. Arewa and Talon horse breeds (Niger)
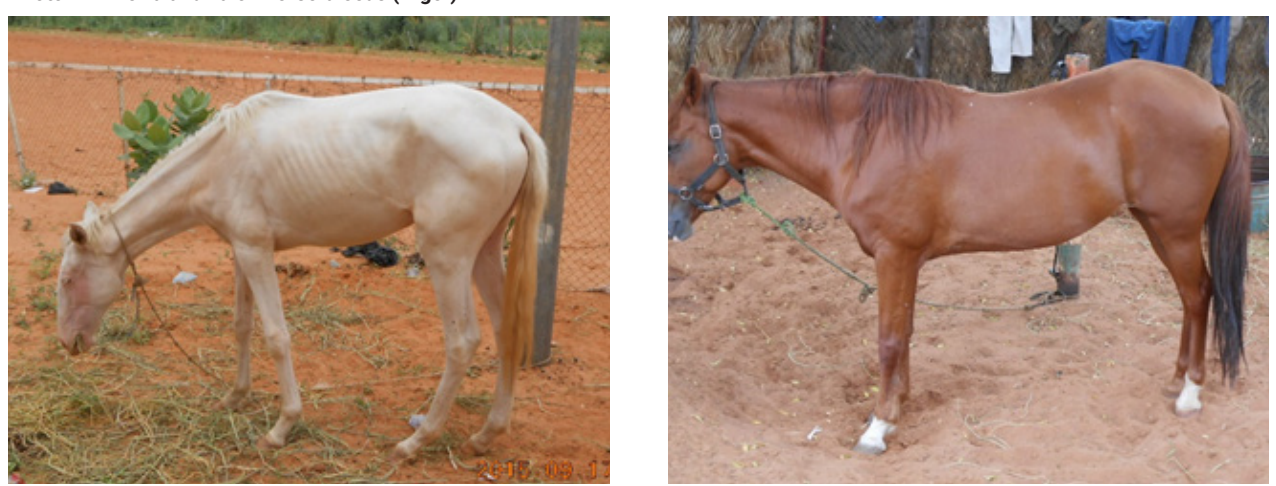

CFAO/DAD-IS/AKM. Gadjimi

\section{Pigs}

Despite cultural and religious influences in some West African countries that limit pork production and consumption, pig farming is generally growing across the subregion. Pigs are mostly kept in rural areas under traditional management, but a growing number is also kept in semi-intensive production systems, usually in peri-urban areas. 


\section{Indigenous pig breeds}

Local pig breeds have not been characterized in most countries and the descriptions available in literature are scarce and often very general. Local West African pigs are all very similar and known under many names: Somo (Mali), West African Dwarf pig (Nigeria), Ashanti Dwarf pig (Ghana), Bush pig (Togo), etc. The numbers of local pig breeds reported by West African countries are not available, but in the case of Benin and Burkina Faso, where pork from local breeds is more appreciated than that from exotic breeds, it is estimated that they represent 90 percent of the national pig herd (Djassi, 2012 and CIRAD, 2015).

The West African local pig breed are runner kind animals, with small narrow bodies (40-50 $\mathrm{cm}$ wither height and $20-60 \mathrm{~kg}$ adult weight) and relatively long legs. They usually have a short forehead, elongated snout and medium, semi-erect, swept-back small ears carried horizontally or slightly erect. The croup is slightly inclined and relatively muscular hams and straight tail, with a slight predominance of the previous train in males. The skin is often dark, sometimes pie, gray, red, rarely white. They have variable coat that can be scarce or long, in that case with rough hairs almost hiding the skin and a strip of longer hair along the spine. Even if described as "non-improved" breeds, they may have relatively good average dressed carcass (70-75 percent) and can be very prolific (4-15 piglets per litter), but their most highlighted features are their hardiness in terms of food scarcity tolerance, adaptability to heat and disease resistance (Blench, 1999 and Serres, 1989).

\section{Exotic pig breeds}

The Large White, Hampshire, Landrace, Duroc, Large Black, Craonnais, Yorkshire and Pietrain pig breeds were introduced to several countries in West Africa. In fact almost all modern piggeries use exclusively these exotics breeds. However, their genetic potential has deteriorated over time due to inbreeding and a substantial dilution of exotic genes into the local breeds (FAO, 2007).

\section{Stabilized crossbreed pigs}

The multiple crossings between local breeds and exotic breeds such as Large White, Hampshire, Landrace, Duroc, Large Black, Craonnais, Yorkshire and Pietrain have produced the so called "improved" pigs, representing an estimated 10-20 percent of the pig population in the subregion (FAO, 2007). The stabilized crossbreeds succeeded in those regions where there was larger number of local breed or a significantly larger local pig size. This is the case of the Korhogo (Craonnais x Local x Yorkshire) in Côte d'Ivoire, widely exported to neighbouring countries (i.e. Burkina Faso, Guinea, etc.), the Dapaong from Togo and the Matéri from Benin (D’Orgeval, 1997).

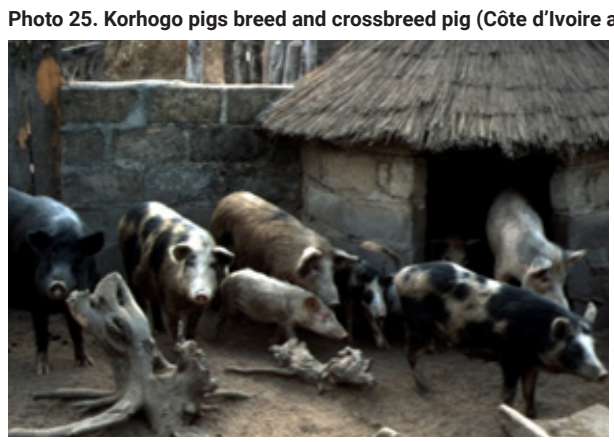

CFAO/DAD-IS/HH. Sambrau

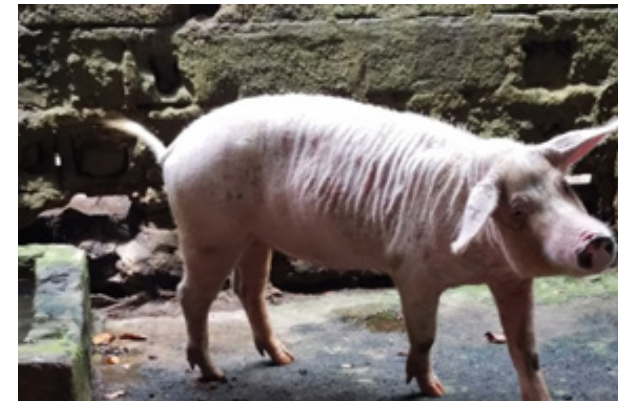

CFAO/G. Lamielle 


\section{Poultry}

Smallholder poultry production is a common practice in most rural and some urban areas of West Africa. It represents important part of subsistence farming and, while it is generally not a primary economic activity, the sale of poultry generates revenue to pay for household basic expenses. The commercial poultry sub-sector has experienced a rapid growth in the subregion, characterized by modern industrial or semi-industrial production, whose size varies greatly among countries, being largest in the coastal countries of Côte d'Ivoire and Senegal and least developed in Niger and Sierra Leone (Schneider, 2010).

\section{Indigenous chicken breeds}

Traditional poultry farming (village/backyard system) in West Africa is mainly dominated by the local type chicken, constituting the bulk of the exploited population in some countries (i.e. Benin), but it is difficult to define them as breeds because almost no studies on their characterization have been conducted. Most of the local chickens in West Africa are of dual purpose (i.e. meat and egg). Some specialized varieties of birds evolved in different ecological areas. These chickens are the result of constant interbreeding between different local varieties and strains. Phenotypes are very varied in body size and conformation, colour, plumage type, sizes and shapes of the ridge, etc. However, all these chickens have in common their relatively small size (1-2 kg), low laying ability (3-4 cycles per year laying 10-60 eggs) but also certain hardiness, disease resistance, little care and feed requirements, and for having good instinct for brooding and looking after chicks. These breeds are popular with consumers for their taste and, in some countries, they are also sought for traditional rituals (Sangaré, 2005).

Local undescriptive breeds of chicken are reported in all the West African countries. In Benin, local strains of poultry called "bush chicken", known also in local languages as Adjagbéto, Guin, Kpinkoun, etc. have been described. Ghanaian local chicken varieties distributed throughout the country are generally described as Frizzle, Barred and Naked-neck types. Guinea has reported local chicken types commonly known as Benna, Simba Sisse, Dandawoura, etc. In Mali local Koko-Ché chickens are relatively homogeneous phenotypically and somewhat different from those elsewhere in the subregion (Djiro, 1980; Traoré, 1981 and Kane, 1990). The Kolonto chickens have been reported in western Niger as a long-lived large-size breed with a variety of plumage colour, good layers and chick brooders. Local chickens in Senegal are described as small rustic chickens with mostly smooth plumage, sometimes wrinkled, white, red or black coloured, and can have a normal distribution, Naked-neck or feathered legs (Gueye and Bessei, 1995). In Togo, the existence of specific local types, such as the Naked-neck and the curly-plumage chicken, is common.

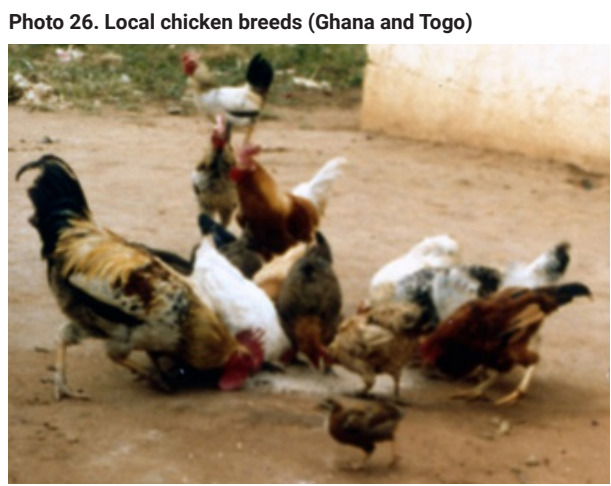

CCFA/DAD-IS/K. Boa-Amponsen

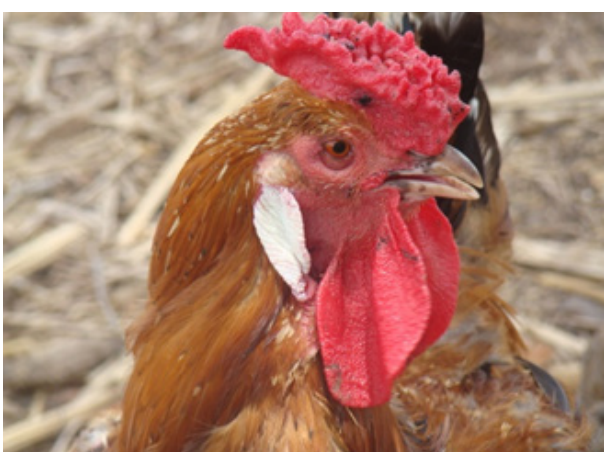

CILRI 


\section{Exotic chicken breeds}

As reported in FAO/SFW livestock sector reviews, exotic chicken breeds are reared in peri-urban farms of West Africa under the commercial poultry production system. These farms use strains relatively well adapted to tropical conditions in most cases, while other strains are raised under a controlled environment ${ }^{7}$. Commercial layer poultry producers in the region use different exotic breeds (i.e. Leghorn, Sussex Red, Lohman, etc.). Similarly, commercial broiler poultry production uses the most common established market brands (i.e. Cobb, Hubbard, Arbor Acres, ISA, Ross, etc.) usually imported as day-old chicks (DOC) or hatching eggs and, in some poultry farms, locally born from raised parental strains. The Animal Research Institute (ARI) in Ghana has successfully developed nucleus breeding flocks to create grandparent and parent lines used to produce DOCs for commercial broiler poultry farmers (Aboagye et al., 2003). It is difficult to identify the comparative advantages of the broad variety of hybrid strains and lines. Mostly, decisions are made based on price and market availability.

\section{Stabilized crossbreed chickens}

In general, improvement of local chicken by the introduction of exotic breed cockerels (i.e. Holland Blue, Rhodes Island Red, Plymouth, Wyandotte, etc.) has been conducted without much success. This is due to lack of real genetic improvement plans and monitoring. However, some stabilized crossbreeds with improved productivity have been developed by government livestock research stations in West African. This is the case in Mali of the Wassa Chè (Rhode Island Red x Kokochè), literally meaning in native language "Chicken of satisfaction". It was developed by the Centre Régional de Recherche Agronomique to improve egg laying quality (reaching $200-220$ eggs per year) and meat (2.5 - $3.8 \mathrm{~kg})$ production (Fomba, 2016). In Nigeria the Shika-Brown is a layer strain with very good performances (278-290 eggs per year weighing $62.5 \mathrm{~g}$ ) and well adapted to the tropical climate. This breed gives best economic returns for small and medium scale producers, which make it a preferred layer strain in the region (NAPRI, 2009).

\section{Photo 27. Wassa Chè and Shika-Brown chicken breeds (Mali and Nigeria)}

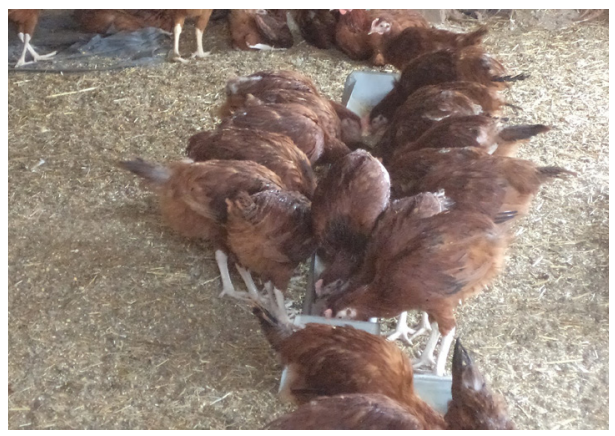

C.JSTM

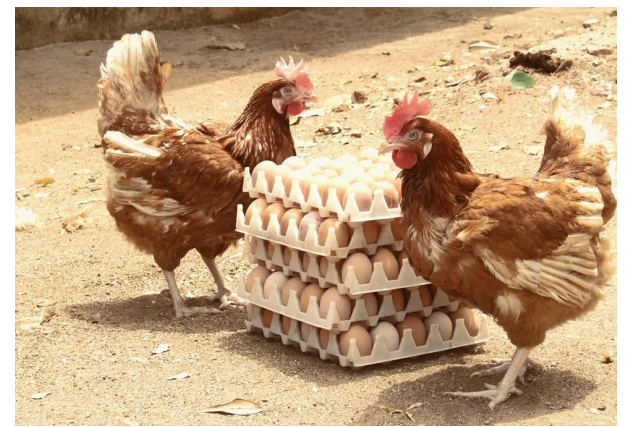

CNAPRI

\section{Other poultry species}

The above-mentioned FAO/SFW livestock sector reviews revealed other poultry species raised in West Africa in a lesser scale and that do not usually exist as large commercial flocks:

- Guinea fowl are native to the region, usually kept under extensive or semi-intensive management, having a great potential of producing meat (1.4-1.6 kg) and particularly egg (60-100 per year reported in Nigeria) production.

- Ducks, such as the Barbary (Cairina moschata), Pekin and Rouen (Anas platyrhynchos) breeds are reared for meat $(2-5 \mathrm{~kg})$ in rice-growing areas under free-range conditions. 
- Local pigeons (150-300 g) are characterized by a high variability of colours and drawings of plumage, they use to live on the roofs of houses and do not are usually fed.

- Turkeys (4-8 kg) kept by rural producers are usually black or barred. Farmers in northwestern Nigeria have specialized in breeding turkey in commercial quantities.

- Geese are less commonly found, but its fatty meat is well accepted by the local population.

- $\quad$ Quails, raised for egg production (200-300 per year), have been described as a lucrative business in Nigeria due to its high rate of returns and low cost of production.

- Ostriches have been also reported in a few farms in Nigeria, Ghana and Mali.

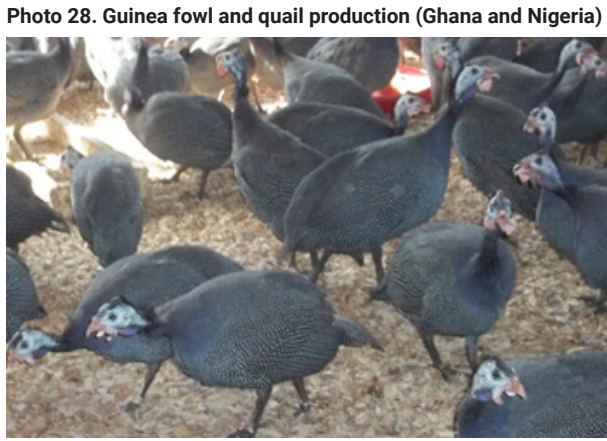

(CB. Bedane

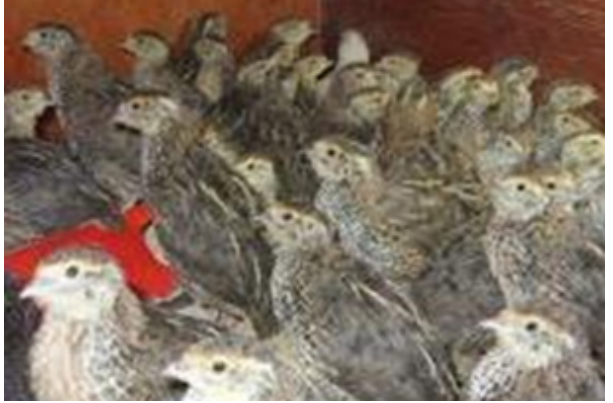

CKarfi Quail Farm

\subsection{Non-conventional livestock}

The importance of rearing non-conventional animal species in West Africa has only been recognized recently (Finzi, 2000). The interest particularly increased after the Ebola Virus Disease outbreaks in West Africa between 2014 and 2016, which led to banning of bushmeat. Small non-conventional livestock species are very efficient, do not compete with humans for food, are easy to house and manage, and can be easily incorporated into mixed production systems to expand the available food resource base. Due to significant dependence on bushmeat particularly in coastal countries in the past, the taste of meat of most non-conventional animals is closer to what these consumers used to (FAO, 1995).

The production of non-conventional animals demands little capital investment and husbandry skills, presenting minimal economic risks. In addition to valuable protein for home consumption, marketing these animals and their products can also provide readily available cash (BSTID and NRC 1991). Finally, the smaller quantities of meat from these animals can be consumed at once without wastage, which is an important consideration where proper conservation and storage facilities are not available. Despite their now generally recognized advantages, there are not yet exhaustive records and information available on this kind of livestock production in the region. This sub-chapter attempts to summarize the main non-conventional livestock species reared in West Africa, according to their ecological and economic importance (Peters, 1985).

\section{Rabbits}

Rabbit production is relatively important to the economy of some countries in West Africa. The two main producers are Nigeria and Ghana, where there is a lively tradition of rabbit husbandry, and to a lesser extent Benin, Cabo Verde, Côte d'Ivoire, Liberia and Sierra-Leone (FAOSTAT, 2019). There is commercial production in these countries, but most rabbitries are family-owned, with part of the output destined for market. Rabbits eat almost anything, including table leftovers, agricultural byproducts, various kinds of grass and local flora and brewer's mash residues. The attributes which make rabbits conventional animals of choice include their high growth rate, high efficiency in converting forage to meat, short 
gestation period, and high prolificacy, relatively low cost of production, meat of high nutritional quality which includes low fat, sodium, and low cholesterol levels (Mailafia, Onakpa and Owoleke, 2010). They are extremely prolific (3-4 litters averaging 6-8 offspring every year). An adult rabbit weight is 3.5-4.5 $\mathrm{kg}$ (dressed carcass 50-55 percent), it is more efficient than beef in terms of feed energy conversion and the supply of meat is continuous, furnishing an excellent source of protein (Lebas et al., 1997). Challenges to rabbit production in West Africa include heat stress and lack of management skills (Mailafia, Onakpa and Owoleke, 2010). The further promotion of rabbit production in the region needs to find local solutions to dry season feeding, genetic material, marketing together with an emphasis on training producers.

\section{Guinea pigs (Cavia porcellus)}

This Latin-American rodent, also known as domestic cavy, has been introduced in several West African countries, including Benin, Burkina Faso, Côte d'Ivoire, Ghana, Guinea, Mali, Nigeria, Senegal, Sierra Leone and Togo. It is usually reared under backyard conditions by resource-limited farmers. Guinea pig farming is considered very promising for rural development, requiring little capital, equipment, space and labour. They are able to adapt to almost all types of vegetable food, as well as farm and kitchen wastes, with high feed conversion ratios reported (Kouakou, 2011). Adults weight $0.5-2.0 \mathrm{~kg}$, with dressed carcass of 65 percent and meat of higher protein content than that of conventional livestock. They are very prolific (5 litters per year and 1-5 young per litter) and reported weaning survival rate is higher than in rabbits. According to estimates, 20 females and 2 males may produce cheap but high-quality meat supply enough to feed a family of six people. Its productivity in West Africa should be improved through the development of more appropriate feeding systems and management technics (Jori, Mensah and Adjanohoun, 1995 and Nuwanyakpa et al., 1997).

\section{Photo 29. Rabbit and Guinea pig production (Liberia and Benin)}

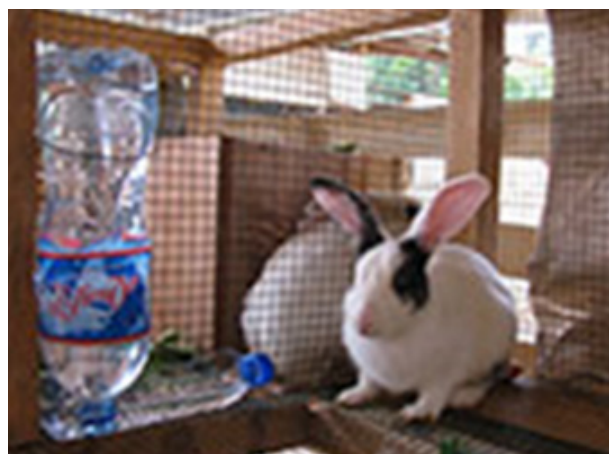

CF. Imarhiagbe

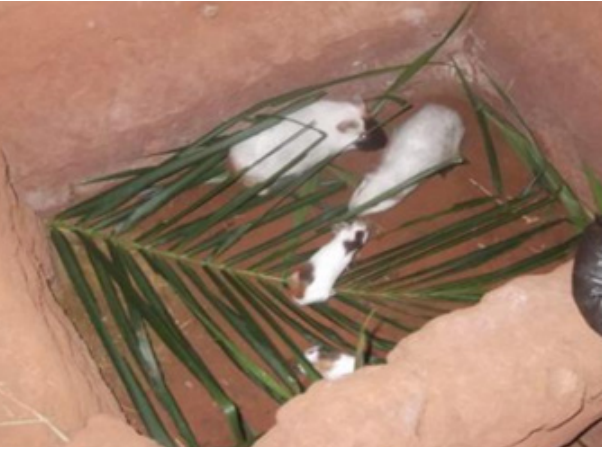

(C)AML Faihun

\section{Grasscutters (Thryonomys sp.)}

Commonly known as "alaucodes" in French-speaking West Africa and "cane rats" in English-speaking West Africa, these rodents are more closely related to porcupines than to common rats, weighing around $9 \mathrm{~kg}$ and measuring up to $60 \mathrm{~cm}$. Although widely hunted, they are easy-to-rear monogastrics with a wide tolerance for different diets that can fit in a backyard production scheme (Opara, 2010 and Titiola, Olaniyi and Adebusola, 2015). They can eventually fit the local production conditions than other species, including rabbits. Considered an agricultural pest, they are nevertheless highly valued for the quality of their meat, whose price can even quadruple beef (Jori, Mensah and Adjanohoun, 1995). The production system is similar to that of rabbit rearing, kept in cages or pens and fed mainly on green forage. Grasscutters are relatively prolific ( 2 litters per year and 4 young per litter). Given the high demand and the feeble contribution by conventionally reared animals, the promotion of domesticating Grasscutters is more advisable than that of guinea pigs (Box 1 ). 


\section{Giant rat (Cricetomys sp.)}

Also known as "pouched rat", this large (1-2 kg) rodent is found from the semiarid Sahel to the humid coast of West Africa, where they are traditionally trapped, fattened in cages and slaughtered. They are fed with fruits, tubers, leaves, agriculture and kitchen wastes, but do not eat grass. Giant rat farming may have as much or more potential than grasscutters, since they are easier to feed and handle. Its meat is very appreciated, having a nutritional value similar to that of domestic livestock (NtiamoaBaidu, 1997). They reproduce rapidly and year-round (4 litters per year and 4 young per litter). The captivity management techniques were developed in Nigeria, breeding stocks have been established and commercial-scale giant rat farms are operating in the country (Malekani, 1996). Further research on giant rat farming would open up the potential for extra meat supplies in rural and urban areas. This may include identifying low cost husbandry techniques applicable in rural areas, as well as outlining the basics of husbandry (i.e. capital costs, feed conversion, growth rates) (Wilson, 2012).

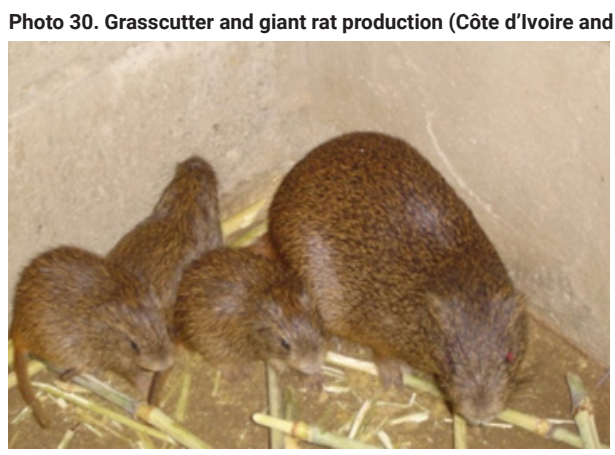

CK. Bakayoko

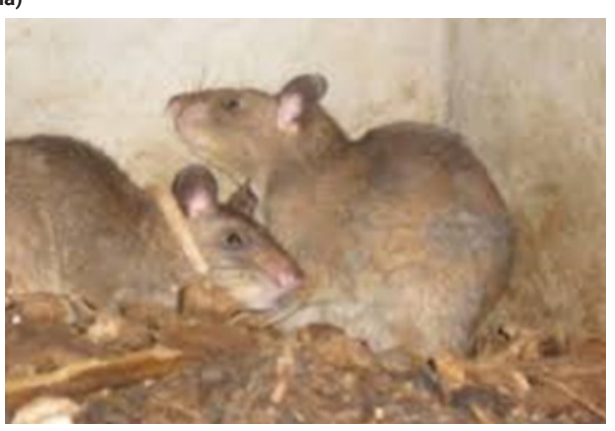

(C) SCB. Pomalegni \& GA. Mensah

W.

Box 1

Grasscutters or guinea pigs? Enabling environment in West Africa.

Consumption of small rodents, particularly Guinea pigs, is well assumed as a traditional practice in the tropical areas of South America. Hence, they are included in livestock statistics. In West Africa, however, lack of specific data hides the importance of the sub-sector. Although the introduction of Guinea pigs has been suggested and studied in the region, its extent seems to be limited by the ecologically and functionally equivalent grasscutters, also called cane rats. Grasscutters are considered an agricultural pest but are also highly valued for the quality of their meat, whose price can even quadruple beef (Jori, Mensah and Adjanohoun, 1995 and Nuwanyakpa et al., 1997).

Much of the recorded regional consumption of bushmeat (Table 22 and section 5.1.1) is actually based on grasscutters, reaching up to 80 million animals or 300,000 Metric Tonnes of meat per year. FAO does not collect specific information on "other rodents" outside of South America. Because of the huge potential of a grasscutter-based industry in terms of food security and job creation, several experiences towards its full domestication have taken place in Nigeria, Ghana, Benin and Côte d'Ivoire (Titiola, Olaniyi and Adebusola, 2015; Jori, Edderai and Houben, 2005 and Rahman, 2014). Although the practice still needs improvements and investments, perspectives seem to be good for further development. The major constraint seems to be the lack of investment capital (Aiyeloja and Ogunjinmi, 2013; Akinola, Etela, and Emiero, 2015 and Kamuanga et al., 2008). 


\subsection{Livestock breeding and conservation programmes}

\subsubsection{Livestock breeding programmes}

In general, and with the exceptions of few examples previously mentioned, the West African livestock sub-sector is lacking appropriate breeding programmes at local, national and regional level. Obviously, this is consistent with the general belief of livestock producers in the region on keeping large numbers of livestock as source of prestige rather than few productive herds and flocks (Herrero et al., 2013). On the other hand, smallholder farmers keep small numbers of livestock, since their priority is crop cultivation, and they are not often interested in the establishment of systematic breeding programmes (Köhler-Rollefson, 2003). Therefore, in most traditional livestock systems, breeding programme is merely observance of priority criteria in choosing breeding animals. This mainly involves the use of supposedly "good males", often selected by visual assessment and without control over mating. This approach frequently result in low genetic improvement. Nevertheless, traditional knowledge of livestock breeder does not have to be underestimated (Mason and Buvanendran, 1982).

Participatory survey techniques among herd owners and herders used to assess traditional breeding systems in twenty-seven villages in Gambia demonstrated that the size, strength (vigor and fitness), libido, "good offspring" and disease resistance, were important treats in selecting N'Dama bulls for breeding purpose (Steglich and Peters, 2003). According to these authors, the priority criteria for selecting N'dama cows for breeding include milk production, yearly calving, strength and disease resistance. A similar approach has been used by traditional farmers for the breeding programme of West African Dwarf goats and Djallonke sheep under low input production environment (Glich and Peters, 2002). As mobile livestock producers, West African pastoralists also have their own breeding goals, actively pursuing livestock adaptative traits useful to the hostile marginal areas they exploit (i.e. endemic diseases, poor feeding, water scarcity, etc.), since they must respond rapidly to changing environmental conditions. They play a major role in the development of livestock breeds, due to the relatively closed gene pools they manage, but also in the spreading of animal genetics by bringing new breeding stock to the markets for selling and practicing crossbreeding (Köhler-Rollefson, 2003).

Livestock breeding programmes for genetic improvement in most of West African countries, have generally been implemented by governments and in some cases with the support of international organizations and non-governmental organizations (NGOs). The involvement of the private sector, usually is motivated by the need for fast productivity gains and lacks clear strategy and long-term view (AU-IBAR, 2014). The genetic improvement programmes remain primarily driven by imported technological packages (i.e. artificial insemination) and have usually favored the use of exotic breeds for crossbreeding, upgrading, or replacement (Rege, 2003). These animal breeding technologies and exotic breeding material can be an opportunity for improving animal production and productivity in West Africa. However, the indiscriminate, uncoordinated or uncontrolled crossbreeding, may not only become unsuccessful but could also poses a risk of genetic erosion of indigenous breeds and a loss of their adaptive traits (Biscarini, et al., 2015).

Crossbreeding of N'dama cows with high milk producing exotic breeds in low to medium tsetse challenge urban/peri-urban areas in Gambia resulted in considerable decrease of the trypanotolerance trait for first filial generation (F1) crossbred, which was recommended to be reared only in low or zero tsetse/trypanosomiasis challenge areas (DSA/DLS, 2003). In Nigeria, a private-public partnership (PPP) initiative promoted the importation of Friesian bulls and semen. Import of these genetic materials was liberalized with the objective of boosting milk yield of rural smallholder dairy producers through crossbreeding. However, no control has been placed on the extent of the level of exotic blood injected into the national indigenous cattle herd (Ogundip, and Adeoye, 2013). Similarly, in Ghana a government 
run dairy goat improvement programme has used Anglo-Nubian goats to upgrade the Djallonke and Sahelian goats through artificial insemination (Aboagye et al., 2003). However, in subsistence production system setting, improved management practices are those which generate higher benefits than crossbreeding of indigenous goats (Ayalew et al., 2003).

On the other hand, very few livestock breeding programmes in West Africa are based on selection and improvement of indigenous breeds and when they exist, they tende to focus only on specific market driven production traits, without considering the wider role of livestock and the specific organizational patterns of traditional livestock systems in the region. Moreover, the involvement of local communities in the implementation of these programmes has been very limited, despite being the main direct beneficiaries (AU-IBAR, 2014). Nevertheless, since the last few decades, there is a revival of interest in indigenous livestock breeds, mainly attributed to the increasing number of comparative studies indicating that, within the context of their respective production systems, traditional breeds may be able to compete in terms of productivity with exotic breeds, and their high genetic diversity provides opportunities for selection and improvement through the implementation of customized breeding programmes (Köhler-Rollefson, 2003).

Some West African countries have successfully set-up national initiatives regarding indigenous animal genetic resource improvement programmes and there is a regional common agenda on the sustainable use of certain transboundary livestock breeds (AU-IBAR, 2014). In Côte d'Ivoire, a community-based national sheep improvement programme focusing on smallholders was established by the government in the 1970s. The primary goal of this programme was the performance improvement of the Djallonke sheep based on an open-nucleus breeding scheme. The selection scheme included an on-farm preselection of breeding animals based on individual performance, followed by an on-station selection and finally the distribution of selected rams to farmers for mating (Yapi-Gnaoré, Dagnogo and Oya, 2003). In Ghana, an open nucleus breeding scheme has been implemented by the Animal Production Directorate of the Ministry of Food and Agriculture (MoFA) to improve the Djallonke sheep and goats, the Ashanti Black pigs and the WASH cattle using individual performance test and selection in participating farms (MoFA, 2016).

Some regional and international organizations have also implemented several multi-country projects and initiatives in West Africa regarding indigenous livestock breeding programmes. The International Trypanotolerant Centre (ITC), now the West African Livestock Innovation Centre (WALIC) has played a significant role in increasing the performance of the N'Dama cattle, West African Dwarf goat and Djallonke sheep and goats, through breeding programmes and implementation of projects such as the "Sustainable management of endemic ruminant livestock of West Africa", known by its French acronym of PROGEBE (WALIC, 2019). The International Livestock Research Institute (ILRI), through its Livestock genetic Programme, is actively working with national breeding programmes identifying genetic/breeding bottlenecks limiting the benefits of small-scale livestock farmers. As an example, ILRI has implemented the "African Chicken Genetic Gains" project in close cooperation with several countries in the continent, including Nigeria. The project has been successful in testing indigenous and exotic chicken breeds and enhancing access of smallholder farmers to more productive, agro-ecologically adapted, and farmerpreferred chicken breeds and strains (ILRI, 2018).

\subsubsection{Livestock conservation programmes}

The indigenous livestock breeds in West Africa represent valuable genetic resources, providing a diversified genetic pool reservoir, which can help mitigate present and future challenges linked to changes in production systems, market requirements and environmental degradation. Despite their importance, lack of information and consensus on the status and trends of livestock genetic 
resources in the region, has constrained the development of appropriate policies and strategies for their conservation and improvement, as well as for contingency planning programmes to protect endangered breeds (AU-IBAR, 2014). Nevertheless, information on indigenous breeds and their production systems is slowly being accumulated at national and regional levels, but the characterization of many of the ruminant breeds is still incomplete and the situation is much worst for indigenous pigs, poultry and other small species. According to Scherf, and Pilling, (2015), the population size is missing for over two-thirds of African livestock breeds, while in West Africa, from a total of 216 local breeds reported by countries, the risk status of 187 of them is unknown, two are classified as critical and ten have already disappeared (DAD-IS, 2019).

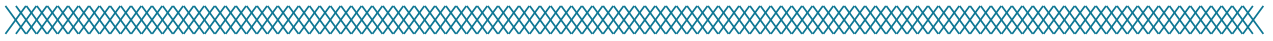

Figure 11. The risk status of West African local breeds reported by selected countries ${ }^{8}$

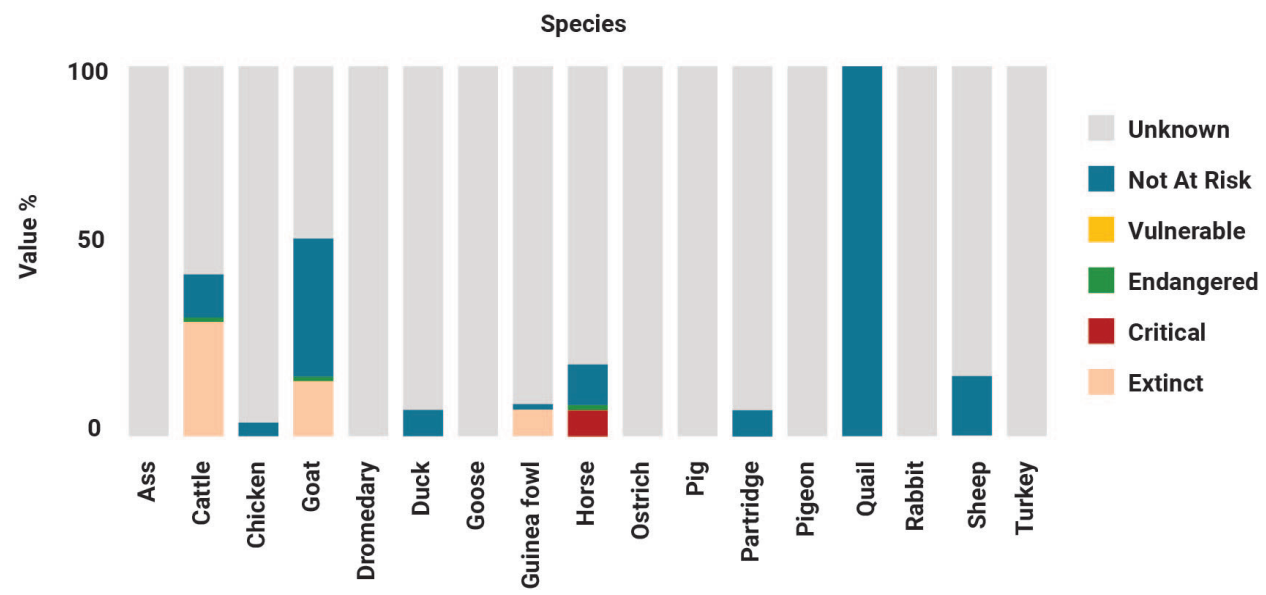

Source: Adapted from DAD-IS, (2019).

The concept or definition of "breed" itself represent a dilemma for decision making on conservation of genes versus genotypes. In West Africa, some livestock breeds are frequently known by the same name in different places, but often look quite different from one place to another. On the other hand, there are livestock breeds that look similar but have different names in different places places (Köhler-Rollefson, 2003). For example, it is difficult to assume that the Djallonke sheep, distributed across the coastal part of West Africa, is a single breed. Certainly, the natural selective pressure of the Sudan and Guinea AEZs, together with historical livestock movement, have influenced the conformation of a common sheep genotype showing similar phenotypical characteristics. However, the artificial breeding efforts of the diverse traditional farming and livestock communities rearing this sheep in different countries must be also considered (Rege, 2003). Therefore, in the context of West Africa, a definition of breed that applies a combination of sociocultural and ecological criteria must be applied (Köhler-Rollefson, 1997).

The traditional livestock breeding communities play a significant role in the conservation and management of livestock genetic resources and must be involved in the implementation of any related initiative or programme. Since they influence livestock producers decisions and choices, understanding the sociocultural factors involving breed development is important. Indeed, traditional practices, local ways of life and ethnic or community identity are often the most important forces for the development and diversification of livestock breeds and production systems (FAO, 2007). The value of a breed in the lifestyle or identity of a particular social group is what encourages its maintenance. Therefore, 
any initiative or programme for the conservation and management of indigenous breeds requires a preliminary study to identify what are the social, cultural and economic factors that will have an impact on execution and results (Köhler-Rollefson, 2005). There is also a need to be aware of property right issues regarding access to genetic resources, guaranteeing a fair distribution of any possible originated benefits that include the rural communities where the indigenous breeds comes from among West African countries (AU-IBAR, 2014).

Indigenous livestock breeds may be valued by local communities for different reasons. They may have unique adaptive traits that can be very specific and attuned to certain types of geographical and climatic conditions, such as tolerance to local diseases or feeding and water regimes. In Nigeria, for instance, breed distribution is strongly linked to the preference of individual breeds for different types of vegetation and changes as the overall environment of the country evolves (Köhler-Rollefson, 2003). Local breeds may also be valued because they provide products appreciated in traditional meals. For example, in Burkina Faso local chicken is appreciated for its superior taste, justifying the existence of a specialized market niche for this type of poultry (Kondombo et al., 2003). Local tradition and social practices can also contribute to conservation and genetic diversity of indigenous livestock breeds. That is the case of the Muturu cattle breed, which was once widely distributed across West Africa's Sahel AEZ, has survived extension because this breed is still sacred to many communities. Muturu's meat and hide are used mainly for ritual ceremonies, particularly funerals, while its milk is widely used in traditional medicine (Blench, 1998).

The lack of competitiveness among local livestock breeds is probably the main cause of being at risk of extinction. The safest way of conserving indigenous animal population, therefore, is to continuously develop it. Adding value and improving market-access strategies would help the region to better respond to the erosion of animal genetic resources. However, there is a dilemma regarding the use of resources for conservation of least productive local breeds versus investing in the improvement of the most promising ones (Bélanger, and Pilling, 2019). Another important issue to be addressed is how to prevent indigenous breeds from being at risk of extinction or genetic erosion. The impact of trade on exotic animal genetic material in West Africa must be better understood in order to generate recommendations and put in place policies and measures to reduce the effect of trade on the dilution of indigenous livestock breeds. Moreover, extreme weather condition and other emergencies such as floods, drought, disease outbreaks, etc. may have direct negative impacts on livestock genetic resources in the region, leading to increased risk of extinction of indigenous livestock breeds (FAO and AU-IBAR, 2014).

Transhumance has important role in sustainable management of livestock genetic resources in West Africa as it enable the continued use of rangelands by maintaining the indigenous breeds (FAO and AUIBAR, 2014). Although conservation measures are more efficient and cost effective when conducted at regional level, inadequate regional policies and strategies on land tenure in securing access rights to grazing land for pastoralists has hindered the conservation and the protection of local animal genetic resources (Köhler-Rollefson, 2003).

The lack of harmonized methodologies for characterization, inventory and monitoring of livestock genetic resources in the region, makes it difficult to provide evidence-based information for policy formulation and decision-making (AU-IBAR, 2014). Absence of appropriate infrastructure is also a serious constraint for developing functional conservation and improvement programmes for indigenous livestock breeds. Except for Burkina Faso, Gambia, and Niger, there are few facilities in West Africa for 
ex situ conservation of animal genetic resources, particularly cryogenic storage and gene banks, and all of them need to be upgraded (Scherf, and Pilling, 2015). In Burkina Faso, the Centre International de Recherche-Développement sur l'Élevage en Zone Subhumide (CIRDES), is one of the most promising facilities and as such has been recommended to serve as regional animal gene bank in West Africa. Additionally, in situ conservation of animal genetic resources in West Africa must also be supported through the establishment and strengthening of national and regional livestock breeders' associations (AU-IBAR, 2014).

In addition to those already mentioned in this and previous sections, other regional and international organizations are also involved in different projects and initiatives in West Africa regarding indigenous livestock conservation. One of these examples is a project titled "Strengthening the capacity of African countries to conservation and sustainable use of African animal genetic resources", implemented between 2013 and 2018 by the African Union-Interafrican Bureau for Animal Resources (AU-IBAR) and financed by the European Union (EU). The project identified challenges and opportunities for the various regions in Africa, including for West Africa. It mainly focussed on capacity building for effective formulation and implementation of policies and strategies for animal genetic resources, creating awareness for its inclusion into national and regional agricultural investment priorities (AU-IBAR, 2019). FAO, under its management role of Global Plan of Action for Animal Genetic Resources, has been promoting characterization of livestock breeds and animal identification and recording systems in West Africa and other parts of the continent, which are the basis to be used for starting any conservation and improvement programme of indigenous livestock breeds (FAO, 2016a). 


\section{LIVESTOCK PRODUCTION SYSTEMS IN WEST AFRICA}
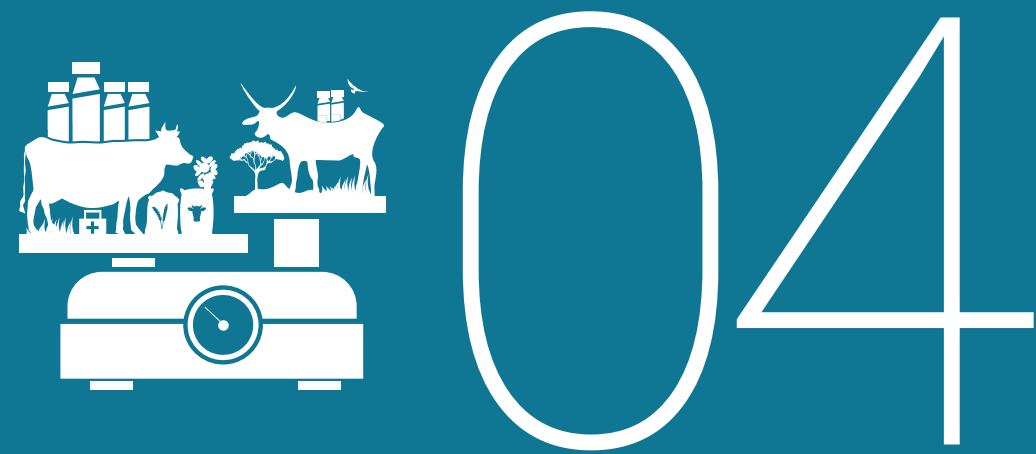



\section{ChAPTER IV}

\section{LIVESTOCK PRODUCTION SYSTEMS IN WEST AFRICA}

\subsection{Historical perspective and current status}

Since historical times, livestock production in most parts of sub-Saharan Africa has been characterized by seasonal movements in search for grazing and water. Animal husbandry (i.e. large and small ruminant production) is relegated to remote and unproductive lands where staple food and cash crops could not be cultivated with any efficacy or efficiency. For centuries, large tracts of rangelands were used to support steady numerical growth of ruminant livestock population.

Under the weight of recurrent drought of the 70 s and the 80 s, the trend of increasing livestock population size was reversed due to significant losses in ruminant population in many Sahelian countries of West Africa. In response and with the main objective of preserving the remaining stock, pastoralists were forced to move southward where animal feed availability was better. This was, at the same time, facilitated by government and international organizations supported programmes for livestock restocking and accompanying health and production related interventions (Gautier, Denis and Locatelli, 2016).

These shocks also brought about pastoral land degradation in many countries, especially at livestock concentration points (such as watering points and rest areas) for which the quest for workable and sustainable solution continued to date. Most of the available solutions are not feasible for the West African situation, where the bulk of rangelands are public properties and communally grazed. There is practically no incentive or motivation for the pastoralist to invest in the rehabilitation of degraded rangeland (Twose, 1984).

Another important phenomenon that was an outcome of the droughts of the $70 \mathrm{~s}$ and $80 \mathrm{~s}$ is the shift in livestock ownership. New actors from other occupations such as active or retired public servants, traders, investors, etc. able to invest in the livestock sub-sector joined. As a result, some of the traditional pastoralists became labour force for the 'new' livestock owners for whom livestock rearing is a brandnew activity. Due to the fact that the majority of these new livestock owners live in towns and cities and the increasing demand for animal products as a result of the rapid urbanization in most countries, instalments of livestock farms in the vicinity of cities have been emerging to present days (Blench and Marriage, 1999). However, the daily management of these new peri-urban and urban livestock farms by poorly paid attendents and managers requires improvement owning to the fact that the livestock owners are mostly absent. 
The current classification of livestock production systems recognize that crop-farming and livestock cannot be considered in isolation due to the interdependence and potentially mutual benefits of crops and animals in mixed farms, which are heavily influenced by AEZs and, increasingly, by economic and socio-cultural forces. In line with these principles (Robinson et al., 2011) classified livestock production systems according to a three levels structure taking into consideration crop-livestock integration, agricultural practices and climate (Figure 12).

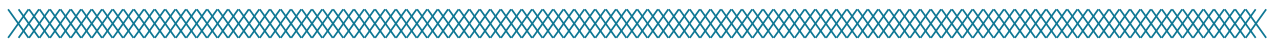

Figure 12. Livestock production systems distribution in West Africa9

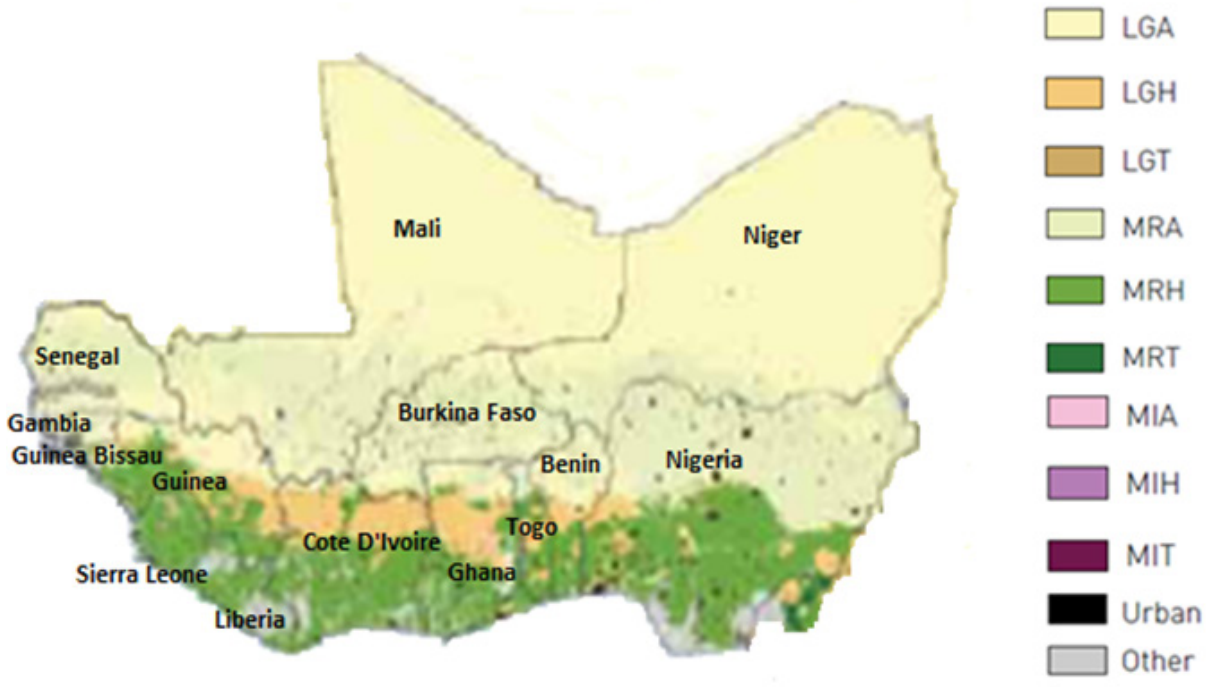

Source: Adapted from Robinson et al., (2011).

\subsection{Pastoral system}

This is the predominant livestock production system in the Sahara and Sahel AEZ, encompassing mainly the countries of Burkina Faso, Mali, Niger, Nigeria and Senegal. Under the pastoral production system, all the productive activities revolve around livestock. In these countries, the pastoral system is not only the source of livelihood for many but also provides the bulk of national red meat production. The sociocultural attributes of the system for most owners (especially for those who own the major ruminant species) out-weigh the economic aspects, with owners keeping livestock mainly for food, prestige and as asset rather than exploiting them as business to improve their living standard or their economic status, even if surplus production is available during rainy seasons. Pastoralists are well known for their high knowledge of transhumance practices but have limited capacity to use and access to modern animal production techniques and technologies. They are not well organized to defend their collective interests and take advantage of economy of scale within different commodity supply chains and market opportunities, risking often of being marginalized because of their low representation on relevant local decision-making bodies.

' L: Livestock only production system; M: Mixed, crop-livestock production system; G: Grassland-based; R: Rainfed; I: Irrigated; A: Arid and semi-arid tropics and subtropics; H: Humid and sub-humid tropics and subtropics; T: Temperate and tropical highlands (e.g. LGA: Livestock only, grassland-based, arid and semi-arid tropics and subtropics). 


\subsubsection{Definition and description}

The concept "Pastoral system" was first coined by (ILCA, 1983) as a system where more than 50 percent of the income of people practicing it derived from livestock production. There may be many definitions or refinement of the concept before or after ILCA's definition, but all have in common that the livelihoods of the people who practice it depend on the exploitation of animal resources. It is characteristically extensive and subsistence in nature, being a largely "free-range" system. The species of livestock kept under this system comprise camels, cattle, small ruminants (dominant species), horses, donkeys and occasionally poultry and other non-conventional livestock ${ }^{10}$. Because of its limited use of inputs and technology, the pastoral system is characterized by very low productivity. The subsistence function of livestock is a principal feature of the pastoral system, within which milk and meat are the main animal products, used primarily for domestic consumption. The excess milk is traded to acquire cereals and other goods (Garrity, Dixon, and Boffa, 2012).

\subsubsection{Types of pastoral systems}

Transhumant pastoralism sub-system

It is characterized by the cyclical movement of animals and their keepers over long or short distances and with more or less defined duration, depending on the availability of water, pasture and security. Short distance transhumance (below $100 \mathrm{~km}$ ) is practiced where dry season grazing is available; otherwise, pastoralists embark upon long distance transhumance, which may involve crossing several AEZs within the same country or crossing national borders (SWAC/OECD, 2007). The cross-border transhumant pastoralism is practiced in many countries within and outside the region, including Mali, Burkina Faso, Niger, Nigeria and Senegal as countries of origin, while Benin, Côte d'Ivoire, Ghana, Senegal and Togo, are mainly classified as host countries of transhumant herds and flocks. Whatever distance covered and duration, the livestock producers always return to the point of origin during certain period of the year. Lactating cows are kept at the camping site or the village and milk off-take above the fraction suckled by calves is used to cover domestic needs. Some variants of transhumant pastoralism are associated with food crops agriculture (i.e. millet, sorghum, rice, etc.) and others with complementary pasture zones, such as the post flood pasture in the inner Delta of the Niger River in Mali (Otte and Chilonda, 2002).

Photo 31. Fulani cattle herders crossing the Niger River at Diafarabé village (Mali)
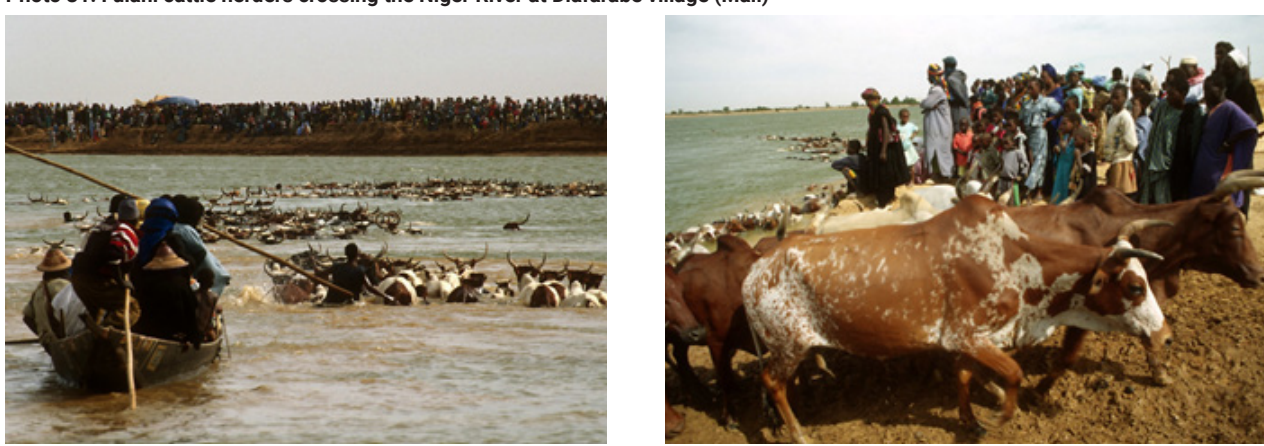

(CFAO/A. Gandolfi 
Nomadism or pure pastoralism sub-system

This sub-system is practiced in areas characterized by low and irregular rainfalls, so pastoralists must be in perpetual movement over immense territories, with part of their family, searching for better pasture and water sources. Contrasting with transhumance pastoralism, nomadism has neither specific pattern of returning necessarily to the departing point during certain seasons nor associated with food- or cashcrop agriculture. Pastoralists live essentially on a milk and meat-based diet and trade culled females (i.e. cow, ewe, doe and camel), extra males not used for reproduction and castrated 4-5 years old steers and rams. The nomadism sub-system pertains to Northern Sahel and adjacent areas of the Sahara AEZ in Mali and Niger, involving primarily flocks of small ruminant and camel herds (Otte and Chilonda, 2002).

Photo 32. Nomadic and transhumant livestock at watering point (Niger)

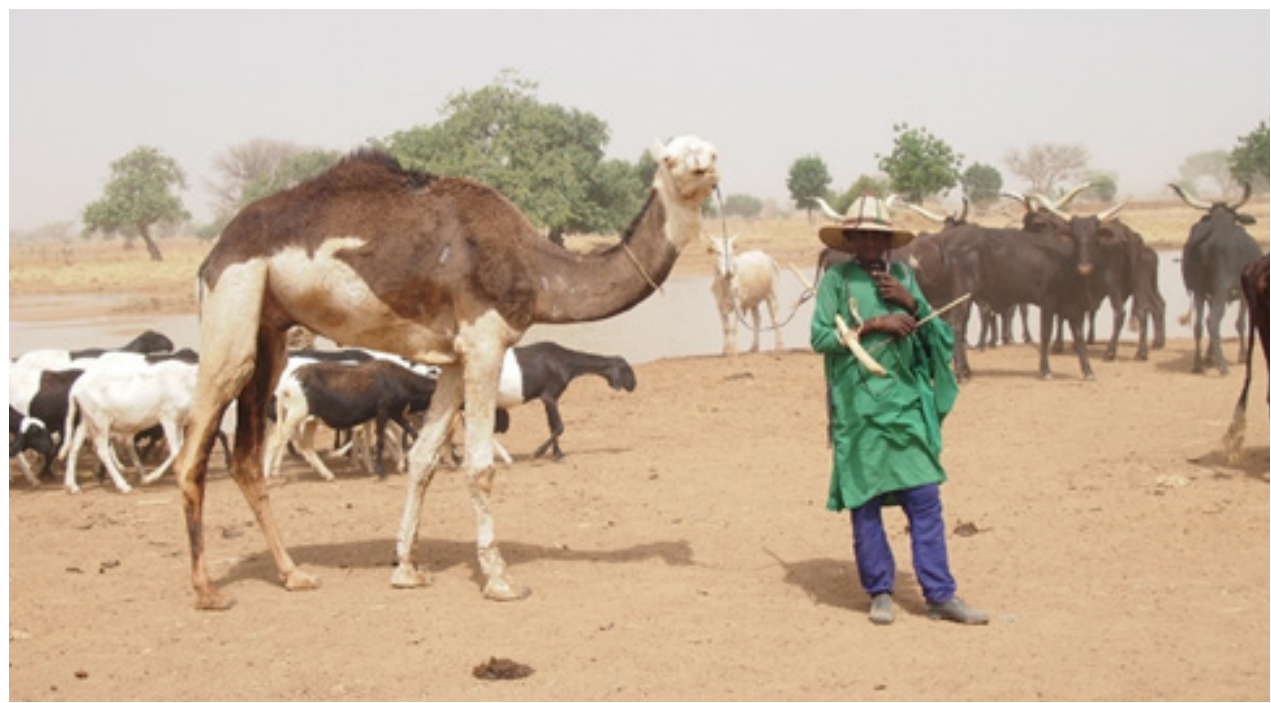

CFAO/G. Velasco-Gil

\subsubsection{Proportion of livestock and profile of producers}

The proportion of the livestock population kept by the pastoral system varies widely from one country to another, ranging from 16 to 80 percent. In Nigeria, pastoralists hold up to 95 percent of the nation's ruminant livestock population (Gefu, 2009). In Senegal, the transhumant pastoralism system involves about 32 percent of the cattle population and 35 percent of that of small ruminants (Gueye, 2012). In Mali, both types of pastoralism exist, involving 80 percent of the national herd, representing 45 percent of the total TLU of the country and contributes for 81 percent to the revenue of livestock owners (Modibo, 2010). In Burkina Faso, long and short distance transhumance is practised by about 11.9 percent of cattle owners, 3.4 percent sheep owners and 2.5 percent of goat owners throughout the country (Badolo, 2009). In Niger, 18 percent of the livestock population is reared under the nomadism sub-system, while the transhumant pastoralist livestock represents 16 percent of the total livestock population in the country (Djibrillou, 2012). To some extent, the profile and ethnic groups of livestock keepers also vary from country to country, and there are also subtle differences related to the type of pastoralism practiced. The transhumant pastoralism is practiced mainly by the Fulani while the nomadism is the attribute to Touareg, Maure, Bellah and Arabe tribes (Sankhare, 2011 and Diop, 2012). 


\subsubsection{Transhumance routes in West Africa}

As shown in Figure 13, up to 22 large annual pendular transhumance routes (livestock migratory routes greater than $75 \mathrm{~km}$ ) have been identified in West Africa. Among these, 16 are cross-border routes, connecting rainy season grazing areas in the north and crop residues and flooded pasture in the south and central zones. It is worth mentioning that these migratory routes do not include trade routes, which may be internal, interconnecting livestock markets within countries, or international for livestock exports. Pastoralists from Mali, Burkina Faso and Niger undertake more cross-border transhumance than pastoralists from any other West African country.

The northward movement takes place in general during the rainy season, running from June to September, to access abundant natural pasture in Burkina Faso, Mali and Niger. This movement also allows to avoid trampling crop fields in central and southern agro-pastoral zones, the main reason of frequent clashes between sedentary crop producers and transhumant pastoralists. To the contrary, during the dry season (October-May) large herds and flocks are moved southward to exploit pasture and crop residues, in Sudan and Guinea savannah grasslands located in Benin, Côte d'Ivoire, Ghana, Guinea, Nigeria and Togo, the flooded pasture, such as in the inner Niger delta and around the Maghi Lake (Mali) and Lake Chad (Chad) (FAO and CIRAD, 2012).

\section{Ү}

Figure 13. Cyclic annual transhumance routes in West Africa'1

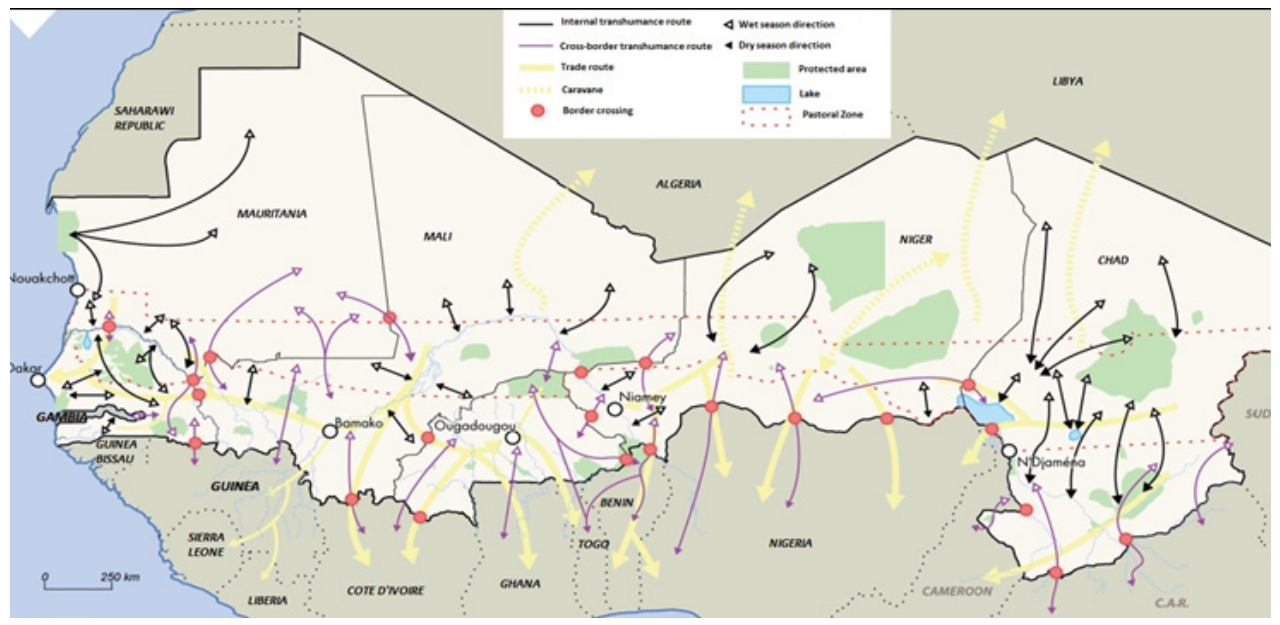

Source: FAO and CIRAD, (2012).

\subsubsection{Environmental determinants governing transhumance}

The seasonal shrinking of pasture and water is a natural phenomena in the Sahara and Sahel AEZs, where annual average rainfall ranges from 50 to over $600 \mathrm{~mm}$ and evapotranspiration is severe because of high temperatures ${ }^{12}$. Transhumance, as a livestock rearing practice governed by the desire of maintaining healthy herds and flocks based on timely search for good pasture and quality water wherever they may be found, is a major risk management practice undertaken by pastoralists for centuries. The production strategy has been influenced by seasonal variation in the availability of pasture and water (Suttie, Reynolds and Batello, 2005). 
In addition to seeking access to fodder in large quantities and of good quality, drivers behind transhumance include lack of water for the livestock during the dry season; refreining from damaging crops during the rainy season; avoiding zones affected or threatened by animal diseases; searching for mineral nutrients (salt licks); reducing the risks of losing cattle through rustling; avoiding intertribal conflicts; searching for genes to improve herd's productivity; avoiding insecurity associated with the proliferation of small armament and as a result banditery and crimes; etc. (Trémolières, 2010). Over the last half century, climate change effects have fast becoming an issue in the West Africa. Reduced and erratic rainfalls, resulting in the deterioration of the soil and water resources, have contributed to desertification of large proportion of the Sahel and, consequently, the progress of the Sahara to the south. This has resulted in more transhumant movement in numbers, frequencies and distance further south (Reynolds et al., 2007).

\subsubsection{Problems and conflicts linked to transhumance pastoralism}

A variety of reasons can be attributed to the increased incidences of problems and conflicts experienced by pastoralists in West Africa, particularly associated with the mobile nature of the transhumance pastoralist category. The rate at which pastoral resources are shrinking, owing to successive droughts and non-rational grazing practices in the Sahel, have had adverse effects on the pastoral system, forcing herders to move towards the southern areas of West Africa and even to coastal countries. Significant numbers and movements of live animals within and across borders have increased. There are no reliable statistics to quantify the flows of animals involved in this southward movement. However, estimates by various organizations indicate that more than two million cattle are involved annually in transhumance in Benin, Nigeria, Mali and Burkina Faso (FAO, 2011a and Diop, 2012). Conflicts, at times violent, linked to transhumance and tension between "native" land users and "stranger" transhumant livestock producers, whether the latter are from other areas of the same country or coming from another country, have been increasingly reported within the subregion (Diop, 2012 and De Haan et al., 2016).

As a result of rapid human population growth, and the subsequent need to produce more food crops to meet the demand, pressure on land and other natural resources, has increased in West Africa. Virgin lands, including traditional pastoral areas and cattle migratory routes utilized by pastoralists, are increasingly used for crop production. Traditional grazing resources often used during the wet season are fast disappearing. The same is true for dry season grazing resources provided by wetlands, which are being increasingly utilized for dry season farming of vegetables for urban and peri-urban markets. This is creating anxiety among pastoralists who are often denied access to grazing and watering points, or even forced to pay bribes and fines to access grazing on state ranches, as it happened during the 2004/2005 crisis in Niger, thus limiting transhumance. Consequently, competition on land and other natural resource use, resulting in serious conflicts between crop and livestock producers have taken place in several countries within the region (Diop, 2012; De Haan et al., 2016 and Gefu, Alawa, and Maisamari, 2008).

The conflicts result from clashes of interests between pastoralists and the other users of natural resources, particularly crop producers. Sometimes, however, conflicts among pastoralists themselves may occure when grazing and water resources become scarce. The causes of conflict related to transhumant pastoralists vary depending on those involved. However, in general terms, it can be classified under five main categories: conflicts over damaged crops; conflicts over cattle rustling; conflicts over the use of watering points; land disputes; and conflicts over the use of protected areas (Diop, 2012). 


\section{Box 2}

The Gouanan pastoralist conflicts in Mali.

For decades, the Wassoulou area in Southern Mali, has experienced problems of pacific co-existence between sedentary crop producers and Fulani transhumant coming from the central regions of the country. The situation got worse leading to the death of a crop farmer in Gouanan whose body was found in his crop field in the morning of the 29th December 2009. Alleging full responsibility of the crime to Fulani transhumants, the population of the area, in a unified movement, decided to expel all transhumants out and curtail any transhumance activity (L'independent, 2009). Several hundreds of cattle were attacked and killed, and the meat left at the disposal of local populations. The conflict took more than eight months to settle and required the intervention of high-level authorities and local government officials as well as local community leaders. The matter was settled after many long and laborious meetings including a one-week forum on transhumance. To prevent such serious incidents in the future, the forum called for (i) strict respect of transhumance rules and regulations as laid in the Transhumance Charter in Mali; (ii) wider dissemination of the Transhumance Charter at community level; (iii) training sessions targeting the mastering of the Transhumance Charter by community leaders; and (iv) the implementation of collective conventions regarding the peaceful land use at communal level (Doumbia, 2010; Yosso, 2010 and Le Hub Rural, 2010).

\subsubsection{On-going change in pastoralism}

Despite its economic viability, as a management system of pastoral resources that has enabled pastoral people to survive the major ecological and climatic crisis affecting the Sahel periodically, pastoralism still faces serious obstacles that threaten its potential production. The dramatic reduction of grazing land as a result of expanding crop cultivation, the occupation of key dry season grazing resources by crop producers and the neglect of livestock sub-sector in major agricultural and development policies, restricts the access of livestock to the Sahel's resources (FAO, 2018a). In fact, several studies and reports indicated already a significant gradual decline of pastoralism in the subregion (FAO, 2011a and Diop, 2012).

The environmental, socio-economic and political dynamics since the 1970s are influencing changes in pastoralist system, particularly the transhumant pastoralsm. Many transhumant pastoralists are gradually settling where the physical and social environment is conducive and supportive of their livelihoods. The gradual shift starts with cultivation of some crop to reduce the risk of relying only on livestock, slowly becoming semi-transhumant pastoralists and finally settling as sedentary agropastoralists. The pastoralists settled in this manner face new production environment, including structure and organization of production, pattern of social relationship with other pastoral groups and the host community at large. One of the immediate adjustment the settled pastoralists experience is the reduction of herd size in adaptation to the limited grazing resource available to them (FAO, 2001).

The number of cattle in crop production areas of Burkina Faso, Senegal, Mali and Niger, has increased because pastoralists (not necessarily only from Sahel) have established there. Transhumant pastoralists from Mali and Burkina Faso have been gradually settling in Northern Côte d'Ivoire and Guinea after the 
drought of 1970s and 1980s by leasing land there to grow cereals for their own consumption. They practice semi-transhumant livestock farming along with growing crops, which enables a transfer of organic fertilizer to farmland and the use of excess crops for livestock. The same trend can be seen in Northern Benin, where transhumant pastoralists from Niger and Nigeria have settled and created new villages. They practice semi-transhumance while diversifying into growing cereals for their own consumption and sometimes cotton (Bolling, Schnegg and Wotzka, 2013).

Photo 33. Cattle on a crop field to deposit manure for soil fertility improvement (Niger)

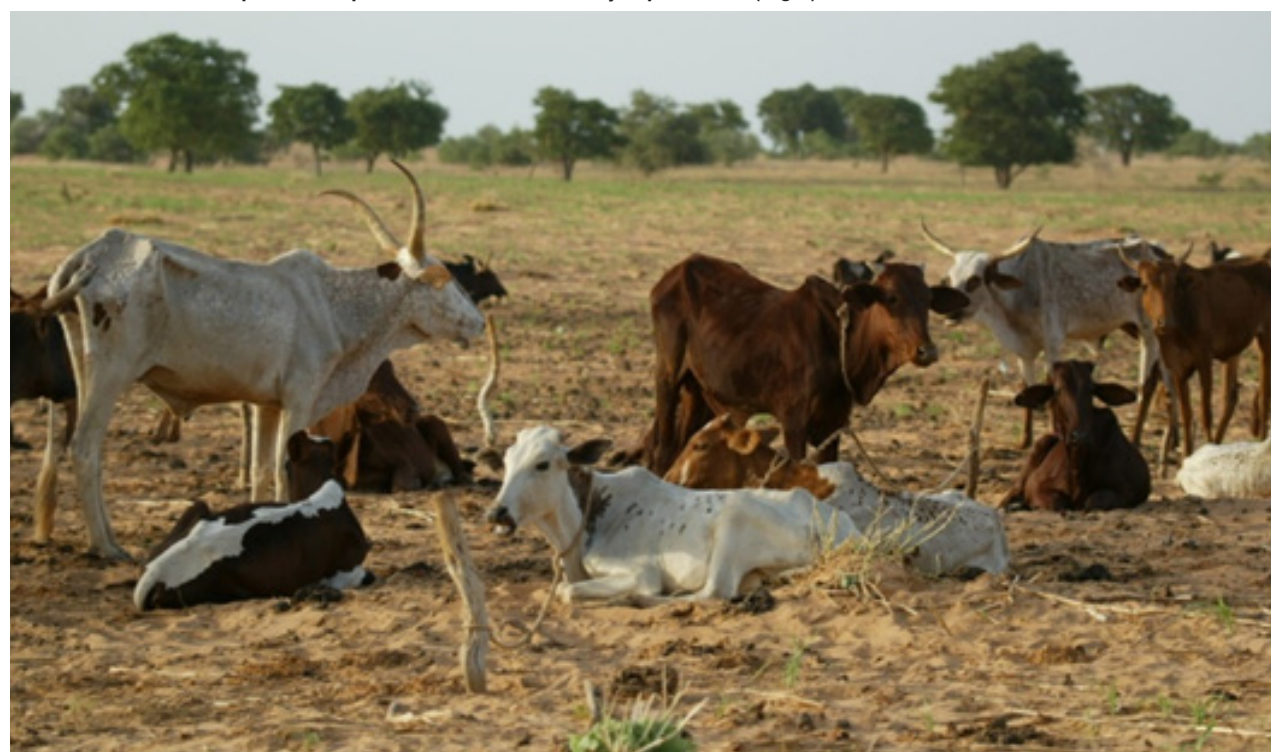

CILRI/S. Mann

\subsection{Agro-pastoral systems}

This is the predominant livestock production system in West Africa. It is particularly practiced mainly in the Sudano-Sahelian and Guinean AEZs, with rain fall of $400 \mathrm{~mm}$ and above and practically in all the countries of the region. Depending on the zones or countries, it combines the husbandry of virtually all the ruminant animal species.

\subsubsection{Definition and description}

Agro-pastoralism, involving both livestock and crop production in a settled environment, constitutes the livelihood activities where the livestock rearing component contributes less than 50 percent of family income as opposed to its contribution in the pastoral system. The agro-pastoral system is by definition a crop-livestock mixed production system. The crop-livestock production system denotes land use system in which livestock husbandry and crop production are practiced in association (Jahnke, 1982). This association may be close and complex, whereby crop production and livestock production display pronounced and mutually beneficial interactions within a farm, or livestock husbandry and cropping may be parallel activities without interaction, possibly not even belonging to the same management unit (Ayantunde et al., 2011). Therefore, the term agro-pastoralism will be reserved throughout this book only to the first type of interdependent crop-livestock association often referred to as mixed farming. 
The advantage of being able to integrate crop production with livestock rearing provides additional source of feed, especially during the critical months in terms of crop residue, and input for crop production, i.e. draft power and fertiliser. The demand for meat and dairy products is largely being met by this group of producers as they are found not only in rural settings but also in peri-urban areas and fringes of towns and cities. The main animal species under this system are cattle, small ruminants and sometimes poultry, whose production is higher than those under the pastoral system in terms of milk and meat quantity and quality (Garrity, Dixon, and Boffa, 2012). Dairy production is becoming an important activity among this group as there is a ready market for milk and dairy products in nearby urban and periurban centers. This has contributed significantly to enhancing household income especially disposable income for women in agro-pastoral communities (Moritz, 2010).

Photo 34. Milking goats in a village of Ségou District (Mali)
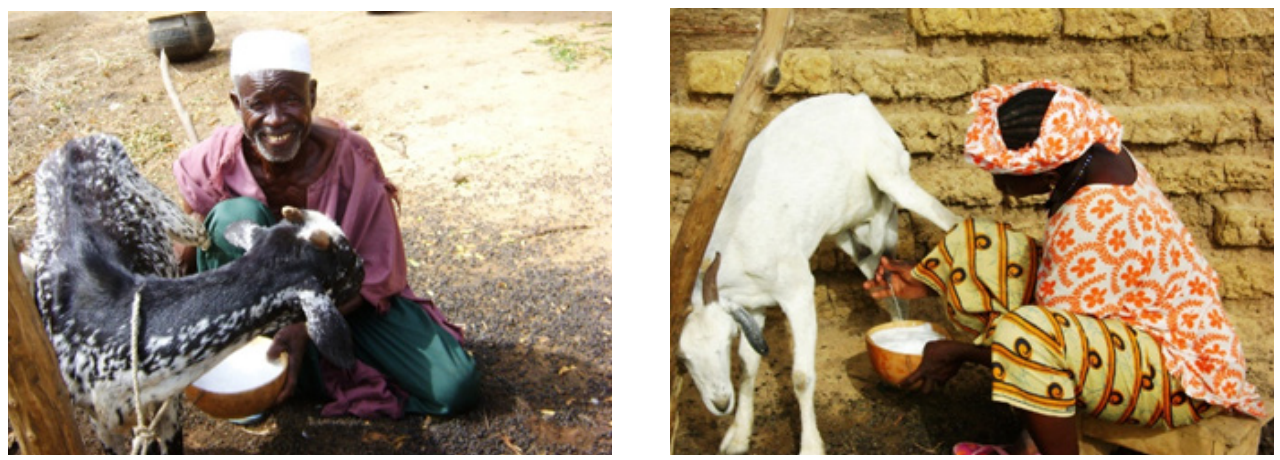

CILRI/V. Bognan Koné

\subsubsection{Types of agro-pastoral systems}

\section{The rain fed crop-livestock agro-pastoral sub-system}

Under this sub-system, there are two types of crops produced by agro-pastoralists. These are the food crops such as maize, millet, sorghum, yam and cassava and the cash crops, which include cotton, peanut, cacao, oil palm, coconut and banana. In transitional areas between semi-arid and sub-humid zones, maize is the predominant crop in the rainfed crop-livestock agro-pastoral sub-system. As conditions get wetter, cassava followed by yam become the main crops. Typical cash crops also differ with the AEZ. The production of peanut and cotton predominate in the semi-arid and sub-humid zones. Tree cash crops (i.e. cacao, oil palm, coconut) become important as the zone gets even wetter (FAO, 1983 and Ickowicz et al., 2012).

\section{The irrigated crop-livestock agro-pastoral sub-system}

This sub-system occurs in areas where irrigated or floodplain agricultures are implemented. Floodplains and deltas of the Senegal River (Senegal and Mali), the Niger River (Guinea, Mali, Niger and Nigeria) and the Sokoto River (Nigeria), in the Sahelian AEZ of West Africa, support very productive wetlands and important areas of irrigated crop production (Garcia-Landarte Puertas et al., 2015). The indigenous communities have developed sequential uses of the floodplain in relation to inundation and recession of flood waters, promoting forestry, crop cultivation (basically rice), fisheries and livestock husbandry, synchronized with annual inundation patterns (Santoir, 1997). The irrigated crops provide important forage biomass in the forms of hay or straw available to livestock during the dry season. During the wet season, when the crop fields are under cultivation, livestock are grazed on natural pasture as to avoid crop destruction and potentially resulting conflicts between livestock and crop producers (FernandezRivera et al., 2004). 


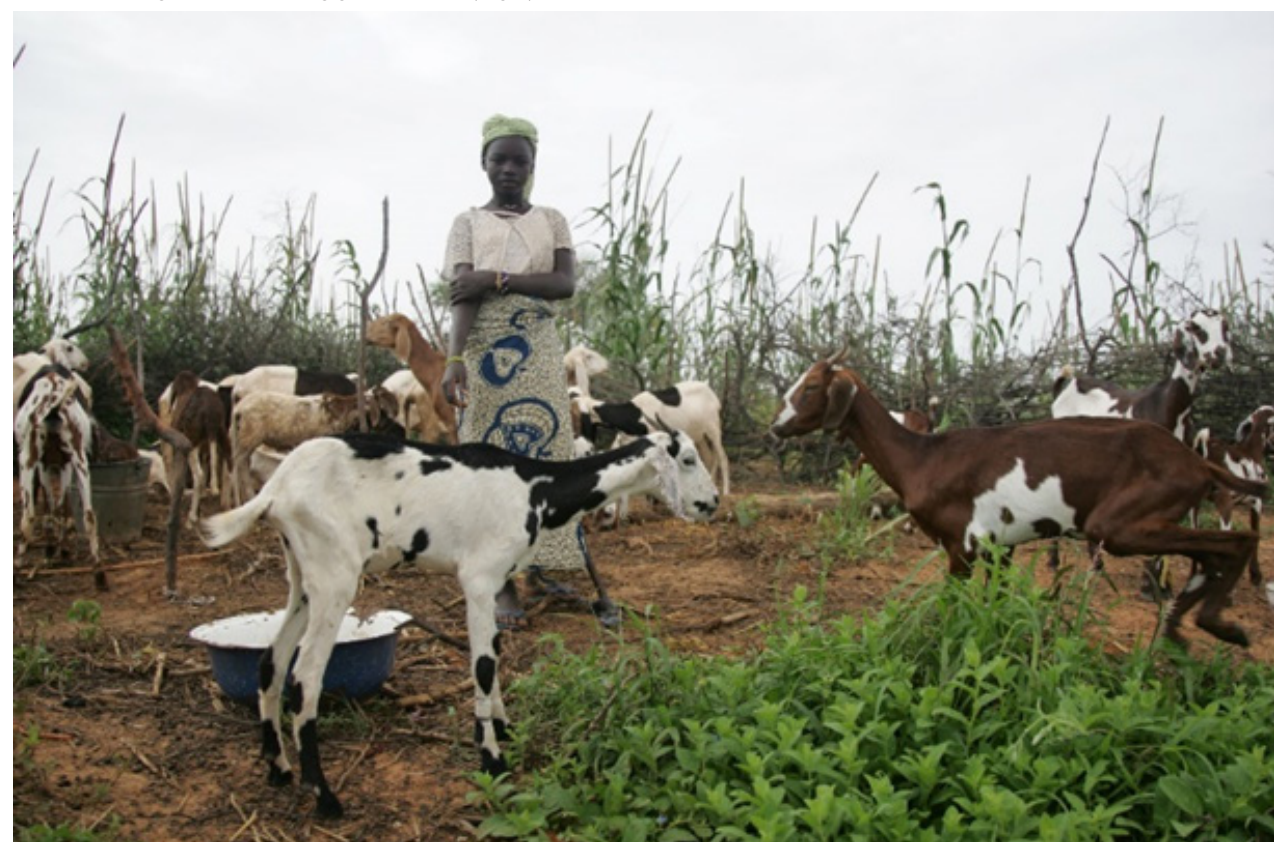

CILRI/S. Mann

\subsubsection{Proportion of livestock and profile of producers}

The proportion of livestock population in the agro-pastoral system out of the total and the species involved vary widely from one country to another, ranging from 20 to 96 percent. In Mali, the agropastoral systems occupy 23 percent of the national territory, account for 55 percent of the total livestock population expressed in TLU and contribute 18 percent income for livestock producers (Modibo, 2010). This contribution level has a steady increasing trend. In Togo, 96 percent of herds surveyed are in the agro-pastoral system, being predominantly a low input natural grazing system (Talaki, 2012). In Senegal, the agro-pastoral system holds 67 percent of cattle and 62 percent of the small ruminant population in the country and livestock contribute for 10 to 50 percent of the farm household income (Gueye, 2012). In Benin, the settled portion of the agro-pastoral system accounts for about 20 percent of the total livestock population of the country, characterized by multi-species herds with 3 to 20 head of cattle (Hounsou-ve, 2009 and Codjia, 2012). The profiles of livestock producers also vary from country to country. In most cases they are settled pastoralists and peasants belonging to different ethnic groups, but also civil servants or traders who invest their excess revenues in livestock. Livestock is usually gathered in family herds (with several different owners) or in individual herds, but in most cases looked after by hired herders.

\subsection{Peri-urban system}

The Peri-urban livestock production system, which can be semi-intensive or intensive, is not a modern or recent phenomenon, but definitely has grown in importance and scope in recent times as a response to market demands arising from rapid urbanization in West Africa. Currently, about 44.5 percent of the population in West Africa lives in urban areas (UNDESA, 2018) and it is estimated that this may reach over 65 percent by 2050 (UNFPA, 2010). The poverty level in many West African countries has also promoted the development of this type of livestock production system as an opportunity to diversify 
sources of income and improve nutrition (Thys et al., 2005). Therefore, peri-urban livestock production system does not only contribute substantially to meeting food requirements of urban residents (as part of food and nutrition security), but also have the potential to contribute to income generation (Dossa et al., 2011).

\subsubsection{Definition and description}

The peri-urban livestock production system is relatively an improved production system developed around urban agglomerations driven by market forces of responding to demands for animal source food of urbinites. This system puts more emphasis on rearing livestock for business by attempting to consolidate the strengths and improve on the weaknesses of the traditional extensive production systems. The primary strategy used is the intensification with focus placed on better management of feed, water and disease control to improve productivity. In these systems, livestock may graze on sown pasture as well as natural pasture, which are often improved with forage legumes (Abdulkadi et al., 2012). The livestock breeds used in this system are local or improved crossbreds or imported exotic stock, depending on the country and the target production. The parastatal entities in many countries practice this type of livestock production system. A variety of peri-urban livestock production system can be described in the region. Most livestock species reared are the usual conventional animals like cattle for milk, small ruminants and pigs for meat and poultry for eggs and meat. However, some nonconventional livestock like rabbits are becoming popular as well (Roessler et al., 2016).

\subsubsection{Types of peri-urban livestock production system}

\section{Milk production sub-system}

In an attempt to meet the growing demands for milk and dairy products, generate income and maximizing profit, small holders or commercial dairy operators in many West African countries use dairy type exotic breeds or their crosses for milk production. They rely on either natural mating or artificial insemination for reproduction. At national level, importation of exotic animals and semen for artificial insemination has been liberalized to the extent that no control has been placed on the level of exotic blood injected into the national herds. Whether local, exotic crossbred or purebred females are used will depend on the type of operation considered by the producer. The introduction of exotic crossbred or purebred animals is accompanied by new production strategies (i.e. zero grazing, improved feeding and health care and confinement in netted houses). An improved milk processing technology is also introduced in order to supply safe milk to consumers (Duteurtre and Corniaux, 2013).

Photo 36. Milking time in a smallholder dairy household (The Gambia)
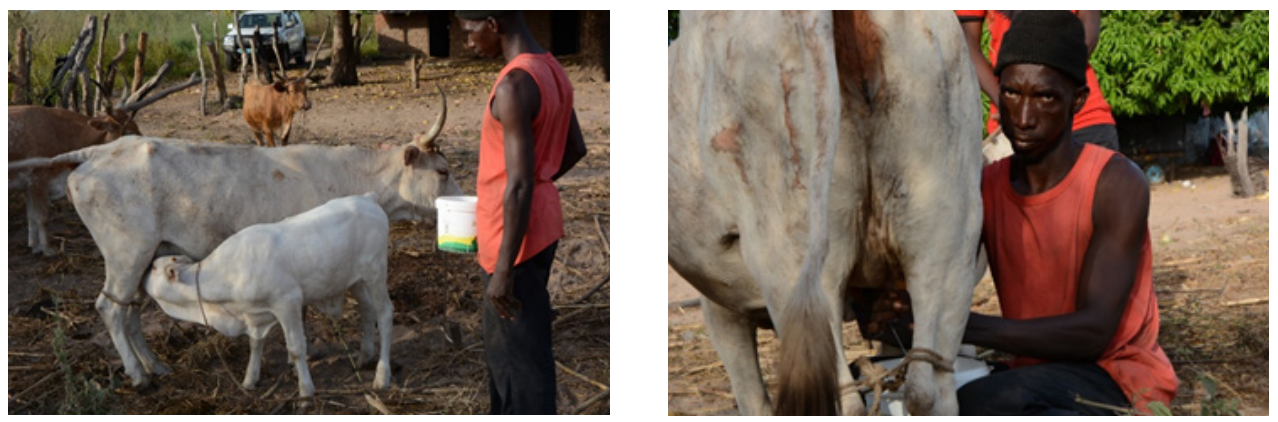

CFAO/S. Creppy 


\section{Smallholder peri-urban milk production operations}

This type of milk production operation is developing around urban centers where it is implemented by diverse actors. This type of operation has the advantage of its ideal location for marketing. The main feature of the operation is its semi-intensive and market-oriented nature where milk is the target product. A minimum level of investment is achieved to improve production requirements including housing, small equipment and the regular acquisition of animal feed (Okantah et al., 1998). The system is based on grazing of natural pasture associated with complementary feeding from cut and carry of forage from natural grasslands, household wastes, mainly cassava and plantain peels, crop residues and crop by-products. On average, milk off-take from the F1 crossbreed cow ranges from 3.5 to 5.5 litres per day when milking is done once or twice daily. Milk off-take from indigenous cows varies widely from country to country ranging from 0.8 to 4 litres per day (Diack, Sanyang and Münstermann, 2005 and Milogo et al., 2008).

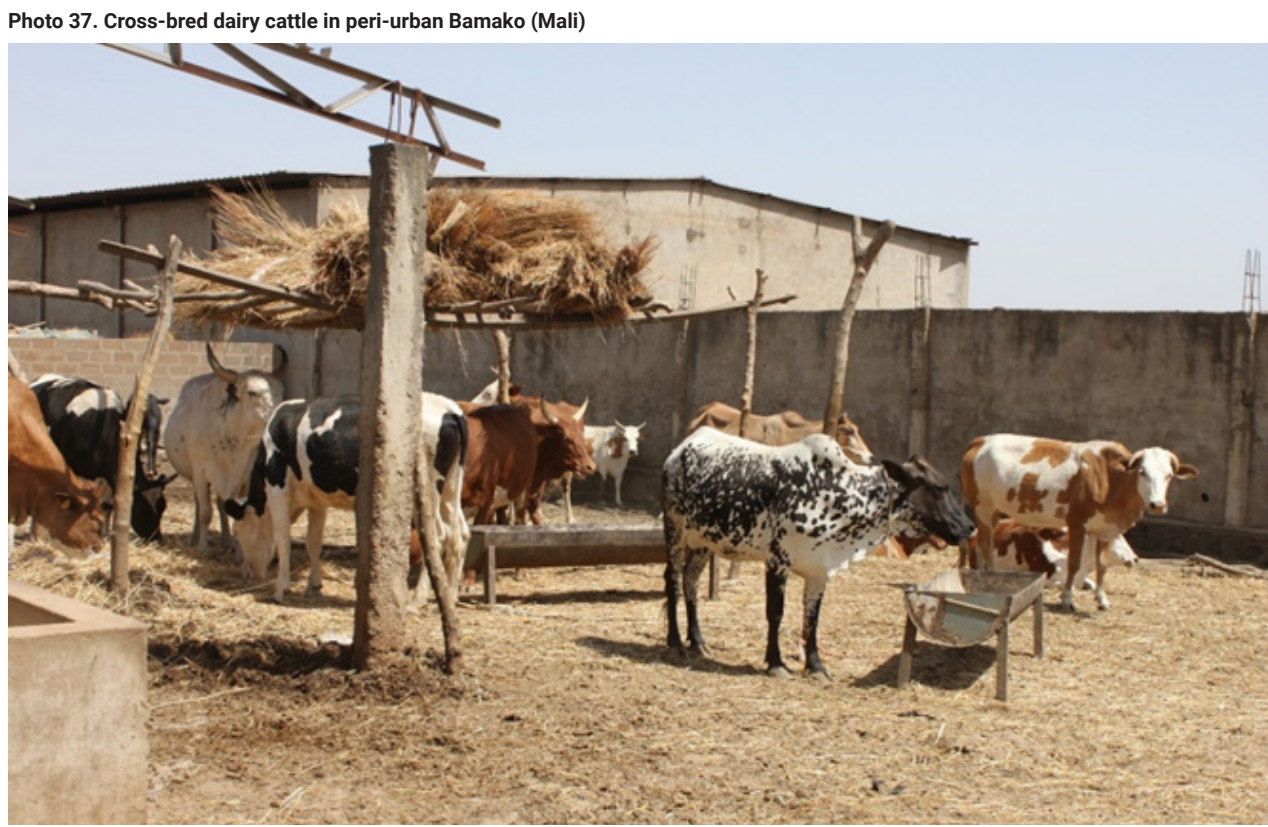

CILRI/Karen Marshall

\section{Commercial peri-urban milk production operations}

The private commercial dairy farms, compared with small holders, use more exotic breed cows and their crosses with indigenous breeds, in more improved production environment and, therefore, achieve better results. The system still experiences bottlenecks associated with the fact that exotic cattle are less adapted to local conditions and are, therefore, more susceptible to diseases and heat stress. This could hinder the animals from expressing their full genetic potential, particularly in terms of milk yield. Furthermore, the need for special skilled human resources plus the capital-intensive nature of the investment environment are major constraints to farmers, who in most cases do not have access to credit facilities and other production inputs and infrastructure (Okantah et al., 1998). Animal feeding relies on grazing of natural pasture coupled with complementary feeding, 1 to $1.5 \mathrm{~kg} / \mathrm{head} /$ day of industrial by-products (i.e. cottonseed meal, groundnut cake, cereal milling products, cassava, yam peals, etc.) or forage collected from natural grasslands. When genetic improvement is induced, milk yield ranges from 6 to about $20 \mathrm{~kg} / \mathrm{head} /$ day over 230 days of lactation. The true ambition of these farmers is milk supply to urban population year-round and not during only one season (Seck, Marshall, and Fadiga, 2016; Codjia, 2016 and Rouamba, 2016). 


\section{Meat production sub-system}

Like in the milk production system, farmers invest more in inputs, infrastructures and labour to give livestock the opportunity to better express production potentials. Several benefits are expected from animal fattening operations for meat production, among which an increased production of quality meat; sustained meat market; securing and increasing revenues through the specialization of livestock producers and other actors of the livestock value chains; sustained job creation; judicious exploitation of herds; and reduction of grazing pressure on rangelands (Dossa et al., 2015).

\section{Cattle fattening operations}

Cattle fattening operations are practiced by smallholder agro-pastoralists during the dry season over four to six months and with one batch a year. The animals used as feeder are three to four-year-old bulls or five to seven mature males weighing about $250-300 \mathrm{~kg}$, sourced from family herds or bought from neighbouring markets or "cow-calf" operations by the end of the dry season where prices are good. The feeder animals graze on natural pasture and are fed crop residues. They then receive agro-industrial byproducts as supplementary feed (i.e. oil seed meal, cereal bran). Upon finishing, all animals are taken to markets for sale (Salla, 2016).

Commercial cattle fattening operations, generally implemented by livestock traders, are speculative activities comprising 10 - 100 feeder animals per batch with one to three batches produced per year. They target the same types of animals the small-holder or family operations fatten. Once purchased, feeder animals are grazed on the rainy season natural pasture, exploiting the compensatory growth. The actual intensive feeding takes place during the dry season, when animals are finished-off receiving a roughage (i.e. bush hay, cereal haulms) based maintenance ration complemented with industrial byproducts (i.e. oilseed meal, cereal bran) or commercial feed and mineral supplements. Upon finishing, fattened animals are either sold to local wholesale butchers or end up in high value coastal city markets such as Abidjan or Accra. In this kind of operations receiving veterinary care is common and may include, among others, periodical vaccinations (Codjia, 2016 and Rouamba, 2016).

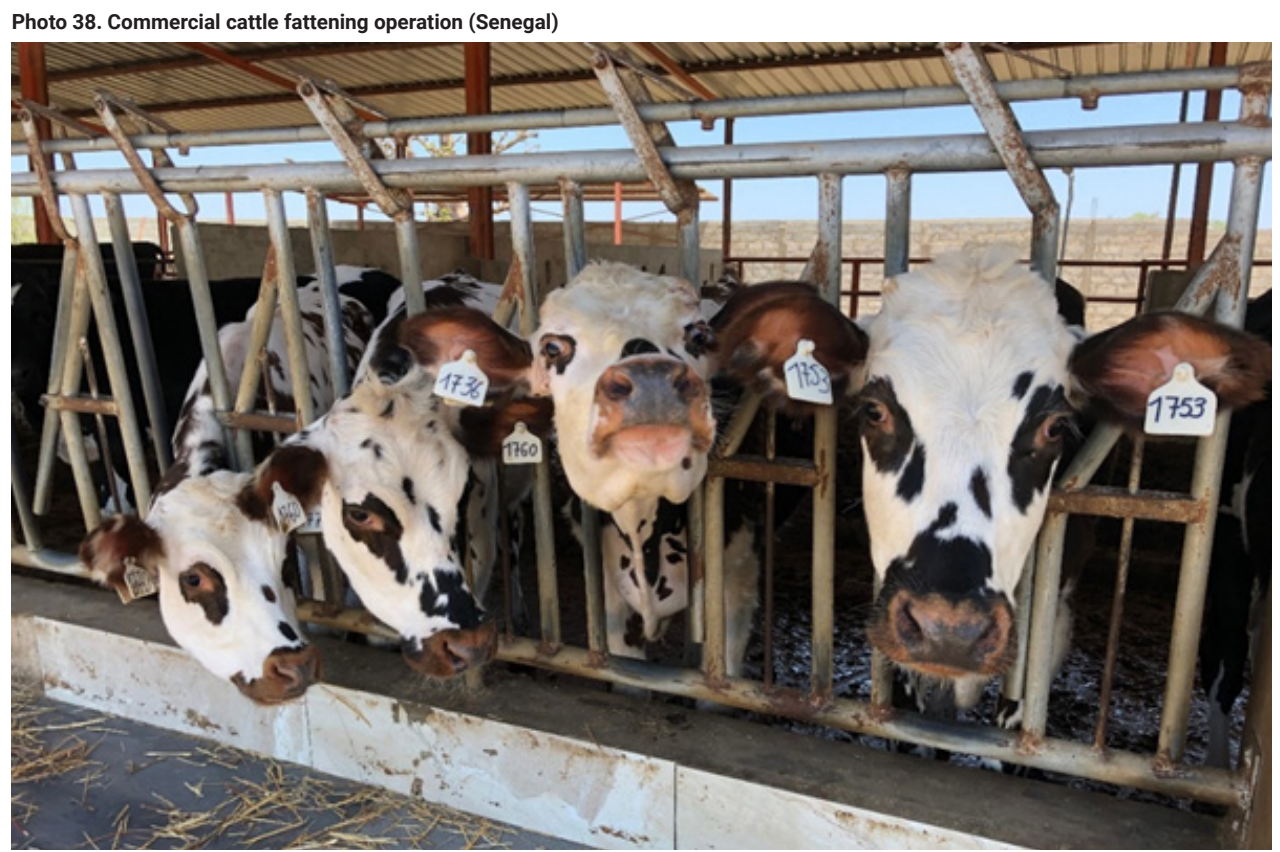

CUSUNVIE 


\section{Sheep fattening operations}

Sheep fattening is an economic activity undertaken by rural, urban, and peri-urban farmers, including women and youth mainly in Burkina Faso, Senegal, Mali, Niger, Togo, Ghana and Nigeria. The main strategy is to fatten lean rams over a three-month period using groundnut hay, oil seed cakes and cereal bran. The animals are sourced from local markets or from neighbouring pastoral homesteads. The procurement of such animals usually targets critical feeding periods when animals are at their lowest body conformation due to limited feed. Occasionally, a limited number may be obtained from the farmer's own flock (Tindano et al., 2015).

Depending on capital available to the operator, two to 50 head of sheep, are intensively raised over 90 to 120 days, on high energy feed stuff, comprising mainly agro-industrial by-products and high-quality crop residues like groundnut haulms and grain brans. The rams are kept in a small enclosure at the backyard, fed, and watered individually. Tabaski ${ }^{13}$ is the most profitable time to market rams. In areas where Christian population predominates, Christmas, New Year and Easter are other holidays providing some marketing opportunities. The lack of capital to purchase animals, feed and veterinary inputs as well as inadequate institutional support and absence of or weak producers organizations, hinder small holders participation in these schemes (Baah et al., 2012).

\section{Pig production sub-system}

Pork is a popular meat among non-Muslim people, and many specialty restaurants thrive in urban centers. Data from FAOSTAT (2019) shows that pork is the most consumed type of meat in Cabo Verde and Guinea Bissau and the second most in Liberia. Although predominantly practiced as a subsistence or semi-extensive production system (estimated 90 percent of total production), there is a certain trend towards intensification, although hampered with socio-economic, environmental and health constraints (Mfewou and Lendzele, 2018). In peri-urban areas the presence of pig farms is already questioned due to pollution and health problems related to the concentration of uncontrolled farms, insufficient biosecurity and public health concerns, as well as the resurgence of African swine fever (Penrith, 2013). Other concerns of pig production in West Africa are related to inputs price fluctuations and the strong competition with imported meat. The investment capacities are still low and supply chain organizations face the economic and social difficulties inherent to the region. Despite these challenges, it is a subsector in expansion and good potential as well as bridging the gender gap in livestock production (Porphyre, 2009).

\section{Subsistent or scavenging production operations}

The primary purpose of the subsistent pig production is to meet family needs and involves little or no commercial exchanges. Many peri-urban families keep a few pigs for occasional consumption, but the animals might also constitute a financial safety net, fulfil a role in cultural traditions, or provide additional cash for school fees, medical treatment or small investments (Dietze, 2011). Very often these households do not have breeding animals and they are just dedicated to finish pigs that have been purchased in local markets. The peri-urban subsistence pig producers exploit an average of three to four pigs per herd. There is little or no investment made into the housing, feeding and health care of the animals (Djassi, 2012). The animals scavenge for a large part of their feed requirement, but are supplemented with household waste and kitchen leftovers, agro-industry products and crop residue, as and when available. These factors, together with a poor herd management, contribute to the weak performance and high mortality of this type of production system (AU-IBAR, 2015). 
Smallholder or semi-intensive production operations

This is the most common pig production sub-system in peri-urban areas of many West African cities and towns. The primary purpose is to raise enough animals for sale, and secondly for occasional home consumption. The main feature of these units is a substantial but unremunerated family labour input, mainly required for feed procurement and distribution, as well as sanitation of the piggeries. The system is characterized by flock sizes ranging from five to 15 pigs. Producers supply their animals a variety of feed, some of which may be purchased. Other financial inputs go into health care mainly for anthelmintic treatments (Dossa et al., 2015). A popular system of management is by confinement in the backyard, particularly for households close to city centres. The more successful producers confine their animals in houses that vary in sophistication from the makeshift, to the roofed and concrete floor houses, depending on market demand for pork, and the means available to the producer. Where market demand is high, producers invest more in infrastructure, in order to meet the demand. The producers market their animals mainly at the farmgate directly to consumers or to intermediary. The performance of the pigs depend largely on the type of improved breed used and the level of intensification of the husbandry system adopted (Nwanta et al., 2011).

Photo 39. Smallholder semi-intensive pig production operation (Liberia)

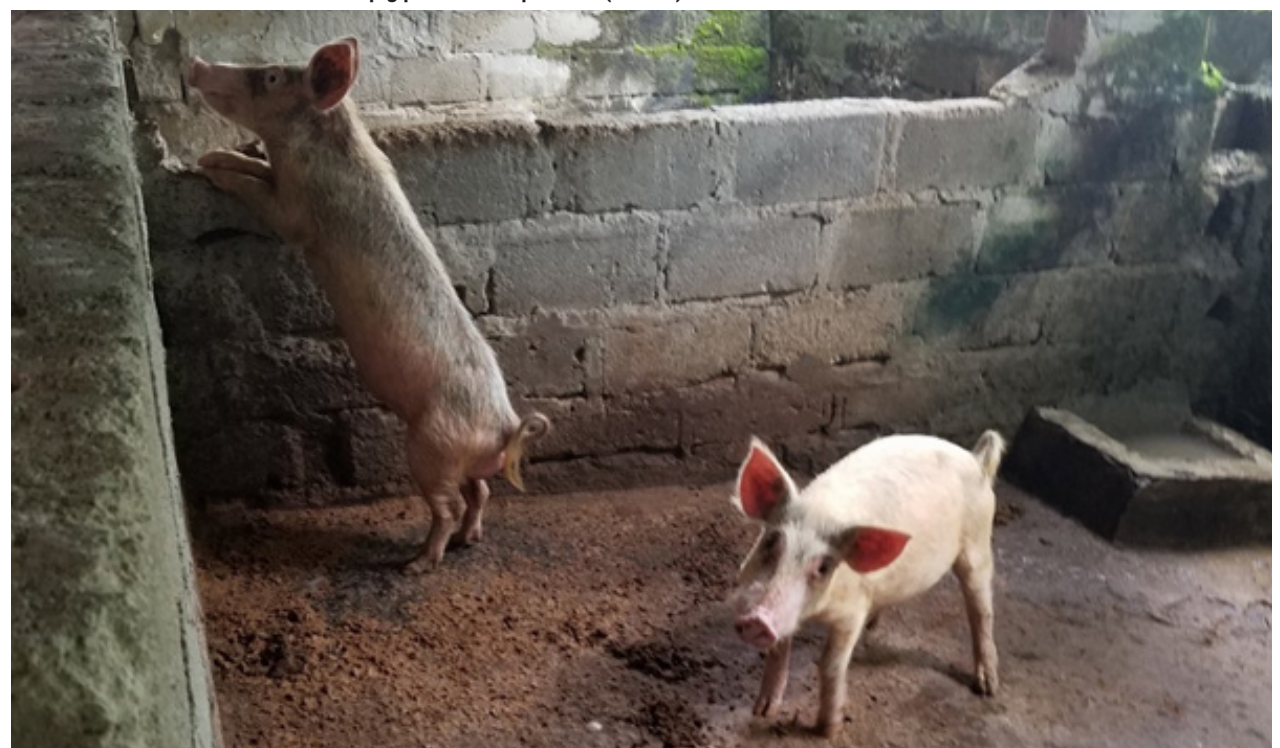

CFAO/G. Lamielle

Commercial large-scale intensive production operations

This is a growing and modern sub-sector in West Africa, but for now very limited. It is mainly based on exotic breeds (i.e. Large White and Landrace) and their crosses with local pig (Amills et al., 2013). The silent feature of this operation is the remuneration of family labour when involved or completely commercial with little or no family input except at management level. The units are usually situated at the outskirts of towns and cities, where land is available for growing feed-crops, which constitutes the main feed source, supplemented with purchased concentrates. This system is characterized by an improved habitat, feeding and good monitoring of reproduction and animal health. When the required inputs in the form of improved genotypes, adequate nutrition, effective health coverage and management are supplied, supported by good pricing policies and effective infrastructural, the system potentially becomes profitable. The growth of the intensive system appears to fluctuate with the most rapid increases occurring when there is a shortage of maize, the time when some poultry producers switch to pig farming (Okai, 2019). 


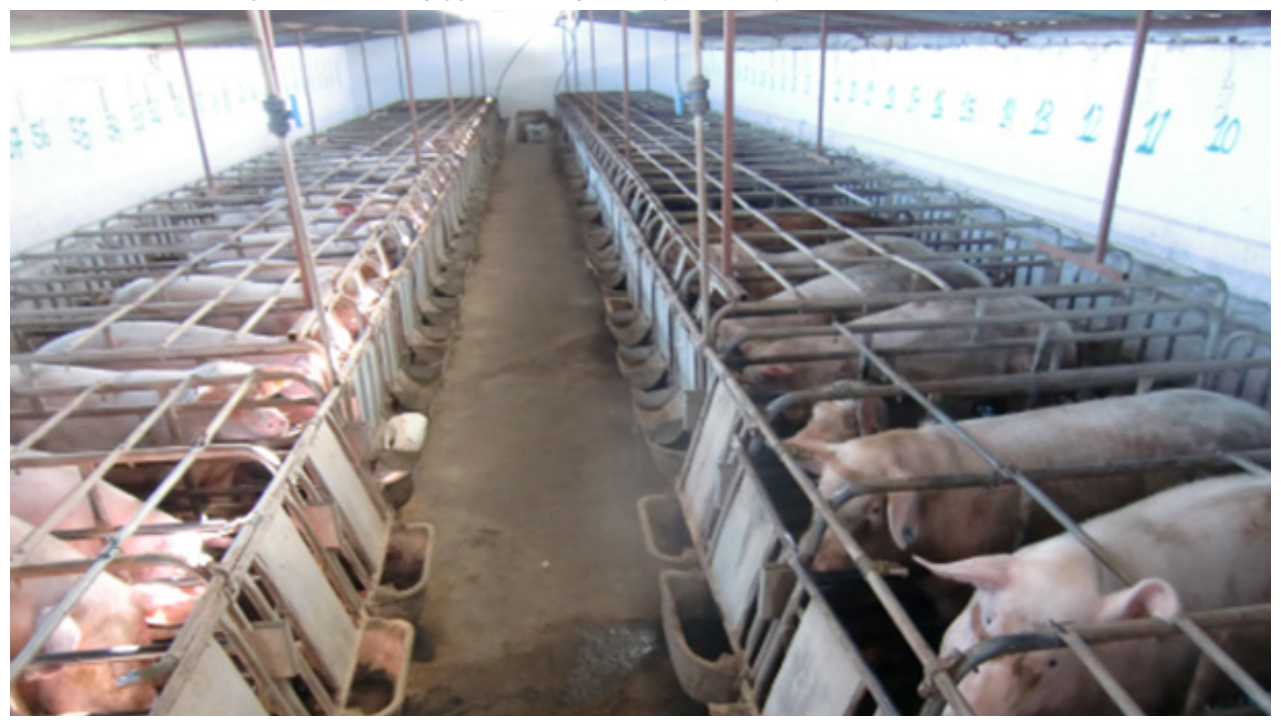

(C)B. Bedane

\section{Poultry production sub-systems}

In West Africa, village or backyard poultry production systems are common practices in peri-urban areas. For those involved in backyard poultry production systems, broiler and egg production are generally not a primary economic activity but is an important source of nutrition and income in Burkina Faso, Benin, Mali and Côte d'Ivoire (FAO, 2007; Kone and Danho, 2008; Traoré, 2013 and Megnibeto-Aplogan, 2015). The sale of poultry generates revenue to pay for medical care and schooling, or to repay debts. Most households in Nigeria and Senegal as well as an average 59 percent of households in Sierra Leone are involved in poultry keeping as a source of food and financial security (Adene and Oguntade, 2006; Schneider, 2010 and Traoré, 2014).

A semi-intensive to intensive commercial poultry industry also exists in all of the countries within the region, whose size varies greatly among countries. The commercial poultry sub-sector is larger in Senegal, Nigeria and Côte d'Ivoire (53,31 and 30 percent of the national production share respectively) and least developed in countries such as Benin, Mali, Niger and Sierra Leone, where at most 10 percent of the national production falls under the commercial sub-sector. The commercial poultry sub-sector has experienced a rapid growth in Ghana, dominated almost exclusively by urban, industrial production (Schneider, 2010).

\section{Village or backyard production operations}

These are extensive or scavenging management systems, quite similar and widely extended across West Africa. The poultry species kept in the region vary. However, chicken predominate in terms of numbers (more than 70 percent) and economic contribution, followed by Guinea fowls. Indigenous breeds remain predominant and flock sizes are highly variable, ranging from three to 130 birds according to estimates made by different authors (FAO, 2007; Kone and Danho, 2008; Traoré, 2013; MegnibetoAplogan, 2015; Traoré, 2014; FAO, 2008; Idi and Ganda-Idé, 2009; Akunzule, 2014 and Kangni, 2015). The village chicken system is characterized by low-input and low-output production pattern, short life cycles and quick turnover, associated with little investments in housing, feeding and disease control. The relative significance of Newcastle disease (NCD) compared with other poultry diseases in village 
chicken production systems is one of the main constrains. The production from village chicken system is mainly used for home consumption and the surplus for sale (Alders, 2018). Even if there is a clear consumer preference for village chicken meat in most West African countries, not much has been done in promoting value added poultry products and improving marketing system.

\section{Semi-intensive production operations}

The poultry operations within this sub-system manage 50 to 500 birds and are generally located within and around urban areas with a commercial purpose. They are all private farms with individual, family, or group ownership involved in egg and/or broiler production. Under semi-intensive production systems, there are various species of poultry kept. However, chickens are the predominant species. Here, exotic and crossbred chicken types predominate, due to the fact that these farmers are relatively afford higher input requirements than those within the backyard systems. The fowls are most commonly housed and rarely allowed to roam about. The management and input requirements of the semi-intensive operations are higher than in the backyard systems but still rudimentary if compared with the intensive ones. The marketing of products is conducted in local markets, restaurants and supermarkets, but most farmers depend on intermediary who buy the birds for urban markets. The major constraints affecting semiintensive system include lack of good quality feed, poor infrastructure, diseases including parasites, limited research and extension support and marketing bottlenecks (Sonaiya and Swan, 2004 and Atuahene, Attoh-Kotoku, and Mensah, 2010).

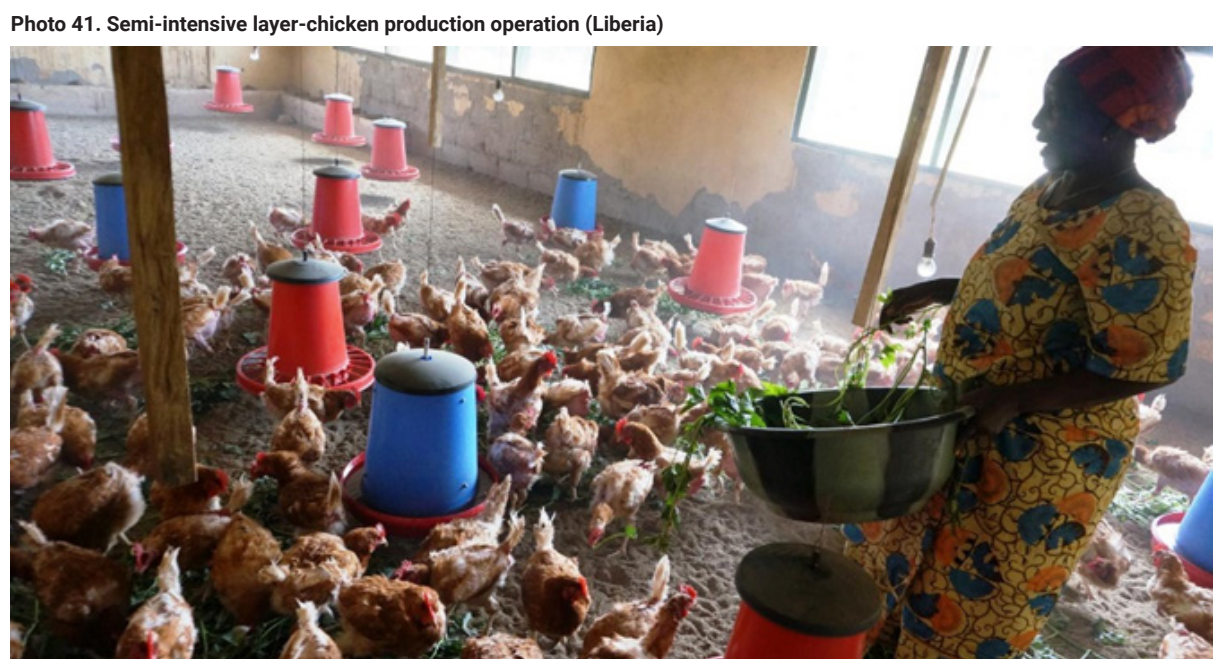

(C)FAO/J. Monibah

Intensive commercial production operations

The commercial layer and broiler operations are those targeting 1,000 to over 10,000 birds, mostly found around important urban centers, where a relatively high market and purchasing power exist. These systems are highly intensive and input-dependent, demanding efficient and effective management, proper feeding and effective disease prevention and control to succeed. The intensive operations utilize modern production systems, raising exotic breeds from national or imported sources kept indoors on deep litter and provided with compounded feed. They generally follow recommended vaccination programmes and rely on private veterinarians for provision of services, but biosecurity levels often vary from moderate to low. The marketing of products is mainly conducted through retailers. The key constraints to intensive poultry production are related to the high cost and availability of inputs (i.e. feed or feed ingredients, DOC or hatching eggs, veterinary drugs and vaccines), which are mainly imported; 
lack of processing and cold storage facilities for poultry products; inadequate or weak support and regulatory services; strong competition from cheap imported poultry products (i.e. frozen chicken); lack of access to credit and high interest rates on bank loans; and the impact of diseases such as avian influenza. Evidence suggests that production costs are higher in West Africa owing to the lack of an integrated industrial poultry sub-sector (FAO, 2014).

Photo 42. Intensive commercial poultry farm near Sikasso (Mali)

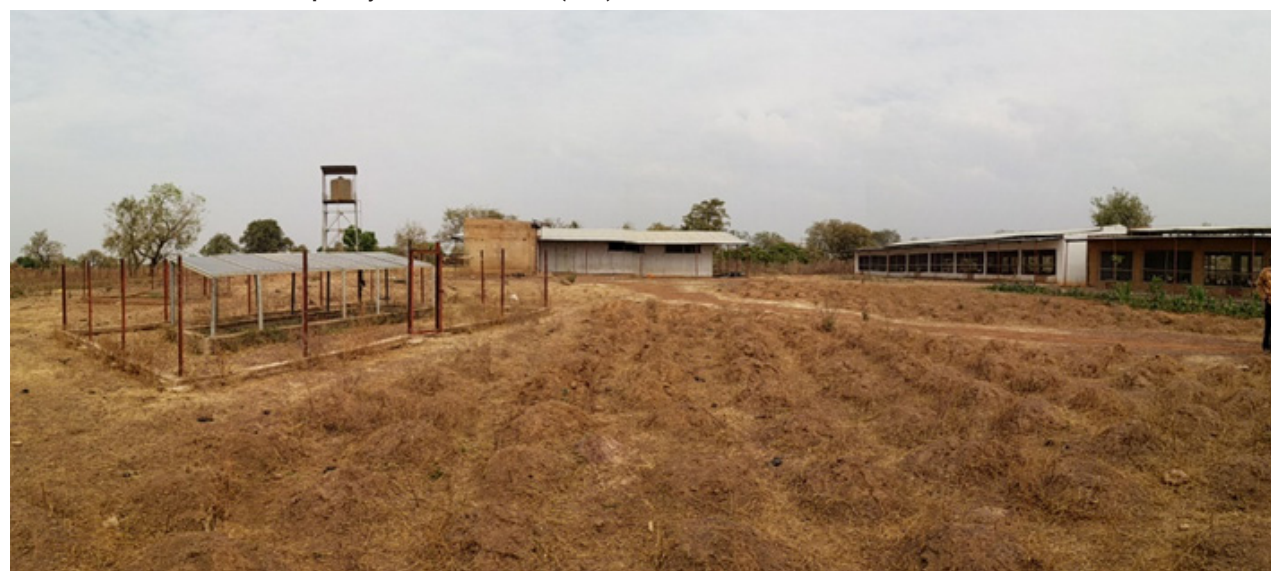

CFAO/G. Lamielle

\subsubsection{Proportion of livestock and profile of producers}

The information on the relative importance of peri-urban livestock production systems in West Africa are scanty for many countries. The proportion of livestock population in the peri-urban livestock production systems varies widely from one country to another, ranging from 5 to 25 percent. In Burkina Faso, 25 percent of the cattle population and 20 percent of the small ruminant population are found in the peri-urban systems (Badolo, 2009 and Some, 2012). In Côte d'Ivoire, the peri-urban systems account for 5 percent of cattle, sheep and goat population and 15 percent of pig population (Fadiga, 2011 and Bakayoko, 2012). In Ghana, Guinea and Mali, the proportion of livestock reared in peri-urban commercial farms has been estimated at 20, 28 and 10 percent, respectively (Mane, 2009; Modibo, 2010; Akunzule, 2013; Diallo, 2012 and Haidara, 2012). The profiles of livestock keepers also vary from country to country and to the sub-system in question. In most cases, commercial peri-urban farms are owned by absentee owners and businessmen and operated by hired individuals with varying levels of management skills, which are better than those in pastoral and agro-pastoral systems. There are also cases of farms belonging to state institutions falling under these systems. In most cases, smallholder, small scale or family enterprises are operated by livestock owners themselves (Amadou et al., 2012). 


\section{INPUTS TO THE LIVESTOCK SUB-SECTOR IN WEST AFRICA}
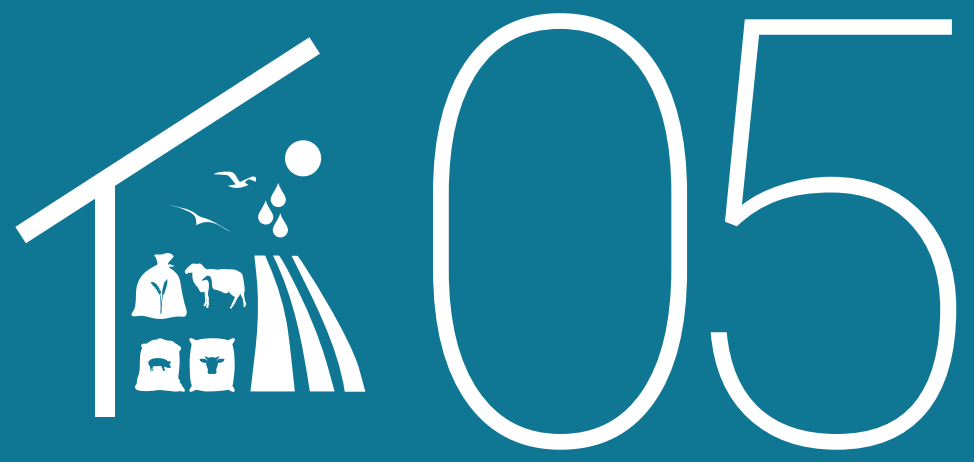



\section{CHAPTER V \\ INPUTS TO THE LIVESTOCK SUB-SECTOR IN WEST AFRICA}

\subsection{Feed and livestock feeding}

Feed scarcity is one of the major constraints to livestock production in the entire West African region, particularly in the Sahel and Sudan AEZs. Available animal feed resources include forages from rangelands, crop residues and agro-industrial by-products. Overgrazing has gradually led to depletion of rangelands soil fertility, deterioration of its structure, increased erosion and decreased biological activity $\mathrm{w}$ In addition, population growth and increased cultivation of marginal lands and fallows is leading to a significant decline in the available grazing areas and to a consequent growing demand for crop residues and agro-industrial by-products.

\subsubsection{Rangelands}

Livestock production in West Africa largely depends on natural resources, i.e. grassland and shrubland, grazed by animals on uncultivated land with open, uncontrolled access by both sedentary and tranhumant livestock producers. They represent the main source of feed during most part of the year for livestock (i.e. cattle, camels, sheep and goats) reared under extensive production systems.

Across the region, the productivity of the rangelands varies extremely with season, rainfall pattern and location. It varies from one country to another, or even within the same country, but it is generally greater in costal countries compared with Sahelo-Saharan countries. As one moves southwards from the Sahara to the Guinean $A E Z$, rangeland forage availability increases while quality drops. In the southern part of the Sudan AEZ and most part of the Guinean AEZ, high rainfall gives rise to a generally dense woody component and tall grasses that have low nutritive value ${ }^{14}$. During the three to four months of the dry season, this vegetation quickly become coarse and unpalatable, leading to wildfires or underutilization of the grass component by the grazing livestock, and thus loss of a valuable resource.

The savannah is the most suitable area for grazing livestock during the wet season both in terms of availability of the grazing biomass and its nutritive value. The production and chemical composition of grazing biomass varies according to rainfall pattern and location (Savadogo et al., 2007). The savannah 
present widely scattered trees and shrubs and the herbaceous cover is dominated by perennial grasses. In the more arid rangelands, such as the northern band of the Sahel, the grasses maintain a reasonable degree of palatability and digestibility through the dry season, but availability is limited.

It is essential that this potential be evaluated each year at country level for appropriate year-round management of pasture as well as for assessing the amount of complementary feed needed from other feedstuff. The assessment of forage resources involves the yearly or seasonal estimation of gross forage production from which all losses due to trampling, winds, mite attacks, etc. are deducted. The grazing potential must be appropriately managed, so as the amount of biomass generated during the rainy season (i.e. three to four months in the Sahel) could meet the feeding requirements of livestock during the eight to nine months of the dry season (Harris, 2000).

Unfortunately, evaluation of the status of pasture is seldom carried out on a yearly or seasonal basis in many countries of West Africa. Indeed, the calculation of rangelands potential production or carrying capacity in the region is a very controversial issue. Some authors argue that it is rarely stable, hard to predict and very difficult to evaluate with reasonable accuracy. For instance, in some areas within the region, such as the Sahel, erratic and variable rainfall conditions cause particular confusion in estimating carrying capacity (Baker, 2000).

\subsubsection{Cultivated forages}

One complementary feedstuff source to rangeland is cultivated forages. The versatility of forages allows them to be used in different ways under the different livestock production systems of West Africa, i.e. grazing, cut-and-carry and use as hay and/or silage. Cultivated forages are also of better-feed quality for ruminants compared with weed fallow, and therefore particularly recommended for dairy and fattening production systems, enhancing the possibility to maintain animals on the farm and improving soil fertility through manure production. Moreover, cultivated forages integrated in farming systems can have direct and indirect effects in increasing resource and land use efficiency. Planting forage shrub or trees, in addition to use as animal feed, serve useful purposes such as the provision of shadow, fencing and building materials (Mannetje, 1993 and Adjolohoun et al., 2008).

In West African, livestock development projects have implemented a range of technologies to address the issue of fodder shortages including the introduction of improved forage species (Thomas and Sumberg, 1995). These include perennial legumes species Leucaena leucocephela, Gliricidia sepium, Sesbania sp., Cajanus cajan, Macroptilium lathyroides, Macroptilium artropurpureus, Stylosanthes gracilis, Stylosanthes humilis, Pueraria phaseolides, Centrosema pubescens, Aeschynomene histrix and most recently Moringa oleifera. Annual legumes species include improved cultivar of Vigna unguiculata, Dolichos lablab, and most recently soybean. The grass species include Panicum maximum, Digitaria unfolozis, Andropogon gayanus, Bracharia ruziziensis, and Echinocloa Stagnina, among others.

Unfortunately, the bulk of these introductions, particularly the perennial species, reportedly failed to persist. This is due to adverse climatic conditions, availability and difficulties to pay for external inputs (i.e. seed, fertilizer, etc.) and, in general, due to the limited scientific results and knowledge on welladapted forage species or cultivars for West Africa (Atta-Krah and Reynolds, 1993). Therefore, the integration of cultivated forages in the region involving the adoption of new crops by smallholders, must consider important factors, such as the possibility to be established during cropping season, the 
low financial household resources, the availability of seeds for pasture establishment and the farmer's perception for each forage (Gbenou et al., 2019). Additionally, when introducing new forage resources in the Savanah areas, special attention must be paid on annual rainfalls, particularly during the drier years (Tarawali, and Hiernaux, 2002).

Based on these considerations, there is a range of well-adapted grasess and legume forages which can lead to an optimal solution to increase sustainability of animal and crop production. In fact, important surface areas have been and are still planted and cultivated each year with annual forage crop species in the region. However, comprenhensive data gathered from extension and government sources is usually missing. For instance, in 2012, within the Malian peri-urban production system over 2,200 ha were sown with forage crop including forage sorghum, maize, Dolichos lablab, Vigna sp., Stylosanthes hamata and Panicum maximum (DNPIA, 2013). In Burkina Faso, the Institut National de l'Environnement et de Recherches Agricoles (INERA) is producing seed for forage crops, which the Ministry of Livestock Resources (MRA) provides to livestock producers at a subsidized rate, together with forage harvesting equipment (ILRI and CGIAR, 2015).

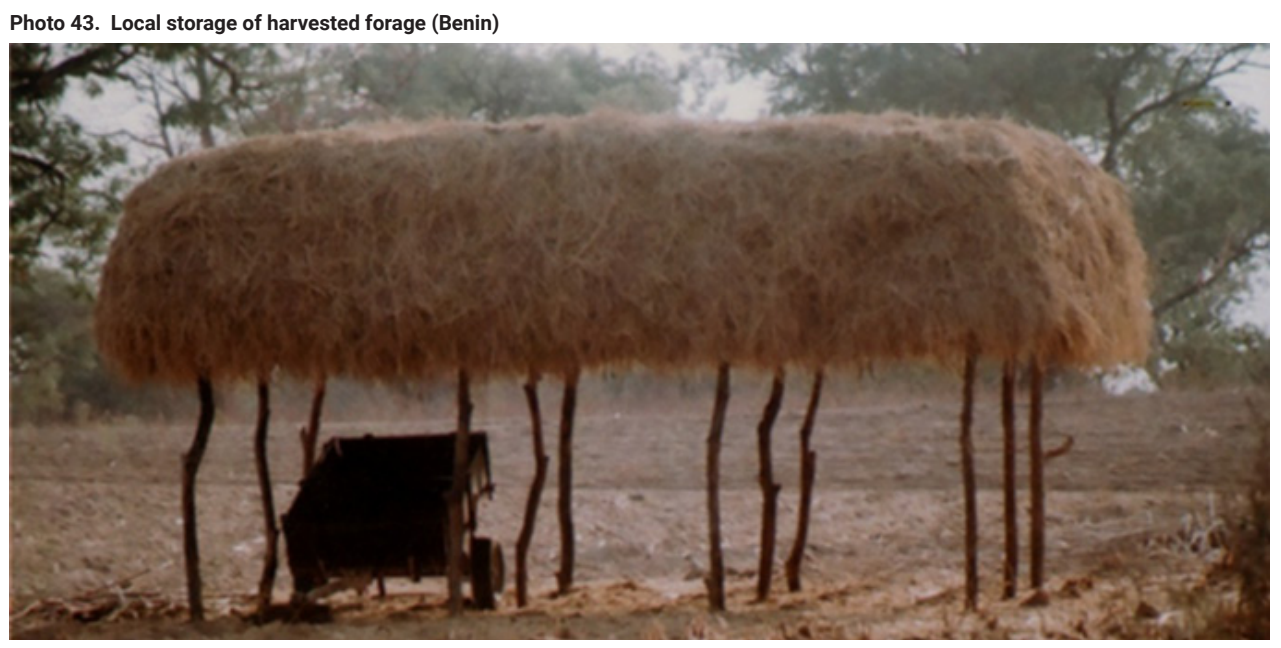

(C)FAO/V.Codja

\subsubsection{Crop residues}

In many West African countries, crop residues or agricultural by products constitute an important complementary feed resource for livestock. They include rice, maize, millet and sorghum stovers; cowpea veins and groundnut haulms; rice straw and soybean crop wastes. Other crop residues include sorghum panicles, sugarcan topping, cassava peels, etc. These crop residues may be grazed or collected and fed to livestock under confinement. After harvest, livestock graze on crop fields during the dry cold season, which extends from November to February. This exploitation of crop residues may require short seasonal livestock movements and 'manure contracts' between pastoralists and local crop farmers. There is a significant increase of the daily distance covered by the herds, but the effort deployed to walk over longer distances is compensated by an improved body condition and milk yield of the animals (Kagone, 2001).

Part of the cereal hay and the total amount of legume haulm are collected and stocked by agropastoralists to feed their livestock and/or draft oxen. Part of the stocked residue may be sold as reported in the Sahel and northern part of the Sudan AEZ. In fact, the increasing value of crop residues 
as marketable commodities in West Africa is generating income for poor farmers (Lenné, and Thomas, 2005). Nevertheless, collection and transportation of crop residues are the main challenges to their wider utilization, because it is not easy and definitely not profitable to transport large quantities over long distances in a short time, which explains their wide local use at production sites.

Estimates of the potential, availability and effective use of crop residue for livestock feeding are not readily available each year in West African countries. Where the information is available, it is not reported in any consistent manner among countries. In Gambia for instance, the production of crop residues in 2008 and 2009 was estimated at 133,472 tonnes of dry matter (TDM), which can support 211,737 TLU over 90 days (Table 6). This is equivalent to maintaining over 50 percent of the total livestock population of the country over 90 days. In Burkina Faso (Table 7) crop residue production amounts to a stocking capacity of 5 million TLU, which correspond to more than half of the total national livestock population. There are huge zonal differences. For instance, the northern part of Sudan AEZ, accounts for more than half of the total crop residue production. In Niger, about 4 million TDM are available (Table 8). This corresponds to the feed requirement of about 15 percent of the Niger total livestock population.

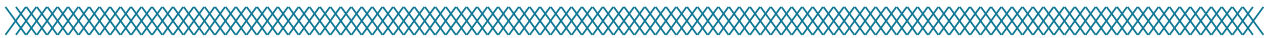

Table 6. Crop residue production and quantity available in Gambia

\begin{tabular}{|l|r|r|r|r|r|r|r|}
\hline Crop & $\begin{array}{c}\text { Crop } \\
\text { Residues } \\
\text { (TDM }{ }^{15} \text { ) }\end{array}$ & Use Factor & $\begin{array}{c}\text { Available } \\
\text { Crop } \\
\text { Residues } \\
\text { (TDM) }\end{array}$ & $\begin{array}{c}\text { Available } \\
\text { Crop } \\
\text { Residues } \\
\text { (TDM/TLU) }\end{array}$ & & & TLUs Supported \\
\hline & & & & & 30 days & 60 days & 90 days \\
\hline Early Millet & 5000 & 0.5 & 2500 & 0.007 & 13333 & 667 & 4440 \\
\hline Late Millet & 4100 & 0.5 & 2050 & 0.006 & 10933 & 5467 & 3641 \\
\hline Sorghum & 5315 & 0.5 & 2658 & 0.008 & 14173 & 7087 & 4720 \\
\hline Maize & 2252 & 0.5 & 1126 & 0.003 & 6005 & 3003 & 2000 \\
\hline Rice straw & 1805 & 0.9 & 1625 & 0.005 & 8664 & 4332 & 2885 \\
\hline Groundnuts & 115000 & 0.9 & 109250 & 0.320 & 582667 & 291333 & 194050 \\
\hline Total & 133472 & & 119208 & & 635776 & 317888 & 211737 \\
\hline
\end{tabular}

Source: Touray, (2012).

Table 7. Availability and stocking capacity of crop residues in Burkina Faso

\begin{tabular}{|c|c|c|c|c|c|}
\hline \multirow{2}{*}{$\begin{array}{l}\text { Agro-ecological } \\
\text { zones }\end{array}$} & \multicolumn{4}{|c|}{ Crop residues (1,000 TDM) } & \multirow{2}{*}{$\begin{array}{l}\text { Stocking capacity } \\
\text { (TLU) }\end{array}$} \\
\hline & Cereal & Legume & Total & $\begin{array}{l}\text { Available for } \\
\text { consumption }\end{array}$ & \\
\hline Sahel & 499 & 11 & 510 & 170 & 301954 \\
\hline South-Sahel & 873 & 99 & 972 & 324 & 575488 \\
\hline North-Sudan & 3931 & 431 & 4362 & 1454 & 2582591 \\
\hline South-Sudan & 1872 & 170 & 2042 & 681 & 1209591 \\
\hline Total & 7175 & 711 & 7886 & 2629 & 4932624 \\
\hline
\end{tabular}

Source: Savadogo, (2000). 


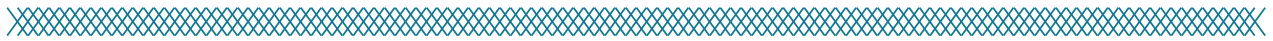

Table 8. Crop residue production in Niger

\begin{tabular}{|c|c|c|c|c|c|}
\hline Regions & $\begin{array}{c}\text { Available stubble } \\
\text { (TDM) }\end{array}$ & $\begin{array}{c}\text { Available rice hay } \\
\text { (TDM) }\end{array}$ & $\begin{array}{c}\text { Available haulm } \\
\text { (TDM) }\end{array}$ & $\begin{array}{l}\text { Available bran } \\
\text { (TDM) }\end{array}$ & Total (TDM) \\
\hline Agadez & 283 & $\mathrm{NA}^{16}$ & NA & 67 & 350 \\
\hline Diffa & 45215 & NA & 1977 & 10661 & 57853 \\
\hline Dosso & 559103 & 19919 & 41194 & 127841 & 748058 \\
\hline Maradi & 783763 & NA & 84845 & 184803 & 1053411 \\
\hline Tahoua & 599829 & NA & 25853 & 141433 & 767116 \\
\hline Tillabéri & 415750 & 30796 & 17414 & 91862 & 555822 \\
\hline Zinder & 653865 & 5648 & 54066 & 153043 & 866622 \\
\hline Niamey & 24125 & 14700 & 506 & 2745 & 42075 \\
\hline Total & 3081933 & 71063 & 225855 & 712455 & 4091306 \\
\hline
\end{tabular}

Source: Rhissa, (2010).

At regional level, cereal residue supplies per animal are larger than leguminous haulm and root and tuber peels supplies. The estimates for all West African Economic and Monetary Union (UEMOA) countries ${ }^{17}$ in 2010, suggest that a total quantity of 157 million TDM of straw and cereal bran residues were produced. About half of these were from millet and sorghum and 90 percent of these were produced in Sahelian countries. The other half cames from maize and rice and most of it was produced in subhumid countries. The leguminous haulm production in 2010 was estimated to be 88 million TDM, whose cultivation is generally dominated by Sahelian countries, led by Senegal (groundnut production), and Niger (cowpea production). About six million TDM of root and tuber peels, mainly from cassava and yam, were produced during 2010 in sub-humid countries, essentially in the southern part of Benin and in Côte d'Ivoire. There is an increasing trend towards the availability of these residues, as a result of the steady increase in production of these crops over the past years (Gouro, Ly and Makkar, 2014).

Photo 44. Cattle feeding on crop residues (Senegal)

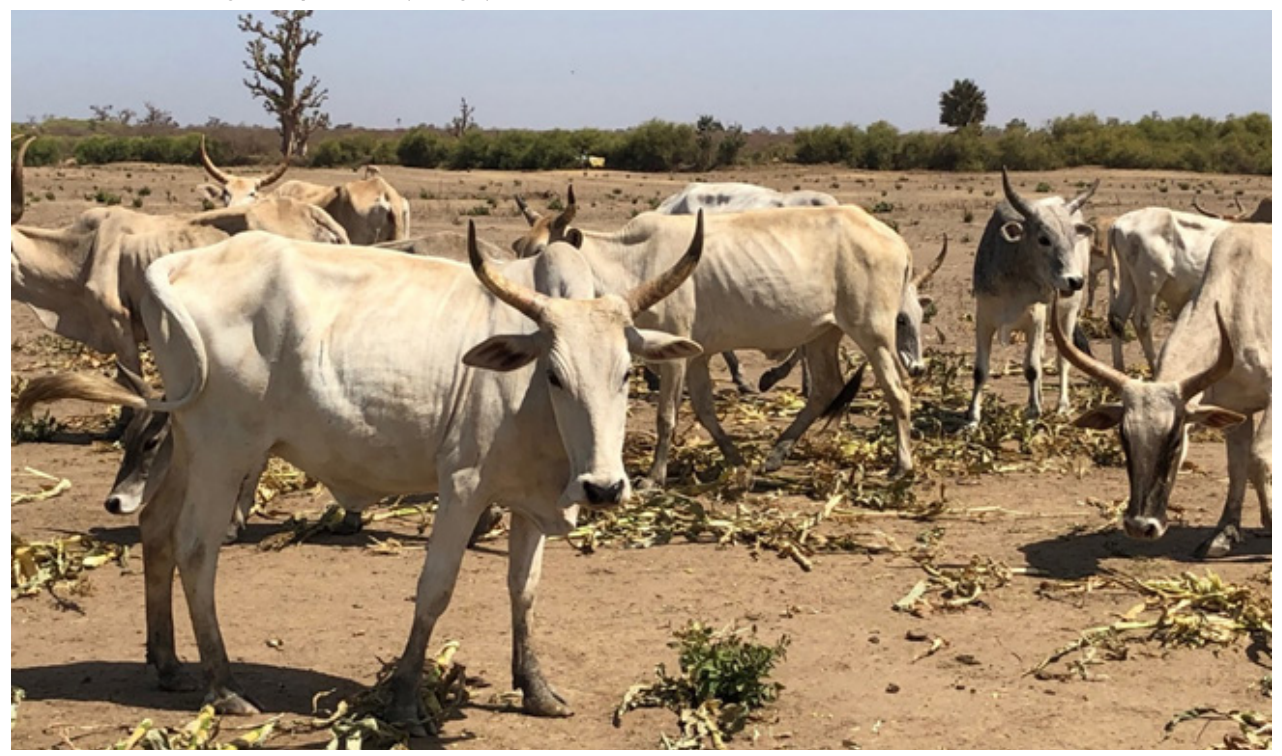

CUSUNVIE

${ }^{16}$ Not Available (NA).

${ }^{17}$ These are eight mostly French speaking West African countries which include Benin, Burkina Faso, Cote d'Ivoire, Guinea Bissau, Mali, Niger, Senegal and Togo. 


\subsubsection{Agro-industrial by-products}

The main agro-industrial by-products potentially useful as livestock feeds include: cottonseed, cottonseed cake, palm kernel cake, palm oil sludge, molasses, brewer's grain and yeast, wheatings ${ }^{18}$, bran and husk, husk free bran, fruit waste, dried fish, fish meal and oyster shell. This category of animal feedstuff includes also animal-edible by-products resulting from the food processing at family level. These include cereal brans, peels from cassava, yam, sweet potatoes, and plantain.

Among these agro-industrial by-products, offal from cereal grain processing (wheat, maize, sorghum and millet) and oil seed cakes (groundnut, soy and cottonseed) are probably the most important ones. Their importance is not only in terms of quantity but also in terms of quality. The cereal grain byproducts provide the energy and the later the nitrogen to complement intake from natural pasture and crop residue, to achieve nutritionally balanced rations for grazing animals.

As shown in Table 9 below, quantities and levels of use of this wide variety of agro-industrial by-products found across West Africa are not well documented in country reports used for this book. They are commonly used in intensive livestock fattening, milk production and poultry operations in peri-urban systems.

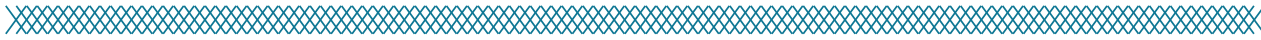

Table 9. The quantity of selected agro-industrial by-products produced in eight countries of West Africa

\begin{tabular}{|l|r|r|r|r|}
\hline Country & Oilseed (TDM) & Oilseed cake (TDM) & Wheat bran (TDM) & Molasses (TDM) \\
\hline Benin & 229 & 126 & 0 & 1228 \\
\hline Burkina Faso & 484 & 270 & 25060 & 13650 \\
\hline Côte d'Ivoire & 125 & 63 & 157917 & 48900 \\
\hline Guinea-Bissau & 55 & - & 0 & 180 \\
\hline Mali & 236 & NA & 14659 & 11310 \\
\hline Niger & 5 & NA & 3587 & 6356 \\
\hline Senegal & 2 & - & 146515 & 25080 \\
\hline Togo & 29 & NA & 26313 & 0 \\
\hline Total & 1135 & 581 & 37405060 & 106704 \\
\hline
\end{tabular}

Source:Gouro, Ly and Makkar, (2014).

The food processing industry is potentially an important, yet inexpensive source of feed raw materials. Canneries, breweries and distilleries produce an assortment of protein-rich by-products that have potential as feed for livestock, poultry and fish. For example, sludge from palm oil industry is currently discarded in many countries. While it represents a major industrial pollutant, it has a high nutrient value (CP 12.5 and $\mathrm{ME} 8.37 \mathrm{MJ} / \mathrm{kg}$ ) that has the potential to be developed into a major raw material for the animal feed industry (Wan Zahari and Alimon, 2012).

\subsubsection{Commercial feed and feed manufacturing}

Commercial feed includes formulated feed, mineral licks and multi-nutritional blocks (molasses-urea). For many West African countries, the use of formulated feed is not common and, when available, is very irregular from the year-round perspective, being one of the major constraints for livestock intensification in the region. Mineral licks and nutritional blocks are partly imported and partly produced locally by artisanal small-scale family production (Makkar, Sánchez and Speedy, 2007). An efficient commercial feed industry is, therefore, crucial to the sustainability of viable livestock production enterprises.

${ }^{18} \mathrm{~A}$ milling by product comprising mostly bran with some pieces of endosperm also left over, useful as feed for poultry and other livestock, as part of a balanced ration with other inputs 233 .

78 The role of livestock in food security, poverty reduction and wealth creation in West Africa 
Currently, the availability of good concentrate feed for ruminants is lacking on markets within the region, and most of feedstuff available for ruminants are agro-industrial by-products. To the contrary, there is a better availability of formulated commercial feed for monogastrics (pig and poultry), the cost of which accounts for 70 percent of the total production cost in the semi-intensive and intensive pig and poultry industry. In West African countries, feedstuff supplies for the feed industry are met either by domestic production and/or imports. The domestic supplies to the feed industry are dependent on the overall agricultural production, the degree of industrialization and the demand for quality food products in each country (Cadiou, 2018).

In the region, particularly in countries like Cote d'Ivoire, Ghana, Nigeria and Senegal, there are quite a number of large capacity commercial feed mills. These mills produce mainly poultry feed but, because of costs, quality problems and irregular availability, most large-scale poultry operations started to produce their own feed some years ago. However, the small-scale poultry producers lack the capacity of preparing their own feed at farm level. They rely on feed factories that are most of the time operating below capacity due to constraints including insufficient financing and shortages of feed ingredients. Nevertheless, the commercial feed industry has been growing in recent times, due to increased government support as well as foreign investment into this sub-sector (Cadiou, 2018). Some efforts are also being made to produce commercial feed from viable alternative sources (i.e. cassava peels), especially for poultry and pigs (Olumide, 2004).

Feedstuff quality varies depending on their ingredients, sources and production methods. The quality of imported ingredients currently available to the feed industry tends to be good. They have to meet the demands of a sophisticated feed milling industry. However, the poor quality of local feedstuff, together with feed safety related issues (i.e. mycotoxins), is a concern for achieving productivity and can even cause high mortalities, which, consequently, produce a low rate of return on investment (Cukwuka et al., 2010). The prices are fairly consistent with product quality, and for some items, pegged to those specifications that are most likely to vary (i.e. moisture levels for grains or crude protein levels for fishmeal). The larger feed mills maintain specialized laboratories that check on raw material quality and monitor the feed manufacturing process to guaranty its safety. The involvement of the larger feed mills in commodity trading also helps to maintain the quality of feedstuff (Oirere, 2018).

However, even if there is a will for self-regulation from the feed industry, the necessary governmental regulatory framework and structure is still very limited. In many West African countries, as in the rest of the continent, there is not in place a robust feed legislation allowing to set and monitor basic quality standards for feed importers, traders and manufacturers, including licensing, processing specifications, buildings and infrastructure. The limited financial resources and lack of sector organization, due to a fragmented regional feed industry, appear to be the main reasons prohibiting an integrated approach for effective legislation and enforcement. Both public and private stakeholders are unable to effectively align and interact within the same system. This is due to the different stages of development and maturity they operate and a lack of regional coordination regarding feed regulatory aspects, which makes difficult also international trade (Köster and Köster, 2016). 
Photo 45. Quality livestock feed provided to farmers during drought crisis (Senegal

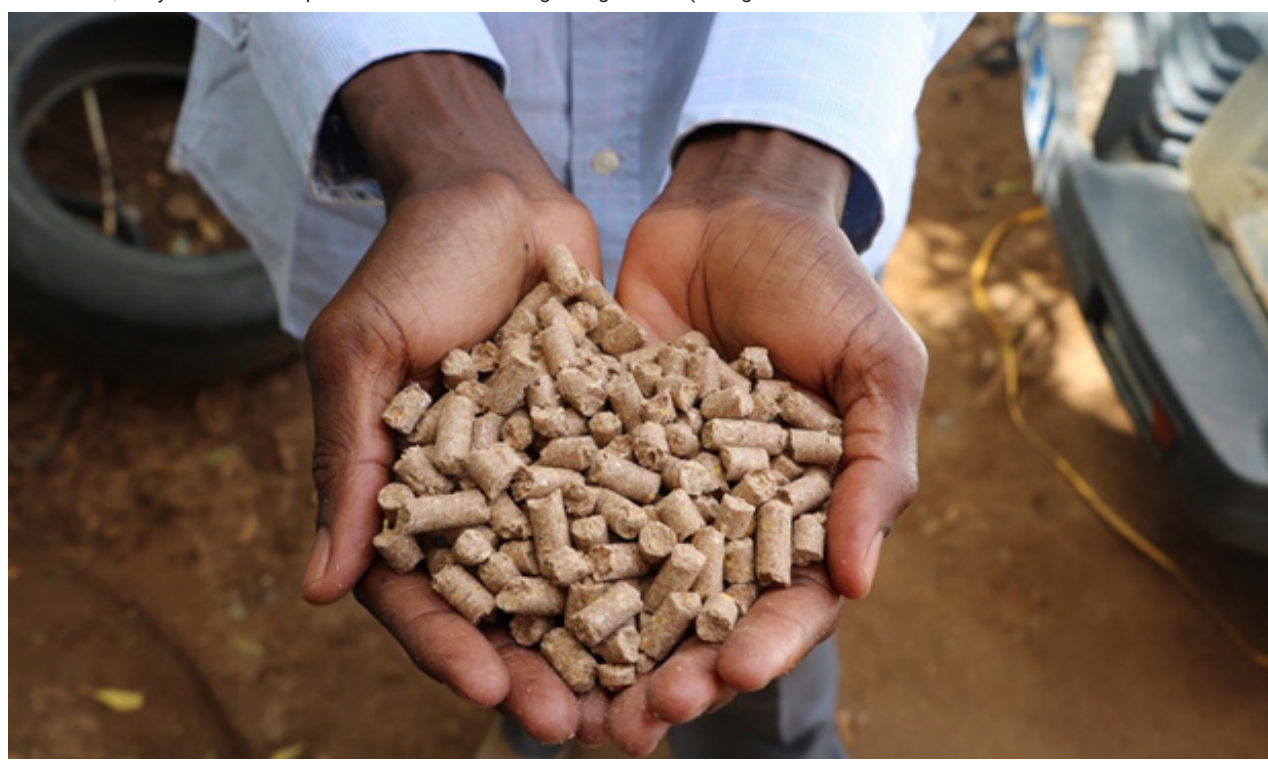

(CFAO/Y. Cisse

At present, the total supply of all the locally produced feedstuff in West Africa does not appear to be enough to meet demands, and large quantities of them are imported. Locally produced maize is the main component of commercial feed, especially for poultry, as well as being the major staple food for human and also used as raw material by different food industries. Due to this heavy demand, maize prices and supply have always been a problem for the local commercial feed manufacturing industry. On the other hand, fishmeal and soymeal, the main protein sources used in animal commercial feed, are generally imported. Although in Nigeria and Ghana soybean farming and processing is a growing industry and in Côte d'Ivoire, Ghana and Cabo Verde, fishmeal production could also play a major role in West Africa's feed industry (De Heer, 2016).

\subsubsection{Trade of feed and feed ingredients}

The regional livestock production depends mainly on local resources, either pasture or locally provided fodder. This factor, combined with the great inter-annual variation in agricultural outputs, is behind the great variations in milk or meat or poultry production. Feed imports are therefore an obviously important element for the stability of livestock production that needs to be analyzed.

\section{Feed imports}

Most of the animal feed imported by countries in West Africa is oil seed cakes or fish meal to complete feed formulations (i.e. poultry feed). Fish meal is the most expensive feed source (Moehl and Halwart, 2005), which is not well captured into FAOSTAT data. The trends from available statistics (Table 10) show that there is a powerful import market worth almost 72.8 million United States Dollar (USD). There is a clear difference in the availability of cottonseed cake in the Sahel and soybeans cake in coastal countries. The cottonseed, a by-product of local crop fields, is preferred as an emergency/dry season fodder for pastoralists (RBM, 2012) as well as for semi-intensive Sahelian livestock systems (Aboubacar, 2017), while soybeans-based fodder is preferred for a more intensive/ backyard setting (Moehl and Halwart, 2005). While the source of cottonseed is mainly regional, most of the soybean, which is the most relevant imported animal feed both in terms of volume and monetary value, comes from outside West Africa. 
Table 10. The amount of selected animal feed imported by West African countries ${ }^{19}$

\begin{tabular}{|c|c|c|c|}
\hline Country & Quantity (TDM) & Value (USD) & Main products \\
\hline Benin & 8346 & 668000 & $\begin{array}{l}\text { AMP, MB, WB, CSC, PKC, SBC, } \\
C S, F P\end{array}$ \\
\hline Burkina Faso & 8905 & 625000 & $\mathrm{MB}, \mathrm{CSC}, \mathrm{GNC}, \mathrm{SBC}, \mathrm{CS}$ \\
\hline Cabo Verde & 4610 & 2815000 & $\begin{array}{l}\text { AMP, MB, WB, PKC, SBC, SFC, } \\
\text { FP }\end{array}$ \\
\hline Côte d'Ivoire & 52715 & 20554000 & CSC, SBC \\
\hline Gambia & 29 & 10,000 & SBC, SFC \\
\hline Ghana & 32253 & 15006000 & $\begin{array}{l}\text { MB, WB, CSC, PKC, SBC, SFC, } \\
\text { CS }\end{array}$ \\
\hline Guinea & 2633 & 1379000 & $\mathrm{MB}, \mathrm{GNC}, \mathrm{SBC}$ \\
\hline Guinea-Bissau & 2634 & 1000 & FP \\
\hline Liberia & 0 & 0 & - \\
\hline Mali & 102756 & 6441000 & $\begin{array}{l}\text { MB, WB, CSC, GNC, PKC, SBC, } \\
C S, F P\end{array}$ \\
\hline Niger & 3064 & 995000 & $\begin{array}{l}\text { AMP, MB, WB, CSC, GNC, SBC, } \\
\text { CS, FP }\end{array}$ \\
\hline Nigeria & 5642 & 2507000 & $\begin{array}{l}\text { AMP, WB, CSC, PCK, SBC, CS, } \\
\text { FP }\end{array}$ \\
\hline Senegal & 60503 & 0 & WB, SBC, SFC \\
\hline Sierra Leone & 0 & 0 & - \\
\hline Togo & 489 & 53000 & $\mathrm{GNC}, \mathrm{SBC}$ \\
\hline West Africa & 119783 & 72819000 & $\begin{array}{l}\text { AMP, MB, WB, CSC, GNC,PKC, } \\
\text { SBC, SFC, CS, FP }\end{array}$ \\
\hline
\end{tabular}

Source: FAOSTAT (2019)

\section{Feed exports}

Few countries in West Africa are involved in the export of animal feed. This is heavily influenced by the availability main cash crops in the subregion. In fact, cottonseed cake dominates in the cotton producing belt of West Africa, while Senegal, well known for its groundnut production, has groundnut cake as its main export. The coastal countries are prime exporters of palm kernel cake, but they achieve a low value for it (Table 11). In fact, while West Africa exported nearly 586 million $\mathrm{kg}$ of animal feed (importing almost the fifth part, i.e. 120 million $\mathrm{kg}$ ), the region only got 83.8 million USD as an export revenue, while it had to invest 72.8 million USD in imports. While there is an internal regional market for animal feeds exports, particularly for cottonseed cake, a considerable number of products are exported outside West Africa.

\section{0}

Table 11. The amount of selected animal feed exported by West African countries

\begin{tabular}{|c|c|c|c|}
\hline Country & Quantity (TDM) & Value (USD) & Main products \\
\hline Benin & 54105 & 10304000 & CSC, SBC, CS \\
\hline Burkina Faso & 41635 & 17540000 & WB, CSC, SBC, CS \\
\hline Cabo Verde & 0 & 0 & - \\
\hline Côte d'Ivoire & 179521 & 20554000 & $\mathrm{MB}, \mathrm{WB}, \mathrm{CSC}, \mathrm{GNC}, \mathrm{KPC}, \mathrm{SBC}, \mathrm{CS}$ \\
\hline Gambia & 0 & 0 & - \\
\hline Ghana & 51938 & 4101000 & $\mathrm{MB}, \mathrm{WB}, \mathrm{PKC}, \mathrm{CS}$ \\
\hline
\end{tabular}

${ }^{19} \mathrm{AMP}$ : Alfalfa meal and pellets, MB: maize-bran, WB: wheat-bran, CSC: cottonseed cake, GNC: groundnuts cake, PKC: palm kernel cake, SBC: soybeans cake, SFC: sunflower cake, CS: cottonseed, FP: forage products. 


\begin{tabular}{|l|r|r|l|}
\hline Guinea & 42417 & 1379000 & WB, CSC, CS \\
\hline Guinea-Bissau & 0 & 0 & - \\
\hline Liberia & 311 & 5591000 & WB \\
\hline Mali & 18989 & 37000 & $\mathrm{CSC}$ \\
\hline Niger & 0 & 0 & - \\
\hline Nigeria & 167665 & 29684000 & AMP, MB, WB, CSC, GNC, PKC, SBC, CS, FP \\
\hline Senegal & 2211 & 632000 & MB, GNC, SBC \\
\hline Sierra Leone & 0 & 0 & - \\
\hline Togo & 26912 & 3729000 & MB, CSC, PKC, SBC, CS \\
\hline West Africa & 585704 & 83819000 & AMP, MB, WB, CSC, GNC, PKC, SBC, CS, FP \\
\hline
\end{tabular}

Source: FAOSTAT (2019).

\subsection{Water and livestock watering}

The availability of water for livestock is generally very limited in West Africa, particularly in the Sahara and Sahel AEZs. Surface water resources, i.e. rivers, ponds, lakes and water holdings, are available during the three to eight months of the rainy season depending on the AEZ. However, during the four to nine months of the dry season, livestock access to groundwater is limited to wells and boreholes. By its geography, West Africa is naturally endowed with important watersheds, particularly in its southern portion, including the Gambia, Senegal, Niger, Volta and Comoé river basins. These rivers and their tributaries and attached lakes run across large areas of West Africa where they permanently provide clean water for all kinds of human needs including livestock watering. In addition, the region is endowed with countless number of ponds, which are permanent or intermittent and contribute substantially to livestock watering. Unfortunately, this natural endowment in water resources does not cover all the region, especially the northern portion (GWP, 2000).

Photo 46. Cattle watering at a river (Niger)

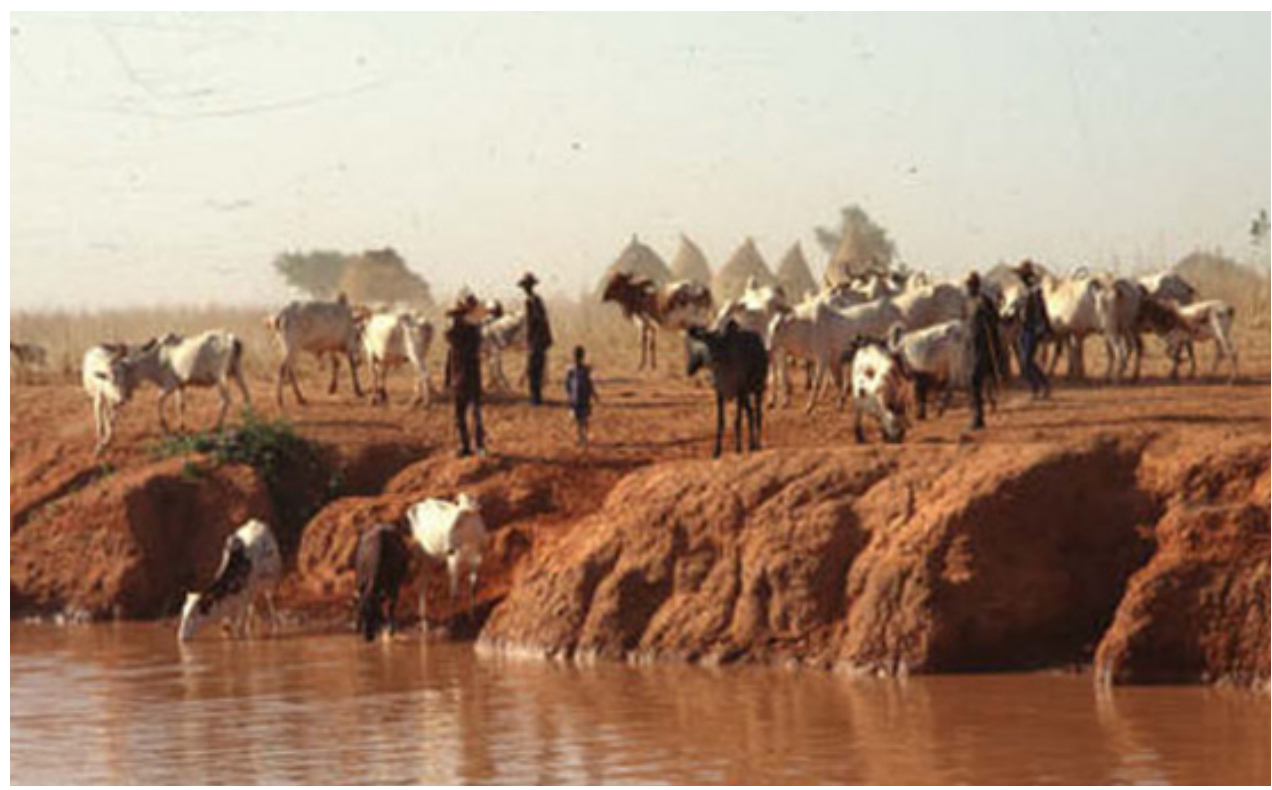

CᄋILR I

82 The role of livestock in food security, poverty reduction and wealth creation in West Africa 
In the Sahara and Sahel AEZs, surface water is particularly scarce during the dry season, which in certain areas lasts over ten months of the year. In areas where surface water stays very short, the opportunity of using freely the excellent rangelands year-round is lost. In Mali, Niger, and northern Nigeria, traditional water lifting devices using simple rope and bucket, called locally shaduf and delou systems, are still used in some places to lift water for human and animal consumption and for small-scale irrigation (Kimmage and Adams, 1990). Since colonial times hydraulic projects have been implemented to access underground water but despite the deployed efforts, the development of pastoral hydraulics does not cover all the areas in need. Hence, the limited number of permanent water points is the main limiting factor to the optimum utilization availabile forage. Indeed, the implementation of most of the hydraulic technologies available so far requires high capital investment and operating cost. These seriously hamper their satisfactory implantation and undermine their sustainable use by pastoral communities. Without external capital input by states and other donors users alone cannot raise such funds. So, it is still the case that during the dry season southward transhumance movement are always justified (Toutain et al., 2012).

The amount of water resources used by livestock in Mali was estimated to be 75 million $\mathrm{m}^{3}$ in 2006 , representing 0.38 percent of the total volume exploited or used in the country. The problem of pastoral livestock watering lies frequently in the spatial distribution of resources. Indeed, where there is pasture, there is little or no water, and where there is abundant (perennial) water, there is no pasture. The absence of a national policy on pastoral hydraulics, together with a lack of coordination among livestock stakeholders and insufficient and inefficient local institutions dealing with pastoral issues, has led to a built watering infrastructure that does not always match to the needs of transhumant pastoralists and are hardly accessible to their herds. Nevertheless, in the last few years, the government has completed several water points at livestock markets and along the main transhumance routes and has drawn up the National Adaptation Action Programme (NAPA) for climate change, with priority given to the optimal use of water resources by agriculture and livestock (GWP/MDR, 2015 and AQUASTAT, 2019).

In Niger, the volume of surface water taken for livestock production from the Niger River and its tributaries was estimated at 45 million $\mathrm{m}^{3}$ in 2005 . However, this represents only a small portion of the water used by the national herd, since most of it comes from groundwater and other sources of surface water. The lack of sufficient water points for watering animals during the dry season is a recurrent problem in Niger, mainly because of the absence of an intervention strategy in the field of pastoral hydraulics (AQUASTAT, 2019 and GWP, 2009). A total amount of 18,261 modern watering points (Table 12) included in the 2001 work plan to boost livestock development (MRAN, 2001) contribute to cover only 51.5 percent of water requirement for livestock. The number of non-functional traditional wells, unable to serve livestock watering, reached as many as 7,381 (almost 40 percent). Most of the surface water in the pastoral zone of Niger are intermittent and do not allow maximum use of forage resources.

It is believed that any form of water development in West Africa, and particularly in the Sahel AEZ, may improve the living standards of pastoralist. But the water development often is inadequate, which contribute to imbalances in the use of land and water resources. Irrigation has been traditionally practiced in West Africa on a very small scale. However, during the colonial period and just after independence, medium to large-scale irrigation investments were made. Later, community-managed small-scale irrigation programmemes were initiated and expanded gradually and, more recently, smallholder private irrigation has been heavily promoted by governments. More sophisticated drilling, pumping, and water distribution techniques have been introduced and are now practiced in 55 percent of the irrigated area 
in Niger and 75 percent of the irrigated area in Nigeria. Nevertheless, it is estimated that only 20 percent of the Sahel's irrigation potential has been developed so far and one quarter of the area equipped with irrigation lies in a state of disrepair (Abric et al., 2011).

Bringing more water to parched lands of West Africa allows farmers to improve food production and get higher revenues in local and regional markets. With the rapid changes now taking place, progression towards integrated crop and livestock production systems is happening. While it is clear that livestock also benefits from agricultural irrigation through increased availability of water and feed resources, water shortages can lead to conflicts between pastoralist and farmers and this has been heightened by increased irrigation and cropping. To address this issue, conflict resolution mechanisms involving all stakeholders must be promoted. The smallholder private irrigation schemes have proven to yields better results than large-scale irrigation, in enhancing food security, improving soil fertility, helping to protect biodiversity and preserving water resources. In order to make irrigation more compatible with pastoralism, it is important to guarantee that irrigation projects do not deprive pastoralists of access to dry-season water, preserve some potentially irrigable areas as forage reserves, and ensure that irrigation does not aggravate vector-borne diseases of people or animals (Ickowicz et al., 2012).

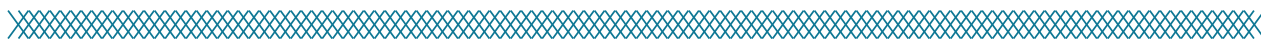

Table 12. The distribution of water points in Niger per administrative region ${ }^{20}$

\begin{tabular}{|c|c|c|c|c|c|c|c|c|c|c|}
\hline Regions & $\mathrm{CW}$ & $\%$ & DW & $\%$ & HMP & $\%$ & Total SMH & $\%$ & TW & $\%$ \\
\hline Agadez & 279 & 2.5 & 101 & 1.5 & 0 & 0 & 380 & 2 & 2179 & 29 \\
\hline Diffa & 614 & 5.5 & 102 & 1.5 & 0 & 0 & 716 & 4 & 858 & 12 \\
\hline Dosso & 1660 & 14.9 & 1305 & 19.4 & 0 & 0 & 2965 & 16 & 741 & 10 \\
\hline Maradi & 2854 & 25.6 & 533 & 7.9 & 0 & 0 & 3387 & 18 & 1153 & 16 \\
\hline Tahoua & 2085 & 18.7 & 430 & 6.4 & 432 & 14 & 2903 & 16 & 1207 & 16 \\
\hline Tillabéri & 2082 & 18.7 & 1667 & 24.7 & 0 & 0 & 3747 & 20 & 0 & 0 \\
\hline Zinder & 1551 & 13.9 & 2596 & 38.5 & 2652 & 86 & 4163 & 23 & 1243 & 17 \\
\hline Total & 11125 & 100 & 6734 & 100 & 3084 & 100 & 18261 & 100 & 7381 & 100 \\
\hline
\end{tabular}

Source: MRAN, (2001)

Photo 47. Nomadic and transhumant livestock at watering point (Niger)
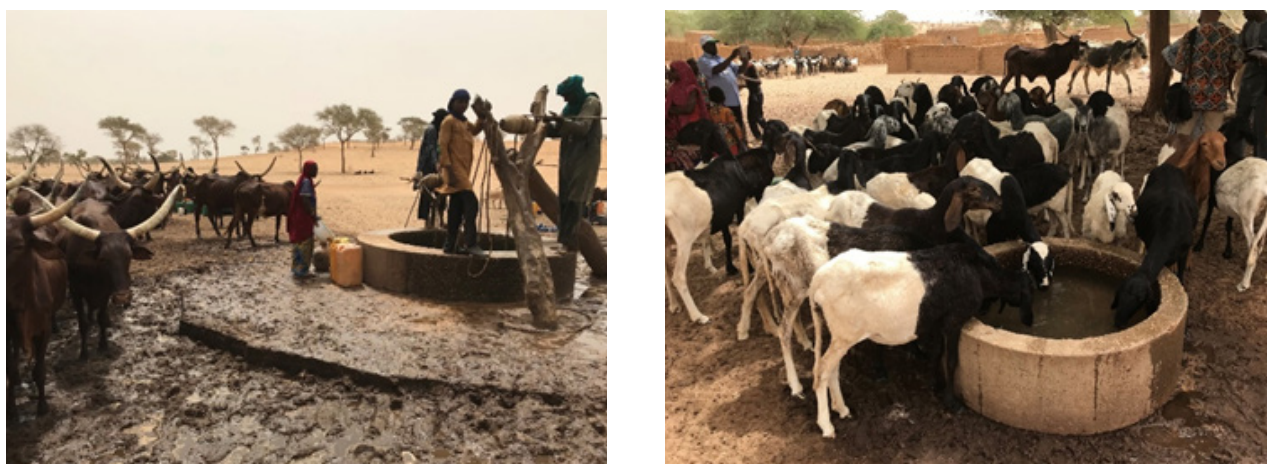

(CFAO/D. Bako 


\subsection{Livestock infrastructures}

Livestock development in West Africa is constrained by low investments in infrastructure. Since colonial times, the rehabilitation or establishment of new livestock infrastructure have been generally poor in West Africa and a considerable amount of it, dated back from this period, is still being used (De Haan, Quarles van Ufford and Zaal, 1999). The West African countries often lack the financial capacity to invest in livestock public goods. The private sector has taken up part of the space left by governments, mainly in areas with good agro-climatic conditions and market access, where larger livestock commercial farms are usually located. However, many smallholder farmers and livestock producers in the region have been left with inadequate and costly access to basic livestock services and infrastructure. The developments on efficient livestock infrastructure in West Africa should contribute to regional food security and economic growth, improving farmer income and encouraging trade (Atsushi, 2007).

There is a range and diversity of livestock infrastructures to support the various segments of the livestock value chains, from production and health, to processing, marketing and trade. The country reports used as inputs for the preparation of this book generally lacked detailed on different types of livestock infrastructures, which may encompass structures under different denomination and eventually different physical specification from country to country. Hence, it is difficult to provide a realistic and consistent comparison between livestock infrastructure of different countries in the region. In addition to livestock specific infrastructure, general and basic infrastructure, such as roads, communications and ports, are also critical for access of livestock and their products, to external markets.

\subsubsection{Livestock production infrastructure}

The main infrastructures in the initial phase of the livestock value chain include breeding, watering and feed manufacturing infrastructure, being the last two already covered ${ }^{21}$. The livestock breeding infrastructures include stations and ranches, most of them owned and operated by governments, as well as hatcheries, which are generally privately owned.

\section{Livestock breeding infrastructures}

Several livestock breeding stations or ranches are found throughout West Africa. Most of these were established in the 60s, while others were developed specifically to reconstitute herds after the catastrophic droughts of the 70s and 80 s. Some of them are considered livestock research and extension centers, geared towards the development, demonstration and exploitation of livestock technologies to the benefit of livestock production. Others also have a role to ensure the conservation and improvement of animal breeds, multiplying, selling and distributing "improved" animals to upgrade local breeds raised by farmers or to facilitate the development of new enterprises. Examples include the Dahra and Kolda stations in Senegal (Gueye, 2012), the Niono station and Madina Diassa ranch in Mali (Modibo, 2010); the Avétonou center and Adélé ranch in Togo (Talaki, 2012); the Toukounouss station and Maradi center in Niger (Djibrillou, 2012); the Abokouamékro, Sipilou and Marahoué ranches in Côte d'Ivoire (Fadiga, 2011).

Most of the privately-owned breeding stations are part of poultry farms that rear parent stock in order to hatch out their own replacement flock. Ghana has up to nine private parent poultry stations (Akunzule, 2014). Some chicken parent stock farms for the production of fertile eggs were recently established in Mali (Traoré, 2013), Senegal (Traoré, 2014) and Gambia (FAO, 2008). In 2012-2013, three Guinea fowl 
breeding and demonstration centers were established, with the assistance of FAO, in three different locations of Ghana: Pong-Tamale in the Northern Region, Paga in the Upper East Region and Babile in the Upper West Region (Akunzule, 2014). Hatcheries for the production of commercial layer DOCs are found in many West African countries as well, but little information is available on how they are operated. In Gambia, there are two poultry hatcheries: Tee Farms Hatcheries with 20,000 eggs hatching capacity and Gambia-Netherlands Investment Partners (Abuko) with 9,000 eggs hatching capacity (FAO, 2008). In Mali, the Maraka Foro Farm has a capacity for hatching 3,000 eggs (Traoré, 2013).

\section{$\times$}

\section{Box 3}

The West Africa Livestock Innovation Centre (WALIC).

WALIC is a regional centre of excellence on livestock innovation for West Africa, built on the legacy and achievements of the ITC, it has expanded its focus from concentrating mainly on indigenous breeds of cattle, sheep and goats that are naturally tolerant to tsetse-transmitted trypanosomosis, to a broader regional reach in order to unlock the potential of the West African ruminant livestock sub-sector through innovative partnerships and knowledge-based solutions that empower stakeholders along value chains. The beginning of the ITC can be traced back to the early 70s, when the Rockefeller Foundation provided some funding for researchers to work on the problem of trypanosomosis which was decimating livestock in many parts of Africa. The Gambia was chosen as the site of research in West Africa firstly, because trypanotolerance in cattle was almost exclusively of the N'Dama breed from The Gambia. In 2012 the ITC started, with the support of FAO, an internal process to rejuvenate itself through the development of a 10-year Strategic Plan (2013-2022), the main outcomes of it was the rebranding from ITC to WALIC, and the significant shift on the way to do business from a linear technology development and transfer approach to an innovation systems approach that embeds the value chain concept.

WALIC focus on four Strategic Themes: (i) genetic improvement, conservation and enhanced use of West African livestock; (ii) capacity development of actors along livestock value chains; (iii) knowledge management; and (iv) advocacy and partnership brokerage. Hence, the vision of WALIC is a vibrant West African livestock sub-sector, which boosts food security and wealth creation while safeguarding the environment. Although research for development is part of its mandate, WALIC's agenda pay substantial attention to promoting institutional change through capacity building, knowledge management, advocacy and partnership, among other activities (WALIC, 2019).

\subsubsection{Livestock health infrastructure}

The main livestock health infrastructures include veterinary clinics, veterinary pharmacies and veterinary laboratories. While clinics and pharmacies are run either by governments or private businesses, most veterinary laboratories in West Africa are exclusive public institutions. Other livestock heath infrastructures include vaccination crushes and dip-tanks, most of which are generally operated by the government or community managed. 
Veterinary clinics and pharmacies

There are very few veterinary clinics in West Africa satisfying minimum requirements. Most of the privately owned clinics are located in big cities or towns, where they mainly deal with companion animals. Public veterinary clinics dedicated mostly to farm animals operate in small towns or rarely in rural areas. These kinds of establishments may range from a simple room with small facilities for making basic diagnosis and treatment to large facilities equipped with laboratory and other means of diagnosis and isolation pens for monitoring sick animals. In contrast, there are several veterinary pharmacies in the region classified as wholesalers, in charge of importing and distributing drugs and retailers (agro-vets dealers) selling the products directly to livestock producers. Among the retailers, it is not uncommon to find drug stores operating without license, with improper conditions to keep veterinary pharmaceuticals and run by none qualified personnel. Farmers have also access to veterinary drugs from veterinary clinics and occasionally from direct import (Luseba, 2015).

Photo 48. Advertisement of private veterinary clinic (Ghana)

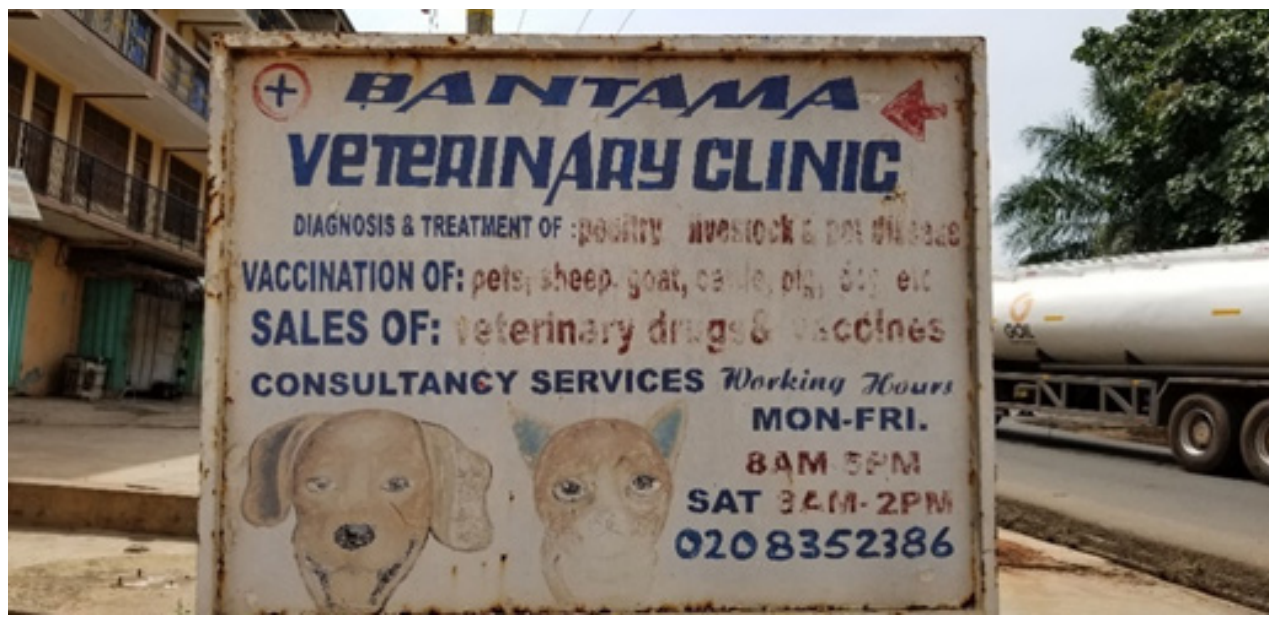

CFAO/R. Aguanno

Photo 49. Regional Veterinary Office's community clinic in Ho (Ghana).

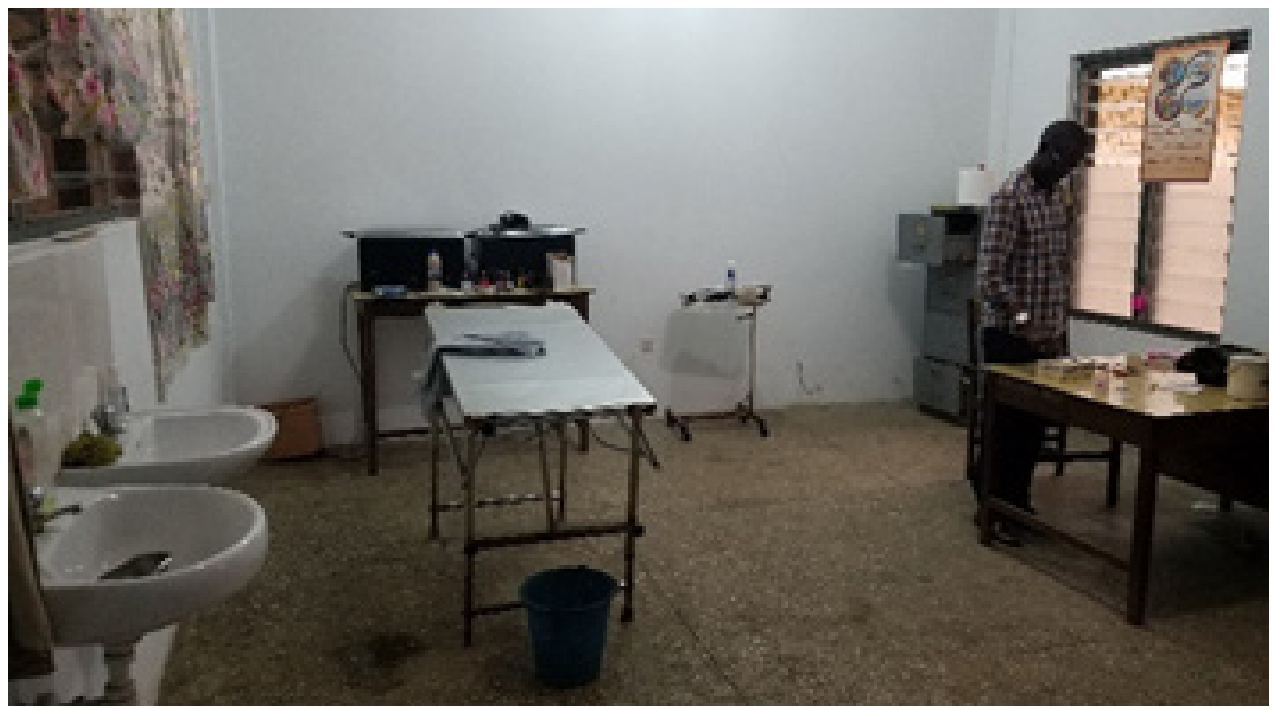

CFAO/G. Lamielle 


\section{Veterinary laboratories}

All West African countries have at least one national laboratory and several regional or district laboratories. The technical capacity of these laboratories is vary considerably, ranging from almost none functional to good facilities equipped with the necessary material and qualified personnel. Through the RESOLAB ${ }^{22}$ Network supported by FAO, the capacity building of the national veterinary diagnostic laboratories in West Africa has been supported since the first incursion of Highly Pathogenic Avian Influenza (HPAI) in the region, which led to the establishment of the Emergency Centre for Transboundary Animal Diseases (ECTAD)(FAO, 2012a).

More recently, FAO has developed a Laboratory Mapping Tool to assist identifying constraints in laboratory functionality, in order to define mechanisms and targets for capacity building to fill the gaps (Mouillé et al., 2018). Most of these laboratories have developed through years of experience diagnosis capabilities for the major animal diseases. Therefore, the region should be, in one way or the other, self-sufficient in terms of diagnostic needs of the major animal diseases. However, some countries (i.e. Côte d'Ivoire, Guinea Bissau, Liberia and Sierra Leone) still rely on outside laboratory facilities to carry out appropriate and complete diagnostic for livestock disease and most are still completely dependent on research projects and foreign donors for the purchase of reagents and consumables (Romero Tejeda, 2016; El Harrak and Abouchoaib, 2016; Godenir, 2017; Kwiatek, 2016; Angot and Baurier, 2016; Hammoumi and Mainguet, 2016; Gauthier and Dauphin, 2016; Beaute and Micout, 2016 and Letellier, 2016).

Photo 50. Accra and Kumasi Veterinary Diagnostic Laboratories (Ghana)

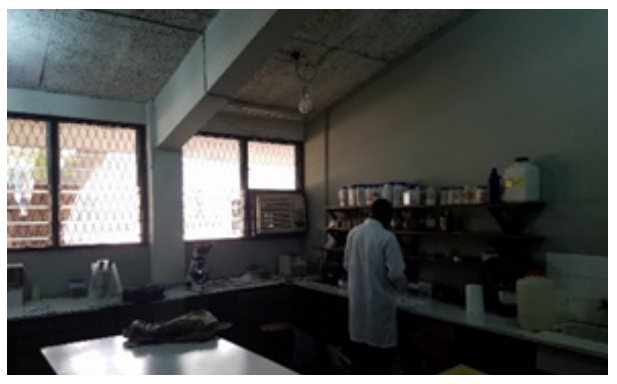

(c)FAO/G. Lamielle

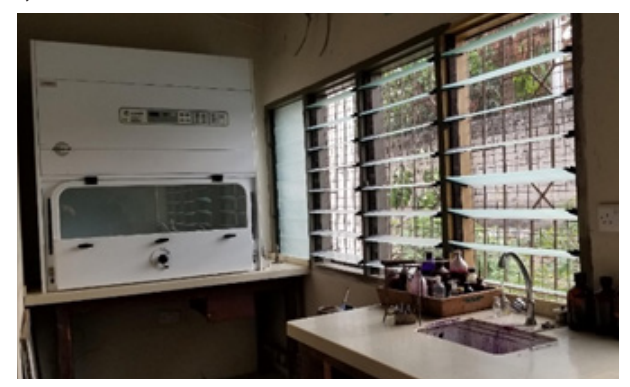

CFAO/R. Aguanno

The National Veterinary Research Institute (NVRI) of Vom in Nigeria, and the Laboratoire National d'Elevage et de Recherches Vétérinaire (LNERV) of Dakar in Senegal, often play the role of regional reference laboratories for some of the major diseases in West Africa. Overall, the state of the facilities, the existing equipment and the staff's technical skills of both laboratories are very good, but still there are challenges that need to be addressed, particularly regarding the development of a quality management system, in compliance with international norms and standards. Although yet to be accredited, the NVRI is the only high biosecurity veterinary laboratory (type BSL3) present and functional in the entire region (Diop and Guillotin, 2017 and Niang and Boussini, 2018). The Veterinary Services Directorate (VSD) Laboratory of Accra in Ghana recently got a modular container BSL3 laboratory from a foreign donor that, even if fully equipped and functional, it is not being used for infectious materials (Hammoumi and Mainguet, 2016).

\subsubsection{Livestock products processing infrastructure}

The processing infrastructures include different kind of facilities for treating different livestock product from raw to finished goods. In this document the meat, dairy and hide/skin value chains have been considered. Generally, these facilities are privately owned, except for meat processing facilities, which are usually owned and operated by governments. 


\section{Meat processing infrastructures}

While conducting the inventory of meat processing infrastructures, a clear distinction must be made with regards to the slaughtering capacities and (mainly) the level of compliance with sanitary and hygienic standards. According to this classification, three broad category of meat processing infrastructure can be distinguished in West Africa. These are i) abattoirs (industrial or municipal), which are facilities with the highest capacity and standards, followed by ii) slaughterhouses and then by iii) slaughter slabs, which are basic open slaughtering facilities. According to information from the FAO/SFW livestock sector reviews, inventory made in the West African region resulted in 53 abattoirs, 189 slaughterhouses and an undetermined number of slaughter slabs. Most of these facilities are operational but need upgrading in terms of physical infrastructure and capacity to meet sanitary and hygienic standards. According to ECOWAS, (2010a), the infrastructure and equipment for processing, preservation, storage and transport of meat in West Africa is outdated and/or unconventional. In order to address shortcomings and increase market access, the livestock exporting countries in West Africa (i.e. Burkina Faso, Mali and Niger) are building or are planning to build larger and adequate abattoirs. The high profile abbatoirs in the region include Johnny's Food and Meat Complex, an integrated abattoir slaughtering different species of animals in Ghana, two poultry slaughtering and processing plants operated by Moggie Farms in Faroto and Tee Farms in Latriya in Gambia and three other poultry slaughterhouses in Côte d'Ivoire with a capacity of more than 3,500 birds/day each.

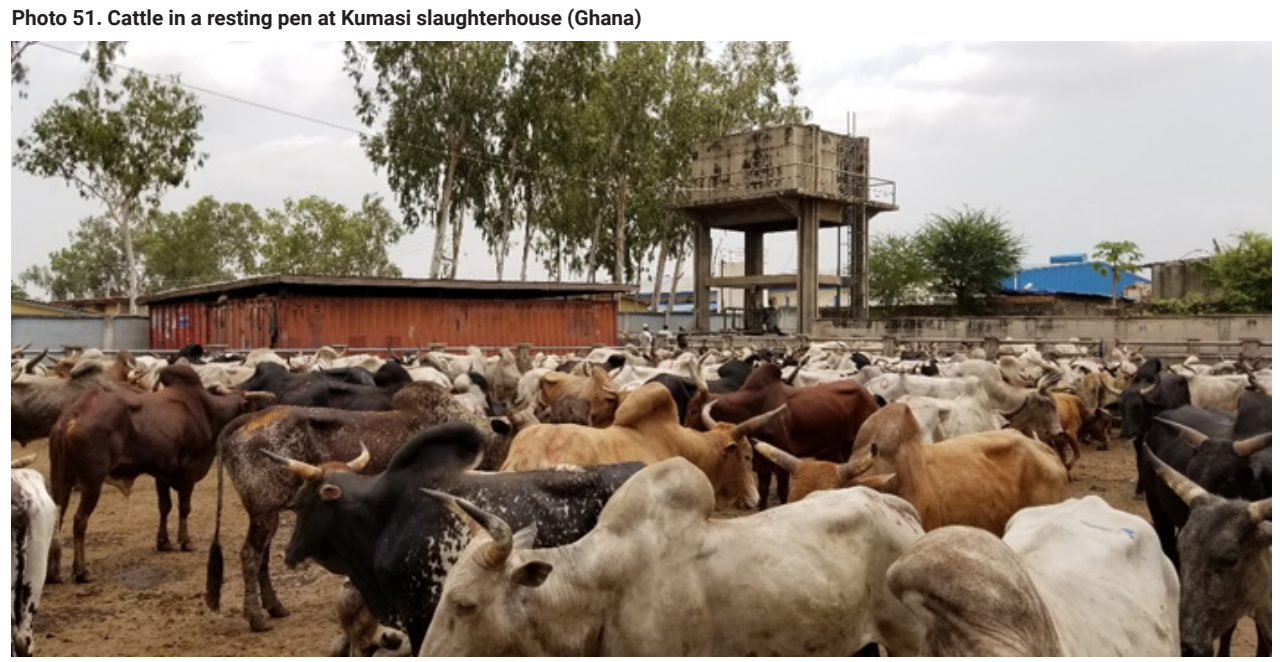

(CFAO/R. Aguanno

\section{Dairy processing infrastructures}

The information compiled from the FAO/SFW livestock sector reviews indicate that there are different types of dairy processing plants in West Africa. These include commercial dairy plants, semicommercial dairy plants and community based dairy units. The difference, essentially, is about the size, the location (urban vs rural) and (mainly) the level of processing and quality of the dairy products they handle. Commercial dairy plants are modern infrastructures complying with hygienic and safety regulations with a processing capacity of at least 10,000 litres of milk per day. These are converted in to a wide range of milk products commercialized nationally and/or within neighbouring countries. Semi-commercial dairy plants use modern technologies but with a modest level of investment and a processing capacity of about 1,000 - 2,000 litres of milk per day. Community based dairy processing units involve traditional or semi-traditional technologies with improved hygienic practices but a low 
processing capacity, since raw milk is purchased from livestock producers within the community and products (i.e. sour milk, yoghurt, ghee) are marketed in municipal markets and along the main roads. Nevertheless, according to ECOWAS, (2010a), the lack of standard transport, processing equipment and infrastructure, is one of the main problems for the dairy sub-sector in the subregion.

\section{The hide and skin processing infrastructures}

According to FAOSTAT (2019), a total amount of 80.95 million of ruminant hides and skins were produced in the West Africa in 2013. Most of these are processed in traditional or artisanal tanneries, which are commonly spread throughout the region, both in the major cities and in rural areas, and usually managed by cooperatives. These artisanal tanneries are still using traditional tanning agents (i.e. excrements, urine, bark, crushed nuts), with a negative impact on the quality of the leather produced, which usually restrict the possibilities to sell it beyond the domestic market. Their production capacity is extremely limited but enough for the local manufacturing leather artisans to make shoes, small leather objects, briefcases and many other items, providing most of the employment in the industry, virtually tens of thousands of jobs (Leather International, 2013) Burkina Faso, Mali, Senegal and Niger have few small but industrial tanneries, while in Nigeria the main tanneries are foreign owned and produce excellent crust leather, making it the most important player in the West Africa. The commercial or industrial tanneries process hide and skin mainly to the wet-blue stage, using composite chemicals, and most of their production are exported to Europe (Kiruthu, 2007).

Photo 52. Cattle hide left to dry on frames before transferred to tannery (Mali)

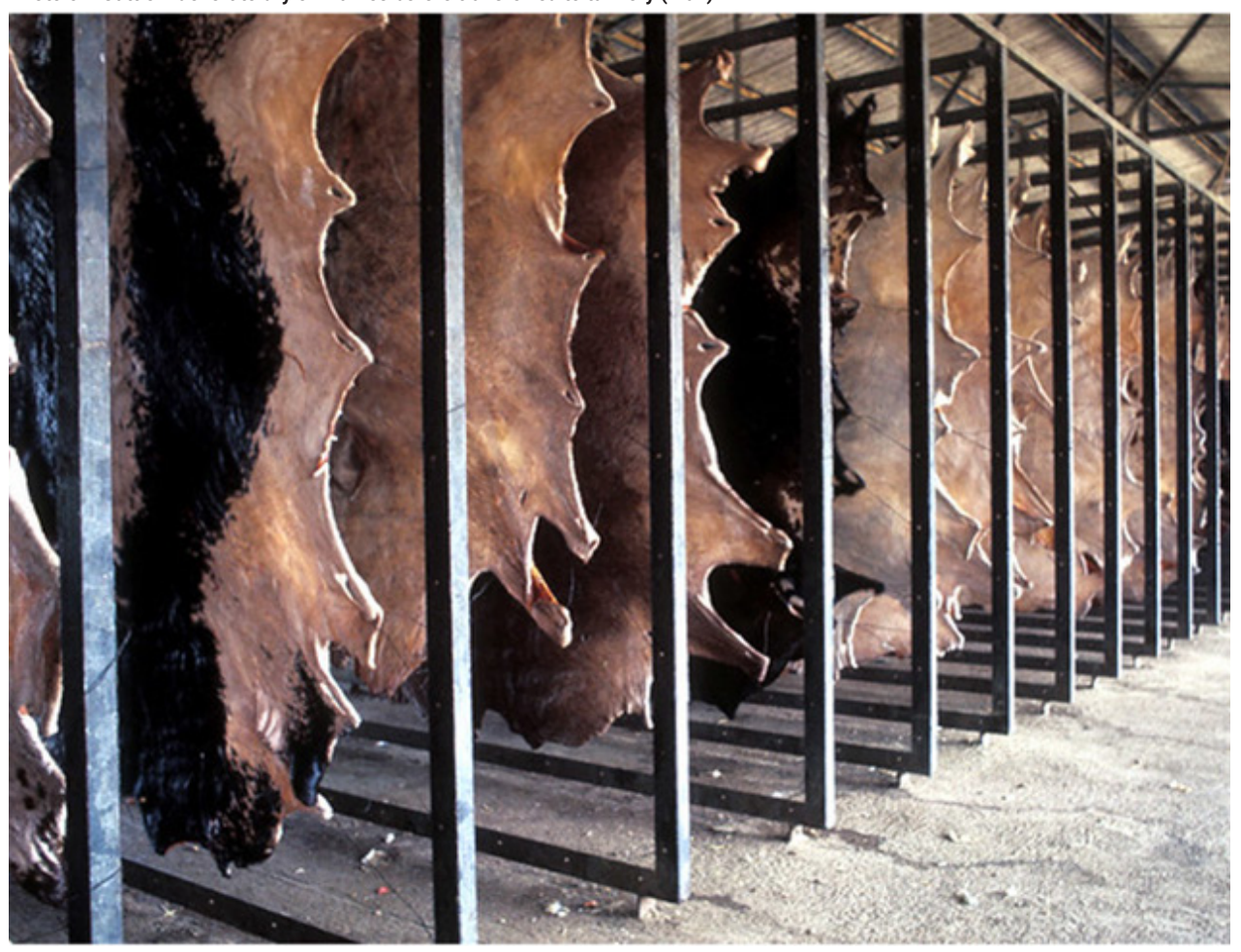

CFAO/P. Rocher 


\subsubsection{Livestock marketing and trade infrastructure}

The main livestock marketing and trade infrastructures in West Africa include livestock trekking corridors, markets, quarantine stations and veterinary check points. While most livestock markets are informally managed by private businesses, quarantine stations and veterinary check points in West Africa are public owned and run premises. The management of livestock trekking corridors remains ambiguous due to the limited understanding of the matter and low capacities to manage them by government authorities.

\section{Livestock trekking corridors}

The main marketing channels for live animals (cattle and small ruminants) trade in West Africa operate from the major livestock production basins in the Sahel and Sahel-Saharan countries, to the animal products consumer basins in the coastal countries. The livestock trekking corridors are physical paths of 5 to 25 metters wide extending between pastoral areas and markets towards coastal cities and town through which livestock are driven on hoof to access markets. Along these corridors, there are dispersed encampment points, often near water sources, where animals can graze (Kitchell, Turner and McPeak, 2014). Unfortunately, most livestock corridors are not demaracated. Furthermore, there is a need for the establishment of bulking sites as temporary holding grounds for livestock before transportation them to the major markets. These infrastructures, where they exist, are generally outdated and poorly organized, hampering access to market by livestock producers (ECOWAS, 2010a).

The management of livestock trekking corridors remains mainly the responsibility of local level government. However, since they extend beyond local and national jurisdictions, administrative coordination becomes a challenge unless there is a strong pastoralist organization at the local level. There are multiple interests regarding the location, recognition and use of livestock trekking corridors, likely influenced by a combination of favoritism of local authorities toward the interest of crop producers and internal and external politics (Sankhare, 2011 and Alidou, 2016). However, these corridors must be considered as a public good requiring some government involvement at different administrative levels to represent interests beyond local politics. The maintenance and improvement of this infrastructure, together with a modern market information system, is a priority for improving market access and profitability of the livestock sub-sector in West Africa (Diop, 2012).

\section{Livestock markets}

In West Africa, livestock marketing has an informal characteristic whereby most of the transactions are dominated by intermediary. This ultimately favours, in a way, the multiplication of a number of markets any animal selected for sale passes through. The livestock markets are usually located in or closer to urban areas of livestock production zones and, based on the stage of trade, are commonly classified as primary or collection, secondary or distribution and tertiary or terminal markets (Bekure and Tilahun, 1983 and SWAC/OECD, ECOWAS, UEMOA, CILSS and ROPPA 2008a). The collection markets are holding grounds where first step of transaction takes place between producers and small livestock traders and/ or local butchers. The distribution, better known as aggregation, markets are mostly supplied with animals purchased from collection markets by the first level traders and sold mainly to local butchers or to second level traders, with much higher purchasing capacity, for resale in terminal markets. The terminal markets are supplied with livestock coming from distribution (aggregation) markets, which are destined to either export outside the country or to slaughterhouses for domestic consumption. They are dominated by livestock exporters or wholesale butchers. Some terminal markets are located close to the border, where there is a significant cross-border trade in livestock between countries (ILCA, 1990). In order to improve livestock trade, new livestock markets should be established in border areas, 
infrastructure of the existing livestock markets improved and upgraded and the adoption/usage of existing facilities such as weighing bridges, which are available in some of the markets but largely ignored by traders, should be promoted (Williams et al., 2004b).

Photo 53. Niamana livestock market in Bamako (Mali)

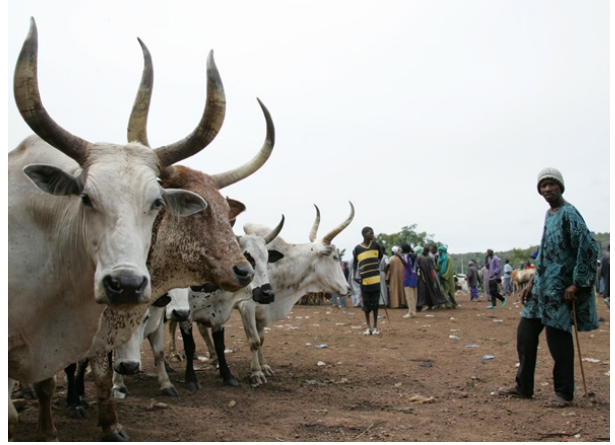

CILRI/S. Mann

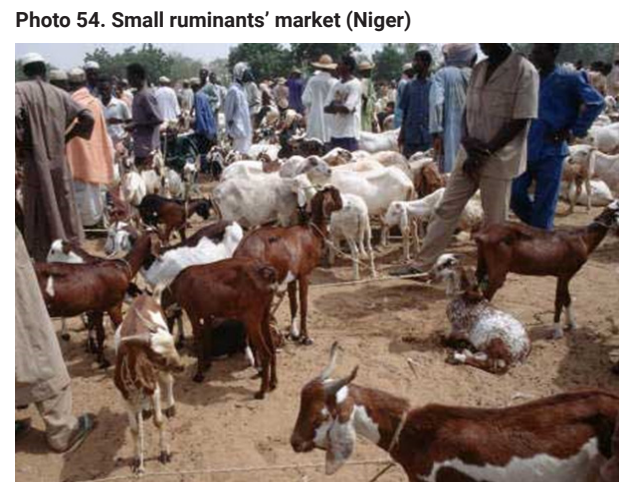

CILRI

\section{Quarantine stations and veterinary check points}

Most quarantine stations are usually located at the ports of entry (i.e. seaports, international airports and border crossings) of countries. Despite the importance of livestock trade within West Africa, quarantine facilities are generally absent or when present, inadequate. This constitute a potential risk for the spread of transboundary animal diseases (TADs) through cross-border livestock trade (Dean et al., 2013). On the other hand, veterinary check points are most commonly distributed along the main stock trade routes, commonly shared with police and customs officials. During the last few years, these check points proliferated along the main national highways used for livestock cross-border trade. However, in most cases these checkpoints are ill-equipped and often associated with the so-called illegal tax collection (Van der Lee et al., 2014).

In West Africa, Nigeria is the country with the highest number of international livestock and livestock products trade. Despites this, there are no functional quarantine facilities along the borders (Jajere et al., 2018). However, there are plans now to build one in the State of Kano (Jack, 2019).

The international veterinary border post network in Nigeria includes 11 terrestrial border posts, 4 airport border posts and 4 seaport border posts, but these are not adequately equipped (Gary, Diop and Barbosa, 2010). In addition to these and according to the National Veterinary Quarantine Services of Nigeria (NVQSN), there are 111 inter-state veterinary control posts and 905 state veterinary check points under the responsibility of this institution. The levels of functional efficiency of the NVQSN are rated high for revenue collection, medium for animal movement monitoring and low for disease monitoring. Illegal entry points are estimated at 3,445 (one per each $1.13 \mathrm{~km}$ border) (Ogundipe, 2002).

\section{Photo 55. Cattle transportation in Borno State (Nigeria)}

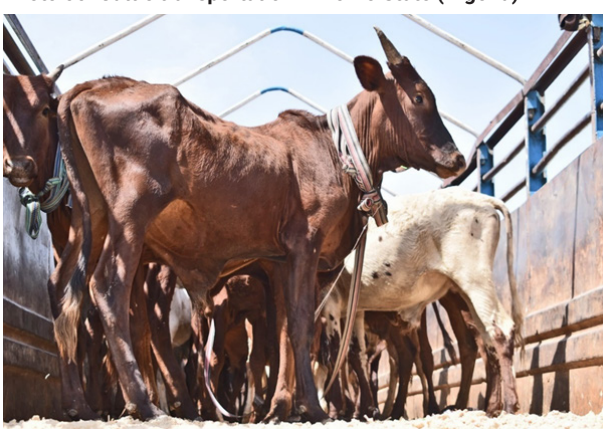

CFAO/Nigeria 


\section{DISEASES PREVALENT IN WEST AFRICA AND ANIMAL HEALTH CARE}
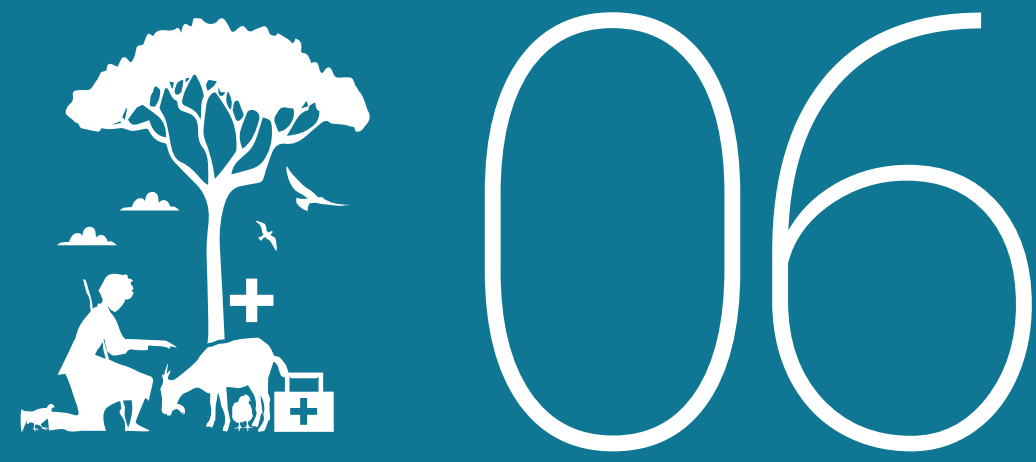



\section{ChAPTER VI \\ DISEASES PREVALENT IN WEST AFRICA AND ANIMAL HEALTH CARE}

The importance of animal diseases as a constraint to the development of the livestock industry in West African countries is well recognized. A specific estimate of animal disease impact at West Africa level is not available. A survey conducted by Grace et al, (2015) at continental level revealed that 35 priority diseases recorded by state Veterinary Services among African countries cost nearly 9 billion USD per year, equivalent to 6 percent of the value of the livestock sub-sector. Several infectious (viral and bacterial) and parasitic diseases are responsible for this loss by reducing livestock production and productivity. The various zoonotic diseases in West Africa are constant threats to the public health. According to a study conducted by FAO Subregional Office in West Africa to determine the priority TADs for control in West Africa (Kabore, 2012), four diseases affecting cattle, small ruminants, pigs and poultry were identified as priority diseases. These TADs are: Peste des petits ruminants (PPR), NCD, contagious bovine pleuropneumonia (CBPP) and African swine fever (ASF). Three of these four diseases coincide with the findings of Grace, Songe and Knight-Jones, (2015) at continental level, which categorized foot-and-mouth disease (FMD), PPR, ASF, NCD and rabies as priorities in multiple ranking among African countries.

Considerable progress has been made in West Africa regarding the control of TADs, but the other less visible animal diseases, have received a lot less attention, despite their significant economic importance causing not only clinical disease with mortalities but, more importantly, chronic production losses as a result of weight loss, reduced milk/egg production and condemnation of organs or carcasses at abattoir level (Tisdell, Harrison and Ramsay, 1999). The prevention and control programmes for these diseases should be based on a thorough understanding of their epidemiology under local conditions and a reliable estimate of production losses. Unfortunately, most of the Veterinary Services in West African countries do not have such information. The extension services transferring disease prevention and control knowledge to producers are not strong enough. Hence, these animal diseases continue posing problems to livestock producers in the region.

An effective holistic management of animal health in the region requires the adoption of an integrated One Health $(\mathrm{OH})$ approach. Understanding the important relationship that exists at the human-wildlifeanimal ecosystems interface regarding the emergence, as well as the endemicity, of animal diseases and zoonoses is extremely important. A good example is the recent Ebola pandemic that has caused 
immense economic and human losses in Guinea, Liberia and Sierra Leone during 2014-2016 (CDC, 2014). Therefore, collaboration among the sectors responsible for animal health, human health, plant protection and the environment as well as improve their capacities for the management of diseases becomes a priority to mitigate these threats and reduce negative impacts on health within the region.

Photo 56. Laboratory training workshop on diagnosis of CBPP in Bamako (Mali)

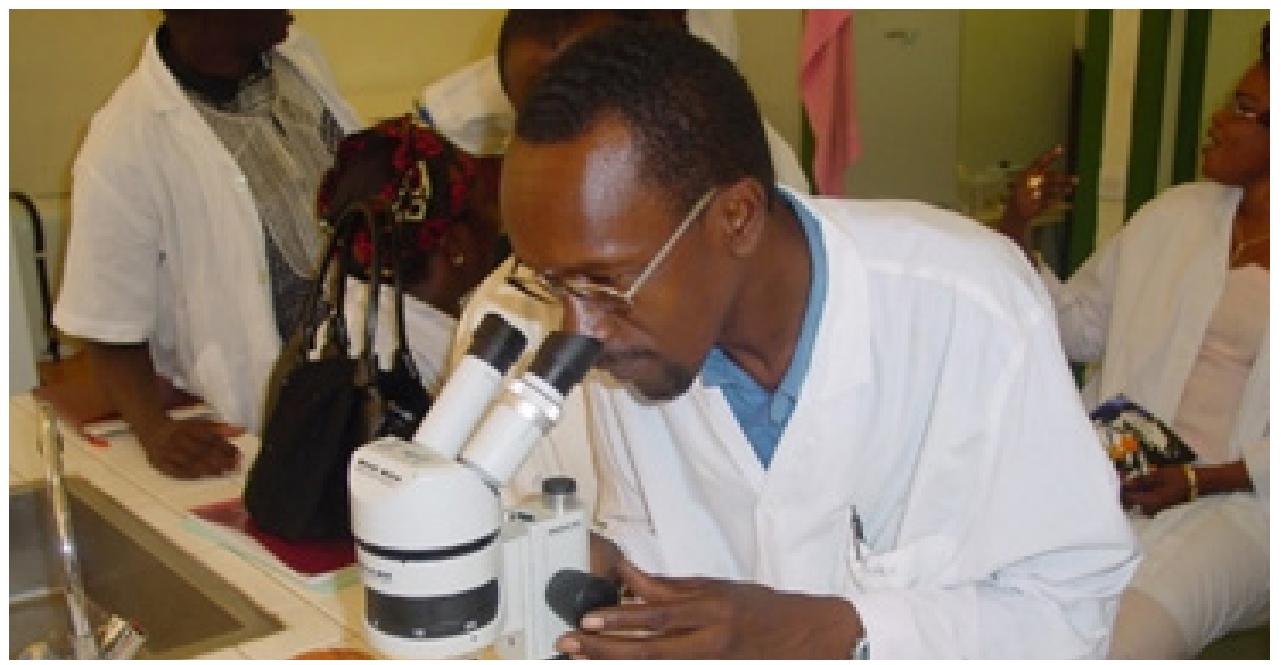

CFAO-IAEA/R. Geiger 2003

\subsection{An overview of main animal diseases reported in West Africa}

One of the legacies of rinderpest eradication in most of the countries in West Africa is the establishment of epidemio-surveillance networks. Although most of these networks are not effectively functional where there is no project funding, the passive surveillance component is still able to gather information on disease occurrence. Intensification of disease surveillance at field and abattoir level, farmer sensitization and awareness campaign assist in capturing disease situation for taking timely action and reporting. Disease reporting also needs the support of an effective veterinary diagnostic laboratory system to confirm what the surveillance component detects on the ground ${ }^{23}$. However, the low level of reporting animal diseases in many countries is noteworthy. In fact, because of endemic nature of many diseases and lack of sampling or diagnostic facilities, field veterinary services are often obliged to report diseases based on clinical diagnosis (Ouagal et al., 2008).

The notifiable animal diseases are reported on regular basis to different organizations through different reporting systems, such as the World Animal Health Information System (WAHIS) of the World Organisation for Animal Health (OIE), the Animal Resources Information System (ARIS) of AU-IBAR, as well as to different systems run by the national veterinary serices of different countries. The Global Early Warning System (GLEWS) for Animal Diseases, including major zoonoses, is a joint tool that builds on the added value of linking FAO, OIE and World Health Organization of the United Nations (WHO) alert mechanisms. The zoonotic diseases are also reported throught the WHO through its Event Management System (FAO, 2011b). One of the major challenges in disease reporting to regional and internation organizations is the diversity of formats that exist, causing duplication of efforts. Harmonizing data capturing formats or creating data sharing facility among the different databases (interoperability) help avoid unnecessary duplication of efforts and facilitate data availability for analysis. 
Using data gathered from the above-mentioned disease reporting systems, a classification of the major animal diseases prevalent in West African countries has been established according to their aetiological agent (i.e. infectious - viral and bacterial - and parasitic diseases) and the animal species most commonly affected (ruminants and monogastrics) for ease of presentation in this book. A further category on zoonosis, without distinguishing the aethiolgical agent has been created. The situation of these diseases in terms of their prevalence, impact and reporting varies largely from one country to another.

\subsubsection{Livestock infectious diseases (viral and bacterial)}

The two major viral diseases affecting mainly cattle in West Africa are FMD and lumpy skin disease (LSD). Although FMD is known to affect other species of animals (i.e. sheep, pig, etc.), most outbreaks in the region involve cattle. The bacterial diseases commonly reported in West Africa among cattle are CBPP, Blackleg (BQ), Pasteurellosis and Anthrax. The latter two also affect other species. Among the small ruminants, PPR and sheep pox and goat pox (SPGP) are viral diseases of significant importance in the region. The ASF and NCD are the leading viral diseases affecting pigs and chicken respectively in the region, causing major economic losses to the local swine and poultry industries. To a lesser extent, Gumboro or Infectious Bursal Disease (IBD) is also found to affect poultry in some countries and, more sporadically, African horse sickness (AHS) has been reported in equines. The diseases with less frequence of occurrence in the region include dermatophilosis (DPH) and heartwater disease (HWD).

Rinderpest was the most devastating disease affecting cattle in West Africa, before it was globally eradicated in 2011, posing then a serious threat to the livelihoods of millions of people and a major barrier to livestock trade. AU-IBAR, in collaboration with FAO and OIE and the financial support mainly from the $\mathrm{EU}$, coordinated the eradication of rinderpest from Africa through five main projects between 1962 and 2010. The contribution of Nigeria to the second project was remarkable. The gaps between actions, for instance disruptions of vaccination in Niger, led to the resurgence of rinderpest outbreaks in West Africa in the 1980s. In addition, sporadic civil strife and insecurity within the region (i.e. Liberia and Sierra Leone) affected the implementation of the various control and eradication projects. Among these, the Pan African Programme for the Control of Epizootics (PACE) helped to strength the capacity of veterinary services and created a framework for promoting goodwill among governments, private sector, civil society and donors, which were instrumental in finalizing the eradication of rinderpest and the control of other diseases (FAO, 2011a).

\subsubsection{Parasitic diseases}

Tsetse-transmitted trypanosomiasis and tick-transmitted babesia and East coast fever (ECF), are the most commonly reported protozoan diseases in West Africa. Tick infestation and tick-borne diseases cause serious economical losses of ruminants in West Africa, especially among the most susceptible exotic breeds of livestock imported into the region. The resistance of ticks to acaricides poses an increasing threat to livestock production in many West African countries because of their almost complete dependence on acaricides for tick control (Adakal, Stachurski and Chevillon, 2013). Other external parasites infestations, such as mange mite (MM), have been also reported in the region.

The internal parasites such as liver flukes, lungworms, gastrointestinal nematodes and cestodes have strong negative impact on livestock production in the region. The occurrence of Fasciola spp. In Senegal and Dicrocoelium spp. In Nigeria are particularly important in livestock. Lungworm nematodes (i.e. Strongyloid spp.) infestations are not very frequently described within the literature, while gastrointestinal nematodes (i.e. Ascaridae, Strongyloidae, etc.) have been described in all species and in several 
countries within the subregion. Most of the references regarding gastrointestinal cestodes concern Moniezia spp. affecting cattle in Ghana, Togo and Gambia. The Echinococcus spp. and Cysticercus spp. are reported in cattle, sheep/goats and pigs, from nearly all countries within the region (Over, Jansen and van Olm, 1992).

\subsubsection{Zoonotic diseases}

In West Africa, anthrax and rabies are the most widespread and important zoonotic diseases but very much under reported. On the other hand, outbreaks of brucellosis and bovine tuberculosis are less frequent and only few countries in the region report them. Cases of Rift Valley fever (RVF) are often reported in border areas of Senegal, Mali and Mauritania. Several outbreaks of HPAl, which is an emerging TAD and zoonosis, were reported in 2006-2008 in seven West African countries, particularly affecting the commercial poultry industrial in Burkina Faso, Côte d'Ivoire, Ghana, and Nigeria among others. The second wave of HPAI in West Africa, which started at the beginning of 2015 raised a major public health concern. The outbreak affected Burkina Faso, Côte d'Ivoire, Ghana, Niger, Nigeria and Togo. According to FAO Emergency Prevention System for Transboundary Animal and Plant Pests and Diseases (EMPRES), over 3.36 million chicken died or culled in Nigeria alone up to August 2016 (FAO, 2011b).

In addition to above-mentioned infectious zoonotic diseases, some livestock parasitic diseases are also transmitted to humans. Examples of parasitic zoonotic diseases in Western Africa are the previously mentioned trypanosomiasis, hydatidosis/ echinococcosis and cysticercosis, as well as trichinellosis, usually found in warthog and domestic pigs, among others. Over the years, a considerable amount of efforts has been put into the control of these parasites. Although the level of control and prevention vary from country to country, some of the major effort in this regard included the implementation of

Photo 57. Inspected meat transported from slaughterhouse to market (Senegal)

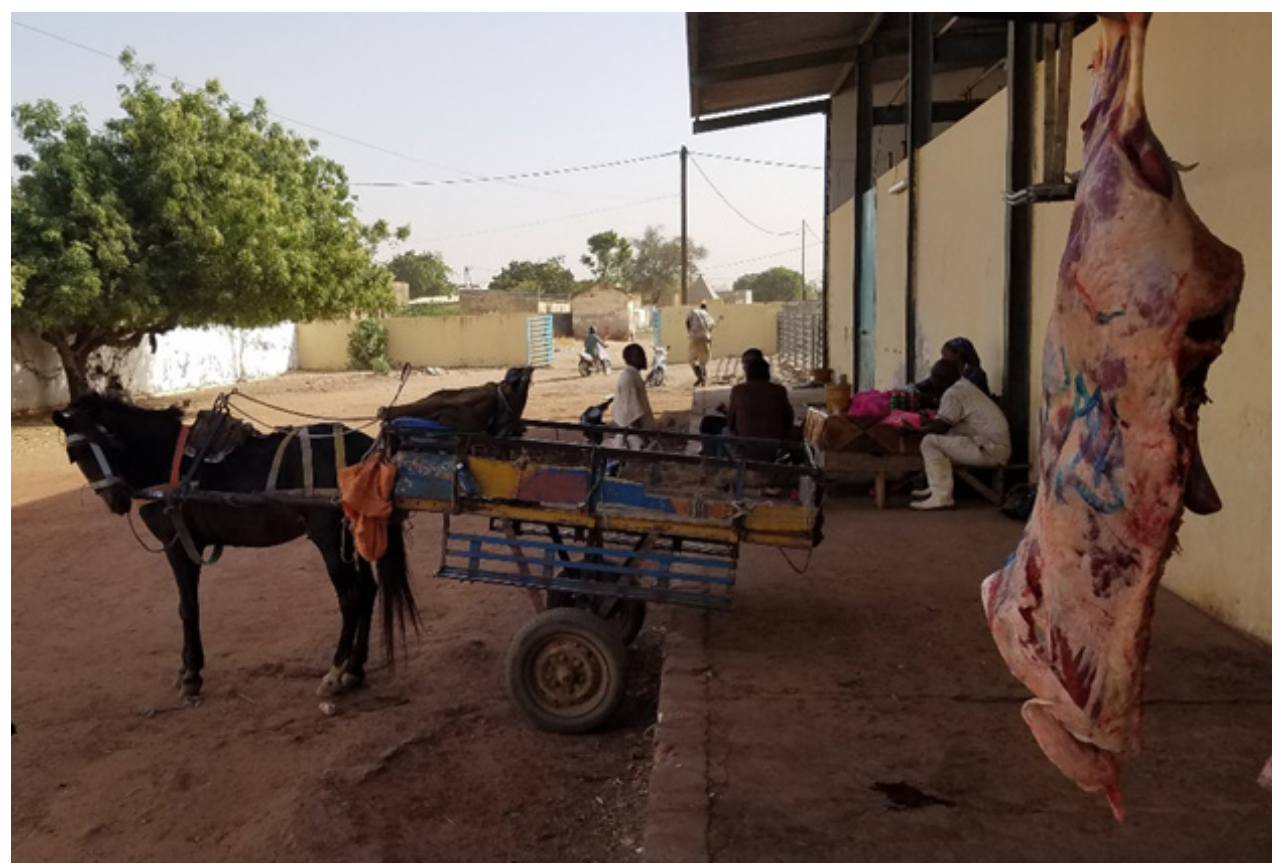

CFAO/G. Lamielle 
meat inspection procedures and the promotion of basic sanitation and hygiene at the community level (Macpherson and Craig, 1991). Foodborne illnesses are also common in the region (ILRI, 2019). These diseases are most commonly transmitted by Campylobacter spp., Escherichia coli, Salmonella spp. and Shigella spp., following the consumption of raw and/or undercooked food of animal origin.

\subsection{Number and spatial distribution of disease outbreaks}

While the reporting rate of animal diseases has continued to improve over the years, underreporting is still a challenge. In addition to underreporting, there are issues with data quality, completeness and inconsistency and sometimes lack of details of important data components (i.e. population at risk, species, age and sex differentiation, details of laboratory diagnostic tests and results, geo-reference of outbreak site, etc.) hampering data analysis and interpretation of results. These are result of lack of effective animal health surveillance systems, inadequate trained/skilled staff and poor record keeping, as well as the lack of capacity in transforming decisions into action, among others.

Notwithstanding this, an analysis conducted on animal disease outbreaks reported by West African countries through the ARIS reporting system to AU-IBAR and published as annual Animal Health Yearbook gives an overall picture of animal health situation in the region. Tables 13 and Figures 14 to 19 provides the number of outbreaks and cases of major animal diseases reported between 2010 and 2014 in West Africa.

Based on these reports, the most widely distributed animal diseases in the region, in terms of the number of countries affected, outbreaks and cases are PPR and NCD. The two diseases were reported by all the countries in West Africa regularly submitting their report to AU-IBAR. Twelve of the fourteen countries filing their monthly reports regularly reported FMD, Pasteurellosis, LSD and Anthrax. Despite considered as priority animal diseases in the FAO report of TADs prioritization of 2012 (Kabore, 2012), CBPP and ASF reported by eleven and nine countries respectively and recorded a smaller number of outbreaks and cases compared with other diseases.

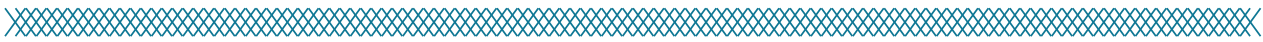

\begin{tabular}{|c|c|c|c|c|}
\hline \multirow[t]{2}{*}{ No. } & \multirow[t]{2}{*}{ Disease } & \multicolumn{3}{|c|}{ Number of } \\
\hline & & Countries & Outbreaks & Cases \\
\hline 1 & PPR & 14 & 3412 & 109013 \\
\hline 2 & NCD & 14 & 2302 & 432800 \\
\hline 3 & FMD & 12 & 1366 & 152579 \\
\hline 4 & Pasteurellosis & 12 & 1056 & 24416 \\
\hline 5 & LSD & 12 & 642 & 24286 \\
\hline 6 & Anthrax & 12 & 388 & 5617 \\
\hline 7 & CBPP & 11 & 531 & 7648 \\
\hline 8 & $B Q$ & 10 & 127 & 10064 \\
\hline 9 & ASF & 9 & 572 & 73655 \\
\hline 10 & Rabies & 8 & 728 & 10797 \\
\hline
\end{tabular}

Source: AU-IBAR/ARIS, (2010, 2011, 2012, 2013 and 2014). 


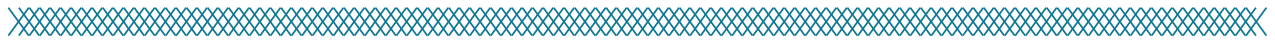

Figure 14. Number of outbreaks of major cattle diseases in West Africa (2010 - 2014)

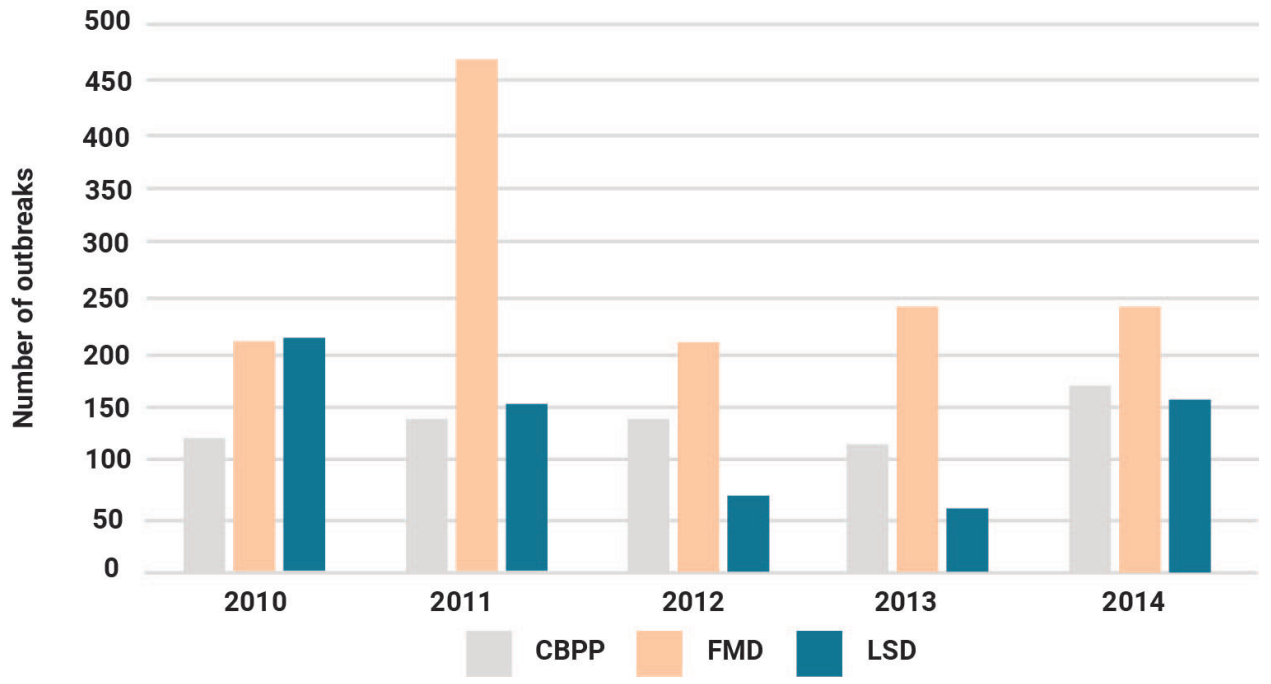

Source: AU-IBAR/ARIS, (2010, 2011, 2012, 2013 and 2014).

Figure 15. Number of outbreaks of major sheep and goat diseases in West Africa (2010 - 2014).

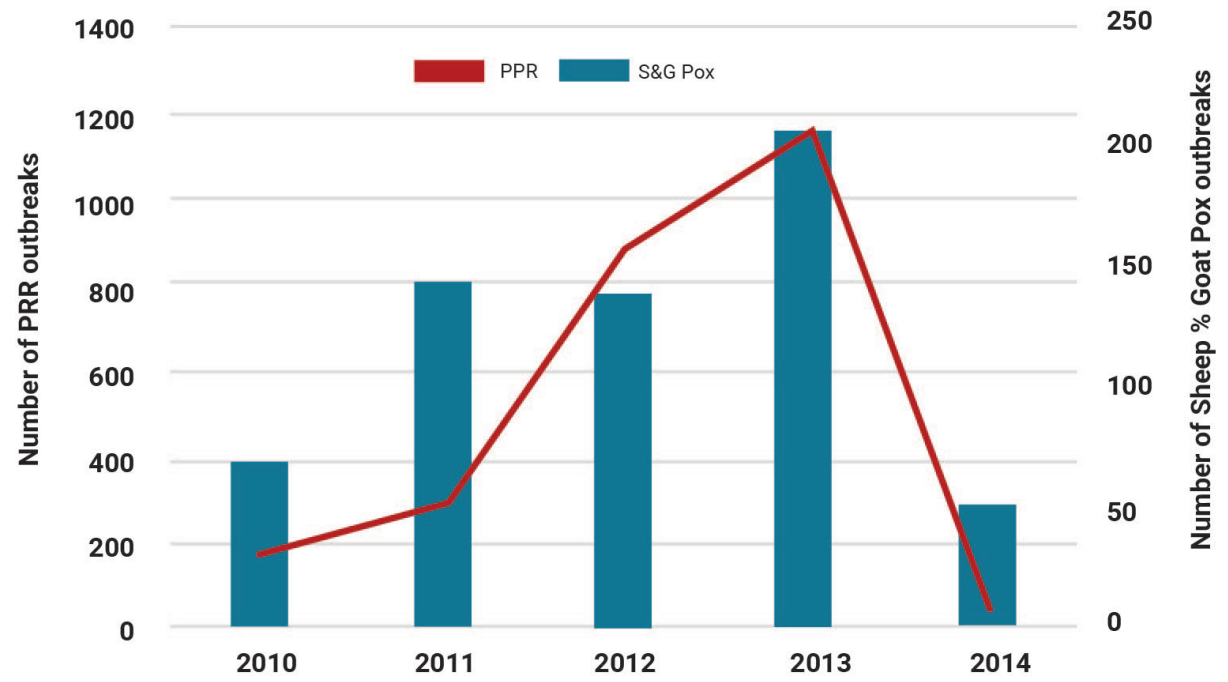

Source: AU-IBAR/ARIS, (2010, 2011, 2012, 2013 and 2014).

100 The role of livestock in food security, poverty reduction and wealth creation in West Africa 


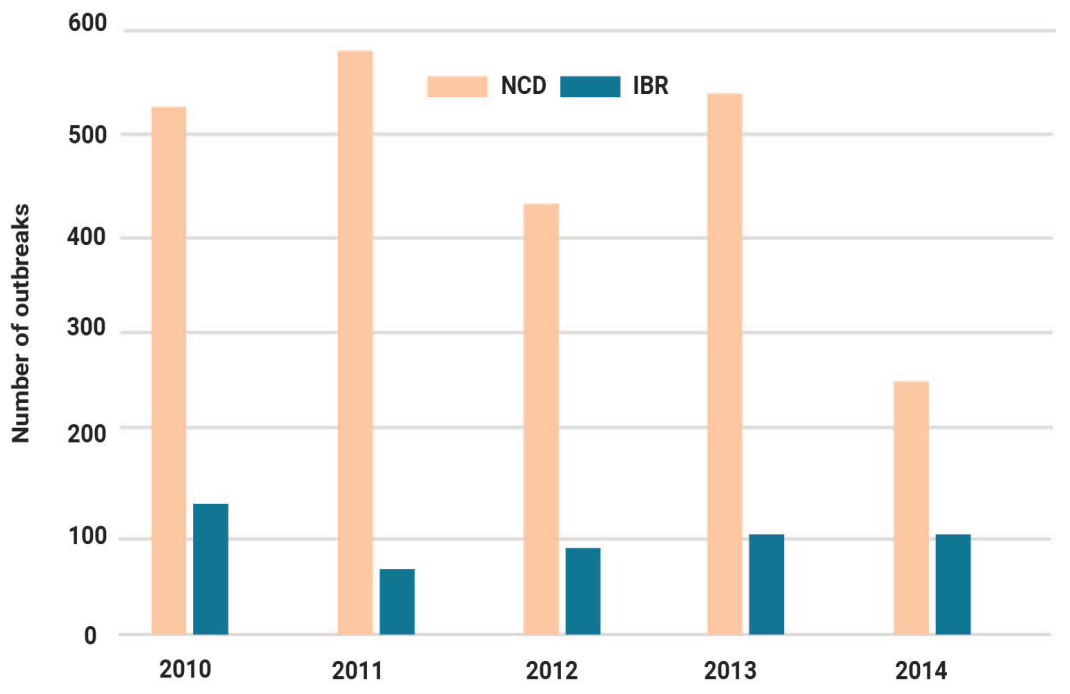

Source: AU-IBAR/ARIS, (2010, 2011, 2012, 2013 and 2014).

Figure 17. Number of outbreaks of livestock bacterial diseases reported in West Africa (2010 - 2014)

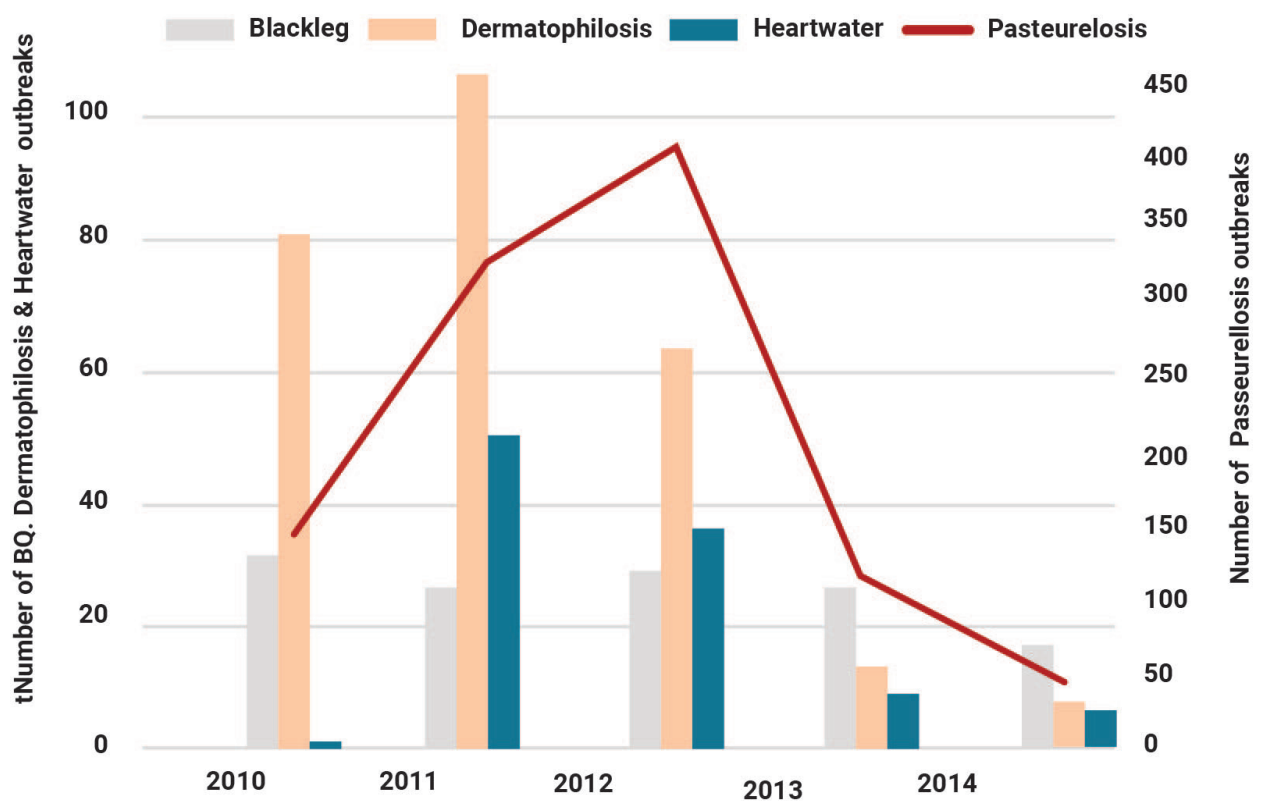

Source: AU-IBAR/ARIS, (2010, 2011, 2012, 2013 and 2014). 

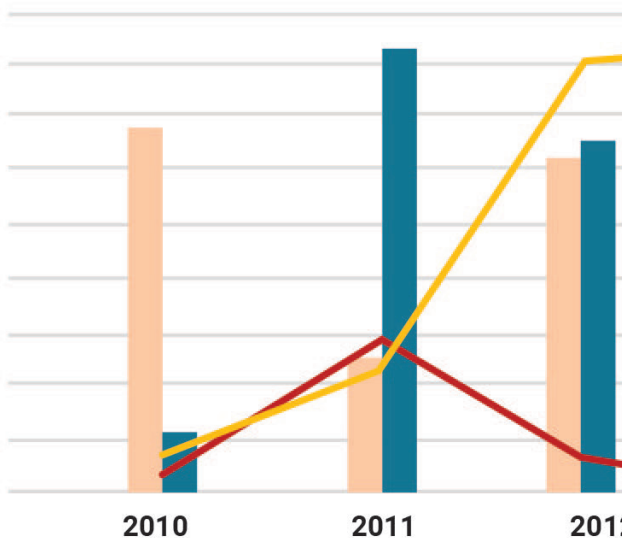

2010

2011

2012

2014

Mange

Tryps

Babesiosis

ECF

Source: AU-IBAR/ARIS, (2010, 2011, 2012, 2013 and 2014).

Figure 19. Number of outbreaks of some zoonotic diseases in West Africa (2010 - 2014)

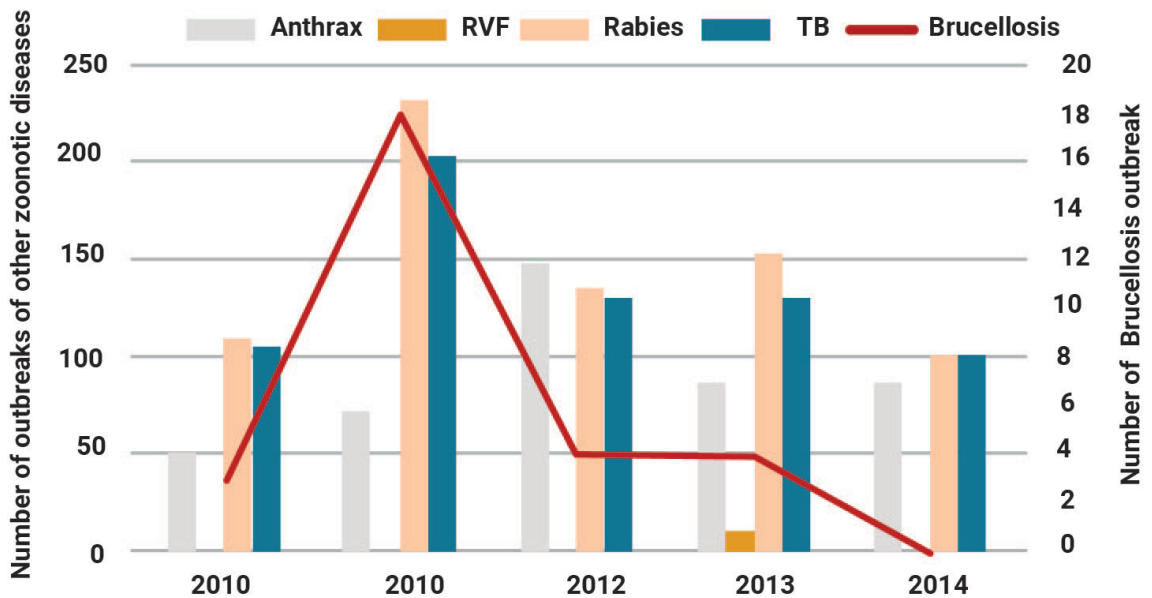

Source: AU-IBAR/ARIS, (2010, 2011, 2012, 2013 and 2014).

As shown in Figure 20, the spatial distribution of disease outbreaks has not changed much in the last decade in West Africa, except for HPAI frequently reported in Nigeria and AHS in Senegal. CBPP is reemerging in some countries, such as Senegal and the Gambia since 2012, while SPGP has shown a remarkably decreasing trend in the region (and in the continent) with no plausible explanation (AU-IBAR/ ARIS, 2013). LSD and FMD are becoming important in terms of their economic impact, especially with the increase in incidence among the more sensitive exotic and crossbred animals in the region. Despite the efforts of different projetcs and programmes, these diseases are becoming endemic as a result of inadequeate coordination and lack of harmonized interventions in controlling animal diseases both at national and regional levels (FAO, 2004; AU-IBAR/ARIS, 2013 and FAO/OIE, 2016). 
Figure 20. Spatial distribution of animal disease outbreaks in West Africa (2005 - 2015)

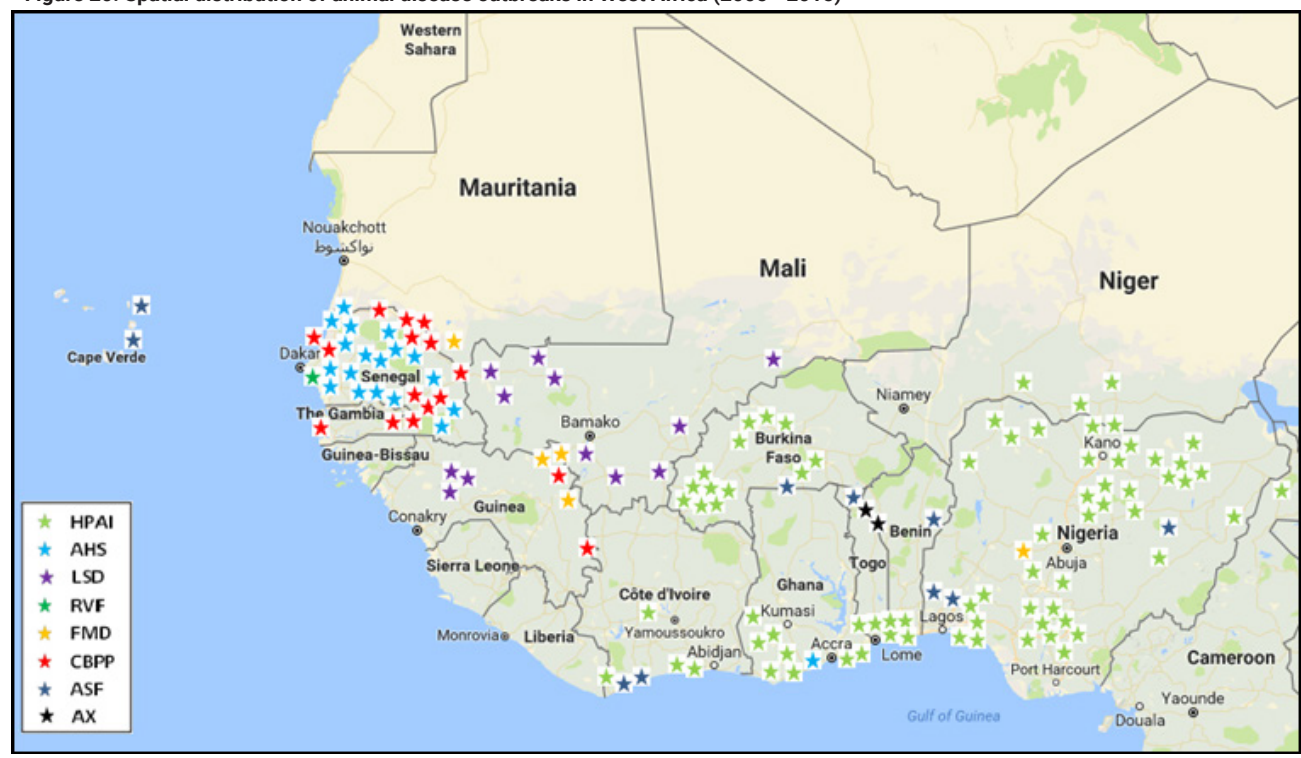

Source: OIE/WAHIS, (2019).

\subsection{Control and prevention measures against major animal diseases}

In West Africa, control and prevention measures for major animal diseases are delivered by the Veterinary Service Directorate under the Ministry in charge of the livestock sub-sector in each country. Other public sector institutions such as Universities and Animal Research Institutes also carry out limited animal health services. In certain countries (i.e. Benin, Côte d'Ivoire, Senegal, Mali and Togo) the private veterinarians are mandated to provide animal health service including treatment, vaccinations and sale of vaccines and drugs. In some cases (i.e. Liberia and Sierra Leone), due to budgetary constraints and limited personnel, veterinary services are not well organized (OIE, 2019). The main control measures applied against major animal diseases in West Africa are movement control, ring vaccination, treatment and stamping out. The preventive measures usually rely on annual vaccination against certain diseases planned and delivered in some countries of West Africa.

In order to minimize the spread of livestock disease at national and regional level, there is a need to improved disease risk assessment and management, including improved emergency disease response capabilities, harmonized disease surveillance, reporting and control strategies. These efforts should involve all stakeholders at the national level with established regional coordination mechanisms to allow transparency and trust among livestock producers and traders within and outside West Africa. Unfortunately, it is difficult for pastoralists to effectively participate in livestock disease control and prevention programmes, such as active surveillance activities and vaccination campaigns, unless they are adequately empowered through sensitization and effective coordination within the veterinary authorities at national and regional levels (Jenet et al., 2016). 


\subsubsection{Animal movement control}

Animal movement control along recognized livestock migratory corridors and trade routes at national and regional level, becomes a must to prevent and control the spread of livestock diseases in West Africa. As previously mentionned, livestock movement monitoring by veterinary services in the region takes place mainly through the establishment of veterinary check points along recognized livestock corridors and trade routes ${ }^{24}$. Livestock markets are also used for monitoring and controlling animal movement, together with the establishment of quarantine stations at border and other points of entry into a country. The use of official health certificate, such as the ECOWAS International Transhumance Certificate (itc), when moving livestock is a common practice within the region and much emphasis has been put on the re-enforcement of harmonized legislation regarding this matter ${ }^{25}$.

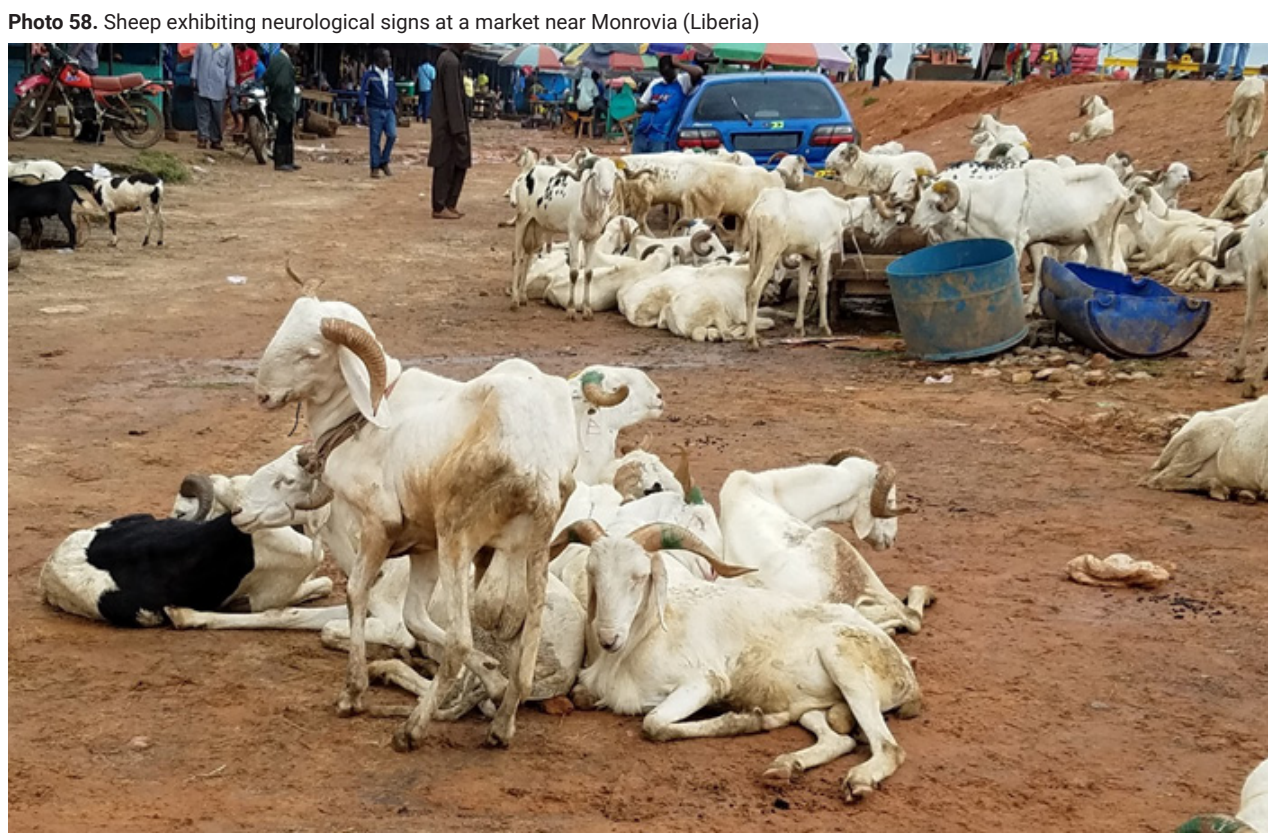

CFAO/G. Lamielle

In addition to the regular movement control through health certificate, specific animal movement restrictions can be imposed as a response to disease outbreaks. Animal Identification and Recording System (AIRS) for livestock traceability are tools that can contribute significantly to the implementation of animal disease control and prevention measures, particularly through a better control of animal movements (FAO, 2016a). While is true that, West African countries do not have any comprehensive AIRS in place as yet, by adopting the Pretoria Declaration on AIRS for Traceability and Livestock Development, they have affirmed their commitment to implement it sooner or later (FAO, 2015a).

\subsubsection{Vaccination against major animal diseases}

Most of the vaccination exercises carried out in the region are either national campaign to prevent or control diseases as response to disease outbreaks. The vaccination coverage varies between countries depending on which programme is used and which target is set against each disease. These will, in turn, depend on the socio-economic impacts of a given disease in a given country. For instance, according to information provided in the FAO/SFW livestock sector reviews, in Ghana vaccination against Anthrax, 
PPR, CBPP and BQ in small and large ruminants is conducted annually, with farmers paying for the cost of vaccines. In Senegal national mass vaccination targets AHS, PPR, LSD and NCD. In Mali mandatory mass vaccination at the national level targets $C B P P$, Pasteurellosis and $B Q$, while Anthrax vaccination is limited to specific zones in the south and north-east of the country. Unfortunately, the reality on the ground is somehow controversial. Most countries conduct annual vaccination campaigns without any clear disease control policy, achieving low vaccination coverages of 20 - 30 percent of their national herds and flocks, which do not guarantee a proper immunity to control these diseases. Vaccination campaigns must be part of a comprehensive disease control programme, which, in the case of TADs, require a regional approach if they are to be successful (Lubroth et al., 2007).

In some countries of West Africa, different vaccines, particularly for local use, are produced in national laboratories and research institutes, often supplied also to other countries within the region. This is the case of the Central Veterinary Laboratory of Bamako in Mali; the Accra Veterinary Laboratory and the Central Veterinary Laboratory at Pong-Tamale in Ghana; the Laboratoire National d'Elevage et de Recherches Vétérinaire (LNERV) of Dakar in Senegal, and the NVRI of Vom in Nigeria. However, few of these llaboratories have the capacity of producing the amount of vaccines required for national campaigns. Therefore most of the countries are dependent on imported vaccines to cover national livestock immunization needs (Kamuanga et al., 2008). Support to increase production capacity and product quality for national and regional vaccine manufacturers is required, particularly for vaccines against diseases of interest only in West Africa (Donadeu et al., 2019). One of the visible gaps is the need to strengthen laboratories in the quality control of human and veterinary medicines. Not all West African countries currently have a laboratory capacity to acceptably control the quality of veterinary pharmaceuticals, and very few are able to control the quality of veterinary vaccines (Boisseau, 2005).

A recent study in Mali (Dione et al., 2017), identified several challenges for animal vaccine delivery in the field, which is also applicable to most countries in West African. Poor adherence of livestock keepers to vaccination campaigns was largely influenced by their lack of knowledge and awareness about the benefits of vaccination and timing, their lack of trust in vaccinators or in the quality of vaccines (ex: adulteration during transportation and handling, use of inappropriate strains, etc.). They are reluctant to participate in vaccination campaigns also to avoid declaring the number of animals as tax evasion strategy, which leads to underestimations of the targeted animal population and low vaccination coverage. In addition, inadequate infrastructure reduces livestock keepers' motivation to participate in vaccination campaigns because of the time and the labour involved in restraining animals. Other factors identified were the lack of equipment and high transport costs for long distances transportation and challenges in maintaining cold chain, leading to the spoilage of vaccines, as well as the large
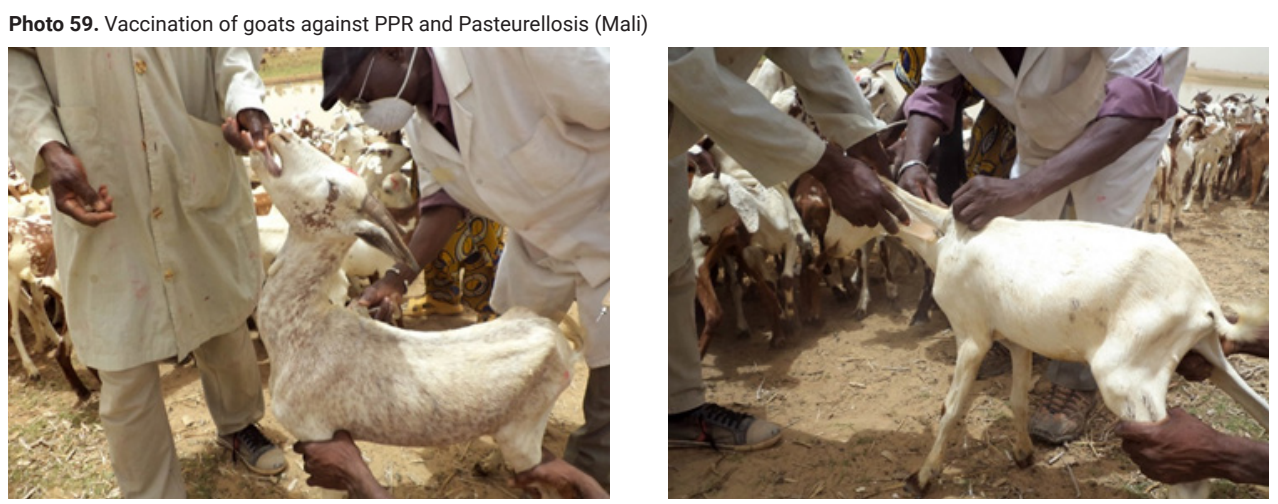

CFAO/B. Geers 
geographical coverage and difficulties in accessing some areas throughout the year or during specific seasons. Finally, the insufficient incentives received by veterinarians to carry out vaccinations in remote areas and the poor management and communication among vaccine chain supply actors, were also mentioned (Dione et al., 2017).

\subsubsection{Stamping out and other control and prevention measures}

For the control and prevention of livestock diseases, stamping out seldom due to the high cost and the complex logistic that this measure involves. Unless fair compensation is paid, most livestock keepers do not allow their animals to be destroyed as part of disease control measure and find a way to avoid even when forced to do so by the authorities. In fact, in a common endemic situation for most livestock diseases in West Africa and with limited trade of livestock and animal products destined for lucrative markets outside Africa, the justification of this measure is questionable (Perry, McDermott and Randolph, 2004). Nevertheless, in the case of commercial farms with high biosecurity standards, stamping out is commonly applied in response to disease outbreaks. This is the case of the poultry industry, which commonly use the culling of an entire batch of animals as a disease control measure, as it happened in the last HPAl outbreaks in the region (FAO, 2019a). Other disease control and prevention measures commonly applied in West Africa are the control of strayed dogss (Rabies), prophylactic treatment during outbreaks (Mange mites and Anthrax) and condemnation of organs and whole or part of carcasses at slaughterhouses (Bovine TB and parasites cystes).

\subsubsection{Animal health products in West Africas}

Besides harmonized regional directives (i.e. ECOWAS and UEMOA), each country in West Africa has its proper legal framework regarding the registration, import and commercialization of animal health products (Kamwanja et al., 2011). However, according to a study conducted in Burkina Faso, Senegal, Mali, Nigeria and Ghana, the system is said to be slow and only about 20 percent of requests submitted by pharmaceutical companies are processed. In general, national institutions or services dealing with animal health products registration are under the ministries of public health and do not have the capacity (or the appropriate training) to register veterinary products, particularly vaccines for veterinary use. About 10 - 20 percent of the total animal health products commercialized in these countries are supposed to be fake. Porous borders, lack of commitment and inadequate legislation, have led to an uncontrollable situation in many countries. Nigeria, however, has been striving to control the port of entry of unregistered and fake products by restricting the ports of entry of all medicines to airports only (Luseba, 2015).

The international pharmaceutical companies usually work with a single main distributor, who in turn supplies recognized retailers (agro-vets), veterinary practices and occasionally large farms. This differs from French-speaking West African countries, where wholesalers act as distributors for $10-12$ companies, and retailers therefore have a choice of suppliers (Grasswitz et al., 2004). However, the staff dedicated to the registration and control of establishments selling animal health products is very limited. The production, import, distribution and sale of vaccines for veterinary use are predominantly under governmental close supervision, which often fix prices (not commonly reviewed) and sometimes even provide insufficient quantities free of charge to livestock producers, making it difficult for the private sector to operate economically with this kind of products. The distribution of animal diagnostics kits are also under governmental control and official veterinary laboratories conduct diagnostics services free of charge, except for large producers seeking specialized tests (i.e.: commercial poultry operations). The field diagnostic products are rarely commercialized in the region, except for mastitis, brucellosis and tuberculosis testing kits used by some small-scale dairy producers (Luseba, 2015). 
A large variety of veterinary drugs are imported by West African countries for animal health care and disease control, and this may be strongly related to various AEZs and diverse species of animals in the region. For the purpose of this book, major groupings of veterinary medicinal products (VMP) were defined as vaccines and serum, anti-parasites (against internal and external parasites), antibacterial, vitamins and others. As illustrated in Figure 21, the anti-parasites group represented the most important VMP, accounting for up to 65 percent of the total annual expenditure. Surprisingly, vaccines and serum accounted only for 11 percent, which could be due to local production or less attention given to livestock immunization against major diseases or combination of both. The expenditures on veterinary drugs in Benin, Burkina Faso, Côte d'Ivoire, Ghana and Senegal, for which data was available, were estimated at 26.4 million USD in 2012. This data is not an exhaustive inventory and the figure could be much higher, if information from the remaining countries could have been available.

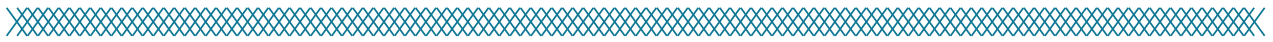

Figure 21. Proportion of veterinary drugs expenditures in selected West African countries ${ }^{26}$

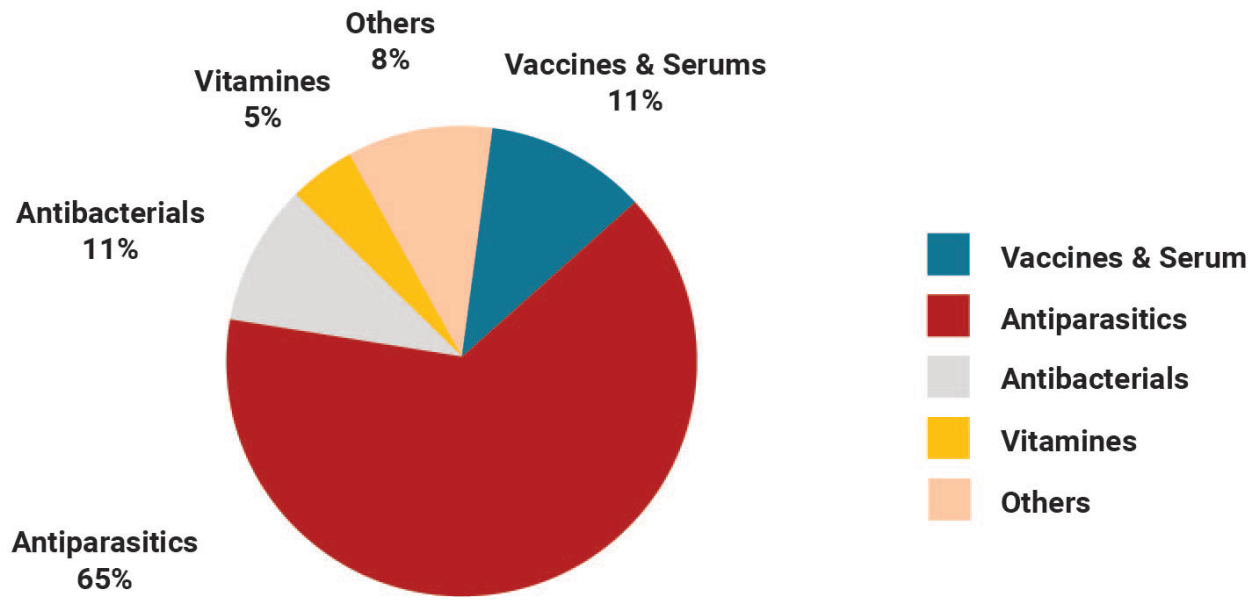

Source: Compiled from FAO/SFW livestock sector reviews (other sources may be involved).

\subsection{Human resources in the livestock sub-sector}

The FAO/SFW livestock sector reviews suggest that in West African countries there are over 9,000 people with livestock related qualifications working in the sub-sector (Table 14). Almost one third of them (close to 2,500) are animal scientists, including professionals with different level of training, working in the government services within the ministry in charge of livestock, in universities, in research centres or working for donor funded development projects, while fewer number of them are engaged in private businesses, NGOs or working as private consultants.

The total number of veterinarians in the region is 1,618 , most of them employed by governments to provide services to livestock owners and conduct veterinary regulatory work. Again, few of them are engaged in the private sector (i.e. private veterinary practice, consultancies, etc.). There are 5,067 veterinary technicians, the vast majority are government employees whose tasks, at field level, cover animal health, animal production and meat inspection. 
In addition to the above-mentioned, there are several veterinary para-professionals, also known as community animal health workers (CAHWs), in all countries of West Africa and particularly in those where the pastoralist system predominates. However, their exact number is unknown. In some countries, such as Senegal, they are officially recognized to execute veterinary duties under the supervision of a veterinary surgeon. In other countries, such as Nigeria and Ghana, training curriculums for CAHWs have been defined (Luseba, 2015). Despite their tremendous importance as links between livestock producers and veterinary services and their recognition by international organizations, they are mostly perceived as temporary agents.

Regardless of its incomplete nature, data presented in Table 14 indicates that the human resources available for providing services to the livestock sector in West Africa estimated at 103.44 million TLU is inadequate. As part of assessing the Performance of Veterinary Services (PVS), the missions undertaken by the OIE in many countries of West Africa (i.e. Niger, Burkina Faso, Mali, Côte d'Ivoire, Ghana, etc.) indicates the need for additional veterinarians and veterinary technicians to make the official veterinary service compliant with OIE recommended standards (OIE, 2019).

The numbers and distribution of livestock personnel and their level of training vary from country to country in West Africa. Acute shortages particularly in less developed and post-conflict countries, like Liberia and Sierra Leone are noticeable. These two countries are threatened by lack of qualified and experienced veterinarians and other livestock professionals. Very few new staff members are recruited at both provincial and national levels leading to increased number of ageing human resources in the livestock sub-sector. As a result, most positions become vacant when the long serving staff members retire. One of the main reasons for this is the lack of new graduates for hiring triggered by the lack of training institutions or at times due to reluctancy of trainees to undergo veterinary and livestock courses, even where offered scholarship. When young graduates become available, most of them do not want to take up public service jobs because of poor pay and working conditions. Most of them instead prefer to work with NGOs where salary is better than what is paid by the government (Kabasa, 2019).

According to OIE (2015), there are a total of 14 veterinary education establishments in West Africa, distributed in five countries: Benin (1), Ghana (2), Guinea (1), Nigeria (9) and Senegal (1). These institutions, in some cases, do not have adequate physical infrastructure (i.e. labs, lecture halls, staff and student's residence) and face shortage of funding and qualified teaching staff. This has created a vacuum in training veterinary students. Moreover, the loss of senior academics to better paying countries (brain drain) has implications in teaching, research quality and development of international partnership. This ultimately affects research output and ability of the veterinary teaching institutions in developing countries to came-up with innovate technologies for solving challenges in the animal industry (Kabasa, 2019).

\subsection{Financing the livestock sub-sector}

The Comprehensive Africa Agriculture Development Programmeme (CAADP) is a strategic framework to restore agricultural growth, endorsed in 2003 by African heads of state and governments at the Maputo Declaration on Agriculture and Food Security in Africa. As per the declaration, African Governments agreed to allocate at least 10 percent of their annual national budget to the agricultural sector, including the livestock sub-sector (NEPAD, 2003). However, the average budgetary resources spent on agriculture in the following years were below five percent (African Union Commission, 2014a). The African heads of state and governments renewed their commitment to CAADP at the meeting held in Malabo, Equatorial Guinea in 2014, which is known as the Malabo Declaration on 
Table 14. The number of personnel working in the livestock sub-sector in West Africa by category

\begin{tabular}{|c|c|c|c|c|c|}
\hline Country & Animal Scientists & Veterinarians & Lab Technicians & Vet Technicians & Total \\
\hline Benin & 63 & 52 & 11 & 595 & 721 \\
\hline Burkina Faso & 115 & 49 & NA & 434 & 598 \\
\hline Cabo Verde & NA & 20 & NA & 31 & 51 \\
\hline Côte d'Ivoire & 28 & 93 & NA & 360 & 481 \\
\hline Gambia & 7 & 4 & 3 & 64 & 78 \\
\hline Ghana & 116 & 150 & NA & 98 & 364 \\
\hline Guinea & 502 & 334 & NA & 408 & 1244 \\
\hline Guinea Bissau & 6 & 18 & NA & 77 & 101 \\
\hline Liberia & 4 & 2 & 1 & 0 & 7 \\
\hline Mali & 684 & 75 & NA & 963 & 1722 \\
\hline Niger & 200 & 60 & NA & 400 & 660 \\
\hline Nigeria & 720 & 680 & NA & 1360 & 2760 \\
\hline Senegal & 8 & 41 & NA & 207 & 256 \\
\hline Sierra Leone & 14 & 6 & 3 & 70 & 93 \\
\hline Togo & 17 & 34 & 7 & NA & 58 \\
\hline West Africa & 2484 & 1618 & 25 & 5067 & 9194 \\
\hline
\end{tabular}

Source: Compiled from FAO/SFW livestock sector reviews (other sources may be involved).

Accelerated Agricultural Growth and Transformation for Shared Prosperity and Improved Livelihoods. The ECOWAS Secretariat developed its own Regional Agricultural Policy for West Africa (ECOWAP) in 2005 for the implementation of CAADP (ECOWAS, 2008). However, budget allocation to the agricultural sector has only slightly increased in the region, despites the fact that the sector accounts for up to 35 percent of the region's GDP (AGRA, 2018). The public expenditure on agriculture from the total GDP in West African countries ranged from as low as 0.15 percent in Guinea-Bissau to 3.73 percent in Burkina between 2009 and 2012 (Shimeles, Verdier-Chouchane and Boly, 2018).

The information on budgetary allocation to the livestock sub-sector is not readly available in all West African countries. However, available information presented in Table 15 clearly indicates that the subsector is evidently underfunded, and huge funding gap has been identified in most countries. The information compiled from FAO/SFW livestock sector reviews, details the different components of the budget allocated to the livestock sub-sector, namely the portions for investment, expenditure on personnel and operational costs.

The analysis of this subset of the information indicates that an average annual total budget allocation (approved) for the livestock sector amounts to 184.3 million USD with a breakdown into 76.3 percent for investment in livestock development activities, 9.0 percent for staff charges and only 5.3 percent for operational cost. When this annual budget allocation is computed against the total TLU in the region, the result shows that an annual expenditure of only 1.78 USD/TLU. The available information also indicates that, only 11.4 percent of the budget for investment in livestock development comes from governments while the source of the bulk of the funding (88.6 percent) are financial and development partners. In general, the staff and operating costs of government services in charge of livestock are funded from national budget. Depending on the country and the year, a portion of up to 50 percent of this budget may not be released at all or released late making it difficult to use it before the end of the budget year, jeopardizing the functioning of livestock services. 
The government financing for the agricultural sector should clearly distinguish the share reserved for the livestock sub-sector from those allocated to other specific areas. This would reflect the political will to promote the development of the sub-sector and give visibility and transparency to the financial resources invested in. Some countries in West Africa have already given more importance to the livestock sub-sector by establishing specific ministerial institutions in charge of animal resources. However, the insufficient financial resources allocated to livestock activities continue to be a recurring problem and do not match the stated ambitions or the macroeconomic importance of a sub-sector with a recognized potential to reduce poverty and ensure food security in the region. In addition, making livestock financing readily available is still a bottleneck that needs to be addressed. This applies to both national and international financing institutions. In general, national financing institutions and banks refuse to take the risks of investing in livestock farming and the sub-sector has had a relatively little visibility in the funding granted by international institutions. The prevailing traditional animal production systems and the high vulnerability of livestock to external factors (i.e. diseases, drought, etc.) in the region, does not lend itself easily to financing (Kamuanga et al., 2008).

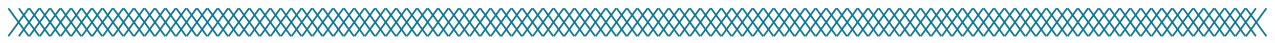

Table 15. The annual budget planned by and allocated to livestock departments in West African countries (in USD)

\begin{tabular}{|c|c|c|c|c|c|c|c|c|}
\hline Country & $\begin{array}{l}\text { National } \\
\text { Invest }\end{array}$ & $\begin{array}{c}\text { External } \\
\text { Invest }\end{array}$ & Total Invest & Staff & $\begin{array}{l}\text { Other } \\
\text { Charges }\end{array}$ & $\begin{array}{c}\text { Total } \\
\text { Approved }\end{array}$ & $\% \mathrm{GDP}^{27}$ & Total Released \\
\hline Benin & 860 & 9613 & 10473 & NA & 23304 & 33777 & 0.0004 & 16985 \\
\hline $\begin{array}{l}\text { Burkina } \\
\text { Faso }\end{array}$ & NA & NA & 31254450 & 5051147 & 667870 & 36973467 & 0.3311 & NA \\
\hline Cabo Verde & NA & NA & NA & NA & NA & NA & NA & NA \\
\hline $\begin{array}{l}\text { Côte } \\
\text { d'Ivoire }\end{array}$ & NA & NA & 5444000 & 4153000 & 3337000 & 12934000 & 0.0478 & 12934000 \\
\hline Gambia & 216667 & NA & 216667 & 42530 & 20710 & 279907 & 0.0307 & 64098 \\
\hline Ghana & 1465333 & NA & 1465333 & 1214050 & 1124228 & 3803611 & 0.0091 & 3224116 \\
\hline Guinea & NA & NA & NA & NA & NA & 9750000 & 0.1720 & NA \\
\hline $\begin{array}{l}\text { Guinea } \\
\text { Bissau }\end{array}$ & 804608 & NA & 804608 & NA & NA & 804608 & 0.0808 & NA \\
\hline Liberia & NA & NA & NA & NA & NA & 7000000 & 0.4033 & 7000000 \\
\hline Mali & NA & NA & 65287928 & 1993214 & 2485712 & 69766854 & 0.5607 & 69766854 \\
\hline Niger & 2400000 & 18694000 & 21094000 & NA & 987432 & 22081432 & 0.3181 & 19873197 \\
\hline Nigeria & NA & NA & NA & NA & NA & NA & NA & NA \\
\hline Senegal & NA & NA & 14807016 & 3907034 & 1056196 & 19770245 & 0.1408 & NA \\
\hline $\begin{array}{l}\text { Sierra } \\
\text { Leone }\end{array}$ & NA & NA & NA & NA & NA & 670500 & 0.0174 & NA \\
\hline Togo & NA & NA & 219221 & 149340 & 57912 & 426473 & 0.0110 & 405432 \\
\hline West Africa & 4887468 & 18703613 & 140603696 & 16510315 & 9760364 & 184294874 & 0.0306 & 113284682 \\
\hline
\end{tabular}

Source: Compiled from FAO/SFW livestock sector reviews (2010 - 2012). 


\section{OUTPUTS FROM THE LIVESTOCK SUB-SECTOR IN WEST AFRICA}
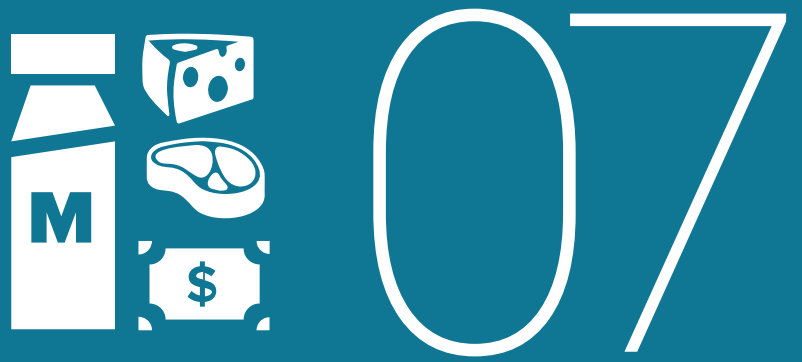



\section{ChAPTER VII \\ OUTPUTS FROM THE LIVESTOCK SUB-SECTOR IN WEST AFRICA}

\subsection{Overview on livestock products in the region}

The main animal products in West Africa are meat, milk, and eggs, as primary products. The secondary products include manure, traction power and processed animal by-products (i.e. hide and skin, wool, bone, blood, etc.). Milk and eggs generate stable income for livestock dependent households while meat, hide, skin or wool are sources of more sporadic income. However, meat is an important pillar in livestock economies for keeping cash in an inflation-proof way, and for generating different amounts of cash if needed (Sansoucy et al., 1995).

In traditional pastoralist settings, the majority of them consume milk and produce a range of dairy products, yet marketing of those commodities is often limited or restricted. Cultural taboos often weaken marketing opportunities of these products. However, despite their weak reach to the market, they can constitute a very important part of the pastoralist herd productivity (Hatfield and Davies, 2006).

The production data of the major animal products produced in West African countries in 2013 (Table 16) show how the ecological differences among countries influence the type and amount of animal product produced. The coastal countries with a more humid climate are more favorable to monogastrics (pigs and poultry) and show a relatively high meat and egg production. In contrast, dryland and pastoralistdominated countries with more number of cattle have a relatively higher milk production. More details on this will be given in section 7.2.1 below. 
Table 16. The amount of major animal products produced in West African countries in 2013

\begin{tabular}{|c|c|c|c|c|}
\hline Country & Meat (TM) & Bush meat (\%) & Milk (TM) & Hen Eggs (millions) \\
\hline Benin & 77446 & 10.3 & 41960 & 232.0 \\
\hline Burkina Faso & 198241 & 3.2 & 326818 & 1304 \\
\hline Cabo Verde & 5342 & NA & 10941 & 45.9 \\
\hline Côte d'Ivoire & 271751 & 53.4 & 31395 & 920 \\
\hline Gambia & 8068 & 16.1 & 9450 & 18.4 \\
\hline Ghana & 254721 & 29.2 & 40950 & 1000 \\
\hline Guinea & 86920 & 6.9 & 133540 & 700 \\
\hline Guinea Bissau & 26261 & NA & 23810 & 29.2 \\
\hline Liberia & 32760 & 24.4 & 845 & 111 \\
\hline Mali & 389816 & 6.3 & 1380308 & 403.7 \\
\hline Niger & 298780 & 9.2 & 1036000 & 235 \\
\hline Nigeria & 1464160 & 11.3 & 570000 & 144 \\
\hline Senegal & 195689 & 0.04 & 230465 & 519.2 \\
\hline Sierra Leone & 43743 & 8.3 & 29750 & 250 \\
\hline Togo & 68392 & 8.3 & 12825 & 200 \\
\hline West Africa & 3422081 & 14.0 & 3879057 & 20400 \\
\hline
\end{tabular}

Source: FAOSTAT, (2013).

\subsection{Meat and meat products}

In West African countries, the conventional animal species raised for meat production include cattle, sheep, goats, camels, pigs and poultry. Grasscutters, rabbits, ostriches, ducks, guinea fowl, turkeys and snails are non-conventional animals commonly used for meat production. A significant amount of population in coastal countries rely on "bushmeat" obtained through hunting. Livestock economies normally use small stock as cash buffer, as their smaller value makes them easier to sell and their faster reproductive cycle guarantees a quicker flock recovery. To the contrary, large animals work as capital reserve, because of their high value, longer reproductive cycle and the higher endurance of these animals.

\section{Amount produced}

The total annual meat production in West Africa is estimated at 3.4 billion $\mathrm{kg}$ (Table 16). Each year large numbers of cattle, sheep, goats, pigs and chicken are slaughtered at designated abattoirs, slaughterhouses or slaughter slabs to produce meat for public consumption. Slaughter may also take place at home or at an outdoor slaughter facility designated for religious and cultural practices. Very rarely, carcasses of animals slaughtered at home or other facilities for cultural or ritual purposes are inspected by veterinary public health officials and therefore are missed from official records. At official abattoirs and slaughterhouses both ante-mortem and post-mortem inspections are carried out to ensure that the meat is fit for public consumption. Here records for the number of animals slaughtered, lesions observed as well as number of carcasses and organs unfit for human consumption removed from food chain are kept. The statistics on meat production are therefore based either on data regularly collected at public facilities by appropriate government services. When such records are used for estimating the amount of meat produced, an estimated production from unofficial slaughters (slaughter at home plus those slaughtered outside of designated slaughter slabs) are also incorporated. At times, 
the meat production figures are computed using national off-take rates, number of animals estimated and average carcass weight for the species. As discussed in Chapter II, in West Africa a wide variety of animal breeds with different body size are raised. Among the major meat producing conventional animal species (cattle and small ruminants), Sahelian zebu breeds and European crossbred animals are much larger in size, with carcass weight ranging between 125 and $150 \mathrm{~kg}$, as compared with Bos taurus type breeds, with carcass weight of $100 \mathrm{~kg}$ or less $^{28}$. Similar comparison can be made between Sahelian sheep and goats and West African dwarf types. As for poultry, the national off-take rates range from the lowest of 9.6 percent to 100 percent in the broiler industry (Gueye, 2012; Bakayoko, 2012; Akunzule, 2013 and Touray, 2012).

Significant differences exist in terms of species used for meat production between Sahelian and coastal countries of West Africa (Table 17). While cattle are important in the entire region, they are much more relevant in dryland Sahelian countries. Goats are also much more important in dry areas. Both species show the adaptability of ruminants to areas where low-quality fodder is dominant and where transhumant practices make economic sense.

On the other hand, while poultry is also important in the entire region, its relevance is more marked in coastal countries. To a lesser extent, the same trend is observed for pigs. This corresponds to a more humid setting where backyard production systems dominant and where monogastrics take advantage of feeding on crop residues ${ }^{29}$.

The importance of bushmeat is very noteworthy for coastal countries, being the main meat source and supplying almost a third of the demand for meat in these countries. The reasons for this dominance are probably emanates from historical tsetse fly infestation of the coastal areas, making livestock production difficult, the culture which continued even after the control of this vector in many parts. The strong tradition for bushmeat and the relatively late introduction of poultry and pig are due to the abundance of forests that constitute good hunting grounds (Luiselli et al., 2017).

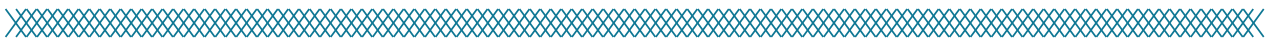

Table 17. The proportion of meat produced per species and per AEZ in West Africa ${ }^{30}$

\begin{tabular}{|c|c|c|}
\hline Area & Species & Total production (percent) \\
\hline \multirow[t]{4}{*}{ Sahel } & Cattle & 42.0 \\
\hline & Chicken & 15.3 \\
\hline & Goats & 15.1 \\
\hline & Sheep & 10.9 \\
\hline \multirow[t]{4}{*}{ Gulf } & Game & 31.5 \\
\hline & Chicken & 24.1 \\
\hline & Cattle & 21.3 \\
\hline & Pigs & 9.6 \\
\hline \multirow[t]{4}{*}{ Whole sub-region } & Cattle & 30.7 \\
\hline & Chicken & 15.8 \\
\hline & Goats & 15.3 \\
\hline & Game & 14.2 \\
\hline
\end{tabular}


However, there are twofold negative implications of this strong game meat consumption. These are, firstly, the chances for the spread of epizootic diseases such as the recent Ebola Virus Disease (EVD) outbreak highlight the food safety issues surrounding this type of consumption (FAOSTAT, 2013). Secondly, the unsustainability of such a practice, especially in a context of demographic expansion and need for conservation of bio-diversity, which is at stake. In both cases, the promotion of livestock production with adapted species can both increase food safety and reduce environmental impacts while guaranteeing the provision of animal protein. Alternatively, the production of non-conventional animals such as grasscutters, (see Box 1) with the taste close to bushmeat and culturally acceptable can reduce the pressure on wild life. In recent years, grasscutter farming is expanding in West Africa with the successful implementation of the Project Benino Allemand d'Aulacodiculture in Benin where some farmers produce up to 7,000 animals (Ntiamoa-Baido, 2016). Grasscutter farms are also operating in Ghana and Cote d'Ivoire.

\subsubsection{Monetary value of meat}

Most of the meat produced in West African countries is sold by weight in kgs. The prices vary from country to country and even from place to place in a specific country. Likewise, meat of different species fetch different prices. Having said that, the price used for computing the estimated total monetary value of meat produced in the region is based on average selling price in each country. The volume of meat produced in West African countries was obtained from records of animals slaughtered in 2011 or 2012. Table 18 present the value of annual meat produced on local market in the different countries of West Africa. Accordingly, the monetary value of annual meat production in the region is estimated at USD12.3 billion.

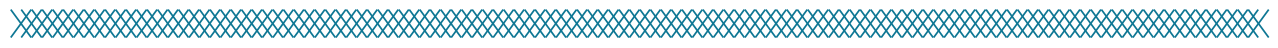

Table 18. Monetary value of annual output of the major livestock products in West Africa ${ }^{31}$

\begin{tabular}{|c|c|c|c|c|c|}
\hline Country & $\begin{array}{l}\text { Meat value (million } \\
\text { USD) }\end{array}$ & $\begin{array}{l}\text { Milk value (million } \\
\text { USD) }\end{array}$ & $\begin{array}{l}\text { Egg value (million } \\
\text { USD) }\end{array}$ & $\begin{array}{c}\text { Country total (million } \\
\text { USD) }\end{array}$ & GDP (\%) \\
\hline Benin & 396 & 32.2 & 47.9 & 475.6 & 5.9 \\
\hline Burkina Faso & 1030 & 250.6 & 229.6 & 1,510 & 13.5 \\
\hline Cabo Verde & 36.4 & 18.0 & 11.1 & 65.5 & 3.7 \\
\hline Côte d'Ivoire & 430.4 & 24.1 & 176.0 & 630.4 & 2.3 \\
\hline Gambia & 16.8 & 5.3 & 3. 6 & 25.7 & 2.8 \\
\hline Ghana & 366.5 & 31.4 & 159.1 & 557.0 & 1.3 \\
\hline Guinea & 124.2 & 102.4 & 93.7 & 320.3 & 5.7 \\
\hline Guinea Bissau & 110.2 & 18.3 & 5.4 & 133.8 & 13.4 \\
\hline Liberia & 96.00 & 0.6 & 20.1 & 116.7 & 6.7 \\
\hline Mali & 2226 & 1397 & 89.7 & 3713 & 29.8 \\
\hline Niger & 482.4 & 794.4 & 33.3 & 1310 & 20.4 \\
\hline Nigeria & 6028 & 437.1 & 2487 & 8957 & 1.9 \\
\hline Senegal & 432.7 & 168.7 & 75.3 & 676.7 & 4.7 \\
\hline Sierra Leone & 185.8 & 22.8 & 45.8 & 254.4 & 6.6 \\
\hline Togo & 341.7 & 9.8 & 38.3 & 389.8 & 10.1 \\
\hline West Africa & 12303 & 3313 & 3516 & 19131 & 3.2 \\
\hline
\end{tabular}

Source: FAOSTAT, (2013).

${ }^{31}$ Derived from production and price data from 2011 and/or 2012. Some unavailable price data were extrapolated from prices from neighbouring countries or from similar products. Bush meat is excluded from this analysis. 
Meat contributes to the bulk of livestock products' monetary value in most countries of the region. This confirms the importance of livestock as a capital asset in the region's agricultural economy and the ease of converting it into cash. It should be noted, though, that meat is more easily captured into statistics than other livestock products, so its importance tends to be somehow overvalued (Hatfield and Davies, 2006).

\subsubsection{Trends in meat production in recent years}

In order to conduct trend analysis, serial data for meat production over a given period of time is required. Serial data gathered through the FAO livestock sector reviews during 2009/2010 and 2011/2012 is not long enough for trend analysis, in addition to same gaps in the dataset. Hence, an illustration of meat production trend was carried out using total meat data from FAOSTAT over the period of years 2002-2013 for the West African subregion (Figure 22). As the figure shows, meat production increased constantly over the 2002-2009 period. Then an important increase to its peak of 46.4 million TDM was observed in 2010 and a drop in 2011. The drop in meat production in 2011 is related to the drought experienced in that year, which mainly affected pastoralist communities in Sahelian countries (IUCN, 2012). On average, an increasing pattern of meat production at a yearly rate of 896,000 TDM was observed during the 11 years between 2002 and 2013.

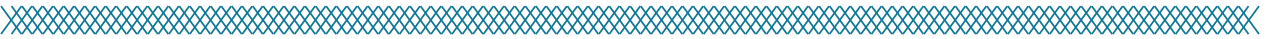

Figure 22. Meat, milk and egg production trends in West Africa.

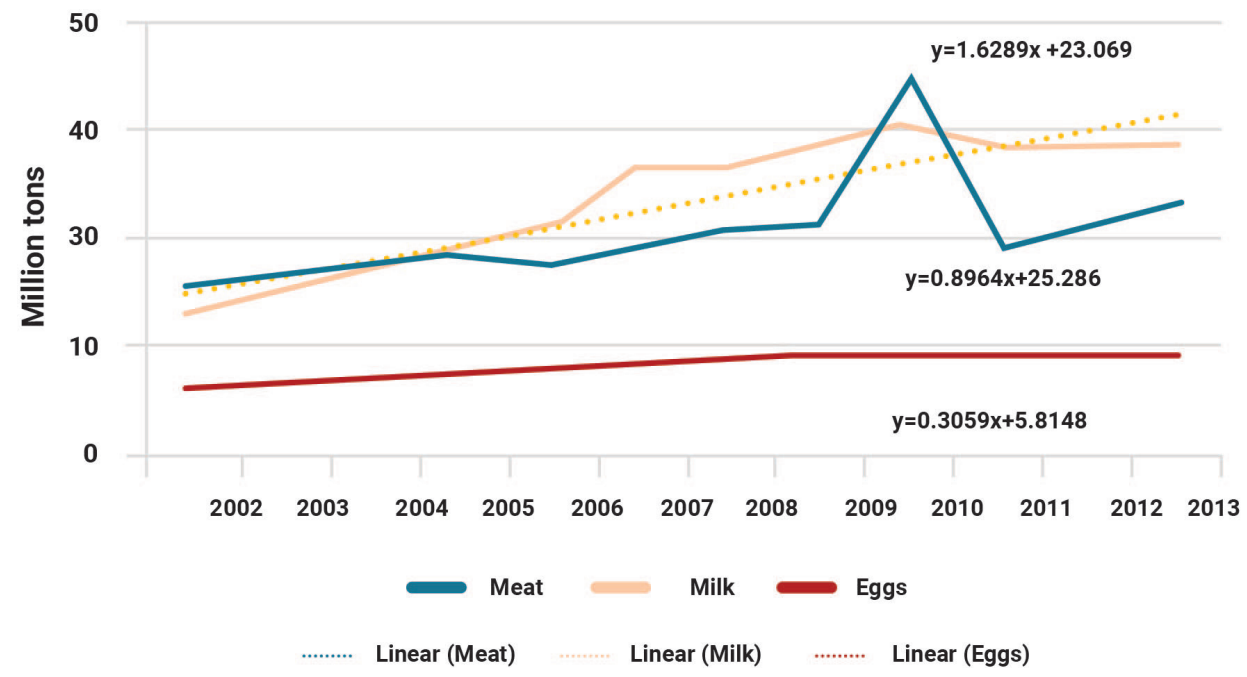

Source: FAO, (2013).

\subsection{Milk and dairy products}

Together with eggs, milk and dairy products tend to be the main source of protein for the livestock producer households in West Africa. In remote settings these products are difficult to sale. Furthermore, the taboos surrounding their marketing, at times linked to ensuring the nutrition of children, (cf. sections 7.1 \& 10.4.1), undermine opportunities for income. The collection and transformation of milk is a traditional role of women. Therefore, initiatives stimulating marketing ventures for milk and dairy products have the opportunity to increase women's empowerment. However, they should be very carefully planned in order to ensure the nutrition objective of children and local communities. 


\subsubsection{Amount of milk produced}

There are several challenges making it difficult to know the amount of milk produced in West African countries. Some of these challenges include the well-established practices of barter trade within communities, the preferential use of milk for children, the high milk production in remote areas during rainy season with abundant pasture where marketing becomes difficult, and the lack of a wellestablished recording system. Additionally, the farmers are not necessarily interested in collecting data, not even for evaluating the productivity and efficiency of their own herds. The governments either lack incentive or means to establish such programme, or even pilot projects whose results could have been extrapolated ${ }^{32}$.

Another complicating factor is the manual milking, which is a common practice. In manual milking, the ultimate decision on whether to milk or not, frequency of milking or how much milk to take off the lactating cow and how much milk to leave for the calf rest with the person milking. Hence, the person milking ultimetly takes decisions which heavly influence milk off-take. This factor introduces biases representing a major difficulty when comparing or compiling milk off-takes from different sources (i.e. herds, production systems and countries). A further major source of variation that must be controlled when doing comparison in such data is the dependency of lactation on calf viability.

The different breeds used for milk production reflect the different production systems. In traditional systems, the indigenous livestock breeds tend to be multi-purpose and milk and meat productions compete (de Besi ans Thieme, 2013). Hence, the milk yield is not that high. The pastoralist systems have developed their own breeds, which are well adapted to the local environment, of which the Maure, Wadara, Bunaji or Fulani cattle, Fulani or Touabire sheep, or the Sahelian goat are good examples. Further south, in crop livestock mixed farming systems, the Gudali and N'dama cattle, Djallonke sheep and Maradi goat breeds have better adaptation to the environment. More information on production levels of these breeds has been provided in Tables 5 and 6 .

Regarding the introduction of exotic breeds to tropical areas, productivity becomes a challenges due to the dramatic need of the animals to disperse heat (Berman, 2011 and Mwai et al., 2015). The following example from different dairy cattle breeds illustrates the challenges better. While better performing breeds such as Wadara or Gudali manage yields of $4.7 \mathrm{Kg}$ (DAGRIS, 2007) and $5.2 \mathrm{~kg}$ of milk per day (Olorunnisomo, 2013) respectively under best local conditions, crosses with high-productive breeds such as Friesian manage just up to $6.7 \mathrm{~kg}$ of milk per day under similar conditions (Buvanendran et al., 1981). This contrasts with the manifold higher performance in temperate areas. Given their higher sensitivity to ticks, insects and to poor fodder quality or climatic stress, the convenience of intervening the local genetic stock should be critically assessed ${ }^{33}$.

The total milk production in West Africa for 2013, (FAOSTAT, 2013), is estimated to be 3.9 billion $\mathrm{kg}$, or a milk availability of 11.4 litres per capita, for the region. While most of the milk consumed is cow milk ( 50.9 percent of the total), goat milk is very relevant (30.3 percent of the total) and is even more relevant than cow milk in semi-arid areas (68.7 percent in Cabo Verde, 52.2 percent in Mali). Camel milk is only important in the driest countries (17.6 percent in Mali and 10.1 percent in Niger). These trends illustrate the importance of milk from different species for pastoralist. 


\subsubsection{Monetary value of milk}

The bulk of milk production in West Africa comes from the extensive pastoral system composed of some 48 million agropastoralists (Glo.be, 2019), where a good portion of milk produced is earmarked for family consumption or barted inside the community and serves for social ties and relationships. The remaining fresh milk is processed into various dairy products by pastoral women utilizing simple traditional methods (often labour-intensive and energy consuming) to produce sour milk, yoghurt, butter and cheese. These products are usually sold in the homestead or nearby markets and the proceeds are at the disposal of the women. More income is derived from the sale of sour milk, yoghurt, butter and cheese than from raw milk sale. However, it is difficult to capture and record such income and include in such publication. A rather small portion of milk produced by semi-intensive and intensive peri-urban dairy farms is sold as raw milk to milk processing entities (Salla, 2016).

The estimated monetary values of annual milk production in West Africa as reported in the FAO livestock sector reviews 2009 - 2013 is 3.3 billion USD (Table 18). It should be noted that milk has a relatively stronger importance in the Sahelian countries, reflecting the relevance in pastoralist economies. The most significant case is Niger, the driest country in the region together with Mali, where the value of milk production exceeds the one of meat and egg production combined.

\subsubsection{Trends in milk production in recent years}

In West Africa, the trend of milk production in recent years has experienced a steady increase. The result from analysis conducted using data from FAOSTAT over the period 2002-2013 show almost similar trend with that of meat. The only difference when the two are compared is the milder decreasing trend of milk production in 2011 after the peak in 2010. There are two explanations for this: primarily, pastoralist population which severely affected by the drought, are more dependent on milk. However, the market is unable to capture the production level, as explained earlier. As pastoralists use the market much more to commercialize meat, this is the sub-sector where the impact was more visible. Secondly, the incipient industrial milk production in the coastal countries of the region, using high-performing mixed breeds, could have partially masked the decrease in production in areas further north. As the West African region is periodically subjected to droughts ${ }^{34}$, it is important to analyze such complex situation by taking in to account various factors.

The trends of milk production was analyzed in detail for selected West African countries and the result presented in Figure 23. The result shows that an increasing trend in production in Benin at a rate about 11.6 million TDM per year and in Senegal at a rate about 950000 TDM per year over the period of 20022013. In Côte d'Ivoire and Gambia, milk production increased but at much smaller rate yearly over the same period of time. For the trend in the entire region, Figure 22 shows an increasing pattern, reaching its peak of 40.4 million TDM of milk in 2010. The annual production growth rate is $1,629,000$ TDM of milk.

\subsection{Eggs}

The egg production in West Africa is dominated by backyard production system. Combined with the very important broiler production in the region, they provide a stable, albeit reduced, income for the producers. The egg production is also a key source of micronutrients and protein for the households. There are no religious or cultural taboos related to poultry production or consumption of meat or eggs, positive factor contributing to their potential expansion. Given that poultry is the most characteristic species of backyard system in the region, egg and poultry meat production guarantee a good recycling system of the agricultural waste, especially in the more humid countries. 


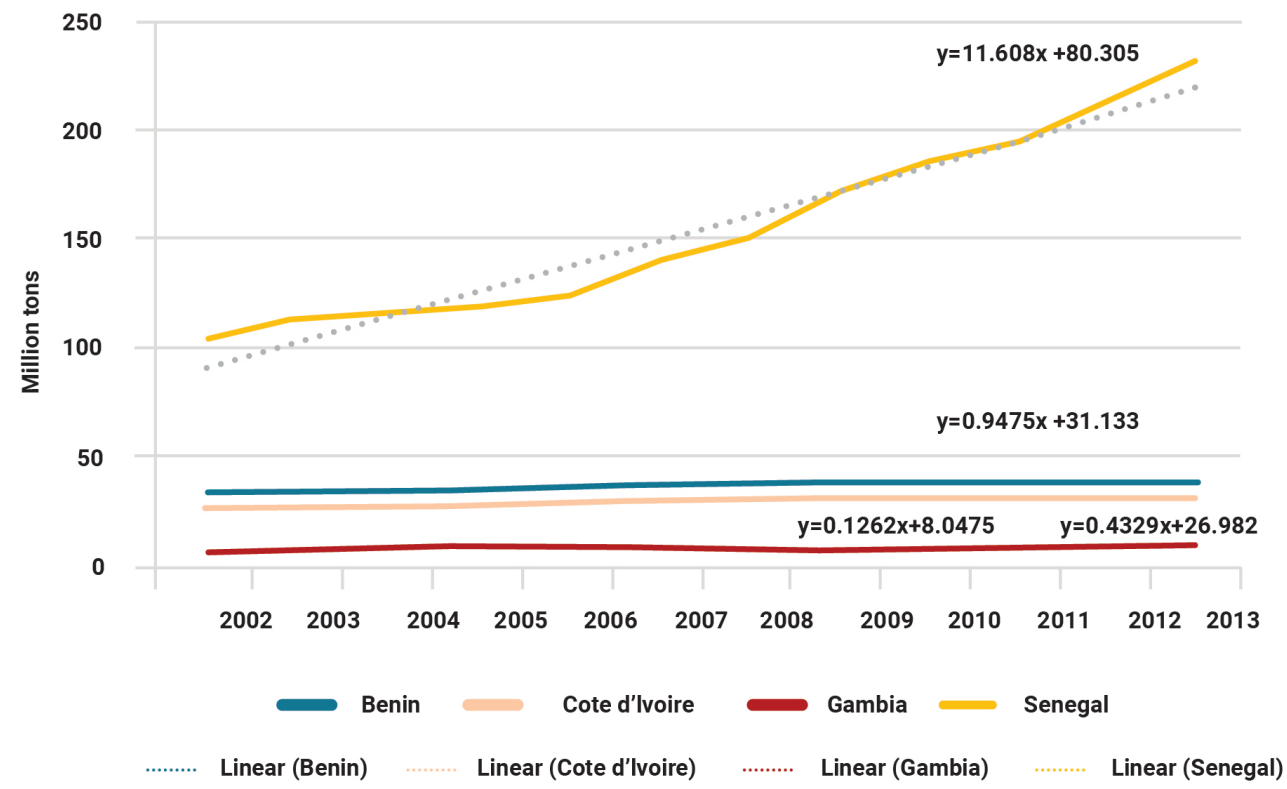

Source: FAOSTAT, (2013).

\subsubsection{Amount produced}

The poultry population of West Africa was estimated at about 560 million birds in 2017 (FAOSTAT, 2019), the bulk of which is made up of chicken, the main table egg producing fowl in the region. The birds are reared mainly in backyard, low-input system or in a growing peri-urban modern sub-sector. The backyard system uses native, less productive breeds and is not really geared toward commercial egg production. The farmers breed poultry mostly for white meat production. In the peri-urban intensive system, three products are targeted: eggs, broiler and DOC. Amog these, the layer and broiler industries are more developed than the DOC, which can be also considered as an input to the former two industries. The DOC operations of parent breeders are not common in all the countries in West Africa, as most of them are still importing the bulk of their DOC or fertilized eggs from outside the region (Bakayoko, 2012; Touray, 2012; Akunzule, 2013 and Gueye, 2012).

The availability of production data depends much on the production system. In the backyard poultry production system, as in any other extensive systems, there is no established systematic record keeping on operations, especially on the number of eggs produced, considered as intermediate products for the system. There is a more solid record concerning the weaned chicks that are sold (or slaughtered, rarely, for family consumption) between weaning and twelve months of age. Hence, egg production is an estimate-based bio-economic data of the flock, as established by research.

In the modern intensive peri-urban or urban farms, data recording is pretty much under control as one of the best practices and is in fact the bedrock of the success and sustainability of intensive farming systems where the level and nature of inputs are high. Hence, the number of eggs, broilers and DOCs produced are recorded and known precisely. 
The information on the production of broiler has been already provided while dealing with meat production ${ }^{35}$. Hence, this section focuses only on table eggs. The average amount of eggs produced annually in West African is estimated at 20.4 billion eggs. This roughly show that about 58 eggs are available per capita per year in the region.

Despite its crucial importance for the poultry industry as a whole, few countries in West Africa are actively engaged in DOCs production. Hence, this section reports only activities in those few countries. The production of DOCs in Côte d'Ivoire, Gambia, Ghana and Senegal amounts to a total of 50 million chicks (Table 19), 21 percent of which were chicks to become future layers, 71 percent for broilers and 8 percent for cockerels. The DOC production is used locally or exported to countries within the region.

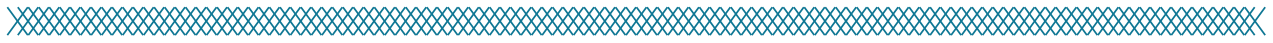

Table 19. The amount of Day-Old-Chicks produced in selected West African countries

\begin{tabular}{|l|r|r|r|r|}
\hline Country & \multicolumn{1}{|c|}{ Layer DOC } & Broiler DOC & Cockerel DOC & Country total \\
\hline Côte d'Ivoire & 4200000 & 15779000 & NA & NA \\
\hline Gambia & 4500 & 36831 & 41331 \\
\hline Ghana & 4183686 & 796916 & 4113706 & 909308 \\
\hline Senegal & 2105113 & 18810943 & NA & 20916056 \\
\hline
\end{tabular}

Source: Bakayoko, (2012), Touray, (2012); Akunzule, (2013) and Gueye, (2012).

\subsubsection{Monetary value of eggs}

The total monetary value of eggs produced annually in West Africa is estimated at 3.5 billion USD (Table 20). The calculations are based on local markets prices in the different countries where in the majority of cases, eggs are sold in crates containing 30 eggs. The price range of such crates of 30 eggs goes from USD 3.50 to 7.80 which is equivalent to USD $0.12-0.26$ per egg.

The total monetary value of annual DOC production is estimated at 50.6 million USD, a relatively reduced amount compared with the value of the total egg production. The DOC monetary value information is for the few countries which managed to set up industrial facilities to produce them listed in Table 20. It should be noted that most of the DOC are imported, which has negative consequences on the longevity and quality of the birds. Local DOC production takes place in incipient industrial facilities that operate well below their capacity (FAO, 2014). The operating costs of the local industry become expensive due to reliance on imported fodders and other inefficiencies, which need to be tackled (Tiémoko, 1992).

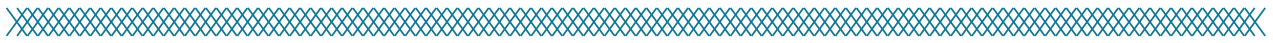

Table 20. The monetary value in USD of Day-Old-Chick production in selected West African countries in 2011.

\begin{tabular}{|l|r|r|r|r|}
\hline Country & \multicolumn{1}{|c|}{ Layer DOC } & Broiler DOC & Cockerel DOC & Country Total \\
\hline Côte d'Ivoire & 5628000 & 15463420 & NA & NA \\
\hline Gambia & 4408 & 46662 & 51070 \\
\hline Ghana & 5271444 & 1171467 & 1871736 & 8314647 \\
\hline Senegal & 2820851 & 18434724 & NA & 21255575 \\
\hline
\end{tabular}

Source: Bakayoko, (2012), Touray, (2012); Akunzule, (2013) and Gueye, (2012). 


\subsubsection{Trends in production}

As mentioned earlier, the records on egg production are scarce and when available incomplete in most of the West African countries. As this makes trend analysis difficult, data from FAOSTAT was used to illustrate egg production pattern over the years in the region (Figure 43). The result shows a steady increase of egg production by an average of 306000 eggs per year in the region throughout the period of 2002 - 2011.

\subsection{Other animal products}

The other major animal outputs in West Africa include hide and skin ${ }^{36}$, manure and draft power. These are considered secondary outputs to those discussed in earlier section and their statistics are rarely recorded and reported in any country of the region.

The statistics of hide and skin production is generally derived from the annual off-take rate of cattle and small ruminant. Indirect estimates of the number of hide and skin production available at FAOSTAT (Table 21) show that the region has significant production of skin, 80.95 million and hide, 323 million $\mathrm{kg}$ in 2013. Both hide and skin constitute valuable resource of revenue for countries that could probably be further exploited. The required improvement include increased productivity per animal and improved processing that yields better quality (TLC, 2002 and Leach and Wilson 2009). Under current export prices of about 0.6 USD per $\mathrm{kg}$ of fresh skin (FAOSTAT, 2013), equivalent to wet salted skin (TLC, 2002), the monetary value of the hide and skin production in West Africa reach around 200 million USD. Although this figure is well below the value of primary livestock products described in Table 18, it is significant in terms of international trade (Table 29).

The secondary outputs of the livestock sub-sector, i.e. manure, traction power and transport, mainly serve the crop sub-sector. However, there is no adequate reference which enabels meaningful analysis on the amount produced and estimate the monetary value of these secondary outputs (Hatfield and Davies, 2006 and Krätli, 2014).

以

Table 21. The amount of hide and skin produced in West Africa in 2013

\begin{tabular}{|c|c|c|c|c|c|c|}
\hline \multirow[t]{2}{*}{ Country } & \multicolumn{2}{|c|}{ Cattle hides } & \multicolumn{2}{|c|}{ Goat skins } & \multicolumn{2}{|c|}{ Sheep skins } \\
\hline & tons & thousands & tons & thousands & tons & thousands \\
\hline Benin & 5130 & 285 & 981 & 545 & 567 & 315 \\
\hline Burkina Faso & 12081 & 671 & 6947 & 3308 & 3652 & 1660 \\
\hline Cabo Verde & 85 & 3 & 1050 & 100 & 1525 & 3 \\
\hline Côte d'Ivoire & 5,300 & 294 & 250 & 420 & 10 & 610 \\
\hline Gambia & 434 & 31 & 94 & 78 & 48 & 40 \\
\hline Ghana & 2538 & 175 & 4248 & 1699 & 2169 & 1205 \\
\hline Guinea & 9900 & 600 & 1307 & 726 & 1120 & 560 \\
\hline Guinea Bissau & 1525 & 61 & 322 & 134 & 305 & 122 \\
\hline Liberia & 182 & 9 & 234 & 117 & 246 & 85 \\
\hline Mali & 26000 & 1300 & 11120 & 5560 & 11948 & 4120 \\
\hline Niger & 28560 & 1428 & 8840 & 4420 & 4576 & 2,288 \\
\hline Nigeria & 62000 & 3100 & 46600 & 23300 & 32000 & 16000 \\
\hline Senegal & 10982 & 439 & 3,905 & 1562 & 7430 & 1886 \\
\hline Sierra Leone & 2408 & 112 & 650 & 224 & 354 & 177 \\
\hline Togo & 1413 & 79 & 650 & 650 & 855 & 450 \\
\hline West Africa & 168538 & 8588 & 87198 & 42843 & 66805 & 29522 \\
\hline
\end{tabular}

122 The role of livestock in food security, poverty reduction and wealth creation in West Africa 
TRADE IN LIVE ANIMALS AND ANIMAL PRODUCTS IN WEST AFRICA
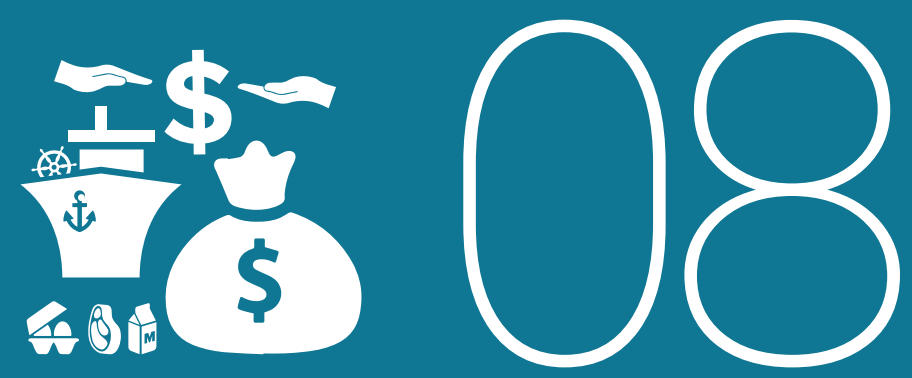



\section{ChAPTER VIII \\ TRADE IN LIVE ANIMALS AND ANIMAL PRODUCTS IN WEST AFRICA}

\subsection{Current demand and consumption of animal products in West Africa}

In West Africa, as in most parts of the world, trade is greatly dictated by the local demand and consumption pattern of animal products. These in turn are influenced by physiological and ecological requirements, eating habits, price of and availability of products and the purchase power of households. The per capita consumption of meat and dairy products is higher in urban than in rural areas because of higher income in cities and towns. In many West African countries, the amount of animal products available for consumption is made up of domestic production and imports. The region as a whole is not self-sufficient in most animal products. The coastal countries, especially, are net importers of these commodities. Furthermore, data is not available on how much animal products are wasted due to postproduction loss or not consumed within the region.

Animal products have an important role in preventing malnutrition. Although the specific protein needs of individual vary from person to person based on many factors, the FAO's livestock division recommends a daily intake of $20 \mathrm{~g}$ protein per person per day. This translates to a yearly intake per adult of either $33 \mathrm{~kg}$ of lean meat, $45 \mathrm{~kg}$ of fish, $60 \mathrm{~kg}$ of eggs or $230 \mathrm{~kg}$ of milk (FAO, 2019b). The lack of Vitamin B12, an essential component in diet of exclusively animal origin, has also shown to cause widespread malnutrition and disease in sub-Saharan Africa (Stabler and Allen, 2004). A minimum of animal protein is particularly suited to cover these and other nutrient needs, especially among children or pregnant women (Bender, 1992; Neumann, Harris and Rogers, 2002 and Abubakari and Jahn, 2016). The malnutrition due to micronutrient deficiency is a widespread problem than malnutrition due to protein and energy deficiency. Animal products such as eggs are excellent sources of 13 essential micronutrients (i.e. choline, biotin, riboflavin, vitamin B12, pantothenic acid, vitamin A, folate, vitamin $E$, vitamin $\mathrm{D}$, calcium, magnesium, sodium, phosphorus, potassium, and zinc), in addition of being a source of high-quality protein (Lora et al., 2017) 
The per capita consumption of major livestock products in West Africa was calculated by adding the amount of animal products produced in the countries to the imported amount and substracting the amount exported. The result shows that the per capita consumption of animal products is well below the above-mentioned standards (Figure 24), with the exception of Cabo Verde. The average regional per capita consumption of meat and meat products (including fat and offal) stands at $12.4 \mathrm{~kg}, 12.7 \mathrm{~kg}$ for milk and dairy products (butter, cheese, etc.) and $2.9 \mathrm{~kg}$ for eggs. As a result, West Africa is one of the regions with low consumption of animal products in the world, which may indicate possible malnutrition (FAO, 2019b).

\section{У}

Figure 24. Per capita consumption of major livestock products in West Africa

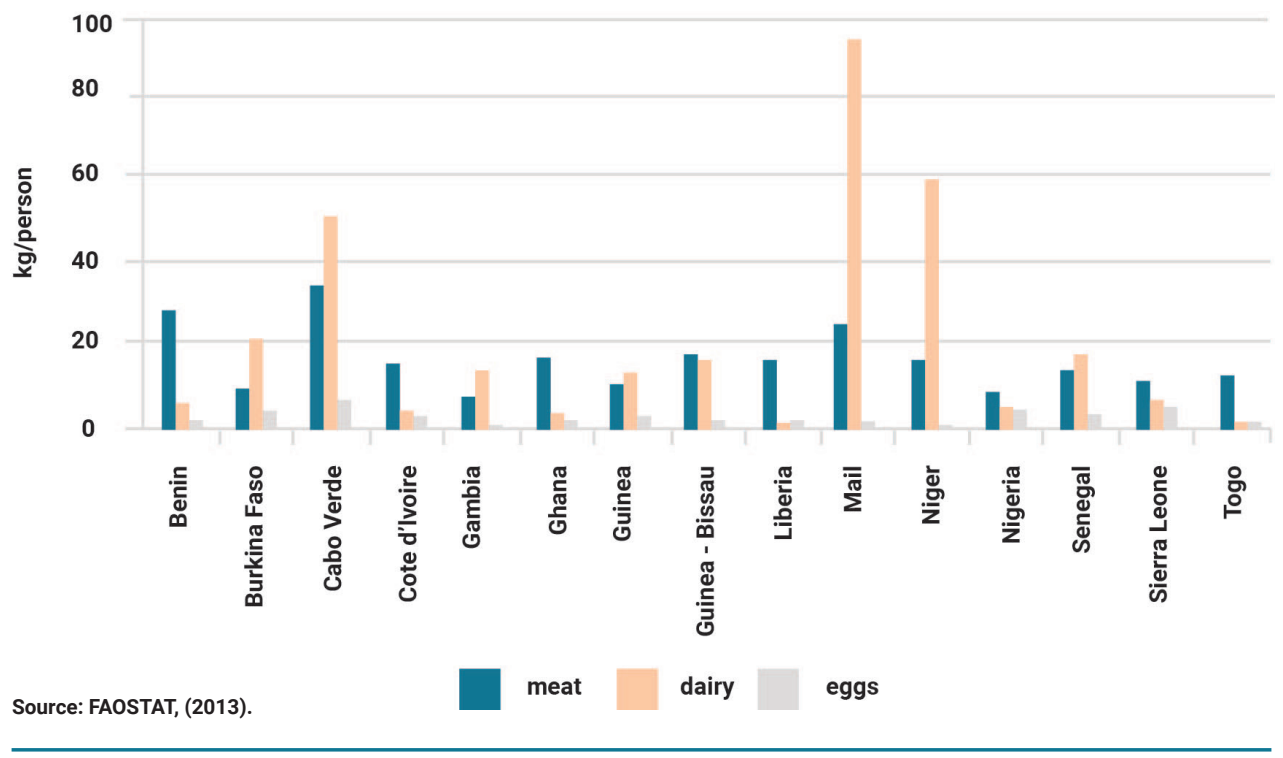

The above-mentioned per capita consumption translates into a total demand of about 4.1 million TDM of meat, 4.2 million TDM of milk and 0.9 million TDM (equivalent to 20.7 billion eggs) for West Africa. Table 29 illustrates the annual animal product demand in individual countries for 2013. Product demands were highest for meat (1.5 million TDM) and for eggs (0.65 million TDM) in Nigeria and for dairy (1.4 million TDM) in Mali. To meet these demands, domestic production (Table 23) is insufficient in most countries. Huge amounts of products have to be imported to bridge the gap. The difference to be imported is 640 thousand TDM for meat, 290 thousand TDM for dairy and 12 thousand TDM for eggs. This demand by itself can fuel important trading activities between the West African countries and those outside the subregion, notwithstanding the trade created by the different transformation industries in the region and the specific needs for transformed products.

The ECOWAS region has one of the fastest human population growth rate, i.e. 2.7 percent per annum, ranging between 1.5 percent in Cabo Verde and 3.8 percent in Niger. As a result, the population of West Africa estimated to be 327 million in 2013 is projected to grow to 449 million in 2025 and to 805 million in 2050. To this, one has to add the rapid urbanization in the region and the steady growth of middle-income population segment (Allen, Heinrigs and Zoundi, 2015). These are indicators that the current high demand for animal products will increase further more in the coming years in West Africa. For example, it was estimated that milk consumption is likely to triple by 2050 in Sub-Saharan Africa (Herrero et al., 2014). The same study projected that the consumption of meat and eggs will grow six to seven folds in West Africa by 2050. 
Table 22. The demand for major animal products in West Africa.

\begin{tabular}{|c|c|c|c|}
\hline Country & Meat (TDM) & Dairy (TDM) & Eggs (TDM) \\
\hline Benin & 264782 & 48535 & 12544 \\
\hline Burkina Faso & 198542 & 344133 & 60042 \\
\hline Cabo Verde & 17,353 & 25850 & 2615 \\
\hline Côte d'Ivoire & 346263 & 47341 & 46165 \\
\hline Gambia & 11899 & 23268 & 1452 \\
\hline Ghana & 481402 & 66478 & 41857 \\
\hline Guinea & 103245 & 143935 & 24513 \\
\hline Guinea Bissau & 27588 & 26970 & 1400 \\
\hline Liberia & 67347 & 4213 & 10999 \\
\hline Mali & 399916 & 1388931 & 24358 \\
\hline Niger & 301360 & 1048356 & 9439 \\
\hline Nigeria & 1489831 & 716082 & 650674 \\
\hline Senegal & 205464 & 242659 & 26872 \\
\hline Sierra Leone & 63321 & 29750 & 15212 \\
\hline Togo & 83793 & 11134 & 10000 \\
\hline West Africa & 4062106 & 4167635 & 938142 \\
\hline
\end{tabular}

Source: FAOSTAT, (2013) Meat products include fat and offals. Dairy products include milk and derivatives (butter, cheese, etc.).

\subsubsection{Meat and meat products}

In general, meat is considered to be the most important source of animal protein in West Africa. The meat consumption trend (including beef, mutton, goat meat, pork, poultry, camel, rabbits and grasscutters) show similar pattern among countries. The highest meat consumption is recorded in Cabo Verde and Mali, with $34.8 \mathrm{Kg}$ and $26.1 \mathrm{~kg}$ per person per year, respectively. Gambia $(6.4 \mathrm{~kg})$, Nigeria $(8.6 \mathrm{~kg})$ and Guinea $(8.8 \mathrm{~kg})$ are among countries with the lowest consumption of meat in the region.

Regarding the type of meat consumed, trends follow the same pattern as in production. The ruminant meat is consumed more in Sahelian countries ${ }^{37}$ while pork is a preferred meat type in Portuguesespeaking countries (Cabo Verde and Guinea Bissau). The consumption of bushmeat, much of it sourced from grasscutters ${ }^{38}$, is very relevant in the region (Table 23), particularly in the coastal countries. Unlike for tropical South America, where there is specific data on Guinea pigs in FAOSTAT, lack of this for West Africa, including in national statistics, mask the importance of this species ${ }^{39}$ as good source of meat in the region. Another source bushmeat, the grasscutter may reach up to 80 million animals, producing about 300,000 TDM of meat per year (Jori, Mensah and Adjanohoun, 1995). Its volume is declining because of unsustainable use and habitat degradation (Wilkie et al, 2016) as well as increased accessibility and population pressure (Benítez-López et al., 2017) that affect bigger-sized species more heavily (Koerner et al., 2017). Although hunting was initially based on sustainable practices by local population, it has largely been overtaken by more commercial oriented and less sustainable practices (Fa et al., 2016). The widespread preference for bushmeat combined with increased scarcity has driven it to become a luxury food for the last three decades (Falconer, 1990). The Ebola epidemics crisis in 2015 has made urban consumption of bushmeat to drop because of increased fear (Alpha and Figué, 2016), but consumption in rural areas remains high and given the lack of alternative meat supplies it is expected to go back to pre-crisis levels. 


\subsubsection{Milk and dairy products}

Unlike meat products, there is a clearly much higher consumption trend for dairy in Sahelian countries proportional to the higher milk production in there ${ }^{40}$, Herrero et al., (2014) project a three-fold increase of milk consumption in West Africa by 2050 . The highest milk producers in the region, Mali and Niger, are also the ones recording the highest dairy consumption rate $(90.8$ and $58.9 \mathrm{~kg}$ per person and per year, respectively). Cabo Verde also has a high milk consumption rate, with $51.8 \mathrm{~kg}$ per person and per year (Bari, 2016). All Coastal countries, except Guinea and Guinea-Bissau, has a very low dairy consumption rate below $12 \mathrm{~kg}$ per person and per year (Liberia 0.98; Togo 1.63; Côte d'Ivoire 2.33; Ghana 2.57; Nigeria 4.12; Sierra Leone 4.88). This strong regional trend reflects the cultural considerations around milk and the relative importance it has for pastoralist populations (Check, 2006).

The dairy processing industries in West Africa are increasingly industrialized mainly in coastal countries ${ }^{41}$ where Dairy Processing Units are being introduced. However, most of the milk used as input by these units comes from powder milk imported from European countries (Salla, 2016). Most of the dairy processing in many countries of the region is still made traditionally by women at home, who produce curdled milk, butter cheese, or dry cheese. Modern facilities are able to add butter, yoghurt, ice cream or pasteurized milk to the local dairy products.

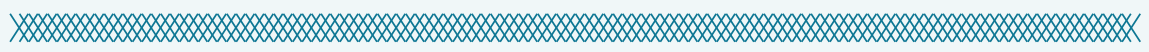

\section{Box 4}

Lactose intolerance and its importance for food security in West Africa.

Lactose intolerance makes much of the dairy products inedible for populations not adapted to its consumption during adulthood (Curry, 2013). The West African countries mainly import unprocessed milk, 92.3 percent, as opposed to cheese and butter, which represent only 2.3 percent and 5.4 percent, respectively (FAOSTAT, 2013). Lactose intolerance may also reflect malnutrition among children passed a certain age, which are indeed able to digest animal milk that can be a critical component of their diet (Neumann, Harris and Rogers, 2002). These data also show how current studies on lactose intolerance worldwide may ignore pockets of population with strong livestock culture where ability to digest lactose may be widespread among adults. The importance of milk may therefore have been neglected as a source of food aid among Sahelian populations not only in West Africa but also further east, as current revisions on the matter interpret a low milk digestibility because of interpolation from other areas, mainly due to the lack of data for local populations (Itan et al., 2010).

\subsubsection{Eggs}

Regarding eggs, while data on the volume in TDM reveals a much more reduced consumption rate than meat or milk, it should be taken into account that eggs provide high-quality protein in a concentrated manner (Sparks, 2006). Eggs are also sources of valuable micronutrients, a factor making difference when chickens are reared in backyard or village conditions (Giannenas et al., 2009 and Samman et al., 2009). An analysis of the number of eggs consumed in West Africa (Figure 25) shows that there is high consumption trend in some of the countries which showed lowest milk consumption, such as Nigeria, Liberia, Sierra Leone and Côte d'Ivoire (with values of 82.7, 56.5, 55.1 and 50.1 eggs per person and 
per year, respectively). The lowest consumption rate is observed in Niger (11.7 eggs per person and per year), one of the countries with highest milk consumption rate, followed by the Gambia (17.3) and Guinea-Bissau (18.1), in both cases milk consumption not being low either. The combination of this data may be indicative of the importance of milk and eggs as protein and micronutrient suppliers in households with reduced income level, be it pastoralist or backyard production systems.

It is worth noting that Cabo Verde, with the highest egg consumption (115.6 eggs per person and per year in 2013), shows the highest animal product consumption rates, which matches its higher GDP per capita and Human Development Index in the region. Given its higher consumption rate of dairy products and milk, compared to other countries in the region, it is the only country that is getting animal-sourced protein in the average range recommended by FAO livestock's division ${ }^{42}$ (FAO, 2019b).

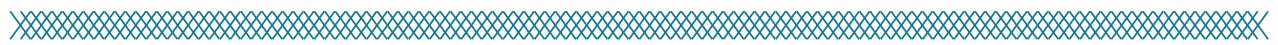

Figure 25. Average number of eggs consumed per person and year in West Africa

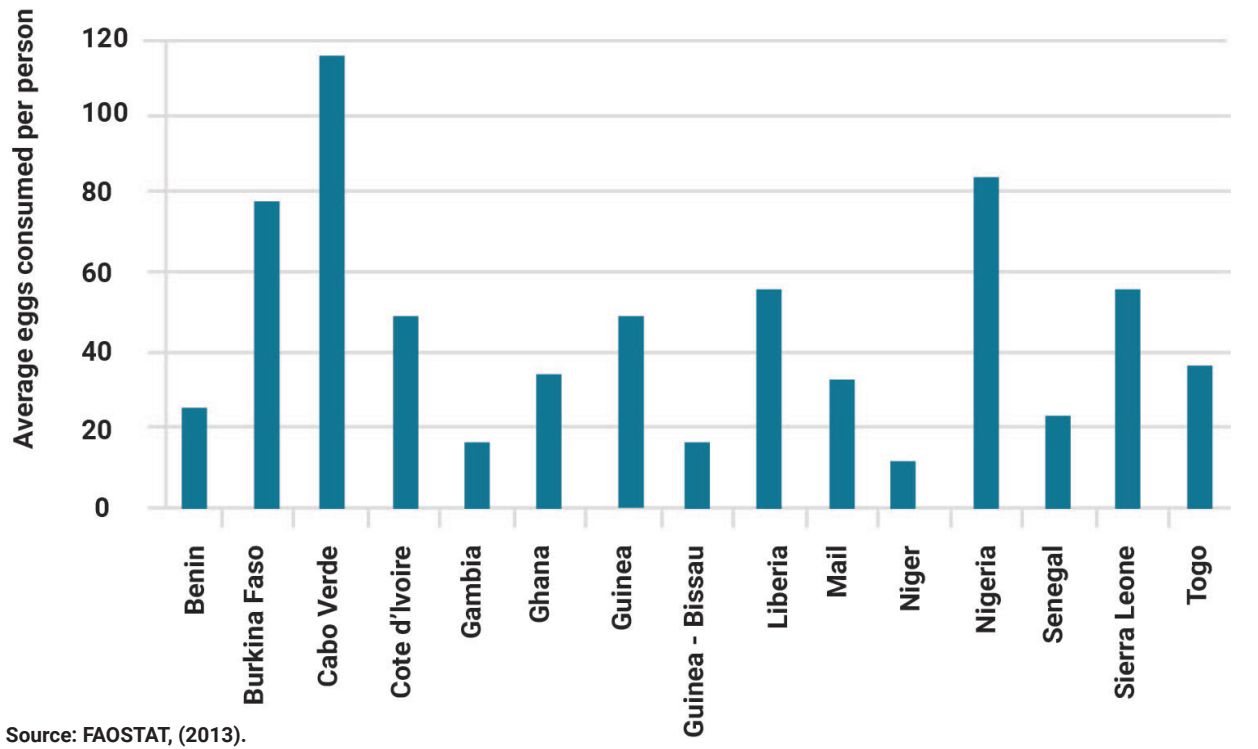

\subsection{Trade dynamics}

When comparing the amount of food of animal origin produced (Table 16) with the demand (Table 22), it is evident that currently West Africa cannot adequately supply with the domestic demand through local production, particularly meat ( 16 percent of the consumption is imported) and dairy ( 7 percent). There is a clear division of countries in the region between exporters and importers (Figure 26), but gaps still persist because the trade within the region is mainly focus on live animals (Josserand, 2013). To bridge the remaining large gap, requires imports, mostly from outside the region. The regional cross border trade involves primarily live animals (cattle, sheep and goats for meat purposes), coming from the Sahelian countries in the north towards the major consumption centers in the coastal countries to the south. The trade of other type of products faces obstacles such as lack of year-round supply (particularly for milk), lack of processing facilities, cold storage and transport, and occasionally strong and conservatory country specific veterinary regulatory measures. The demand for both dairy and meat products comes often in a form of processed products that also influence the trade relationships between countries in the region. 


\subsubsection{Live animals}

Trade in live animals is characterized by lesser needs for infrastructure in comparison with trade in processed animal products, as no meat and milk preservation measures are required. Hence, trade in live animals is easier and more common in developing countries. In regions subjected to protracted crises and in response to climatic variability, live animal trade offers the potential to quickly destock or replenish livestock production system. The strategic import of live animals can help overcome infrastructure deficits that may be limiting animal production locally, because of the issues around preservation of meat mentioned above. Live animal trade comes, however, at the expense of having a lower value addition on the sales, as well as less control on cross-border trade. Because live animals can be easily carried across borders without losing much value, a lot of the trade tends to happen over informal channels. This also poses the potential risk of transmitting TADs.

There is a relatively significant level of international trade in live animals in West Africa (Tables 23 and 24), even if statistically it is dwarfed by trade in livestock products. Trade involving live animals such as cattle, sheep and goats takes place either across borders or on domestic markets and is often fueled by the need to replenish productive ventures with younger animals. Only Burkina Faso, Mali, Niger and Guinea offer a positive trade balance in terms of live animal exports, while all the others are strong importers (Figure 26). Other countries probably also offer a positive trade balance, given the large informal export to Nigeria, but this data is obviously not reflected in official statistics. Benin plays a role as a transit country for animal product import into Nigeria (Codjia, 2012), as probably does Togo too (see Boxes 6 and 7).

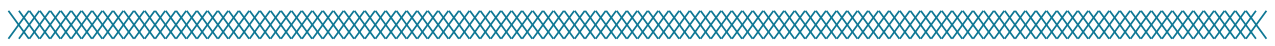

Figure 26. Trade balance for live animals in West Africa

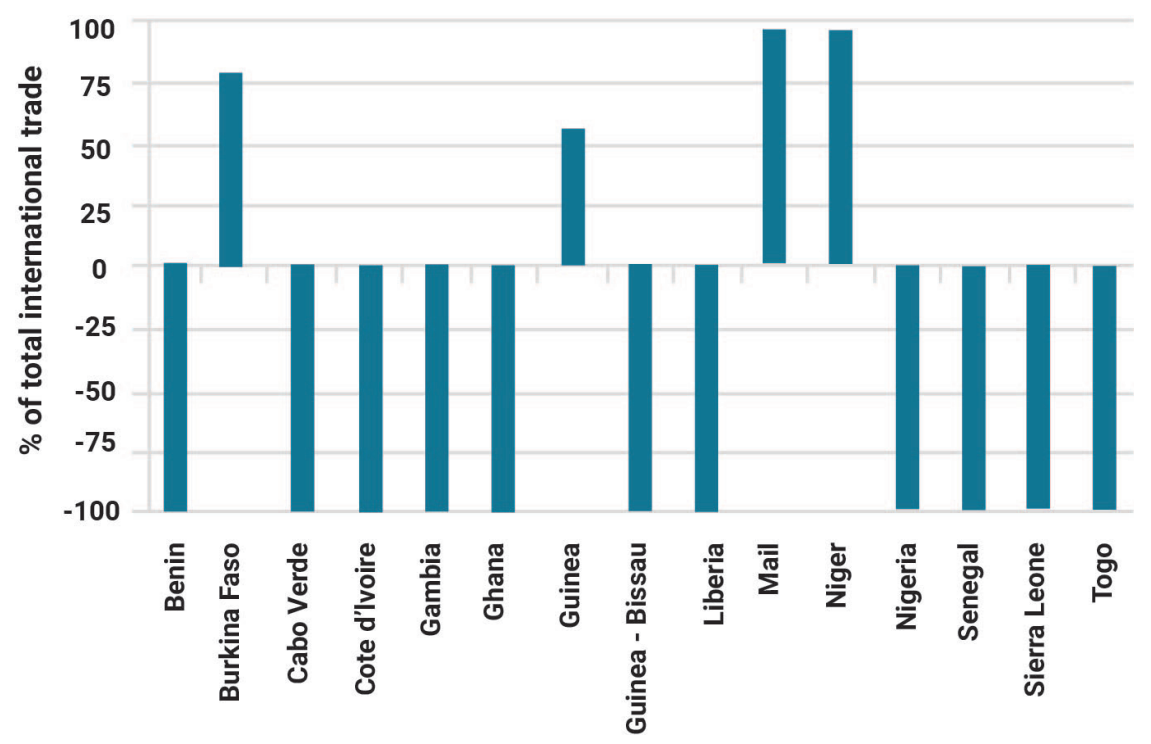

Source: FAOSTAT, (2013). Positive values indicate a dominance of live animal exports, while negative ones indicate a dominance of live animal imports. 


\section{Supply of live animals}

In general, Africa is self-sufficient regarding live animals (Mankor, 2013). However, this does not seem to apply to West African region, where probably due to high number of live poultry imports (particularly juveniles), the balance is negative. The weak ruminant exports outside the region may have also contributed. Even if the deficit exists, the gap is limited because of the small difference between the demand for live animal and the local supply (see Tables 23 and 24).

The weak demand for live animals probably originates from widespread family farming systems (either backyard or pastoral) that rely on local genetic stock, whose number is adjusted to locally available resources. Such systems gain little with the incorporation of external live animals because of the weak capacity to access external inputs that these family farming systems have. It is therefore better for producers to reserve some of their own animal production to replenish stocks rather than investing in animals from elsewhere.

\section{Import of live animals}

Records in FAOSTAT indicate that West African countries imported about 600,000 cattle, sheep and goats and more than 12 million chicken in 2013. The total monetary value of this transaction was 303 million USD (Table 23). The greatest importer of live animals was Nigeria, followed by Senegal, Côte d'Ivoire and Sierra Leone. When comparing with national populations, these last three countries are the ones investing more heavily in live animal imports - Senegal showing the highest figure, with an expenditure of almost seven USD per person and year in imported live animals (Gueye, 2012 and Mbaye, 2009). While trading partners in the region (see below) are the most important providers of ruminants, creating a strong transfer of live animals from the Sahel towards the Coast, almost all live chicken imports come from outside the region, mainly from Europe. When comparing with the national stock, poultry is the sub-sector that attracts a higher proportion of live imports ( 2.3 percent). The weak production and productivity of local chicken failing to satisfy demands and the ban on chicken meat imports such as the ones in place in Nigeria or Senegal ${ }^{43}$, are behind the increased numbers of live chicken import. For cattle, the higher survival rate after transport and the higher capital value could be the reason behind its relatively high import numbers compared with small ruminants. Most of the ruminant animals imported are for meat production, while the bulk of the sheep imported to Côte d'Ivoire and Senegal is for the Tabaski (feast sacrifices).

\section{Photo 60. Transporting sheep from Burkina Faso to Cote d'Ivoire for Tabaski market}

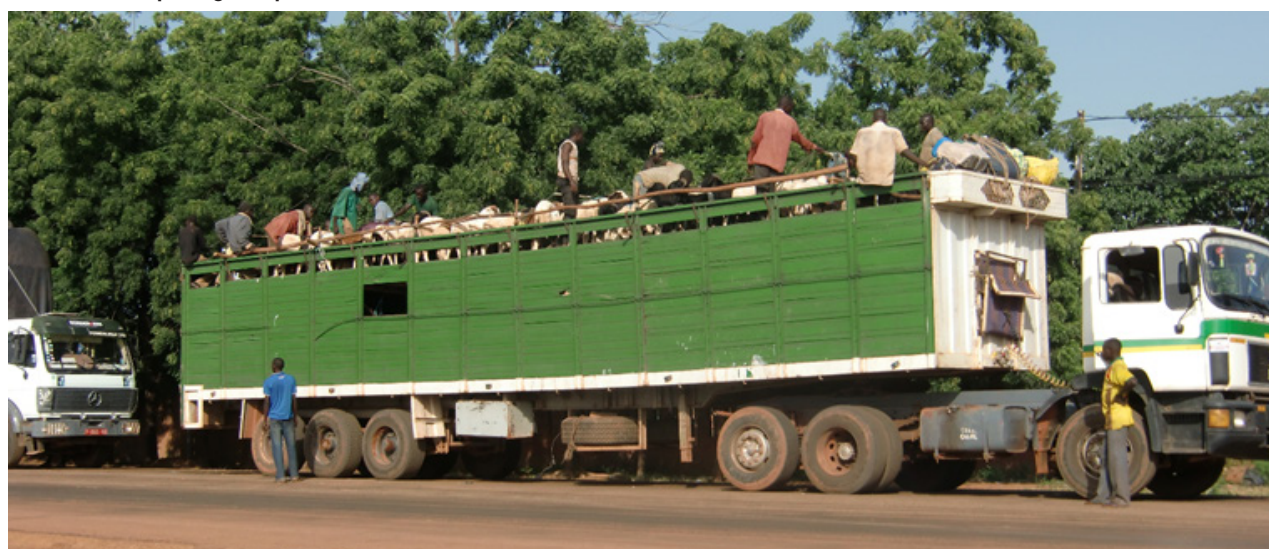

CFAO/B. Bedane 


\section{Export of live animals}

The number of live animals exported from West African countries and their monetary values recorded in 2013 are presented in Table 24. The export market is much less than imports except for the Sahelian countries (i.e. Burkina Faso, Mali and Niger). The exporting countries mainly sell animals to markets in other countries within the region with few camel, sheep and goats destined to neighbouring countries in North Africa. This kind of trade, being cross-border, most probably happens informally and may be the reason for it not being captured by FAOSTAT. Most of the animals exported are ruminants, where Niger exports mainly to Nigeria (95.8 percent of exports; cattle, sheep and goats) while Burkina Faso's exports are destined to more than one country but within the region (62.3 percent of exports to Benin, mainly cattle with some sheep, and 24.1 percent to Ghana, mainly sheep but with significant numbers of cattle and goats). Mali mainly exports cattle to Senegal and Côte d'Ivoire, sheep and goat to Algeria and Côte d'Ivoire, donkeys to Niger and Burkina Faso and camels to Mauritania and Algeria (Haidara, 2012). A survey conducted by Agribusiness and Trade Promotion, a project supported by the United States Agency for International Devevelopment (USAID), in October 2012 showed that at least 25,000 head of cattle were exported from Mali to Guinea (Josserand, 2013). This data shows the powerful role of the Sahelian drylands as a breeding site for ruminants, a significant portion of them ending up being exported further south to the Coastal countries for fattening and consumption. The same dynamics probably occur in trade within borders i.e. between northern and southern Nigeria. New dynamics can arise abruptly and unexpectedly and further influence international live animal trade in the region (Box 5).

\section{Ү网}

\section{Box 5}

The trade of donkey skin and its impact on livelihoods in West Africa.

Since time immemorial, donkeys played diversified roles, but mainly as pack, transport and draft animals. They generating income for the household when rented to perform one of the various functions. Women and children can easily handle these hardy but docile animals (Yilmaz, Boztepe and Ertugrul, 2012). Hence, donkeys are valuable assets for the households mainly women in the rural areas, reducing their burden of domestic responsibilities (Kathy Marshall and Ali, 2004). Although rare, donkey meat and milk is a delicacy among some communities. This case study discusses the new role of donkey skin as input for Chinese traditional medicine called E-Jiao and as a result, the impact of the 'booming' trade in donkeys and their skin on rural economy and livelihood.

In the past, Chinese royalties used E-Jiao as a remedy against aging and for improving blood circulation. It is made of donkey skin gelatin, herbs and other ingredients. The other health benefits attributed to E-Jiao, include aphrodisiac properties, cure for insomnia, preservation of women's beauty and solution to menstrual problems. E-Jiao now became popular and affordable among ordinary citizens thanks to the growing middle class and on-line marketing. China produces about 5,000 tons of E-Jiao per year, using four million donkey skins (El Pais, 2016). The current production level and demand for donkey skin will definitively double or triple. E-Jiao producers deny involvement, and it's true that donkeys have declined in all countries undergoing industrialization and motorization (Yilmaz, Boztepe and Ertugrul, 2012). But the Chinese donkey population has reduced drastically from 11.1 million in 1990 to 4.6 million in 2017 (FAOSTAT, 2019) by 60\% in 26 years. With the short supply, the price of skin from the remaining few donkey in China increased from 32 US dollars in 2000 to 435 US dollars in 2017 (Xinhuanet, 2018). Hence, E-Jiao producers had to source donkey skin from abroad, including West Africa. 
The main target in West Africa included Niger, with 1.8 million, Nigeria, 1.3 million, Burkina Faso, 1.2 million and Mali, 1.1 million donkeys out of the total six million in the region. Donkey abattoirs were established in Burkina Faso and Ghana mainly for skin export to China. This sudden interest in donkey skin has raised the price of donkeys, doubling or tripling it in Burkina Faso and Niger in less than a year. This price rise in turn has led to theft of donkeys, illegal and inhumane slaughter and smuggling across borders, fraudulent practices of mixing beef with donkey meat, etc. The pace with which donkeys were slaughtered for exporting their skin became alarming. For example, donkey skin export jumped from 1000 to 65000 just in a year in Burkina Faso, while in Niger it increased from 27000 units to 80000 in less than a year year (Trace, 2016). Some may think this is an opportunity to seize. However, it is difficult to satisfy the multi-billion E-Jiao industry's requirement of four million donkey skins yearly. The poor regeneration of donkey population does not allow that. The sharp price increase, theft, drastic reduction of donkeys, etc. impact negatively on the livelihood of the rural community, relying heavily on donkeys. Animal welfare issues and the increased workload on and risk of theft of the remaining donkeys (The Donkey Sanctuary, 2019) are other negative effects. Hence, countries like Burkina Faso, Ghana, Mali, Niger, and Senegal, took swift action in banning the export of donkeys (Studio Timani, 2017) or their skin and where opened, closed down the donkey abattoirs. In order to ensure cross border collaboration among West African countries in stopping donkey skin trade, FAO and ECOWAS organized a meeting in September 2016. The meeting recommended that member states should step up measures to stop donkey skin trade and close all the avenues used by individuals using the opportunity of porous borders and smuggle donkeys or their skins from one country to another.

\section{${ }_{X}$}

Table 23. The number of live animals by species imported by West African countries.

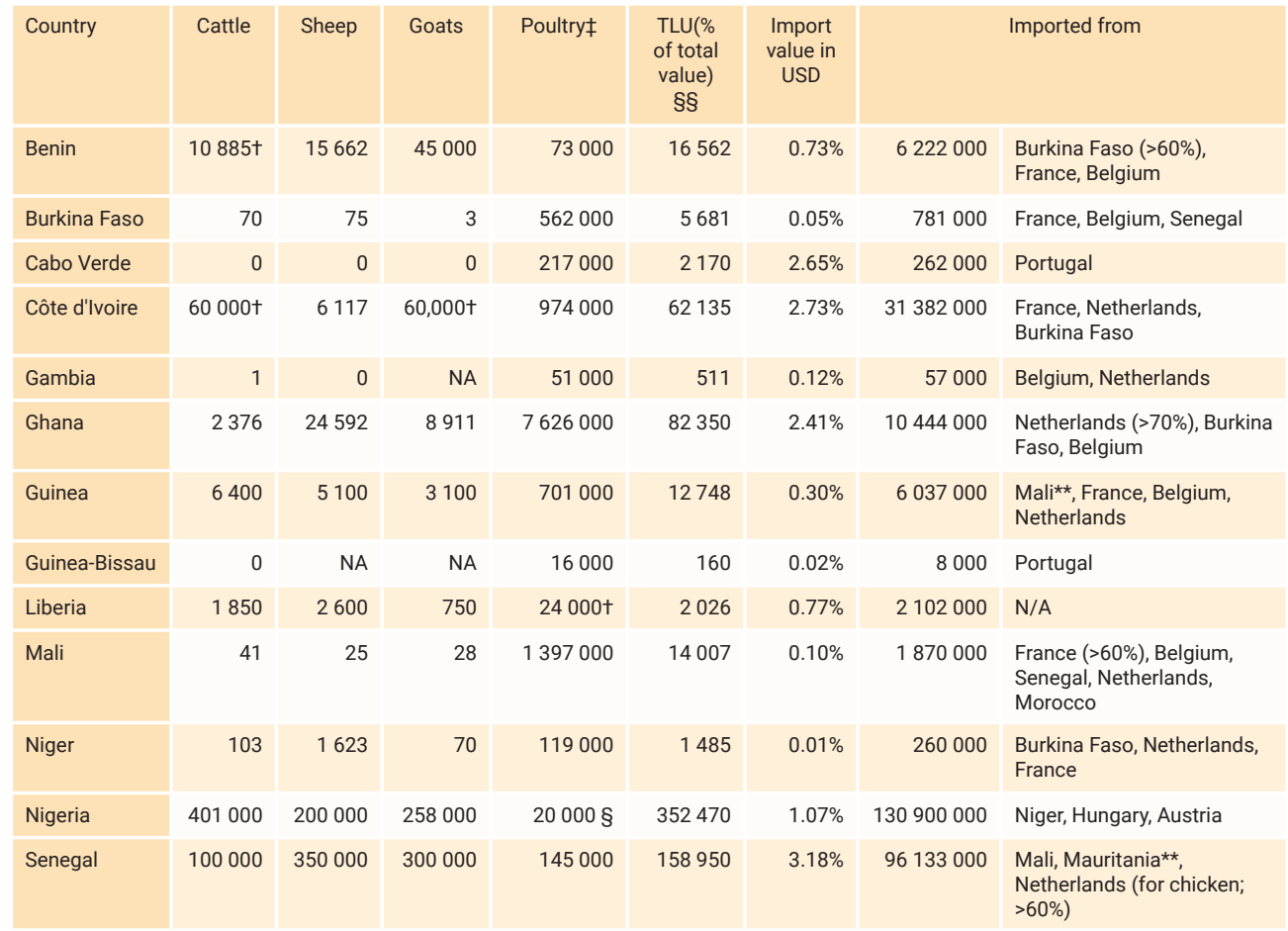




\begin{tabular}{|c|c|c|c|c|c|c|c|c|}
\hline Sierra Leone & 55000 & 5500 & 18900 & 69000 & 44012 & $4.04 \%$ & 16503000 & $\begin{array}{l}\text { Guinea***, Belgium \& } \\
\text { Netherlands (chicken) }\end{array}$ \\
\hline Togo & 514 & 232 & 127 & 168000 & 2102 & $0.15 \%$ & 525000 & Niger, Belgium \\
\hline West Africa & 638240 & 611526 & 694889 & 12162000 & 757369 & $0.81 \%$ & 303486000 & \\
\hline $\begin{array}{l}\text { proportion } \\
\text { of regional } \\
\text { herd } \S \S\end{array}$ & $0.96 \%$ & $0.66 \%$ & $0.49 \%$ & $2.29 \%$ & & & & \\
\hline
\end{tabular}

Source: FAOSTAT, (2013)*; † indicates data for $2012 ; \ddagger 99.5 \%$ chicken, $0.37 \%$ turkeys, $0.13 \%$ ducks; $\S$ Nigeria informally imports large quantities of chicken from Benin (see Box 8), of which many may be live animals; §§ data from Table 5 of this report; * table includes corrections from detailed trade matrices; **Gueye, (2012); ***Manzano and White, (2019):30.

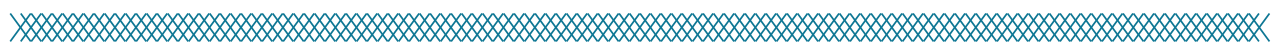

Table 24. The number of live animals by species exported by West African countries

\begin{tabular}{|c|c|c|c|c|c|c|c|}
\hline Country & Cattle & Sheep & Goats & Poultry & \multicolumn{2}{|c|}{ TLU(\% of total value) $\S \S$} & Value, USD \\
\hline Benin & 0 & 0 & NA & $0 \S$ & 0 & & 0 \\
\hline Burkina Faso & 371873 * & 586082 * & 744782 * & 554134 * & 13654 & $0.12 \%$ & $6035000 \S \S$ \\
\hline Cabo Verde & 0 & NA & NA & NA & 0 & & 0 \\
\hline Côte d'Ivoire & NA & 0 & NA & 8000 & 0 & & 11000 \\
\hline Gambia & 0 & 0 & NA & 0 & 0 & & 0 \\
\hline Ghana & 32 & 0 & 0 & NA & 0 & & 18000 \\
\hline Guinea & 20000 & 7000 & 4000 & 0 & 16030 & $0.37 \%$ & 22627000 \\
\hline Guinea-Bissau & 0 & NA & NA & NA & 0 & & 0 \\
\hline Liberia & NA & NA & NA & NA & 0 & & NA \\
\hline Mali & 200235 ** & 510888 ** & 28776 ** & 235677 ** & 198432 & $1.42 \%$ & 114865000 \\
\hline Niger & $\begin{array}{r}465595 \\
\star \star \star *\end{array}$ & 990245 *** & 1006663 *** & 5000 & 74841 & $0.52 \%$ & 18385000 \\
\hline Nigeria & 3 & 71 & NA & 4000 & 0 & & 4000 \\
\hline Senegal & 37 & 7 & 0 & 188000 & 1908 & $0.04 \%$ & 275000 \\
\hline Sierra Leone & NA & NA & NA & 0 & 0 & & 0 \\
\hline Togo & 0 & 0 & NA & NA & 0 & & 13000 \\
\hline West Africa & 279597 & 502455 & 173267 & 994811 & 305020 & $0.33 \%$ & 162233000 \\
\hline $\begin{array}{l}\text { proportion of } \\
\text { national herd } \S \S\end{array}$ & $1.58 \%$ & $2.25 \%$ & $1.23 \%$ & $0.19 \%$ & & & \\
\hline
\end{tabular}

Source: FAOSTAT, (2013)v; $¥ 99.16 \%$ chicken, $0.84 \%$ turkeys; § Benin informally exports large quantities of chicken to Nigeria (see Box 8), of which many may be live animals; $\S \S$ data from Table 5 of this report; + table includes corrections from detailed trade

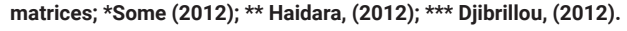

Prices of live animals

A peculiarity which is important in determining live animals prices in West Africa is that livestock trade remains a multi-actor activity ${ }^{44}$ (i.e. farmers, livestock dealers, transport brokers, wholesale or retail butchers, public officials especially at customs, the army or police, etc.). The high number of actors involved and the 'overhead' cost each one of them demands, contributes to significant price increase. In addition, price in the Western Africa marketplaces are determined by bargaining. The buyer relies on physical appraisal of the animal by observing, without actually weighing the animals. Auction sale is not practiced and there is resistance to a set price based on live weight. Apparently, traders prefer bargaining for their businesses, introducing variables such as breed, age, frame and body condition of the animal, market location and type, season and availability of the species, religious feasts, etc. Depending on the situation, a whole batch of animals with different frame and body condition may be

${ }^{44} \mathrm{cf}$. section 5.3 .4 
sold for an average price. A general picture of live animals' price for the major livestock species in the region is presented in Table 25 .

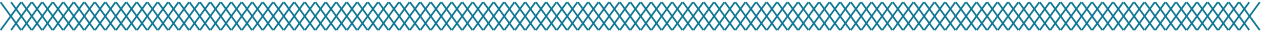

Table 25. The price of live animal for the major livestock species in West Africa (in USD)

\begin{tabular}{|l|r|r|r|}
\hline Livestock Species & Minimum Price & Maximum Price & Average Price \\
\hline Cattle & 125.80 & 1200.00 & 516.66 \\
\hline Sheep & 25.00 & 294.00 & 87.33 \\
\hline Goat & 11.75 & 150.00 & 56.58 \\
\hline Local Chicken & 2.00 & 8.83 & 4.89 \\
\hline Broiler & 4.91 & 7.00 & 6.05 \\
\hline Pig & 23.49 & 300.00 & 136.49 \\
\hline Camel & 250.00 & 815.19 & 492.15 \\
\hline
\end{tabular}

Source: Gueye, Gueye, (2012); Djibrillou, (2012); Talaki, (2012); Codjia, (2012); Akunzule, (2013); Haidara, (2012); Aboubacar, (2017); Some, (2012); Dembele (2017); Gueye, (2017); Maïga, (2012); Loum, (2012); Djata, (2012) and Talaki, (2017).

The very complex pricing system of livestock vary widely from one country to another, or from a livestock 'producing' Sahelian country to a 'consuming' coastal country. For any given species of animal, there are differences in terms of breeds, age and sex categories, etc. which account for price differences. The assumed potential of the animal as a replacement stock and their future use are also important features determining livestock price. For these reasons, cattle, sheep and goats appear to have the widest price ranges. In fact, throughout West Africa, these species have more breeds and crossbreeds than the other species. To illustrate the within-species price variation, price data from Ghana are given in Table 26.

\subsubsection{Animal products}

The trade of livestock products such as meat, dairy and eggs takes place between countries as well as on domestic markets. In all cases, prices are strongly dependent on local market conditions, mainly on supply. The influence of products from outside the region, particularly the EU, is very important. Other animal products, particularly hide and skin, are poorly commercialized but possess a concealed enormous economic potential.

\section{Supply of animal products}

The supply of primary livestock products (i.e. meat, milk and eggs) vary from product to product. As most West African countries do not export meat or meat products in significant quantities, it can be assumed that the entire meat produced ( 3.4 million TDM) is available for domestic consumption within the region ${ }^{45}$. This quantity is largely below the potential demand for meat in the subregion (4.1 million TDM), leaving a gap of 640 Thousand TDM, which triggers large amount of meat and meat product import from outside the region.

The situation for milk and other dairy products is slightly more complex. The total production of 3.9 million TDM of milk does not satisfy the demand of 4.2 million TDM of dairy products. West Africa imports the shortfall of 290 Thousand TDM from sources outside Africa. The import of milk and dairy products is on the rise driven by population growth and shifting preference of the gradually increasing middle class, which can afford paying for high quality sources of protein. The amount of milk imported to West Africa, in terms of value, has more than doubled between 1984 and 2004 from 223.7 million USD to 529.4 million USD (Kamuanga et al., 2008). Records from FAOSTAT indicate that the milk import value in West Africa jumped from 588 million USD in 2005 to 718.6 million in 2017, an increase of 22 percent in 12 years (FAOSTAT, 2019). 
Table 26. The price range and average price of different livestock species in Ghana (in USD)

\begin{tabular}{|c|c|c|}
\hline Livestock Species & Price ranges & Average Price \\
\hline West African Shorthorn Cow & $450.00-1200.00$ & 600.00 \\
\hline Sanga & $1200-2000.00$ & 1400.00 \\
\hline Young Bull & $1600.00-1,800.00$ & 1200.00 \\
\hline Local Zebu-type Adult Bull & $600.00-1,500.00$ & 1300.00 \\
\hline West African Dwarf Goat & $40.00-80.00$ & 55.00 \\
\hline Sahelian-type Goat & $250.00-320.00$ & 300.00 \\
\hline West African Dwarf Sheep & $60.00-80.00$ & 74.00 \\
\hline Djallonke Sheep & $70.00-100.00$ & 80.00 \\
\hline Sahelian Sheep & $350.00-400.00$ & 360.00 \\
\hline Sow (indigenous) & $80.00-150.00$ & 85.00 \\
\hline Boar (indigenous) & $100.00-300.00$ & 130.00 \\
\hline Sow (Exotic) & $200.00-400.00$ & 350.00 \\
\hline Boar (Exotic) & $300.00-600.00$ & 400.00 \\
\hline Spent Layer (white) & $10.00-20.00$ & 17.00 \\
\hline Spent Layer (brown) & $10.00-20.00$ & 15.00 \\
\hline Broiler & $15.00-20.00$ & 15.00 \\
\hline Local fowl, female & $15.00-20.00$ & 15.00 \\
\hline Local fowl, cock & $15.00-20.00$ & 15.00 \\
\hline Guinea fowl & $10.00-15.00$ & 12.00 \\
\hline Turkey & $50.00-80.00$ & 60.00 \\
\hline DOC, Layer (local) & $1.70-2.00$ & 1.80 \\
\hline DOC, Broiler (local) & $2.00-2.20$ & 2.10 \\
\hline DOC, Cockerel (local) & $0.50-0.80$ & 0.65 \\
\hline DOC, Layer (Imported) & $2.70-2.85$ & 2.66 \\
\hline DOC, Broiler (Imported) & $2.40-2.50$ & 2.30 \\
\hline
\end{tabular}

The factors steering milk and dairy products trade dynamics are also related to the type of products demanded and the availability of local industries. The high temperature in the region coupled with difficulties of maintaining the cold chain for dairy products without compromising food safety is a challenge. Box 6 shows the difficulty of keeping safe dairy products imported to satisfy unmet demands due to low production capacity in the region. Moreover, 90 percent of local raw milk is produced in traditional extensive livestock production systems and less than 10 percent in peri-urban systems. Milk production by the extensive system is characterized by seasonal fluctuations, reaching significantly high volumes during the Sahelian rainy season (June to September) but with a fairly low level of collection and processing. The supply of milk in producing areas during rainy season is largely above milk demand, which results in spoilage of a good portion of it, as it does not access the high demand in urban centers. In Burkina Faso (Badolo, 2009) and Mali (Modibo, 2010), only 0.8 percent and 0.1 percent of the potential milk production respectively was collected in 2010 for processing and commercialization. The locally processed dairy products include pasteurized milk, cream milk, sour milk, butter and traditional cheese, the latter two traditionally done at the household level by women (Gefu, 2009 and Gueye, 2017). 


\section{Box 6}

Trade in dairy products in Togo

Togo offers a paradigmatic case to analyze the trade of dairy product dynamics in West Africa, as it is the only country in the region where national milk production (12.8 million litres) exceeds the national consumption (11.1 million litres). It is, therefore, the only net exporter of milk and dairy products. In addition to that, the country has good quality data, as the ones available in FAOSTAT for 2013 are official data. It is noteworthy that most of the trade involves long life dairy products. The trade of fresh dairy product is exceptional.

Togo, being in a coastal area, is one of the countries with the lowest dairy consumption rates. However, although the resident livestock population is not that significant, it hosts transhumant livestock coming from Niger and Burkina Faso.

When analyzing the import/export data for the four dairy products that are more relevant for trade, the whole condensed milk takes the lion's share when it comes to the exported quantity. This is followed by powdered milk, being considerably more lucrative possibly because of a less saturated import market. This trade could not happen without the necessary industrial infrastructures.

On the other hand, imports are dominated by skimmed dry milk, given that the amount nationally produced or possibly its quality is not able to satisfy the local market. The buttermilk and condensed milk are important in terms of volume but much less in terms of monetary value, possibly because of available national/local production that pushes prices down.

Table 27. Import and export of dairy products, Togo

\begin{tabular}{|l|r|r|r|r|r|}
\hline Export/Import & $\begin{array}{c}\text { Buttermilk, } \\
\text { curdled, acidified } \\
\text { milk }\end{array}$ & $\begin{array}{c}\text { Milk, skimmed } \\
\text { dried }\end{array}$ & $\begin{array}{c}\text { Milk, whole } \\
\text { condensed }\end{array}$ & $\begin{array}{c}\text { Milk, whole dried } \\
\text { Portion of total } \\
\text { dairy trade }\end{array}$ \\
\hline Export Quantity & $0.6 \%$ & $12.0 \%$ & $66.8 \%$ & $18.2 \%$ & $97.5 \%$ \\
\hline Export Value & $0.4 \%$ & $29.1 \%$ & $40.7 \%$ & $28.0 \%$ & $98.3 \%$ \\
\hline Import Quantity & $26.3 \%$ & $38.6 \%$ & $18.1 \%$ & $4.4 \%$ & $87.5 \%$ \\
\hline Import Value & $12.8 \%$ & $65.9 \%$ & $8.5 \%$ & $5.1 \%$ & $92.3 \%$ \\
\hline
\end{tabular}

Source: Talaki, (2012).

Togo, as the only surplus-producing country in terms of the volume of dairy products, has also a positive trade balance. Its export earnings from dairy products was 19.2 million USD in 2013 while important stood at 18.1 million USD (FAOSTAT, 2019). Similar trend was observed fro the official data submitted to FAOSTAT in 2017, where export value of 26.3 million USD exceeds 15.1 million USD of import expenditures. Analyzing Togo's detailed dairy trade matrix reveals that most of its imports come from outside Africa (Ireland, the Netherlands and Malaysia). The destination of most of its exports is within the region, mainly in the coastal countries (Talaki, 2012). 
The supply of eggs in West Africa is essentially ensured by local production, with some anomalies only in Mali, Senegal and Niger (Schneider, 2010). In Mali, eggs are not widely consumed and the bulk of the eggs from the traditional backyard poultry system are destined to chick production (Traoré, 2006). In Senegal, women have traditionally avoided eggs during pregnancy (a trait currently disappearing), while in Niger there is a preference for guinea fowl eggs when available. Most countries in the region are almost self-sufficient in covering the table eggs demand, with the exception of Liberia where there is 52.3 percent gap. The other countries where there is gap include Gambia (34.6 percent), Sierra Leone (21.3 percent) and Cabo Verde (14.0 percent), all above the 10 percent gap (FAOSTAT, 2013). The cost of egg production is high as a result of high feed cost and limited feed manufacturing facilities. In the absence of specialized poultry industries fulfilling these requirement (Salla, 2016) dependence on backyard production system is inevitable (Schneider, 2010). The current policy banning chicken import in some countries of the region (see below) also influences the availability and price of eggs.

The West African region produces on average 80.95 million units of hide and skin annually worth an estimated 200 million USD. The local processing of these products tend to be artisanal, with low investment and low quality, reducing the potential value of these products (TLC, 2002 and Leach and Wilson, 2009). Most of the industrial tanneries are mainly concentrated in Nigeria ${ }^{46}$.

\section{Animal products imports}

The livestock product import value in West Africa reached nearly 2 billion USD in 2013 (Table 28). Nigeria is the biggest importer in terms of monetary value, followed by Ghana, Benin and Côte d'Ivoire. These four countries share three-quarters of the regional import in terms of value. As previously mentioned, this volume of trade indicates the current deficit in animal products, especially for meat and dairy. However, a closer look into the situation shows how the lack of local processing industries is having a big influence in import dynamics.

An analysis of meat import in the region (Figure 27) shows that up to 55.8 percent of all the import volume and 53.6 percent of all the trade value are made up of chicken meat import. This indicates a major structural gap between chicken meat demand and chicken production in the region (Box 7). The second most important type of import is prepared meat, with 11.6 percent of the volume and 13.2 percent of the value of all trade in animal prodcuts, indicating the lack of processing facilities in the region. The third most important import is turkey meat. The preference for this animal product, which is not produced in the region, is very costly compared with other poultry sources (Adene and Oguntade, 2006). The trade of cattle offal (constituting 10.7 percent of the volume but just 9.7 of the value) may be due to the preference for such products in some countries and its relatively cheaper price.

The dairy products import to West Africa is dominated by processed products (butter/buttermilk, cheese, and dry, evaporated and condensed milk) taking the major share of 87.3 percent of the import volume and 97.1 percent of its value (FAOSTAT, 2013). The category of transformed milk (either dry, evaporated or condensed) represents 79.6 percent of the import volume and 88.1 percent of the trade volume. The strong demand for dairy products that can be preserved without refrigeration and the lack of processing industries in the region (Box 6 for an example in Togo) are the likely factors of such an outcome. The consumption of dairy products is higher in urban areas with poor access to traditional dairy sources, as the case in Guinea (Mane, 2017) and probably better purchasing power of urban dwellers. 
X

Table 28. The volume and value of animal products imported by West African countries

\begin{tabular}{|c|c|c|c|c|c|c|c|}
\hline \multirow[t]{2}{*}{ Country } & \multicolumn{2}{|c|}{ Meat } & \multicolumn{2}{|c|}{ Dairy } & \multicolumn{2}{|c|}{ Egg } & \multirow{2}{*}{$\begin{array}{c}\text { Total } \\
1,000 \text { USD }\end{array}$} \\
\hline & TDM & 1,000 USD & TDM & 1,000 USD & TDM & 1,000 USD & \\
\hline Benin & 187336 & 235182 & 10755 & 23351 & 22 & 11 & 258544 \\
\hline Burkina Faso & 301 & 662 & 17344 & 24289 & 17 & 9 & 24960 \\
\hline Cabo Verde & 12,011 & 27848 & 14911 & 30423 & 365 & 852 & 59123 \\
\hline Côte d'Ivoire & 74651 & 82515 & 18165 & 75592 & 177 & 1183 & 159290 \\
\hline Gambia & 3906 & 1304 & 14896 & 4344 & 502 & 875 & 6523 \\
\hline Ghana & 226801 & 271084 & 28108 & 88423 & 86 & 357 & 359864 \\
\hline Guinea & 16379 & 26889 & 10395 & 46380 & 13 & 21 & 73290 \\
\hline Guinea Bissau & 1327 & 2212 & 3160 & 14325 & 5753 & 9081 & 25618 \\
\hline Liberia & 34619 & 34280 & 3387 & 8101 & 140 & 409 & 42790 \\
\hline Mali & 10131 & 7727 & 8712 & 40191 & 739 & 191 & 48109 \\
\hline Niger & 2580 & 2742 & 12955 & 35511 & 674 & 7850 & 46103 \\
\hline Nigeria & 25671 & 35890 & 147960 & 638804 & 1009 & 5860 & 680554 \\
\hline Senegal & 10217 & 21494 & 21999 & 72164 & 3242 & 5249 & 98907 \\
\hline Sierra Leone & 19578 & 26236 & 13047 & 17874 & 0 & 0 & 44110 \\
\hline Togo & 15464 & 12526 & 13345 & 21481 & 22 & 11 & 34018 \\
\hline West Africa & 640972 & 788591 & 339139 & 1141253 & 12,761 & 31,959 & $1,961,803$ \\
\hline
\end{tabular}

Source: FAOSTAT, (2013) Meat products include fat and offals. Dairy products include milk and derivatives (butter, cheese, etc.).

Figure 27. Volume and value for the four most important meat import types in West Africa

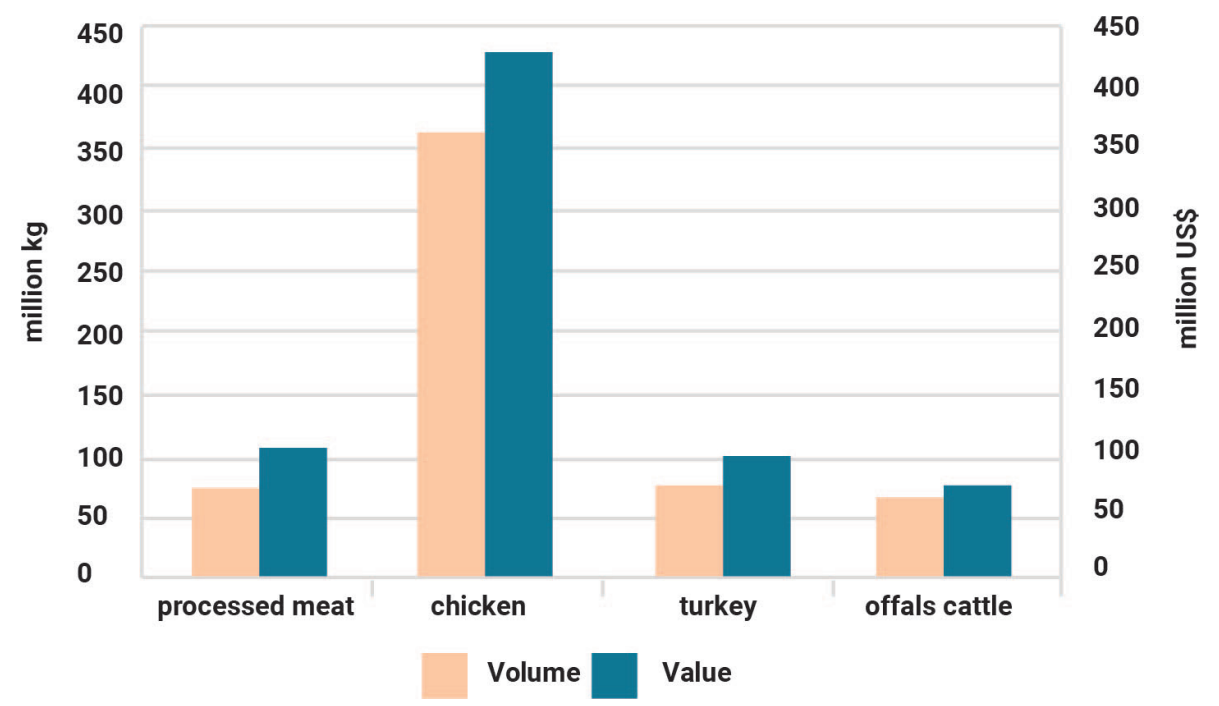

Source: FAOSTAT, (2013). Processed meat includes: bacon and ham, lard, fat (prepared), beef and veal sausages, beef preparations, canned chicken, dried meat, pig sausages \& pig preparations. 
The trade of eggs is much more reduced both in volume and value, as 98.7 percent of the demand in the countries is covered by domestic production. As explained earlier, only Liberia, Gambia, Sierra Leone and Cabo Verde import eggs to fill the shortfall. This is in contrast with the meat and dairy trade where a protective regional policy for chicken and egg production may be justified (Box 7).

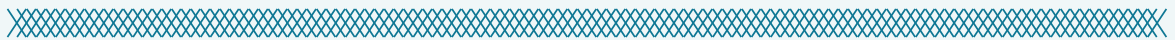

Box 7

Chicken and egg production environment in West Africa.

The high demand for chicken meat in the region has, for many years, boosted a large import trade of chicken products, mainly the import of frozen chicken from Europe, at the expense of a heavy trade balance for the individual countries. The main constraints for local poultry production are weak productivity, poor biosecurity and production practices, such as efficient veterinary services and lack of skills to implement them (with a potential threat to human health in case of avian influenza), adequate shelter for birds, or access to feed not subjected to fluctuations, an issue that even affects industrial ventures (Schneider, 2010 and Nwandu et al., 2016). This, coupled with the introduction of the Common External Tariff (CET) in 2013, which reduced the tariff rate applied in most countries, facilitated an influx of cheap poultry imports (Schneider, 2010). The increase in poultry importy to West Africa seems to worsen with time (Figure 28).

Figure 28. The evolution of chicken and eggs import in selected West African countries

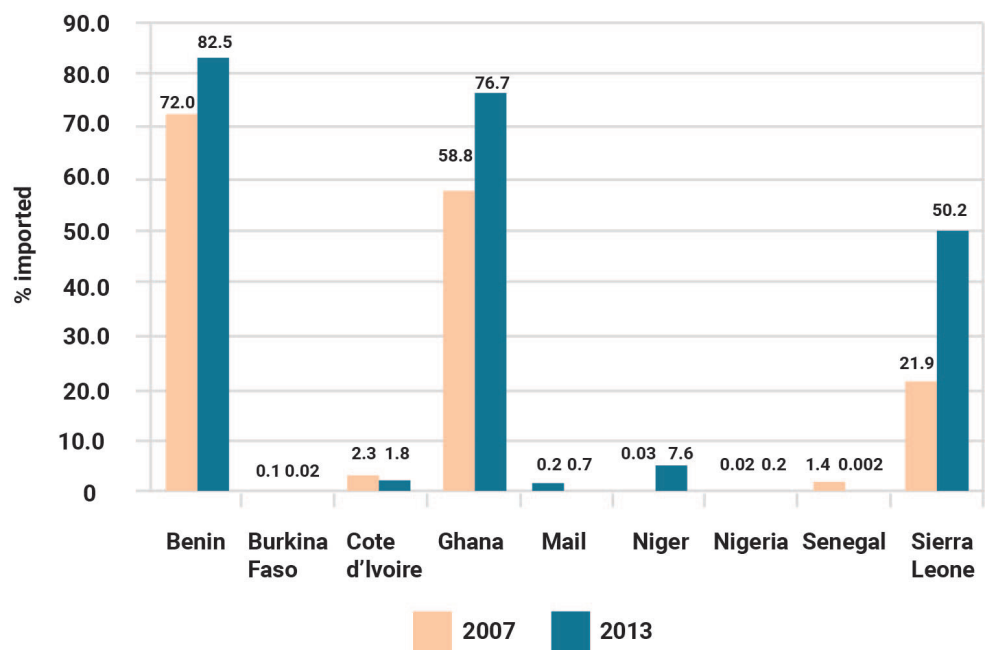

Source: FAOSTAT, (2013) data, Schneider, (2010) for FAOSTAT 2007-based data. Figures for Benin and Nigeria are likely distorted by the magnitude of undocumented imports entering Nigeria from Benin, which may reach up to 3 million TDM (Nwandu et al., 2016).

To mitigate this effect, some countries have introduced measures to regulate poultry trade in order to boost the national industry and limit the competition from cheap frozen chicken imports, including total bans by Nigeria in 2002 (resulting soon later in an informal import from Benin), Cote d'Ivoire in 2005 and Senegal in 2006, following the Avian Influenza outbreak. The apparent strong national production is less robust when data on hatching eggs and dayold chicks is explored: Togo (Talaki, 2012), Mali, Niger, Nigeria and Senegal (Schneider, 2010) import much of them from Europe. The demand of Senegal for fertilized eggs (importing them is allowed) skyrocketted, reaching 17.8 million units in 2011, worth 9.3 million USD. The import was aimed to cover the deficits of national egg and poultry production (Traoré, 2014). 
The import of fibre (wool) and skin has a much less economic importance in West Africa, accounting for only 6.5 million $\mathrm{kg}$ volume and 5.7 million USD value. Hide dominate the volume of import, with 91.3 percent of the imported volume. However, it represents only 52 percent of the imported value, as the 208 TDM of imported lanolin and grease (3.2 percent of the imported volume) represent 42.3 percent of the monetary transactions. Ghana is the main importer of hide (mainly wet salted cattle hide, the majority of it from Togo although some originates from Europe), while lanolin and grease imports are shared mostly by Côte d'Ivoire, Nigeria and Senegal - possibly for industrial uses.

\section{Export of animal products}

The export market for animal products from West Africa is very weak (Table 29). As mentioned above, the local production cannot cope with the regional demand; local production conditions are not enough to guarantee competitive prices. Only dairy has some important role, representing a trade of 78.2 million USD, of which transformed milk represents 80.4 percent of the volume and 88.3 percent of the value. The relative importance of dairy products is probably related to the difficulties of preserving dairy products without the adequate facilities at the households (i.e. refrigerators, etc.). The extremely reduced meat trade is probably influenced by the protective measures for national production explained in Box 7 , which affect the animal product trade among countries in the region.

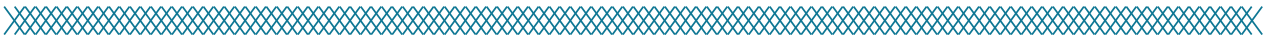

Table 29. The volume and value of animal products exported from countries in West Africa

\begin{tabular}{|c|c|c|c|c|c|c|c|c|c|}
\hline & \multicolumn{2}{|c|}{ Meat } & \multicolumn{2}{|c|}{ Dairy } & \multicolumn{2}{|c|}{ Eggs } & \multicolumn{2}{|c|}{ Hide \& skin } & \multirow{2}{*}{$\begin{array}{c}\text { Regional } \\
\text { amount }\end{array}$} \\
\hline & Quantity & $\begin{array}{l}\% \text { total } \\
\text { trade }\end{array}$ & Quantity & $\begin{array}{l}\% \text { total } \\
\text { trade }\end{array}$ & Quantity & $\begin{array}{l}\% \text { total } \\
\text { trade }\end{array}$ & Quantity & $\begin{array}{l}\% \text { total } \\
\text { trade }\end{array}$ & \\
\hline Volume (TDM) & 947 & 0.15 & 37533 & 10.2 & 340 & 2.6 & 8900 & 2.8 & 38820 \\
\hline $\begin{array}{l}\text { Value (1000 } \\
\text { USD) }\end{array}$ & 3631 & 0.46 & 78182 & 6.4 & 546 & 1.7 & 9800 & 4.9 & 82359 \\
\hline
\end{tabular}

The hide, skin and fibre export sector in West Africa represents 8.9 million $\mathrm{kg}$ volume and 9.8 million USD value (FAOSTAT, 2013), being much more important than meat or egg export and accounts for a very significant 4.9 percent of the regional production value described in Table 29. Among animal products in this category, hide and skin are the two mostly exported ( 99.5 percent of imports), with insignificant amount of wool and wool products sent abroad.

Most of the national production of hide and skin in Senegal, the leading exporter in the region with 47.6 percent of the export volume and 56.2 percent of the value, is used by local crafts workers. Togo, with 42 percent of the volume and 22 percent of the value, follows. Mali, with 9.5 percent of the export volume and a 19.7 percent of the trade value, achieves a much better added value in its trade (Jabbar et al., 2002).

Interestingly, the hide and skin sector has a positive trade balance for the region, being the only sector among all animal products. Such trade balance is nevertheless mostly positive because of Senegal and Mali (4.7 million USD and 1.3 million USD, respectively). Pakistan is the biggest trade partner for hide and skin for Senegal, buying products worth 3.2 million USD, while Portugal, Italy and China each buy around 0.5 million USD of the products. Most of Senegal's export, therefore, target world leather hubs outside Africa. On the other side, Togo exports most of its registered production to Ghana (98 percent of its volume and value), which may give clue for its reduced prices. Normally, regional markets pay less than global ones. 
The trade figures presented here are minimal when compared with the potential that the livestock subsector in West Africa has. The 2012 livestock country review for Burkina Faso (Some, 2012), for example, estimates the total potential value of the sub-sector around 3.3 billion USD, if properly managed.

\section{Price of animal products}

The average retail price list of major animal products as recorded on local markets in West African countries is given in Table 30. On the average, small ruminant meat, especially mutton is the most expensive meat in market places whereas imported chicken is the cheapest. Coastal countries, especially Liberia, Sierra Leone and Guinea, as well as Cabo Verde, show the highest retail prices.

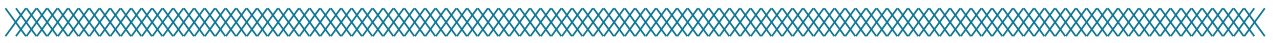

Table 30. The average retail prices of major animal products in West Africa

\begin{tabular}{|l|r|r|r|}
\hline Animal products & Maximum Price & Average Price \\
\hline Beef, USD per kg & 1.60 & 8.00 & 4.50 \\
\hline Mutton/Goat, USD per kg & 2.10 & 9.30 & 4.50 \\
\hline Chicken, USD per piece & 4.00 & 14.10 & 5.00 \\
\hline Broiler, USD per kg & 1.27 & 9.29 & 3.00 \\
\hline Pork, USD per kg & 1.15 & 6.00 & 3.50 \\
\hline Milk, USD per liter & 0.33 & 2.60 & 1.00 \\
\hline Egg, USD per piece & 0.07 & 0.26 & 0.13 \\
\hline
\end{tabular}

Source: Gueye, 2012; Talaki, (2012); Codjia, (2012); Codjia, (2016); Rouamba, (2016); Traoré, (2013); Megnibeto-Aplogan, (2015); Traoré, (2014); Akunzule, (2013); Kangni, (2015); Akunzule, (2014), Diallo, (2012); Haidara, (2012); Aboubacar, (2017); Bari, (2016); Gueye, (2017); Nwandu et al., (2016); Some, (2012), Correia, (2016); Oppong-Anane, (2016); Bakayoko, (2016); Dembele, (2017); Sesay, (2016); Frank and Annatte, (2016); Touray, Ceesay and Njai, (2010); Maïga, (2012); Loum, (2012); Djata, (2012) and Talaki, (2017).

Based on ranges, the highest price is recorded for local chicken, due to a combination of higher consumer preference attached to taste and their higher production costs (Box 7). The widest price range is recorded for milk, as prices are dependent on the type of milk and milk product, although all products are put on fresh milk equivalent basis. In general, milk products are imported and they do not large consumption base in West Africa (Box 6). Moreover, local preference is for fresh milk when available and its price goes up during off-season (dry season) periods in many countries and in urban areas. Reconstituted milk from imported powder is the cheapest and the most accessible milk yearround.

However, it is noteworthy that Table 30 gives only a general indication of livestock product prices in West African on local markets. There are huge differences between countries and even between towns and cities in a given country (Akunzule, 2014). The price variation may be also related to specific socioeconomic situations that are not captured in the data. Poor data recording and availability in most of the countries does not allow sensible comparisons between countries. 


\section{POLICIES AND LEGISLATIONS GOVERNING}

THE LIVESTOCK SUB-SECTOR IN WEST AFRICA
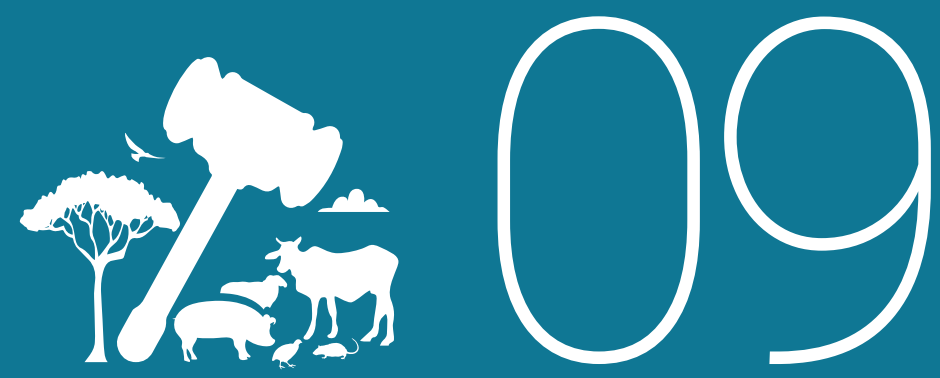



\section{ChAPTER IX}

\section{POLICIES AND LEGISLATIONS GOVERNING THE LIVESTOCK SUB-SECTOR IN WEST AFRICA}

\subsection{Livestock policies}

In West Africa where agriculture is still an important part of the national economies, especially among the poorest portion of the society, livestock has been in the spotlight for many development policies. Up to 60 to 80 percent of the poor in Africa depend on livestock at least partly, and the consumption of livestock products is increasing greatly (Pica-Ciamarra, Otte and Chilonda, 2007 and Smith et al., 2013). In West Africa, beef supports up to 70 million people and small ruminants up to 81 million (PicaCiamarra, Otte and Chilonda, 2007). Governments have seen the sub-sector both as an opportunity to reduce hunger and to boost economic activity, and they have focused on trying to correct existing inefficiencies ${ }^{47}$. The implementation of these policies is impeded by lack of resources for investments in the sub-sector, sometimes compounded by a lack of commitment and will by decision makers to do so. Country level policies are complemented by regional level strategies for governing livestock development, health and trade through the harmonization of actions in order to maximize the derived benefits (ECOWAP, 2005 and Kamuanga et al., 2008). This chapter deals with livestock policies both at the national and regional levels, and explores the regulations governing the livestock sub-sector.

\subsubsection{Policies at national level}

The untapped potential of the livestock sub-sector is a general concern among the National governments in West Africa. Past efforts on livestock policies were centered on improving the quality and numbers of production, animal health, enhancing trade infrastructures and strategies, and improving natural resource management. Unfortunately, they often have had limited success due to several reasons including an absence of continuing research and knowledge management, as well as political commitment. As a result, despite the effort to improve production, there has been an equally increasing demand in livestock products due to the change in demographics with increasing numbers of highly young population (ECOWAP/RAIP, 2016). Traditional production methods have therefore being unable to cope with demand, resulting in constant increases in import of livestock and livestock products (PicaCiamarra, Otte and Chilonda, 2007 and ECOWAP/RAIP, 2016).

${ }^{47} \mathrm{cf}$. section 11 . 


\subsubsection{Policies on competitiveness}

It is pertinent to note that the livestock sub-sector is increasingly becoming competitive and attractive for strategic national investment in West Africa despite the challenges confronting it. However, it is believed that with the appropriate investments, the sub-sector can support national production against cheap and lower quality imports, and also save foreign exchange spent on import, while at the same time earning some foreign exchange for the country. Producing the quality of products that will enable access to profitable export markets as well as compete with some of the high quality imported products has been challenging for countries in West Africa (Codjia, 2016 and Correia, 2016). That goal, however, has been achieved in other parts of Africa, namely in Botswana, through the implementation of a national coordination body of beef production (the Botswana Meat Commission) that has achieved a more efficient production, well-planned infrastructure, and safe standards for accessing export markets.

However, similar attempts in Burkina Faso and Niger have failed due to a lack of appropriate combination of adequate infrastructure and necessary professional management as was the experience with the Office Nationale d'Exploitation des Ressources Animales (ONERA) and the Société National d'Exploitation des Ressources Animales (SONERAN), respectively (SWAC/OECD, ECOWAS, UEMOA, CILSS and ROPPA, 2008a). It is nevertheless noteworthy, that although the outcome of the Botswana policy on meat has been positive at the macro level, the consequences have been dire for smallholder farmers. The centralization of the livestock governance, coupled with widespread intensification for control of animal diseases through widespread fencing and less emphasis on extensive cattle production practices has deepened inequality, has been counter-productive to poverty reduction, and created concerns for its long term sustainability (Henry and Manzano, 2016).

Investing in local value addition for economic and environmental sustainability remains consequential for the transformation of the livestock sub-sector (Manzano, 2016). But the Botswana example shows the complexity and inadvertent effects of interventions in the livestock sub-sector that seek to transform the age-long extensive systems of production to intensive systems to meet the standards for competitive markets, and the risk to oversee trade-offs with social and environmental factors (Manzano, 2017b). Senegal is working on several projects to improve productivity and commercialization at the national level of the milk sub-sector (Gueye, 2017). After several starts and stops at livestock intensification programmes for competitiveness (Maina, 2017) and in the wake of the challenges it is currently facing with continuing violent clashes between pastoralists and crop farmers, Nigeria is currently grappling with the formulation of a livestock policy aimed at transforming the livestock subsector through intensification by ranching, implying pastoralist sedentarization (Box 8). Its outcome remains to be seen, but previous experiences elsewhere show a great decrease of profitability in the targeted livestock systems (Hatfield and Davis, 2006), again, determining social factors that surround the problem are likely to be overseen (Manzano and Slootweg, 2017).

In the 1980s and 1990s, Ghana's goal for the livestock sub-sector was aimed to generalize institutional reforms that included "decentralization, liberalization, privatization and civil service reforms" (Ayee, 2001 and MoFA, 2004), involving investments that included recovering costs from operations, deemphasizing unproductive government operations and structuring the animal production and health service delivery for efficiency and effectiveness. Although Ghana achieved some successes in its drive towards transformation for competitiveness in the livestock sub-sector, again as in other countries, the challenge was the impact of such transformation on the livelihoods of smallholders in rural populations, and the inadvertent political and socio-economic changes they trigger. More recently, Ghana has formulated and adopted its Livestock Development policy (MoFA, 2016 and AfricaLead, 2017) that aims at ensuring support for competition through improved breeding stocks, improving animal nutrition, 
controlling diseases, and ensuring adequate infrastructure for mobile herds during the dry season. The outcome of this new strategy will be seen in due course.

It is pertinent to note that policy changes at the international level inadvertently have implications at the country levels. Generally, country level policies are derived from international policy outlooks, and when there are sudden changes in policy at the international level, countries are left to absorb the shocks. Many countries do not absorb such shocks so well due to persisting weak systems. Changes in food standards and regulations also have such consequences on low income countries. For example, the Millennium Development Goals (MDGs) came on stream at a time Ghana was trying to implement its Accelerated Agricultural Growth and Development Strategy (AAGDS). With the MDGs focused on poverty reduction, international agencies began to streamline their support towards the MDGs, and Ghana's AAGDS suffered from a lack of interest from such agencies. Ghana had to beat a retreat from its own growth and development policy to realign with the international order on MDGs. This scenario plays out in various forms in developing countries resulting in an inability to be consistent with livestock policy implementation.

\subsection{Extension Services}

The quality of the genetic stock has been a major target for competitiveness policies ${ }^{48}$. Local breeds are poorly adapted to industrial production and are therefore considered to yield low production. Actions to provide more productive genetic stock have been conducted in Ghana (Akunzule, 2014 and OppongAnane, 2016), and Benin (Megnibeto-Aplogan, 2015 and Codjia, 2016) poultry and ruminant meat, in Côte d'Ivoire (Bakayoko, 2016) and Cabo Verde (Bari, 2016) for meat and dairy, and in Burkina Faso (Rouamba, 2016) and the Gambia (Touray, 2016) for dairy. In Nigeria, there have been efforts to improve genetic stock for meat and dairy production, poultry as well as fisheries (Maina, 2017). The genetic management can certainly be improved to ensure success, but requires effective extension service delivery from competent extension officers. For example, if not well planned and managed, improving genetic stock has inherent danger such as inbreeding and transmission of undesirable recessive genes in to population. Furthermore, genetic improvements should be planned together with other actions that support intensification, such as improved nutrition. Otherwise, such actions can adversely impact local breeds and production systems with consequences on food security and nutrition, and poverty reduction. An example being the erosion of hardy traits at backyard poultry or pastoralist ruminants, with low production but high resilience and adaptations to low quality feed (Idi and Ganda-Idé, 2009). Additionally, approaches that link genetic stock improvement to intensification tend to overlook the absorption capacity of local markets in terms of volume, and also ignore food security and nutrition aspects for citizens, as these aspects seem invisible to national governments during data collection and policy planning (Kay, 2016).

The weak extension service delivery, coupled with low knowledge capacity of local livestock keepers in genetic management is compounded by poor understanding of other knowledge areas. In many West African countries, including Cabo Verde, such lack of knowledge affects all levels of the value chain management, which is compounded by a general weak support by government (Bari, 2016). This is not an isolated situation and, unfortunately, policies for supporting extension services are scarce and, when available, weak. In some countries such as Burkina Faso, livestock keepers depend on the private sector to provide support (Rouamba, 2016), while in other countries such as Gambia and Nigeria, the public sector offers limited livestock extension service support (Adisa, 2015 and Touray, 2016) that is restricted to livestock production aspects such as feeding, handling, housing and production. However, 
such services do not include managing practices such as selection of breeds, breeding practices, nor animal disease and pest control despite government policy of delivering vaccinations free and paying compensation to farmers that loose animals due to disease outbreaks of epidemic proportions, such as the HPAI. Only 16 percent of those engaged in livestock extension service delivery in Nigeria had the qualification and competence to do so (Adisa, 2015).

The practices to increase biosecurity for the food products produced, or resilient pro-poor livestock systems that guarantee the producers' food security (Touray, 2016), are also weakly represented. In Niger, the investment on extension services and their quality has been dramatically dropping since independence, in spite of the importance of the sub-sector for the national economy (Rhissa, 2010). In Benin the issue of weak support has been tackled to the point of being included in a national support project (Codjia, 2016), as has in Mali (Dembele, 2017), while Côte d'Ivoire is investing in improving the farmers' capacity (Bakayoko, 2016). In Liberia, the delivery of services remain weak to non-existent, due to lack of competent livestock expertise and funding challenges in the centralized Ministry of Agriculture (Touray, 2017), while Guinea depends substantially on the cooperation and support from development partners (Mane, 2017).

Some policies that are implemented explore new niches for farmers around non-conventional livestock such as smoked cane rats, commonly referred to as "grasscutter or bushmeat" 49 . The government of Benin seeks to support grasscutter keepers through a 5-year project (Projet d'Appui au Développement de la Filière Aulacode (PADFAu) lasting up to 2017 (Codjia, 2012 and 2016). In Côte d'Ivoire, Ghana and Nigeria the importance of grasscutter farming for food security and nutrition and income generation for rural populations, as well as to satisfy the appetite of the wealthier population that see it as a delicacy, has been recognized and encouraged (Boakye, 2008; Bakayoko, 2016; ljeomah, Ofodile and Okereke, 2016 and Ibitoye, Kolejo and Gabriel Akinyemi, 2019) Ghana has further supported the production of guinea fowl for food security and nutrition, and income generation (Akunzule, 2013).

Since the 1980s and framed within its work with national governments, FAO has been promoting the approach of Farmer Field Schools, which encourages self-learning of farmers by their own practice (FAO, 2016b). Additionally, the ECOWAP aims at encouraging and supporting family farms for food and nutrition security, income generation and improved livelihoods (ECOWAS, 2015). These are long-lasting approaches that empower producers by promoting a horizontal learning, away from the conventional top-down approach, encourage the spreading of innovations and traditional knowledge while reinforcing farmers' networks that start with family sized units. The FAO approach initially benefitted backyard livestock keepers. However, ILRI has further developed the concept into Pastoralist and Agro-Pastoralist Field Schools (FAO and FFSPS, 2013). In West Africa, it is being applied under the Integrated Production and Protection Management in Benin, Burkina Faso, Guinea, Niger, Mali and Senegal (FAO, 2014).

\subsection{Investment}

Following the 2003 Maputo declaration, West African countries pledged to increase their investment in the agricultural sector including livestock by 10 percent from 2005 to 2015 . However, analyses on how the National Agriculture Investment Plans (NAIPs) have been unfolding show that financial strength of the actual investments have been weak (ECOWAS, 2015), with less than 1 percent of the GDP going to the sub-sector even in countries where livestock contributes 20 percent or more of the GDP50. The revision of ECOWAP for 2016-2025 and the associated NAIPs is expected to give livestock a much more relevant role ${ }^{51}$ (FAO, 2017a). 
Poor competitiveness is often affected by the inability of farmers to undertake investments and consequently, specific agricultural soft credit policies are a tool aimed at improving their situation. In Guinea, 70 percent of the rural population cannot access credit (Mane, 2017). In West Africa, such policies are fatally affected by the lack of consistency of government's follow-up, as they involve significant budget allocations in the long term. The existing credit policy to stimulate investments in Cabo Verde is weak and unreliable (Bari, 2016). The Ghana Agricultural Development Bank, a public facility devoted to such tasks, no longer exists (Oppong-Anane, 2016), while existing facilities in Senegal provide credits that have too high taxes to be affordable for livestock producers (Gueye, 2017). Sierra Leone plans to set up an agricultural credit facility, but the project is experiencing troubles for its deployment (Sesay, 2016), related to low capacity and commitment. In Côte d'Ivoire there is a positive response from the civil society following the inaction of the public sector. There are no specifically designed agricultural credit facilities, or others that are more favorable to farmers. However, poultry producers have associated themselves to provide credit under better conditions. Following that initiative, the government plans to put a mechanism in place to benefit livestock producers in general (Bakayoko, 2016). In Nigeria, several policies to support agriculture production have been tried over the years, but have not advanced as planned. For example, the Nigeria Bank of Agriculture (BOA) and the Nigerian Agriculture Insurance Corporation (NAIC, 2019) are government-owned institutions with mandate to support the development of the agriculture sector. However, it is difficult to assess their impact in supporting the development of the livestock sub-sector in Nigeria. As a result of this, producer organizations have formed associations to support each other in advancing their investments in the livestock sub-sector. Among these, the Poultry Association of Nigeria (PAN) (PAN, 2019) stands out with membership in each of the thirty-six States of Nigeria, and the Federal Capital Territory.

\subsection{Trade policies}

West Africa could greatly benefit from intra-regional trade, avoiding imports from outside the area, improving synergies and boosting local productivity. A strong live animal trade has existed for very long from the Sahel countries, which are net livestock producers, to the Coastal countries, which are net consumers. This trade has benefited in the last decades from a change of policy in EU countries to reduce the subsidies for export. At the same time, the ECOWAS and UEMOA provide a promising framework to increase trade. The ECOWAS Trade Liberalization Scheme, planned for 1979 but finally launched in 1990; (Ukahoa and Ukpe, 2013), the creation of a CET adopted in 2013; (von Uexkull and Shui, 2014), the free movement of people, goods and services, as well as other related regional policies have been aimed at harmonizing actions and promoting intra-regional trade. However, the outcomes for improvements in livestock trade, particularly cattle and poultry, is yet to reach its maximum, with deterioration in poultry production and trade since 1980s being evident (Williams, Spycher and Okike, 2006 and SWAC/OECD, ECOWAS, UEMOA, CILSS and ROPPA, 2008b). While there has been some progress at the national level in suppressing tariff barriers or working towards a custom union, there is still a long way to go. Harmonization and co-ordination of livestock trade policies, especially regarding outer tariffs and protection of regional systems, has been much weaker, and the tightening of law enforcement to stop illicit taxations is a problem that hugely affects regional trade and which is still far from being tackled ${ }^{52}$.

Regarding the trade with countries outside West Africa, a general push towards protectionism is seen in the region especially for the poultry sub-sector, much affected by cheap industrial imports (Box 7), to the point even of triggering corrections by the International Monetary Fund and the World Bank in Ghana in 2003 (Akunzule, 2014). Controlling prices by decree in order to guarantee food security, as in Guinea, has also proved ineffective (Diallo, 2012). This is in any case a measure not recommended by any economist school as it may cause product shortages. 


\subsection{Natural resource base policies}

The extensive production system, including family backyard monogastric production and pastoralism for ruminants, is the most widespread production system in West Africa. This system minimizes inputs by making animal feed highly dependent on the natural resource base, as made visible by the high increase of chicken price following scarcity of corn in 2008 in Togo (Kangni, 2015). Furthermore, even the coastal countries of Guinea Bissau and Sierra Leone depend on natural pasture for feeding their ruminant livestock, overwhelmingly owned by the pastoralist Fulani ethnic group (Correia, 2016 and Sesay, 2016). Conflicts also further undermine livestock production, as undemarcated stock routes are encroached upon, and grazing/watering points are taken over by crop farming and infrastructural development as is the case in the Gambia (Touray, 2016). In Nigeria, 90 percent of the national agricultural production is achieved by small farmers. Depletion of rangelands is going on because of lack of organization and integration of systems, which drives farmer-pastoralist conflict, depletion of aquifers through irrigation, and widespread soil erosion (Frank and Annatte, 2016). In Niger, national policies seem to promote crop farming at the expense of pasture development (Snorek, 2016), a heritage of the 'Land to the Tiller' policy of the 1970s and 1980s (Snorek, Renaud and Kloos, 2014). As a consequence of such dependence, some countries in the region have specific policies to protect the natural resource base. Among these, policies attempting to protect livestock mobility and to prevent land degradation are particularly important.

In Niger, the livestock sub-sector relies on the natural resources but its productivity and stability is affected by conflicts due to the land tenure system. Despite the difficult conditions, the livestock producer beneft from regulation on stock routes (FAO, 2002). The conflicts on natural resources happens in spite of being more innovative than many other countries in the region, including a thorough regulation of stock routes (Rhissa, 2010). This situation is exacerbated by land grabbing (Touré, 2016). In Mali, the contribution of livestock mobility to the sub-sector is legally recognized, and there are further policies supporting livestock production including backyard systems. Unfortunately, their implementation is very weak with little benefits to the livestock producers (APESS, 2014a). Several national policies in Burkina Faso specifically protect the rangelands, on which the meat and milk sub-sectors depend (Rouamba, 2016). In Cabo Verde, where livestock production is almost entirely family-farmed and fed on natural pasture, issues are arising around land degradation due to inadequate livestock management. This has triggered a number of development projects oriented to tackle the challenge (Bari, 2016).

In Côte d'Ivoire, the livestock system depends on natural pasture due to pastoralism, but also relies on secondary agricultural by-products for animal feed such as cottonseed cake, this itself highly dependent on climatic variations (Bakayoko, 2016). Forests and biodiversity are particularly affected by intensive livestock, whereas extensive livestock is acknowledged for some benefits such as carbon stocks. Being aware of the problem, the state has an active policy to improve natural resources use. In general, the regional livestock policy is aimed at gradual intensification, implying pastoralist sedentarization (Gonin, 2014) even if it is shown to be detrimental for production and if it collides with legislation (Gefu, 2009 and Zakaria, 2014).

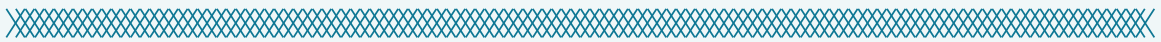

\section{Box 8}

The experience of grazing reserves in Nigeria.

The first attempt of introducing grazing reserves in Nigeria started in 1954, with the Government allocating four hectares of pastureland to each pastoral household. With the grazing reserves allocated to them, it was hoped that they would discontinue seasonal movement and engage in some kind of mixed farming. The pastoralists never enjoyed this facility. Following the failures 
of this experiment, in 1964 a new grazing reserve system was established, based on pieces of land from 50 to 100 hectares, acquired and developed by the government, allocating each settler a plot according to herd size and carrying capacity of the land. The settler was required to pay an annual rent to the government and agree to apportion the land for grazing, settlement, farming of legumes and fallow. The government regulated the seasonal use of reserves to ensure land conservation. The reserves were open to the animals during the rainy season, and closed during the dry season, when animals went seeking for pasture. During severe shortages of feed, communal grazing areas were open to distressed herds whose owners applied for a grazing permit (Iro, 1994). This policy did not succeed due to several reasons including overstocking, overgrazing, degradation of the ecology, animal and human health problems, lack of adequate fodder, land right issues and conflicts between pastoral and agricultural communities (Gefu, 2009).

An estimated 415 grazing reserves to settle pastoralists, covering 4.275 million hectares were identified, with (Modibo, 2010) covering 2.7 million hectares established under the Grazing Law of Northern Nigeria 1965, in 19 Northern States of Nigeria (Abdullahi, Daneyel and Aliyara, 2015). Recently, the Federal Government of Nigeria is attempting to revive the Grazing Reserves (Vanguard, 2017) and Stock Routes (Premium Time, 2017), as a solution to the increasing violent conflicts between crop farmers and pastoralists, and among pastoralists themselves. Assessments were made and various stakeholders were consulted. Not only interests of many groups differ but the grazing reserves themselves are far from social amenities and exposed to banditry, making them less attractive to pastoralists. The general perception is that pastoralists feel that their mode of life is not appreciated and proposed solutions are not based on those premises. 'This age-old system should stop and pastoralists should lead a settled life' is the statement mostly heard (Gundu, 2016). Failing to achieve the proposed objectives, the proposal is now to turn the Grazing Reserves to Ranches with voluntary pastoralists and others interested in livestock farming taking part in the scheme.

\subsection{Animal Health Policies}

The evaluation and gap Analysis performed by the OIE through its Performance of Veterinary Services (PVS) evaluation tool (OIE, 2013) show a negative insight on the animal health sector in the region. The analysis conducted in Benin, Ghana, Guinea, Guinea Bissau, Niger, Nigeria and Togo paints a picture of veterinary services too weak to design and implement policies because of shortage of human resources, material and financial resources (OIE, 2017). Early detection of diseases, confirmation by laboratory and rapid response are all lacking. As a result, major epidemics like the Avian Influenza affected the region in 2006/2007 and again in 2015/2016. The outbreaks of major TADs such as PPR, ASF, RVF and CBPP are endemic in the region and most of them cannot be controlled without assistance from abroad.

The animal health sector suffers poor commitment to funding in the region, in parallel with other investments, as in Niger, where the privatization of veterinary services and the lack of consistency in long-term strategies have driven to the failure of otherwise well-planned programmes (Rhissa, 2010). In Mali, the shortcomings have been mitigated by putting veterinarians with private practices under the control of the national veterinary services (Haidara, 2012). 
The avian influenza epidemics in the first decade of the 21st century triggered widespread specific measures that nevertheless lack a bigger picture approach and show a reactive rather than a proactive approach in many West African countries including Nigeria (Adene and Oguntade, 2006), Togo (Kangni, 2015), Côte d'Ivoire (Kone and Danho, 2008), Ghana (Akunzule, 2014), Guinea (Souare, 2008), Senegal (Traoré, 2014), Burkina Faso (Salam Richard, 2008), and Mali (Traoré, 2013). Furthermore, general sanitary measures are also weak, as reported in the poultry sub-sector in Togo (Kangni, 2015). More recently, due to continuing outbreaks and the fear of zoonosis, there have been efforts to improve veterinary services delivery and fund such services. In Benin, the avian influenza epidemic triggered a stronger, free public support for poultry vaccination in general (Megnibeto-Aplogan, 2015). Similarly, in Côte d'Ivoire there is a planned investment in improving animal health and food safety (Bakayoko, 2016), as is in Senegal (Gueye, 2017); the few investments of Guinea Bissau actually target animal health (Correia, 2016), and the little extension capacity available in Sierra Leone is dedicated to it, as well as many of the investment projects (Sesay, 2016). In Cabo Verde, ASF is a disease that is getting extensive funding (Bari, 2016). Conversely, in Senegal the prevention of animal diseases so far has been left to the interaction of producers and private providers, the producers in the more remote areas being therefore more exposed (Traoré, 2014). In Nigeria, the current effort is aimed at reviewing obsolete laws on disease prevention and control, as well as streamlining regulatory agencies to ensure enforcement and compliance (Garba et al., 2014).

The different reports prepared on the poultry sub-sector in the region demonstrated high losses due to vaccine preventable diseases such as NCD. Several countries, including Ghana (Akunzule, 2014) are engaging in large-scale vaccination programmes for rural, backyard systems. Ghana has further classified poultry farms based on biosecurity standards.

\subsection{Policies on livestock statistics and data collection}

The official data collection on livestock in West Africa is generally weak, being of poor quality wherever it exists. This, therefore, hampers planning interventions in the livestock sub-sector, and has become a key policy issue. Lack of accurate data creates uncertainties and poses challenges of planning for national poverty reduction that then further impacts the rural poor, with the effects of detrimental policies or new international settings taking effect on their livelihoods (Toulmin and Guèye, 2003). Planning for the disease prevention and control is also affected by unavailable, inaccurate or poor data ${ }^{53}$.

The Nigeria example is maybe the most instructive. Nigeria is the most populated country, not only in West Africa but across the continent and with the largest economy in the region. However, it is pertinent to note that due to unavailable official data, the FAO Statistics (FAOSTAT) data seem to have reached its limits of estimations due to continuing estimated projections over the years. For example, the FAOSTAT value of demand for milk, as shown in Table 22, possibly represents less than 50 percent of the total milk demand, with the balance covered by informal trade in communities or by domestic consumption (Frank and Annatte, 2016). Distortions to official data estimates as a result of poorly captured informal trade records have consequences on the estimated yearly milk consumption of $4.12 \mathrm{~kg} /$ person shown in section 5.1 .2 , and contrasts with the $20-25 \mathrm{~kg}$ if the informal supply were accurately accounted for. This can be extrapolated to other livestock products such as meat, given that most slaughtering does not take place in designated and certified abattoirs. In Burkina Faso, 86 percent of meat is estimated to be processed informally (Some, 2012). Such weakness in data collection makes policy planning, and project design extremely challenging.

To further illustrate this point, it is to be noted that an FAO report on Burkina Faso states, without citing the source other than "trade balance statistics", that livestock export earned the country 120 million USD in 2009, divided equally between live animal trade and hide and skin trade (Rouamba, 2016). However,

${ }^{53} \mathrm{cf}$. section 6.2

152 The role of livestock in food security, poverty reduction and wealth creation in West Africa 
the FAOSTAT data compiled in this report show a much more reduced revenue of 6 million USD from live animal exports (Table 24) and an insignificant amount from hide and skin ${ }^{54}$. Similarly, live animal exports excluding poultry are estimated to be more than 1.5 million in the report (Rouamba, 2016) and 34000 by FAOSTAT. In the same report, figures from other sources are given, valuing total meat and skin exports at 16 million USD for meat and 3.51 million USD for skin (Rouamba, 2016). Such divergence shows a weak data recording policy by governments and its reporting agencies, and in the general philosophy of elaborating reports. There is need for Livestock Ministries, Departments and Agencies, who often claim to have good data, to improve collaboration with National Statistics agencies on data collection and processing.

The processed animal products, i.e. dairy, meat, leather, sausages, etc., are classified under the industrial sector, and not under agriculture or livestock, while the agriculture and livestock sub-sector carries out surveys of animal numbers that end up being far from reality. Therefore, collaboration is needed to align live animal counts to industry production figures to avoid the current mismatch. Such collaboration for livestock sample surveys was recently conducted jointly by the Bureau of Statistics and the Livestock Department in Sierra Leone with useful outcomes (FAO, 2017b). In the Gambia, the live pig population is reported to be grossly underestimated by official data, with the real population estimated at 12 times the size indicated by official data sources (Touray, 2016); and the official poultry estimates considered to be half the size of other estimates in Niger (Idi and Ganda-Idé, 2009). In Mali, it is reported that the official livestock trade statistics may represent only a third of the total trade value (Josserand, 2013).

Regarding the economic valuation of livestock activities, particularly pastoralism, there have been a few attempts to capture its full economic significance, particularly by the International Union for Conservation of Nature (Wane, 2006 and ADG, 2007). However, it is extraordinarily challenging given the poor quality of data, and it is evident that official statistics grossly underestimate its importance (Rodríguez, 2008). For example, the comprehensive studies on the economic contribution of livestock to national economies in Eastern Africa conducted by the Intergovrnmental Authority on Development (IGAD) showed that Kenya's milk sales are one twentieth of national milk production, and milk is three quarters of all livestock output by value (Behnke, unpublished). The studies further estimated that 22 percent of total meat supply comes from neighbouring countries transhumant herds and flocks not recorded officially in Kenya. The information on the situation of livestock goods and services pose additional challenges. For example, only 42 percent of livestock products are recognized on Ethiopia's national earnings. Only 10 percent of financial services by livestock in Kenya are recognized. Corrections of livestock census from 2007 to 2008 show a difference of almost double in East Africa, two third in the case of Kenyan camels. With 30 years without a proper livestock census, it is shown that what is not accounted for is ignored. The national livestock authorities are confronted with formidable challenges of showing the real contribution of the livestock sub-sector to the national GDP and to the income of rural households in order to persuade decision makers for more public investment. The East African experience is not any different from the West African situation with regards to live animal trade by pastoral system. It is therefore pertinent to identify appropriate tools for tracking such trade and informal trade of livestock products.

\subsubsection{Regional level policies}

The main institutions regulating the regional initiatives in West Africa are the ECOWAS and UEMOA (Kamuanga et al., 2008; Ickowicz et al., 2012 and Hollinger and Staatz, 2015). The ECOWAS is one of the eight Regional Economic Communities (RECs) of AU, established by a treaty with 15 West African countries as Member States in an area spanning 5.2 million square kilometres. The ECOWAS Community is governed by the Authority of Heads of State and Governments. Its governance structure 
comprises three arms including the Executive, the Legislature, and the Judiciary. The Community is headed by a Chairperson of the Authority of Heads of States and Government that is appointed by fellow Heads of States and Government to oversee the affairs of the Community for a period of one year. This arrangement enables seamless work as the country holding the Chairperson presides over all Statutory, Technical Committee and Senior level meetings. The ECOWAS Commission is the Executive arm of the Community, and is presided over by the President of the Commission, who is appointed by the Authority of Heads of States and Government for a non-renewable tenure of four years. The President of the Commissioner is assisted by a Vice President and thirteen Commissioners. The Legislative arm of the Community is the Community Parliament that is headed by a Speaker of the Parliament, with the administrative functions directed by a Secretary General of the Parliament. The Judicial arm of the Community is the Community Court of Justice that is headed by the President of the Court. The Court interprets the application of Community laws, protocols, and conventions. A Court Registrar administers the Court. The ECOWAS Community is guided by some fundamental principles, most of which are enshrined in the Treaty.

The ECOWAS Community also has several Specialized Institutions and Agencies based in several countries of the region, including the Regional Animal Health Center based in Bamako, Mali established through Supplementary Act A/SA.20/02/12. The Center has the overall mandate for the prevention and control of TADs and zoonoses for the improvement of food security and nutrition, livelihoods, wealth creation and poverty reduction through efficient animal health management in the ECOWAS region. This is achieved through strategies, regulations and programmes in alignment with the ECOWAP.

The ECOWAS has a vision of a borderless, integrated, peaceful, and prosperous region built on the principles of good governance that creates opportunities for citizens to access and harness resources for sustainable development and environmental preservation to live in dignity (ECOWAS, 2019). The reforms authorized by the ECOWAS Authority of Heads of States and Governments that transformed the ECOWAS Secretariat into the ECOWAS Commission, empowered the Commission with some supranational powers particularly in the area of policy and regulation. This was intended at ensuring that when regional policies or regulations undergo the appropriate process and are adopted and published, such can be implemented in Member States.

The livestock sub-sector is governed under the Chapter IV, Article 25 of the ECOWAS treaty that mandates the Commission to coordinate all aspects of agriculture for food security and nutrition, increased productivity, improved value addition and trade (ECOWAS, 2006). This instruments for delivery of this mandate is the ECOWAP and the regional agriculture investment plan (RAIP), which is aligned with CAADP of the African continent and has the NAIP as the national component for each ECOWAS Member State (ECOWAP/RAIP, 2011). These overall policy initiatives sets out guidelines that encompass and benefit the livestock sub-sector in the region.

\subsection{Economic development}

The ECOWAS Member States have aligned their policies on agriculture and livestock to the CAADP/ ECOWAP/RAIP/NAIP development frameworks. These development frameworks seek to fulfill the African Heads of State pledge at Maputo in 2003 to commit 10 percent of the national budgets to agriculture and rural development to ensure food security and agriculture production in order to achieve an annual growth rate of six percent (NEPAD, 2003). At the continental level, such positioning has translated into the formulation the African Union's Livestock Development Strategy (LiDeSa) (African Union Commission, 2014b). At the regional level, livestock development is guided by the ECOWAS Strategic Action Plan for the Development and Transformation of the Livestock sub-sector. These 
strategies aim at tackling the identified challenges in the livestock sub-sector such as high dependence on imports, poor productivity and expected demand, in line with challenges faced in West Africa ${ }^{55}$, through national and private sector investments, as well as the support of development partners. This would help the initiatives for diversification of livestock systems that have started emerging e.g. in urban and peri-urban areas following the increased urbanization trend (Ly, Fall and Okike, 2010) and the more diverse local consumer preferences (Staatz and Hollinger, 2016).

The Malabo Declaration of 2014 was a recommitment of the African Heads of State to CAADP and the Maputo commitment, which emphasized competitiveness in agricultural trade for wealth creation, and set specific targets and goals. The goals include enhancement of investment finance in agriculture, curbing malnutrition to 10 percent and ending hunger by 2025. This is to be achieved by doubling agricultural productivity by ensuring inputs supply, irrigation and mechanization, as well as halving poverty by inclusive agricultural growth and transformation. It also aims to boost intra- African trade in agricultural commodities and services, to commit to mutual accountability to actions and results, and to enhance resilience of production systems to climate variability and other shocks (NEPAD, 2014). The current commitments also take into account the Agenda 2030 for the integration of the Sustainable Development Goals (SDGs) (Abdulai, Kagumire and Geoghegan, 2018). This is a much needed step considering that the gains in production for African farming systems have basically been achieved through an expansion in the area used, and not by increasing the efficiency of production as in the rest of the developing countries (Staatz and Hollinger, 2016). In aligning with the Malabo declaration, the ECOWAS assessed, reviewed and updated its regional and national agriculture investment plans to take cognizance of the directives of the African Heads of State (ECOWAS, 2015).

Such alignment will create a forum for peer review, dialogue and experience sharing with the framework of ECOWAP, the RAIP and NAIP. ECOWAP has been a part of the CAADP implementation and one of the main objectives of the livestock component is to reduce dependency on imports of food of animal origin from outside of the region. It has been envisaged to achieve this objective through the development of livestock/meat and dairy value chains (Touray, 2016). The CAADP Compact for many countries recognizes the importance and potential of regional bodies including agricultural trade, regional integration for forestry and fisheries, the development of the private sector in key commodities, and the training of experts to solve the emerging issues relating to the sub-sector.

In collaboration with ECOWAS, the FAO Subregional office for West Africa reviewed the livestock, meat and milk value chain and elaborated a regional plan for improving these livestock value chains. However, the Regional Agriculture Investment Programme (RAIP) indicated challenges at coordination the 15 NAIPs, most of which did not have livestock component (ECOWAS, 2015). The second phase of ECOWAP/RAIP 2016-2025, is committed to focus on the livestock sub-sector for investment in "regional integration of production and trade in livestock and livestock products" being one of its three sectorial priorities (FAO, 2017a). The ECOWAP/RAIP 2016-2025 was adopted during 2017 with the investment support from partners of regional multimillion livestock projects including the regional project to support pastoralism in the Sahel (PRAPS) and regional programme for the development of livestock in the coastal countries (PRIDEC).

Several other bodies work in the ECOWAS region to frame multi-country collaboration including the Niger Basin Authority, aimed at fostering co-operation and ensuring an integrated development of the River Niger; the Authority on Integrated Development of Liptako Gourma Region among Burkina Faso, Mali and Niger; the Mano River Union, aimed at maintaining dialogue for unity and solidarity and the development 
of the Mano River Basin; the Senegal River Basin Organization aimed at governance of the Senegal River for cooperation and peaceful co-existence among Member States. The WALIC ${ }^{56}$, formerly referred to as the International Trypanotolerant Center is an example of a Center for technical collaboration. Funding organizations in the region that are useful for supporting livestock development the African Development Bank (Kamuanga et al., 2008), the ECOWAS Bank for Investment and Development (EBID), and commercial banks including ECOBANK.

\subsection{Policies on Trade}

The regional trade-oriented measures promoted by ECOWAS to regulate livestock production and its impact on livelihood of the populations of the region include i) the ECOWAS Strategic Action Plan for the Development and Transformation of the Livestock sub-sector, ii) the ECOWAS Trade Liberalization Scheme, iii) the ECOWAS Free Movement of People, Goods, and Services protocol, and iv) the ECOWAS CET. The Strategic Action Plan for the Development and Transformation of the Livestock Sub-Sector was adopted in 2009 to promote regional livestock production, regional trade and coordination of national policies towards the gradual intensification of livestock production systems (ECOWAS, 2019). The UEMOA-led Trade Liberalization Scheme attempts to establish a Customs Union among all member states aimed at the total elimination of customs duties and taxes of equivalent effect, removal of non-tariff barriers and the establishment of CET. The CET is one of the instruments adopted since 2000 and strengthened through a customs union in 2007 (CILSS, 2010), to protect goods produced in ECOWAS member states, harmonizing the Value Added Tax (VAT) and strengthening its Common Market throughout the establishment of the ECOWAS-CET. Such agreement simplifies border tariffs by providing four tariff bands, and creates a common nomenclature for achieving transparent and quicker customs procedures. In spite of the intentions of the CET, it provides a very limited protection to local production, especially if compared with other free trade areas as the European Union (Guibert et al., 2009). There is a generalized worry for the cheap imports from Europe that compete with local

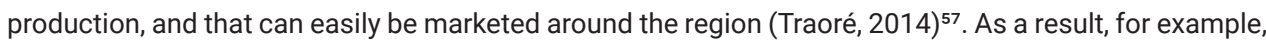
in Benin, legislative frameworks restrict or prohibit imports of poultry and dairy products from outside the region, with the intention of protecting national production, even though they have weak enforcing capacity, as discussed in Box 7 (Megnibeto-Aplogan, 2015 and Codjia, 2016). The high contribution of informal cross-border trade to the overall trade volume and regional GDP, and the consequent troubles in regulating and optimizing it, are also a great source of concern (FAO and ECA, 2018).

The Permanent Interstate Committee for Drought Control in the Sahel (CILSS) developed a plan to work on improved market access through the Exchange's Fluidification and Policy Reconciliation Project (FERAP) until 2001, and later through the "Border Markets" Project (Project to Improve Commercialization and Regional Livestock Trade in West Africa) until 2004, and then the Regional Programme of Market Access Support since 2005 (CILSS, 2009). This plan is aimed at promoting local capacity through information exchange and private sector support to encourage safe commercial exchanges within the region.

After a survey in Burkina Faso, Côte d'Ivoire, Mali, Niger, Ghana and Nigeria (CILSS, 2010), there has been a progressive liberalization in live animal cross-border trade in the region, including a simplified fee structure, a reduction of border fees, and a more limited reduction in other rights and taxes. More work still needs to be done in curbing taxes on regional trade, non-tax barriers, and illegal taxes. This requires deeper harmonization and collaboration between countries in working for improved regional trade, and a more comprehensive implementation of both UEMOA and ECOWAS trade agreements, as well as the ECOWAS transhumance regulations. Considering the increased open access of West African markets, the livestock sub-sector will still be non-competitive against exports outside the region as long as it lags behind in term of resource allocation by governments (Ly, Fall and Okike, 2010).

${ }^{57} \mathrm{cf}$. Box 7 


\subsection{Animal Health and Traceability}

While the ECOWAS 2011-2020 regional strategy for the development and transformation of the livestock sub-sector in the ECOWAS region has components on disease prevention and control as well as identification and traceability, the ECOWAS Commission has further formulated strategies for the control of specific diseases (OECD, 2009 and ECOWAS, 2010a). The ECOWAS regional strategy for the prevention and control of the HPAI has an accompanying document on pandemic preparedness (ECOWAS, 2006), the ECOWAS regional prevention and progressive control of PPR, as well as the roadmap for the prevention and control of FMD (ECOWAS, 2006; ALive, 2006 and ECOWAS, 2012a). Furthermore, the ECOWAS Authority of Heads of States took a decision in 2012 on the establishment of the Regional Animal Health Center, with the mandate to ensure the control of animal diseases in the region (ECOWAS, 2012b) The Center collaborates with the FAO and the OIE as technical partners, and implementing projects on disease prevention and control with the support of development partners in the region.

CILSS has been accompanying UEMOA in the control of avian influenza (Guibert et al., 2009). There has been a harmonization process of legislation on the veterinary pharmaceutical, consisting in the elaboration of a veterinary committee and a series of common legislative texts between 2006 and 2007, including five regulations and one directive of the UEMOA (CILSS, 2010). The PROGEBE project has been implemented in the Gambia, Guinea, Mali and Senegal to protect their shared genetic resource of trypanotolerant livestock (Gueye, 2017).

Continent-wide disease surveys, mainly through the ARIS/AU-IBAR reporting system ${ }^{58}$, or global surveys by OIE, end up being the reference data repositories. Such scale of action has proven very useful in the eradication of rinderpest through the Pan African Rinderpest Campaign (PARC) and PACE projects. The PACE project was instrumental in establishing Epidemio-surveillance Networks in several countries in West Africa, which contributed to the surveillance of diseases and certification of freedom from rinderpest. The animal health infrastructure established as well as the surveillance system introduced will serve in the progressive control and eradication of PPR planned to achieve by 2030.

FAO and the International Committee for Animal Recording (ICAR) have long been strong actors in promoting animal identification for recording, answering to the increased demand for systems that guarantee food safety, safe trade, and reduce fraud by ensuring animal traceability (Hoffmann et al., 2012). FAO and ICAR in collaboration with the World Health Organization (WHO), African Union Interbureau for Animal Resources (AU-IBAR), and the International Livestock Research Institute (ILRI), issued a Declaration in Pretoria on an Africa continent-wide pledge from 30 African countries to promote traceability systems adapted to local conditions (ICAR, 2015). In the ECOWAS region, the issue of animal identification is gaining prominence and vaccination programmes now include identification systems as components. For example, an ongoing vaccination campaign for PPR and FMD stipulates identification by ear piercing as an integral part of the campaign. However, it is pertinent to formulate and adopt a regulation on identification and traceability in the region.

\subsection{Policies on Pastoralism and transhumance}

The main livestock production system in the ECOWAS region, as mentioned earlier, is extensive livestock production system mainly involving transhumant pastoralism. As a result, the ECOWAS Authority of Heads of State and Government decided on the Transhumance regulation in 1998 (ECOWAS, 1998) aimed at controlling and managing animal movement in the region. However, despite the economic 
and environmental importance of pastoralism and transhumance in the region, implementation of the regulation by Member States has remained a challenge, and there continues to be hurdles to its practice and its sustainability with the current associated recurring conflicts among pastoralists themselves and between crop farmers and pastoralists, and the consequent insecurity (De Haan et al., 2016). In a bid to curb the growing insecurity and call attention to the challenges of transhumant pastoralism, the ECOWAS Ministers of Security and Agriculture/Livestock in collaboration with their counterparts in Central Africa, agreed to implement a four-pronged approach to curtail the violent conflicts in the region covering policy, legislation, and investment actions to ensure livestock productivity (ECOWAS, 2018).

The awareness has attracted concerned technical and development partners to support initiatives to curb the insecurity in the region due to uncontrolled animal movement. Among the region-wide actions recently started, the World Bank notably has two important initiatives in the region supporting pastoralism and livestock-associated drylands livelihoods, namely the Regional Sahel Pastoralism Support Project (PRAPS), worth 248 million USD and the 1.1 billion USD Sahel and West Africa Programme (SAWAP) in support of the African Union-led Great Green Wall for the Sahara and Sahel Initiative (GGWSSI), including the Building Resilience through Innovation, Communication and Knowledge Services (BRICKS) project.

The initiatives are not exclusively centered on the Sahel; Coastal countries will also receive investment through the upcoming PRIDEC. This is a programme complementary to PRAPS under the understanding that both ends of the transhumance corridors have to be operational if the whole system has to be functional (SWAC/OECD, 2017) and that is conceived in the frame of the ECOWAP 2016-2025 (Allen, Heinrigs and Zoundi, 2015). High-level regional meetings on the theme, "Peaceful transhumance and livestock mobility in the Sahel and West African coastal countries" have also been organized since 2014 with further ones started in 2019 in Dakar for the Western Corridor and in Ndjamena for the Eastern Corridor (Figure 29).

\subsection{Livestock Legislation and Regulation}

The livestock policies in West Africa are accompanied by a regulatory framework both at the national and the regional level. National laws and regulations are often outdated, dating from the colonial period. Some countries have taken steps in updating them, often pressed by burning issues around the spread of animal diseases or around conflict on land use and livestock mobility. Because regional bodies are a relatively new creation, the laws and regulations issued by them are framed in more up-todate analysis and involve cross-border and regional issues, mainly transhumance and the avoidance of potential conflicts from it. A major challenge usually revolves around the enforcement of such regional regulations despite endorsements by Member States. For example, the ECOWAS regional Sanitary and Phyto-sanitary regulations, adopted in 2010 and aimed at ensuring food safety and the veterinary medicine governance in the region is yet to be fully domesticated and used in the Member States.

\subsubsection{Legislation and regulations at national level}

At the national level, the existing legal regulations and legislation in the subregion are mostly centered on animal health regulations and biosecurity (food safety), by administrative traditions and probably because of the immediate danger to the local population if regulations are not tight. Some legislative aspects also touch upon livestock mobility, probably because of the potential conflict in case of unregulated mobility and because of the loss of productivity caused by collapsed mobility. Finally, there are also examples for trade regulation, although the latter tends to be regulated by the regional trade associations. In any case, legislation, when not accompanied with adequate funding or capacity to enforce, can be rendered useless, which unfortunately is a common case in the region. (Rhissa, 2010 and APESS, 2014b). 


\subsection{Animal health}

The national livestock legislations are almost exclusively centered on animal health as the case in Togo (Kangni, 2015) and Sierra Leone (Sesay, 2016), while Cabo Verde and Ghana includes elements on food safety in addition to the control of diseases (Bari, 2016 and Oppong-Anane, 2016). Côte d'Ivoire has specific legislation for avian influenza (Kone and Danho, 2008) and regulations on the veterinary inspections and protective measures for national production (Bakayoko, 2016). Following the strong regional impact for controlling avian influenza, specific legislation to combat it has also been approved in Mali (Traoré, 2013) and Niger (Idi and Ganda-Idé, 2009), the latter also having general livestock legislation regulating mobility, veterinarian services and food safety.

Benin has adopted regulations on hygiene and control of traded animals and potential danger of epizootics, as well as of safe foods (Megnibeto-Aplogan, 2015 and Codjia, 2016), while Nigeria has a comprehensive veterinary legislation, food safety laws, as well as export-import regulations (Adene and Oguntade, 2006). Furthermore, the reviewed Nigeria Veterinary and disease legislation provides for a compensation scheme for farmers in the event of an outbreak that requires stamping out through culling as a disease control strategy. Where compensation is absent, farmers have been unwilling to report outbreaks for fear of incurring losses through stamping out, preferring instead to sell off diseased animals and therefore spreading the disease as in the case of outbreaks of avian influenza in Côte d'Ivoire and Ghana (FAO and ECOWAS, 2015).

\subsection{Regulations on Transhumance at national level}

Benin regulates both the national livestock mobility and for the cross-border mobility of herds and flocks coming from its northern neighbours (Traoré, 2013 and Codjia, 2016). Burkina Faso has a livestock legislation strongly focused on ruminant systems, namely on pastoralism, regulation of land use and genetic improvement (Rouamba, 2016). There is comprehensive legislation for transhumance in countries of origin, namely Niger, Burkina Faso and Mali, but also in host countries of Benin, Nigeria and Togo (ECOWAS, 1998 and Zakaria, 2014).

Furthermore, Niger's Pastoral code and Mali's Pastoral Charter of 2001, and additional regulatory decrees of 2006, make local government and pastoralist organizations accountable for the management of pastoral resources. The regulations define what constitutes pastoral resources in the Malian context and clearly determine how they can be utilized and protected (FAO and CIRAD, 2012 and Zakaria, 2014). In Senegal, a decree passed in 1980 identifies pastoral land and determines conditions of their use by livestock (FAO and CIRAD, 2012). In Côte d'Ivoire three decrees regulate pastures and livestock movements, by establishing dispute commissions since 1996 and creating principles for compensation of damages caused by transhumant livestock (Ministère de l'Agriculture et des Ressources Animales de Côte d'lvoire, 1996). As of 2015, there is a draft law to manage transhumance and reduce conflicts (Ministère des Ressources Animales et Halieutiques de Côte d'Ivoire, 2015). In Togo, an inter-ministerial ordinance of 2008 governs transhumance activities (CORAF, 2015). The livestock development policy on "Securing and sustainable management of natural resources" in Burkina Faso emphasizes two priority action areas on (i) securing pastoral mobility and of access to pastoral resources, and (ii) development and adding value to areas aimed for pastoralist production in Burkina Faso (Ministère des Ressources Animales et Halieutiques de Burkina Faso, 2015 and UICN-Burkina Faso, 2015).

Bilateral agreements among some Member States including Niger, Burkina Faso, Mali, Senegal, and nonECOWAS neighbouring countries such as Mauritania exist, and are aimed at facilitating cross-border transhumance (FAO and CIRAD, 2012). The 2003 Memorandum of Understanding between Burkina Faso 
and Niger set up a Consultative Framework which aimed at ensuring the proper implementation of ECOWAS decisions on the regulation of transhumance ${ }^{59}$, as well as to promote dialogue and exchange between the two states in order to support the definition and implementation of regional policy on transhumance and the management of natural resources.

An Inter-State Commission between Mauritania and Mali determines that the host country be responsible for the security of transhumant pastoralists, who are subject to the regulation and compliance with laid down conditions. In addition to a pass issued by either country, by the prefect (Mali) or Hakem (Mauritania), cross-border transhumant pastoralists must possess an itc that highlights the identity of the pastoralist, the exact composition of livestock, and the proposed destination in Mali and/or in Mauritania. Furthermore, pastoralist are to possess a health and vaccination certificate, transhumant herds being potentially quarantined and vaccinated in the host country at a cost to the pastoralist, in case of non-compliance. Additional conditions include ensuring effective day and night guards for their animals by persons aged 15 years at least, payment of grazing fees set in the host country, respect for traditions and customs of host villagers, compliance with animal and human census operations and prohibition to hunting, choping trees or starting bush fires. These provisions are in line with the ECOWAS Transhumance regulations

In other countries, attempts were made to confine pastoralists into specialized grazing areas conceived to attract pastoral producers, especially the mobile pastoralists, to settle permanently and become agropastoralists. The establishment of grazing reserves is not a new concept in countries like Nigeria (Box 8). It can also be seen as a new development in other countries targeting the settlement of pastoralists. The practice of settling transhumant pastoralists would definitely reduce the number of individuals involved in pastoralism but would also definitely reduce its productivity (Hatfield and Davies, 2006 and CORAF, 2015)

\subsection{Regulations on Pastoralism and Transhumance at regional level}

The herd and flock mobility has been the field where more comprehensive regulations have been issued. Potential conflict among mobile pastoralists themselves and between these and sedentary crop farmers, as well as the fundamental role of mobility in preserving resilience, has triggered the existence of such regulations in order to minimize conflict and maximize food security.

The ECOWAS has been instrumental in promoting legislation on cross-border transhumance at the regional level. As mentioned in section 9.11 above, the ECOWAS Heads of States Decision A/ DEC.5/10/98 on Transhumance sets out guiding principles on the animal movement in the region (ECOWAS, 1998), and Council Regulation C/REG.3/01/03 of 2003 provides for the implementation of the Heads of States Decision, setting out roles and responsibilities for the Member States, the Local Authorities and producer organizations as well as for the ECOWAS Commission (ECOWAS, 2003). These laws are aimed at regulating and promoting livestock mobility, and thereby pastoralist resilience. The decision and the regulation define the conditions for movement of livestock, looking after animals and hosting of transhumant livestock, and establish internationally accepted documents to regulate and monitor transhumance.

The itc of ECOWAS (ECOWAS, 1998) is a tool developed to implement this framework, and is a sort of laissez-passer for transhumant pastoralists and their livestock that guarantees protection for their rights of non-resident, but also encourages them to obey the laws of the host country. Such laws include the access and use of forest areas, wildlife, water points and pasture. Any conflict arising from 


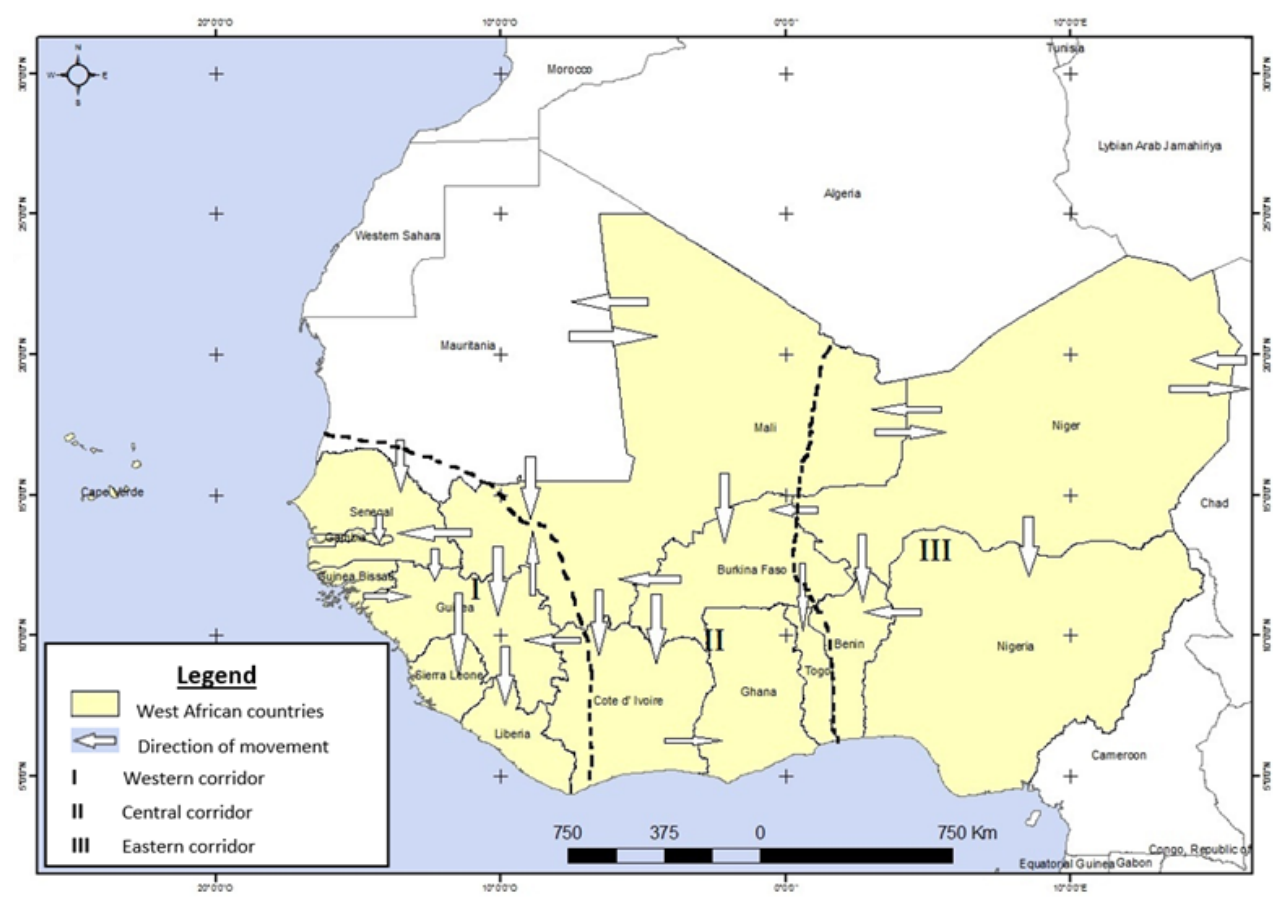

Source: Diop, (2012) consultancy report on cross-border transhumance in West Africa.

this arrangement will be resolved through a Reconciliation Commission consisting of pastoralists, farmers, local authorities and others concerned stakeholders. The regulations further provide for the establishment of a transhumance observatory with the participation of pastoralist grassroot organizations, and the transhumance routes have been identified in the region including the Western Corridor, the Central Corridor and the Eastern Corridor (Figure 29).

While the ECOWAS has made efforts to ensure the control of animal mobility, recognizing its role in preserving resilience and improving food security and nutrition, challenges remain in the implementation of the ECOWAS regulations. In the face of conflicts among pastoralists, and between pastoralists and sedentary crop farmers, recurring criminality including cattle rustling, and the general insecurity including rural banditry and terrorism, pastoralists have been at the receiving end of the ire of communities, even where there has been no proof of their complicity in such acts. There is need for sensitizing and educating communities on the perceptions and stigmatization of pastoral ethnic groups to avoid current and future tensions. The communities have to identify criminality for what it is, rather than linking it to a particular ethnic group or religion. CILSS supports ECOWAS and UEMOA at protecting pastoralists systems for the diversification of the West African livestock economy (Guibert et al., 2009 and Dodo, 2012). FAO also collaborates with ECOWAS to strengthen the protection of transhumant systems (Diop, 2012).

At the continental level, the support to pastoralism has been further strengthened by the approval of the AU Pastoralist Policy Framework (African Union Commission, 2013), a continental policy document adopted by the AU Assembly of Heads of States and Governments in February 2011, in Addis Ababa, 
Ethiopia. It highlights the importance of pastoralism and livestock mobility for sustainability and poverty reduction while alerting on past misguided policy actions (Schlee, 2010) and is the first continent-wide policy initiative, which aims at securing, protecting and improving the lives, livelihoods and rights of African pastoralists (Haile-Gabriel, 2012). The policy framework is a platform for mobilizing and coordinating political commitment to pastoral development in Africa, and emphasizes the need to fully involve pastoralist women and men in the national and regional development processes from which they are supposed to benefit. The framework also emphasizes the regional nature of many pastoralist ecosystems in Africa and therefore, the need to support and harmonize policies across the Regional RECs, and AU Member States.

\section{Food Safety and Veterinary Drugs Regulation}

In order to enhance trade in livestock and livestock products, the ECOWAS adopted a set of regulations on Sanitary and Phyto-sanitary Standards (SPS). While these standards do not deviate from international standards in any material way, the processes leading up to the adoption required sensitizing stakeholders on the need for such standards in the region, and enabled ECOWAS to put the standards together for easier comprehension by stakeholders. It also enabled the ECOWAS to provide training-of-trainers (ToT) activities to support Member States to have a pool of trainers to disseminate the knowledge in-country. Some of the ToT activities were supported by the AU-IBAR under the European Union funded project on Participation of African Nations in Sanitary and Phyto-sanitary Standards-setting Organizations (AUIBAR, 2016). The project awakened Africa to need for ensuring sanitary standards for trade.

The ECOWAS legislation on the SPS has three Regulations and one Directive rolled together, including the Council Regulation C/REG.21/11/10 on Rules pertaining to the Safety of Foods, Plants and Animal Health; Regulation C/REG.22/11/10 Establishing Community Procedures on Veterinary Drugs and Biologics; Regulation C/REG.23/11/10 on the Creation and Modalities for the Functioning of a Regional Veterinary Committee; and Directive C/DIR.1/11/10 on ECOWAS Veterinary Pharmacy (ECOWAS, 2010b). These regulations are aimed at strengthening regulatory framework for the delivery of veterinary services and the control and management of veterinary medicinal products in the region. The regulations were in response to the outdated legislations in Member States on the areas of food safety and veterinary drugs management.

\section{Regional Animal Health Networks}

To ease coordination of the management of animal health, the ECOWAS now runs network of professional and producer organizations with the support of the FAO. Promenent among the regional animal health networks are the Regional Network of Epidemio-surveillance better known with the French acronym of RESEPI (Reseau de Epidemio-surveillance) and RESOLAB (Reseau des Laboratoires). These two networks were initially established under PACE towards the final years of rinderpest eradication from Africa. From 2006 onwards, FAO revitalized and strengthened them, deploying them mainly for the prevention and control of the first outbreak of Avian Influenza (H5N1) in the region. The two Networks operated successfully in bringing the Unit Heads of Epidemiology and Veterinary Laboratories from West and Central Africa together in harmonizing and coordinating the prevention and control of Avian Influenza but also created capacity for the control of other diseases through the establishment of subnetworks for diseases such as FMD, rabies, CBPP, ASF, etc. (FAO, 2015b). After several years of support by FAO in strengthening the Networks, the ECOWAS now owns and supports these Networks dedicated to West Africa as part of its institutional structure. Similar structure operates in Central Africa. The ECOWAS has further established the Regional Veterinary Committee provided for in the SPS Regulations as an advisory body made up of the Directors/Chief Veterinary Officers of Member States in the region 
Photo 61. Group photograph of participants of the animal health network meeting, Abuja, Nigeria, 2015

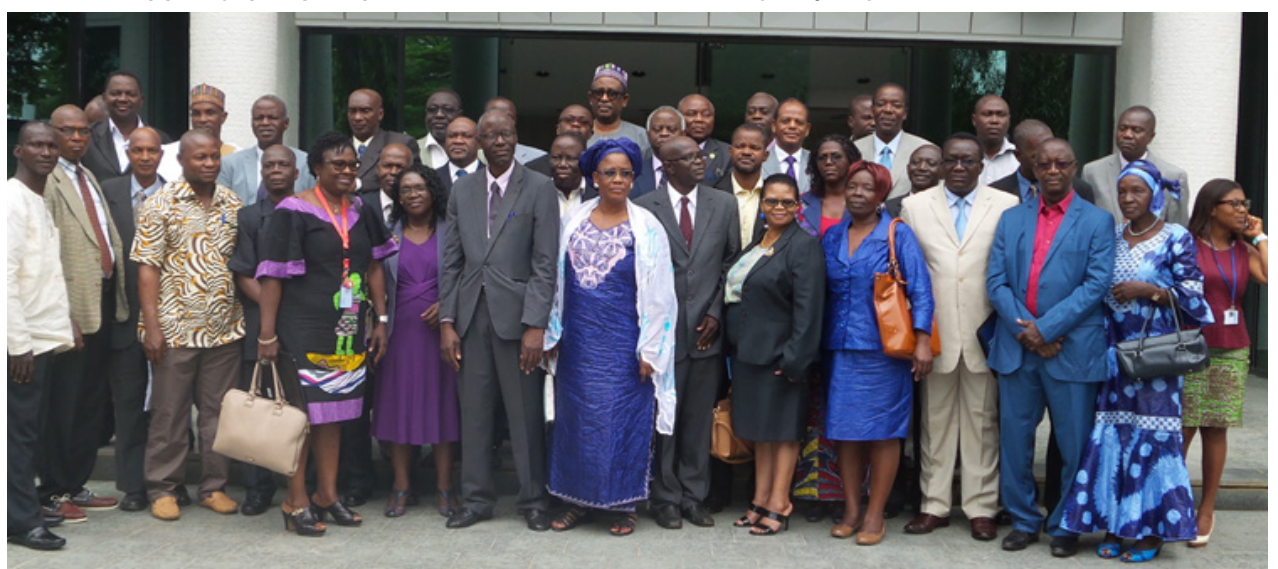

CBerhanu.Bedane

(ECOWAS, 2010b). This pool of expertise are available to call upon from where it is available to where needed at short notice in cases of major outbreaks and when needed for the implementation of mass vaccination campaign programmes. They further support disease surveillance and reporting activities. FAO identified and strengthened two Regional Support Laboratories in West Africa, i.e. Laboratoire National de l'Elevage et de Recherches Vétérinaire (LNERV/Dakar) and National Veterinary Research Institute (NVRI/Vom) serving the ECOWAS region. 
164 The role of livestock in food security, poverty reduction and wealth creation in West Africa 
THE ROLES OF THE LIVESTOCK SUB-SECTOR IN WEST AFRICA
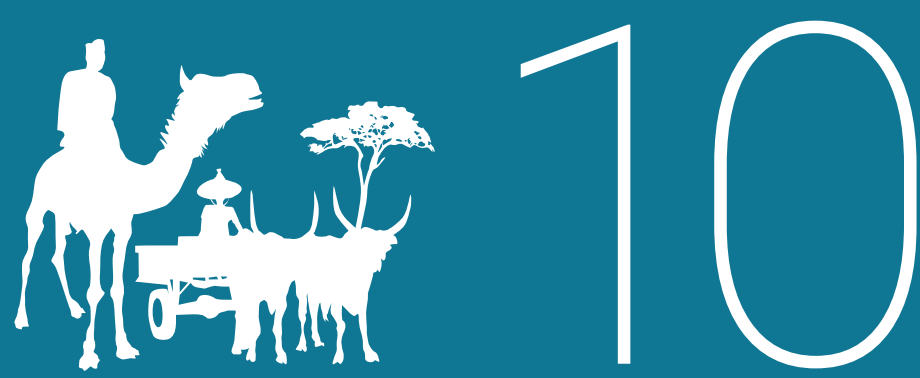



\section{ChAPTER X \\ THE ROLES OF THE LIVESTOCK SUB-SECTOR IN WEST AFRICA}

The United Nations 2030 Agenda for Sustainable Development with its 17 Sustainable Development Goals (SDGs) has become the universally endorsed framework accepted by all and applicable to all countries. The SDGs aim to end poverty and hunger among others.

For decades, the livestock debate has focused on how to produce more from less to feed 9.8 million people by 2050. However, the United Nations 2030 Agenda for SDGs has now added a new and broader dimension to the discussion. It has shifted the focus from fostering sustainable livestock production per se, to enhancing the sub-sector's contribution to the achievements of the SDGs. SDG 1 targets include eradicating extreme poverty; building resilience among the poor; and creating sound policy frameworks (FAO, 2018b).

The livestock sub-sector can contribute in multiple ways to ending hunger and all forms of malnutrition. They include: increasing the direct consumption of nutritious animal-source foods; helping to generate income; supporting the creation of employment; generating fiscal revenue and earning foreign exchange; and providing the world with sufficient and reliable supplies of meat, milk, eggs and dairy products, and of primary commodities used for clothing, bedding and other household items (FAO, 2018b).

\subsection{Diversity of livestock roles}

In most of the West African countries, livestock plays a predominant role in the livelihood of rural populations, whose daily activities revolve around the exploitation of livestock and whose monetary needs are animal-dependent. The sales of livestock contribute to the acquisition of basic livelihood foodstuff and goods (i.e. cereals, sugar, clothing, etc.) and to support expenses for raising or educating children, to pay for health services and for other social activities. In agro-pastoral systems, farmers invest in livestock excess revenues that can be spared from crop cultivation activities as a means of storing wealth. In addition, livestock plays important cultural and religious roles in the livelihood of the populations in West Africa. A study conducted in Niger to understand why households raise livestock showed that 69 percent of them target income generation, while 15 percent primarily do it to use them as source of draft power in agriculture and transport (Pica-Ciamarra et al., 2014a). The percentage 
of households rearing livestock as source of food and those making use of them as security against reduced income for crop production were eight percent each. This illustrates the role of livestock at household level in addition to the role as prime commodity for the generation of foreign currency for national economy and source of employment.

\subsection{Food security, nutrition and health}

Livestock plays an important role in household food security and the development of crop production, the latter through animal draft power and the supply of manure for soil fertility. It provides high nutritional value protein, in form of meat, milk and eggs ${ }^{60}$, and plays a vital role in food security on its own or exchange with grain. In the case of pastoralists, milk and its products make up a big portion of the basic diet and provide essential micronutrients, and for whom meat provides either resources to purchase grain, or is consumed occasionally as a high-quality food (Hatfield and Davies, 2006 and FAO, 2019b). Crop farmers very often keep poultry or, less commonly in the region, pigs in backyard systems that are also fundamental in providing essential nutrients (Idi and Ganda-Idé, 2009), cheaply fed on leftover and scraps in such systems. Indeed, animal products provide energy, minerals and vitamins. But their predominant role is the supply of some essential amino acids and vitamins, which the human body cannot synthesize and must be necessarily provided by food. Foods of animal origin are also important in the recuperation of nutritionally deficient kids and pregnant or lactating women, and many cases of malnutrition in the region may be related to the poor animal product intake (Stabler and Allen, 2004 and Muehlhoff, Bennett and McMahon, 2013). Additionally, the role of draft power and manure provision is particularly important in West Africa, due to the abundance of integrated crop-livestock systems where livestock producers need the crop residues to feed their animals and crop farmers need manure to maintain soil fertility. Draft animals provide a valuable resource to prepare the land for cropping (Williams, Hiernaux and Fernández-Rivera, 2000 and Smith et al., 2013) and transport products to markets and inputs from markets to farms.

Revisiting the supply of animal products locally produced ${ }^{61}$ and the demand for these products ${ }^{62}$, West Africa shows a significant gap of self-sufficiency in the major animal products, especially meat and dairy products (Table 31). This explains dependence on import to meet current demands for major animal products that will likely to increase in the coming years. It also highlights the current food security and nutritional constraints that poor population segments face in the region, aggravated by the fluctuations in production across the years at poorer households, both for ruminant and monogastric systems. Inadequate policies that exclusively promote sizeable livestock systems, leaving poorer producers behind ${ }^{63}$, or increasing limitations for resilient practices, associated with the demographic evolution of the region ${ }^{64}$, further poses danger to the health and food security of the population.

Nonetheless, West Africa has a significant potential for improvement, and 'livestock rich countries' like Burkina Faso, Mali and Niger are self-sufficient in meat and meat products and contribute significantly, through live animal exports, to meat supply of net-importing coastal countries like Benin, Côte d'Ivoire, Ghana, Liberia and Togo (Zakaria, 2014). Gaining efficiencies for milk production and trade can potentially curb the current deficit. So far, no country achieves the dairy standard requirement of $62 \mathrm{~kg}$ of milk/ per capita per year. Nigeria, the largest importer of milk and dairy products, with half of the volume ${ }^{65}$ imported to the region, has a domestic dairy production which is weakly integrated into the market (Rhodes, 2014). Government restrictions to milk and dairy imports, as well as successive devaluations of the national currency that led to reduced purchasing power and drops in imports (Ndambi, Hemme and Latacz-Lohmann, 2007) that did not improve the situation. While Burkina Faso, Ghana, Guinea Bissau and Togo are self-sufficient in egg production ${ }^{66}$, the remaining countries are not. The Gambia, 
Table 31. The proportion of demand for animal products covered by local production in West Africa

\begin{tabular}{|l|r|r|r|}
\hline Product & Demand (TM) & Production (TM) & Demand covered (\%) \\
\hline Meat & 4062106 & 3344644 & 82.3 \\
\hline Milk & 4167635 & 3879057 & 93.1 \\
\hline Eggs & 938142 & 925743 & 98.7 \\
\hline
\end{tabular}

Source: FAOSTAT, (2013).

Liberia and Sierra Leone are countries where large gaps between egg production and demand still exist. The rest of the countries cover over 90 percent of the demand through national production, highlighting the important role that chicken have in covering minimal animal-sourced nutrient needs and providing resilient strategies at the household level, as most of the production originates in backyard systems.

\subsection{Economic roles}

Livestock represents an important component of the West African's agricultural sector, directly contributing to an average of 12 percent to the sector's GDP. It also contributes about 3.2 percent of the overall regional GDP, or 19.1 billion USD (Table 32). This amount does not include the value of processed products mostly accounted for under industry and secondary products, such as manure, draught power and transport, which are provided mainly to the crop sub-sector but are extremely difficult to quantify (Hatfield and Davies, 2006 and Krätli, 2014). Country level details are displayed in Table 32.

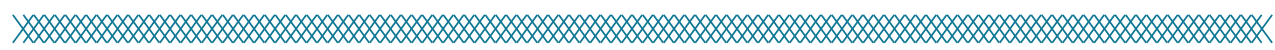

Table 32. Contribution of livestock to agricultural and national GDP in West African countries

\begin{tabular}{|c|c|c|c|c|}
\hline Country & $\begin{array}{l}\text { National GDP (million } \\
\text { USD) - } 2012\end{array}$ & \multicolumn{3}{|c|}{ Contribution in GDP (percent) - 2013} \\
\hline Benin & 8117 & 25.2 & 22.6 & 5.9 \\
\hline Burkina Faso & 11166 & 35.1 & 37.1 & 13.5 \\
\hline Côte d'Ivoire & 27041 & 22.5 & 8.9 & 2.3 \\
\hline Gambia & 912.6 & 24.5 & 11.4 & 2.8 \\
\hline Ghana & 41940 & 23.6 & 5.1 & 1.3 \\
\hline Liberia & 1736 & 38.8 & 15.4 & 6.7 \\
\hline Mali & 12443 & 41.3 & 82.0 & 29.8 \\
\hline Niger & 6409 & 38.3 & 46.3 & 20.4 \\
\hline Nigeria & 460954 & 22.1 & 7.7 & 1.9 \\
\hline Senegal & 14440 & 15.7 & 29.4 & 4.7 \\
\hline Sierra Leone & 3853 & 51.8 & 12.0 & 6.6 \\
\hline Togo & 3867 & 42.6 & 21.1 & 10.1 \\
\hline
\end{tabular}

Source: World Bank, 2019b; * FAOSTAT, (2013); $†$ indicates data available only for 2011; $¥$ Agricultural GDP for Liberia is World Bank data but sourced from Tradingeconomics.com. 
The contribution of the livestock sub-sector to the national GDP varies largely among countries, with the highest contribution (30 percent) observed in Mali, a typical Sahelian country, and the lowest (1.3 percent) in Ghana, which combines a humid Gulf climate where crops have more potential than livestock and an economy that is relatively developed by regional standards, where the weight of agriculture is reduced. The Sahelian livestock producing countries (i.e. Burkina Faso, Mali and Niger) have the overall highest contribution because of their adequate climate for livestock production and their buoyant export markets to the Coastal countries. In general, in dryland countries (i.e. the Sahel plus Cabo Verde) livestock makes a very significant contribution to the agricultural GDP, in all cases surpassing one third of the total. In absolute USD value terms (Table 32) Nigeria has the highest contribution of the subsector to national GDP ( 9 billion USD) while Gambia has the lowest ( 26 million USD) contribution.

The contribution of the livestock sub-sector to economic growth can be boosted through vertical and horizontal multiplier effects that go beyond production. Indeed the non-agricultural sectors tend to have a higher response to changes in livestock production than agriculture itself. Nevertheless, in West Africa as for other developing countries, the livestock sub-sector is highly segmented and the levels of labour productivity differ between processing and production and within production, between commercial and subsistence farmers. Thus, a simple multiplication of similar opportunities could result in an expansion of underemployment. Policies should promote livestock system models that lead to higher labour productivity, facilitate value-addition, and are labour-intensive (FAO, 2018b).

\subsubsection{Poverty reduction and wealth creation}

Livestock is intimately associated with wealth. In fact, the word "capital" originates from the Latin word "caput", or head (of cattle), denoting the use of livestock for generating revenues and accumulating wealth more than 2000 years ago. Livestock ownership has therefore a very important role that impacts both the economy of rural households and the use as a financial tool.

Poverty is a more or less generalized phenomenon in West Africa, especially in rural communities. It is manifested as weakness in major areas of the human well-being: analphabetism, malnutrition, low life expectancy, poor health, unhospitable habitat and reduced participation in socio-economic life. It is measured by monetary indicators such as poverty threshold, incidence of poverty, depth and severity of poverty, or by livelihood indicators such as the Human Development Index (HDI), of which the subregion displays the worst score worldwide (AFDB, OECD and UNDP, 2016), with only Cabo Verde and Ghana not being considered least developed countries. According to HDI report of 2019, 40 percent of the 10 countries at the bottom of the list of 189 countries and territories are found in West Africa (UNDP, 2019).

While livestock rearing is an important economic activity in the subregion, West African households own relatively less number of cattle than households in other regions. However, they hold more small ruminants, especially sheep, which is related to the widespread animal diseases (Seo and Mendelsohn, 2007). Poultry ownership is particularly widespread because of the little labour required to keep them in a backyard system. As village chicken are mainly reared near homestead, they are largely managed by women, as are most livestock associated to the household (Niamir-Fuller, 1994). The smallholder farmers raise small ruminants and poultry mainly for cash and household consumption. The small ruminants and poultry are relatively easy to own by resource-poor farmers, especially women, as these animals have short cycle reducing the risks inherent to agricultural production.

The study conducted by Livestock Data Innovation for Africa in Niger showed that 79 percent of rural households rear livestock to generate revenues (Pica-Ciamarra et al., 2014a). The dairy industry provides a means of livelihood for a significant proportion of rural households, mainly in the arid regions of West Africa, but also in the sub-humid zones to some extent. Among the animal products, milk and local 
cheese play an important role in the livelihood of populations. They not only constitute a permanent income source for pastoral and agro-pastoral households, especially women who are traditionally processing and selling cheese, but also represent the main available and accessible protein during the wetter eight months of the year, i.e. April through December.

The contribution to the fight against poverty in rural areas requires a set of strategies targeting better resilience of the agricultural production systems to external shocks, value addition of products, and the diversification of income sources. In this sense it is fundamental to take into account the trade-offs arising from the resilience of local breeds ${ }^{67}$ and the high value they achieve in the local market (Sodjinou et al., 2014) when designing actions to relieve poverty for example when supporting more productive breeds.

\subsubsection{Livestock as savings and in-kind transactions}

Livestock plays a financial facilitation role for rural economies in most African countries. It constitutes an income source readily available to carry out rural household expenditures (i.e. medical expenses, student fees and supplies, off-season food supplies, etc.). For rapid small and fast expenditures, fast-reproducing poultry or small stock (sheep, goats and pigs) are used, while family savings larger payments usually involve more resilient but less prolific cattle and/or camels (Water-Bayer and Bayer, 1992). In that aspect, resilient animals and breeds are preferred over those highly productive but less resilient ones, as the main objective is to minimize risk. The role of livestock as a source of capital to mitigate climate shocks has been debated. Research in West Africa, nevertheless, shows that other capital sources are actually used to protect the livestock breeding stock, for the opportunities it presents to livestock owners after a post-drought scenario, with pressure released from i.e. communal grazing grounds (Fafchamps, Udry and Czukas, 1998).

Rural populations who have limited access to financial services use livestock as a mean for saving and for capitalizing benefits earned through agricultural and non-agricultural activities (Alary, Corniaux and Gautier, 2011). The large herds of cattle in the Office du Niger rice production zone and in the Compagnie Malienne pour le Développement du Textile (CMDT) cotton production zone in Mali, are good examples of using livestock as storing wealth from saving of extra cash earned through other activities.

In many instances, livestock is used as mean of in-kind payment (Baroin and Boutrais, 2009). Salaries of farm workers, especially herders, may be paid on a seasonal or yearly basis as agreed upon, out of the yearly calf crop. The in kind payment received is generally kept in the same herd by the herder until it is mobilized by him whenever need arises. Part of herders' salaries may also be paid in milk (Wymann et al., 2006), and such payment is usually made on a weekly basis. Another common use of livestock as means of payment is the dowry (bride price) - although sometimes animals are returned after the wedding (Baroin and Boutrais, 2009), the meaning of a livelihood provision is clear. The "blood money" for compensation of death or crimes committed using livestock is also common.

\subsection{Equality and empowerment}

The livestock production in West Africa is usually managed by adult males, usually visible in livestock markets and registerd as owners of the animals. However, both women and children play significant roles in the livestock-associated livelihoods, and their roles imply also their social importance within their communities. The role they play in livestock production gives important opportunities for their empowerment and for designing entry strategies in achieving it. 


\subsubsection{Gender}

In general, accurate data are not available on the breakdown of agro-pastoralists and pastoralists by gender. It is nevertheless known that women tend to own less livestock than men, but that they tend to control small stocks such as small ruminants and backyard animals (pigs or poultry) (FAO, 2011c). While livestock assets, unlike land, tend to be generally distributed equally among men and women, West African women, particularly those in Nigeria, seem to be affected by poor livestock ownership rates (Kristjanson et al., 2014). As mentioned earlier, among many livestock rearing households, small ruminants and poultry are predominantly owned and managed by women and youth. This is partly due to the importance of these species as source of cash for day-by-day family expenditure, while large ruminants are considered the family long term savings (Flintan, 2008). As an illustration, in the Gambia (Touray, Ceesay and Njai, 2010) women manage 74 percent of the goats, 47 percent of the sheep and own and manage 90 percent of the poultry. A slightly different percentage (52 percent of sheep and 67 percent of goats) are reported by (Distefano, 2013) but the fact that small ruminant ownership is tilted towards women in Gambia remains.

Women often control milk production and its value chain because of its relevance in the nutrition of small children, and they often take care of less mobile elements of the herd, such as lactating ewes and cows, or lambs and calves. The role of women in controlling livestock that ensures household food security sometimes reinforce their empowerment in rural societies. Their involvement in managing livestock has even stimulated their participation in credit schemes (Kristjanson et al., 2014). However, the low productivity of livestock controlled by women due to poor access to inputs, social norms or extension services (Croppenstedt, Goldstein and Rosas, 2013) is a concern in West Africa.

Traditionally, milking is not a gender specific task in pastoral and agro-pastoral systems. However, milk processing and marketing is women's attribute, as the transformation and storage of milk products has been associated with the provision of food to the family in times of crisis (Flintan, 2008). Consequently, women can have the control of surplus sales, as in Fulani communities in Ferlo, Senegal. However, an increased commercialization of milk may erode women's control over dairy products (Kristjanson et al., 2014).

The milk processing and marketing activities generate large numbers of jobs, equivalent to 30,000 people full time in a country like Burkina Faso, which is especially relevant for women and youth in the small ruminant sub-sector (ILRI, 2014). This is particularly important in urban areas where animal industries constitute a buffer against shortage of employment. Most of these milk and milk product distributors sell in urban and peri-urban markets, thus making the channel a good supply link to urban population. Dairy products are often valued in the way they are processed and presented for sale. Most of the times, preference is given to processing of whole milk rather than the unprocessed raw milk. Women derive higher income from butter sales. They make between 12-15 percent more if butter is sold in the urban market. But this means that women have to walk some distance or pay for transport to the urban market (Gueye, 2017).

\subsubsection{Youth}

Children often contribute to the family's economy in poorer households relying on livestock. Their contribution is sometimes key to sustain the family's food security, even if this collides with their chances to attend school or puts them in danger due to the risk such activities pose such as being trampled by oxens or exposure to zoonoses (Gooren, Seiffert and Demeranville, 2013). 
In pastoralist systems, herds of large ruminant are looked after essentially by men and young herders. Children are often given the responsibility to herd the family's animals because of how important it is for them to learn on the local rangeland ecology and to establish social relationships with other herders, both being fundamental pieces in the resilience of the pastoralists system (IUCN, 2012). In this case, any moves to incorporate children from pastoralist communities into conventional education face severe challenges. Admiting these children into commonly used facilities such as boarding schools and unrelated curricula mean an alienation from their own culture and livelihood skills (Krätli and Dyer, 2009 and Dyer, 2010). Hence, that is not an easy decision to make (Gooren, Seiffert and Demeranville, 2013). In this sense, the shortcomings of current delivery methods for formal education put severe constraints for the maintenance of the pastoralist youth role in food security and livelihood generation in their societies. The youth, mainly young boys, are the most involved group in the producing meat in abattoirs, in processing it into various products and finally selling it in markets and streets of many towns and cities in West African countries (Coulibaly, personal communication).

\subsection{Socio-religious roles}

The livestock-associated livelihoods in West Africa are not only conditioned by sociological elements. They are also an important component of many sociological and cultural traits, because of their productive nature and capital value and because of their physical characteristics (i.e. coat or feather colour and pattern, comb nature, etc.).

\subsubsection{Social prestige}

Livestock has an important role in terms of livelihood asset and family capital ${ }^{68}$. Such direct economic roles, especially linked with large ruminants, imply a degree of social prestige through provision of wealth, capacity to invest in bride dowry, and alike (Baroin and Boutrais, 2009). The economic skills necessary to manage herds in changing climatic conditions translate into the prestige of being able to build wealth in a difficult environment (IUCN, 2012).

The ownership of livestock confers a certain social status to the individual and the household. Thus huge herds of cattle, small ruminants and/or camels are hold in pastoral and agro-pastoral systems because, among others, they are indicators of richness and confer high position and prestige in the hierarchical structure of the society (Randolph et al., 2007).

Additional sources of social prestige are related to other livelihood management aspects. A good genetic management of local breeds is positively valued for large ruminants in the Sahel, with traits associated with the perceived "beauty" of the animals (Belli et al., 2008). Such social traits have been mistaken by the so-called "cattle complex" (Baroin and Boutrais, 2009), where pastoralists would encourage the accumulation of livestock or the selections of traits that are culturally positive but wouldn't translate in a better productivity. However, such considerations, formulated by outsiders with an incomplete knowledge of pastoralist livelihoods, have ignored the reality of the necessary economic management in such an environment (IUCN, 2012) and the usefulness of such "beauty" traits such as large horn size for heat dissipation in an environment where productivity is limited by high temperatures (Parés-Casanova and Caballero, 2013 and Knierim, Irrgang and Roth, 2015). With the growing scarcity of grazing land, particularly during the long dry season and stiff competition on limited natural resources with other users, which often leads to conflicts, pastoralists seem to gradually move from owning large herds to fewer and more productive herds as coping mechanism (Manzano and Slootweg, forthcoming). 


\subsubsection{Culture and tradition}

There is large demand for small ruminants in West Africa. For certain populations, goat meat is a delicacy while for others like the Kpa Mende tribe in Sierra Leone preference for goat is related to secret society purposes. Among Muslim population, sheep, particularly rams have gained preference for carrying out many Islamic religious feasts (i.e. naming ceremonies, Tabaski celebration - the feast of sacrifice. Tabaski or Eid al-Adha is the biggest public holiday in Senegal, Guinea, Mali and many other countries in West Africa. Around four million of sheep are slaughtered every year for Tabaski in Senegal alone. In general, non-Mulsim populations have kept a richer collection of cultural practices around livestock, associated with sacrifices or celebrations of the agricultural calendar (Baroin and Boutrais, 2009).

In West Africa, poultry, in addition to its economic value, is raised and used for elaborate ritual practices associated with situations ranging from isolated individual sacrifice needs to annual social events. In this case, the selection of different traits seems particularly more important than meat production (Faustin et al., 2010). Indeed, the use of indigenous poultry, in particular, for ritual events is common in many countries in West Africa, where chickens are sacrificed during various traditional ceremonies.

In Benin, the colour of plumage of poultry has an important role. White chickens are sacrificed to the (Faustin et al., 2010). Black-speckled white Guinea-fowl are sacrificed to the voodoo god "Doukounou" (associated to wealth). White or ash-coloured ducks are preferentially used in women's dowry, while red chickens are sacrificed to the voodoo god "Hebiosso" (god of thunder) to bring rains. The pure, white Guinea Fowl is used for religious sacrifices and to perform certain funeral rites. Customarily, the Frafras, Dagabas, and Bulsas tribes of Northern Ghana use Guinea fowls to welcome mothers-in-law (Teye and Adam, 2000).

In Ghana (Sonaiya and Swan, 2004) the Mamprusi in the north of the country sacrifice red cockerels to propitiate rain or good harvests. White-speckled black chickens (called "Kpinkoun") are offered to the voodoo gods "Dan" and "Sakpata". Black, white or red chickens are sacrified to beg for good luck and believed to combat misfortune. Black chickens are also used to invoke death spirits, but black colour does not influence the price of chicken because of their wide availability.

However, the consumers often do not like black chickens because of the assumption of bringing misfortune (Asgedom, 2007) and are often used in magic (Faustin et al., 2010). The black guinea fowl is offered to ancestors ("kouvito"), supposedly bringing luck in life. Overall, there is significant effect of the plumage colour on the price of poultry (Sodjinou et al., 2014).

\subsection{Environmental roles}

Livestock is often perceived to cause a series of negative impacts on the environmental. In reality, the traditional more extensive livestock rearing has a series of wide environmental benefits, through especially pastoralist practices that are more linked to the surrounding ecosystems (Teillard et al., 2016) and traditional livestock practices in general (Eisler et al., 2014).

Following an extensive review of the main environmental roles structured after the three main United Nations Environmental Conventions (Manzano and Salguero, 2018), livestock provides environmental services in terms of biodiversity conservation, prevention of soil degradation and in combating climate change. 
Regarding biodiversity, adequately managed extensive livestock production system, is proven to sustain diverse ecosystems through animals feeding on plants, including species numbers at intermediate disturbance levels but also including the control of invasive species. The livestock migratory corridors also play a significant role in the maintenance of ecological habitat connectivity, as well as in maintaining food webs that benefit a wide range of animals, from scavengers to dung buriers and other arthropods. Land degradation can be prevented through adequate livestock management, of which African livestock keepers have extensive knowledge (Oba, 2012). Regeneration of tree cover can be influenced positively by adequate management of transhumant herds, similarly to soil restoration through the action of manure. The role of domestic animal dung (including both ruminants and monogastrics) in nutrient cycling has proven to be extremely useful both in rangelands and croplands, especially in low-input systems such as the one in West Africa. Food production with a reduced competition for water usage or arable land in the region is also key.

The influences on climate change can be divided into mitigation (cf. section 11.3.2) and adaptation (cf. section 11.3.1). Regarding mitigation of greenhouse gas emissions, adequate livestock management is a very important and cheap tool to increase soil carbon stocks, while traditional low-input systems are very helpful in producing animal products at a very low cost of fossil fuel use. The natural resilience of smallholder livestock system provides a rich array of adaptation strategies that include locally adapted indigenous breeds ${ }^{69}$, and ruminant system based on mobility and communal land tenure. 
176 The role of livestock in food security, poverty reduction and wealth creation in West Africa 


\section{CONSTRAINTS LIMITING THE DEVELOPMENT OF THE LIVESTOCK SUB-SECTOR IN WEST AFRICA}
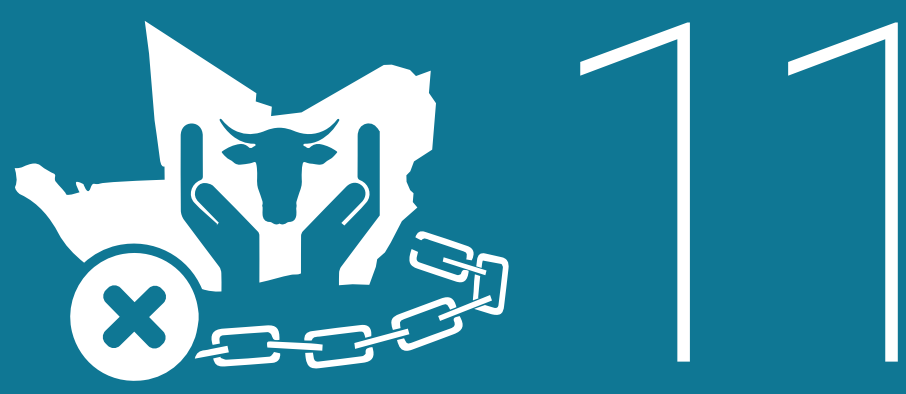



\section{CHAPTER XI}

\section{CONSTRAINTS LIMITING THE DEVELOPMENT OF THE LIVESTOCK SUB-SECTOR IN WEST AFRICA}

\subsection{General limitations and constraints}

The growing population of West Africa has an increasing demands for animal products. Even before the challenges of meeting the growing demand for food of animal origin, the livestock sub-sector in West Africa is confronted with different problems ranging from socio-cultural to environmental to policy, investment and institutional constraints that ultimately cause low productivity, weak processing and supply levels deeping rural poverty. While some of these challenges require thorough investment, others arise from misguided views on the local livestock production system and from counterproductive investments. These in turn are related to structural limitations, in terms of both constraints posed by the local environment and its natural resource base, and by the socioeconomic adaptations to it. As a result, several limitations are combined one with another, creating even bigger and complex hurdles for livestock development.

\subsection{Structural limitations}

The local environmental condition in West Africa exerts a strong limitation on the type of expected livestock production. As a tropical area, the climatic condition of the region with high temperatures, partly humid and partly dry, determines the type of animals reared, limiting in this way the profitability of investment. Such limitations have also conditioned the cultural adaptation developed locally, both in terms of animals exploited and in economic arrangement among local producers. Finally, the low economic development of the region hampers the benefits of investment aimed at large-scale production, as a large portion of the population depend on small-scale livestock keeping, subjected to low inputs, for their livelihood. 


\subsubsection{Animal breeding and genetics}

The genetics of livestock species in West Africa is greatly influenced by the production systems that have dominated the region so far, namely pastoralist and backyard systems. In both cases, the preference is rather for endurance and resilience of the animals, and not the criteria for high productivity. Such criteria may not make sense in hot climate, such as the ones prevailing in the region, where those conditions are known to affect productivity greatly (Renaudeau et al., 2015). This has triggered the selection for diverse adaptations (Berman, 2011 and Mwai et al., 2015) including cattle (Parés-Casanova and Caballero, 2013 and Knierim, Irrgang and Roth, 2015) but also monogastrics, known to be dramatically affected by heat (Lara and Rostagno, 2013). The indigenous breeds of West Africa are also trypanotolerant in tsetse fly infested areas of the Coastal countries, a resistance that gets diluted if crossed with exotic breeds (Maïga, 2012). Thanks to their higher resilience, local breeds can be an important tool for tackling climate change. Hence, any move into more intensive production system without a careful evaluation of the potential negative environmental outcomes will cause higher environmental impacts ${ }^{70}$.

As the main selection factor is resilience, the genetics of native breeds has low potential for generating high productivity. Local chicken (Besbes, 2009 and Islam and Nishibori, 2010) or small ruminants (Shafie, 1992), for example, will rather have adaptation to heat (a slim body) that will go against the logic of high-yield breeds. Similarly, some local cattle are known to be selected for their large horns. This is the case of the longhorn N'Dama or Kuri71, which is perceived as part of the "cattle complex"72 (Baroin and Boutrais, 2009), i.e. a misperception by observers that are external of the livestock system and have little traditional knowledge on it (Manzano, 2017a), judging livestock keepers to select for wrong traits or wrong economic strategies. The role of long horn for dissipating heat is of paramount importance in an environment where temperature greatly limits productivity (Parés-Casanova and Caballero, 2013 and Knierim, Irrgang and Roth, 2015) and where many adaptations for the same limiting factors are observed among wildlife (Nature Editorial, 2017). The low input environment they are kept in further prevents a full expression of the potential of high-yield breeds. The strong temptation to upgrade them by introducing some exotic gene pools has often proved unsuccesful because of harsh production environmental conditions for crossbred animals in most countries and the danger of diluting their natural resistance to environmental challenges.

In fact, investments in poorly adapted breeds have greatly undermined the resilience capacity of local rural communities. The results obtained in the array of production conditions in West Africa show that the great majority of introduction of exotic gene pool has not been successful in inducing a sustainable increase in milk and beef productivity as it was aimed at the planning stage (Blench, 1999 and Oba, 2012). This trend is likely to be deepened in the future because of an increased need to rely on pasture sources and to restrict fodder use (Hoffmann, 2010). The exotic pure breed production system did not adapt well to the West African production environment, which is generally harsh (Blench, 1999).

The current state of genetic resources highlights the lack of well-developed breeding institutions or breeding programmes for the local, adapted breeds, which are the ones offering highest potential for development (Hoffmann, 2013) ${ }^{73}$. The use of new livestock species such as domestic-bred grasscutters $^{74}$ lies further beyond the current capacities of local extension services.

\footnotetext{
${ }^{70} \mathrm{cf}$. section 11.3.1

$71 \mathrm{cf}$. section 2.1 .2

72 cf. section 10.5 .

${ }^{73} \mathrm{cf}$. sections $11.4 .4 \& 11.5 .2$

${ }^{74} \mathrm{cf}$. section 3.2
} 


\subsubsection{Husbandry and management}

The management options of resilience strategies of local livestock producers in West Africa are dominated by traditional practices. However, some of these local practices have major limitations for development.

The shelters poorly prepared for monogastrics, for example, are known to be a limiting factor, at least for chicken production, and a major reason for loss of competitiveness that triggers cheap imports from Europe ${ }^{75}$ (Box 7). Despite high potential of the agricultural systems in West African, failure of shifting towards intensification may indicate either cultural constraints or low investment potential, but is definitely related to weak agricultural extension services (Ollenburger et al., 2016). The lack of capital and unwelcoming environment for foreign investment drives the widespread insufficient use of modern production infrastructures and equipment.

In the case of pastoralist system, a different array of issues is limiting the husbandry practice. In the first place, these system is constrained by the financial structure of rural settings in West Africa. The banking or financing services are absent, and cash is neither available nor secure to keep. Hence, livestock constitutes the major financial asset, both as a cash source (small ruminants) and as a capital investment (cattle and camels) (IUCN, 2012). Therefore, there is a capital-based livestock management in pastoralist system, not a productivity-based one. The outsider perception is therefore that herd management is non-rational, driven by number rather than productivity. The constraints of such production system also render separation between extensive production, calving and fattening phases useless, leading to further limitations. Investments tend also to ignore these systems (Magnani et al., 2019).

The deterioration of the traditional management system (Manzano, 2015) has further escalated with limitations to mobility because of the increased population growth (Ollenburger et al., 2016) and because of limited outreach of positive policies (de Jode, 2010) with few good innovating practices that keep the producing and resilience logic of these systems (Herrera, Davies and Manzano Baena, 2014). This further illustrates the understanding of drought as a sociological issue, i.e. the incapacity of local production systems to cope with environmental variability, and the need to respect their underlying logic in order to prevent crises (Krätli, 2015 and Krätli et al., 2015). The regulated access to water points has been traditionally used as a management tool for rational use of pasture. However, increasing pressure is disrupting such system, causing high concentration of animals at a given water point leading to land degradation and to increased disease transmission.

The extensive nature of livestock production system coupled with seasonality of production does not allow the development of large scale and continuous collection of locally produced milk. However, private-driven actions ${ }^{76}$ like the ones seen in Somalia (Krätli et al., 2015 and Mauritania (Nori, 2010) are possible.

\subsubsection{Land tenure}

While not very relevant for backyard systems, a key factor in the ruminant livestock production is the access to rangelands, both in terms of grazing area and in terms of migratory corridors during transhumance. Land tenure systems in West Africa are largely communal, dictated by the social and environmental history of the region ${ }^{77}$ and shaped mainly by pastoralist ${ }^{78}$ and agro-pastoralist ${ }^{79}$ production types. The rapid population growth in the region is fueling mostly unplanned expansion of crop cultivation that block transhumance corridors (Ollenburger et al., 2016).

${ }^{75} \mathrm{cf}$. section 8.2.2

${ }^{76} \mathrm{cf}$. sections 11.4 .2

${ }^{77} \mathrm{cf}$. section 1.1.

${ }^{78} \mathrm{Cf}$. section 4.2
${ }^{79} \mathrm{cf}$. section 4.3 
The communal land tenure, which is fundamental to spread risk and increase resilience, is constantly threatened by policies pushing for land privatization to follow the ranching model, on the belief that it would increase productivity, even if it has been repeatedly proven to be wrong ${ }^{80}$ (Hatfield and Davies, 2006 and Krätli, 2014). At the same time, investment that shows a short-sighted perspective and a weak understanding of pastoralist system often promote the conversion of dry-season grazing grounds and drought reserves into intensive agricultural production. This can cause the collapse of the whole grazing system and turning into a less profitable production system, because of losing the use of vast rainyseason grazing land (Behnke and Kerven, 2012). Careful land planning can prevent such problems but is precluded by weak agricultural institutions and extension services ${ }^{81}$

Lack of security in land tenure is also a major factor constraining the sustainable use of land and it is relevant in a region subjected to policy changes and great demographic pressure. When future use of land is not guaranteed, short-term profits tend to be prioritized at the expense of the conservation of the natural resource base, which is otherwise guaranteed by traditional customary regulations (Herrera, Davies and Manzano Baena, 2014 and Davies et al., 2016).

The limited access to land in peri-urban farming is also a major constraint to private investment for the modernization and intensification of peri-urban animal production operations.

\subsection{Climate change}

West African is likely the region that has suffered the most dramatic consequences of human impact on the atmosphere so far. The Sahel suffered a dramatic reduction in rainfall in the 1970s and 1980s, followed by a recovery phase of "Greening of the Sahel".

\subsubsection{The impact of climate change on livestock}

The total rainfall and its temporal distribution are subject to annual variations in West Africa. The rainfall data in the Sahel between 1900 and 2010 (Figure 30) shows an unusually wet period from 1950 until 1970 , followed by extremely dry years from 1970 to 1990 . The latter resulted in the drought of 1970s and 1980 s during which about 30 percent of the livestock population of the subregion succumbed. That time has been linked to the abundance of aerosols in the tropics and dubbed "global dimming" (Ramanathan and Carmichael, 2008), the drought also affecting the Sudanian and Guinean AEZs.

A net rainfall and vegetation recovery, also known as "Greening of the Sahel", has taken place across the region during the following 30 years, although occasionally overlooked due to the confounding effects of land degradation (Ouedraogo et al., 2014 and Dardel et al., 2015). The whole phenomenon has triggered deeper debates on how real the concept of desertification is (Benjaminsen, 2017 and Davies, 2017). In any case, it took between one and two decades for livestock numbers in the region to recover from the previous crises. Between 1990 and 2010 rainfall returned to levels slightly below normal average, but year-to-year variability was high. The drought and famine that resulted hit again the Sahel in 2005 and 2009. The worst affected areas included Niger, northeast Mali, northern Burkina Faso and the northernmost part of Nigeria. The drought caused substantial deficits in cereal production, animal fodder and drinking water for livestock, which directly contributed to the food and nutrition crisis that affected more than ten million victims. The pattern was recently repeated in 2012, and many pastoralists were systematically forced to sell their livestock or to see them die. In Mali, comparison of cattle and small ruminant numbers during different years clearly illustrate the consequences of climatic crisis of the 1970s and the 1980s on population size of these species (Kamuanga et al., 2008). This has induced permanent relocation of non-negligible portions of livestock population to southern zones, either within the same country or across borders, where production conditions have remained conducive.

${ }^{80} \mathrm{cf}$. section 11.5 .2

${ }^{81}$ cf. sections $11.4 .4 \& 11.5 .1$ 


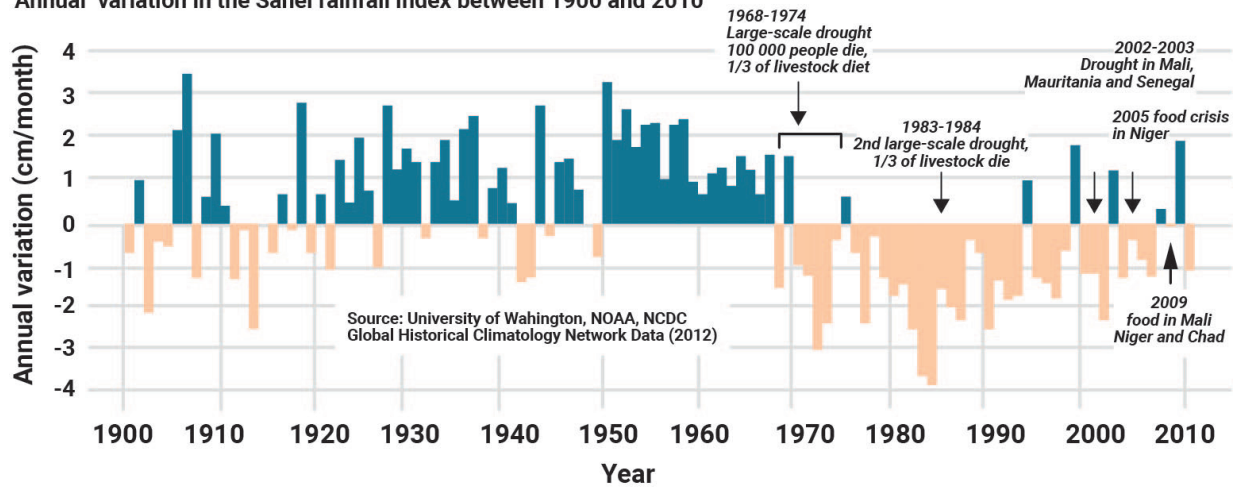

Source: FAO and CIRAD, (2012).

The future trends have proven difficult to predict. Some climatic models indicate that there will be a significant increase in the average temperature (around $1.5^{\circ} \mathrm{C}$ ) in the Sahelian band, with direct consequences in terms of increased evapo-transpiration and stress on crops (FAO and GEF, 2014). The recovery in rainfall expressed by the "Greening of the Sahel", while possibly linked with reduction in aerosols, seems also to be related to human-mediated global warming, a strengthening of the monsoon would be triggered by warmer conditions in the surrounding seas (Baisutti, 2016). Such outcome can be considered unexpected as the climate models may have been overvaluing the effects of potential evapotranspiration in continental drying (Milly and Dunne, 2016). Even if drought is the most feared outcome in the region, because of devastating effects of the past droughts, an increase in rainfall may also pose severe challenges. The huge extension of lakes in the recent past has a potential to force massive population displacement of the current sedentary populations. Lake Chad basin is particularly worrying, having occupied a surface similar to the Caspian Sea in the Holocene, as is the area around the Niger River in central Mali (Larrasoaña, Roberts and Rohling, 2013). Changes in either average amount or extremes of rainfall require adaptation strategies for animal production that is highly dependent on natural resources. The susceptibility of animal species to different diseases and parasites varies with rainfall levels, humidity and temperature posing a real threat not only for camel husbandry or other animal breeds adapted to drought, but also for the widespread occurrence of arthropod-borne diseases (Olwoch, Reyers and van Jaarsveld, 2008). The floods can also trigger effects that are as catastrophic as droughts.

The precipitation in West Africa is reported to be increasingly variable, with consequences in terms of unexpected flash floods and changes in the onset and duration of the rainy season. Important number of livestock is occasionally lost to flooding related to excessive amount of rainfall on short periods of time, especially in animal husbandry situations in West Africa where livestock is seldom properly housed and is not always attended to throughout the year. The floods deny access to grazing areas till they recede and may create conducive environment for multiplication of disease vectors. In 2009 , floods in northern Senegal affected nearly 40,000 households in some rural areas. The rainy season in 2010 brought abundant rainfall, which caused serious flooding affecting 1.8 million people and over 141,000 hectares of crops, especially in Benin, followed by Burkina Faso, Niger and to a lesser extent the Gambia, Ghana, Guinea, Mali, Senegal and Sierra Leone. Livestock production was also affected by 
floods, which led to numerous cattle deaths, whether by drowning or by water related diseases. Over 70,000 head of cattle died in Niger and about 3,000 died in Mali (FAO, 2011b). In Niger in 2012 more than 500,000 people were affected by floods (IFRC, 2012). Successive years of flooding may also cause the crop producers in the extensive system of production tend to switch from depressions to mounds initially used as pastoral land.

The adaptation mechanisms are therefore strongly linked with strengthening veterinary services and maintaining pastoralist mobility, while keeping a resilient genetic stock both for backyard and pastoral systems. Such measures have a critical outcome for reducing rural poverty and vulnerability. A further level of complexity is added by "divergent adaptation" strategies (Snorek, Renaud and Kloos, 2014) that entangle a competition among livelihoods and adaptive measures that are taken at the expense of the adaptive capacity of other stakeholders.

\subsubsection{The impact of livestock on climate change}

Although burning fossil fuels is the main cause for global climate change on earth, livestock production has been reported to be a great contributor to climate change. Methane, mainly produced from enteric fermentation by ruminants, and manure emissions of nitrogen oxides, are the bulk of the livestock emissions, and mitigation strategies are also being discussed, especially in the context of sustainable intensification of mixed farming system (Herrero et al., 2016). The pastoralist system with minimum external input are assumed to have zero net effect on climate change (Manzano and White, 2019). The same authors suggest that any mitigation measures for mixed farming systems should be evaluated with extreme care if applied to pastoralist contexts.

The deterioration of the otherwise sustainable traditional rangeland management systems triggers ${ }^{82}$ degradation of rangelands by uncontrolled grazing and logging. Degradation leads to the loss of soil carbon and exacerbation of climate change effects (Lal, 2004), while also triggering change in the albedo that can diminish local rainfall (Sinclair and Byrom, 2006).

Recently, concerns regarding large-scale intensive livestock production were raised. The environmental impact of intensive modern livestock production in developing countries is little documented. However, the impact of high-intensity, large-scale livestock production on the environment, particularly in terms of fossil fuel use and derived greenhouse gas (GHG) emissions, has been in the spotlight in recent years. Similarly, the impact of intensive livestock farming on water resources compared with traditional livestock (Scholtz et al., 2013 and Toro-Mujica et al., 2016) and clearing of forests for livestock grazing are some of the growing concerns. In the particular case of West Africa, intensive livestock farming is minimal and the impacts listed above are yet to be quantified.

\subsection{The constrains related to livestock inputs}

Some of the major limitations of livestock production in West Africa are related to inadequate inputs into the system, be it in a form of feed, water or health care, infrastructure, investments or extension services. The issue here is related to the inadequacy of the management that is applied to them in terms of shelter, feed or health care, or the support in terms of technical expertise provided. The scale for action at this level is determined by the farmer, who can undertake changes for improving productivity. 


\subsubsection{Feed and feeding systems}

The availability and accessibility of animal feed are major constraints for livestock development in West Africa. Due to scarce market infrastructure and protectionist policies, backyard and industrial systems are greatly conditioned by local agricultural output (Box 7). The low care generally provided to backyard systems, reflected in poor investment on shelters and other domestic infrastructure ${ }^{83}$, is also reflected in the lack of chicken feeding practice and the low availability and quality of poultry feeds, for which there is little market. The advantage of periurban systems vis-à-vis extensive systems in terms of a less fluctuating feed environment is therefore lost. As a consequence, the few animal feed factories also have a low output and low access and high cost of agro-industrial by-products, mainly oilseed products.

The limited purchasing power in the region causes concentrate feed to be very limited and expensive for those involved in livestock fattening. This is reflected in the relatively reduced numbers of fodder imports from outside the region, key especially for intensive/backyard settings, and their high cost compared with locally produced resources ${ }^{84}$. The low prices of locally produced feed also impede the valorization of fodder production cost.

In pastoralist systems, livestock feeding still depends strongly on natural pasture, with rare fodder cultivation. The agro-pastoralist in extensive systems seasonally depend on stubbles ${ }^{85}$, a system proving to be very efficient for the regional settings. While sustainable intensification is being promoted in the context of climate change mitigation, but also in order to increase yields ${ }^{86}$, most producers are not aware of exotic fodder varieties and have difficulties accessing quality seeds.

A regional fodder strategy has been demanded by pastoralist collectives as a tool to buffer climatic variability (RBM, 2012) and is being discussed to be put in place place (Allen, Heinrigs and Zoundi, 2015). While there is a logic for this strategy of reducing losses during crises, evidence from Arab countries shows that it can be a risky strategy in the long term (Allen, Heinrigs and Zoundi, 2015). Sustained fodder provision can increase herd numbers well above the carrying capacity of ecosystems, even if mobility and transhumance strategies are in place, causing land degradation in the long term due to trampling and selective grazing and, at the very end, a collapse of the pastoralist production system. It is advisable to keep fodder-fed animals confined, even in emergency situations, to prevent damages to the ecosystem. Such environmental consideration does not withstand that an increase of fodder production in sustainable ways, considered in a context of increased investment in processing and connections to markets, will be a key driver to transformation and growth but always avoiding land degradation effects.

\subsubsection{Livestock infrastructure}

The poor livestock infrastructure in West Africa at different levels poses severe constraints for livestock development. Poor road network are the most visible side of it, with transportation hampered especially during the rainy season, as well as lack of appropriate livestock hauling trucks.

The challenges caused by poor infrastructure to commercialization of milk may be the reason behind high persistant milk imports from outside the region (Box 6). In West Africa, raw milk collected is channeled through three different ways to the end consumer: direct consumption by the farming household, processed through simple traditional methods by pastoral women (in rural areas) or 
collected by industrial processing units (located in peri-urban areas). The latter is faced with many types of constraints because of the transport and cold chain needs (Aboubacar, 2017) and (Gueye, 2017) the little confidence given to producers by the processing plants (Gefu, 2009). Milk processing in rural areas of West Africa is rather a preservation method than a value addition venture, because most of the transformed products (sour milk, yoghurt, butter and cheese) have longer shelf live than fresh milk. There is a long time span from farm gate to milk plant related to the absence of well organized milk collection scheme. The initiatives imitating successful experiences elsewhere (Nori, 2010 and Abeiderrahmane and Abeiderrahmane, 2010) could combine adapted collection methods and creation of infrastructure for preserving milk up to the dry season, therefore introducing anti-cyclic measures to achieve higher added value. Success stories with the production and commercialization of dehydrated milk trace the potential for change (Aboubacar, 2017) in the milk value chain. On the production side, the poor state of troughs and other water infrastructure for livestock, as well as its poor regulation with invading crop farmers, can drive to high production losses and conflict (Bakayoko, 2012). The poor state of roads and lack of collection points with cold chain along the roads, and low availability of electricity in general make it extraordinarily challenging to collect, preserve and deliver unspoiled milk during the rainy season, which is ironically the calving season and the time when milk production is more abundant (Breman and de Wit, 1983). On a broader scale, poor roads hinder very much the overall access to markets (Berg et al., 2017). They have also proven to affect the adaptation capacity of local populations to climate variability (Shively, 2017). Poorly constructed roads can also affect resilience of livestock keepers as well as wildlife (Said et al., 2016), the latter influencing the overall quality of the natural resource base as well as complementary livelihoods.

In addition, road harassment, in terms of several illegal check points set for collection of undue payments, long transit delays and bribery to avoid these $\mathrm{e}^{87}$, are some of the challenges of live animals' trade in West Africa. The result is high transport cost, devaluation and loss of perishable goods, poor access to markets in rural areas and increased isolation of large parts of traditional livestock producing areas.

While poor sanitary conditions in markets have already been described as threats to animal health ${ }^{88}$, slaughterhouses tend also to be scarce, distant and with inadequate preservation facilities, lacking materials and equipment. This is a driving force for live animal market where the animal's body condition deteriorates on the way to faraway market or slaughter house. In a typical journey from Niagre in Burkina Faso to llesha market in Nigeria, a bull will lose approximately 5 percent of its bodyweight and has a 1 in 20 chance of dying en route. This diminishes the potential value of average sales by 10 percent (USAID, 2010 and Walker, 2013).

The poor financial infrastructure in rural West Africa (scarce and unsafe financial service delivery points such as banks) not only makes it challenging to turn livestock economies from capital-oriented to production-oriented ${ }^{89}$, but it makes it also challenging for private investment that could partly solve the shortcomings of public investment. Mobile money, already present and widely used in East Africa (Mwangi and Rutten, 2012 and Chambers, Wild and Foresti, 2013), offers very promising opportunities to solve such issues.

The availability of DOCs is probably the number one limiting factor of poultry production in most West African countries, which is also related to infrastructure limitations and high costs of transport. In the best cases, for example in Mali, more than 50 percent of DOC needs are not met (Traoré, 2013). The capacity of local hatcheries is low and producers rely on importing chicks from outside, with a high cost of DOC (Schneider, 2010). This is caused by a low access to power sources (electrical or solar) for rearing chicken.

${ }^{87} \mathrm{cf}$. sections 5.3.4 \& 11.5.2.

${ }^{88} \mathrm{cf}$. section 11.4 .3 .

${ }^{89} \mathrm{cf}$. section 11.2 . 
The prevention of conflict over land use and maintenance of reasonable traditional practices could benefit from the yet scarce or non-existing infrastructure of rangelands and migratory corridor demarcation ${ }^{90}$. Land planning can make use of various tools of conflict resolution at the local/village level, such as community-based natural resource management (Peter Castro and Engel, 2007), with specific adaptations to livestock producers' setting (Gibbons, Roba and Mahadi, 2013; Mahadi, Roba and Gibbons, 2013 and Roba, Gibbons and Mahadi, 2013). Specific consultations and incorporation of customary arrangements in the form of the Voluntary Guidelines on the responsible Governance of tenure of land, fisheries and forests in the Context of national food security (VGGTs), have been endorsed at the Committee on World Food Security (CFS) by all UN Member States including those from West Africa (FAO, 2012b). Specific applications of them exist for pastoralists and agro-pastoralists (Davies et al., 2016) and other livestock systems (HLPE, 2016). Such endorsement of community-based planning allows for much more efficient and socially sustainable interventions.

\subsubsection{Animal health care}

In West Africa, disease surveillance in the field is weak or lacking and animal diseases pose a big challenge to the development of the livestock production. Many inputs necessary for livestock production and animal health care are not readily available, because they are not produced locally ${ }^{91}$. The proportion of products smuggled in, especially veterinary drugs, are on the increase and drug resistance is becoming a real challenge in the treatment of diseases such as trypanosomiasis in tsetse infested zones (FAO, 2016a).

The overall weakness of veterinary services is due to poor human, material and financial resources failing to match the high prevalence of animal diseases such as CBPP, PPR, Pasteurellosis, ASF, NCD, Anthrax and BQ, trypanosomiasis or Brucellosis, etc. (AU-IBAR/ARIS, 2013). The persistence of certain avian diseases, for example, add to the poor vaccination level and the poor bio-security ${ }^{92}$, leading to high mortality rates of 40-90 percent, especially among young birds.

There is a low number of private veterinarians delivering veterinary services in pastoral areas, and the training and incorporation of paravets (Chambers, Wild and Foresti, 2013) is still weak. As a consequence, the sanitary status of the milking herd is low, with presence of zoonotic diseases, salmonellosis and staphylococcus-borne mastitis, and residues of drugs used for treatment or for conservation purposes are present in milk.

Current market infrastructure in the region also poses challenges for livestock health, as in the example for poultry. The different types of markets where livestock are traded in West Africa are: collectors', gathering/aggregation, terminal and frontier markets. With few exceptions, there is no stand-alone poultry market. The aggregation markets for poultry are oftentimes integrated to traditional market places where they occupy an area. In these markets there is no separation amongst poultry species (including chicken, guinea fowl, ducks, and pigeons) which are mostly intermingled in the same cages. Sick birds or even dead birds may mix with live ones, creating high risks of contamination. Such situations are generally observed in aggregation and terminal markets. In all these markets storage conditions are in general rudimentary for most poultry products and little information is available on trade actors. Transportation to and from markets is by bicycle, motorbikes, minibus and bush taxis. The birds are crowded in traditional cages or suspended in open air, grouped by tied legs. As a result, important losses may occur due to high heat and excessive crowding (FAO, 2016a). Poor hygiene and biosecurity in live bird markets and transport remain major sources of introduction and spread of diseases such as the HPAI with devastating effects on the sub-sector and a threat to human health. 


\subsubsection{Human resources}

Livestock production in West Africa suffers from a general lack of highly qualified technical workers (veterinarians, animal feed specialists, lab technicians) and extension services. For example, Sierra Leone reported not to have a functional Veterinary Department in 2012, with dire consequences for disease control (Loum, 2012), while Senegal has witnessed a deterioration of country-wide animal health strategies following the complete privatization of veterinary services in 1995 (Gueye, 2012). The weakness of the sub-sector due to lack of agricultural extension workers (Ollenburger et al., 2016) is combined with a reduced investment and a community of ageing professionals among the veterinary services ${ }^{93}$. Strategies encouraged by many international donors, such as bee keeping (an aspect of animal husbandry not included in this book), proven to significantly reduce rural poverty, also suffer from lack of extension services to the point of missing their intended impact (Amulen et al., 2017). The small investment of the public sector in extension services, and the low capacity of its officials, often having been educated on highly producing systems that have little to do with the local genetics and resilienceoriented livelihoods, sum up to create a landscape of general lack of capacity.

Moreover, there is high level of illiteracy rates in West Africa (IRIN, 2009 and UNESCO, 2009), affecting mainly women and rural populations and more particularly nomadic communities (Pearce, 2009). Such a circumstance has a direct effect on agricultural productivity, similarly to what happens i.e. with female education (Browne and Barrett, 1991). Illiteracy has a direct impact on understanding extension messages and materials as well as record keeping of animal production units. It limits the way to tackle low operational capacity of producers or low technical skills of livestock farmers and in livestock fattening operations. Along the supply chain, further problems arise, beginning with the insufficient level of specialization and low number of technicians or the low technical level of processors (butchers' shops) in the case of meat, or the lack of technical skills of milk processors, not observing milk hygiene, pertaining to hand milking, and poor collection and transport conditions.

The high number of intermediary and multiplicity of actors in the supply chain ${ }^{94}$, part of an "easy money" business culture linked with the generalized low education levels, adds further challenges to the efficiency and competitiveness of the system. However, such considerations should not ignore the role that intermediary play in remote areas. The great fluctuations and unpredictability in the market creates very meagre economic opportunities for them (Roba et al., 2019), highlighting the need for better information systems (Roba et al., 2018) as well as a better coordination in the livestock supply chain (Roba, Lelea and Kaufmann, 2017).

\subsection{Institutional constraints}

The institutional environment is also a source of very important limitations, affecting the whole production system in which farms are embedded. Individual action has little or no potential for change, and changes are to be undertaken either by farmers themselves as a collective, or by upper instances with enough investment power, such as the state or international donors.

\subsubsection{Investment in livestock}

In West Africa, limited investment is a major hurdle to livestock development. Private investment seems to be weak, as driven by diverse cultural issues and local contexts (Ollenburger, 2016). Political instability doesn't also contribute to an adequate investment environment, the extreme of it being the known instability of pastoralist regions (De Haan et al., 2016).

${ }^{93}$ cf. sections 6.4 \& 9.6.

${ }^{94} \mathrm{cf}$. sections 5.3.4 \& 8.2.1 
The livestock sub-sector, just like the agricultural sector in general, does not attract the funding (public or private) it deserves to achieve its function of contributing to food security and reducing poverty, especially with rural households. There is no proven well-established adequate credit system to encourage investment in livestock production or livestock product processing. In most cases, financial tools do not even reach the not-so-remote areas ${ }^{95}$. The existing credit system has high interest rate for investment in livestock business, and at times intermediaries introduce prohibitive commissions (Touray, 2017). The stakeholders in the sub-sector have limited investment resources and there is a strong social stratification determining who is able to invest in the most input-intensive systems, as in the example of Togo (Talaki, 2012). As a result, pro-poor systems are invariably backyard, agropastoralist or pastoralist systems with low level of investment and high efficiency at minimum inputs. The semiintensive systems are held by professionals with some saving capacity such as public servants, traders or retired people, and the most capital-intensive, modernized systems are owned by wealthy people.

In West Africa, the industry for slaughtering animals and processing meat and meat product is at an embryonic stage, if it exists at all. Hence, livestock are often traded as live animals and their products and by-products continue to be commercialized unprocessed and without value addition. Significant efforts need to be deployed to improve the cold chain for meat and milk storage and handling. It appears that, despite existing livestock development policies, the promotion of processing and value addition of livestock, meat and animal by-products still faces several difficulties.

This situation, however, is contradictory with the relatively high availability of resources from governments, the potential for public spending, and the commitments towards agricultural development. The West African region receives 40 to 80 million USD as Overseas Development Aid per year (with the exceptions of Cabo Verde in the higher end and Nigeria in the lower end (OECD Data Lab, 20132014). The governments in the region have committed in 2003 through the Maputo declaration and recommitted at Malabo 2014 declaration to dedicate 10 percent of their GDP to agricultural production. This would have corresponded to about 3 percent of the GDP to be invested in livestock, while in reality it is less than 1 percent what is invested. Among the biggest economies in the subregion and for 2012, in Senegal it was i.e. 0.41 percent (Gueye, 2012) and in Côte d'Ivoire 0.21 percent (Bakayoko, 2012). Among the economies with a higher contribution of livestock to GDP (Table 39), the livestock sub-sector in Mali got only 3 percent of the budget just dedicated to the rural sector for 2009, agriculture getting 91.6 percent (Haidara, 2012), while Niger is dedicating less than 1 percent of the national budget for the functioning of the livestock sub-sector, even if the investments have improved in the last years (Djibrillou, 2012). These data are noteworthy considering that livestock contributes more than 20 percent to the national GDP. Guinea Bissau, with a contribution of livestock to more than 10 percent to the national GDP, only has 0.3 to 0.4 of the national budget dedicated to the functioning of livestock services (Djata, 2012). Paradoxically, the little amount approved as public investment of the livestock sub-sector cannot be entirely used due to different bureaucratic hurdles, mainly the timely release of funds. In Burkina Faso, for example, only 24 percent of the budget approved in 2012 for the Ministry of Animal Resources was fully used (Some, 2012), and in Ghana only 17 percent in the case of the Department of Livestock was used (Akunzule, 2013). Adding the big challenges that many countries in the region face regarding corruption, there is little left for effective improvement through investment.

Of the little portion reaching the final target, misguided investment is also a big issue. Massive investments in Eastern Africa following the same misguided logic as described in section 11.2.1 have led to loss of money into massive counter-productive infrastructures, but also into millions of dollars lost in terms of agricultural productivity, therefore driving to dispossession and poverty of locals, with 
effects even extending to communities beyond national border (Mousseau and Martin-Prével, 2016). The priorities for cash-producing crops and rapid industrialization of the agricultural sector inadvertedly drive to ill-adapted production systems, usually without prior consultation and consent of local residents. Similar practices in the livestock sub-sector can lead to equally negative results (Manzano, 2017a).

\subsubsection{Policies and regulations}

A first aspect where policy and regulation are lagging behind in West Africa is the availability of reliable statistics $^{96}$. A simple revision of the data provided to the FAOSTAT database in the last years reveals that most countries in the region have poor livestock statistics, the most relevant case being Nigeria, with practically no sources being official but rather extrapolated from other sources. Lack of reliable statistics is a very big handicap both for efficiently planning policy and for designing proper advocacy (Manzano and Agarwal, 2015 and Pica-Ciamarra et al., 2014b).

The specific challenges of livestock statistics include insufficient and poor quality information on the value chain, including supply, demand and transfer costs. While pastoralist contributions are very difficult to track, especially in terms of Total Economic Value (Hatfield and Davies, 2006), in backyard systems such as traditional poultry production, the contribution to household income in rural areas is not well known. This is also key for gender issues, as it is a major support to revenue of women in rural areas.

The efficacy of policy and regulatory measures are also hampared due to rumpant corruption at different levels and poor institutional environment. There are numerous road blocks, long delay at border crossing points with frequent road harassment from public security services along the livestock migratory corridors to coastal countries. This leads to irregular but significant overhead costs, a lot of wasted time on the road and by train and loss of market value of animals and perishable animal products. This stimulates non-contracted and informal nature of transactions between actors and in cash payment, which does not secure export traders nor guarantees quality.

The existing policy measures are scant and most regulations which might affect the livestock subsector are outdated. Misguided measures include regulations to stimulate local production through bans, as in the case of chicken that ends up encouraging smuggling (Box 7), instead of focusing on, or at least accompanying it with, increasing competitivity that would stimulate local production (Gefu, 2009). Studies in other African countries for the milk value chain (PPD Consultants, 2013) see more opportunities in increasing the quality of products for creating a dynamic, high-added value and competitive market.

The product quality (sanitary, organoleptic, nutritional value, etc.), trade policies and safety requirement are the major areas, which pose problems to trade channels of livestock products within and outside the West African region. Unfortunately, African countries tend to focus in promoting raw material exports with little transformation, instead of encouraging locally-based processing facilities that would not only add value to local employment and poverty reduction, but also potentially open markets that are closed so far because of food safety regulations.

An unwelcoming environment for cooperation between publics and private veterinarians as well as paravets also limits development options. As a consequence, livestock processing units benefit little support in norms and quality. Existing infrastructures have an undefined juridical status and little scope 
for implementation of regulatory measures of animal transportation or monitoring and evaluation of programmes and activities for development of the sub-sector. There is little organization of livestock merchants and export traders and an unorganized commercialization circuit.

Pastoralist mobility is increasingly considered key for the sustainability of rangeland systems ${ }^{97}$, triggering recognition both at the continental (African Union Commission, 2013) and regional (ECOWAS, 1998) levels. However, they still are insufficient because of the weak coordination among countries and the low level of implementation.

\subsubsection{Producers' organizations}

Contrary to their countless numbers in many countries of West Africa, organizations of producers and other actors in the livestock sub-sector are weak, particularly in terms of organizational and capacity for resource mobilization (Bassi, 2017). The lack of appropriate funding for capacity development (Codjia, 2012 and Touray, 2012) prevents the public-private partnership framework to play a real role. This is a major handicap for livestock farmers and other groups access to services and communal resources and defend their interest. The situation is a major concern in most livestock value chains and prevent their expected contribution to food security, rapid poverty reduction and increased income for families of livestock farmers. There are limited farmer training programmes in livestock production techniques and management, which is at times linked to the paucity of livestock training institutions, both academic and vocational.

While producers' associations have managed to establish cross-regional networks in the past, such as Réseau Billital Maroobe (RBM), Réseau des Peuples Pasteurs du Sahel (RPPS), Association pour la Promotion de l'Élevage au Sahel et en Savane (APESS), Réseau des Organisations Paysannes et de Producteurs de l'Afrique de l'Ouest (ROPPA) or the Confederation of Traditional Herder Organizations in Africa (CORET), the low strength of civil society in many countries and the authoritarian nature of many governments certainly limits the scope of pro-poor advocacy that can be excercised. The support from international organizations in sharing good practices can be helpful for increasing the impact of advocacy in a non-inviting policy environment where organizations have to be inventive, as proven for example in land rights advocacy (IUCN, 2011). The effectiveness of producers' organizations in improving the conditions of the productive sector, particularly in the livestock sub-sector, is unquestionable. However, the challenges faced are many and not easily resolved, especially without the involvement of the public sector (Mazano and Agarwal, 2015).

\subsection{Livestock emergencies}

The natural disasters, such as droughts and floods, animal diseases, and civil conflicts are at the origin of livestock emergencies, weakening the food and nutrition security of the populations in West Africa. Given the increasing frequency and complexity of such events in the region, early warning systems are being put in place by different national and international organizations, as a major device for emergency preparedness in order to prevent and mitigate risks, through effective and rapid response under an integrated and holistic approach. Examples of early warning systems include the Quarterly Early Warning Bulletin of Food and Agriculture edited by FAO; the monthly Bulletin de suive de la campagne agropastorale en Afrique de l'Ouest, edited by AGRHYMET (CILSS); the bi-monthly newsletter Securite Alimentaire et implicationes humanitaires en Afrique de l'Ouest et au Sahel, edited by FAO and WFP, or the Famine Early Warning Systems Network website (FEWS Net, 2019), edited by USAID. FAO has a comprehensive guide to deal with livestock emergencies, called Livestock-related interventions during emergencies, the how-to-do-it manual edited in several languages. Likewise, the 2nd edition of Livestock Emergency Guidelines and Standards is available (Ankers et al., 2016) to advise practitioner in how to intervene under such circumstances.

${ }^{97} \mathrm{cf}$. section 11.2.2. 


\subsubsection{Natural disasters}

The causes and effects of natural disasters related to climate change have already been well described ${ }^{98}$. Hence, mitigation measures are very important. The local population and national governments in West Africa have in general a rather limited capacity to deal with natural disasters. Improving the prediction of these events using meteorological indicators is the best way to mitigate risk and impact. The different forecasting models and early warning systems based on satellite images and weather/ climate forecasting data have been successfully developed by specialized agencies and are available for practically all the West African countries (FEWS Net, 2019). These tools allow national authorities to predict climate-related emergencies, identify potential risk areas and thereby to implement measures to prevent their emergence and mitigate their consequences. The challenge still remain on how better disseminate and use this information for the development of preparedness, contingency and mitigation plans at national and regional level. The National adaptation programmes of action (NAPA) on climate change provide a way to identify priority actions that need to be taken to respond and to adapt to climate change. In West Africa, 12 countries have developed NAPAs: i.e. Benin, Burkina Faso, Cabo Verde, Gambia, Guinea, Guinea-Bissau, Liberia, Mali, Niger, Senegal, Sierra Leone and Togo.

The animal losses during emergencies described in section 11.3.1 can be significantly reduced through the implementation of animal health interventions such as vaccination, provision of anthelmintic, vitamins and minerals and improved diagnosis and treatment (Ankers et al., 2016) and the provision of feed and water. Destocking is another practice commonly used in response to drought, when livestock conditions deteriorate and they are likely to die. Destocking will help to relieve pressure on grass and water resources to the benefit of the remaining selected breeding stock, providing as well a source of meat and cash for their owners or source of meat for emergency feeding of the population requiring food assistance. Ideally, destocking programmes should be state-supported in order to avoid significant decrease in market prices and speculation by traders. In the recovery phase, the provision of livestock or restocking can make a significant contribution to rebuilding livestock assets. Flooding can result in the death of thousands of livestock, presenting a considerable challenge regarding the disposal of livestock carcasses, which may have negative environmental and animal/human health impacts. The provision of livestock shelter and feed, as well as restocking schemes during the recovery phase, should be also considered in this case, although with the limitations considered in section 11.4.1. Several international organizations in West African countries have engaged in these activities over the last climate-related emergencies in recent past years.

\subsubsection{Animal diseases}

The high-impact animal diseases such as CBPP, FMD, PPR, or ASF, constitute a crucial risk for the livestock sub-sector in West Africa, affecting animal production and trade as well as food security and nutrition ${ }^{99}$. Most of these diseases are endemic in the region, and the risk of spreading is increased by environmental and socio-economic trends. Other diseases, such as HPAl, are originally exotic to West Africa. The first incursion of HPAl in West Africa occurred in 2006. It was eliminated by 2008 and reintroduced towards the end of 2014 in Nigeria. Other countries in the region, i.e. Burkina Faso, Niger, Côte d'Ivoire and Ghana reported the disease in 2015, causing the destruction of millions of poultry due to the disease or control measures. Livestock can also become more vulnerable to some diseases such as RVF or Anthrax during natural disasters, such as drought, heavy rains and prolonged flooding. This does not only result in production losses, but also increases the risk of human sickness and death, 
since most of them are zoonosis. The RVF outbreak in Niger, which caused 266 human cases and 32 deaths between August and November 2016 (FAO, 2011b) followed the flooding caused by unusually heavy rainfall in Tahoua region (FAO CMC-AH, 2016). A general lack of updated, accurate information on the livestock sub-sector, combined with insufficient veterinary services, non-existent or inadequate regulations concerning animal production, trade and health, are also other important obstacles for the prevention and control of such diseases.

International organizations are supporting, through different initiatives, specific activities on animal disease involving early warning, rapid reaction, enabling research and promoting coordination in order to implement measures to prevent their emergence and mitigate their consequences within the region. Since 1994, the FAO EMPRES is promoting the effective control of the most serious livestock diseases by progressive elimination on a national, regional and global basis through international co-operation. The joint FAO-OIE-WHO GLEWS is a result of the above programme whose ultimate goal is to promote disease prevention and control measures of potential concern at the human-animal-ecosystem interface. The FAO ECTAD was established in Bamako in 2006, following the spread of HPAI to Africa. Later the OIE and AU-IBAR joined FAO in establishing the Regional Animal Health Centre for West and Central Africa (RAHC-WCA), a technical platform of coordination under the Global Framework for the progressive control of Transboundary Animal Diseases (GF-TADs). The RAHC is now the specialized center of ECOWAS.

\subsubsection{Civil and socio-political conflicts}

Those civil conflicts linked to pastoralism (particularly within the transhumance sub-system), as well as examples of mitigation measures and policies to cope with these problems within the region, have already been well described in sections 4.2.6 and 9.11, respectively, as well as illustrated with concrete case studies. Hence, this section will mainly focus on socio-political conflicts. The livestock movement due to political or military conflicts has also gained significant importance over the last decade or so (De Haan et al., 2016), causing vandalism, theft of livestock and killing of herders within and across borders in many circumstances and in many places. The conflicts related to livestock restling are also common and cause each year substantial losses to pastoralist. Cattle rustling has increased over the past twenty years to become a "modern" well organized activity and which has adopted motorized vehicles and automatic weapons and hardly or not related to pastoralism and cross-border livestock movements.

Today, the majority of West African countries are politically stable. However, a certain number of them have been or are currently affected by socio-political crises (i.e. Côte d'Ivoire, Guinea, Liberia, Sierra Leone, Nigeria, Mali or Burkina Faso during the last few years), resulting in population displacements, as people leave their countries and their belongings in search of refuge, often in host communities. Currently, this situation is exacerbated by the presence of radical groups in certain West African countries, which has resulted in increased security restrictions and limited humanitarian access to vulnerable populations. In $2015,737,000$ people were internally displaced in Nigeria due to conflict, adding up to a total of more than 2 million internally displaced people (IDPs) by last years' conflicts; meanwhile, in Niger 47,000 new IDPs due to conflict were added to the more than 100,000 already in place (Kemp, 2016). Niger also hosted more than 150,000 refugees from Nigeria at the end of 2016, while Mali is currently a source of refugees, 32,000 of which were then hosted by Burkina Faso (UNHCR, 2017). IDPs and refugee camps may result in unusually high livestock populations in a restricted area. Although the provision of feed and water may sustain livestock in these situations, early recognition of 
possible environmental impacts, such as competition for pasture, land degradation and waste disposal, can help to limit damage to natural resources and reduce animal/human disease incidence. Derived problems from such an increased density can trigger tensions with local populations and these are issues that require specific agendas to be dealt with (Manzano, 2017b). The disruption of transhumance has a potential explosive situation much related with social turmoil, and interventions should take such factors into account (IUCN, 2012 and De Haan et al., 2016). 
THE PROSPECTS OF THE LIVESTOCK SUB-SECTOR IN WEST AFRICA

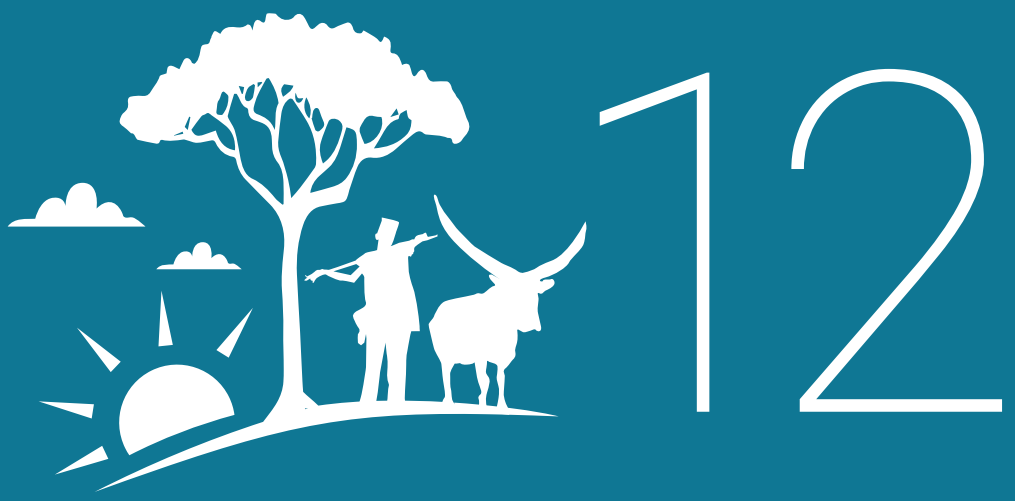





\section{CHAPTER XII \\ THE PROSPECTS OF THE LIVESTOCK SUB-SECTOR IN WEST AFRICA}

\subsection{Trends in shifting production systems or level of intensification}

The recent development of peri-urban livestock farming around urban cities in West Africa, with varying level of intensification, is a major shift in the regional animal production systems, which was before mostly under traditional, low-input management system. The peri-urban farms are indeed a departure from 'low input, low output' traditional system towards a modernized and market-driven animal production. The growing demand for milk products due to population growth and urbanization (Delgado, 2003 and Amadou et al., 2012) has presented opportunities for the development of smallholder commercial periurban milk production system based on crossbred cattle and and/or imported pure breeds.

Depending on the species, five to 40 percent of livestock farming households practice some form of intensification in herd management at varying levels, and yield remarkably important amount of animal products. In countries like Côte d'Ivoire, modern poultry farms contribute to 50 percent of the national poultry meat production, and cover 100 percent of domestic demand for table eggs, according to the 2009 statistics (Bakayoko, 2012).

Peri-urban livestock farming is an income-generating system that has mostly been owned by poor urban dwellers in order to complement income (Thys et al., 2005 and Amadou et al., 2012); the increasing trend for intensification invites, nevertheless, to think that the main livestock owners will be what can be called the new actors with enough investment power, i.e. rich livestock export traders and employed or retired civil servants. The production system is shifting from a low-input, low-output backyard system into a capital-intensive system using livestock infrastructures and significant use of exotic breeds, feed and veterinary inputs, with animals permanently maintained inside well established housing system and depending little on natural grazing resources. Such practices are often promoted through the private sector and project interventions at village level, supported by the public sector and NGOs especially in sheep fattening and small-scale commercial poultry. 
The peri-urban livestock production, especially for poorer livestock keepers, relies massively on crop residues in peri-urban crop production system and provisioning of cottonseed cake, together with cereal bran and fresh grasses (Amadou et al., 2012). Cultivating fodder is part of the animal husbandry methods to improve nutrition for ruminant livestock. The new developments in fodder cultivation are encouraging support for intensification of animal agriculture in peri-urban farms (Haidara, 2012 and Gueye, 2012). Even though the importance of fodder production has long been demonstrated at research level, its adoption by livestock farmers has been remarkably low. The 2009 powder milk shortage in West Africa has convinced the private sector to establish sustainable milk production farms using exotic cattle breeds which require high quality feed. Hence, cultivated grass species are being promoted under National Livestock Services and Livestock Development Projects and fodder banks are increasingly expanding in and from these new farms. The main species cultivated include Stylosanthes spp., Panicum spp, Pigeon pea (Cajanus cajan) and Gliricidia spp., bourgou (Echinochloa stagnina), dolique (Lablab purpurens), sorghum and maize.

Artificial insemination is a reproduction biotechnology, which is moving out of research stations and infrastructures into peri-urban farming system, pushed by the high milk yield potential of crossbred animals (Kamuanga et al., 2008). In fact, research has produced a considerable body of knowledge about artificial breeding. Much of this is shared by people involved in the industry, but the challenge is to apply what is known in an efficient, cost effective and sustainable way in different cattle farming systems under varying socio-economic environments, including the implementation of adequate extension services (IAEA, 2005). However, there are many determinants of the use of breeding technologies in livestock farms. In a survey carried out in dairy farms in Senegal Senegal (Tebug et al., 2014), farmers' cultural values and wealth were the determinants for using artificial insemination service and crossbred or exotic cattle rearing. Crossbreeding within the indigenous cattle breeds secures better production and adaptation than exotic breeds. Hence, it is considered as a better alternative (Ndambi, Hemme and Latacz-Lohmann, 2007) even if evidence shows that indigenous breeds can outperform crossbreds under improved conditions from the traditional settings (Ayalew et al., 2003). Few private commercial dairy farms using crossbred animals in peri-urban areas are achieving modest results and not without bottlenecks, associated with higher susceptibility of these germplasm to diseases and environmental stress (Ndambi, Hemme and Latacz-Lohmann, 2007).

The viability of local livestock pure breed genetic improvement programmes could also be compromised by artificial insemination. The potential of indigenous livestock breeds in the region must be better utilized through the development of adequate livestock breeding programmes that will facilitate access by poor farmers and pastoralist to improved adapted local genetics (AU-IBAR, 2014). There is still an urgent need for characterization of indigenous livestock breeds and their traditional production system, allowing to a better knowledge of genetic interaction for different productivity and ecological adaptations traits. Similarly, there is a need to developed policy and protocols (i.e. frameworks, technical standards, guidelines, etc.) for the use of biotechnology for genetic improvement and the sustainable management of livestock genetic resources in the region (Scherf, and Pilling, 2015). The sustainable conservation and utilization of livestock genetic resources requires comprehensive legal and regulatory frameworks in each country and at regional level to regulate breed utilization, including breed improvement and exchange of genetic materials and define the roles and responsibilities of stakeholders involved in the management and development of livestock genetic resources (FAO and AU-IBAR, 2014) ${ }^{100}$.

Record keeping together with information and knowledge transfer are still the basis for any breeding programme. Recording of the performance of local livestock breeds is a necessary part of conservation and sustainable use of animal genetic resources. Raising awareness of farmer on the importance of 
performance recording and evaluation with the participation of strategic partners and organizations is very important. The promotion of capacity building initiatives in animal breeding at all levels, able to translate new knowledge into actions for sustainable use of indigenous genetic resources is the task the region has to embark on (AU-IBAR, 2019). Success stories and lessons learnt from past within the region must be promoted, as well as awareness of the roles of indigenous animal genetic resources. There is a need to strengthen research, education and awareness, encouraging the participation of all interested parties, particularly farmers, and favoring the introduction of policies and legal frameworks that support all actions that prevent the loss of diversity of domestic animals (Scherf, and Pilling, 2015).

Even if intensive livestock system in the periphery of cities is on the rise, the rationale for low-input, low-output production systems with cheap access to animal food resources ${ }^{101}$ remains relevant in rural areas. The widespread presence of pastoralist systems in more developed economies, including the world's wealthiest countries (IUCN, 2012), and the need to encourage circular economies that promote nutrient recycling and environmentally efficient agrarian systems, such as in livestock feed based on food residues (Wang et al., 2016), is a proof that both pastoralist and backyard systems are going to co-exist with more intensified production methods. The productivity in these systems is expected to greatly increase, but rather through improved access to market that allow both better sale prices and better access to fodder that increase the resilience of animal farming (ILRI, 2011 and Manzano, 2015). The policies that encourage better extension services, tailored to the needs of poor livestock keepers, will also be determinant to improve their economic and food security status.

\subsection{The trends of demand and supply of food of animal origin}

The human population in Africa has increased threefold in the last forty years, from 279 to 826 million people. Although the increase is felt in both rural and urban areas, cities have grown fastest because of an associated migration towards them. While they hosted 20 percent of the population in the 1970s, they currently host 36 percent and are expected to host half of sub-Saharan Africans in 2050 - even if part of these figures originate from the expansion and reclassification of urban boundaries (Djurfeldt and Jirström, 2013) The population of West Africa was estimated to be 347.7 million in 2015, out of which 193 million (55.5 percent) lived in rural areas (UNDESA, 2019). The urban population is expected to increase to 49.9 percent in 2020, when the total population will be around 400 million, and 65.7 percent in 2050, when the total is expected to reach nearly 500 million (UNDESA, 2019) While in 2011 the region had 17 cities that exceeded one million inhabitants, the rapid growth will be felt in secondary cities and big towns.

The number of livestock has also doubled in Africa between 1974 and 2014, but per capita meat production has stayed stable at $14 \mathrm{~kg} /$ person, while milk has declined by 17 percent to currently 29 $\mathrm{kg} /$ person (AGRA, 2014). Such large increase in both human and livestock numbers has triggered intensification in the land use, crop production and natural resources use. It is expected that the consolidation of urban middle classes, able to increasingly afford foods of animal origin, will drive strong increases in demand. For the West African region, meat production increased at a yearly rate of 127,286 tonnes over the period of 2002-2011, while an annual increase of 214,270 tonnes of milk was observed. The human population increased at a rate of around 19 million per year. An analysis of the FAOSTAT data for the West Africa over the period of 2002 to 2010, indicates that the per capita meat production increased from 11 to $15 \mathrm{~kg} /$ person, while that of milk increased from 10 to $14 \mathrm{~kg} /$ person still well below the intake recommended by $\mathrm{FAO}^{102}$. 
The countries in the ECOWAS region are endowed with large numbers of livestock. From the entire livestock population estimated in Africa in 2013 by FAO, the 15 countries in ECOWAS subregion together account for 41 percent of pigs, 36 percent of goats, 30 percent of chicken, 27 percent of sheep and 22 percent of cattle of the continental livestock population. Despite this large number, the production and productivity of these herds and flocks is limited due to various factors ${ }^{103}$. As a result, the amount of animal products available and their consumption per capita in the region is minimal even by African standards ${ }^{104}$.

On the other hand, the region has one of the highest population growth rates, 2.7 percent per annum ranging between 1.5 percent in Cabo Verde to 3.8 percent in Niger. This is translated to rapid population growth in the region from the 327 million estimated in 2013 to 449 million in 2025 and to 805 million in 2050. If the rapid urbanization and the steady growth of the middle class are added, this indicates that animal product demand will rise in West Africa in the coming years. For example, it was estimated that milk consumption is likely to triple by 2050 in Sub-Saharan Africa. The consumption of meat and eggs will grow six-to-seven fold in West Africa by 2050 (AGRA, 2014). Current demand for animal products is partially met with imports ${ }^{105}$, into which a large proportion of foreign exchange is spent every year, often for products of intensive animal husbandry in developed countries.

It is doubtful that the current trend of increased dependence on import will be economically sustainable. As the sub-sector is subjected to immense inefficiencies that could be met with adequate moderate investment ${ }^{106}$, it is realistic to expect an increase in the productivity of the livestock sub-sector. Tools for the achievement of these goals are the comparative advantage each country has, and the complementarity principle achieved through the promotion of intra-regional trade.

\subsection{Livestock global trends and their impact on West African livestock sub-sector}

The livestock production in the West African region is very vulnerable and influenced in different ways by several global trends. The high reliance on natural resources, the low market connectivity and the low resilience of production systems mean a great sensitivity to climate fluctuation and natural disasters ${ }^{107}$, in the same way as inefficiencies and high production costs mean vulnerability to cheap imports from developed countries ${ }^{108}$. However, the increasing domestic demand for animal proteins, be it due to population growth or to rising prosperity, and the ensuing animal source protein consumption, is probably the single most important driving force for sustainable increase of livestock production in the region. The introduction of modern production technologies is likely to trigger industrialized periurban dairy and poultry farms, in an attempt to meet the growing demand of urban population from local production. The improvement of extension services and market connectivity is likely to also have a profound effect of less input-intensive livestock systems ${ }^{109}$. If the pledges for the ECOWAP 2016-2025 phase translate into real investment, better veterinary services and better policies for increasing the production standards are likely to have a beneficial effect in all systems.

The climate variation, whether related to global warming or to other causes, have direct major effects of resource scarcity (a decrease in volume of resources due to low levels of precipitation), natural disasters (floods and droughts) and rising sea levels, all of which are going to impact livestock production. Climate change is already affecting African agriculture. Between 1886 and 2012, global average temperatures

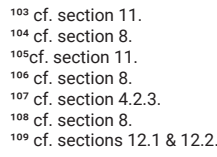


have risen by $0.85^{\circ} \mathrm{C}$ and this is reflected across all regions of Sub-Saharan Africa; and further increases of about $1.5^{\circ} \mathrm{C}$ by 2050 are almost certain (AGRA, 2014). The effects of climate change have often led to security problems in the Sahel and West African region because of increased conflicts and reduced resources (Trémolières, 2010 and De Haan et al., 2016). A study on the impact of climate change (Maddison, Manley and Kurukulasuriya, 2007) confirms that African agriculture is particularly vulnerable to climate change. Even with perfect adaptation, regional climate change by 2050 is predicted to entail production losses reaching 19.9 percent in Burkina Faso and 30.5 percent in Niger.

The resilience strategies, therefore, become fundamental to face the future climate challenges. An increased support to Climate Smart Agriculture from the main donors and extension service providers invites to be optimistic (AGRA, 2014), applying interventions that will increase yields, resilience and carbon fixation, while reducing GHG emissions. These include better, more efficient use of nutrients and water, increase the varieties of livestock species and breeds, promoting agroforestry and sylvopastoralism systems and improving the management of grasslands, with the aim to tap of synergies among food security, adaptation and mitigation (AGRA, 2014). In that sense, many of the pastoralist, agro-pastoralist and livestock backyard strategies become very relevant for low-impact income generation, especially in resource-limited situations (Manzano, 2015 and 2017a).

Animal diseases are also important limiting factors for the development of the livestock sub-sector in West Africa ${ }^{110}$. Climate change and the increased exchange of animals and animal products can favor the emergence and increase the spread of animal infectious diseases within and outside the region. This situation can be more devastating in a future scenario that seems to prioritize the intensification of animal production and the exploitation of exotic breeds, more susceptible to endemic diseases. To mitigate the impact of diseases on the West African livestock sub-sector it will be necessary to invest in efficient animal health services and innovative technologies that can be applied under the subregion's context, following a regional approach and promoting public/private partnerships (Lubroth, et al., 2007). It is also a priority to strengthen research for the development of new vaccines and veterinary drugs for the control and prevention of livestock diseases. For example, thermostable vaccines with better efficacy and duration of immunity, together with developing optimal vaccination strategies, are necessary for CBPP and PPR sustained control and eradication programmes within all African regions (ILRI, 2019).

The use of fake or uncontrolled substandard veterinary drugs, particularly antimicrobials, is generating a negative impact on the livestock sub-sector of the region ${ }^{111}$. West Africa has one of the largest gaps in data on the prevalence of antimicrobial resistance (Bernabé et al., 2017). Antimicrobials are used in animal production, either as growth promoters or for therapeutic use in many countries of the world. The abuse or misuse of antimicrobials will lead to resistance, which poses serious threats to public and animal health. The antimicrobial resistance is a new challenge in the region, especially for the intensification of animal production, where it will be necessary to propose alternative measures (i.e. improvement of biosecurity, development of new drugs and vaccines, etc.) to increase productivity and control animal diseases. There is a need of adequate legislation to regulate the use of antimicrobials at national and regional levels. The veterinary profession, through their role of supervising and offering advice to livestock producers on the proper use of antimicrobials, is also an important key partner (OIE, 2015).

\footnotetext{
${ }^{110} \mathrm{cf}$. section 6.

111 cf. section 11.4.3

$112 \mathrm{cf}$. section 11.3.1.
} 
The Pastoralist system deserves a special mention, both because of its economic and environmental importance and because of the stresses to which they are subjected, particularly in the context of regional insecurity. During the 1970 s and 1980 s, drought ${ }^{112}$ has triggered sedentarization, pro-agropastoralism policies that drive to less productive livestock systems (Hatfield and Davies, 2006 and FAO, 2019b) and that adds to the pressure posed by increased population and increase occupancy of pastoral resources such as pasture or stock routes. The decentralization of natural resource governance could be an opportunity for better access. However, pastoralist risk to be more marginalized because of being inadequately represented at decision-making bodies (SWAC/OECD, 2007). The link of poor, misguided investment in pastoralist and agro-pastoralist settings with insecurity and conflict has been thoroughly analyzed, with clear recommendations on enabling an inclusive development environment in pastoralist and agro-pastoralist societies that allows prosperity, coexistence and synergies with crop farming, and not exit strategies into poorly adapted livelihoods (De Haan et al., 2016). In this context, two international conferences were held in 2013 in Ndjamena (SWAC/OECD and AFD, 2013) and Nouakchott (Nouakchott Declaration, 2013 and World Bank, Government of Mauritania and CILSS, 2013). Those resulted in political declarations by the participating states, and another one in 2014 in Abuja (IWGIA, 2014), which led into PRAPS, an investment loan project worth 250 million USD by the World Bank and implemented by six Sahelian countries and CILSS and aimed at improving access to services, markets and assets (World Bank, 2015a). The project, along with a parallel one in the Horn of Africa, has been accompanied by PASSHA, a further 2.8 million USD project working on conflict and stability issues around pastoralist livelihoods (World Bank, 2015b). The involvement of governments in such projects, and the magnitude of investments specifically in pastoralist livelihoods, shows how a new understanding has been built on pastoralism that foresees its full social and economic integration in Sahelian countries. 


\section{BIBLIOGRAPHY}

$1 \times 1 \times$

Abdulai J., Kagumire R., Geoghegan T. 2018. Africa's Agenda 2030: channeling the SDGs towards inclusive, resilient and accountable development. Independent Research Forum, 37 pp. https:// pubs.iied.org/pdfs/G04378.pdf

Abdulkadi, A., Dossa, L.H., Lompo, D.J.P., Abdu, N. and, van Keulen, H. 2012. Characterization of urban and peri-urban agroecosystems in three West African cities. Int. J. Agric. Sustain., 10: 289-314.

Abdullahi, U. S., Daneyel, H. N., Aliyara, Y. H. 2015. Grazing Reserves and Pastoralism in Nigeria: A Review. Vom J. Vet. Sci. 10, 137-142. Available at https://www.ejmanager.com/

Abeiderrahmane, M.; Abeiderrahmane, N. 2010. Tiviski: A dairy that sources milk from pastoralists in Mauritania. In: LPP, LIFE Network, IUCN-WISP and FAO. Adding value to livestock diversity - Marketing to promote local breeds and improve livelihoods. FAO Animal Production and Health Paper. No. 168. Rome, pp. 85-98. http://www.fao.org/docrep/012/i1283e/i1283e00. pdf

Aboagye, G.S., Boa-Amponsem, K., Okantah, S.A., Ahunu, B.K. 2003. State of Ghana's Animal Genetic Resources. Animal Production Directorate - Ministry of Food and Agriculture. Available at ftp://ftp.fao.org/docrep/fao/010/a1250e/annexes/CountryReports/Ghana.pdf

Aboubacar, D. 2017. Revue des filières bétail/viande \& lait et des politiques qui les influencent au Niger. FAO-ECOWAS, Rome and Abuja. Available at http://www.fao.org/3/a-i5271f.pdf

Abric, S., Sonou, M., Augeard, B., Onimus, F., Durlin, D., Soumaila, A. and Gadelle, F. 2011. Lessons Learned in the Development of Smallholder Private Irrigation for High-Value Crops in West Africa. Joint Organizational Discussion Paper- Issue 4. The World Bank. Washington DC, USA. Available at http://documents.worldbank.org/curated/en/825281468151146898

Abubakari, A., Jahn, A. 2016 Maternal Dietary Patterns and Practices and Birth Weight in Northern Ghana. PLoS ONE 11, e0162285. http://doi.org/10.1371/journal.pone.0162285

Adakal, H., Stachurski, F. and Chevillon, C. 2013. Tick control practices in Burkina Faso and acaricide resistance survey in Rhipicephalus (Boophilus) geigyi (Acari: Ixodidae). Exp Appl Acarol59(4):483-491

Adene, D.F. and Oguntade, A.E. 2006. Poultry Sector Country Review: Nigeria. Food and Agriculture Organization of the United Nations. Rome, Italy. Available at ftp://ftp.fao.org/docrep/ fao/011/ai352e/ai352e00.pdf

ADG, 2007. Valeurs économiques totales (TEV) du pastoralisme au Mali. IUCN-WISP, Nairobi. Available at https://www.iucn.org/sites/dev/files/import/downloads/mali_tev_fr.pdf

Adisa, R. S. 2015. Livestock Extension Practice and Competency among Agriculture Extension Agents in North Central Nigeria. S Afr. Jnl. Agric. Ext. 43, 12-21. http://www.scielo.org.za/pdf sajae/v43n1/02.pdf/

Adjolohoun, S., Bindelle, J., Adandédjan, C. and Bulgen, A. 2008. Some suitable grasses and legumes for ley pastures in Sudanian Africa: the case of the Borgou region in Benin. Biotechnol. Agron. Soc. Environ. 2008 12(4), 405-419. Available at http://www.pressesagro.be/base/text/ v12n4/405.pdf

AfDB, OECD, UNDP, 2016. Human development in Africa. In: AfDB, OECD, UNDP: African Economic Outlook 2016: Sustainable cities and structural transformation, Abidjan, Paris, New York, pp. 91-114. Available at http://www.africaneconomicoutlook.org/

AfricaLead, 2017. Ghana livestock sector Boosted by new policy. www.africaleadftf. org/2017/04/19 Retrieved 19th June 2019 
African Union Commission, 2013. Policy framework for pastoralism in Africa. Securing, protecting and improving the lives, livelihoods and rights of pastoralist communities. Department of Rural Economy and Agriculture, African Union, Addis Ababa. https://au.int/sites/default/files/ documents/30259-doc-pastoral_policy_framework_-_low_res.pdf

African Union Commission, 2014a. Malabo Declaration on Accelerated Agricultural Growth and Transformation for Shared Prosperity and Improved Livelihoods. African Union.

Malabo, Equatorial Guinea, June26-27, 2014. Available at: https://au.int/sites/default/files/ documents/31006-doc-malabo_declaration_2014_11_26-.pdf

African Union Commission, 2014b. The livestock development strategy for Africa (LiDeSa) 2015 to 2035. The roadmap to a successful livestock sector. African Union, Addis Ababa. Available at http://www.au-ibar.org/component/jdownloads/finish/77/2419 (Executive Summary), http:// www.au-ibar.org/component/jdownloads/finish/77/2832-the-livestock-development-strategy-forafrica-lidesa (principal document).

AGRA, 2014. Africa Agriculture- Status report 2014. Climate change and smallholder agriculture in Sub-Saharan Africa. Alliance for a Green Revolution in Africa. http://reliefweb.int/sites/ reliefweb.int/files/resources/agra-africa-agriculture-status-report-2014.pdf

AGRA, 2018. Africa Agriculture Status Report: Catalyzing Government Capacity to Drive Agricultural Transformation (Issue 6). Nairobi, Kenya: Alliance for a Green Revolution in Africa (AGRA). Available at https://agra.org/wp-content/uploads/2018/10/AASR-2018.pdf

Aiyeloja, A.A. and Ogunjinmi, A.A. 2013. Economic aspects of Grasscutter Farming in Southwest Nigeria: Implications for Sustainable Adoption and Conservation. International Journal of Scientific \& Engineering Research 4, 17-23.

Akinola, L.A.F., Etela, I. and Emiero, S.R. 2015. Grasscutter (Thryonomys swinderianus) production in West Africa: prospects, challenges and role in disease transmission. American Journal of Experimental Agriculture 6, 196-207.

Akunzule, A.N. 2013. Livestock sector profile of Ghana. Food and Agriculture Organization of the United Nations (FAO). ISBN 978-92-5-107497-8.

Akunzule, A.N. 2014. Poultry Sector Ghana. FAO Animal Production and Health Livestock Country Reviews. No. 6. Rome, Italy. Available at http://www.fao.org/3/i3663e/i3663e.pdf

Alary, V., Corniaux, C., Gautier, D. 2011. Livestock's Contribution to Poverty Alleviation: How to Measure It? World Development 39, 1638-1648. https://doi.org/10.1016/j.worlddev.2011.02.008

Alders, R.G., Dumas, S.E., Rukambile, E., Magoke, G., Maulaga, W., Jong, J. and Costa, R. 2018. Family poultry: Multiple roles, systems, challenges, and options for sustainable contributions to household nutrition security through a planetary health lens. Matern Child Nutr. 2018 Oct;14 Suppl 3:e12668.

Alidou, S.M. 2016. Cross-border transhumance corridors in West Africa. Agriculture and Food Security of the Swiss Agency for Development and Cooperation (SDC). Available at https://www. shareweb.ch/site/Agriculture-and-Food-Security/aboutus/Documents/pastoralism/pastoralism_ brief_couloirs_transhumance_e.pdf

ALIVE, 2006. Avian Influenza Prevention and Control, and Human Influenza Pandemic Preparedness in Africa: Assessment of Financial Needs and Gaps. Fourth International Conference on Avian Influenza Bamako - Mali - December 6-8, 2006. Available at https://www. un.org/influenza/africa_assessment.pdf

Allen, T., Heinrigs, P., Zoundi, S.J. 2015. ECOWAP+10 : Mutations de l'économie agro-alimentaire et implications. Club du Sahel et de l'Afrique de l'Ouest. Available at https://www.oecd.org/swac/ publications/ECOWAP10.pdf

Alpha A., Figuié M. 2016 Impact of the Ebola virus disease outbreak on market chains and trade of agricultural products in West Africa. FAO, Dakar. Available at http://www.fao.org/3/a-i5641e. pdf 
Amadou, H., Dossa, L.H., Lompo, D.J.P., Abdulkadir, A. and Schlecht, E. 2012. A comparison between urban livestock production strategies in Burkina Faso, Mali and Nigeria in West Africa. Trop. Anim. Health Prod., 44(7):1631-42. https://doi.org/10.1007/s11250-012-0118-0. Available at https://www.ncbi.nlm.nih.gov/pubmed/22430479

Amills, M., Ramírez, O., Omitogun, 0. and Clop, A. 2013. Domestic Pigs in Africa. The African Archaeological Review, Vol. 30, No. 1, Special Issue: Animal Genetics and African Archaeology, pp. 73-82.

Amulen, D.R., D’Haese, M., Ahikiriza, E., Agea, J.G., Jacobs, F.J., de Graaf, D.C., Smagghe, G., Cross, P. 2017. The buzz about bees and poverty alleviation: Identifying drivers and barriers of beekeeping in sub-Saharan Africa. PLoS ONE 12, e0172820. https://doi.org/10.1371/journal. pone. 0172820

Angot, A. and Baurier, F. 2016. On site mission for the assessment of the Teko Central Veterinary Laboratory and Njala University vet lab, Sierra Leone. FAO \& FVI (unpublished).

Ankers, P., Bishop, S., Mack, S., Dietze, K., eds. 2016. Livestock-related interventions during emergencies - The how-to-do-it manual. FAO Animal Production and Health Manual No. 18. FAO, Rome. http://www.fao.org/3/a-i5904e.pdf

APESS, 2014a. Eléments de bilan du soutien public à l'élevage au Mali depuis Maputo. Document de travail. APESS - Inter-réseaux Développement rural, Ouagadougou/Paris. Available at http:// www.inter-reseaux.org/IMG/pdf/note_apess_mali_mise_en_page.pdf

APESS, 2014b. Le financement public dans l'élevage au Sahel depuis 10 ans : un double sousinvestissement. Document de travail. APESS - Inter-réseaux Développement rural, Ouagadougou/ Paris. https://www.apess.org/wp-content/uploads/2017/05/synthese-etudes-bilan-maputoapess.pdf

AQUASTAT, 2019. FAO's Global Information System on Water and Agriculture (AQUASTAT). Available at http://www.fao.org/aquastat/en/

Aregheore, E.M. 2005. Country Pasture/Forage Resource Profiles: Nigeria. FAO Rome. Available at http://www.fao.org/ag/agp/agpc/doc/counprof/regions/africa.htm

Aregheore, E.M. 2009. Country Pasture/Forage Resource Profiles: Benin/Côte d'Ivoire. FAO Rome. Available at http://www.fao.org/ag/agp/agpc/doc/counprof/regions/africa.htm

Asgedom A.H. 2007 Village poultry in Ethiopia: socio-technical analysis and learning with farmers. PhD Thesis, Wageningen University, 178 p. Available at https://hdl.handle. net/10568/81579

Atsushi, I. 2007. Infrastructure and trade preferences for the livestock sector: empirical evidence from the beef industry in Africa. World Bank Policy Research Working Paper 4201. Available at http://documents.worldbank.org/curated/en/423691468010012097

Atta-Krah, A.N. and Reynolds, L. 1993. Utilization of pasture and fodder shrubs in the nutrition of sheep and goats in the humid tropics of West Africa. In: Strategies for sustainable animal agriculture in developing countries. Food and Agriculture Organization of the United Nations. Rome, Italy. Available at http://www.fao.org/3/s8374b/S8374b05.htm\#ch5

Atuahene, C.C., Attoh-Kotoku, V. and Mensah, J.J. 2010. Poultry production Ghana: Prospects and challenges. Ghana J. Anim. Sci., 4: 93-99.

Aubréville, A. 1949. Climats, forêts et désertification de l'Afrique tropicale. Société d'éditions géographiques, maritimes et coloniales, Paris, $351 \mathrm{pp}$.

AU-IBAR, 2014. Report of the Regional Inception Workshop of the Project Animal Genetics. African Union Interafrican Bureau for Animal Resources. Ouagadougou, Burkina Faso 6th to 9th November 2013. Available at http://www.au-ibar.org/angr-resources/angr-reports

AU-IBAR, 2015. Local African Pig. African Union Inter-African Bureau for Animal Resources. Available at http://www.au-ibar.org/2012-10-01-13-08-42/features/series/know-youranimalsseries/local-african-pig 
AU-IBAR, 2016. Participation of African Nations in Sanitary and Phytosanitary Standard-setting Organizations (PAN-SPSO). http://www.au-ibar.org/component/jdownloads/finish/30/834

AU-IBAR, 2019. Current Programmes and Projects. Animal Genetics Resources (AnGR) [20132018]. African Union Interafrican Bureau for Animal Resources. Available at http://www.au-ibar. org/angr

AU-IBAR/ARIS 2010. Panafrican Animal Health Yearbook, issue of 2010, extracted from Animal Resources Information System. African Union Interafrican Bureau for Animal Resources.

Available at http://www.au-ibar.org/pan-african-animal-resources-yearbook?showall=\&limitstart= AU-IBAR/ARIS 2011. Panafrican Animal Health Yearbook, issue of 2011, extracted from Animal Resources Information System. African Union Interafrican Bureau for Animal Resources.

Available at http://www.au-ibar.org/pan-african-animal-resources-yearbook?showall=\&limitstart= AU-IBAR/ARIS 2012. Panafrican Animal Health Yearbook, issue of 2012, extracted from Animal Resources Information System. African Union Interafrican Bureau for Animal Resources.

Available at http://www.au-ibar.org/pan-african-animal-resources-yearbook?showall=\&limitstart= AU-IBAR/ARIS 2013. Panafrican Animal Resources Yearbook, issue of 2013, extracted from Animal Resources Information System. African Union Interafrican Bureau for Animal Resources. Available at http://www.au-ibar.org/pan-african-animal-resources-yearbook?showall=\&limitstart= AU-IBAR/ARIS 2014. Panafrican Animal Resources Yearbook, issue of 2014, extracted from Animal Resources Information System. African Union Interafrican Bureau for Animal Resources. Available at http://www.au-ibar.org/pan-african-animal-resources-yearbook?showall=\&limitstart= Ayalew, W, King, J.M., Bruns, E.W. and Rischkowsky, B. 2003. Cross-Breeding does not lead to a greater Contribution of Goats to Household Welfare, but Improved Management does. In: Community-Based Management of Animal Genetic Resources. Proceedings of the workshop held in Mbabane, Swaziland, 7-11 May 2001. Food and Agriculture Organization of the United Nations. Rome, Italy. Available at http://www.fao.org/3/y3970e/y3970e0c8.htm\#bm12.9

Ayantunde, A.A., Leeuw, J.D., Turner, M.D. and Said, M. 2011. Challenges of assessing the sustainability of (agro)-pastoral systems. Livestock Science 139: 30-43. Available at http://www. sciencedirect.com/science/article/pii/S1871141311001028

Ayee, J.R.A. 2001. Civil Service Reform in Ghana: A Case Study of Contemporary Reform Problems in Africa. Afr.J. Polit. Sci. 6 (1), 1-41. https://www.jstor.org/stable/23495258

Baah, J., Tuah, A.K., Addah, W. and Tait, R.M. 2012. Small ruminant production characteristics in urban households in Ghana. Livest. Res. Rural Dev., 24, 86.

Badolo, A. 2009. Revue du secteur de l'élevage au Burkina Faso avec un accent particulier sur le développement des sous-secteurs du lait et bétail-viande en favour des petits producteurs en Afrique de l'Ouest. Organisation des Nations Unies pour l'alimentation et l'agriculture (FAO) (unpublished)

Bakayoko, K.V. 2012. Revue du Secteur Elevage en Côte d'Ivoire. Sous-secteur Ressources Animales. Organisation des Nations Unies pour l'alimentation et l'agriculture (FAO). ISBN 978-925-207499-1.

Bakayoko, K.V. 2016. Revue des filières betail/viande \& lait et des politiques qui les influencent en Côte d'Ivoire. FAO-ECOWAS, Rome and Abuja. Available at http://www.fao.org/3/a-i5266f.pdf

Baker, K. 2000. Indigenous Land Management in West Africa: An Environmental Balancing Act. Oxford University Press Inc. New York, USA.

Bari, I. 2016. Revue des filières betail/viande \& lait et des politiques qui les influencent au Cabo Verde. FAO-ECOWAS, Rome and Abuja. Available at http://www.fao.org/3/a-i5265f.pdf

Baroin, C., Boutrais, J. 2009. Bétail et société en Afrique. Journal des africanistes 78, 9-52.

Available at http://africanistes.revues.org/2231

Bassett, T. J. and Crummey, D. E., 1993. Land in African agrarian systems. pp. 427 
Bassi, M. 2017. Pastoralists are Peoples: Key issues in Advocacy and the Emergence of Pastoralists' Rights. Nomadic Peoples 21, 4-33. https://doi.org/10.3197/np.2017.210102 Beaute, V. and Micout, L. 2016. Rapport de mission sur le laboratoire national d'élevage (LNE) de Ouagadougou assurance qualité et techniques de laboratoire, Burkina Faso. FAO \& FVI. (Unpublished)

Behnke, R. (unpublished). The contribution of pastoralism to national economies: lessons from Africa.

Behnke, R.H.; Kerven, C. 2012. Counting the costs: replacing pastoralism with irrigated agriculture in the Awash valley. In Catley, A., Lind, J. and Scoones, I. (eds). Pastoralism and Development in Africa: Dynamic changes at the margins. Earthscan from Routledge, London, pp. 57-70. Available at https://www.researchgate.net/publication/286060381

Bekure, S. and Tilahun, N. 1983. Livestock marketing studies. In: Pastoral systems research in sub-Saharan Africa. Proceedings of the IDRC/ILCA workshop held at ILCA, Addis Ababa, Ethiopia, 21-24 March 1983. ILCA (International Livestock Centre for Africa), Addis Ababa, Ethiopia. pp. 327-355. ILCA, 1990. Section 1 - Module 9: Livestock marketing. In: Livestock systems research manual. Working Paper 1, Vol. 1. International Livestock Centre for Africa. Addis Ababa, Ethiopia. 287 pp. Available at https://cgspace.cgiar.org/bitstream/handle/10568/4317/wp12-vol1. pdf?sequence $=1$

Bélanger, J. and Pilling, D. (eds.) 2019. The State of the World's Biodiversity for Food and Agriculture. FAO Commission on Genetic Resources for Food and Agriculture Assessments. Rome. 572 pp. http://www.fao.org/3/CA3129EN/CA3129EN.pdf

Belli, P., Turini, J., Harouna, A., Garba, I.A., Pistocchini, E., Zecchini, M. 2008. Critères de sélection des bovins laitiers par les éleveurs autours de Niamey au Niger. Revue d'Elevage et de Médecine Vétérinaire des Pays Tropicaux 61, 51-56. Available at http://revues.cirad.fr/index.php/ REMVT/article/viewFile/10013/10007

Bender, A. E. 1992 Meat and health. In: Bender, A. E. Meat and meat products in human nutrition in developing countries. Food and Nutrition paper 53. FAO, Rome. Available at http://www.fao. org/docrep/t0562e/t0562e00.htm

Benítez-López A., Alkemade R., Schipper A.M., Ingram D.J., Verweij P.A., Eikelboom J.A.J., Huijbregts M.A.J. 2017. The impact of hunting on tropical mammal and bird populations. Science 356, 180-183. https://doi.org/10.1126/science.aaj1891

Benjaminsen, T.A. 2017 Review of The Arid Lands. History, Power, Knowledge by Diana K. Davis. Pastoralism: Research, Policy and Practice 7, 23. https://doi.org/10.1186/s13570-017-0099-8

Berg, C.N., Deichmann, U., Liu, Y., Selod, H. 2017. Transport Policies and Development, The Journal of Development Studies 53, 465-480. https://doi.org/10.1080/00220388.2016.1199857

Berman, A. 2011 Are adaptations present to support dairy cattle productivity in warm climates? J. Dairy Sci. 94, 2147-2158. https://doi.org/10.3168/jds.2010-3962

Bernabé, K.J., Langendorf, C., Ford, N., Ronat, J.B., Murphy, R.A. 2017. Antimicrobial resistance in West Africa: a systematic review and meta-analysis. International Journal of Antimicrobial Agents, Volume 50, Issue 5, Pages 629-639. Available at: https://www.sciencedirect.com/ science/article/pii/S0924857917302741

Besbes, B. 2009. Genotype evaluation and breeding of poultry for performance under suboptimal village conditions. World's Poultry Science Journal 65, 260-271. https://doi.org/10.1017/ S0043933909000221

Biasutti, M. 2016 Hydrology: What brings rain to the Sahel? Nature Climate Change 6, 897-898. https://doi.org/10.1038/nclimate3080

Biscarini, F., Nicolazzi, E.L., Stella, A., Boettcher, P.J. and Gandini, G. 2015. Challenges and opportunities in genetic improvement of local livestock breeds. Frontiers in Genetics, vol. 6:33. Available at https://www.ncbi.nlm.nih.gov/pmc/articles/PMC4340267/ 
Blench, R. 1993. Ethnographic and linguistic evidence for the prehistory of African ruminant livestock, horses and ponies. In: Andah B, Okpoko A, Shaw C \& Sinclair P (eds) The Archaeology of Africa: Food, Metals and Towns. Routledge, New York, pp. 71-103.

Blench, R. 1999. Traditional livestock breeds: geographical distribution and dynamics in relation to the ecology of West Africa. ODI working paper 122. Overseas Development Institute, London, 67 pp. Available at http://www.rogerblench.info/Ethnoscience/Animals/Livestock/ODI\%20 Livestock\%20breeds\%20WP.pdf

Blench, R. and Marriage, Z. 1999. Drought and Livestock in Semi-Arid Africa and Southwest Asia. Overseas Development Institute. London, UK. 138pp. Available at https://www.odi.org/sites/odi. org.uk/files/odi-assets/publications-opinion-files/2533.pdf

Blench, R.M. 1998. Le West African Shorthorn au Nigeria. Cameroun: Des taurins et des hommes, 249-292.

Boakye, L. G. 2008. Assessing the Effect of Grasscutter Farming on the Livelihood of Smallholder Framers: A Case Study of Action Aid from the Asutifi District of Ghana. BSc Thesis, Kwame Nkrumah University of Science and Technology in Kumasi. http://doi.org/10.13140/ RG.2.2.11215.07847

Boisseau, J. 2005. Audit technique des laboratoires de contrôle de la qualité des médicaments vétérinaires dans les pays membres de l'UEMOA. Rapport de consultations. Abuja, Nigeria, UEMOA, juillet 2005.

Bollig, M., Schnegg, M. and Wotzka, H.P. 2013. Pastoralism in Africa: Past, Present and Future. Berghahn Books. 544 p. Available at http://www.jstor.org/stable/j.ctt9qcrb7

Bourn, D., Wint, W., Blench, R. and Woolley, E. 1994. Nigerian livestock resources survey, World Animal Review, 78(1):49-58.

Breman, H., de Wit, C.T. 1983. Rangeland Productivity and Exploitation in the Sahel. Science 221, 1341-1347. https://doi.org/10.1126/science.221.4618.1341

Browne, A.W., Barrett, H.R. 1991 Female Education in Sub-Saharan Africa: the key to development? Comparative Education 27, 275-285. https://doi.org/10.1080/0305006910270303 Bruce, J. W., 1998. Country Profiles of Land Tenure: Africa, 1996 LTC Research Paper 130 Land Tenure Center University of Wisconsin-Madison.

BSTID and NRC 1991. Microlivestock: Little-Known Small Animals with a Promising Economic Future. Board on Science and Technology for International Development \& National Research Council. 472 pages. National Academy Press. Washington DC, USA. Available at http://pdf.usaid. gov/pdf_docs/PNABL279.pdf

Buvanendran, V., Olayiwole, M.B., Piotrowska, K.I., Oyejola, B.A. 1981 A comparison of milk production traits in Friesian $\times$ White Fulani crossbred cattle. Animal Production 32, 165-170. https://doi.org/10.1017/S000335610002496X

Cadiou, X. 2018. Africa: Growth and challenges in the animal feed sector. All About Feed. Available at https://www.allaboutfeed.net/Feed-Additives/Articles/2018/4/Africa-Growth-andchallengesfor-animal-animal-feed-275953E/

CDC, 2014. 2014-2016 Ebola Outbreak in West Africa. Available at https://www.cdc.gov/vhf/ ebola/outbreaks/2014-west-africa/index.html

Chakravarty, S., Ghosh, S.K., Suresh, C.P., Dey, A.N. and Shukla, G. 2012. Deforestation: Causes, Effects and Control Strategies. In: Okia CA (Ed.) 2012. Global Perspectives on Sustainable Forest Management. Available at http://cdn.intechopen.com/pdfs/36125.pdf

Chambers, V., Wild, L., Foresti, M. 2013. Innovations in service delivery. International experience in low-density countries. ODI, London. Available at https://www.odi.org/projects/2707innovationsservice-delivery-mali

Check, E. 2006 Human evolution: How Africa learned to love the cow. Nature 444, 994-996. https://doi.org/10.1038/444994a 
Chevalier, A. 1933. Le territoire géo-botanique de l'Afrique tropicale nord-occidentale et ses subdivisions. Bulletin de la Société Botanique de France, 80 (4)

CILSS, 2009 Note de présentation : Programme Régional Accès aux Marchés. Secrétariat Exécutif, CILSS. Available at http://www.cilss.int/wp-content/uploads/2016/07/notepresentation_ pramarches.pdf

CILSS, 2010. L'élevage au Sahel et en Afrique de l'Ouest. 26ème réunion annuelle du Réseau de Prévention des Crises Alimentaires (RPCA). Accra (Ghana), 14-16 décembre 2010. Available at https://www.on-mali.org/joomlaa/_GED/pdf/elevage_en_aocs5.pdf

CIRAD, 2015. Porc local en Afrique intertropicale/Les populations porcines en Afrique de l'Ouest. Available at http://pigtrop.cirad.fr/

Codjia, V. 2012. Revue du secteur de l'élevage de la République du Benin. Organisation des Nations Unies pour l'Alimentation et l'Agriculture (FAO) (unpublished).

Codjia, V. 2016. Revue des filières bétail/viande \& lait et des politiques qui les influencent au Benin. Organisation des Nations Unies pour l'Alimentation et l'Agriculture (FAO). Available at http://www.fao.org/3/a-i5263f.pdf

CORAF, 2015 Un cadre juridique adapté et harmonisé pour une transhumance transfrontalière durable dans l'espace CEDEAO. Note aux décideurs. http://www.coraf.org/pmb/opac_css/doc_ num.php?explnum_id=70

Correia, F. 2016. Revue des filières bétail/viande \& lait et des politiques qui les influencent en Guinée Bissau. FAO-ECOWAS, Rome and Abuja. Available at http://www.fao.org/3/a-i5267f.pdf Coulibaly, A. 2003. Country Pasture/Forage Resource Profiles: Mali/Sierra Leone. FAO Rome. Available at http://www.fao.org/ag/agp/agpc/doc/counprof/regions/africa.htm

Croppenstedt, A., Goldstein, M., Rosas, N. 2013. Gender and Agriculture: Inefficiencies, Segregation, and Low Productivity Traps. The World Bank Research Observer 28, 79-109. https://doi.org/10.1093/wbro/lks024 Available at http://documents.worldbank.org/curated/ en/957311468161359832

Cukwuka, O.K., Okoli, I.C., Opara, M.N., Omede, A.A., Ogbuewu, I.P. and Iheshiulor, O.O.M. 2010. The growing problems of mycotoxins in animal feed industry in West Africa: a review. Asian Journal of Poultry Sciences 4 (3): 122-134.

Curry, A. 2013 Archaeology: The milk revolution. Nature 500, 20-22. https://doi. org/10.1038/500020a

D'Orgeval, R. 1997. Le développement de la production porcine en Afrique. Thèse INA-PG, Paris, 201p.

DAD-IS, 2019. FAO's Domestic Animal Diversity Information System. Available at http://www.fao. org/dad-is/en/ http://www.fao.org/dad-is/en/

DAGRIS, 2007. ILRI's Domestic Animal Genetic Resources Information System. Available at http://dagris.ilri.cgiar.org/

DAGRIS, 2015 - http://dagris.info/node/2466

DAGRIS, 2019. ILRI's Domestic Animal Genetic Resources Information System. Available at http://dagris.ilri.cgiar.org/

Dardel C., Kergoat L., Hiernaux P., Grippa M., Mougin E., Ciais P., Nguyen, C.-C. 2015. Rain-UseEfficiency: What it Tells us about the Conflicting Sahel Greening and Sahelian Paradox. Remote Sensing 6, 3446-3474. https://doi.org/10.3390/rs6043446

Davies, J. 2017. Review of Roy Behnke and Michael Mortimore (eds), The End of Desertification? Disputing Environmental Change in the Drylands. Nomadic Peoples 21, 330-332. https://doi. org/10.3197/np.2017.210209

Davies, J., Herrera, P., Ruiz-Mirazo, J., Mohamed-Katerere, J., Hannam, I., Nuesri, E. 2016 Improving governance of pastoral lands. Implementing the Voluntary Guidelines on the Responsible Governance of Tenure of Land, Fisheries and Forests in the Context of National 
Food Security. Governance of Tenure Technical Guide No. 6. http://www.fao.org/3/a-i5771e. pdf\#page $=37$

De Haan, C., Dubern, E., Garancher, B. and Quintero, C. 2016. Pastoralism Development in the Sahel: A Road to Stability? World Bank, Washington DC. Available at http://hdl.handle. net/10986/24228

De Haan, L., Quarles van Ufford, P. and Zaal, F. 1999. Cross-border cattle marketing in SubSaharan Africa since 1900. Geographical patterns and government induced change. In: H.L. van der Laan, Dijkstra, T. and van Tilburg, A. (eds), Agricultural Marketing in Tropical Africa, African Studies Centre Leiden, Research Series 15, Leiden: Ashgate, pp. 205-226. Available at https:// core.ac.uk/download/pdf/18510595.pdf

De Heer, E. 2016. Grain shortages restrict West African feed production. Feed International. Vol. 35 (5). Available at http://www.fi-digital.com/201608/index.php\#/8

de Jode, H. 2010. The obstacles of mobility. In: Modern and Mobile. The Future of Livestock Production in Africa's Drylands (IIED \& SOS Sahel, London and Edinburgh), pp. 35-48. Available at http://pubs.iied.org/12565IIED/

De Leeuw, P.N. and Reid, R. 1995. Impact of human activities and livestock on the African environment: an attempt to partition the pressure. In: Wilson RT, Ehui S and Mack S (Eds). 1995. Livestock Development Strategies for Low Income Countries. Proceedings of the Joint FAO/ILRI Roundtable on Livestock Development Strategies for Low Income Countries, ILRI, Addis Ababa, Ethiopia, 27 February - 02 March 1995. Nairobi, Kenya. Available at http://www.fao.org/Wairdocs/ ILRI/x5462E/x5462e00.htm\#Contents

de'Besi, G., Thieme, 0. 2013 Optimum use of milk in traditionally managed cattle herds in the tropics. Tropical Animal Health and Production 45, 1079-1086. https://doi.org/10.1007/s11250013-0372-9

Dean, A.S., Fournié, G., Kulo, A.E., Boukaya, G.A., Schelling, E. and Bonfoh, B. 2013. Potential risk of regional disease spread in West Africa through cross-border cattle trade. PloS one. 8. e75570. Available at https://www.researchgate.net/publication/257840039_Potential_Risk_of_ Regional_Disease_Spread_in_West_Africa_through_Cross-Border_Cattle_Trade

Delgado, C.L. 2003. Rising Consumption of Meat and Milk in Developing Countries Has Created a New Food Revolution. Journal of Nutrition 133, 3907S-3910S. https://doi.org/10.1093/ jn/133.11.3907S

Dembele, A. 2017. Revue des filières bétail/viande \& lait et des politiques qui les influencent au Mali. FAO-ECOWAS, Rome and Abuja. Available at http://www.fao.org/3/a-i5269f.pdf

Diack, A., Sanyang, F.B. and Münstermann, S. 2005. Lactation performance on-station of F1 crossbred cattle in The Gambia. Livestock Research for Rural Development 17 (12) 2005. Available at http://www.Irrd.org//rrd17/12/diac17140.htm

Diallo, A. 2012. Revue du secteur de l'élevage en Guinée. Organisation des Nations Unies pour l'alimentation et l'agriculture (FAO) (unpublished).

Dietze, K. 2011. Pigs for Prosperity. Diversification booklet No. 15. Rural Infrastructure and Agro-Industries Division. Food and Agriculture Organization of the United Nations. Rome, Italy. Available at http://www.fao.org/3/i2471e/i2471e00.pdf

Dione, M., Traore, I., Wieland, B. and Fall, A. 2017. Feed the Future Mali Livestock Technology Scaling Program (FtFMLTSP) - Participatory assessment of animal health service delivery systems in Mali: constraints and opportunities. International Livestock Research Institute (ILRI). Nairobi, Kenya. Available at https://cgspace.cgiar.org/rest/bitstreams/119728/retrieve Diop, A.T. 2012. La transhumance transfrontalière en Afrique de l'Ouest Proposition de plan d'action. FAO, Accra. Available at http://www.inter-reseaux.org/IMG/pdf/Transhumance_ Transfrontalier_en_AO_Rapport_FAO.pdf

Diop, R. and Guillotin. J. 2017. Evaluation et appui technique au Laboratoire (LNERV) Dakar, 
Sénégal. FAO \& FVI (unpublished).

Distefano, F. 2013. Understanding and integrating gender issues in to livestock projects and programmes. FAO, Rome. Available at http://www.fao.org/3/a-i3216e.pdf

Djassi, E.G. 2012. Secteur Porcin Burkina Faso. Revues nationales de l'élevage de la division de la production et de la santé animales de la FAO. No. 1. Rome, Italy. Available at http://www.fao. org/3/a-i2567f.pdf

Djata, H., 2012. Rapport d'étude sur le secteur de l'élevage en Guinée-Bissau-2012. FAO.

Djibrillou, A. 2012. Niger: profil pays du secteur de l'élevage. Organisation des Nations Unies pour l'alimentation et l'agriculture (FAO) (unpublished).

Djiro, A. 1980. Etude ethnologique des races locales de volailles dans le district de Bamako. Mémoire de fin d'études. IPR de Katibougou.

Djurfeldt A.A., Jirström M. 2013. Urbanization and changes in farm size in Sub-Saharan Africa and Asia from a geographical perspective, a review of the literature. Background Paper for CGIAR's ISPC Foresight Study on Farm Size and Urbanization. https://cas.cgiar.org/sites/default/ files/ISPC_StrategyTrends_FarmSize_DjurfeldtJirstrom.pdf

DNPIA, 2013. Direction Nationale des Productions et des Industries Animales. Rapport Annuel2013. Ministère du Développement Rural de la République du Mali. Available at http:// countrystat.org/country/MLI/contents/docs/RAPPORT\%20ANNUEL_DNPIA_2013.pdf Dodo, B. 2012. Legislating for pastoralism: lessons from West Africa and the ECOWAS transhumant certificate. Brussels Policy Briefing no.26. https://brusselsbriefings.net/ pastbriefings/no-26-pastoralism/

Donadeu, M., Nwankpa, N., Abela-Ridder, B. and Dungu, B. 2019. Strategies to increase adoption of animal vaccines by smallholder farmers with focus on neglected diseases and marginalized populations. PLOS Neglected Tropical Diseases 13(2): e0006989. Available at https://journals. plos.org/plosntds/article?id=10.1371/journal.pntd.0006989

Dossa, L.H., Abdulkadir, A., Amadou. H., Sangare M. and Schlecht. E. 2011. Exploring the diversity of urban and peri-urban agricultural systems in Sudano-Sahelian West Africa: An attempt towards a regional typology. Landsc. Urban Plan. 102: 197-206.

Dossa, L.H., Sangare, M., Buerkert, A. and Schlecht, E. 2015. Intra-urban and peri-urban differences in cattle farming systems of Burkina Faso. Land Use Policy, 48: 401-411 Available at https://www.sciencedirect.com/science/article/abs/pii/S0264837715002094?via\%3Dihub

Doumbia, S. 2010. Forum sur la transhumance: La paix revient à Wassoulou. Les Echos. Afribone Mali SA. Available at https://afribone.com/?Forum-sur-la-transhumance-La-paix

DSA/DLS 2003. Current status of animal genetic resources. Contribution to the State of the World Animal Genetic Resources. Country Report: The Gambia. Department of State for Agriculture. Department of Livestock Services. Abuko, The Gambia. Available at ftp://ftp.fao.org/docrep/ fao/010/a1250e/annexes/CountryReports/Gambia.pdf

Duteurtre, G. and Corniaux, C. 2013. Etude relative à la formulation du programme d'actions détaillé de développement de la filière lait en zone UEMOA. CIRAD et UEMOA. Available at http:// www.repol.info/IMG/pdf/rapport_final_etude_lait_uemoa.pdf

Dwinger, R.H., Clifford, D.J., Agyemang, K., Gettinby, G., Grieve, A.S., Kora, S. and Bojang,

M.A. 1992. Comparative studies on N'Dama and Zebu cattle following repeated infections with Trypanosoma congolense. Research in Veterinary Science. 52:292-298.

Dyer, C. 2010. Including pastoralists in Education for All. Commonwealth Education Partnerships 2010, 63-65. Commonwealth Secretariat, London. Available at http://www.cedol.org/wp-content/ uploads/2012/02/63-65-2010.pdf

EB, 2008. Enciclopaedia Britannica Inc. Available at https://www.britannica.com/

ECOWAP, 2005. ECOWAS Agriculture Policy/2005-2015 Regional Agriculture In-vestment Plan. ECOWAP/RAIP, 2011. ECOWAS Agriculture Policy/Regional Agriculture Investment Plan. www. ecowas.int 
ECOWAP/RAIP, 2016. ECOWAS Agriculture Policy/2016-2020 Regional Agriculture Investment Plan and Food Security and Nutrition.

ECOWAS, 1998. Decision A/DEC.5/10/98 relating to the regulations on transhumance between ECOWAS Member States. Twenty-first conference of heads of states. Abuja, 31 October 1998.

Official Journal of the Economic Community of West African States (ECOWAS) nr. 35. Available at http://ecpf.ecowas.int/wp-content/uploads/2016/01/Decision-1998-English.pdf

ECOWAS, 2003. Regulation C/REG.3/01/03 relating to the regulations on transhumance between ECOWAS Member States. Dakar, 28 January 2003. Official Journal of the Economic Community of West African States (ECOWAS) nr. 42. http://ecpf.ecowas.int/wp-content/uploads/2016/01/ Regulation-2003-English.pdf

ECOWAS, 2006. Regional Action Plan for the Prevention and Control of HPAl in the ECOWAS Region. ECOWAS, Abuja

ECOWAS, 2008. Regional Agricultural Policy for West Africa: ECOWAP. Economic Community of West African States (ECOWAS). Available at https://www.diplomatie.gouv.fr/lMG/pdf/01_ ANGComCEDEAO.pdf

ECOWAS, 2010a. Strategic action plan for the development and transformation of livestock sector in the ECOWAS region (2011-2020). Economic Community of West African States. Leather International (LT), 2013. Cute stuff: traditional artisanal tanneries. Available at http://www. leathermag.com/features/featurecute-stuff-traditional-artisanal-tanneries/

ECOWAS, 2010b, ECOWAS Sanitary and Phyto-sanitary Regulations. ECOWAS, Abuja, Nigeria ECOWAS, 2012a. Strategy for the Prevention and Control of PPR and FMD. ECOWAS, Abuja ECOWAS, 2012b. ECOWAS Authority of Heads of States Supplementary Act A/SA.20/02/12. ECOWAS, Abuja, Nigeria

ECOWAS, 2015. Agriculture and Food in West Africa: Trends, Performances and Agricultural Policies. ECOWAS, Abuja. http://ecowas-agriculture.org/sites/default/files/LivretEcowap2014eng-light.pdf

ECOWAS, 2018. Regional Meeting of the Ministers in charge of Security and Agri-culture/ Livestock on Transhumance. Available at www.ecowas.int/wp-content/uploads/2018/05/ Ministers-Meeting-Report-Final.pdf

ECOWAS, 2019. Economic Community of West African States. www.ecowas.int

Eisler, M.C., Lee, M.R.F., Tarlton, J.F., Martin, G.B., Beddington, J., Dungait, J.A.J., Greathead, H., Liu, J., Mathew, S., Miller, H., Misselbrook, T., Murray, P., Vinod, V.K., Van Saun, R., Winter, M. 2014. Agriculture: Steps to sustainable livestock. Nature 507, 32-34. https://doi. org/10.1038/507032a

El Harrak, M. and Abouchoaib, N. 2016. Évaluation et appui technique au Laboratoire Central Vétérinaire de Bamako, Mali. FAO (unpublished).

El Pais, 2016. China importa millones de burros para usarlos en la medicina tradicional. Available at https://elpais.com/economia/2016/10/06/actualidad/1475775231_389146.html

Epstein, H. 1971. The origin of the domestic animals of Africa Volume I. Africana Publishing Corporation. New York. London. Munich. pp. 201-204.

Fa, J.E., Olivero J., Farfán M.A., Lewis J., Yasuoka H., Noss A., Hattori S., Hirai M., Kamgaing T.O.W., Carpaneto G, Germi F., Márquez A.L., Duarte J., Duda R, Gallois S., Riddell M., Nasi R. 2016. Differences between Pygmy and Non-Pygmy Hunting in Congo Basin Forests. PLOS One 11, e0161703. https://doi.org/10.1371/journal.pone.0161703

Fadiga, S. 2011. Revue du Secteur Elevage en Côte d'Ivoire. Sous-secteurs Bétail - Viande et Lait. Organisation des Nations Unies pour l'alimentation et l'agriculture (FAO) (unpublished).

Fafchamps, M., Udry, C., Czukas, K. 1998. Drought and saving in West Africa: are livestock a buffer stock? Journal of Development Economics 55, 273-305. https://doi.org/10.1016/S03043878(98)00037-6 
Falconer, J. 1990. The consumption of wild animals. In: The Major Significance of 'Minor' Forest Products: The Local Use and Value of Forests in the West African Humid Forest Zone. Edited by C.R.S. Koppell. FAO, Rome. Available at http://www.fao.org/docrep/t9450e/t9450e00.htm

FAO \& ECOWAS, 2015. Regional Emergency Consultation for Prevention and Control of H5N1 Highly Pathogenic Avian Influenza in West and Central Africa, 15-16 June 2015, Abuja, Nigeria. FAO \& FFSPS, 2013. Pastoralist Field Schools Training of Facilitators Manual. CHO, EC and SDC funded interventions in the Horn of Africa. FAO, Rome \& Farmer Field Schools Promotion Services, Nairobi. http://www.fao.org/3/a-bl492e.pdf

FAO and AU-IBAR, 2014. Regional Workshop for the Strengthening of Capacities for the management of animal genetic resources in Central and West. CEBEVIRHA, N'Djamena, CHAD. 28 to 30 August 2014. Available at http://www.au-ibar.org/angr-resources/angr-reports FAO and CIRAD, 2012. Atlas of trends in pastoral systems in the Sahel 1970-2012. Information system on pastoralism in the Sahel. FAO, Rome. Available at http://www.fao.org/3/a-i2601e.pdf FAO and ECA, 2018. Regional Overview of Food Security and Nutrition. Addressing the threat from climate variability and extremes for food security and nutrition. Accra. $116 \mathrm{pp}$. http://www. fao.org/3/CA2710EN/ca2710en.pdf

FAO CMC-AH, 2016. Évaluation rapide de la situation épidémiologique de la Fièvre de la Vallée du Rift au Niger. Rapport de mission. FAO Crisis Management Centre - Animal Health (unpublished). FAO, 1983. Integrating crops and livestock in West Africa. FAO Animal Production and Health Paper No. 41. Rome, Italy. Available at http://www.fao.org/docrep/004/x6543e/X6543E00. htm\#TOC

FAO, 1994. Identification and characterization of West African Shorthorn cattle. FAO World animal review 78 - 1994/1. Available at: http://www.fao.org/3/a-t1300t/t1300t00.htm\#Contents FAO, 1995. Rearing unconventional livestock species: a flourishing activity. World animal review N. 83:2. FAO Animal Health, Production and Products Division. Rome, Italy. Available at http:// www.fao.org/ag/aga/agap/frg/feedback/war/v6200b/v6200b00.htm\#Contents FAO, 1996. Agro-Ecological Zoning Guidelines. FAO Soils Bulletin 73. Soil Resources, Management and Conservation Service. FAO Land and Water Development Division. Rome, Italy. FAO, 2001. Pastoralism in the new millennium. FAO Animal Production and Health Paper No. 150. Available at http://www.fao.org/3/y2647e/y2647e00.htm\#toc

FAO, 2002. Land Tenure and Rural Development. FAO Land Tenure Studies No. 3. FAO Rural Development Division. Rome, Italy. Available at http://www.fao.org/docrep/005/y4307e/ y4307e00.htm\#Contents

FAO, 2004. Towards sustainable CBPP Control Programmes for Africa. Proceedings FAO-OIEAU/ IBAR-IAEA Consultative Group on Contagious Bovine Pleuropneumonia. Third Meeting, Rome 12-14 November 2003. Available at http://www.fao.org/docrep/007/y5510e/y5510e00. htm\#Contents

FAO, 2007. Subregional report on animal genetic resources: North and West Africa. Annex to The State of the World's Animal Genetic Resources for Food and Agriculture. Rome, Italy. Available at ftp://ftp.fao.org/docrep/fao/011/a1250f/annexes/Subregional\%20Reports/Africa/ NorthWestAfrica.pdf

FAO, 2008. Poultry Sector Country Review: Gambia. Food and Agriculture Organization of the United Nations. Rome, Italy. Available at ftp://ftp.fao.org/docrep/fao/011/ai321e/ai321e00.pdf FAO, 2009. Livestock, food security and poverty reduction. In: The State of Food and Agriculture 2009 - Livestock in the balance. Rome, Italy. Available at http://www.fao.org/docrep/012/i0680e/ i0680e00.htm

FAO, 2011a. Challenges of animal health information systems and surveillance for animal diseases and zoonoses. Proceedings of the international workshop organized by FAO, 23-26 November 2010, Rome, Italy. FAO Animal Production and Health Proceedings, No. 14. Rome, Italy. 
Available at http://www.fao.org/3/i2415e/i2415e00.pdf

FAO, 2011b. Disaster Risk Management Strategy in West Africa and the Sahel: FAO (20112013). FAO, Rome. http://www.fao.org/fileadmin/templates/tc/tce/pdf/DRM_Strategy _ Sahel_2011-2013_web.pdf

FAO, 2011c. The State of Food and Agriculture: Women in Agriculture: Closing the Gender Gap for Development. FAO, Rome. Available at http://www.fao.org/docrep/013/i2050e/i2050e.pdf FAO, 2012a. Enhancing coordination on laboratory activities in West and Central Africa. Emergency Prevention System for Animal Health (EMPRES-AH). Available at http://www.fao.org/ ag/againfo/programmes/en/empres/news_181212.html

FAO, 2012b. Voluntary Guidelines on the responsible Governance of tenure of land, fisheries and forests in the Context of national food security. FAO, Rome. Available at http://www.fao.org/ docrep/016/i2801e/i2801e.pdf

FAO, 2014. Livestock Country Reviews: Poultry Sector Ghana. Food and Agriculture Organization of the United Nations. Rome, Italy. http://www.fao.org/docrep/019/i3663e/i3663e.pdf

FAO, 2015a. Pretoria Declaration on Animal Identification and Recording Systems for Traceability and Livestock Development in Sub-Saharan Africa. Available at http://www.fao.org/fileadmin/ templates/raf/pdfFiles/AIR_Pretoria_Declaration.pdf

FAO, 2015b. Strengthening Regional Veterinary Networks in Africa and Asia. FCC EMPRES Information Sheet. Available at http://www.fao.org/3/a-bb010e.pdf

FAO, 2015c. West and Central Africa discussed coordination and synergies to contain Avian Influenza. In: Resilience - News \& Events. Available at: http://www.fao.org/resilience/newsevents/detail/en/c/295672/

FAO, 2016a. Development of integrated multipurpose animal recording systems. FAO Animal Production and Health Guidelines. No. 19. Rome, Italy. Available at http://www.fao.org/3/ai5702e.pdf

FAO, 2016b. Farmer Field School guidance document. Planning for quality programmes. FAO, Rome. Available at http://www.fao.org/3/a-i5296e.pdf

FAO, 2017a. Regional Overview of Food Security and Nutrition in Africa 2016. The challenges of building resilience to shocks and stresses. FAO, Accra. http://www.fao.org/3/a-i6813e.pdf

FAO, 2017b. Support to estimation of demographic and production parameters in the livestock population in Sierra Leone (TCP/SIL/3504). Terminal Report.

FAO, 2018a. Pastoralism in Africa's drylands. Rome. Available at http://www.fao.org/3/ CA1312EN/ca1312en.pdf

FAO, 2018b. World livestock: Transforming the livestock sector through the sustainable development Goals. Rome. 222 pp. License: CC B Y-NC-SA 3.0 IGO http://www.fao.org/3/ CA1201EN/ca1201en.pdf

FAO, 2019a. Sub-Saharan Africa HPAI situation update. Emergency Prevention System for Animal Health. Available at http://www.fao.org/ag/againfo/programmes/en/empres/HPAl_Africa/ situation_update.html

FAO, 2019b. Meat consumption. FAO Animal Production and Health Division. http://www.fao.org/ ag/againfo/themes/en/meat/background.html.

FAO \&, GEF, 2014. Integrating climate resilience into agricultural and pastoral production for food security in vulnerable rural areas through the Farmers Field School approach. GCP/BKF/054/

LDF. FAO/Global Environmental Facility project document. 189 pp. https://www.thegef.org/sites/ default/files/project_documents/ID5014_LDCF_BKF_ProDoc.pdf

FAO/OIE, 2016. Report of the 1st West Africa Roadmap Meeting on the Foot-and-Mouth Disease Progressive Control Pathway (FMD-PCP), 6 - 7 December 2016. Lomé, Togo. Global Framework for the Progressive Control of Trans-boundary Animal Diseases (GF-TADs). Available at http:// www.fao.org/3/ca3747en/ca3747en.pdf

FAOSTAT 2013. FAO statistical database. Available at http://www.fao.org/faostat/en/ 
FAOSTAT 2019. FAO statistical database. Available at http://www.fao.org/faostat/en/ Faustin, V., Adégbidi, A.A., Garnett, S.T., Koudandé, D.O., Agbo, V., Zander, K.K. 2010. Peace, health or fortune? Preferences for chicken traits in rural Benin. Ecological Economics 69, 1849-1858. https://doi.org/10.1016/j.ecolecon.2010.04.027

Felius, M. 1995. Cattle breeds: an encyclopaedia. Misset. Doetinchem, The Netherlands. 799 pp. Rege, J.E.O. 1999. The state of African cattle genetic resources I. Classification framework and identification of threatened and extinct breeds. International Livestock Research Institute (ILRI). GRI, No. 25, 1:25. Available at http://www.cattlenetwork.net/docs/agri/agri25_1.pdf Fernandez-Rivera, S., Okike, I., Manyong, V.M., Williams, T.O., Kruska, R.L. and Tarawali, S.A. 2004. Classification and description of the major farming systems incorporating ruminant livestock in West Africa. Sustainable crop-livestock production in West Africa, 87-122 FEWS Net, 2019. United States Agency for International Development (USAID) Famine Early Warning System Network. http://www.fews.net/

Finzi, A. 2000. Integrated backyard systems. A contribution to the special programme for food security. FAO. Rome, Italy. Available at http://www.fao.org/ag/againfo/themes/documents/ibys/ contents.htm

Flintan F. 2008. Women's empowerment in pastoral societies. IUCN-WISP, Nairobi. Available at https://www.iucn.org/sites/dev/files/import/downloads/gender_format.pdf

Fomba, H. 2016. Amélioration génétique de la volaille: les performances du poulet «Wassa Chè». Journal Scientifique et Technique du Mali (JSTM). Available at https://www.jstm.org/ ameliorationgenetique-de-la-volaille-les-performances-du-poulet-wassa-che/

Frank, A.I.I.Y. and Annatte, I. 2016. Review of the livestock/meat and milk value chains and policy influencing them in Nigeria. FAO-ECOWAS, Rome and Abuja. Available at http://www.fao.org/3/ ai5259e.pdf

Garba, A., Danbirni, S., Ahmed, A., Ambursa, A.U., Suleiman, A., Mohammed, M.N. and Muhammed, S.T. 2014. Veterinary Laws and Administration in Nigeria: Historical and Current Perspectives. Zariya Veterinarian 8 (2): 21-28. https://mafiadoc.com/zariya-veterinarianvol82-21a-28_59d321eb1723dd3bbae83c5f.html

Garcia-Landarte Puertas, D., van Steenbergen, F., Haile, A.M., Kool, M. and Embaye, T.A.G. 2015. Flood based farming systems in Africa. Overview Paper No. 5. Spate Irrigation Network Foundation. Available at http://spate-irrigation.org/wp-content/uploads/2015/03/OP5_Floodbased-farmingin- Africa_SF.pdf

Garrity, D., Dixon, J. and Boffa, J.M. 2012. Understanding African Farming Systems: Science and Policy Implications. Australian International Food Security Center and Australian center for International Agricultural Research. Available at https://aifsc.aciar.gov.au/sites/default/files/ understanding_african_farming_systems_report_for_aifsc_conference.pdf

Gary, F., Diop, B. and Barbosa, H. 2010. PVS Gap Analysis report Federal Republic of Nigeria World Organisation for Animal Health. Available at http://www.oie.int/fileadmin/Home/eng/ Support_to_OIE_Members/pdf/PVS_GapAnalysisReport-Nigeria.pdf

Gauthier, D. and Dauphin, G. 2016. Évaluation et appui technique au Laboratoire Central Vétérinaire de Diagnostic de Conakry (LCVD)-Guinée. FAO \& FVI (unpublished).

Gautier, D., Denis, D. and Locatelli, B. 2016. Impacts of drought and responses of rural populations in West Africa: a systematic review. WIREs Clim Change, 7:666-681. Available at https://agritrop.cirad.fr/580714/7/Gautier_2016_Impacts_drought_responses_rural_populations_ West_Africa.pdf

Gbenou, B., Adjolohoun, S., Houndjo, D.B.M., Saïdou, A., Ahoton, L., Houinato, M., Dahouda, M. and Sinsin, A.B. 2019. Difficulties to the Crops Forage Integration in Agricultural Farms in the Sudanian Area of Benin (West Africa). International Journal of Science and Research. International Journal of Science and Research. Vol. 8 (5): 152-159). Available at https://pdfs. semanticscholar.org/f7bf/f0eb9a26fa93437043f753bf5673f6123aab.pdf 
Geesing, D. and Djibo, H. 2001. Country Pasture/Forage Resource Profiles: Niger. FAO Rome. Available at http://www.fao.org/ag/agp/agpc/doc/counprof/regions/africa.htm

Gefu, J. 2009. Nigeria: Review of livestock sector with respect to smallholder dairy, livestock and meat sub-sectors development. Food and Agricultural Organization of the United Nations (FAO). (unpublished).

Gefu, J.O., Alawa, C.B.I. and Maisamari, B. (eds.) 2008. The future of transhumance pastoralism in West and Central Africa: strategies, dynamics, conflicts and interventions. Proceedings of the International Conference on the Future of Transhumance Pastoralism in West and Central Africa, Abuja, Nigeria, November 21-25, 2006. Shika, Nigeria: National Animal Production Research Institute; Zaria, Nigeria: Ahmadu Bello University, 2008.

Giannenas I, Nisianakis P, Gavriil A, Kontopidis G, Kyriazakis I. 2009 Trace mineral content of conventional, organic and courtyard eggs analysed by inductively coupled plasma mass spectrometry (ICP-MS). Food Chemistry 114, 706-711. https://doi.org/10.1016/j. foodchem.2008.09.079

Gibbons, S., Roba, G., Mahadi, Y. 2013. Booklet 3: Enabling Community Benefits from Sustainably Managed Drylands. IUCN ESARO, Nairobi. Available at https://www.iucn.org/sites/dev/files/ import/downloads/handbook_3_web.pdf

Glich, M.S. and Peters, K.J. 2002. Participatory Methods to Assess Traditional Breeding Systems: The Case of Cattle Breeding in The Gambia. In: CIP-UPWARD 2002. Conservation and Sustainable Use of Agricultural Biodiversity: A Sourcebook. Volume 1: Understanding Agricultural International Potato Center-Users Perspectives with Agricultural Research and Development, Los Banos, Laguna, Philippines. Available at https://idl-bnc.idrc.ca/dspace/ bitstream/10625/35111/4/118718_v1.pdf

Glo.be, 2019, Local milk: an enormous potential for economic growth. Available at https://www. glo-be.be/en/articles/local-milk-enormous-potential-west-africa

Godenir, J. 2017. Évaluation de la mise en oeuvre du Système d'Assurance Qualité et des Pratiques de Biosécurité en place au Laboratoire National Vétérinaire du Cameroun, Annexe de Yaoundé. FAO \& FVI (unpublished).

Gonin, A. 2014. Territoires de la sédentarité versus territoires de la mobilité : géopolitique de l'élevage en Afrique de l'Ouest. Colloque international « Agriculture et géopolitique », SFER, AGP, CIRAD, CEMOTEV, 12 - 13 février 2014, Université de Versailles Saint-Quentin.

Gooren, H., Seiffert, B., Demeranville, J. (2013). Children's Work in the Livestock Sector: Herding and Beyond. FAO, Rome. Available at http://www.fao.org/docrep/017/i3098e/i3098e.pdf

Gouro, A.S., Ly, C. and Makkar, H. 2014. Crop residues and Agro-industrial by-products in West Africa: Situation and way forward for livestock production. FAO Regional Office for Africa. Accra, Ghana. Available at http://www.fao.org/docrep/019/i3562e/i3562e.pdf

Grace, D., Songe, M. and Knight-Jones, T. 2015. Impact of neglected diseases on animal productivity and public health in Africa. OIE Regional Commission for Africa. http://www.oie.int/ fileadmin/Home/eng/Publications_\%26_Documentation/docs/pdf/TT/2015_AFR1_Grace_A.pdf Grasswitz, T.R., Leyland, T.J., Musiime, J.T., Owens, S.J. and Sones, K.R. (eds) 2004. The veterinary pharmaceutical industry in Africa: a study of Kenya, Uganda and South Africa. African Union/Interafrican Bureau for Animal Resources (AU/IBAR), Nairobi, Kenya. Available at http:// sites.tufts.edu/capeipst/files/2011/03/Grasswitz-et-al.pdf

Gueye, A. 2012. Sénégal: profil pays du secteur de l'élevage. Organisation des Nations Unies pour l'alimentation et l'agriculture (FAO) (unpublished).

Gueye, A. 2017. Revue des filières bétail/viande \& lait et des politiques qui les influencent au Sénégal. FAO-ECOWAS, Rome and Abuja. Available at http://www.fao.org/3/a-i5272f.pdf

Gueye, E.F. and Bessei, W. 1995. La poule locale sénégalaise dans le contexte villageois et les possibilités d'amélioration de ses performances. Paper presented at ANRPD Workshop and 
General Meeting, 13-16 June 1995, Addis Ababa, Ethiopia

Guibert, B., Banzhaf, M., Soule, D.B.G., Balami, D.H., Ide, G. 2009. Etude régionale sur les contextes de la commercialisation du bétail/accès aux marchés et défis d'amélioration des conditions de vie des communautés pastorales. Rapport final. IRAM-SNV, Paris et Montpellier. Available at http://www.reca-niger.org/IMG/pdf/Rapport_Commercialisation_betail_IRAM_ SNV_2009.pdf

Gundu, Z. A. 2016. Nigeria: Grazing Reserves - an Interrogatory Discourse. Daily Trust, Abuja, April 3rd 2016. Available at https://www.dailytrust.com.ng/grazing-reserves-an-interrogatorydiscourse.html

GWP 2009. Evaluation de la gouvernance de l'eau au Niger: analyse de la situation et actions prioritaires. Available at https://www.gwp.org/globalassets/global/gwp-waf_files/gireiwrmgovernance/gouvernance-eau-niger.pdf

GWP, 2000. Water for the 21st Century: Vision to Action for West Africa. Global Water Partnership. Second World Water Forum and Ministerial Conference at The Hague, the Netherlands, 17 to 22 March 2000. Available at http://hubrural.org/IMG/pdf/watervision-westafrica.pdf GWP/MDR, 2015. Rapport final de consultation nationale sur l'eau et sécurité alimentaire au Mali. Global Water Partnership West Africa and Ministere du Developpement Rural du Mali. 64 pp. Available at https://www.gwp.org/globalassets/global/activities/news/october-2015/ rapportconsultation-eau-securite-alimentaire-pne-mali.pdf

Haidara, L.N.Y. 2012. Revue du secteur de l'élevage au Mali. Organisation des Nations Unies pour l'alimentation et l'agriculture (FAO) (unpublished).

Haile-Gabriel, A. 2012. Policy Framework in Support of Pastoralism in Africa. Brussels Policy Briefing no.26. https://brusselsbriefings.net/past-briefings/no-26-pastoralism/

Hammoumi, S. and Mainguet, J.M. 2016. Evaluation and technical support of the Veterinary Services Directorate (VSD) Laboratory in Accra, Ghana. FAO \& FVI (unpublished).

Harris, P.S. 2000. Grassland Resource Assessment for Pastoral Systems. FAO Plant Production and Protection Paper No. 162. Food and Agriculture Organization of the United Nations (FAO). Rome, Italy. Available at http://www.fao.org/3/X9137E/x9137e00.htm\#TopOfPage

HarvestChoice, 2010. Agro-ecological Zones of sub-Saharan Africa. International Food Policy Research Institute, Washington, D.C., and University of Minnesota, St. Paul, Minnesota, USA. Available at http://harvestchoice.org/node/8853

Hatfield, R. and Davies, J. 2006. Global Review of the Economics on Pastoralism. WISP-IUCN, Nairobi. 44 p. Available at https://www.iucn.org/sites/dev/files/import/downloads/global_review_ ofthe_economicsof_pastoralism_en_1.pdf

Hazell, P.B.R., Oram, P., Chaherli, N. 2001. Managing droughts in the low-rainfall areas of the Middle East and North Africa. Environment and Production Technology Division Discussion Paper No 78. Washington: International Food Policy Research Institute http://ebrary.ifpri.org/utils/ getfile/collection/p15738coll2/id/67074/filename/67075.pdf\#page=23

Hendricks, B.L. 2007. International Encyclopedia of Horse Breeds. University of Oklahoma Press, Norman.

Henry, B. and Manzano, P. 2016. Case Study \#10. Land management for arid grazing in Botswana. In: LEAP. Principles for the assessment of livestock impacts on biodiversity. FAO, Rome, pp.127-129. Available at www.fao.org/3/a-i6492e.pdf\#page=159

Herrera, P. M.; Davies, J.; Manzano Baena, P., eds. 2014 The Governance of Rangelands: Collective Action for Sustainable Pastoralism. Routledge, London. 320 pp. https://www.iucn.org/ sites/dev/files/import/downloads/governance_book.pdf

Herrero, M., Grace, D., Njuki, J., Johnson, N., Enahoro, D., Silvestri, S. and Rufino MC 2013. The roles of livestock in developing countries. Animal. 7 Suppl 1:3-18. Available at https://www.ncbi. nlm.nih.gov/pubmed/23121696

Herrero, M., Havlik, P., McIntire, J., Palazzo, A. and Valin, H. 2014. African Livestock Futures: 
Realizing the potential of livestock for food security, poverty reduction and the environment in Sub-Saharan Africa. Office of the Special Representative of the UN Secretary General for Food Security and Nutrition and the United Nations System Influenza Coordination (UNSIC), Geneva, Switzerland, 118 p. Available at https://hdl.handle.net/10568/41908

Herrero, M., Henderson, B., Havlík, P., Thornton, P.K., Conant, R.T., Smith, P., Wirsenius, S., Hristov, A.N., Gerber, P., Gill, M., Butterbach-Bahl, K., Valin, H., Garnett, T., Stehfest, E. 2016. Greenhouse gas mitigation potentials in the livestock sector. Nature Climate Change 6, 452-461. https://doi.org/10.1038/nclimate2925

HLPE, 2016. Sustainable agricultural development for food security and nutrition: what roles for livestock? A report by the High Level Panel of Experts on Food Security and Nutrition of the Committee on World Food Security, Rome. Available at http://www.fao.org/fileadmin/user_ upload/hlpe/hlpe_documents/HLPE_Reports/HLPE-Report-10_EN.pdf

Hoffmann, I. 2010. Climate change and the characterization, breeding and conservation of animal genetic resources. Animal Genetics 41 (s1), 32-46. https://doi.org/10.1111/j.13652052.2010.02043.x

Hoffmann, I. 2013. Adaptation to climate change - exploring the potential of locally adapted breeds. Animal 7 (s2), 346-362. https://doi.org/10.1017/S1751731113000815

Hoffmann, I., Besbes, B., Bataglia, D. and Wagner, H. 2012. Capacity building in support of animal identification for recording and traceability: FAO's multipurpose and global approach. Proceedings of the First OIE Global Conference on Identification and Traceability 'From Farm to Fork', pp. 140-145. Available at http://www.fao.org/ag/againfo/home/documents/2012 Traceability_as_utility_to_animal_Identification.pdf

Hollinger F., Staatz JM. 2015. Agricultural Growth in West Africa. Market and policy drivers. AFD and FAO, Rome. 406 pp. Avaiable at http://www.fao.org/3/i4337e/i4337e.pdf

Hounsou-ve, G. 2009. Revue du secteur de l'élevage avec un accent particulier sur le développement des sous-secteurs lait et bétail-viande en faveur des petits producteurs en Afrique de l'Ouest. Cas du Benin. Organisation des Nations Unies pour l'Alimentation et l'Agriculture (FAO) ) (unpublished).

IAEA, 2005. Improving artificial breeding of cattle in Africa. Guidelines and recommendations. Animal Production and Health Section. International Atomic Energy Agency, Vienna. http:// wwwnaweb.iaea.org/nafa/aph/public/te_1437_web.pdf

Ibitoye, O., Kolejo, O., Gabriel, Akinyemi, G. 2019. Burgeoning and Domestication of Grasscutter (Thryonomys swinderianus) in a Post-Ebola Era: A Reassessment of its Prospects and Challenges in Nigeria. World Scientific News 130, 216-237. http://www.worldscientificnews.com/ wp-content/uploads/2019/04/WSN-130-2019-216-237-1.pdf

ICAR, 2015. Pretoria Declaration on Animal Identification and Recording Systems for Traceability and Livestock Development in Sub-Saharan Africa. 16 April 2015. Available at http://www.icar. org/wp-content/uploads/2015/12/AIR-Pretoria-Declaration.pdf

Ickowicz, A., Ancey, V., Corniaux, C., Duteurtre, G., Poccard-Chappuis, R., Touré. I., Vall, E., and Wane, A. 2012. Crop-livestock production systems in the Sahel - increasing resilience for adaptation to climate change and preserving food security. In: Building resilience for adaptation to climate change in the agriculture sector. Proceedings of a Joint FAO/OECD Workshop. 261294. Available at http://www.fao.org/3/i3084e/i3084e17.pdf

Idi, I. and Ganda-Idé, 0. 2009. Revue du secteur avicole: Niger. Food and Agriculture Organization of the United Nations. Rome, Italy. Available at http://www.fao.org/3/ak770f/ak770f00.pdf IFRC, 2012. DREF operation update. Niger: Floods. DREF operation $n^{\circ}$ MDRNE011. GLIDE $n^{\circ}$ FL2012-000141-NER. Update $n^{\circ} 1$ - 14 December, 2012. International Federation of Red Cross and Red Crescent Societies. https://reliefweb.int/sites/reliefweb.int/files/resources/MDRNE01101. pdf 
Ijeomah, H. M., Ofodile, E. A. U., Okereke, V. 2016. Challenges and Prospects of Grasscutter Farming in Selected Areas of River State. International Journal of Agriculture \& Rural Development 19 (1), 2600-2610. Available at https://www.researchgate.net/ publication/319065409

ILCA, 1983. Pastoral systems research in sub-Saharan Africa Proceedings of the IDRC/ILCA workshop held at the International Livestock Centre for Africa (ILCA), Addis Ababa, Ethiopia, 2124 March 1983. ILCA (International Livestock Centre for Africa), Addis Ababa, Ethiopia. 480 pp. ILCA, 1990. Section 1 - Module 9: Livestock marketing In: Livestock systems research manual. Working Paper 1, Vol. 1. ILCA, Addis Ababa, Ethiopia. 287 pp

ILRI and CGIAR 2015. Revue des innovations technologiques et des options politiques relatives aux chaines de valeur des petits ruminants au Burkina Faso. 1ere version provisoire. Rapport Synthese. Ouagadougou, Burkina Faso.

ILRI, 2011. Towards priority actions for market development for African farmers. Proceedings of an international conference, Nairobi, Kenya, 13-15 May 2009. Nairobi: Alliance for the Green Revolution in Africa and International Livestock Research Institute. Available at https://hdl.handle. net/10568/16491

ILRI, 2014. Burkina Faso small ruminants value chain business case. 9th Program Planning and Management Committee Meeting held on 3-4 April 2014 at WorldFish Penang, Malaysia. CGIAR research program on livestock and fish. Available at https://hdl.handle.net/10568/41575

ILRI, 2018. African Chicken Genetic Gains: Building the Business Case. International Livestock Research Institute. Nairobi, Kenya. Available at https://cgspace.cgiar.org/handle/10568/100242 ILRI, 2019. Food Safety in Africa: past endeavors and future directions. Global Food Safety Partnership (GFSP). Available at https://www.gfsp.org/sites/gfsp/files/public/GFSP\%20Report_ Food\%20Safety\%20in\%20Africa-web.pdf

ILRI, FAO and UNED, 1979. Trypanotolerant Livestock in West and Central Africa. Addis Ababa, Ethiopia.

IRIN, 2009. Combating world's lowest literacy rates. Available at http://www.irinnews.org/ news/2009/04/22/combating-worlds-lowest-literacy-rates

Iro, I. 1994. Grazing Reserve Development: A Panacea to the Intractable Strife between Farmers and Herders. Available at http://www.gamji.com/fulani8.htm

Islam, M.A.; Nishibori, M. 2010. Crossbred chicken for poultry production in the tropics. Journal of Poultry Science 47, 271-279. https://doi.org/10.2141/jpsa.010033

Itan, Y., B.L. Jones, C.J. Ingram, D.M. Swallow, M.G. Thomas 2010. A worldwide correlation of lactase persistence phenotype and genotypes. BMC Evolutionary Biology 10, 36. https://doi. org/10.1186/1471-2148-10-36

IUCN, 2011. The land we graze. A synthesis of case studies about how pastoralists' organizations defend their land rights. IUCN ESARO office, Nairobi, Kenya. viii + 48pp. Available at https://www. iucn.org/sites/dev/files/import/downloads/land_rights_publication_english_web.pdf

IUCN, 2012. Supporting Sustainable Pastoral Livelihoods: A Global Perspective on Minimum Standards and Good Practices. 2nd Edition March 2012: published for review and consultation through global learning fora. Nairobi, Kenya: IUCNESARO office. vi + 34pp. Available at https:// www.iucn.org/content/supporting-sustainable-pastoral-livelihoods-global-perspectiveminimumstandards-and-good

IWGIA, 2014. International conference on security and development challenges of pastoralism in West and Central Africa. Final communiqué for the conference "The Role of Pastoralists in Preventing Insurgency and Conflicts for Sustainable Peace and National Security", 23rd to 25th June 2014, Abuja, Nigeria. Available at http://eddyogunbor.blogspot.com/2016/04/reportonproceeding-of-international.html 
Jabbar, M.A., Kiruthu, S, Gebremehdin, B., Ehui, S. 2002 Essential actions to meet quality requirements of hides, skins and semi-processed leather from Africa. A Re-port Prepared for the Common Fund for Commodities, Amsterdam. Available at https://www.researchgate.net/ publication/264457334

Jack, A. 2019. Kano State secures \$95 million agriculture loan from Saudi Arabia. Voice Of Nigeria. Available at https://www.von.gov.ng/kano-state-secures-95-million-agriculture-loan-fromsaudiarabia/

Jahnke, H.E. 1982. Livestock Production Systems in Livestock Development in Tropical Africa. Kiel,FRG: Kieler Wissenschaftsverlag Vauk.

Jajere, S.M., Atsanda, N.N., Bitrus, A.A., Hamisu, T.M., Goni, M.D. 2018. A retrospective study of bovine tuberculosis at the municipal abattoir of Bauchi State, North-eastern Nigeria. Vet World. 2018;11 (5):598-605. Available at https://www.ncbi.nlm.nih.gov/pmc/articles/PMC5993755/ Jalloh, A., Nelson, G.C., Thomas, T.S., Zougmoré, R. and Roy-Macauley, H. 2013. West African agriculture and climate change: A comprehensive analysis. IFPRI Re-search Monograph. Washington, D.C. International Food Policy Research Institute. Available at http://www.ifpri.org/ publication/west-african-agriculture-and-climate-change-comprehensive-analysis

Jarrett, H.R. 1980. A geography of West Africa. London, Evans Brothers.

Jenet, A., Buono, N., Di Lello, S., Gomarasca, M., Heine, C., Mason, S., Nori, M., Saavedra, R. and Van Troos, K. 2016. The path to greener pastures. Pastoralism, the backbone of the world's drylands. Vétérinaires Sans Frontières International (VSF-International). Brussels, Belgium. Available at http://vsf-international.org/wp-content/uploads/2016/09/REPORT-pastoralism-2017pag1-1401.pdf

Jori, F., Edderai, D., Houben, P. 2005. The potential of rodents for mini-livestock in Africa. In: Paoletti, M.G. Ecological implications of mini-livestock; rodents, frogs, snails and insects for sustainable development. Enfield, USA: Sci Publ; 2005. p. 25-47.

Jori, F., Mensah, G.A. and Adjanohoun, E. 1995. Grasscutter production. A model of rational exploitation of wildlife. Biodiversity and Conservation, 4 (3): 257-265. https://doi.org/10.1007/ BF00055972

Josserand H.P. 2013. Estimation des volumes et de la valeur du commerce régional des denrées de base. USAID. Document préparé pour la conférence «Libre circulation des produits alimentaires», Accra, 29-31 janvier 2013. Available at http://www.inter-eseaux.org/IMG/pdf/ Josserand_-_Estimation_des_volumes_et_de_la_valeur.pdf

Kabasa, J.D. 2019. Introduction to Veterinary Medical Education in Africa. Council for International Veterinary Medical Education. Available at https://www.aavmc.org/civme/africa. aspx

Kabore, Y. 2012. Identification and prioritization of TADs and zoonotic diseases in West Africa, FAO consultancy report (unpublished).

Kagone, H. 2001. Country Pasture/Forage Resource Profiles: Burkina Faso. FAO Rome. Available at http://www.fao.org/ag/agp/agpc/doc/counprof/regions/africa.htm

Kamoun, M. 2005. Meat recording systems in camelids. In: Cardellino R, Rosati A and Mosconi C (Eds.) 2005. Current Status of Genetic Resources, Recording and Production Systems in African, Asian and American Camelids. ICAR Technical Series - No. 11. Rome, Italy. Available at http:// cisdna.com/wp-content/themes/cisdna/pdfs/camelid-development-program.pdf

Kamuanga, M.J.B., Somda, J., Sanon, Y. and Kagoné, H. 2008. Livestock and regional market in the Sahel and West Africa; Potentials and challenges. SWAC-OECD/ECOWAS. Available at https:// www.oecd.org/swac/publications/41848366.pdf

Kamwanja, L.A., Saka, J., Awotedu, A., Fute, I. and Ndomondo-Sigonda, M. 2011.Situation analysis study on medicines registration harmonisation in Africa - Final report for the Economic Community of West African States (ECOWAS). New Partnership for Africa's Development 
(NEPAD) of the African Union (AU). Available at file: https://www.nepad.org/publication/situationanalysis-studymedicines-registration-harmonisation-africa-final-report-2

Kane, M. 1990. Aperu sur l'Aviculture au Mail. Proceedings CTA International Seminar on Smallholder Rural Poultry Production, Thessaloniki, Greece, Oct. 9-13. Vol. 2, pp. 149-158. Kangni, T. 2015. Secteur Avicole Togo. Revues nationales de l'élevage de la division de la production et de la santé animales de la FAO. No. 9. Rome, Italy. Available at http://www.fao. org/3/a-i4584f.pdf

Kathy Marshall, K. and Ali, Z. 2004. Gender issues in donkey use in rural Ethiopia. Available at https://www.atnesa.org/donkeys/donkeys-marshall-gender-ET.pdf

Kay, S. 2016. Connecting smallholders to markets. Civil Society Mechanism, Rome, 46 p. Available at http://www.csm4cfs.org/wp-content/uploads/2016/10/CONNECTINGSMALLHOLDERS-TOMARKET. compressed.pdf

Keay, R.W.J. 1959. Vegetation map of Africa south of the Tropic of Cancer. London, Oxford University Press.

Kemp, E. 2016. African report for internal displacement - December 2016. Internal Displacement Monitoring Centre \& Norwegian Refugee Council. http://www.internal-displacement.org/ publications/2016-africa-report-on-internal-displacement

Kimmage, K. and Adams, W.M. 1990. Small-scale farmer-managed irrigation in Northern Nigeria. Geoforum, Volume 21, Issue 4, Pages 435-443. Available at http://www.sciencedirect.com/ science/article/pii/001671859090023Y

Kiruthu, S. 2007. Present and future role of Africa in the world leather and derived products industry and trade. United Nations Industrial Development Organization (UNIDO). Available at https://leatherpanel.org/sites/default/files/publications-attach-ments/present_and_future_role_ of_africa_in_the_world_leather_and_derived_products_industry.pdf

Kitchell, E., Turner, M.D. and McPeak, J.G. 2014. Mapping of pastoral corridors: practices and politics in eastern Senegal. Pastoralism, December 2014, 4: 17. Available at https://link.springer. com/article/10.1186/s13570-014-0017-2\#citeas

Knierim, U., Irrgang, N. and Roth, B.A. 2015. To be or not to be horned - Consequences in cattle. Livestock Science 179, 29-37. https://doi.org/10.1016/j.livsci.2015.05.014

Koerner S.E., Poulsen J.R., Blanchard E.J., Okouyi J., Clarck C.J. 2017. Vertebrate community composition and diversity declines along a defaunation gradient radiating from rural villages in Gabon. Journal of Applied Ecology 54, 805-814. https://doi.org/10.1111/1365-2664.12798

Köhler-Rollefson, I. 1997. Indigenous practices of animal genetic resource management and their relevance for the conservation of domestic animal diversity in developing countries. J. Animal Breeding and Genetics, 114: 231-238.

Köhler-Rollefson, I. 2003. Community-Based Management of Animal Genetic Resources with Special Reference to Pastoralist. In: Community-Based Management of Animal Genetic Resources. Proceedings of the workshop held in Mbabane, Swaziland, 7-11 May 2001. Food and Agriculture Organization of the United Nations. Rome, Italy. Available at http://www.fao.org/3/ y3970e/y3970e02a.htm\#bm02.2

Köhler-Rollefson, I. 2005. Indigenous breeds, local communities: Documenting animal breeds and breeding from a community perspective. Eschborn, Germany: GTZ. Available at https://hdl. handle.net/10568/10312

Kondombo, S.R., Nianogo, A.J., Kwakkel, R.P., Udo, H.M.Y. and Slingerland, M. 2003.

Comparative analysis of village chicken production in two farming systems in Burkina Faso. Tropical Animal Health and Production 35: 563-574.

Kone, S. and Danho, T. 2008. Revue de secteur avicole: Cote d'Ivoire. Food and Agriculture Organization of the United Nations. Rome, Italy. Available at ftp://ftp.fao.org/docrep/fao/011/ ak072f/ak072f00.pdf 
Köster, H. and Köster, H. 2016. Africa: The feed situation in Kenya and Tanzania. All About Feed. Available at https://www.allaboutfeed.net/Compound-Feed/Articles/2016/7/Africa-Thefeedsituation-in-Kenya-and-Tanzania-2833454W/\#comments

Kouakou, N.D.V. 2011. Improvement strategies of Guinea pig (Cavia porcellus) breeding in Ivory Coast. Symposium VET 2011, Veterinary Medicine in the tropics. Liège, Belgium.

Krätli , S., Kaufmann, B., Roba, H., Hiernaux, P., Li, W., Easdale, M., Hülsebusch, C. 2015. A House Full of Trap Doors: Identifying barriers to resilient drylands in the toolbox of pastoral development. IIED, London and Edinburgh. 48 p. Available at http://pubs.iied.org/10112IIED/ Krätli, S. 2014. If Not Counted Does Not Count? A programmatic reflection on methodology options and gaps in Total Economic Valuation studies of pastoral systems. IIED, London. Available at http://pubs.iied.org/10082IIED/

Krätli, S. 2015. Valuing Variability: New perspectives on climate resilient drylands development. IIED, London and Edinburgh. Edited by E. de Jode. Available at http://pubs.iied.org/10128IIED/ Krätli, S., Dyer, C. 2009. Mobile Pastoralists and Education: Strategic Options. Education for developments. Livestock Research for Rural Development 19 (8), 111. Available at http://www. Irrd.org//rrd19/8/ndam19111.htm

Kristjanson, P., Waters-Bayer, A., Johnson, N., Tipilda, A., Njuki, J., Baltenweck, I., Grace, D., MacMillan, S. (2014). Livestock and women's livelihoods. In: Quisumbing, A.R., Meinzen-Dick, R., Raney, T.L., Croppenstedt, A., Behrman, J.A., Peterman, A. (eds.), Gender in Agriculture: Closing the Knowledge Gap, FAO and Springer, Rome and Dordrecht, pp. 209-233. http://libcatalog. cimmyt.org/download/general/98958.pdf

Kwiatek, 0. 2016. Rapport de mission sur le laboratorio nacional de veterinaria de Bissau: assurance qualité et techniques de laboratoire. Guinea Bissau. FAO \& FVI (unpublished).

L'independent, 2009, Crise entre éleveurs et sédentaires au Wassoulou ; La tension a été désamorcée par la forum de Yanfolila. Afribone Mali. Available at https://afribone. com/?Criseentre-eleveurs-et

Lal, R. 2004. Soil Carbon Sequestration Impacts on Global Climate Change and Food Security. Science 304, 1623-1627. https://doi.org/10.1126/science.1097396

Lara, L.J., Rostagno, M.H. 2013. Impact of Heat Stress on Poultry Production. Animals 3, 356369. https://doi.org/10.3390/ani3020356

Larbi, A. 2012. Country Pasture/Forage Resource Profiles: Liberia. FAO Rome. Available at http:// www.fao.org/ag/agp/agpc/doc/counprof/regions/africa.htm

Larrasoaña, J.C., Roberts, A.P. and Rohling, E.J. 2013. Dynamics of Green Sahara Periods and Their Role in Hominin Evolution. PLoS 8, e76514. https://doi.org/10.1371/journal.pone.0076514 Le Hub Rural, 2010. Un forum pour mettre fin à la crise entre agriculteurs et éleveurs dans le Cercle de Yanfolila. Appui aux acteurs des politiques foncières : Actualités. Le Hub Rural Available at http://hubrural.org/Un-forum-pour-mettre-fin.html?lang=fr\&id=28

Leach I. and Wilson R.T., 2009 Higher value addition through hides and skins. Diversification booklet number 8. FAO, Rome. Available at http://www.fao.org/3/a-i0523e.pdf

Leather International, 2013. Cute stuff: traditional artisanal tanneries. Available at http://www. leathermag.com/features/featurecute-stuff-traditional-artisanal-tanneries/

Lebas, F., Coudert, P., Rochambeau, H. and Thébault, R.G. 1997. The rabbit: husbandry, health and production. FAO Animal Production and Health Series, No. 21. Rome, Italy. Available at http:// www.fao.org/docrep/t1690e/t1690e00.htm\#Contents

Lenné, J.M. and Thomas, D. 2005. Addressing poverty through crop-livestock integration: the contribution of past research to future challenges. In: Integrating livestock-crop systems to meet the challenges of globalization, AHAT/BSAS International Conference, Nov 14-18, Khon Kaen, Thailand, pp. 13-26.

Letellier, S. 2016. On site mission for the assessment of the Leon Q. Ledlum Central Veterinary Diagnostic Laboratory - Monrovia, Liberia. FAO \& FVI (unpublished). 
Lora L. lannotti, L.L., Lutter, C.K., Stewart, C.P., Gallegos Riofrio, C. A., Malo, C., Reinhart, G., Palacios, A., Karp, C., Chapnick, M., Cox, K. and Waters, W.F. 2017. Eggs in Early Complementary Feeding and Child Growth: A Randomized Controlled Trial. PEDIATRICS Volume 140, number 1, July 2017

Loum, B. 2012. Livestock sector profile of West African countries for 2012. The Republic of Sierra Leone. Food and Agriculture Organization of the United Nations (FAO). ISBN 978-92-5-107497-8.

Lubroth, J., Rweyemamu, M.M., Viljoen, G., Diallo, A., Dungu, B. and Amanfu, W. 2007. Veterinary vaccines and their use in developing countries. Rev. sci. tech. Off. Int. Epiz, 26 (1), 179-201.

Available at https://www.oie.int/doc/ged/D4025.PDF

Luiselli, L., Hema, E.M., Segniagbeto, G.H., Ouattara, V., Eniang, E.A., Di Vittorio, M., Amadi, N., Parfait, G., Pacini, N., Akanib, G.C., Sirima, D., Guenda, W., Fakae, B.B., Dendi, D. and Faj, J.E. 2017. Understanding the influence of non-wealth factors in determining bushmeat consumption: results from four West African countries. Acta Oecologica, vol. 94, 47-56. https:// doi.org/10.1016/j.actao.2017.10.002

Luseba, D. 2015. Review of the policy, regulatory and administrative framework for delivery of livestock health products and services in West and Central Africa. GALVmed. Available at https:// assets.publishing.service.gov.uk/media/5aa66772e5274a3e3603a626/47_West_Africa_Review_ of_Policy_Regulatory_and_Administrative_Framework_for_Delivery_of_Livestock_Health_ Products.pdf

Ly C., Fall A., Okike I. 2010. West Africa: The livestock sector in need of regional strategies. In: Livestock in a Changing Landscape Volume 2: Experiences and Regional Perspectives, eds. Gerber, P.; Mooney, H.A.Dijkman, J.; Tarawali, S.; de Hann, C. Island Press, Washington 2010, pp 27-54. http://www.fao.org/3/am075e/am075e00.pdf

Macpherson, C.N.L. \& Craig, P.S. 1991. Zoonotic helminths of wild and domestic animals in Africa. In: Macpherson, C.N.L., Craig, P.S. (eds) Parasitic helminths and zoonoses in Africa. Springer, Dordrecht. pp 260-272

Maddison D., Manley M., Kurukulasuriya P. 2007. The Impact of Climate Change on African Agriculture. A Riccardian approach. Policy Research Working Paper 4306. The World Bank, Washington DC. http://hdl.handle.net/10986/7510 Volume 50, Issue 5, Pages 629-639. https:// doi.org/10.1016/j.ijantimicag.2017.07.002

Mahadi, Y., Roba, G., Gibbons, S. 2013. Booklet 2: Participatory Rangeland Planning: A Practitioners Guide. IUCN ESARO, Nairobi. Available at https://www.iucn.org/sites/dev/files/ import/downloads/handbook_2_web.pdf

Maïga, A.M. 2012. Livestock sector profile of Liberia for 2012. Food and Agriculture Organization of the United Nations (FAO). ISBN 978-92-5-107497-8.

Mailafia, S., Onakpa, M.M. and Owoleke O.E., 2010 - Problems and prospects of rabbit production in Nigeria - a review, Bayero Journal of Pure and Applied Sciences, 3(2): 20 - 25 Maina, J. 2017. Overview of Livestock Production Systems in Nigeria: Options for Change and Sustainability. National Conference on transformation of the Nigerian Livestock Industry, 12th15th July, 2017. Abuja, Nigeria

Makkar, H.P.S., Sánchez, M. and Speedy, A.W. (Eds.) 2007. Feed Supplementation Blocks. Urea molasses multi-nutrient blocks: simple and effective feed supplement technology for ruminant agriculture. FAO Animal Production and Health Paper 164. Rome, Italy. Available at http://www. fao.org/3/a-a0242e.pdf

Malekani, M. 1996. Study of the Factors which can favorise the Reproduction in Captivity of the Cricetomas, Cricetomys in Zaire. Tropicultura, Vol. 14 No 3 p. 91-93.

Mane, S. 2009. Revue du secteur élevage avec un accent particulier sur le développement des sous-secteurs bétail/viande, lait en faveur des petits producteurs en Afrique de l'Ouest. République de Guinée. Organisation des Nations Unies pour l'alimentation et l'agriculture (FAO) (unpublished). 
Mane, S. 2017. Revue des filières bétail/viande \& lait et des politiques qui les influencent en Guinée. FAO-ECOWAS, Rome and Abuja. Available at http://www.fao.org/3/a-i5268f.pdf Mankor, A. 2013. Promoting intra-africa trade in animals and animal products. Conf. OIE. http:// www.oie.int/doc/ged/D12803.pdf

Mannetje, L.T. 1993. Practical technologies for the optimal use of tropical pastures and rangelands in traditional and improved livestock production systems. In: Strategies for sustainable animal agriculture in developing countries. Food and Agriculture Organization of the United Nations. Rome, Italy. Available at http://www.fao.org/3/T0582E/T0582E14.htm\#ch14 Manzano, P. 2016. Improvements of livestock disease management through enhanced beef supply chain hazard analysis procedures around Transfrontier Conservation Areas in Southern Africa. Case Study \#12. In: LEAP. Principles for the assessment of livestock impacts on biodiversity. Livestock Environmental Assessment and Performance Partnership. FAO, Rome, pp 134-139. Available at www.fao.org/3/a-i6492e.pdf\#page $=166$

Manzano, P. 2015. Pastoralist Ownership of Rural Transformation: The adequate path to change. Development 58, 326-332. https://doi.org/10.1057/s41301-016-0012-6 - Available at http://rdcu. be/pAqc

Manzano, P. 2017a Development interventions on pastoralist areas: a new decision matrix to identify win-win situations and no-go zones. Solutions 9 (3). Available at https://tinyurl.com/ ycf7xhry

Manzano, P. 2017b. Nexus between Smallholder farmers and livestock keepers and forcibly displaced people in East and Central Africa. Good practice note. UN-HCR \& The World Bank, Nairobi.

Manzano, P., Agarwal, M. 2015. Pastoralist Participation and Networking in Policy dialogue: Dimensions and Challenges. Perspectives 18, 1-16. http://hdl.handle.net/20.500.11822/10003 Manzano, P.; Salguero, C. 2018. Mobile Pastoralism in the Mediterranean: Arguments and evidence for policy reform and to combat climate change. Mediterranean Consortium for Nature and Culture (Liza Zogib, ed.). https://tinyurl.com/yalgh87o

Manzano, P.; Slootweg, S. 2017. Demography, social services and conflict: keys for the future of African pastoralist systems. In: Camara, A.D.; Taugourdeau, S. Pastoralism in the current of global changes: stakes, challenges and prospects. 20th-24th November, Dakar, Senegal, pp: 215-216. Available at https://www.researchgate.net/publication/338146636

Manzano, P.; White, S.R. 2019 Intensifying pastoralism may not reduce greenhouse gas emissions: wildlife-dominated landscape scenarios as a baseline in life cycle analysis. Climate Research 77, 91-97. https://doi.org/10.3354/cr01555

Mason, I.L. 1996. A World Dictionary of Livestock Breeds, Types and Varieties. Fourth Edition. C.A.B. International. Spore 65. CTA, Wageningen, The Netherlands. 273 pp.

Mason, I.L. and Buvanendran, V. 1982. Breeding plans for ruminant livestock in the tropics. FAO Animal Production and Health Paper N. 34. Rome, Italy.

Maule, J.P. 1990. The cattle of the tropics. Centre for Tropical Veterinary Medicine, University of Edinburgh. Redwood Press Limited, Melksham, Wilts. UK. 225 pp.

Mbaye M 2009. Revue du secteur de l'élevage au Sénégal axée sur les sous-secteurs bétail/ viande et lait, rapport provisoire. Organisation des Nations Unies pour l'alimentation et l'agriculture (FAO) (unpublished).

McDowell, R.E. and De Haan, C. 1986. West African Agricultural Research Review: Livestock Research.

Megnibeto-Aplogan, H. 2015. Secteur Avicole Bénin. Revues nationales de l'élevage de la division de la production et de la santé animales de la FAO. No. 10. Rome, Italy. Available at http://www. fao.org/3/a-i4583f.pdf

Mfewou, A. and Lendzele, S.S. 2018. Urban-Pig Farming: Easy Gain and Danger to the 
Environment (Yaounde-Cameroon). Agricultural Studies, 2:190-198. DOI: 10.31058/j. as.2018.24018

Milly, P.C.D., Dunne, K.A. 2016. Potential evapotranspiration and continental drying. Nature Climate Change 6, 946-949. https://doi.org/10.1038/nclimate3046

Milogo, V., Ouédraogo, G.A., Agenäs, S. and Svennersten-Sjaunja, K. 2008. Survey on dairy cattle milk production and milk quality problems in peri-urban areas in Burkina Faso. African Journal of Agricultural Research Vol. 3 (3), pp. 215-224, March 2008. Available at http://www. academicjournals.org/article/article1380809204_Millogo\%20et\%20al.pdf

Ministère de l'Agriculture et des Ressources Animales de Côte d'Ivoire, 1996. Décret n 96-431 du 3 juin 1996. Journal officiel $n^{\circ} 36$, jeudi 5 septembre 1996. Ministère de l'Agriculture et des Ressources Animales de Côte d'Ivoire. http://abidjan.net/JO/JO/1041996.asp

Ministère des Ressources Animales et Halieutiques de Burkina Faso, 2015. Guide méthodologique pour l'aménagement, la sécurisation et la valorisation des espaces pastoraux et des pistes à bétail. Ministère des Ressources Animales et Halieutiques de Burkina Faso. http:// extwprlegs1.fao.org/docs/pdf/Bkf177664.pdf

Ministère des Ressources Animales et Halieutiques de Côte d'Ivoire, 2015. Projet de loi relatif à la transhumance et aux déplacements de bétail. Ministère des Ressources Animales et Halieutiques de Côte d'Ivoire. http://news.abidjan.net/h/563377.html

Mitchell, P. 2017. Why the Donkey Did Not Go South: Disease as a Constraint on the Spread of Equus asinus into Southern Africa. African Archaeological Review, vol. 34 (1), pp 21-41. Available at https://link.springer.com/article/10.1007/s10437-017-9245-3mnstemps/98/98-1462792531. pdf

Modibo, T. 2010. Revue du secteur de l'élevage avec un accent particulier sur le développement des sous-secteurs du lait et de la viande bovine pour les petits producteurs d'Afrique de I'Ouest: le cas du Mali. Organisation des Nations Unies pour l'alimentation et l'agriculture (FAO) (unpublished).

Moehl, J. and Halwart, M. 2005. A Synthesis of the Formulated Animal and Aquafeed Industry in Sub-Saharan Africa. CIFA Occasional Paper No. 26. FAO, Rome. Available at http://www.fao.org/ docrep/008/a0042e/a0042e00.htm

MoFA, 2004. Ministry of Food and Agriculture: Livestock Development in Ghana, Policies and Strategies.

MOFA, 2016. Ghana livestock Development policy and strategy. Ministry of Food and Agriculture. Accra, Ghana. Available at http://mofa.gov.gh/site/wp-content/uploads/2016/11/ GHANALIVESTOCK-DEVELOPMENT-POLICY-AND-STRATEGY-final.pdf

Moritz, M. 2010. Crop-livestock interactions in agricultural and pastoral systems in West Africa. Agriculture and Human Values 27(2):119-128. DOI: 10.1007/s10460-009-9203-z

Mouillé, B., Dauphin, G., Wiersma, L., Blacksell, S.D., Claes, F., Kalpravidh, W., Kabore, Y. and Hietala, S. 2018. A Tool for Assessment of Animal Health Laboratory Safety and Biosecurity: The Safety Module of the Food and Agriculture Organization's Laboratory Mapping Tool. Trop. Med. Infect. Dis. 2018, 3, 33. Available at https://www.ncbi.nlm.nih.gov/pmc/articles/PMC6136606/ Mousseau, F., Martin-Prével, A. 2016. Miracle or mirage? Manufacturing hunger and poverty in Ethiopia. The Oakland Institute, Oakland. 26 pp. http://www.oaklandinstitute.org/miraclemiragemanufacturing-hunger-poverty-ethiopia

MRAN 2001. Document cadre pour la relance du secteur de l'élevage au Niger. État des lieux, axes d'intervention et programmes prioritaires. Ministère des Ressources animales, Niamey, Niger, $120 \mathrm{pp}$.

Muehlhoff, E.; Bennett, A.; McMahon, D. 2013. Introduction. In: Muehlhoff, E.; Bennett, A.; McMahon, D. (technical eds.): Milk and dairy products in human nutrition. FAO, Rome, pp. 1-9. Available at http://www.fao.org/docrep/018/i3396e/i3396e.pdf 
Mukasa-Mugerwa, E. 1981. The Camel (Camelus Dromedarius): A Bibliographical Review. ILCA Monograph 5. ILRI

Mwai, O., Hanotte, O., Kwon, Y.-J., Cho, S., 2015 African Indigenous Cattle: Unique Genetic Resources in a Rapidly Changing World. Asian-Australas J Anim Sci. 28, 911-921. https://doi. org/10.5713/ajas.15.0002R

Mwangi, M; Rutten, M. 2012. Mobile cash for nomadic livestock keepers: The impact of the mobile phone innovation (M-Pesa) on Maasai pastoralists in Kenya. In: Transforming Innovations in Africa. Explorative Studies on Appropriation in African Societies (Gewald, J.-B., Leliveld, A., Peša, l., eds), pp. 79-101 (Brill, Leiden, 2012). https://doi.org/10.1163/9789004245440_006 NAIC, 2019. Nigeria Agriculture Insurance Corporation. www.naic.gov.ng

Naish, D. 2015. Domestic Horses of Africa. Tetrapod Zoology. Available at https://blogs. scientificamerican.com/tetrapod-zoology/domestic-horses-of-africa/

NAPRI 2009. National Animal Production Research Institute of Nigeria. Available at http://www. napri-ng.org

Nature Editorial, 2017. Giraffes could have evolved long necks to keep cool. Nature 549, 132. http://doi.org/10.1038/549132a

Ndambi, O.A., Hemme, T., Latacz-Lohmann, U. 2007. Dairying in Africa - Status and recent developments. Livestock Research for Rural Development 19 (8), 111. Available at http://www. Irrd.org/Irrd19/8/ndam19111.htm

NEPAD, 2003. Comprehensive Africa Agriculture Development Programme (CAADP). New Partnership for Africa's Development (NEPAD) and African Union (AU). Available at https://www. nepad.org/caadp/publication/au-2003-maputo-declaration-agriculture-and-food-security NEPAD, 2014. Malabo Declaration on Accelerated Agricultural Growth. http://www.nepad.org/ caadp/publication/malabo-declaration-accelerated-agricultural-growth

Neumann, C., Harris, D.M., Rogers, L.M., 2002 Contribution of animal source foods in improving diet quality and function in children in the developing world. Nutrition Research 22 (1-2), 193-220. https://doi.org/10.1016/S0271-5317(01)00374-8

Ngere, L.0. 1985. The Gudali of Nigeria - Review. Animal Genetic Resources in Africa - High potential and endangered livestock. Proceedings of 2nd OAU Expert Committee Meeting, 24-28 November 1983, Bulawayo, Zimbabwe, pp. 77-81.

Niamir-Fuller, M. 1994. Women Livestock Managers in the Third World: a focus on technical knowledge. Appendix 3: Women's role in livestock production. IFAD, Rome. Available at http:// agris.fao.org/agris-search/search.do?recordID=GB2013202491

Niang, I., Ruppel, O.C., Abdrabo, M.A., Essel, A., Lennard, C., Padgham, J. and Urquhart, P. 2014. Africa. In: Climate Change 2014: Impacts, Adaptation, and Vulnerability. Part B: Regional Aspects. Contribution of Working Group II to the Fifth Assessment Report of the Intergovernmental Panel on Climate Change. Cambridge University Press. Available at http://ipcc-wg2.gov/AR5/images/ uploads/WGIIAR5-Chap22_FGDall.pdf

Niang, M. and Boussini, H. 2018. On site mission to support the assessment diagnostic capacities of National Veterinary Research Institute (NVRI) and to carry out other laboratory related activities. Vom, Nigeria. FAO (unpublished).

Nori, M. 2010. The golden Udder: Marketing milk from camels in Puntland, Somalia. In: LPP, LIFE Network, IUCN-WISP and FAO. Adding value to livestock diversity - Marketing to promote local breeds and improve livelihoods. FAO Animal Production and Health Paper. No. 168. Rome, pp. 99-106. Available at http://www.fao.org/docrep/012/i1283e/i1283e00.pdf

Nouakchott Declaration (2013). Mobilizing Jointly an Ambitious Effort to Ensure Pastoralism without Borders. Nouakchott Declaration on Pastoralism, October 29, 2013. http://documents. worldbank.org/curated/en/433331468007201906 
Ntiamoa-Baido, Yaa 2016 - The Bushmeat Commodity Chain in Ghana and implications for Ebola Virus Disease Risk, FAO Consultancy report Manzano, P. 2012 Food crisis in the Sahel in 2012: a Somali deja-vu? WISP Web-story. IUCN, Nairobi. Available at https://www.iucn.org/content/foodcrisis-sahel-2012-somali-d\%C3\%A9j\%C3\%A0-vu

Ntiamoa-Baidu, Y. 1997. Wildlife and food security in Africa. FAO Conservation Guide No. 33. FAO, Rome. Available at http://www.fao.org/docrep/w7540e/w7540e00.htm\#Contents

Nuwanyakpa, M., Lukefahr, S.D., Gudahl, D. and Ngoupayou, J.D. 1997. The current stage and future prospects of guinea pig production under smallholder conditions in West Africa. Livestock Research for Rural Development. Volume 9, Article \#42. Aailable at http://www.Irrd.org//rrd9/5/ gp951.htm

Nwachukwu, E.N., Amaefule, K. U., Ahamefule, F. O., Akomas, S. C., Nwabueze, T. U., Oyebinama, U. A. U. and Ekumankama, O. 0. 2013. Evaluation of pure and crossbred prgenies of Red Sokoto and West African Dwarf goats in the rainforest Zone of South Eatern Nigeria. African Journal of Agricultural Research Vol. 8(17), pp. 1688-1692. Available at: http://www.academicjournals.org/ journal/AJAR/article-full-text-pdf/DD70E6C35968

Nwandu, P.I., Ojogbane, J. A., Okoh, C., Okechukwu, F. 2016 Poultry Production Business: A Means of Alleviating Poverty among Farmers. International Journal of Innovative Agriculture \& Biology Research 4, 21-30. http://seahipaj.org/journals-ci/june-2016/IJIABR/full/IJIABR-J-3-2016. pdf

Nwanta, J.A., Shoyinka, S.V.O., Chah, K.F., Onunkwo, J.I., Onyenwe, I.W., Eze, J.I., Iheagwam, C.N., Njoga, E.O., Onyema, I., Ogbu, K.I., Mbegbu, E.C., Nnadozie, P.N., Ibe, E.C. and Oladimeji, K.T. 2011. Production characteristics, disease prevalence, and herdhealth management of pigs in Southeast Nigeria. J Swine Health Prod. 19(6):331-339. Available at https://www.aasv.org/ jshap/issues/v19n6/v19n6p331.pdf

NWE, 2013 - New World Encyclopedia. Available at http://www.newworldencyclopedia.org Oba, G. 2012. Harnessing pastoralists' indigenous knowledge for rangeland management: three African case studies. Pastoralism: Research, Policy and Practice 2, 1. http://doi. org/10.1186/2041-7136-2-1

OECD Data Lab, 2013-2014. Available at https://data.oecd.org/oda/oda-by-sector.htm OECD, 2009. Guiding Principles for the Development of the Livestock Sector in West Africa. Available at www.oecd.org/swac/publications/43806010.pdf

OECD/FAO, 2016. OECD-FAO Agricultural Outlook 2016-2025. Special focus: Sub-Saharan Africa. OECD Publishing, Paris, France. Available at http://www.fao.org/3/a-i5778e.pdf

Ogundip, R.I. and Adeoye, A.A. 2013. Evaluation of the dairy potential of Friesian, Wadara and their crossbreds in Bauchi State Scholarly Journal of Agricultural Science Vol. 3(6), pp. 223-225. Available at http://www.scholarly-journals.com/sjas/archive/2013/jun/pdf/Ogundipe\%20and\%20 Adeoye.pdf

Ogundipe, G.A.T. 2002. The roles of veterinary quarantine services in monitoring the movements of animals and disease prevention in Nigeria. Nigerian Veterinary Journal. Vol 23, No 1 (2002).

Available at http://www.ajol.info/index.php/nvj/issue/view/383

OIE, 2013. OIE Tool for the Evaluation of Performance of Veterinary Services. 6th ed. OIE, Paris. Available at http://www.oie.int/fileadmin/Home/eng/Support_to_OIE_Members/pdf/A_PVS_Tool_ Final_Edition_2013.pdf

OIE, 2015. Antimicrobial resistance. OIE Fact sheets. Available at : https://www.oie.int/fileadmin/ Home/eng/Media_Center/docs/pdf/Fact_sheets/ANTIBIO_EN.pdf

OIE, 2017. PVS Gap analysis reports. http://www.oie.int/support-to-oie-members/pvsgapanalysis/pvs-gap-analysis-reports/ Retrieved 24th December 2019.

OIE, 2019. PVS Pathway State of Play and Mission Reports. World Animal Health Organization (OIE). Available at https://www.oie.int/solidarity/pvs-pathway-state-of-play-and-mission-reports 
OIE/WAHIS, 2019. World Animal Health Information Database. World Organisation for Animal Health. Available at https://www.oie.int/wahis_2/public/wahid.php/Wahidhome/Home

Oirere, S. 2018. Bright prospects for Nigeria's animal feed market. International Milling and Grain Directory. Available at https://www.internationalmilling.com/bright-prospects-for-nigeriasanimalfeed-market/

Okai, E.K. 2019. Africa's pig farmers confront the challenge of costly feed. The Pig Site. Available at https://thepigsite.com/articles/africas-pig-farmers-confront-the-challenge-of-costly-feed Okantah, S., Oddoye, E., Obese, F., Gyawu, P. and Asante, Y. 1998. Characterization of peri-urban dairy production in Ghana. Ghana J. Agric. Sci., 31:197-202

Ollenburger, M. H., Descheemaeker, K., Crane, T. A., Sanogo, O.M., Giller, K.E. 2016. Waking the Sleeping Giant: Agricultural intensification, extensification or stagnation in Mali's Guinea Savannah. Agricultural Systems 148, 58-70. https://doi.org/10.1016/j.agsy.2016.07.003

Olorunnisomo, 0.A. 2013 Milk production in Sokoto Gudali cows fed legume or elephant grass ensiled with cassava peel. Livestock Research for Rural Development 25, 105. Available at http:// Irrd.cipav.org.co/Irrd25/6/olor25105.htm

Olumide, O.T. 2004. Cassava for livestock feed in sub-Saharan Africa. FAO and IFAD. Available at http://www.fao.org/tempref/docrep/fao/007/j1255e/j1255e00.pdf

Olwoch, J.M., Reyers, B., van Jaarsveld, A.S. (2008). Host-parasite distribution patterns under simulated climate: implications for tick-borne diseases. International Journal of Climatology 29, 993-1000. https://doi.org/10.1002/joc.1801

Opara, M.N. 2010. The Grasscutter. In: A livestock of tomorrow. Research Journal of Forestry, 4: 119-135.

Oppong-Anane, K. 2001. Country Pasture/Forage Resource Profiles: Ghana. FAO Rome. Available at http://www.fao.org/ag/agp/agpc/doc/counprof/regions/africa.htm

Oppong-Anane, K. 2016. Review of the livestock/meat and milk value chains and policy influencing them in Ghana. FAO-ECOWAS, Rome and Abuja. http://www.fao.org/3/ai5264e.pdf Ordaz-Németh, I., Arandjelovic, M., Boesch, L., Gatiso, T., Grimes, T., Kuehl, H.S., Lormie, M., Stephens, C., Tweh, C. and Junker, J., 2017 The socio-economic drivers of bushmeat consumption during the West African Ebola crisis. PLOS Neglected Tropical Diseases 11(3): e0005450. https://doi.org/10.1371/journal.pntd.0005450

Otte, M.J. and Chilonda, P. 2002. Cattle and small ruminant production systems in sub-Saharan Africa. A systematic review. Food and Agriculture Organization of the United Nations (FAO). Rome, Italy. Available at http://www.fao.org/3/a-y4176e.pdf

Ouagal, M., Hendrikx, P., Berkvens, D., Ncharé, A., Akpeli, P.Y., Sory, K. and Saegerman, C. 2008. Les réseaux d'épidémiosurveillance des maladies animales en Afrique francophone de l'Ouest et du Centre. Rev. sci. tech. Off. int. Epiz., 27 (3), 689-702. Available at http://boutique.oie.int/extrait/ ouagal.pdf

Ouedraogo I., Jürgen Runge J., Eisenberg J, Barron J., Sawadogo/Kaboré, S. 2014. The ReGreening of the Sahel: Natural Cyclicity or Human-Induced Change? Land 3, 1075-1090. https:// doi.org/10.3390/land303107

Over, H.J., Jansen, J. and van Olm, P.W. 1992. Distribution and impact of helminth diseases of livestock in developing countries. FAO Animal Production and Health Paper No. 96. Food and Agriculture Organization of the United Nations. Rome, Italy. Available at http://www.fao.org/3/ T0584E/T0584E00.htm\#TOC

PAN, 2019. Poultry Association of Nigeria. www.poultryassociationng.com

Parés-Casanova, P. M.; Caballero, M. 2013. Possible tendency of polled cattle towards larger ears. Revista Colombiana de Ciencias Pecuarias 27, 221-225. http://www.scielo.org.co/pdf/rccp/ v27n3/v27n3a8.pdf

Payne, W.J.A. 1970. Cattle Production in the Tropics. Volume 1. Longman Group Limited. London, UK. 336pp. 
Pearce, C. 2009. From closed books to open doors-West Africa's literacy challenge. African Network Campaign for Education for All (ANCEFA), Pamoja West Africa, the African Platform for Adult Education, Oxfam International, and ActionAid, Oxford, $24 \mathrm{pp}$. Available at https://pdfs. semanticscholar.org/eec7/9671051a291aa786a1137f40fa7007e2c993.pdf

Penrith, M.L. 2013. The African swine fever pandemic in West Africa - a modern tragedy. Available at http://www.sapork.biz/the-african-swine-fever-pandemic-in-west-africa-\%E2\%80\%93a-moderntragedy/

Perry, B.D., McDermott, J.J. and Randolph, T.F. 2004. Control of infectious diseases: making appropriate decisions in different epidemiological and socio-economic conditions. In: Coetzer, J.A.W. and Tustin, R.C. (eds.). Infectious diseases of livestock, Vol. 1, pp. 178-224. Oxford University Press. Cape Town, South Africa.

Peter Castro, A., Engel, A. 2007. Negotiation and mediation techniques for natural resource management. Case studies and lessons learned. FAO, Rome. http://www.fao.org/3/a-a1081e/ Peters, K.J. 1985. Unconventional livestock: classification and potential uses. In: International Livestock Centre for Africa Bulletin No. 27. Addis Ababa, Ethiopia. Available at https://www.ilri. org/InfoServ/Webpub/fulldocs/Bulletin27/Contents.htm\#TopOfPage

Pica-Ciamarra, U., Baker, D., Morgan, N., Ly, C. and Nouala, S. 2014a. Business and livelihoods in the livestock sector in Africa: Investments to overcome informationgaps. Washington, D.C., USA: World Bank. Available at http://hdl.handle.net/10568/35161

Pica-Ciamarra, U., Baker, D., Morgan, N., Zezza, A., Azzarri, C., Ly, C., Nsiima, L., Nouala, S., Okello, P. and Sserugga, J. 2014b. Investing in the livestock sector: Why good numbers matter: A sourcebook for decision makers on how to improve livestock data. Rome, Italy: FAO. http://hdl. handle.net/10568/35162

Pica-Ciamarra, U., Otte, J., Chilonda, P. 2007. Livestock Policies, Land and Rural Conflicts in SubSaharan Africa. PPLPI Research Report 07-04. FAO, Rome. Available at http://www.fao.org/3/ abp290e.pdf

Porphyre, V. 2009. Enjeux et contraintes des filières porcines en Afrique de l'Ouest. Revue Grain de Sel n 46-47 : Répondre aux évolutions alimentaires, un défi majeur pour l'élevage africain. Available at http://www.inter-reseaux.org/IMG/pdf_p26_27_Porc.pdf

Portar, V. 1991. A handbook to the breeds of the world: Cattle. Christopher Helm Publishers. London, UK. $400 \mathrm{pp}$.

PPD Consultants, 2013. Dairy Sector Policy Study and Capacity Needs Assessment of Stakeholder Associations. SNV Kenya /Netherlands Development Organization, Nairobi. 79 pp. http://www.snv.org/public/cms/sites/default/files/explore/download/kmdp_-_dairy_policy_ study_report_2013.pdf

Premium Times, 2017. Nigerian govt to demarcate 6,000km cattle routes in 2017 - Official. Premium Times, Abuja, April 7th 2017. Agency report. Available at https://www.premiumtimesng. com/news/headlines/228177-nigerian-govt-demarcate-6000km-cattle-routes-2017-official.html Rahman, M.H., 2014. Grasscutter rearing in Accra, Ghana: a novel way to ensure food security in the inner city. Available at http://www.cityfarmer.info/2014/05/20/grasscutter-rearing-inaccraghana-a-novel-way-to-ensure-food-security-in-the-inner-city/

Ramanathan, V., Carmichael, G. 2008. Global and regional climate changes due to black carbon. Nature Geoscience 1, 221 - 227. https://doi.org/10.1038/ngeo156

Randolph, T.F., Schelling, E., Grace, D., Nicholson, C.F., Leroy, J.L.., Cole, D.C., Demment, M.W., Omore, A., Zinsstag, J., Ruel, M., 2007. Role of livestock in human nutrition and health for poverty reduction in developing countries. Journal of Animal Science 85, 2788-2800. https://doi. org/10.2527/jas.2007-0467

RBM, 2012. Filières d'approvisionnement en aliments de bétail en Afrique de l'Ouest: stratégie de mise en place de la réserve régionale - VERSION PROVISOIRE. Réseau des Organisations d'Eleveurs et Pasteurs de l'Afrique. Niamey, Niger. Available at www.inter-reseaux.org/IMG/pdf/ 
Rapport_synthese_filiere_approvisonnement_aliments_betail_07_11_2012-2.pdf

Rege, E.0. 2003. Defining Livestock Breeds in the Context of Community-Based Management of Farm Animal Genetic Resources. In: Community-Based Management of Animal Genetic Resources. Proceedings of the workshop held in Mbabane, Swaziland, 7-11 May 2001. Food and Agriculture Organization of the United Nations. Rome, Italy. Available at http://www.fao.org/3/ y3970e/y3970e02b.htm\#bm02.3

Rege, J.E.O. and Tawah, C.L.1999. The state of African cattle genetic resources II. Geographical distributions, characteristics and uses of present-day breeds and strains. FAO/UNEP Animal Genetic Resources Information Bulletin. 26:1-

Renaudeau, D. D., Collin, A., Yahav, S., de Basilio, V., Gourdine, J. L., Collier, R. J. 2015. Adaptation to hot climate and strategies to alleviate heat stress in livestock production. Animal 6, 707-728. https://doi.org/10.1017/S1751731111002448

Reynolds, J.F., Smith, D.M.S., Lambin, E.F., Turner, B.L., Mortimore, M., Batterbury, S.P.J., Downing, T.E., Dowlatabadi, H., Fernández, R.J., Herrick, J.E., Huber-Sannwald, E., Jiang, H., Leemans, R., Lynam, T., Maestre, F.T., Ayarza, M. and Walker, B. 2007. Global Desertification: Building a Science for Dryland Development. Science, 316 (5826): 847-851. Available at https:// science.sciencemag.org/content/316/5826/847.full

Rhissa, Z. 2010. Revue du secteur de l'élevage au Niger. Rapport Provisoire. FAO/SFW. Available at http://www.reca-niger.org/IMG/pdf/Niger_Revue_national.pdf

Rhodes, D. 2014. Understanding dairy imports in Nigeria. CNBC Africa, 19 May 2014.

Riddell, J.C. 1982. Land tenure issues in West African livestock and range development projects. LTC Research Paper 77. Land Tenure Center - University of Wisconsin Madison.

Roba, G., Gibbons, S., Mahadi, Y. 2013. Booklet 1: Strengthening natural resource governance in Garba Tula. IUCN ESARO, Nairobi. Available at https://www.iucn.org/sites/dev/files/import/ downloads/handbook_1_web.pdf

Roba, G.M., Lelea, M.A., Hensel, O., Kaufmann, B. 2018. Making decisions without reliable information: The struggle of local traders in the pastoral meat supply chain. Food Policy 76, 3343. https://doi.org/10.1016/j.foodpol.2018.01.013

Roba, G.M., Lelea, M.A., Hensel, O., Kaufmann, B. 2019. Elusive profits: understanding economic performance of local traders in the pastoral small ruminant value chain in Northern Kenya. Nomadic Peoples 23, 78-105. https://doi.org/10.3197/np.2019.230105

Roba, G.M., Lelea, M.A., Kaufmann, B. 2017. Manoeuvring through difficult terrain: How local traders link pastoralists to markets. Journal of Rural Studies 54, 85-97. https://doi.org/10.1016/j. jrurstud.2017.05.016

Robinson, T. and Conchedda, G. 2014. Livestock Production Systems. Technical paper prepared for The Economics of Resilience of Livestock in the African Drylands. In: Confronting Drought in Africa's Drylands. World Bank and Agence Française de Développement, February 2016, Washington DC, USA.

Robinson, T.P., Thornton, P.K., Franceschini, G., Kruska, R.L., Chiozza, F., Notenbaert, A., Cecchi, G., Herrero, M., Epprecht, M., Fritz, S., You, L., Conchedda, G. and See, L. 2011. Global livestock production systems. FAO and ILRI, 152 pp. Rome, Italy. Available at http://www.fao.org/ docrep/014/i2414e/i2414e.pdf

Rodríguez, L. 2008. A global perspective on the total economic value of pastoralism: Global synthesis report based on six country valuations. IUCN-WISP, Nairobi. https://www.iucn.org/sites/ dev/files/import/downloads/tev_report.pdf

Roessler, R., Mpouam, S.E., Muchemwa ,T. and Schlecht, E. 2016. Emerging Development Pathways of Urban Livestock Production in Rapidly Growing West Africa Cities. Sustainability, 8 , 1199, DOI:10.3390/su8111199

Romero Tejeda, A. 2016. Mission d'appui sur site pour l'évaluation de la mise en œuvre du 
système d'assurance qualité et des pratiques de biosécurité en place au sein du Laboratoire Régional Vétérinaire de Bouaké, Côte d'Ivoire. FAO (unpublished).

Rouamba. J.P. 2016. Revue des filières bétail/viande \& lait et des politiques qui les influencent au Burkina Faso. Organisation des Nations Unies pour l'Alimentation et l'Agriculture (FAO). Available at http://www.fao.org/3/a-i5261f.pdf

Said, M.Y., Ogutu, J.O., Kifugo, S.C., Makui, O., Reid, R.S., de Leeuw, J. 2016. Effects of extreme land fragmentation on wildlife and livestock population abundance and distribution. Journal for Nature Conservation 34, 151-164 https://doi.org/10.1016/j.jnc.2016.10.005

Saka, N. 1996. Agricultural development in the age of sustainability: Livestock production. In: Benneh, G., Morgan, W.B. and Uitto, J.I. (Eds) 1996. Sustaining the Future: Economic, Social, and Environmental Change in Sub-Saharan Africa. The United Nations University. Princeton Academic Press, New York, USA. Available at http://archive.unu.edu/unupress/ unupbooks/80918e/80918E00.htm\#Contents

Salam Richard, K. 2008. Revue du secteur avicole. Burkina Faso. Division de la production et la santé animales, FAO, Rome. Available at http://www.fao.org/3/a-ai376f.pdf

Saley, M. and Steinmetz, P. 1998. Approche quantitative de la production laitière destinée à la consommation humaine, répercussion sur la croissance du chamelon, p. 87-94; In: Dromadaires et chameaux, animaux laitiers: actes du colloque, 24-26 octobre, Nouakchott, Mauritanie. CIRAD. $301 \mathrm{pp}$.

Salla, A. 2016. Review of the livestock/meat and milk value chains and policy influencing them in West Africa. Food and Agriculture Organization of the United Nations. Available at http://www. fao.org/3/a-i5265f.pdf

Samman, S., Kung, F. P., Carter, L. M., Foster, M. J., Ahmad, Z. I., Phuyal, J. L., Petocz, P. 2009. Fatty acid composition of certified organic, conventional and omega-3 eggs. Food Chemistry 116, 911-914. https://doi.org/10.1016/j.foodchem.2009.03.046

Sangaré, M. 2005. Monographie sur l'aviculture traditionnelle en Afrique de l'Ouest. CIRDES, Bobo- Dioulasso, Burkina Faso.

Sankhare, B. 2011. L'etude sur la transhumance transfrontaliere en Afrique de l'Ouest. Organisation des Nations Unies pour l'alimentation et l'agriculture (FAO) (unpublished). Sansoucy, R., Jabbar, M.A., Ehui, S., Fitzhugh, H. 1995. The Contribution of livestock to food security and sustainable development. In: Wilson, R.T., Ehui, S., Mack, S. (Eds), Livestock Development Strategies for Low Income Countries. Food and Agriculture Organization/ International Livestock Research Institute

Santoir, C. 1997. Une ressource «durable»: l'élevage chez les villageois du Fouta (vallée du fleuve Sénégal). Autrepart (3), 105-128. Available at https://core.ac.uk/download/pdf/39851448.pdf Savadogo, M. 2000. Crop residues management in relation to sustainable landuse. A case study in Burkina Faso. Tropical Resources Management Papers 31. Wageningen University, $159 \mathrm{p}$.

Savadogo, P., Zida, D., Sawadogo, L., Tiveau, D., Tigabu, M. and Oden, P.C. 2007. Fuel and fire characteristics in savanna-woodland of West Africa in relation to grazing and dominant grass type. International Journal of Wildland Fire, 16 (5).

Scherf, B.D. and Pilling, D. (eds.) 2015. The Second Report on the State of the World's Animal Genetic Resources for Food and Agriculture. FAO Commission on Genetic Resources for Food and Agriculture Assessments. Rome, Italy. Available at http://www.fao.org/3/a-i4787e/index.html Schlee, G. 2010. A Comment on the 'Policy Framework for Pastoralism in Africa' Adopted by the African Union in January 2011. Nomadic Peoples 14, 158-163. https://doi.org/10.3167/ np.2010.140211

Schneider, K., Gugerty, M.K., Plotnick, R. and Anderson, C.L. 2010. Poultry Market in West Africa: Overview \& Comparative Analysis. Evans School Policy Analysis and Research (EPAR) of the Bill \& Melinda Gates Foundation. University of Washington. EPAR Brief No. 82. Available at 
https://evans.uw.edu/sites/default/files/Evans\%20UW_Request\%2082_Poultry\%20Market\%20 Analysis\%200verview_7-16-2010_0.pdf

Scholtz, M.M., van Ryssen, J.B.J., Meissner, H.H., Laker, M.C. 2013. A South African perspective on livestock production in relation to greenhouse gases and water usage. South African Journal of Animal Science 43 (3), 247-245. https://doi.org/10.4314/sajas.v43i3.2

Schwennesen, E. 2005. Overgrazing: The Crux of the Pastoralist Controversy. Winkelman: Resource Management International. Available at http://managingwholes.com/downloads/ overgrazing.pdf

Sebastian, K. (Ed.) 2014. Atlas of African agriculture research and development: Revealing agriculture's place in Africa. Washington, D.C.: International Food Policy Research Institute (IFPRI). Available at: http://www.ifpri.org/publication/atlas-african-agriculture-researchdevelopment

Seck, M., Marshall, K. and Fadiga, M.L. 2016. Policy framework for dairy development in Senegal. Nairobi, Kenya: International Livestock Research Institute (ILRI). Available at https://cgspace. cgiar.org/bitstream/handle/10568/78106/PR_senegal_dairy.pdf?sequence=5

Seo, S.N., Mendelsohn, R. 2007. Climate change adaptation in Africa: A microeconomic analysis of livestock choice. World Bank Policy Research Working Paper 4277. Available at http://library1. nida.ac.th/worldbankf/fulltext/wps04277.pdf

Serres, H. 1989. Précis d'élevage du porc en zone tropicale. Paris : Ministère de la Coopération et du Développement, 331p.

Sesay, A.R. 2016. Review of the livestock/meat and milk value chains and policy influencing them in Sierra Leone. FAO-ECOWAS, Rome and Abuja. http://www.fao.org/3/a-i5273e.pdf

Shafie, M.M. 1992. Morphological and anatomical characteristics of subtropical sheep and goats as means of adaptation to hot climate. In: Proceedings of the 43rd Annual Meeting of European Association on Animal Production, Madrid, Spain, 14-19 September.

Shimeles, A., Verdier-Chouchane, A. and Boly, A. (Eds.), 2018. Building a resilient and sustainable agriculture in Sub-Saharan Africa. Palgrave Macmillan, Cham, Switzerland. Available at http://dx.doi.org/10.1007/978-3-319-76222-7

Shively, G.E. 2017. Infrastructure mitigates the sensitivity of child growth to local agriculture and rainfall in Nepal and Uganda. PNAS 114, 903-908. https://doi.org/10.1073/pnas.1524482114

Sinclair, A.R.E., Byrom, A.E. 2006. Understanding ecosystem dynamics for conservation of biota. Journal of Animal Ecology 75, 64-79. https://doi.org/10.1111/j.1365-2656.2006.01036.x

Smith, J.W., Sones, K., Grace, D., MacMillan, S., Tarawali, S., Herrero, M. 2013. Be-yond milk, meat, and eggs: Role of livestock in food and nutrition security. Animal Frontiers 3, 6-13. https:// doi.org/10.2527/af.2013-0002

Snorek, J. 2016. Contested views of the causes of rural to urban migration amongst pastoralists in Niger. In: B. Gebrewold and T. Bloom (eds.) Understanding Migrant Decisions: From SubSaharan Africa to the Mediterranean Region. Routledge. New York. Available at https://www. researchgate.net/publication/289980057

Snorek, J., Renaud, F.G. and Kloos, J. 2014. Divergent adaptation to climate variability: A case study of pastoral and agricultural societies in Niger. Global Environmental Change 29, 371-386. https://doi.org/10.1016/j.gloenvcha.2014.06.014

Sodjinou, E., Henningsen, A., Koudande, D.O., Biaou, G., Mensah, G.A. 2014 Consumers' Preferences for "Bicycle Poultry" in Benin: Implications for the Design of Breeding Schemes. IFRO Working Paper 2014/05. Available at http://okonomi.foi.dk/workingpapers/WPpdf/WP2014/ IFRO_WP_2014_05.pdf

Some, D. 2012. Burkina Faso: profil pays du secteur de l'élevage. Organisation des Nations Unies pour l'alimentation et l'agriculture (FAO). ISBN 978-92-5-207499-1

Sonaiya, E.B. and Swan, S.E.J. 2004. Small-scale poultry production: technical guide In FAO animal production and health manual \#1. Food and Agriculture Organization of the United 
Nations. Rome, Italy. Available at http://www.fao.org/docrep/008/y5169e/y5169e00.htm

Souare, M.L. 2008. Revue du secteur avicole. Guinée. Division de la production et la santé animales, FAO, Rome. Available at http://www.fao.org/3/a-ak068f.pdf

Sparks, N. H. C. 2006. The hen's egg - Is its role in human nutrition changing? World's Poultry Science Journal 62, 308-315. https://doi.org/10.1079/WPS200599

Staatz, J. and F. Hollinger, 2016, West African Food Systems and Changing Consumer Demands, West African Papers, No. 04, OECD Publishing, Paris. https://doi.org/10.1787/b165522b-en \& http://www.fao.org/3/a-i6716e.pdf

Stabler, S.P., Allen, R.H. 2004. Vitamin B12 deficiency as a worldwide problem. Annual Review of Nutrition 24, 299-326. https://doi.org/10.1146/annurev.nutr.24.012003.132440

Starkey, P. 2000. The history of working animals in Africa. In: The origins and development of African livestock: archaeology, genetics, linguistics and ethnography (Eds. McDonald KC \& Blench RM), pp. 478. Available at http://www.animaltraction.com/StarkeyPapers/StarkeyHistoryAnimalTractioninAfrica-97-draft.pdf

Starkey, P.H. 1984. N'Dama cattle - a productive trypanotolerant breed. FAO, World Animal Review. 50: 2-15.

Steglich, M. and Peters, K. 2003 - Participatory Methods to Assess Traditional Breeding Systems: The Case of Cattle Breeding in The Gambia

Studio Timani, 2017, Commerce illégal : exportation de peaux d'ânes du Mali vers la Chine, available at https://www.studiotamani.org/index.php/themes/societe/10959-le-mali-interditlexportation-de-la-peau-d-anes-vers---asie

Suttie, J.M., Reynolds, S.G. and Batello, C. 2005. Grasslands of the world. Plant Production and Protection Series No. 34. Food and Agriculture Organization of The United Nations. Rome, Italy. Available at http://www.fao.org/3/y8344e00.htm\#Contents

SWAC, ECOWAS, UEMOA, CILSS and ROPPA, 2008a. Note aux décideurs $n^{\circ} 2$ : Mettre en oeuvre des politiques commerciales renforçant le marché régional de produits animaux. https://www. oecd.org/fr/csao/publications/38403269.pdf

SWAC, ECOWAS, UEMOA, CILSS and ROPPA, 2008b. Note aux décideurs $\mathrm{n}^{\circ} 6$ : Transformation agroalimentaire des produits animaux : Un impératif pour le renforcement du commerce intra et extra régional. Available at https://www.oecd.org/fr/csao/publications/38768832.pdf

SWAC-OECD and AFD, 2013. A sustainable contribution to development-security of the SaharaSahelian areas. Regional symposium on pastoral livestock, N'Djaména (Chad), 27-29 May 2013. Available at https://www.oecd.org/swac/events/livestock-symposium.htm

SWAC/OECD, 2007. Rural areas and agricultural changes. In: Atlas on Regional Integration in West Africa - Land series. Sahel and West Africa Club and Organisation for Economic Cooperation and Development. Available at https://www.oecd.org/swac/publications/38903590.pdf SWAC/OECD, ECOWAS, UEMOA, CILSS and ROPPA, 2008). Livestock in the Sahel and West Africa. Promoting and Supporting Change in Transhumant Pastoralism in the Sahel and West Africa. Policy Note Number 3. https://www.oecd.org/swac/publications/38402714.pdf SWAC/OECD, 2017. Livestock in coastal countries. West Africa Brief, Sahel and West Africa Club. Available at http://www.west-africa-brief.org/content/en/livestock-coastal-countries

Talaki, E. 2012. Togo: profil pays du secteur de l'elevage. Organisation des Nations Unies pour l'alimentation et l'agriculture (FAO) (unpublished).

Talaki, E. 2017. Revue des filières betail/viande \& lait et des politiques qui les influencent au Togo. FAOECOWAS, Rome and Abuja. http://www.fao.org/3/a-i5274f.pdf

Tarawali, G. and Hiernaux, P. (eds.) 2002. Improving crop-livestock systems in the dry savannas of West and Central Africa. Reports from the Workshop on crop-livestock systems in the dry savannas of West and Central Africa, 22-27 November 1998. International Institute of Tropical Agriculture (IITA). Ibadan, Nigeria. Available at http://hubrural.org/IMG/pdf/iita_crop_livestock.pdf Tawah, C.L. and Rege, J.E.O. 1996. Gudali Cattle of West and Central Africa. FAO Animal Genetic 
Resources Information Bulletin. 17:159-170.

Tebug S.F., Baltenweck I., Poole E.J., Missohou A., Ema P.J.N., Juga J., Tapio M., Marshall K.

2014. Uptake of artificial insemination and non-indigenous cattle in small to medium scale farms in Senegal. IN: Tropentag 2014 Conference on Bridging the Gap between Increasing Knowledge and Decreasing Resources, Prague, 17-19 September 2014. http://www.tropentag.de/2014/ abstracts/links/Tebug_AkRdssj7.pdf

Teillard F., Anton A., Dumont B., Finn J.A., Henry B., Souza D.M., Manzano P., Milà i Canals L., Phelps C., Said M., Vijn S., White S. 2016. A review of indicators and methods to assess biodiversity - Application to livestock production at global scale. Livestock Environmental Assessment and Performance (LEAP) Partnership. FAO, Rome. Available at http://www.fao. org/3/a-av151e.pdf

Teye, G.A. and Adam. M, 2000. Constraints to Guinea fowl production in northern Ghana: A case study of the Damongo area, Ghana Journal of Agricultural Science, 33, 153 - 157

The Donkey Sanctuary 2019. Under the skin - update. The Donkey Sanctuary, Sidmouth, 31 pp. https://www.thedonkeysanctuary.org.uk/sites/uk/files/2019-11/under-the-skinreportrevised-2019.pdf

Thomas, D. and Sumberg, J.E. 1995. A review of the evaluation and use of tropical forage legumes in sub-Saharan Africa. Agriculture, Ecosystems \& Environment. Vol 54(3): 151-163.

Thys, E., Oueadraogo, M., Speybroeck, N. and Geerts, S. 2005. Socio-economic determinants of urban household livestock keeping in semi-arid Western Africa. J. Arid Environ., 63:475-496. https://doi.org/10.1016/j.jaridenv.2005.03.019

Tiémoko, Y., 1992 The use of cassava broiler diets in Côte d'Ivoire: Effects on growth performance and feed costs. In: Hahn, S.K.; Reynolds, L.; Egbunike, G.N. (eds.). Proceedings of the IITA/ILCA/University of Ibadan Workshop on the Potential Utilization of Cassava as Livestock Feed in Africa, 14-18 November 1988, Ibadan, Nigeria. IITA and ILRI. Available at https://hdl. handle.net/10568/16475

Tindano, K., Moula, N., Traoré, A., Leroy, P., Antoine-Moussiaux, N. 2015. Characteristics and typology of sheep herding systems in the suburban area of Ouagadougou (Burkina Faso). Arch. Tierz., 58: 415-423. Available at https://www.arch-anim-breed.net/58/415/2015/

Tisdell, C.A., Harrison, S.R. and Ramsay, G.C. 1999. The economic impacts of endemic diseases and disease control programmes. Rev. Sci. Tech. Off. Int. Epiz.18(2):380- 398. Available at https:// pdfs.semanticscholar.org/5552/0f2db3c6e3a8f52025264992009624407c11.pdf

Titiola, O.L., Olaniyi, O.Z. and Adebusola, A.A. 2015. Mini-Livestock Farming as a Strategy for Food Security in Oyo State of Nigeria. Journal of Agriculture and Sustainability 7: 171-186.

TLC, 2002. Market Requirements for importers of African Hides and Skins. In: The Hides, Skins and Leather Sector in Africa: Essential Actions to Meet Quality Requirements of Importers.

Revised draft report for UNIDO - submission to a Workshop in Tunis in October 2002. Triple Line Consulting Ltd, London, U.K.

Toro-Mujica P., Aguilar C., Vera R., Cornejo K. 2016. A simulation-based approach for evaluating the effects of farm type, management, and rainfall on the water footprint of sheep grazing systems in a semi-arid environment. Agricultural Systems 148, 75-85. https://doi.org/10.1016/j. agsy.2016.07.011

Toulmin, C., Guèye, B. 2003, Qui sont les gagnants et les perdants ? Impacts globaux sur la pauvreté et les moyens d'existence. Chapter 7. In : Transformations de l'agriculture ouestafricaine et rôle des exploitations familiales. Dossier 123. IIED, Londres, pp. 55-62. Available at http://pubs.iied.org/pdfs/9316FIIED.pdf

Touray, 0. 2017. Review of the livestock/meat and milk value chains and policy influencing them in Liberia. FAO-ECOWAS, Rome and Abuja. Available at http://www.fao.org/3/a-i5270e.pdf

Touray O., Ceesay M., Njai 0. 2010. Review of the livestock sector with respect to smallholder dairy and livestock and meat sub sectors development in West Africa. The Gambia country report, 
Draft report, FAO.

Touray, 0. 2012. Livestock sector review: The Gambia. FAO (unpublished).

Touray, 0. 2016. Review of the livestock/meat and milk value chains and policy influencing them in the Gambia. FAO-ECOWAS, Rome and Abuja. Available at http://www.fao.org/3/a-i5262e.pdf Touré S. 2016 Niger : une société saoudienne en passe d'acquérir 120000 hectares de terres agricoles. Agence Ecofin, 23 aout 2016. http://www.agenceecofin.com/gestion-publique/220840258-niger-une-societe-saoudienne-en-passe-d-acquerir-120-000-hectares-de-terres-agricoles Toutain, B., Marty, A., Bourgeot, A., Ickowicz, A. and Lhoste, P. 2012. Pastoralism in dryland areas. $A$ case study in sub-Saharan Africa. Les dossiers thématiques du CSFD. $N^{\circ} 9$. January 2013. CSFD/Agropolis International, Montpellier, France. 60 p. Available at http://www. csf-desertification.eu/combating-desertification?task=callelement\&format=raw\&item _ id=9\&element=1f8f50af-546b-4e2a-9042-acae011901eb\&method=download

Trace, 2016, Bulletin d'information et d'analyses sur le braconnage et la contrebande d'animaux, n¹4 / 1er juillet - 30 septembre 2016, Publié le 16 novembre 2016

Traoré, A. 2006 Mali. Revue du secteur avicole. Division de la production et la santé animales, FAO. Available at ftp://ftp.fao.org/docrep/fao/011/ai353f/ai353f00.pdf

Traoré, A. 2013. Secteur Avicole Mali. Revues nationales de l'élevage de la division de la production et de la santé animales de la FAO. No. 4. Rome, Italy. Available at http://www.fao. org/3/i3321f/i3321f.pdf

Traoré, E.H. 2014. Secteur Avicole Sénégal. Revues nationales de l'élevage de la division de la production et de la santé animales de la FAO. No. 7. Rome, Italy. Available at http://www.fao. org/3/i3659f/i3659f.pdf

Traoré, H. 1981. Etude des potentialités zootechniques du Kokochiè et du Dakissé-Chiè dans le secteur de Kati. Mémoire de fin d'étude. IPR de Katibougou.

Trémolières, M. 2010. Security and environmental variables: The debate and an analysis of links in the Sahel. OECD Sahel and West Africa Club Secretariat. Available at https://www.oecd.org/ swac/publications/47092980.pdf

TWF, 2014. The World Factbook. Available at https://www.cia.gov/library/publications/theorldfactbook/rankorder/2147rank.html

Twose, N. 1984. The Sahel: Behind the weather. Why the poor suffer most: Drought in the Sahel. Oxfam Public Affairs Unit. Oxford, UK.

UICN-Burkina Faso, 2015. Evaluation des institutions locales de gouvernance des ressources pastorales dans la région de l'Est. UICN, Ouagadougou. https://www.iucn.org/sites/dev/files/ content/documents/4_eval_inst_local_gouv_est_bon_clement_suite_cadreinstitutionnel_a5.pdf Ukahoa, K., Ukpe, A. 2013. The ECOWAS Trade Liberalisation Scheme: Genesis, Conditions and Appraisal. ECOWAS Vanguard 2: 3. http://www.inter-reseaux.org/IMG/pdf/The_ECOWAS_Trade_ Liberalization_Scheme5_Genesis_Conditions_and_Appraisal_ECO_VANGUARD_Jan_2013_ English_Edition_.pdf

UN, 2014. Map No. 4533. United Nations Department of Field Support Cartographic Section. Map Adapted from UN 2014. - Available at http://www.un.org/Depts/Cartographic/map/profile/ westafrica.pdf

UNDESA, 2018. Rural Population at Mid-Year by Region, Sub-region, Country and Area, 1950-2050 UNDESA, 2019. United Nations Department of Economic and Social Affairs, Population Division. World Population Prospects 2019, Online Edition. Available at https://population.un.org/wpp/ Download/Standard/Population/

UNDP, 2019, Human Development Report 2019, beyond income, beyond averages, beyond today: Inequalities in human development in the 21 st century. http://hdr.undp.org/sites/default/files/ hdr2019.pdf

UNEP, 2006. Africa Environment Outlook 2. Division of Early Warning and Assessment (DEWA), United Nations Environment Programme. Nairobi, Kenya. Available at http://www.unep.org/dewa/ 
Africa/publications/AEO-2/content/index.htm

UNESCO, 2009. EFA Global Monitoring Report 2009: Overcoming Inequality: Why Governance Matters. UNESCO and Oxford University Press, Paris and Oxford, 463 pp. Available at http:// unesdoc.unesco.org/images/0017/001776/177683e.pdf

UNESCO, 2015. UNESCO Institute of Statistics. Available at http://data.uis.unesco.org/ UNFPA 2010. State of World Population 2010. External Relations Division of United Nations Population Fund. 116 p. Available at: http://www.unfpa.org/publications/state-world-population2010\#sthash.QZjdMy7Y.dpuf

UNHCR, 2017. Global Trends. Forced displacement in 2016. UNHCR, Geneva. http://www.unhcr. org/5943e8a34.pdf

USAID, 2010. Livestock Target Interventions in Market Logistics Infrastructure and PPPs. USAID Agribusiness and Trade Promotion (ATP), Accra.

Van der Lee, J., Schiere, H., Bosma, R., de Olde, E., Bol, S. and Cornelissen, J. 2014. Aid and Trade for Livestock Development and Food Security in West Africa. Report 745. Wageningen UR Livestock Research, The Netherlands, 110 pp. Available at http://edepot.wur.nl/292476

Vanguard, 2017. FG secures 55,000 hectares in 11 states to develop grazing reserves. Vanguard newspaper, Lagos, October 12th 2017. Available at https://www.vanguardngr.com/2017/10/ von Uexkull, E and Shui, L. 2014. Implementing the ECOWAS Common External Tariff : Challenges and Opportunities for Nigeria. Africa Trade Practice Working Paper Series;No. 5. World Bank, Washington, DC. http://hdl.handle.net/10986/18935

WALIC, 2019. Genetic improvement, Conservation and Enhanced use of West African Ruminant Livestock. West African Livestock Innovation Centre Available at https://www.walic-wa.org/ genetic-improvement/

Walker, R. 2013. Innovations in Value Chain Logistics. Prepared for the Agribusiness and Trade Promotion Project by Abt Associates Inc. in collaboration with CARANA Corporation, Bethesda, MD. http://pdf.usaid.gov/pdf_docs/PA00J6Q5.pdf

Wan Zahari, M. and Alimon, A.R. 2012. Recent advances in the utilization of oil palm by-products as animal feed. In: International Conference on Livestock Production and Veterinary Technology (ICARD), Ciawi, Bogor, Indonesia. Available at http://umkeprints.umk.edu.my/1148/

Wane, A. 2006. Review of the literature on Pastoral Economics and Marketing: West Africa. IUCNWISP, Nairobi. https://agritrop.cirad.fr/549263/1/document_549263.pdf

Wang, X., Wu, X., Yan, P., Gao, W, Chen, Y. and Sui, P. (2016). Integrated analysis on economic and environmental consequences of livestock husbandry on different scale in China. Journal of Cleaner Production 119, 1-12. https://doi.org/10.1016/j.jclepro.2016.01.084

Wardeh, M.F. 2004. Classification of the Dromedary Camels. The Camel Applied Research and Development Network. Journal of Camel Science, 1:1-7. Damascus, Syria. Available at http:// citeseerx.ist.psu.edu/viewdoc/download?doi=10.1.1.137.2350\&rep=rep1\&type=pdf

Waters-Bayer, A., Bayer, W. 1992. The role of livestock in the rural economy. Nomadic Peoples 31, 3-18. https://www.jstor.org/stable/43123370 Available at http://cnp.nonuniv.ox.ac.uk/pdf/ NP_journal_back_issues/the_role_of_livestock_in_rural_economy_A_WatersBayer_and_W_Bayer. pdf

Wikipedia, 2019. Bran. Wikipedia, The Free Encyclopedia. Available at: https://en.wikipedia. org/w/index.php?title=Bran\&oldid=916147727

Wilkie D.S., Wieland M., Boulet H., Le Bel S., van Vliet N., Cornelis D., BriacWarnon V., Nasi R., Fa J.E. 2016 Eating and conserving bushmeat in Africa. African Journal of Ecology 54, 402-414. https://doi.org/10.1111/aje.12392

Williams T.O., Spycher B., Okike I. 2006. Improving livestock marketing and intra-regional trade in West Africa: determining appropriate economic incentives and policy framework. ILRI, Nairobi, 122 pp. Available at https://hdl.handle.net/10568/1572

Williams, T., Hiernaux, P., Fernández-Rivera, S. 2000. Crop-livestock systems in Sub- 
saharan Africa determinants and intensification pathways. In: McCarthy, N., Swallow, B., Kirk, M., Hazell, P. (Eds.), Property Rights Risk and Livestock Development in Africa. IFPRI, Washington D.C., pp.132-154. Available at http://citeseerx.ist.psu.edu/viewdoc/ download?doi=10.1.1.450.6751\&rep=rep1\&type=pdf

Williams, T.O., Tarawali, S., Hiernaux, P. and Fernandez-Rivera, S. (Eds.) 2004a. Sustainable Crop- Livestock Production for Improved Livelihoods and Natural management in West Africa. Proceeding of and International Conference held at International Institute of Tropical Agriculture (IITA). Ibadan, Nigeria, 19-22 November 2001. ILRI and CTA.

Williams, T.O., Okike, I., Baltenweck, I. and Delgado, C. 2004b. Marketing livestock in West Africa: opportunities and constraints. ILRI/CFC/FAO/CILSS-West Africa Livestock Marketing Brief 1. Nairobi, Kenya. Available at https://cgspace.cgiar.org/handle/10568/1593

Wilson, R.T. 1991. Small ruminant production and the small ruminant genetic resource in tropical Africa. FAO Animal Production and Health Paper no. 88. 231p. Rome, Italy.

Wilson, R.T. 2012. Small animals for small farms. FAO Diversification booklet No. 14. FAO, Rome. Available at http://www.fao.org/3/a-i2469e.pdf

Wilson, R.T. 2017. History, status and use of equines in the West African Republic of Gambia. International Journal of Livestock, vol. 8(5), pp. 57-66. Available at https://academicjournals.org/ journal/IJLP/article-full-text-pdf/10C88D063921

World Bank, 2015a. Regional Sahel Pastoralism Support Project. http://www.worldbank.org/en/ news/loans-credits/2015/05/26/africa-regional-sahel-pastoralism-support-project

World Bank (2015b). Pastoralism \& Stability in the Sahel and Horn of Africa (PASSHA). https:// projects.worldbank.org/en/projects-operations/project-detail/P153713?lang=en

World Bank, 2019a. World Bank Open Data. The World Bank Group. Available at https://data. worldbank.org/indicator/SP.DYN.LE00.FE.IN

World Bank, 2019b. World Bank Open Data. The World Bank Group. Available at https://data. worldbank.org/indicator/NY.GDP.MKTP.KD

World Bank, Government of Mauritania and CILSS, 2013. High Level Forum "Beating the Odds, building resilience in the Sahel: Pastoralism in the 21st Century", 29th October 2013. Nouakchott. http://documents.worldbank.org/curated/en/691511468204546013

Wymann , M.N., Bonfoh, B., Schelling, E., Bengaly, S., Tembely, S., Tanner, M., Zinsstag, J. 2006. Calf mortality rate and causes of death under different herd management systems in peri-urban Bamako, Mali. Livestock Science 100, 169-178. https://doi.org/10.1016/j.livprodsci.2005.08.010 Xinhuanet 2018, China's major ejiao producer to raise price, http://www.xinhuanet.com/ english/2018-12/21/c_137690073.htm

Yapi-Gnaoré, C.V., Dagnogo, B. and Oya, B.A. 2003. Community-Based Livestock Improvement and Conservation: Experiences from Open-Nucleus Breeding Programmes in West Africa. In: Community-Based Management of Animal Genetic Resources. Proceedings of the workshop held in Mbabane, Swaziland, 7-11 May 2001. Food and Agriculture Organization of the United Nations. Rome, Italy. Available at http://www.fao.org/3/y3970e/y3970e09.htm

Yılmaz, O., Boztepe, S. and Ertugrul, M. 2012. The domesticated donkey: III - Economic importance, uncommon usages, reproduction traits, genetics, nutrition and health. Available at https://www.researchgate.net/publication/263443681_The_Domesticated_Donkey_III_Economic_ Importance_Uncommon_Usages_Reproduction_Traits_Genetics_Nutrition_and_Health_Care

Yosso, D. 2010. Le ministre Kafougouna Koné demain mercredi au Wassolou: Désamorcer la bombe entre sédentaires et éleveurs. L'Indépendant. Maliweb. Available at https://www.maliweb. net/category.php?NID=63181

Zakaria, Y.N. 2014, La transhumance transfrontalière en Afrique de l'Ouest. Paix et securité internationales 2, 31-46. Available at https://www.academia.edu/10157614/LA_ TRANSHUMANCE_TRANSFRONTALI\%C3\%88RE_EN_AFRIQUE_DE_L_OUEST 






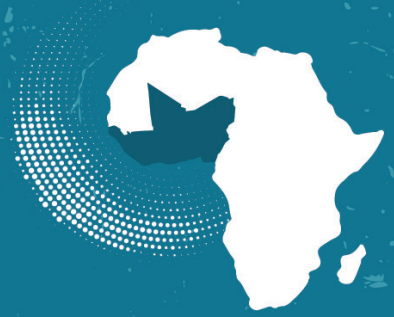

Regional Office for Africa

Food and Agriculture Organization of the United Nations Website: www. fao.org

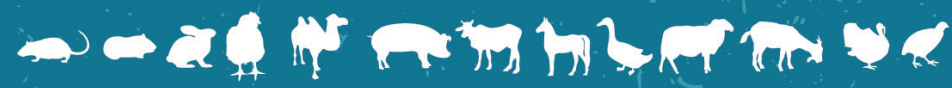

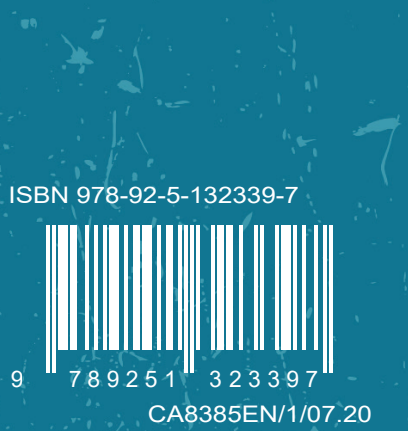

